\title{
Ulrike Brunotte,
}

Rainer Herrn ( $\mathrm{Hg}$.)

Männlichkeiten

und Moderne

Geschlecht in

den Wissenskulturen

um 1900

[transcript] 
Ulrike Brunotte, Rainer Herrn (Hg.)

Männlichkeiten und Moderne

Herausgegeben von Christina von Braun, Volker Hess und Inge Stephan | Band 3 

Ulrike Brunotte, Rainer Herrn (Hg.)

Männlichkeiten und Moderne

Geschlecht in den Wissenskulturen um I900 
Bibliografische Information der Deutschen Bibliothek

Die Deutsche Bibliothek verzeichnet diese Publikation in der Deutschen Nationalbibliografie; detaillierte bibliografische Daten sind im Internet über http://dnb.ddb.de abrufbar.

(C) 2008 transcript Verlag, Bielefeld

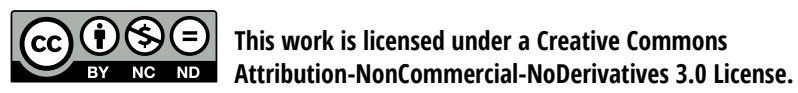

Umschlaggestaltung: Kordula Röckenhaus, Bielefeld Satz: Justine Haida, Bielefeld

Korrektorat: Frank Zimmer

Druck: Majuskel Medienproduktion GmbH, Wetzlar ISBN 978-3-89942-707-3

Gedruckt auf alterungsbeständigem Papier mit chlorfrei gebleichtem Zellstoff.

Besuchen Sie uns im Internet: http://www.transcript-verlag.de

Bitte fordern Sie unser Gesamtverzeichnis und andere Broschüren an unter:info@transcript-verlag.de 


\section{Inhalt}

Ulrike Brunotte, Rainer Herrn

Statt einer Einleitung.

Männlichkeiten und Moderne -

Pathosformeln, Wissenskulturen, Diskurse

Cornelia KLinger

Von der Gottesebenbildlichkeit zur Affentragödie.

Über Veränderungen im Männlichkeitskonzept

an der Wende zum 20. Jahrhundert

Sabine Mehlmann

Das sexu(alis)ierte Individuum -

Zur paradoxen Konstruktionslogik moderner Männlichkeit 37

Ute FreVert

Das Militär als Schule der Männlichkeiten 57

Claudia Bruns

Männlichkeit, Politik und Nation -

Der Eulenburgskandal im Spiegel europäischer Karikaturen 77

MARTIN LÜCKE

Komplizen und Klienten.

Die Männlichkeitsrhetorik der Homosexuellen-Bewegung in der Weimarer Republik als hegemoniale Herrschaftspraktik 97

Birgit DAhlke

Proletarische und bürgerliche Jünglinge in der Moderne.

Jugendkult als Emanzipationsstrategie und Krisenreaktion um 1900 
Christina von Braun

Le petit mal du grand Mâle

Bettina Mathes

»Sollte dieser Mann verunglückt sein?«

»Doktor Faust« zwischen Freud und Busoni

(Bruchstücke eines Dialogs aus dem Off)

Jay Geller

The queerest cut of all: Freud, Beschneidung,

Homosexualität und maskulines Judentum

RAINER HERrN

Magnus Hirschfelds Geschlechterkosmos:

Die Zwischenstufentheorie im Kontext hegemonialer Männlichkeit

Marylin Reizbaum

Die männliche Kunst der jüdischen »Degeneration«

JOSEPH CROITORU

Zwischen Übermacht und Ohnmacht:

Die Figur Simsons in der deutschen, völkischen und zionistischen Literatur um 1900 als Medium des kulturpolitischen Kampfes um hegemoniale Männlichkeit

ULRIKE BRUNOTTE

>Große Mutter<, Gräber und Suffrage.

Die Feminisierung der Religion(swissenschaft)

bei J.J. Bachofen und Jane E. Harrison

Hubertus BüsChel

Im »Tropenkoller« - Hybride Männlichkeit(en)

in ethnologischen Texten I900-I960

Tanja Paulitz

Kämpfe um hegemoniale Männlichkeiten

in der Ingenieurkultur um 1900

INGE STEPHAN

Eisige Helden.

Kältekult und Männlichkeit in den Polarphantasien von Georg Heym 



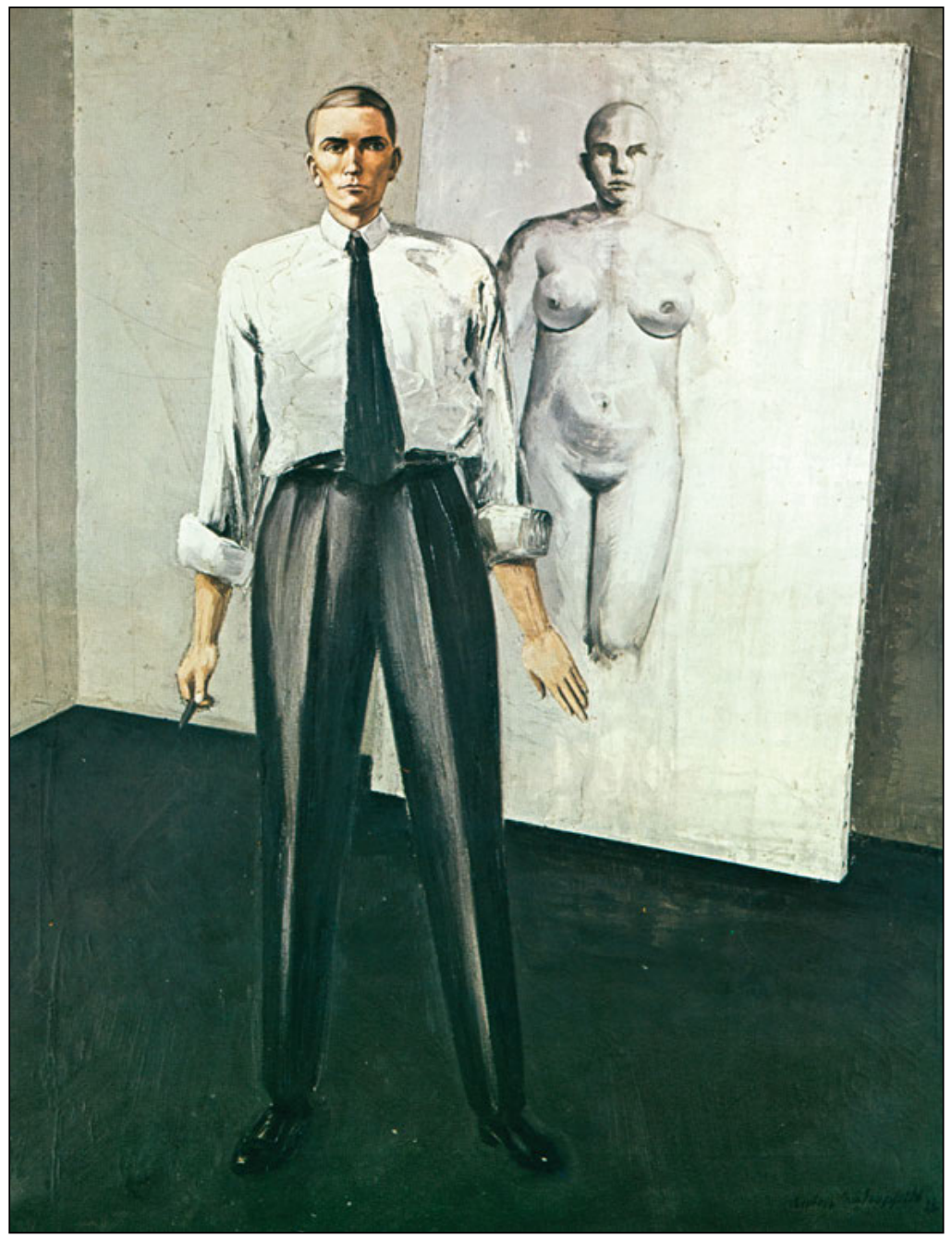

Anton Räderscheidt, Selbstbildnis 1928, Öl auf Leinwand, $99 \times 80 \mathrm{~cm}$ Privatbesitz, Hamburg 


\title{
Statt einer Einleitung.
}

\section{Männlichkeiten und Moderne -}

\section{Pathosformeln, Wissenskulturen, Diskurse}

\author{
Ulrike Brunotte, RAINER Herre
}

Der kulturellen Etablierung des okzidentalen Konzepts hegemonialer Männlichkeit geht die reformatorische Aufhebung des Zölibats, die Entsakralisierung der Enthaltsamkeit und damit eine neue Verknüpfung von Gottesnähe und Sexualität voraus. »Doch stellt die programmatische Verweltlichung der Familie, die Luther einleitet, nur einen Aspekt der reformatorischen Neuerungen dar. Der andere, dazu komplementäre Aspekt besteht in der Vergeistigung der irdischen Verhältnisse, in der Umleitung von Energien des Heiligen in die weltlichen Institutionen« (Koschorke 2000: 149). Träger dieser Geistlichkeit ist in unterschiedlicher Form der Mann, insbesondere der idealisierte »Haus-Vater«. Auch der pater familias konnte als leiblicher Repräsentant des göttlichen Vaters in der protestantischen Familie seine metaphysisch gesicherte Macht ausüben. Als »lachende Erbin« (Weber) des Protestantismus ist das aufklärerische Subjekt- und Männlichkeitsmodell hingegen eng mit der Diskursivierung des transzendentalen Vernunftsubjekts, der Herausbildung der bürgerlichen Nationalideologien und der funktional differenzierten Gesellschaft um 1800 verknüpft. Die modernen Männlichkeitsdiskurse entwickeln sich dabei paradox, wobei die zentralen Konstruktionsmodi idealtypischer moderner Männlichkeit den »Mann« sowohl »als >überlegenes« Geschlecht als auch als geschlechtsneutralen >allgemeinen Menschen definieren« (Klinger 2005: 334; Beitrag Mehlmann). Einerseits wird damit das bürgerliche Subjekt gegen die funktionale Differenzierung der Gesellschaft, ihre Erschütterungen und >wilden< Ursprünge ${ }^{1}$ philosophisch als transzendental, identisch und $>$ ganz gesetzt, andererseits basiert dieses Subjekt auf dem angsterfüllten Zwang ununterbrochener

1| Vgl. die Natur- und Wildheitsszenarien der aufklärerischen Gesellschaftsvertragstheorien, besonders von Hobbes. 
Selbstreflexion, so heißt es etwa in Kants »Kritik der reinen Vernunft« nicht mehr »Ich denke, also bin ich« (Descartes), sondern: »Das Ich denke, muss alle meine Vorstellungen begleiten können, denn sonst würde etwas in mir vorgestellt werden, was gar nicht gedacht werden kann [...]« (Kant 1781: B132, 133). Zudem beginnt das Subjekt seine Sicherheit im Transzendentalen auch dadurch langsam zu verlieren, dass im etwa zeitgleich wirksam werdenden biologischen Zweigeschlechtermodell das männliche Geschlecht als physisches konzeptualisiert wird. Damit fungiert »der Körper als bedeutungsstiftendes Substrat für die Begründung des sozialen Geschlechts« (Mehlmann 1998: 99) und avanciert zugleich zum »erzeugungsmächtigen Analogienoperator« (Honegger 1991: 8). Nicht zuletzt in dieser diskursiven Paradoxie offenbart sich das zwischen Vernunft und `Natur' gespaltene Subjekt selbst als Produkt der Moderne (Kucklig 2006). Dieselbe Paradoxie wiederholt sich in der Ausdifferenzierung und im Verhältnis von Gesellschaft - Berufs-, Erwerbswelt, Öffentlichkeit - einerseits und Gemeinschaft - Haus, Familie, Intimität - andererseits: Obwohl die moderne ausdifferenzierte Gesellschaft >geschlechtsneutral definiert ist, wird sie im 19. Jahrhundert zumindest für das hegemonial wirkmächtige Bürgertum naturalisiert und mit dem männlichen »Geschlechtscharakter« überformt (vgl. Hausen 1976; Kucklig 2006). Im Prozess der diskursiven Produktion hegemonialer Männlichkeit kommt nun den neuen lebenswissenschaftlichen und visuellen Regimen eine ebenso große Bedeutsamkeit zu wie dem Nachleben (Warburg) oder der Nachahmung (Winckelmann) antiker Pathosformeln und Ästhetiken der Maskulinität. Vor allem diese tragen die öffentliche Bildwerdung des hegemonialen weißen Subjekts (Mosse 1997; Schmale 2003: 149-195). In der zugleich körperzentrierten und vergeistigenden Performanz der Subjektwerdung qua erhebender Schmerz- und Schrecküberwindung durch Selbst-Wissen treffen sich um 1800 die neoklassizistischen Diskurse des Erhabenen, Edlen und Schönen mit solchen der Physiologie, der Maskulinität und der politischen Nationenbildung. Connell hat in diesem Zusammenhang zu Recht auf den »relationalen Charakter« (Connell 1999: 188f.) und die historische Machtdynamik (ders. 2005) hingewiesen, in der sich die jeweils hegemoniale Männlichkeit gegenüber anderen Männlichkeiten bewegt und diskursiv wie in sozialer Praxis durchsetzt. Dabei handelt es sich bei diesem Anderen bereits im aufklärerischen Diskurs nicht nur um das »andere Geschlecht« der Frauen, sondern um die als `wild und sunbeherrscht « definierten Männer der Kolonien, des »Orients« oder der unteren Schichten.

\section{Longue dureé und Pluralität von Männlichkeiten}

Im Zentrum der normativen Bildregime und Diskurse des Bildungsbürgertums finden wir um 1800 die Gestalt des Laokoon. Die Frage, warum sich ein bestimmtes Stereotyp, wie das mit Laokoon verbundene, auch in der Konkurrenz visueller und narrativer Regime ebenso als Faszinationsbild wie als Ethos von Körperzucht und Nationenbildung innerhalb einer 
konkurrierenden Pluralität von Männlichkeitskonstruktionen durchzusetzen vermag, lässt zugleich nach der longue durée von Männlichkeitsmodellen überhaupt fragen. Auf die Ambivalenz von historischer Pluralität der Männlichkeiten und der bisher nicht zureichend erklärten longue durée bestimmter vormoderner, ja mythisch-ritueller Formen, Figuren und Handlungsmuster von männlicher Herrschaft haben neben Pierre Bourdieu (1998/2005) zuletzt George Mosse (1997) und Walter Erhart (2005) hingewiesen. Wie ist der Fortbestand vormoderner Orientierungen zu erklären, ohne in ursprungsmythische Ontologie zu verfallen? Diese Frage drängt sich gerade in Bezug auf die rituelle und soziale Produktion von Männlichkeit - den männlichen Habitus - in seiner grundlegenden Dopplung von Geschlechter-enactment und Geschlechter-embodiment auf: »Es geht dabei um Praktiken dessen, was im Englischen doing gender heißt und sich im Deutschen annähernd übersetzten ließe mit >als Geschlecht auftreten oder handeln<. Die Geschlechterordnung bringt neben ihren Machtverhältnissen immer auch >gelebte Denk-, Gefühls- und Körperpraktiken< hervor« (Erhart 2005: 165), die sich manchmal figurativ-bildlich in Pathosformeln verdichten und zu leibgebundenen, affektiv aufgeladenen Faszinationsfiguren avancieren: Neben dem noch im Todes-Schmerz beherrschten Laokoon beschäftigen sich die Beiträge dieses Bandes sowohl mit den Lichtgestalten des göttlichen Jünglings (Beitrag Dahlke), dem effeminierten Rauschgott Dionysos (Beitrag Brunotte) und dem ssomatischen Muskelhelden<, wie er im griechischen Herakles, im hebräischen Simson (Beitrag Croitoru) und im modernen Kampfbegriff des »Muskeljuden« (Beiträge Reizbaum, Geller) um 1900 ein revival erfährt. Mit der Frage nach der longue durée und dem Nach- oder Überleben (survival) des Vergangenen in den energetischen Bildformeln der Moderne tritt das Verhältnis von Kultur und Natur erneut ins Blickfeld, ebenso freilich kulturwissenschaftliche Modelle kollektiver Erinnerung, des Bildgedächtnisses (Warburg), der Faszinationsgeschichte (Heinrich 1995; Didi-Hubermann 2000) oder der »Wiederkehr des Verdrängten« (Freud). Auch der Soziologe Marcel Meuser hat durch die Analyse von Figuren der longue durée gerade von Gestalten hegemonialer Männlichkeit »die Grenze zwischen biologischer Verkörperung und sozialer Rolle eingezogen « (Erhart 2005: 165) und untersucht das »Erzeugungsprinzip« (Meuser 1998: 118) des sozialen Habitus. Dabei geht er vornehmlich »leibgebundenen Expressionen« (ebd.: 121) nach. Ebenso warnte Judith Butler (Butler 2004) davor, »die Frage nach der >Natur< oder der >Kultur< der Geschlechterdifferenz überhaupt entscheiden zu wollen. Statt sich auf die Suche nach dem >Ursprung< oder dem letzten >Fundament der Differenz zu begeben oder die Konstruiertheit von Geschlecht immer wieder zu entlarven, käme es in the long run darauf an, sexuelle Differenz als Frage, als >Grenzvorstellung zu verstehen« (Erhart 2005: 165). 
Abbildung 1: Laokoon-Gruppe, ca. 200 v. Chr. Vatikanische Museen. Aus: R. R. R. Smith, Hellenistic Sculpture.

A Handbook, London: Thames and Hudson 1991, Fig. 143

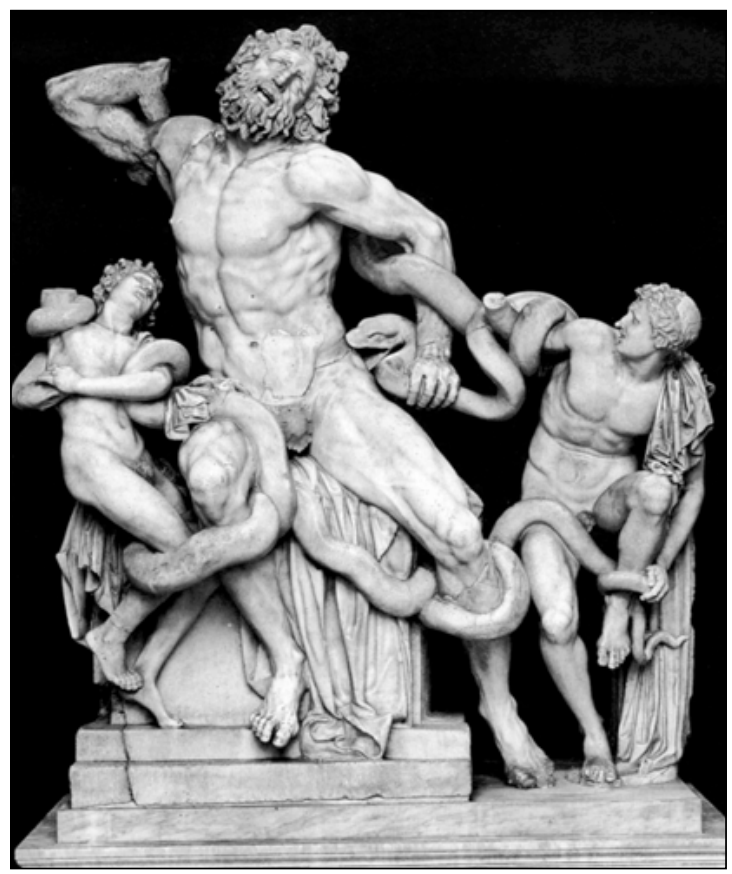

\section{Marmorleiber, Uniformen und Lichtgestalten: vom Nachleben der Antike in der Moderne}

Kein Geringerer als der Pionier der Männlichkeitsforschung George Mosse hat nun zuerst auf den komplexen Zusammenhang hingewiesen, in dem die Entwicklungsphase des okzidentalen bürgerlichen Männlichkeitsstereotyps in der Zeit der Aufklärung und der bürgerlichen Nationenund Staatenbildung mit einer explizit politischen Neuaneignung antiker Männlichkeitsstereotype bei gleichzeitiger Abspaltung von sogenannten »Antitypen« stand. Folgt man nun Mosse, dann fokussierte Johann Joachim Winckelmann (1717-1768) mit seinem figurativen antiken Männlichkeitsideal neben ästhetischen, literarischen, archäologischen, klassizistischen und museumstheoretischen Wissensfeldern auch zentrale politische Diskurse seiner Zeit. Seine zur Nachahmung aufrufende Deutung war es, die die antike Figurengruppe ${ }^{2}$ des mit den tödlichen Schlangen ringenden

2| Es handelt sich um die sogenannte Laokoon-Gruppe, wie wir sie in den Vatikanischen Museen bewundern können. Die römische Marmorkopie stammt aus der Regierungszeit des Tiberius (14-37 n. Chr.). Sie ist nach einem hellenistischen 
Götter-Rebellen und Vaters Laokoon (Andreae 1991) so berühmt machte. Als Inkunabel von Affektbeherrschung und großer Seele trat sie neben die idealische Gestalt des göttlichen Apoll und die Volks- und Arbeitsheroen wie Herakles. Laokoon sollte für den vielstimmigen Diskurs um das klassizistische Haltungsideal und das bürgerliche Männlichkeitsstereotyp zentral werden. 1755 veröffentlichte Winckelmann seine Schrift »Gedanken über die Nachahmung der griechischen Werke in der Malerei und Bildhauerkunst«, mit der er sofort berühmt wurde. Für ihn bedeutete das Studium der Griechen, dem er sich in Rom verschrieb, weitaus mehr als ein ästhetisches oder archäologisches Unternehmen, denn, so Winckelmann: »Der einzige Weg für uns, groß, ja, wenn es möglich ist, unnachahmlich zu werden, ist die Nachahmung der Alten« (Winckelmann 1755/1969: 4). Der Winckelmannsche Held stellte im klassizistischen Programm »edler Einfalt und stiller Größe« (Winckelmann 1755/1995: 30) auch ein ethisches Programm dar. Dabei reagierte Winckelmanns Ästhetik, die den Anspruch absoluter Vorbildlichkeit des griechischen Ideals vertrat, bereits auf die Unsicherheit neoplatonischer Gewissheiten und Urbilder, indem er seine normative ästhetische Argumentation durch modernste naturwissenschaftlich-empirische Methoden abzusichern suchte (zuletzt Franke 2006). Denn die Nachahmer der griechischen Skulptur finden in ihnen nicht allein ein Ideal, sondern auch eine »schöne Natur« (ebd.: 5). Bereits die griechischen Künstler, so führt Winckelmann weiter aus, hatten sich durch die Betrachtung der schönen nackten Jünglinge in den Gymnasien anregen lassen und überhaupt wäre selbst der »schönste Körper unter uns vielleicht dem schönen griechischen Körper nicht ähnlicher, als Iphikles dem Herkules, seinem Bruder, war« (ebd.).

Wichtig an der in Europa nicht allein in den Künsten breit geführten Laokoondebatte um 1800 war vor allem der Versuch, die Repräsentation emotionaler Zustände und auf diesem Weg überhaupt das Verhältnis zwischen Zeichen und Gefühlen, Innen und Außen, Seele und Körper neu zu codieren (vgl. Baxmann 2000: 2). Nicht zuletzt die betonte Spannung zwischen erlebtem Schmerz und gefasstem Ausdruck, ließ die Selbstbezwingungsperformanz und die Körperimago des Laokoon zum Referenzpunkt aufklärerischer Anthropologie, zum l'homme bzw. »Modèl ideal«, ja zur Verkörperung des biologischen Prototypus werden (Franke 2006). Der Winckelmannsche Held sollte als ethisches Modell zugleich induktiv in der »Natur« der Griechen verortet sein.

Einzig, so Winckelmann, in der »gemäßigten Witterung« und unter einem »zwischen Wärme und Kälte gleichsam abgewogenen Himmel« Griechenlands, schafft »die Natur« unter »Menschen die schönsten und wohlgebildetsten Geschöpfe und Gewächse« (1755/1969: 78). Nicht zuletzt in diesen klima- und völkertheoretischen Untertönen sind zumindest An-

Bronzeoriginal aus der Zeit um 140 v. Chr. aus Pergamon verfertigt worden und wurde am 14. Januar 1506 in der Nähe Roms wiederentdeckt. 
deutungen der kommenden kolonialen und rassistischen Legitimationen europäischer weißer Hegemonie nicht zu überhören. Winckelmanns zur Reinheit strebendes Körper-Ideal war dabei rein männlich und von strahlendstem Weiß, edel in seinen Proportionen, ohne ein Gramm Fett zuviel und von erhabener Selbstbeherrschung im Ausdruck. Neben der »Natur« der Griechen basierte gleichwohl die »edle Form « auf Zucht und Training, und »die Körper erhielten durch diese Übungen den großen männlichen Kontur, welche die griechischen Meister ihren Bildsäulen gegeben« (ebd.: 6) hatten. Dabei transportierte die geschlossene glatte Linearität der Körper-Umrisse und ihre festen undurchlässigen Begrenzungen nicht allein die hegemoniale weiße männliche Identität, sondern sie beruhte auf Tabus (vgl. Butler 1991: 190-198) und Verwerfungen (Kristeva 1980) - so war jeder Hinweis auf poröse Oberflächen, vergängliches Fleisch und Falten ebenso abzuwehren wie jede Farbigkeit.

In der Schrift »Gedanken über die Nachahmung der Griechischen Werke in der Malerei und Bildhauerkunst« beschreibt Winckelmann den Laokoon als das beste Beispiel einer vorbildlichen Haltung dem (Todes)Schmerz gegenüber, die er, wie bereits erwähnt, als »edle Einfalt und stille Größe« bezeichnet. Erst innerhalb dieses Kontextes gewinnt dieses klassizistische Schönheitskonzept als Haltungsideal erhabener Größe seine Bedeutung als ein »semiotic system of representation « (Richter 1992: 44) zurück. Denn das neoklassizistische Schönheitsideal des Winckelmannschen Laokoon ist ohne den erlittenen Todesschmerz und seine erhabene Meisterung nicht verkörperbar. In der Formulierung des ErhabenheitsProgramms der aufklärerischen Ästhetiken seit Burke und Kant reißt sich das heroische Individuum in >befreiender Erhebung < von seiner ohnmächtigen Physis und Angst los, um sich mit einem gleichsam sublimen GeistKörper-Ich zu vereinen. Dieses Alter Ego ist nicht mehr göttlich, sondern eins mit der >Gattungsvernunft $<$. Darin spiegelt sich nun mit imperialem Gestus das universelle - dabei gleichwohl männliche - Subjekt. Andererseits werden spätestens dort, wo die Ästhetik des erhaben Schönen sich im Handlungskonzept der Schmerzüberwindung als Bildwerdung den zeitgleichen medizinischen Körper-Diskursen annähert, Gewaltspuren sichtbar (vgl. Sarasin 2003). Es handelt sich einerseits um Zurichtungsspuren am empirischen Männerkörper, die sich im Prozess der massenhaften erzieherischen, biopolitischen und militärischen Umsetzung des erhaben-schönen Habitus in Körpertechniken der Disziplinierung und Grenzziehung im Verlauf des 19. Jahrhunderts durchsetzen werden (Schmale 2003). In diesen außerdiskursiven, aber gleichwohl diskursiv überformten politischen und institutionellen Praxen (Foucault 1973: 231ff.) materialisieren sich die Körper am und durch das normative Ideal innerhalb der veränderten symbolischen Ordnung. Dabei kommt den visuellen Regimen in den neuen Wissens- und Überwachungskulturen eine ebenso große Rolle zu wie den Lebenswissenschaften. Andererseits erhält mit der Vorbildrolle des säkularisierten Schmerzensmannes Laokoon im bildungsbürgerlichen 
Kulturfeld das ausgehaltene Leiden und das geformte Pathos die veredelnde Funktion hegemonialer Subjektbildung. Nicht zuletzt durch ihre überdeterminierte Verknotung in unterschiedlichsten Feldern und Diskursen der Gesellschaft »offenbaren die Laokoontexte [von Lessing, Herder, Goethe u.a.] wie wenig anderes, die versteckten Denkmuster und Dispositive der Wahrnehmung, die die Kultur der Aufklärung bestimmten« (Baxmann u.a. 2000: 1).

Die richtige Betrachtung und Nachahmung der antiken Skulpturen sollte freilich schon bei Winckelmann nicht allein zu einer neuen Kunst, sondern zu einer gesellschaftlichen Gesundung an Leib und Seele führen. Nicht nur das deutsche Gymnasium und die Kunstgeschichte wurden angehalten, bei den Griechen in die Lehre zu gehen, sondern jeder Bürger konnte in der Betrachtung der griechischen Skulpturen und Kopien in Schulen und Museen die formgebende >Zucht $<$ und die richtige >Haltung lernen. Bereits sein Werk enthielt demnach neben dem ästhetisierenden auch den lebensreformerischen Impuls, der nicht allein in der Turner- und Gymnastikbewegung so wirksam wurde! Ein homoerotischer Oberton (Detering 1995) ist freilich bei der zum Teil schwärmerischen Hervorhebung der idealischen Reinheit und Jugendlichkeit der männlichen (Skulpturen)Körper, die Winckelmann in seinen Hymnen auf den göttlichen Jüngling Apoll entwickelt, nicht zu überhören. Es mangelt dabei nicht an ironischer Tragik, so führt George Mosse aus, dass gerade dieses im homoerotischen Kontext entstandene Schönheitsdeal wohlproportionierter, reiner und letztlich >neutraler< Gestaltmacht und edler weißer Physiognomie im Verlauf des 19. Jahrhunderts und - über eine Kette martialischer Zurichtungen - bis in die Monumentalfiguren eines Arno Breker zu einem bedeutenden Repräsentationsmedium des hegemonialen Männlichkeitsmodells werden sollte, in dessen Namen Homosexuelle, Juden und >Nicht-Weiße< ausgegrenzt, pathologisiert und verfolgt wurden.

Um sich freilich in allgemein-gesellschaftlichen Normierungs- und Normalisierungsprozessen, heldischen Narrationen und Totenkulten der Nation als hegemoniales Modell durchzusetzen, bedurfte die politische Ästhetik der Maskulinität der entscheidenden Dynamik der Freiwilligenkriege und der allgemeinen Wehrpflicht (Beitrag Frevert). Diese führte auch in Deutschland zu einer »Militarisierung des Mannes« (vgl. Frevert 2000) und zur Durchsetzung der bürgerlichen Geschlechterordnung. Im männlichen Stereotyp sollte nicht allein der »Mensch und Bürger« (ebd.: 146) sichtbar werden, sondern der »konstitutive Zusammenhang von >Nation « und >Männlichkeit<, von Vaterlandsliebe und Mannesmut, von Bürgertugend und physischer Kraft« (ebd.). Aus den ernsten Spielen des Duells und der dabei zu beweisenden >männlichen Ehre waren freilich nicht allein Frauen, sondern auch nicht satisfaktionsfähige Männer aus unteren sozialen Schichten wie auch Juden (Rürup 2005) ausgeschlossen. 


\section{Wissenskulturen und Krisenrhetoriken um 1900}

Gegen Ende des 18. Jahrhunderts kommt es, gleichsam als Reaktionsbildung auf den aufklärerischen Gleichheitsdiskurs, zur Durchsetzung eines biologisch fundierten Zweigeschlechtermodells, aus dem seither eine »Fundamentaldifferenz von zwei sozialen Geschlechtern « (Honegger 1991) abgeleitet wird (vgl. auch Hausen 1978; Bublitz 1998; Mehlmann 1998). Die Herausbildung des hegemonialen bürgerlichen Männlichkeitskonzepts ist insgesamt verknüpft mit der Etablierung und nachhaltigen Expansion des Sexualitätsdispositivs im 19. Jahrhundert (Foucault 1977). Das geschieht nicht eindimensional, sondern indem der physiologische und der soziale Geschlechtskörper ebenso wie Prozesse von Sexualisierung und Desexualisierung in wechselseitige Spannung treten (Mehlmann 2006). Dem paradoxal codierten männlichen Subjekt wird um 1800 ein völlig von Triebhaftigkeit gereinigtes, zugleich jedoch auf seine Reproduktionsfunktion des >Geschlechts< eingeschränktes, kulturtragendes Modell von Weiblichkeit gegenüber gestellt. Im Laufe des 19. Jahrhunderts spaltet sich davon allerdings ein »gänzlich von Sexualität durchdrungener Körper der Frau« (Foucault 1977) ab und wird als »imaginäre Weiblichkeit« (Bovenschen 1980) wirksam.

Bereits die aufklärerische Anthropologie spiegelte sich auf komplexe Weise in kolonialen Grenzdiskursen, Konstruktionen des imaginären - guten oder barbarischen - »Wilden«, sowie des »Naturzustands « der Gattung als Szenario des Gesellschaftsvertrags (Kucklig 2006). Heroische Männlichkeit fand im wilden, aber zuweilen erziehbaren Mann ihren dämonischen Doppelgänger: So programmatisch verhandelt in Daniel Defoes »Robinson Crusoe« von 1719.

Im 19. Jahrhundert bildet sich im Rahmen der zurichtenden Biopolitik das männlich-heterosexuelle Körper- und Nationenmodell in binären Codes durch die Produktion von »Antitypen« (Mosse 1997) hybrider, sozialer, >rassischer< oder >unfruchtbarer< Männlichkeiten heraus. Die Konstruktionen und diskursiven Präsenzen dieser individualisierten Antitypen fungieren über permanente Abgrenzungsprozesse als selbstreferentielle Bestätigung und Bestärkung hegemonialer Männlichkeit. In den Literaturen des 19. Jahrhunderts werden aber auch andere, neue und positive Geschichten moderner Männlichkeiten erzählt, in denen (un-)männliche $>$ Neurasthenie<, Einfühlsamkeit und Fragmentierung dominieren. So in den europäischen Familienromanen und den »halben Helden« (Erhart 2001) von Fontane und Thomas Mann sowie in den »missglückten Initiationen im Fin de Siècle« (ebd.; Beitrag Matthes).

»Der entscheidende Einschnitt im Männlichkeitsdiskurs erfolgt freilich erst um die Wende vom 19. zum 20. Jahrhundert, also um rund hundert Jahre nach dem Einbruch der Moderne in den Weiblichkeitsdiskurs « (Klinger in diesem Band), der um 1800 zu einer Flut von Wissensbildungen 
über den weiblichen »Geschlechtscharakter« und die »Frauenfrage« geführt hatte. Im Gegensatz zu George Mosse, der von einer Kontinuität des um 1800 erstmals entwickelten Maskulinitätsideals spricht und die »Krisenrhetoriken« um 1900 nur als kurze Irritation beschreibt, werden in dem vorliegenden Band die Erschütterungsdiskurse, die von etwa 1880 bis 1925 die bürgerlich-hegemonialen Männlichkeitsstereotype umgeben, auslöschen und neu definieren, ernst genommen und en détail betrachtet.

In der genannten Zeitspanne vollzieht sich vor dem Hintergrund beschleunigter sozialer, medialer und politischer Modernisierungen auch ein deutlicher Umbruch der sozialen und symbolischen Geschlechterordnung. In dieser Periode sind drei eng miteinander verbundene Tendenzen zu konstatieren: 1. die um Emanzipation d.h. um politische, rechtliche und ökonomische Gleichberechtigung nun erfolgreich kämpfenden Frauen, die zunehmend in den männlich codierten Raum von Wissen, Macht und Arbeit drängen, 2. das Aufkommen neuer Wissensgebiete, die expressis verbis die Verwissenschaftlichung der Geschlechtsdifferenzen und insbesondere den männlichen Geschlechtscharakter, die männliche Sexualität und die »männlichen Perversionen « (Foucault) diskursiv herstellen, formen und fixieren und 3. das Aufkommen entsprechender sozialer Bewegungen, die das überkommene Patriarchat in Frage stellen wie beispielsweise die Frauen-, Arbeiter-, Jugend- und Homosexuellenbewegungen.

In den diversen - aus Reaktionsbildungen entstandenen - Gegenströmungen zur herrschenden Geschlechter- und Klassenordnung entwickelten sich in diesen Bewegungen zum Teil diametral entgegengesetzte Positionen und Strategien im Umgang mit der hegemonialen Männlichkeit, von der (selbst-)bewussten Herausforderung und Infragestellung, über die Submission und mimetische Anpassung bis hin zur überkompensierenden Bestärkung (vgl. Connell 1999: 56 ). Dieser Diversifizierungsprozess verweist zunächst auf die von Connell behauptete »historische Dynamik« bezüglich der Pluralisierung spezifischer, kontextabhängig hervorgebrachter Männlichkeitsformen um 1900 (ebd.: 102ff., ders.: 2005). Die jeweiligen Strategien, mit denen diese unterschiedlichen Männlichkeitsformen ihre Positionen im Sinne der Marginalität oder Komplizenschaft zur hegemonialen Männlichkeit markieren und zu behaupten suchen, machen hingegen die »relationale Betrachtungsweise« (ebd.: 97), also »die Verhältnisse zwischen den verschiedenen Arten von Männlichkeit[en]« (ebd.: 56) deutlich (Beiträge Lücke und Paulitz). In der neueren historischen Männlichkeitsforschung steht die Vielgestaltigkeit und Wandelbarkeit zeitgleich koexistierender und konkurrierender Männlichkeitsformen außer Frage. Dinges, der »hegemoniale Männlichkeiten vom Mittelalter bis heute« betrachtet, meint sogar, dass gerade in der in diesem Band fokussierten historischen Periode »der massivsten Geltung moderner hegemonialer Männlichkeit vor und nach dem Ersten Weltkrieg, weiterhin eine Vielzahl von Modellen >dominanter Männlichkeit< kursierte« (Dinges 2005: 20). Die Beiträge einiger AutorInnen dieses Bandes lassen sich in dieser Richtung interpretieren. 
Die wissenschaftliche Entdeckung des Unbewussten, also die >Entmachtung < des rationalen >Ich< durch Sigmund Freud und die Aufnahme der Kategorie Geschlecht als positive, hegemoniekritische Analysekategorie in die Selbstreflexion der Wissenschaften und der Wissensgeschichte, findet sich in der Frauenkunde, der Sexualwissenschaft und Psychoanalyse, aber auch in einer durch Nietzsche inspirierten Soziologie, Völkerkunde/Ethnologie und Religionswissenschaft. Doch auch brandneue Wissensbereiche, wie Ingenieur- und Technikwissenschaften, rekurrieren und inkorporieren in ihrem Kampf um Anerkennung und Partizipation implizit und/oder explizit verschiedene Konstrukte hegemonialer Männlichkeiten (Beitrag Paulitz).

Während in diesem Netz von Wissenskulturen Männlichkeitsstereotype kontinuiert, aber auch neu definiert und etabliert werden, geraten die ihnen nicht entsprechenden Männlichkeiten über Dekadenz- und Degenerationsdiskurse zu beschädigten Defizitärformen, die als marginalisierte Antitypen, mit Auslagerungen sanktioniert werden (Connell 1999; Mosse 1997: 110). Insofern erweisen sich die vielfältigen Diskursivierungen auch als Verteidigungsstrategien hegemonialer Männlichkeit, in dem sie die ins Wanken geratenden Geschlechterdifferenzen durch normative Grenzverschiebungen zu erneuern suchen.

Denn allgemein lässt die Dialektik zunehmender Differenzierung der Gesellschaft bei gleichzeitiger Entdifferenzierung der Geschlechtscharaktere auch die hegemonial festgeschriebene Geschlechterdifferenz, die alle Felder des Wissens durchkreuzt, zu einer >schwankenden Grenze< werden und führt um $1900 \mathrm{zu}$ einer Krise des Ideals hegemonialer Männlichkeit (Beiträge Croitoru, Dahlke; von Schnurbein 2002; Brunotte 2004). Dabei macht das bürgerliche Konstrukt männlich-neutraler Allgemeinheit und heteronormativer »Väterlichkeit« einen Prozess der Ent-Universalisierung durch, es zerfällt, wird plural sexualisiert, >nervös < und >hysterisch $<$ (Beitrag von Braun). Wenn nun aber das männliche Subjekt, das als Vernunftsubjekt von seinem sinnlichen Begehren abgelöst, das dynamische Ideal von Vaterland und Staates verkörperte, sexualisiert und vieldeutig wird, dann bedeutet das innerhalb des Dispositivs, es wird weiblich (Bublitz 1998). So ist es nicht verwunderlich, wenn in den heftigen Kulturkrisen-Debatten und politischen Prozessen der Zeit, in deren Zentrum oft genug Diskurse um Inversion und >Homosexualität< (Bruns 2001; zur Nieden 2004) und das >Jüdische< (Boyarin 1997; Reizbaum 2003) stehen, die Zunahme von Kontingenz und Vermischung in dem Verdikt einer Feminisierung der Kultur (zuletzt Runte 2006) gipfelt. Dabei spielen koloniale Diskurse und die Hybridisierung von Männlichkeit in frühen ethnologischen »Felderfahrungen« in Übersee (Beitrag Büschel) keine geringe Rolle. Zugleich verdichtet sich die Erschütterung hegemonialer bürgerlicher Männlichkeit in der Radikalisierung der Antitypenbildung. Es kommt zu fortschreitender Dämonisierung, Pathologisierung und Kriminalisierung von »Juden« und »Homosexuellen« (Beitrag Herrn). Wie jüdische Autoren und Wissen- 
schaftler gleichwohl selbst im Spannungsfeld von Antisemitismus, Assimilationswunsch und »heroischem Protest« (Geller) bis hin zur zionistischen Auswanderungsbewegung an dem diskursiven Ringen um hegemoniale Männlichkeit implizit und explizit partizipieren, das untersuchen vor allem zwei Beiträge des Bandes (Geller, »Freud«; Reizbaum, »Nordau und Lombroso $\ll)$.

Sodann treten die bereits erwähnten unterschiedlichen sozialen Bewegungen der Zeit ins Blickfeld, von denen jede auf ihre Weise die hegemoniale Männlichkeit herausfordert bzw. bestätigt: die Jugendbewegung mit ihrem Protest gegen die Vaterherrschaft (Beitrag Dahlke), die Lebensformbewegung und die damit eng verbundenen ästhetischen Revolten (Avantgarden), die frühe Frauenbewegung (Beitrag Brunotte), die Arbeiterbewegung (Beitrag Dahlke), die zionistische Bewegung (Beiträge Croitoru und Reizbaum) und nicht zuletzt die Homosexuellenbewegung(en) und die mit ihnen verbundene kulturelle Homophobie (Beiträge Herrn und Bruns).

Neben Matriarchatsmythen und Mythen vom Großen Weiblichen (Beiträge Brunotte, Croitoru, Matthes) und die Lehre vom Dritten Geschlecht und den Zwischenstufen (Beitrag Herrn), treten die maskulinistischen Reaktionen, die auch als Einschreibversuche in hegemoniale Männlichkeit interpretiert wurden (Bruns 2001; Brunotte 2004). In männerbündischen Utopien und kolonialen Maskeraden jenseits des Patriarchats (Beitrag Büschel) oder im Kult um den »hypervirilen Männerhelden« (Blüher 1918) wird gegen die vermeintlich »jüdische Effeminierung« (Weiniger 1903) der Kultur gekämpft. Mimesis an Technik und ans Anorganische erhalten dabei insbesondere nach den »Materialschlachten « des Ersten Weltkriegs als neue Verhaltenslehren der Kälte (Lethen 1994; Beitrag Stephan) auch in den Natur-, Religions- und Technikwissenschaften eine zunehmende Bedeutung.

In den Beiträgen dieses Bandes wird transdisziplinär den zum Teil konträren Diskursen, Reaktionsbildungen, Reformbewegungen und Utopien nachgegangen, in denen sich die Imaginationen einer vermeintlichen Krise hegemonialer weißer Männlichkeiten in Gesellschafts- und Wissensordnungen, in ästhetischen und politischen Diskursen, in der Konkurrenz von Körpermodellen und performativen Inszenierungen mediatisiert und dynamisiert. Neben dieser historischen und modernetheoretischen Verortung des Krisendiskurses werden hier die zunehmende »Krisen-Rhetorik« (Erhart 2001) in der Männlichkeitsforschung selbst, ebenso wie in den Männlichkeitsnarrationen und nicht zuletzt den rituellen Figurationen kritisch auf ihre hegemonialen Funktionen hin untersucht. Dabei soll nach dem systematischen Ort von Genderkonstruktionen in der modernen Gesellschaft gefragt und die Geschlechterordnung modernetheoretisch erfasst werden. So untersuchen die Beiträge einerseits die technischen und medialen Innovationen, die neuen Dingwelten und Medien mitsamt den veränderten Kulturtechniken und -praktiken in ihrer Wirkung auf die Geschlechterordnung, andererseits werden die Hebelwirkung rekonstruiert, 
die der Umbruch in der symbolischen Geschlechterordnung auf die Transformation in den Medien- und Wissenskulturen hatte (Beitrag Brunotte). So ist die Aneignung performativer, magischer sowie körper- und dingorientierter Praktiken - Bewegung, Energie, Fetisch, Film, Ritual - um 1900 insgesamt von Geschlechterbildern codiert. Zudem erhalten »koloniale Kontaktzonen « und Orientalisierungen entscheidende Relevanz bei der Selbstvergewisserung und Fremdheitserfahrung (in) der Moderne.

Die Beiträge folgen einem wissens(chafts)historischen Interesse, das heißt, es wird nach der impliziten und expliziten Rolle von Geschlecht bei der Erschütterung und Neuformierung von wissenschaftlichem Wissen und nach dessen Wechselwirkung mit kulturellem Alltagswissen gefragt, wie es sich neben der sozialen Praxis auch in Körperimagines, in visuellen Welten und literarischen wie mythischen Narrationen bewusst und unbewusst herstellt. Im Anschluss an die feministische Wissenschaftsforschung wird rekonstruiert, ob und wie sich die Transformation der Geschlechterordnung um 1900 auf die Etablierung - Kanonisierung und Dekanonisierung - neuer Wissenschaften wie etwa der Sexualwissenschaft, Psychoanalyse, Ethnologie und Religionswissenschaft auswirkt. Und inwiefern dieser Umbruch sich andererseits bei der Verschiebung, Krise und Neuerung im methodischen Selbstverständnis etablierter Wissenskulturen in Natur-, Technik- und Lebenswissenschaften bemerkbar gemacht hat. Neben der Frage nach der Einschreibung von geschlechtlichen Codes in die Wissensordnungen der einzelnen Disziplinen, wird auch die geschlechtliche Codierung von Materialität und Körperlichkeit der Wissensobjekte und -träger, der Medien und Methoden selbst untersucht.

Der vorliegende Band geht aus der internationalen DFG-finanzierten Tagung »Produktion und Krise hegemonialer Männlichkeit in der Moderne hervor, die im Winter 2006 von WisenschaftlerInnen und Mitgliedern des Berliner Graduiertenkollegs »Geschlecht als Wissenskategorie« an der Humboldt-Universität zu Berlin unter der Leitung von Ulrike Brunotte organisiert wurde. Eine Intention dieser Tagung war es, aus der Fülle von Einzelstudien, disziplinären Ergebnissen und methodischen Neuerungen, internationaler ForscherInnen und wissenschaftlicher Pioniere auf dem noch jungen Gebiet der Masculinity- und Men's Studies, der Moderne- und der Wissensforschung eine Art resümierende Zwischenschau des Forschungsstandes zu ermöglichen, die zugleich der selbstkritischen Reflexion auf Ergebnisse, Prämissen und Diskurse der noch jungen Männlichkeitsforschung dienen sollte. Mit Bedacht konzentrieren sich die Beiträge okzidentalismuskritisch auf die Zeit von 1880 bis 1925 und die europäische und vornehmlich deutsche Geschichte. Abgesehen von der großen Aktualität der noch transdisziplinär denkenden Wissenschafts- und GenderpionierInnen dieser Zeit, kann nur durch die zeitliche und stoffliche Konzentration des Themas eine Zusammenführung der Wissenspotentiale, 
Erkenntnis- und Blickinteressen der unterschiedlichen Disziplinen, Wissenschaftskulturen, Methoden und Medien erreicht werden.

\section{Literatur}

Andreae, Bernhard (1991): Laokoon und die Kunst von Pergamon. Die Hybris der Giganten, Frankfurt a.M.: Fischer-Taschenbuch-Verlag.

Baxmann, Inge u.a. (Hg.) (2000): Das Laokoon-Paradigma. Zeichenregime im 18. Jahrhundert, Berlin: Akademie-Verlag.

Blüher, Hans (1918): Familie und Männerbund, Leipzig: Neue Geist Verlag. Bourdieu, Pierre (1998/2005): Die männliche Herrschaft, franz. 1998, Frankfurt a.M.: Suhrkamp.

Bovenschen, Silvia (1980): Imaginierte Weiblichkeit. Exemplarische Untersuchungen zu kulturgeschichtlichen und literarischen Präsentationsformen des Weiblichen, Frankfurt a.M.: Suhrkamp.

Boyarin, Danial (1997): Unheroic Conduct. The Rise of Heterosexuality and the Invention of the Jewish Man, Berkeley: University of California Press.

Brunotte, Ulrike (2004): Zwischen Eros und Krieg. Männerbund und Ritual in der Moderne, Berlin: Wagenbach.

Bruns, Claudia (2001): »(Homo-)Sexualität als virile Sozialität. Sexualwissenschaftliche, antifeministische und antisemitische Strategien hegemonialer Männlichkeit im Diskurs der Maskulinisten 1880-1920«. In: Ulf Heidel/Stefan Micheler/Elisabeth Tuider (Hg.), Jenseits der Geschlechtergrenzen - Sexualitäten, Identitäten und Körper in Perspektiven von Queer Studies, Hamburg: MännerschwarmSkript, S. 87-108.

Bruns, Claudia (2007): Politik des Eros. Der Männerbund in Wissenschaft, Politik und Jugendkultur (1880-1934), Köln/Weimar: Böhlau.

Bublitz, Hannelore (Hg.) (1998): Das Geschlecht der Moderne. Genealogie und Archäologie der Geschlechterdifferenz, Frankfurt a.M./New York: Campus.

Butler, Judith (1991): Das Unbehagen der Geschlechter, Frankfurt a.M.: Suhrkamp.

Butler, Judith (2004): Undoing Gender, New York/London: Routledge.

Connell, Robert W. (1999): Der gemachte Mann - Konstruktion und Krise von Männlichkeiten, Opladen: Leske + Budrich.

Connell, Robert W. (2005): »Hegemonic Masculinity. Rethinking the Concept«. In: Gender a Society, 19, S. 829-859.

Detering, Heinrich (1995): Das offene Geheimnis. Zur literarischen Produktivität eines Tabus von Winckelmann bis zu Thomas Mann, Göttingen: Wallstein Verlag.

Didi-Huberman, Georges (2000): Vor einem Bild, München: Hanser.

Dinges, Martin (2005): »)Hegemoniale Männlichkeit< - Ein Konzept auf dem Prüfstand«. In: ders. (Hg.), Männer-Macht-Körper. Hegemoniale 
Männlichkeiten vom Mittelalter bis heute, Frankfurt a.M.: Campus, S. 733.

Erhart, Walter (2001): Familienmänner. Über den literarischen Ursprung moderner Männlichkeit, München: Wilhelm Fink Verlag.

Erhart, Walter (2005): »Das zweite Geschlecht: >Männlichkeit<, interdisziplinär«. In: Internationales Archiv für Sozialgeschichte der deutschen Literatur 30, Heft 2, S. 156-232.

Foucault, Michel (1973): Archäologie des Wissens, Frankfurt a.M.: Suhrkamp.

Foucault, Michel (1977): Sexualität und Wahrheit, Bd. 1. Der Wille zum Wissen, Frankfurt a.M.: Suhrkamp.

Franke, Thomas (2006): Ideale Natur aus kontingenter Erfahrung. Johann Joachim Winckelmanns normative Kunstlehre und die empirischen Naturwissenschaften, Würzburg: Königshausen \& Neumann.

Frevert, Ute (2000): Die kasernierte Nation. Militärdienst und Zivilgesellschaft in Deutschland, München: Beck.

Hausen, Karin (1978): »Polarisierung der >Geschlechtscharaktere Spiegelung der Dissoziation von Erwerbs- und Familienleben«. In: Werner Conze (Hg.), Sozialgeschichte in der Neuzeit Europas: neue Forschungen, Stuttgart: Klett, S. 161-191.

Heinrich, Klaus (1995): Floß der Medusa. 3 Studien zur Faszinationsgeschichte, Frankfurt a.M.: Stroemfeld.

Honegger, Claudia (1991): Die Ordnung der Geschlechter. Die Wissenschaften vom Menschen und das Weib, Frankfurt a.M./New York: Campus.

Kant, Immanuel (1781/1956): Kritik der reinen Vernunft (A), Frankfurt a.M.: Suhrkamp.

Klinger, Cornelia (2005): »Feministische Theorie zwischen Lektüre und Kritik des philosophischen Kanons«. In: Hadumod Bußmann/Renate Hof (Hg.), Genus. Geschlechterforschung/Gender Studies in der Kulturund Sozialwissenschaften, Stuttgart: Kröner, S. 328-364.

Koschorke, Albrecht (2000): Die Heilige Familie und ihre Folgen. Ein Versuch, Frankfurt a.M.: Fischer.

Koschorke, Albrecht (2000a): »Die Männer und die Moderne«. In: Wolfgang Asholt/Walter Fähnders (Hg.), Der Blick vom Wolkenkratzer. Avantgarden - Avantgardekritik - Avantgardeforschung, Amsterdam: Atlanta Verlag, S. 141-162.

Kucklig, Christoph (2006): Das unmoralische Geschlecht. Zur Genese der modernen Männlichkeit aus einer negativen Andrologie, unveröffentlichte Dissertation, Berlin.

Lethen, Helmut (1994): Verhaltenslehren der Kälte. Lebensversuche zwischen den Kriegen, Frankfurt a.M.: Suhrkamp.

Mehlmann, Sabine (1998): »Das vergeschlechtlichte Individuum - Thesen zur historischen Genese des Konzepts männlicher Geschlechtsidentität«. In: Hannelore Bublitz (Hg.), Das Geschlecht der Moderne. Genealo- 
gie und Archäologie der Geschlechterdifferenz, Frankfurt a.M./New York: Campus, S. 95-118.

Mehlmann, Sabine (2006): Unzuverlässige Körper: zur Diskursgeschichte des Konzepts geschlechtlicher Identität, Königstein/Taunus: Helmer.

Meuser, Michael (1998): Geschlecht und Männlichkeit. Soziologische Theorie und kulturelle Deutungsmuster, Opladen: Westdeutscher Verlag.

Mosse, George (1997): Das Bild des Mannes - Zur Konstruktion der modernen Männlichkeit, Frankfurt a.M.: S. Fischer.

Nieden, Susanne zur (2004): »>Heroische Freundesliebe< ist >dem Judengeiste fremd . Antisemitismus und Maskulinismus«. In: Julius H. Schoeps/Vera-Elke Kotowski (Hg.), Der Sexualreformer Magnus Hirschfeld. Ein Leben im Spannungsfeld von Wissenschaft, Politik und Gesellschaft, Berlin: bebraverlag, S. 329-342.

Reizbaum; Marilyn (2003): »Max Nordau and the Generation of Jewish Muscle«. In: Jewish Culture and History 6, no. 1, S. 130-151.

Richter, Simon (1992), Laocoon's Body. And the Aesthetics of Pain. Winckelmann, Lessing, Herder, Moritz, Goethe, Detroit: Wayne State University Press.

Runte, Annette (2006): Feminisierung der Kultur? Krisen der Männlichkeit und weibliche Avantgarden, Würzburg: Königshausen \& Neumann.

Rürup, Miriam (2005): »Auf Kneipe und Fechtboden. Inszenierungen von Männlichkeikeit in jüdischen Studentenverbindungen in Kaiserreich und Weimarer Republik.« In: Martin Dinges (Hg.), Männer - Macht - Körper. Hegemoniale Männlichkeiten vom Mittelalter bis heute, Frankfurt a.M.: Suhrkamp.

Sarasin, Philipp (2003): Geschichtswissenschaft und Diskursananlyse, Frankfurt a.M.: Suhrkamp.

Schmale, Wolfgang (2003): Geschichte der Männlichkeit in Europa (14502000), Köln/Weimar: Böhlau.

Schnurbein, Stephanie von (2002): Krisen der Männlichkeit. Schreiben und Geschlechterdiskurs in skandinavischen Romanen seit 1800, Göttingen: Wallststein.

Weininger, Otto (1903/1997): Geschlecht und Charakter, München: Matthes \& Seitz.

Winckelmann, Johann Joachim (1755/1995): »Gedanken über die Nachahmung der griechischen Werke in der Malerei und der Bildhauerkunst«. In: Helmut Pfotenhauer/Markus Bernauer/Norbert Miller (Hg.), Frühklassizismus. Position und Opposition. Winckelmann, Mengs, Heise, Bibliothek der Kunstliteratur, Bd. 2. Frankfurt a.M.: Deutscher Klassiker Verlag.

Winckelmann, Johann Joachim (1755/1969): »Gedanken über die Nachahmung der griechischen Werke in der Malerei und der Bildhauerkunst«. Hg. von Ludwig Uhlig, Stuttgart: Philipp Reclam Verlag. 



\title{
Von der Gottesebenbildlichkeit zur Affentragödie. Über Veränderungen im Männlichkeitskonzept
}

\author{
an der Wende zum 20. Jahrhundert
}

Cornelia Klinger

Über eine lange Strecke in der Geschichte des europäischen Denkens erhielt die Ordnung der Geschlechter ihre herrschaftliche Prägung dadurch, dass sich das männliche Geschlecht auf einen der Natur überhobenen, metaphysischen Referenzpunkt beziehen zu können meinte. In der christlichen Denktradition war dieser Bezugspunkt ein personal, männlich-väterlich imaginierter Gott, und dieser Vorstellung entsprach die Monopolisierung des Priesteramtes (einschließlich priesterlicher bzw. religiös legitimierter weltlicher Herrscher- und Hausherrenämter) durch das männliche Geschlecht. Wie immer sie im historisch konkreten Fall ausgestaltet gewesen sein mag, erlaubte diese Positionierung dem männlichen Geschlecht eine doppelte Rolle: die der Partei und des Richters zugleich¹. Auf diese Weise konnte der Mann mehr als nur eine sich in Relation zur Frau ergebende und folglich immer bloß relative Überlegenheit beanspruchen; er konnte vielmehr aufgrund seiner einseitigen Identifikation mit einer höheren Macht deren absolute Autorität für sich reklamieren und seine eigene Begrenzung und Partikularität als Geschlechtswesen hintanstellen. Das Geschlechterverhältnis war so durch eine vorgängige Asymmetrie bestimmt, die jegliche Form von Gleichstellung a priori ausschloss - sei es die der wechselseitigen Anerkennung, sei es auch nur die einer Gleichheit der Waffen im Kampf der Geschlechter. Diese Art männlicher Herrschaft, bei der dem Dualismus der Geschlechter ein heimlicher Monismus zugrunde liegt, ist als patriarchal zu bezeichnen, insofern als sie auf der

1| So zitiert Simone de Beauvoir Poulain de la Barre: »Tout ce qui a été écrit par les hommes sur les femmes doit être suspect, car ils sont à la fois juge et partie« (Beauvoir 1949: 24). 
Verordnung eines höheren, heiligen Prinzips gründet, das personal nicht nur als männlich, sondern als väterlich gedacht wird und zu dem sich das männliche Geschlecht in das privilegierte Verhältnis allein erbberechtigter Sohnschaft setzt.

Im Zuge des Modernisierungs- und Säkularisierungsprozesses, in den die westlichen Gesellschaften seit dem Ende des Mittelalters eintreten, verblasst die Vorstellung eines transzendenten Verankerungspunktes und einer von diesem abgeleiteten hierarchisch gegliederten und gestuften großen Kette des Seins. Obgleich sich in der Folge die beiden Geschlechter »vaterlos« auf derselben planen Fläche der Immanenz gegenüber stehen müssten, bleibt die Identifikation des Männlichen mit einer höheren Instanz in Kraft. Wenn nun proklamiert wird, dass das männliche Geschlecht seine Überlegenheit darauf gründet, dass es »zum AllgemeinMenschlichen wird, das die Erscheinungen des einzelnen männlichen und des einzelnen Weiblichen gleichmäßig normiert« (Simmel 1983: 52), dann identifiziert sich der Mann statt mit dem gottväterlichen Geist, mit einer universalen Vernunft, mit einer der Geschlechtlichkeit vorgängigen allgemein-menschlichen Rationalität. Damit treten die geschlechtsneutrale Vernunft bzw. das ungeschlechtliche Vernunftsubjekt Mensch oder Menschheit im Verlauf des 17./18. Jahrhunderts strukturell an die Stelle des transzendenten Bezugspunkts. Über den Graben des Transzendenzverlusts hinweg, der die symbolische Ordnung des Abendlandes tief erschüttert, bewahrt das männliche Geschlecht seine Doppelrolle, seinen privilegierten Zusammenhang mit einer der partikularen Geschlechtlichkeit über- bzw. vorgeordneten Instanz in säkularisierter, modernisierter Form. Demgegenüber bleibt die Frau wie seit jeher auf ihre partikulare, zufällige, vergängliche und nichtige Körperlichkeit reduziert. Auf diese Weise können die alten, auch immer schon geschlechtlich konnotierten Dualismen von Geist und Körper, Verstand und Gefühl, Kultur und Natur, Form und Materie ihre Geltung behalten, obwohl sie ihren ursprünglichen Entstehungs- und Legitimationszusammenhang verloren haben.

In weiterer Folge des Prozesses der Moderne werden die tiefen Differenzen, die zwischen der alten sakralen, metaphysischen, personalen Ordnung und der neuen säkularen, physisch-materiellen, universalen, sachlich-neutralen Ordnung bestehen, zunehmend zutage treten und einerseits zu Verhärtungen und Verschärfungen, aber andererseits auch $\mathrm{zu}$ Herausforderungen und Infragestellungen der Geschlechterordnung Anlass geben. Zunächst jedoch und eigentlich für erstaunlich lange Zeit bleiben diese Unterschiede latent. In den Bildern freilich, in der Wahl der Metaphern, die sich aufdrängen, wenn das Geschlechterverhältnis beschrieben werden soll, treten sie auf diskrete Weise zutage. Nicht mehr die personale Konstellation von Partei und Richter kommt Simone de Beauvoir in den Sinn, wenn sie die Doppelrolle des männlichen Geschlechts und die damit einhergehende Degradierung der Frau resümiert, sondern die materiell-sachliche Metapher der Elektrizität: »Le rapport des deux sexes n'est 
pas celui de deux électricités, de deux pôles: l'homme représente à la foix le positif et le neutre [...] La femme apparaît comme le négatif si bien que toute détermination lui est imputée comme limitation, sans réciprocité« (Beauvoir 1949: 14f.).

Die Auswirkungen dieser Asymmetrie hat Simone de Beauvoir an einem Beispiel aus ihrer alläglichen Erfahrung sehr eindrucksvoll vorgeführt. Sie berichtet: »Je me suis agacée parfois au cours de discussions abstraites d'entendre des hommes me dire: >Vous pensez telle chose parce que vous êtes une femme «.«Dieses Verdikt ist kein zufälliger Einfall eines beliebigen Diskussionspartners, der gerade im Augenblick kein besseres Argument mehr hat, sondern es manifestiert den über die Jahrhunderte hinweg wirkmächtigen Anspruch, den Mann mit dem Menschen, mit dem Gattungsbegriff, die Frau hingegen mit dem Geschlecht, mit dem Gattungsprozess zu identifizieren. Das Lebensprinzip der Frau und zwar ausschließlich der Frau auf ihre leibliche Konstitution zurückzuführen, bedeutet, ihrem Sein und Denken Geltungsansprüche unter Hinweis auf ihre Körperlichkeit zu bestreiten: »La femme a des ovaires, un utérus; voilà des conditions singulaires qui l'enferment dans sa subjectivité; on dit volontiers qu'elle pense avec ses glandes « (Beauvoir 1949: 15). Und obwohl es offensichtlich ist, dass für den Mann grundsätzlich dieselben Konditionen der Kontingenz gelten, wird dies sogar noch um die Mitte des 20. Jahrhunderts, in der Zeit, als Simone de Beauvoir diese Episode niederschreibt, oft »vergessen«: »L'homme oublie superbement que son anatomie comporte aussi des hormones, des testicules« (Beauvoir 1949: 15). Obwohl sie diesen Sachverhalt sieht, berichtet Beauvoir weiter, dass es (ihr) unmöglich gewesen wäre, einfach >den Spieß umzudrehen<, d.h. die Position ihres männlichen Diskussionspartners auf die ihr von diesem unterstellte Ebene der Immanenz herabzustufen und ihrerseits, also symmetrisch zu behaupten: »Et vous pensez le contraire parce que vous êtes un homme« (Beauvoir 1949: 15). Mit dem Einwand der geschlechtlich-körperlichen Einschränkung, mit der darauf gegründeten Ausmanövrierung ihrer Auffassungen konfrontiert, sieht Beauvoir argumentationsstrategisch nur die Möglichkeit, für den von ihr vertretenen Standpunkt den gleichen geschlechtstranszendenten Status universaler Wahrheit zu postulieren, den ihr männliches Gegenüber ganz selbstverständlich für sich beansprucht: »[...] je savais que ma seule défense, c'était de répondre: >je la pense parce qu'elle est vraie« (Beauvoir 1949: 15).

\section{tr}

Die Kontingenz, d.h. in die Bedingtheit und Beliebigkeit, die Partikularität und Pluralität menschlicher Existenz ist eine unausweichliche Folge des Säkularisierungsprozesses. Und so ist die asymmetrische Konzeption des Geschlechterverhältnisses - unbeschadet des langen Schattens, den 
sie noch bis weit ins 20. Jahrhundert hinein wirft - infolge des Verlusts ihrer metaphysischen Grundlagen langfristig zum Scheitern verurteilt. Im Verlauf des 19. Jahrhunderts kommen die Konsequenzen, die sich daraus ergeben, nach und nach zum Vorschein. Die Etappen dieses Weges lassen sich an jenen drei Denkern exemplarisch nachvollziehen, die Paul Ricoeur so zutreffend als »the masters of suspicion« bezeichnet hat, nämlich Karl Marx, Sigmund Freud und Friedrich Nietzsche (Ricoeur 1970: 32-36).

Marx' »Verdacht« richtet sich gegen das universale Vernunftsubjekt, insofern als er in den materiellen Bedürfnissen die eigentlichen Triebfedern des Denkens, Wollens und Handelns erkennt: »Der menschliche Geist erscheint ihm [dem Marxismus, C.K.] nicht mehr als pure Freiheit, als über allen Bindungen schwebende Seele; er ist nicht mehr die reine Vernunft als Teil eines Reiches der Zwecke. Er ist den materiellen Bedürfnissen ausgesetzt« (Levinas 2006: 43). Und diese materiellen Bedürfnisse situieren den Menschen nicht nur allgemein in Raum und Zeit; unter den Bedingungen von Herrschaft platzieren sie die Menschen auch unterschiedlich, ja gegensätzlich in der Gesellschaft und konditionieren sie durch diese sozial partikularen Kontexte. An die Stelle des universalen Vernunftsubjekts tritt der Antagonismus der Klassen mit divergierenden ökonomischen Interessen.

Ist es bei Marx mit der Partikularisierung des Subjekts nach Klassen in erster Linie die Differenz zwischen den Menschen, die zum Vorschein kommt, so bringt Freuds Entdeckung des Unbewussten eine Differenz des Menschen in sich selbst ans Licht. Dass »das Ich nicht Herr sei in seinem eigenen Haus « (Freud 1999: 11), dass dieses Haus noch einen anderen, dunklen Bewohner hat, ja schlimmer noch, dass das Ich selbst dieses Andere ist (»je est un Autre«, Rimbaud 1964), das ist eine mindestens ebenso beunruhigende Erkenntnis wie die Marx'sche. Freud selbst bezeichnet sie sogar als die empfindlichste »narzistische Kränkung der Menschheit« (Freud 1999: 6). Sind es bei Marx die materiellen Interessen des Habens, so sind es bei Freud die materiellen Interessen des Seins, die Triebinteressen, die als das eigentliche Motiv und Movens ins Blickfeld rücken. »Aber nicht nur das Tiefste, auch das Höchste am Ich« - »selbst feine und schwierige intellektuelle Arbeit« und »hoch gewertete seelische Leistungen« - »können unbewußt sein«. Und schließlich ist sowohl das Bewusste als auch das Unbewusste »vor allem ein Körper-Ich«. Die Seele verliert ihre Immaterialität und wird mit der Körperimago identifiziert. So macht nicht die Vernunft, die ratio, den Menschen aus, sondern er ist sein Körper: »Das Ich ist vor allem ein Körperliches« (Freud 2000: 294).

Den »Verdacht« in seiner radikalsten und umfassendsten Form artikuliert Nietzsche. Ähnlich wie bei Freud klingt dieser Verdacht, wenn es heißt: »Leib bin ich ganz und gar und Nichts außerdem; und Seele ist nur ein Wort für ein Etwas am Leibe. Der Leib ist eine große Vernunft [...] >Ich< sagst du und bist stolz auf diess Wort. Aber das Grössere ist, woran du nicht glauben willst, - dein Leib und seine grosse Vernunft: die sagt nicht 
Ich, aber thut Ich« (Nietzsche 1980: IV, 39). »Der schaffende Leib schuf sich den Geist als eine Hand seines Willens« (ebd.: IV, 40). »Dein Selbst lacht über dein Ich und seine stolzen Sprünge. >Was sind mir diese Sprünge und Flüge des Gedankens? cke. Ich bin das Gängelband des Ich's und der Einbläser seiner Begriffe« (ebd.: IV, 40).

Nietzsche erweitert den »Verdacht« gegen das Ich, den er mit Freud teilt, zu einer Herausforderung an das abendländische Denken, zu einer Umwertung aller Werte überhaupt. Scheinbar leichtfüßig, ironisch und witzig kommt seine Attacke daher: »Es steht uns Philosophen nicht frei, zwischen Seele und Leib zu trennen, wie das Volk trennt, es steht uns noch weniger frei, zwischen Seele und Geist zu trennen. Wir sind keine denkenden Frösche, keine Objektivir- und Registrir-Apparate mit kalt eingestellten Eingeweiden, - wir müssen beständig unsre Gedanken aus unsrem Schmerz gebären und mütterlich ihnen alles mitgeben, was wir von Blut, Herz, Feuer, Lust, Qual, Gewissen, Schicksal, Verhängniss in uns haben« (Nietzsche 1980: III, 349). Die Koketterie mit den Mutterpflichten von »uns Philosophen« steht in ebenso eklatantem Widerspruch zur Tradition und ist eine ebenso gezielte Provokation wie der Seitenhieb auf »das Volk«. Tatsächlich ist es wohl kaum und schon gar nicht allein das »Volk«, das so trennt, sondern das Prinzip der Dualismenbildung, diese vielleicht wichtigste Strategie des abendländischen Denkens im »gamble on transcendence« (Steiner 1971: 89), ist ein zentraler Bestandteil der gesamten philosophischen Tradition. Mit der ausdrücklichen Benennung der doppelten Differenzierung zwischen »Seele und Leib « und »Seele und Geist« spielt Nietzsche auf Platons Seelenlehre an, in der die Seele unsterblich und sterblich zugleich als Mittleres zwischen Geist und Körper steht. Aber es ist klar, dass seine Absage den modernen, den unvermittelten cartesianischen Dualismus von res cogitans und res extensa ebenso trifft wie den alten platonischen.

Unter Nietzsches Einfluss räumt die Philosophie die traditionelle, durch den modernen Rationalismus zwar modifizierte, aber noch einmal bekräftigte Position eines die Bedingungen der Kontingenz transzendierenden gottesebenbildlichen bzw. gottgleich souveränen Subjekts. Das Leib-Sein des Ich bedeutet sein Tier-Sein und mit derselben Konsequenz wie sich Nietzsche zum »Tier Mensch« (vgl. Zima 2000: 53) bekennt, erinnert er auch an seine Geschlechtlichkeit: »Grad und Art der Geschlechtlichkeit eines Menschen reicht bis in den letzten Gipfel seines Geistes hinauf« (Nietzsche 1980: V, 87).

Mit anderen Worten: l'homme pense avec ses glandes. - »Was würden frühere Generationen zu dieser Erkenntnis gesagt haben?« (Druskowitz 1988: 35 f.). 
In den Jahren und Jahrzehnten um die Wende zum 20. Jahrhundert kommt das männliche Geschlecht auf der Erde an - wo die Frau immer schon war und seit Ende des 18. Jahrhunderts durch den Diskurs der modernen Naturwissenschaften einmal mehr, noch einmal neu und erst recht degradierend, ja exkludierend verortet wurde. Die Preisgabe des geschlechtstranszendenten Geistes bzw. der geschlechtsneutralen Vernunft bedeutet einen signifikanten Wendepunkt im bis dahin herrschenden Menschenbild: Aus dem autonomen und souveränen Subjekt, das durch Geist und Vernunft vor allen anderen Lebewesen ausgezeichnet war, wird das kontingente Individuum, das durch Körper und Gefühl definiert und determiniert ist - wie alle anderen Lebewesen auch. Dieser Übergang vom universalen Subjekt zum partikularen Individuum kann als Verleiblichung und Verweiblichung, als Individualisierung und Feminisierung des Subjekts aufgefasst werden.

Übrigens sehe ich meine von philosophie- und ideengeschichtlichem Material ausgehenden Überlegungen bestätigt durch historische Studien, die auf eine Tendenz zur Verleiblichung des männlichen Geschlechts in der Zeit um 1900 hinweisen. Ebenso wie schon früher beim weiblichen Geschlecht verläuft die Verleiblichung des Mannes im Diskurs der modernen Naturwissenschaften hauptsächlich über die Schienen Sexualität/Generativität und Krankheit. Zur Sexualisierung des männlichen Geschlechts schreibt beispielsweise Ute Planert: »Blieb die Erziehung des männlichen >Maschinenkörpers zunächst auf seine Funktionstüchtigkeit in Arbeitswelt und Nationalstaat ausgerichtet, waren seit der Jahrhundertwende zunehmend auch seine reproduktiven Qualitäten gefragt. >Zeuge pflichtbewußt< hieß die Formel, die darauf abzielte, auch Männer mit einem Gattungskörper auszustatten [...] (Planert 2000: 547). Auf die Medikalisierung des männlichen Geschlechts macht u.a. George Mosse aufmerksam: »Hysteria had previously been confined to women as a sign of their tender nerves and barely controllable passions. Now, toward the end of the century, the words nervous and nervousness [...] became part of the general vocabulary« (Mosse 1996: 83); »[...] the young Sigmund Freud made his debut at the Vienna medical society in 1886 with a paper that included a discussion of male hysteria. The hysterical male, he told a discomfited audience, is not a rare or peculiar case but an ordinary case of frequent occurrence« (Mosse 1996: 85).

Der Feminisierung des Subjekts läuft - ironischerweise, aber doch kaum zufällig - etwa zeitgleich die Subjektwerdung der Frau entgegen. In vielen Ländern werden in den ersten Jahrzehnten des 20 . Jahrhunderts die Prinzipien der rechtlichen und politischen Gleichstellung, der Zugang von Frauen zu so gut wie allen wichtigen gesellschaftlichen Bereichen und öffentlichen Ämtern durchgesetzt. Mindestens teilweise erreichen Frauen diese Ziele, indem sie eben jene Bastion neutraler Rationalität und allge- 
meiner Humanität erobern, die sich das männliche Geschlecht gerade zu räumen anschickt. Während der Mann seine privilegierte Subjektstellung einbüßt, gewinnt die Frau zum ersten Mal den Status, eines - wenn schon nicht universalen, so doch wenigstens bürgerlichen - Subjekts.

Das Zusammentreffen dieser beiden Entwicklungen in den Jahren und Jahrzehnten rund um 1900 herum lassen es gerechtfertigt erscheinen, den Tod des Patriarchats anzuzeigen: »[...] in or about December, 1910, human character changed [...] All human relations shifted - those between masters and servants, husbands and wives, parents and children. And when human relations shift there is at the same time a change in religion, conduct, politics, and literature « (Woolf 1967: 320f.). Weniger in ihrer Datierung (deren überzogen konkrete Fokussierung auf einen bestimmten Monat in einem bestimmten Jahr wohl vor allem den Zweck verfolgt, der überwältigenden Plötzlichkeit und Heftigkeit des Umbruchs einen poetisch verdichteten Ausdruck zu verleihen), aber dafür umso mehr in ihrer Perspektive verdient es Virginia Woolf, wörtlich genommen zu werden: In der Erschütterung der überlieferten patriarchalen Strukturen - die sie präzise, nämlich in ihren drei traditionalen Dimensionen als Herrschaft des Herrn, des Mannes und des Vaters über Gesinde (»servants«), Frau und Kinder, mithin als Klassen-, Geschlechter- und Generationenherrschaft anspricht - erkennt sie nicht bloß die Folgen, sondern sogar die eigentlichen Ursachen eines grundstürzenden gesellschaftlichen und kulturellen Wandels.

Wenn wir an dieser Stelle einen Schritt zurücktreten, um die Veränderungen der Geschlechterordnung in den Zusammenhang des Modernisierungsprozesses zu stellen und nach den Stationen zu fragen, über welche die Modernisierung der Geschlechterordnung verläuft, so finden wir an der Wende vom 18. zum 19. Jahrhundert (vgl. Klinger 2004) und vom 19. zum 20. Jahrhundert zwei gleichermaßen bedeutsame Schnittstellen. Auch auf die Gefahr unzulässiger Vereinfachung hin würde ich behaupten, dass es um 1800 in erster Linie der Weiblichkeitsdiskurs ist, der zur Disposition und folglich im Zentrum der Diskussion steht. Im Licht von Aufklärung und Revolution stellt sich das Problem, ob und wie der allgemeine Aufbruch der Gesellschaft die überlieferte Geschlechterordnung berührt: Kann und soll die Vorherrschaft des Mannes noch behauptet und begründet werden, wenn die allgemeine Freiheit und Gleichheit aller Menschen postuliert wird? Der Streit, der in der Zeit des Umbruchs um $1800 \mathrm{um}$ die »Frauenfrage« entbrennt, kommt auch in der nachfolgenden Periode der Restauration nicht wieder zur Ruhe. Denn auch dann, wenn die Aufrechterhaltung bzw. Wiederherstellung des hierarchischen Geschlechterverhältnisses intendiert wird, bedarf es dazu eines erheblich vergrößerten und gänzlich veränderten argumentativen Aufwands. Der alte Wein muss in neue Schläuche gefüllt werden. Im Diskurs der sich in diesem Zeitraum entwickelnden modernen Naturwissenschaften, werden die alten Weisheiten der Geschlechterphilosophie, die Weiblichkeit mit Immanenz, Körper, Materie, Passivität identifiziert, in die neuen Begrifflichkeiten von 
Biologie, Anthropologie, Physiologie, Psychologie, Gynäkologie usw. übersetzt. Die untergeordnete gesellschaftliche Stellung der Frau wird mittels Sexualisierung und Medikalisierung, d.h. durch eine einseitig Weiblichkeit betreffende Modernisierung des Geschlechtskörpers legitimiert.

Auf den im großen und ganzen restaurativen Verlauf der Geschlechterdebatten des 19. Jahrhunderts ist es zurückzuführen, dass »the gender trouble«, der an der Schwelle zum 19. Jahrhundert entsteht, vorrangig die gesellschaftliche Stellung der Frau ins Blickfeld rückt und auf den Männlichkeitsdiskurs nicht so recht überspringt - obwohl es sich doch von selbst $\mathrm{zu}$ verstehen scheint, dass die Problematisierung der Position eines Geschlechts auch das andere tangieren muss. Indem das Projekt der Aufklärung wenn schon nicht scheitert, so doch in den arretierten bürgerlichen Revolutionen »unvollendet« bleibt, folgt der kurzen Bewegung des Aufbruchs eine lange Phase der Restauration bzw. der Konsolidierung bürgerlicher Herrschaft. Im Ökonomischen und Politischen geraten die patriarchalen Strukturen zwar zunehmend unter Druck, während das Patriarchat im privaten Bereich, im Geschlechter- und Generationenverhältnis sogar eine merkwürdig verspätete, sentimentalisierte Blütephase erlebt. In dieser gleichsam gestundeten Zeit des langen 19. Jahrhunderts kann sich das männliche Geschlecht noch einigermaßen ungestört im dogmatischen Schlummer seiner göttlichen Vernunft wiegen. Der entscheidende Einschnitt im Männlichkeitsdiskurs erfolgt erst um die Wende vom 19. zum 20. Jahrhundert, also um rund hundert Jahre nach dem Einbruch der Moderne in den Weiblichkeitsdiskurs ${ }^{2}$. An diesem Punkt kann vom Ende des Patriarchats gesprochen werden.

In dem Moment, in dem sich der aus der Transzendenz herabsteigende Mann und die aus der Immanenz der spätpatriarchal-häuslichen Privatsphäre wenigstens zu bürgerlichen Rechten auf- bzw. aussteigende Frau nun gewissermaßen auf gleicher Augenhöhe begegnen, reichen sie einander nicht unbedingt versöhnt die Hände. Es wäre ein schwerwiegender Irrtum, den Tod des Patriarchats mit dem Ende des Herrschaftsanspruchs des männlichen Geschlechts zu verwechseln. Statt die hinfällig gewordenen Privilegien aufzugeben, treten mindestens einige durchaus einflussreiche männliche Zeitgenossen an, sie neu zu reklamieren. Obwohl der Mann sich definitiv auf dieselbe Stufe der Seinsordnung gestellt sieht wie die Frau, hat dieser Wandel für den »Kampf der Geschlechter« um die

2I Damit widerspreche ich George Mosse, der die These vertritt, dass sich das moderne Männlichkeitsideal in der zweiten Hälfte des 18. Jahrhunderts in Korrespondenz mit der Emanzipation und der Machtergreifung des Bürgertums entwickelt habe. Obwohl Mosse das späte 18. Jahrhundert als die Geburtsstunde des sich wenig dramatisch entwickelnden und bis in die Gegenwart einigermaßen ungebrochen in Geltung bleibenden Maskulinitätsideals ansieht, erkennt auch er einen »distinct turning point« zwischen den $1870 e r$ Jahren und dem Ersten Weltkrieg (Mosse 1996: 78). 
Jahrhundertwende ambivalente, ja sogar ausgesprochen problematische Folgen.

Aus der Position vorgeordneter väterlicher sowie neutraler rationaler Autorität vertrieben, wird der spezifisch männliche Charakter aller gesellschaftlichen Aktivitäten und kulturellen Leistungen erkannt und ausgesprochen: »Die künstlerischen Forderungen und der Patriotismus, ebenso wie der Kosmopolitismus, die allgemeine Sittlichkeit und die besonderen sozialen Ideen, die Gerechtigkeit des praktischen Urteils und die Objektivität des theoretischen Erkennens ... all diese Kategorien sind zwar gleichsam ihrer Form und ihrem Anspruch nach allgemein menschlich, aber in ihrer tatsächlichen historischen Gestaltung durchaus männlich « (Simmel 1983: 52). Allerdings folgen diesem Eingeständnis kein Zugeständnisse, sondern ein Beharrungsbeschluss männlicher Vorherrschaft über seine Gleichsetzung mit dem Menschlichen oder Göttlichen hinaus. Das Feigenblatt vor dem männlichen Geschlecht wird fallen gelassen; der seit jeher einseitige Anspruch des männlichen Teils, das Ganze zu repräsentieren, verliert seine sakrale oder neutrale Hülle. Es wird damit ein Dominanzanspruch explizit gemacht, dessen Wirksamkeit über viele Jahrhunderte darauf beruhte, dass er implizit blieb. Kurzum, das Ende des Patriarchats ruft eine extrem maskulinistische Reaktion hervor, hinter deren demonstrativer Stärke sich Schwäche verbirgt.

Nietzsches Einsicht, dass die Geschlechtlichkeit eines Menschen bis in den letzten Gipfel seines Geistes hinaufreicht, bedeutet in diesem historischen Kontext gerade kein bescheidenes Bekenntnis zur Partikularität und Begrenztheit geistiger Leistungen, er lässt lediglich die Forderungen des egalitären/humanistischen Feminismus, der seit Poullain de la Barre unter dem Motto gestanden hat: »the brain is not an organ of sex « 3 bzw. »das Gehirn ist kein Geschlechtsorgan «, ins Leere laufen. Frauen und Frauenbewegung sehen sich nun mit dem Vorwurf konfrontiert, die »Vermännlichung « der Frau anzustreben, da ja alle Felder von Kultur und Gesellschaft männlich besetzt sind. Ein Beispiel, wie aggressiv die Emanzipations- und Partizipationsansprüche von Frauen zurückgewiesen werden, bietet der Philosoph Max Scheler. Er polemisiert gegen jene »Bildungs-Damen«, die ihr Geschlecht verleugnen und »sich das pure Menschentum zum Ziel [machen]« (Scheler 1955: 195). Scheler hält dem entgegen, dass »die Bedeutung des Wortes Mensch nie eine völlig neutrale sein« kann, »da es zum Wesen des Menschen selbst gehört, immer entweder männlich oder weiblich zu sein [...] Ein Weib, das ein >prachtvoller Mensch< sein will, [...] wird faktisch immer ein Affe des Mannes sein«, denn »[...] die Idee eines Menschen, der Mann und Weib umfassen soll, ist nur eine männliche Idee« (Scheler 1955: 195).

3| So die Frauenrechtlerin Charlotte Perkins Gilman (1860-1935) 1898 in Women and Economics. 
Apropos Affe4: Helene von Druskowitz zieht 1905 in ihren pessimistischen Kardinalsätzen folgendes Fazit: »Infolge einer wahrhaft göttlichen Ironie des Schicksals ist es gelungen, ihn [den Mann, C.K.] so zu stellen, daß er auf dem Höhepunkt der Bildung befindlich sich selbst für einen Affensprößling hält. Was würden frühere Generationen zu dieser Erkenntnis gesagt haben? Nun ist das gesamte Leben zur Affentragödie des Mannes geworden « (Druskowitz 1988: 35f.).

Bleibt daran zu erinnern, dass Affentragödien zwar komisch, aber deswegen nicht harmlos sind. Auf das Ende des Patriarchats folgt kein Goldenes Zeitalter des Friedens und der Harmonie im Allgemeinen und zwischen den Geschlechtern im Besonderen, sondern ein Interregnum konkurrierender großer Brüder, deren marodierende Männerhorden eine blutige Spur durch das 20. Jahrhundert gezogen haben. Und bis heute gehören Reaktionen der Essentialisierung von (Geschlechts-)Natur und gesellschaftlich-politische Virilisierungsversuche noch längst nicht der Vergangenheit an. Für die gender studies ergibt sich hieraus das Desiderat, genauer zwischen Patriarchalismus und Maskulinismus zu differenzieren. Nicht jede Art männlicher Herrschaft ist patriarchal, und mit dem Ende des Patriarchats in den westlichen Gesellschaften um die Wende zum 20. Jahrhundert ist noch keineswegs unbedingt und unzweideutig das Ende der männlichen Dominanz erreicht. Der post-patriarchale Maskulinismus ist gerade aufgrund seiner prekären Legitimationsgrundlage und in seiner relativen Schwäche gefährlich und wird es wohl noch für absehbare Zeit bleiben.

\section{Literatur}

Beauvoir, Simone de (1949): Le deuxième sexe, Paris: Gallimard.

Druskowitz, Helene von (1988): Der Mann als logische und sittliche Unmöglichkeit und als Fluch der Welt. Pessimistische Kardinalsätze (1905), hg. v. Traute Hensch, Freiburg: Kore.

4| Noch einmal apropos Affe: Da ich im vorliegenden Zusammenhang das Thema vorwiegend aus einer philosophiegeschichtlichen und subjekttheoretischen Perspektive behandle, bleiben jene Aspekte, die eher in einen (natur-)wissenschaftlichen Kontext gehören, weitgehend unberücksichtigt. Wenigstens in einer Fußnote möchte ich auf die von Freud neben die kopernikanische und die psychologische gestellte »biologische Kränkung « hinweisen, die in der vor allem auf Darwin und die Evolutionstheorie zurückgehenden Erkenntnis liegt, dass der Mensch mit dem Tier einen gemeinsamen Stammbaum besitzt. Eine genauere Auseinandersetzung würde zeigen, dass auch diese Enttäuschung des Anspruchs auf eine Sonderstellung des Menschen in bzw. über der Natur nicht Anlass zu einer grundsätzlichen Revision der Geschlechterordnung geworden ist, sondern lediglich dazu geführt hat, die hierarchische Geschlechterdifferenz mit den neuen Argumenten der Evolutionstheorie zu begründen. 
Freud, Sigmund (1999): »Eine Schwierigkeit der Psychoanalyse«. In: Anna Freud et al. (Hg.), Gesammelte Werke. Bd. 12, Werke von 1917-1920, Frankfurt a.M.: Fischer, S. 3-12.

Freud, Sigmund (2000): »Das Ich und das Es« (1923). In: Studienausgabe. Bd. III: Psychologie des Unbewußten, Frankfurt a.M.: Fischer.

Klinger, Cornelia (2004): »1800 - eine Epochenschwelle im Geschlechterverhältnis? «In: Katharina Rennhak/Virginia Richter (Hg.), Revolution und Emanzipation. Geschlechterordnungen in Europa um 1800, Köln/ Wien: Böhlau, S. 17-32.

Levinas, Emmanuel (2006): »Einige Überlegungen zur Philosophie des Hitlerismus«. In: Frank Miething/Christoph von Wolzogen (Hg.), Après vous. Denkbuch für Emmanuel Levinas 1906-1995, Frankfurt a.M.: Verlag Neue Kritik, S. 38-54.

Mosse, George L. (1996): The Image of Man: The Creation of Modern Masculinity, Oxford University Press.

Nietzsche, Friedrich (1980): Sämtliche Werke. Kritische Studienausgabe in 15 Bänden, hg. v. G. Colli und M. Montinari, Berlin/München: de Gruyter/dtv.

Planert, Ute (2000): »Der dreifache Körper des Volkes: Sexualität, Biopolitik und die Wissenschaften vom Leben«. In: Geschichte und Gesellschaft 26, S. 539-576.

Ricoeur, Paul (1970): Freud and Philosophy: An Essay on Interpretation, New Haven: Yale University Press.

Rimbaud, Arthur (1964): Briefe und Dokumente, hg. v. C. Ochwadt, Reinbek: rowohlt.

Scheler, Max (1955): Vom Umsturz der Werte (1919). In: Maria Scheler (Hg.), Gesammelte Werke. Bern: Francke.

Simmel, Georg (1983): Philosophische Kultur. Über das Abenteuer, die Geschlechter und die Krise der Moderne, Berlin: Wagenbach.

Steiner, George (1971): In Bluebeard's Castle: Some Notes Towards the Redefinition of Culture, New Haven: Yale University Press.

Woolf, Virginia (1967): »Mr. Bennett and Mrs. Brown« (1924). In: Collected Essays, Vol. 1, New York: Harcourt, Brace \& World.

Zima, Peter (2000): Theorie des Subjekts. Subjektivität und Identität zwischen Moderne und Postmoderne, Tübingen/Basel: Francke. 



\section{Das sexu(alis)ierte Individuum -}

\section{Zur paradoxen Konstruktionslogik}

\section{moderner Männlichkeit}

SABine MEHLMANN

\section{Einleitung}

Im Mittelpunkt des Beitrags stehen zwei zentrale Konstruktionsmodi moderner Männlichkeit: die Konstruktion des Mannes als >überlegenes< Geschlecht und die des Mannes als geschlechtsneutralem Menschen (vgl. Klinger 2005: 334). Beide haben - so Cornelia Klinger - in ihrer Verknüpfung wesentlich zur Fundierung und Stabilisierung der hegemonialen Position des Männlichen in der Geschlechterordnung beigetragen.

Im Folgenden möchte ich einen Blick auf die historische Genese dieser beiden Konstruktionsmodi und die darin eingelassenen sinternen< Paradoxien sowie ihre geschlechtertheoretische Einbettung werfen. Ausgehend von der >paradoxen Sexuierung< des mann-menschlichen Individuums im medizinisch-anthropologischen Diskurs über die Geschlechtscharaktere zu Beginn des 19. Jahrhunderts widmet sich der zweite Abschnitt der >paradoxen Sexualisierung< der Geschlechterdifferenz am Beispiel der Evolutionstheorie und der Sexualpathologie im letzten Drittel des 19. Jahrhunderts. Im Mittelpunkt des letzten Abschnitts stehen die Geschlechtertheorien Otto Weiningers und Sigmund Freuds, die im Zeichen einer sich um 1900 zuspitzenden >Erosion < der Geschlechterordnung und ihrer legitimatorischen Naturbegründung stehen.

Der Fokus der Betrachtung liegt auf den Akzentverschiebungen und Verlagerungen, die sich sowohl in Bezug auf die beiden Konstruktionsmodi »männlicher Hegemonie« (Meuser/Scholz: 2005) ${ }^{1}$ als auch im Hinblick

1| Meuser/Scholz führen den Begriff »männliche Hegemonie« ein, um die »Produktion, Reproduktion, aber auch Transformation männlicher Macht« zu fas- 
auf die zugrunde liegenden geschlechtertheoretischen Paradigmen ergeben: Der bei Weininger und Freud in je unterschiedlicher Weise begründete >Paradigmenwechsek von einer biologischen zu einer psychologischen Begründung geschlechtlicher Identität wird vor diesem Hintergrund als $>$ Umschrift einer zweigeschlechtlich und asymmetrisch-hierarchisch strukturierten Geschlechterdifferenz betrachtet: Hier zeichnet sich eine »Vergeschlechtlichung $\ll^{2}$ des mann-menschlichen Individuums (Mehlmann 1998: 97) ab, welches seinen hegemonialen Anspruch nunmehr als erstes Geschlecht behauptet. ${ }^{3}$

\section{'Paradoxer Sexuierung}

Die Kritik feministischer Philosophinnen am Androzentrismus moderner Rationalitäts- und Subjektkonzeptionen hat aufgedeckt, »dass sich hinter den vorgeblich auf das geschlechtneutrale Menschliche beziehenden Positionen männliche Perspektiven und Interessen verbergen bzw. umgekehrt formuliert, daß im Konzept >des Menschen< der weibliche Mensch nicht oder nur in höchst prekärer und sekundärer Weise enthalten ist« (Klinger 2005: 334). Mit der Konzeption des geschlechtsneutralen bürgerlichen Vernunftsubjekts, die sich im philosophischen Diskurs der Aufklärung formiert, wird der Mann als alleiniger Träger von Wissen und Erkenntnis und als Begründer moralischer Werte eingesetzt, während die Frau - metaphorisch und faktisch - aus dem Bereich der selbstreflexiven Vernunft ausgeschlossen und in den Bereich der Familie zur Reproduktion der

sen, die auf der »Dominanz männlicher Wert- und Ordnungssysteme, Interessen, Verhaltenslogiken und Kommunikationsstile etc.« basiert. Bei aller Unterschiedlichkeit liegt, so Meuser/Scholz, der gemeinsame Kern dieser sozialen Praktiken darin, dass »das Männliche [...] als Norm und gegenüber dem Weiblichen als überlegen« (Meuser/Scholz 2005: 223) gesetzt wird. Im Unterschied zu Connell, der in seinem Konzept »hegemonialer Männlichkeit« (Connell 1999), »die symbolische Mächtigkeit der Vorstellung von der männlichen Überlegenheit« (Meuser/Scholz 2005: 224) verkenne, wird im Rekurs auf Bourdieus Konzept der symbolischen Gewalt die Wirkungsmacht der naturalisierten hierarchischen Zweigeschlechtlichkeit akzentuiert, in der diese Vorstellung bereits eingeschrieben ist. Als ein weiteres zentrales Moment der Reproduktion männlicher Hegemonie bestimmen Meuser/ Scholz - mit Simmel - die »Hypostasierung des Männlichen zum AllgemeinMenschlichen«, welche die Herrschaft von Männern »als Herrschaft unkenntlich macht und einer Wahrnehmung als geschlechtlich markiert entzieht« (ebd.: 225).

2। Der Begriff der >Vergeschlechtlichung zielt hier speziell auf die explizite Konstruktion des Mannes als Geschlechtswesen. Der im Folgenden ebenfalls verwendete Begriff der >Sexuierung < bezieht sich demgegenüber allgemeiner auf die geschlechtliche Codierung von Körper, Psyche und sexuellem Begehren.

3 I Vgl. den Beitrag von Cornelia Klinger in diesem Band. 
Gattung verwiesen wird. Die Gestaltung von Gesellschaft und Geschichte nach Maßgabe der Vernunft wird damit zum geschlechtlichen Privileg des männlichen Menschen, ein Privileg, das jedoch nicht als geschlechtliches thematisiert wird bzw. werden muss. Die universalistische Konzeption des selbstreflexiven Subjekts konturiert sich im Kontrast zur Markierung der Frau als Geschlechtswesen - die Bestimmung des Mannes als >allgemein-menschliches Individuum stützt sich auf die Verschiebung alles Geschlechtlich-Partikularen auf die Frau. Das >Besondere< des MenschenMannes besteht demgegenüber in seiner Entbindung vom Geschlecht, dem die vergeschlechtlichte Frau als Negativfolie gegenübergestellt wird.

Im Horizont des Konzepts der Geschlechtscharaktere, das im medizinisch-anthropologischen Diskurs an der Wende vom 18. zum 19. Jahrhundert entsteht, wird diese asymmetrisch-hierarchische Differenzkonstruktion, die der Unterscheidung Individuum Mann/Geschlechtswesen Frau folgt, biologisch fundiert. Die Neubegründung der »Ordnung der Geschlechter« (Honegger 1991), die nicht zuletzt aufgrund des aufklärerischen Postulats einer als Naturrecht verankerten Gleichheit aller Menschen notwendig wurde (vgl. Hark 1999: 84), stützt sich - wie Thomas Laqueur (1992) gezeigt hat - auf das neue Modell einer radikalen Verschiedenartigkeit und Unvergleichbarkeit der weiblichen und männlichen Geschlechtsorgane. Die Konstruktion des Körpers als »erzeugungsmächtiger >Analogien-Operator« (Honegger 1991: 8), aus dessen geschlechtsspezifischer Organisation die Geschlechtscharaktere von Männern und Frauen und deren soziokulturelle Bestimmung nur noch abgelesen werden müssen, basiert - so Claudia Honegger - auf einer epistemologischen Wende in der Thematisierung >des Menschen< durch die Humanwissenschaften. Dabei wird der Körper nicht nur als psycho-physische Einheit aufgewertet, sondern »zum Ursprungsort einer diffusen, dunklen und dennoch zwingenden Kausalität, die die organischen Gegebenheiten in psychische und moralische Qualitäten [der Geschlechter] übersetzt« (Schäffner/Vogl 1998: 224).

Im Mittelpunkt des Diskurses über die Geschlechtscharaktere stehen jedoch vor allem die >Besonderheiten $<$ des weiblichen Geschlechts, das als Abweichung von der Norm des - männlichen - Menschen entworfen wird. Während die >Organisation > des weiblichen Körpers als von Schwäche und Sensibilität durchdrungen charakterisiert ist, wird aus der Konstitution des männlichen Körpers »neben der kraftvollen, der Stärke der Organe geschuldeten Fähigkeit zur Weltveränderung [...] die [...] Überlegenheit des Verstandes zur Wirkung auf die Natur und die übrigen lebenden Wesen« (Honegger 1991: 159) abgeleitet.

Die aus der Struktur und Funktion sexuierter Körper abgelesene hierarchische Differenz der Geschlechter assoziiert Mann und Frau zugleich auf unterschiedliche Weise mit dem Geschlechtlichen (vgl. Bührmann 1995): Während die Frau aufgrund ihrer körperlichen Organisation und ihrer reproduktiven Funktionen den Gesetzen des Geschlechts unterworfen ist, 
gelten diese Gesetze für den Mann in paradoxer Einschränkung: Gerade der männliche Körper soll jene weitgehende Entbindung vom Geschlechtlichen ermöglichen, die den Mann qua Geschlecht zur Verkörperung des Allgemein-Menschlichen macht. Diese Gleichzeitigkeit von >Sexuierung< und >De-Sexuierung<, die die Begründung der Geschlechtscharaktere als Einheit von körperlicher Organisation, Fortpflanzungszweck und psychisch-sozialer Bestimmung zugleich aufgreift und relativiert, wird u.a. im Rückgriff auf anatomisch-morphologische Analogien plausibilisiert: Im Unterschied zum Gattungswesen Frau, das vom Uterus bzw. später den Eierstöcken >beherrscht< ist, werden die spezifische Funktion und Lage der männlichen Zeugungsorgane als Zeichen der Unabhängigkeit von geschlechtlichen Bestimmungen und Begrenzungen gelesen (vgl. Honegger 1991: 198f.; Mehlmann 1998: 105).

\section{'Paradoxe، Sexualisierung}

Das Projekt der »Polarisierung der Geschlechtscharaktere« wird nach Karin Hausen (1976) insbesondere dadurch fundiert und abgestützt, dass das Modell einer grundsätzlichen Verschiedenheit der Geschlechter mit der These einer >natürlichen Komplementarität im Rahmen einer ehelichmonogamen »Liebes- und Fortpflanzungsgemeinschaft« (Soine 2002: 142) verknüpft wird.

Historisch parallel zu den medizinisch-anthropologischen Diskursen über die Geschlechtscharaktere ereignet sich eine >Diskursexplosion< über das >Sexuelle<, die sich - wie Michel Foucault (1989) gezeigt hat - vor allem auf die Abweichungen von der Norm der ehelichen fortpflanzungsbezogenen Sexualität konzentriert. Neben den Figuren des masturbierenden Kindes und der hysterischen Frau avanciert insbesondere der perverse - männliche - Erwachsene zum privilegierten Gegenstand medizinischpsychiatrischen Wissens. Darin wird die Idee eines im Körper verankerten snatürlichen< Sexualtriebs als sinnere Wahrheit< der Individuen hervorgebracht, ein Trieb, der die Geschlechter aufeinander bezieht und zugleich voneinander unterscheidet. Die >Sexualisierung< der Geschlechterdifferenz, die in sinnergeschlechtlicher< Dimension mit der Konstruktion von »Antitypen« (Mosse 1996) als >Kehrseite< der Norm »hegemonialer Männlichkeit« (Connell 1999) einhergeht, möchte ich nun exemplarisch an zwei zentralen Diskurspositionen betrachten: Zum einen an Charles Darwins 1871 veröffentlichtem Werk »Die Abstammung des Menschen«, das zwar nicht explizit den $>$ Wissenschaften vom Sex zugeordnet werden kann, in dem sich aber gleichwohl jene Wendung zum >Sexuellen< spiegelt; zum anderen an Richard von Krafft-Ebings erstmals 1886 erschienener »Psychopathia sexualis«, die zum Standardwerk der Sexualpathologie des 19. Jahrhunderts avanciert. 


\section{Darwin: Geschlechtliche Zuchtwahl als Modus geschlechtlicher Differenzierung}

In der Evolutionstheorie Darwins wird die geschlechtliche Differenzierung in eine umfassende Theorie der Entstehung der Arten integriert, welche die Genealogie des Menschen einschließt. Die >Polarisierung der Geschlechtscharaktere <wird darin als Ergebnis optimierender Ausleseprozesse bestimmt, die als Werk einer durch Nützlichkeit und Zweckmäßigkeit charakterisierten >Natur< erscheinen. Im Rahmen des Konzepts der geschlechtlichen Zuchtwahl erhält Sexualität einen zentralen Stellenwert: Hier wird ein kausaler Zusammenhang zwischen sexueller Begierde, Fortpflanzungsauslese und evolutionärer (Höher-)Entwicklung einerseits und der Ausbildung der sogenannten sekundären körperlichen und geistigen Geschlechtsmerkmale ${ }^{4}$ andererseits hergestellt. Im Unterschied zur natürlichen Zuchtwahl, die nach Darwin auf dem Erfolg beider Geschlechter im >Kampf ums Dasein basiert, wird die geschlechtliche Zuchtwahl als Kampf um die besten Fortpflanzungschancen zwischen rivalisierenden Männchen einer Spezies charakterisiert. Die Aktivität des mit dem >Brutgeschäft< betrauten Weibchens bleibt demgegenüber auf die Wahl des am besten ausgestatteten Männchens beschränkt, das seine superioren Eigenschaften auf dem Wege der Vererbung weitergibt und so zur »Verbesserung der natürlichen Rassen« (Darwin 1951: 220) beiträgt. Die Optimierung zweckmäßiger (Spezies-)Merkmale durch sexuelle Selektion wird damit an das männliche Geschlecht gebunden. Im Rahmen dieser >männlichen Genealogieく, die auf der »heißere[n] Begierde« (ebd.: 232) der männlichen Exemplare bei (fast) allen Tierarten gründet, wird die Entwicklung körperlicher und geistiger Unterschiede zwischen den Geschlechtern als »permanente Steigerung der >Männlichkeit«« (Bergmann 1998: 108) konzipiert, die sich im Laufe der Evolution von einer mit >Kindlichkeit<, >Indifferenzく und (primitiver) >Ursprünglichkeit< assoziierten Weiblichkeit abzuheben beginnt (vgl. Darwin 1951: 556). Hier nimmt Darwin allerdings eine bemerkenswerte Einschränkung vor: Während er »die bedeutendere Größe, Kraft, Kühnheit, Kampflust und Energie« (ebd.: 602) auf die geschlechtliche Zuchtwahl zurückführt, wird die Entwicklung >höherer Fähigkeiten wie »Beobachtung, Verstand, Erfindungsgabe und Phantasie« (ebd.: ${ }_{5}$ 62f.) mit der Funktion des Mannes als Ernährer und Beschützer der Familie verknüpft und in den Kontext der natürlichen Zuchtwahl gestellt. Darüber hinaus hebt Darwin hervor, dass sich die sexuelle Rivalität beim Mann in Folge des Zivilisationsprozesses abgeschwächt habe. Gleichwohl

4| Im Unterschied zu den primären Geschlechtscharakteren, die die Fortpflanzungsorgane bezeichnen, bezieht sich der Begriff der sekundären Geschlechtscharaktere auf alle weiteren körperlichen und geistigen Geschlechterdifferenzen, »die mit dem Fortpflanzungsakt in keinem direkten Zusammenhang stehen« (Darwin 1951: 216). 
unterliege dieser »in der Zeit seiner Mannbarkeit, wenn er für sich und seine Familie zu sorgen hat, einem harten Kampf ums Dasein [...]; das aber wird dazu führen, daß sich seine geistigen Fähigkeiten erhalten oder gar noch vermehren, worauf die jetzige Ungleichheit der Geschlechter beruht« (ebd.: 564). Bezogen auf den organischen Sitz jener geistigen Überlegenheit, nimmt Darwin an, dass diese vor allem im >absolut größeren< (vgl. ebd.) Gehirn des Mannes ihren Niederschlag gefunden hat. Die über die Größe des >Kulturorgans < bestimmte Differenz und Hierarchie zwischen den Geschlechtern wird dabei zugleich als Kriterium für die Hierarchisierung von Rassen bzw. von >zivilisierten< weißen und >unzivilisierten schwarzen Männern eingesetzt. Darwin stützt sich dabei auf eine zentrale Hypothese der auf Gehirnvergleiche und Schädelmessungen spezialisierten anthropologischen Forschung, wonach der »Unterschied der Geschlechter in bezug auf die Schädelhöhle mit der Vervollkommnung der Rasse zunimmt, so daß der Europäer weit mehr die Europäerin überragt, als der Neger die Negerin« (ebd.: Anm. 431).

In geschlechtertheoretischer Perspektive verweist Darwins phylogenetische Argumentation, die den sindirekten< Einfluss des Nervensystems auf die »progressive Entwicklung zahlreicher körperlicher und gewisser geistiger Eigenschaften« (ebd.: 431) hervorhebt, auf eine Entkoppelung anatomischer und psychophysischer Geschlechtscharaktere. Für die Ontogenese wird jedoch der Einfluss der Keimdrüsen auf jene im Gehirn verorteten geistigen Eigenschaften akzentuiert. Hier führt Darwin - am Beispiel des Mannes - die »Tatsache« an, dass »manche[r] unserer [!] geistigen Fähigkeiten [...] bekanntlich erstens zur Zeit der Geschlechtsreife einer beträchtlichen Veränderung unterliegen und daß zweitens Eunuchen Zeit ihres Lebens in diesen Eigenschaften minderwertig sind « (ebd.: $56_{3}$ ).

Darwins Theorie der geschlechtlichen Zuchtwahl markiert eine Neuakzentuierung des Sexuellen für die Höherentwicklung der Gattung und die geschlechtliche Differenzierung, die beide auf die größere >Begierdeく des männlichen Teils der Spezies zurückgeführt werden. In dieser Perspektive ist es die Ausstattung mit den stärkeren >Leidenschaften< (als Wille zur Fortpflanzung), die das >Fortschreiten « der menschlichen Gattung und die Fähigkeit zur Differenzierung und Individuierung an das - überlegene - männliche Geschlecht bindet. Umgekehrt erscheint die Undifferenziertheit und >Stagnation ‘ des weiblichen Teils der Spezies als Folge seiner geringeren sexuellen >Potenz $\prec$. Im Kontext dieser Argumentation zeichnet sich die Tendenz zu einer >Sexualisierung< des männlichen Individuums ab: Wurde im Konzept des männlichen Geschlechtscharakters die Superiorität des Mannes als Repräsentant des Allgemein-Menschlichen mit der Fähigkeit zur Transzendenz der Geschlechtlichkeit begründet, werden in Darwins Theorie der geschlechtlichen Zuchtwahl Triebstärke, individuelle Variabilität und Entwicklungsfähigkeit parallelisiert. Die Bedeutung der sexuellen Dominanz für die Ausprägung der geistigen Individualität (und Überlegenheit) des Menschen-Mannes wird allerdings mit Verweis 
auf den Zivilisationsprozess relativiert und mit Blick auf die männliche Ernährer- und Beschützerrolle als Resultat des Konkurrenzkampfes in einer »aggressive[n] Männerkultur« (Bergmann 1998: 113) konzipiert. Die im ersten Teil skizzierte Strategie einer >paradoxen Sexuierung< des männlichen Körpers finden sich in Darwins Entwurf einer dominanten, virilaggressiven, gleichwohl >kulturtragenden< (weißen) Männlichkeit nur in Ansätzen: Der Hinweis auf die Vererbung, die Macht des Nervensystems sowie die Verortung der geistigen Überlegenheit des Mannes im Gehirn legt zwar eine vom anatomischen Geschlecht unabhängige Entwicklung nahe. Auf der Folie einer >organischen Verbindung zwischen Gehirn und Genitalien werden jene geistigen Fähigkeiten jedoch unmittelbar an die Funktion der männlichen Keimdrüsen gebunden.

\section{Krafft-Ebing: (Hetero-)Sexualität als Ordnung des Geschlechts}

Krafft-Ebings »Psychopathia sexualis« markiert eine Neuordnung von Sexualität und Geschlecht im Rahmen einer fortpflanzungsbezogenen heterosexuellen Matrix, in der sich die Norm eines >gesunden $<$ d.h. reproduktionsorientierten Sexualverhaltens und die Norm einer exklusiven psychophysischen Zweigeschlechtlichkeit überkreuzen. Während bei Darwin die sexuelle >Begierde< noch relativ unbestimmt erscheint, stützt sich Krafft-Ebing auf die Konstruktion eines wirkmächtigen sexuellen Triebes, der, über den >bloßen « Gattungszweck hinausgehend, zur Grundlage des gesamten individuellen und sozialen Daseins erklärt und zugleich als beständige Gefahrenquelle für die körperliche und geistige Gesundheit der Individuen und der Bevölkerung inszeniert wird (vgl. Krafft-Ebing 1886: 2). Als Folie für die Ausarbeitung der >Perversionen< des Sexualtriebes, die den >eigentlichen Gegenstandsbereich der »Psychopathia sexualis« bilden, werden zunächst sittliche, psychologische und anatomisch-physiologische Standards einer >normalen< Sexualität gesetzt. Sexualität und Geschlecht werden dabei auf mehreren Ebenen miteinander verknüpft: An Darwins Konzept der geschlechtlichen Zuchtwahl anschließend entwirft Krafft-Ebing ein >anthropologisch-historisches Stufenmodell einer zunehmenden kulturellen >Versittlichung < des Geschlechtslebens, das die gesellschaftliche Organisation der Sexualbeziehungen mit der Organisation der Geschlechterverhältnisse parallelisiert: Ausgehend von einer noch bei »wilden Völkern« vorfindbaren »primitiven Stufe«, auf der »die Befriedigung sexueller Bedürfnisse der Menschen wie die der Thiere« erfolgte und »das Weib [...] Gemeingut der Männer, temporäre Beute des Mächtigsten, Stärksten« (ebd.: 2) war, wird das bürgerliche Ideal der zum »Liebesbund zwischen Mann und Frau« (ebd.: 4) verklärten ehelichen Reproduktionsgemeinschaft als höchste Stufe der zivilisatorischen Entwicklung bestimmt. Analog zur Konzeption der Geschlechtscharaktere leitet Krafft-Ebing aus der je spezifischen »sexualen Organisation« (ebd.: 10) einen >normalen 
männlichen und >normalen< weiblichen Sexualtrieb ab. Der Charakter des Mannes wird mit einem aktiven und lebhaften Sexualtrieb, der Charakter der Frau mit einem passiven und schwächeren Sexualtrieb verbunden, dem im Unterschied zum männlichen Begehren eine eher geistige als sinnliche Qualität zugesprochen wird, die sich im >Normalfall< zur Mutterliebe transformieren soll. Darüber hinaus schreibt Krafft-Ebing dem >sexuierten Sexualtrieb eine unterschiedliche Wirkungsmacht auf die Psyche zu, wobei sich für Mann und Frau eine je spezifische paradoxe Konstellation von >Sexualisierung < und >De-Sexualisierung< ergibt: Während er der Sexualfunktion des Mannes einerseits eine zentrale Rolle »für die Entstehung und Erhaltung des [männlichen, S.M.] Selbstgefühls« einräumt, betont er andererseits in Bezug auf die »geistige Individualität« des Mannes, dass »das Gebot der Natur nicht sein ganzes psychisches Dasein aus[füllt, S.M.]. Ist sein Verlangen erfüllt, so tritt seine Liebe temporär hinter anderen vitalen und sozialen Interessen zurück« (ebd.). Bei der Frau verhält es sich umgekehrt: So sei die Bedeutung der Sexualfunktion für das weibliche >Selbstgefühl zwar »weniger einschneidend«, gleichwohl mache »sich in dem Bewußtsein des Weibes das sexuelle Gebiet mehr geltend als in dem des Mannes. Das Bedürfniss nach Liebe ist größer als bei diesem, continuierlich, nicht episodisch« (ebd.). In sexualphysiologischer Hinsicht geht Krafft-Ebing (ebd.: 19) von der Annahme einer funktionalen Verbindung zwischen Fortpflanzungsorganen (Keimdrüsen), spinalen Zentren und einem psychosexuellen Zentrum im Gehirn aus. Dieses psychosexuelle Zentrum wird als >organischer Sitz des Geschlechtstriebs und psychischer Geschlechtscharaktere sowie als »centrale und oberste Instanz« bestimmt, die den gesamten »sexualen Mechanismus« steuert und über »hemmende Vorstellungen« (ebd.) reguliert. Vor dem Hintergrund der Verknüpfung geschlechtlicher Identität mit der Ausrichtung des sexuellen Begehrens steigt das nicht-fortpflanzungsbezogene gleichgeschlechtliche Begehren in Gestalt der sogenannten konträren Sexualempfindung nicht nur zum »Paradigma sexueller Perversion« (Müller 1991: 126), sondern zugleich zum Modell- und Problemfall einer pathologischen >Verkehrung der Geschlechtscharaktere 5 auf, die beim Sexualtrieb beginnend, das >ganze psychische Sein< erfasst und im Extremfall in einer morphologischen Annäherung an das andere Geschlecht mündet. Diese >rätselhaften< Formen einer progressiven Verweiblichung bzw. Vermännlichung, die bei ansonsten völlig >normaler< Gestaltung der Fortpflanzungsorgane auftreten,

5| Krafft-Ebing entwickelt seine Konzeption der konträren Sexualempfindung (auch) im Rückgriff auf Karl Heinrich Ulrichs Entwurf der mannmännlichen Liebe als Merkmal einer geschlechtlichen >Sondernatur<, eines >dritten Geschlechts<. $\mathrm{Zu}$ Ulrichs emanzipatorischem Entwurf der Männerliebe als Ausdruck einer >im männlichen Körper eingeschlossenen weiblichen Seele<, der den sexualwissenschaftlichen Diskurs entscheidend prägen sollte, vgl. den Beitrag von Rainer Herrn. 
führt Krafft-Ebing (1886: 21) - im Horizont der Degenerationstheorie - auf angeborene oder erworbene »meist erbliche krankhafte Veränderungen des Zentralnervensystems« zurück, die als >cerebrale Anomalien< im Gehirn lokalisiert werden. Bei der erworbenen Genese wird insbesondere der Onanie eine zentrale Rolle für eine >Zerrüttung ‘ der Nerven und >Zerstörung des männlichen Selbstgefühls zugeschrieben, die am Beginn einer psychosexuellen Metamorphose stehen.

Im Unterschied zur Evolutionstheorie Darwins, in der die sexuelle Differenz in erster Linie quantitativ definiert wird, ist die >Sexualisierung der Geschlechterdifferenz in der Sexualpathologie Krafft-Ebings mit einer >Sexuierung< des Sexualtriebs verbunden, der die Geschlechter entlang der Achse aktiv/passiv, Stärke/Schwäche, Sinnlichkeit/Liebe unterscheidet und in ein komplementär-hierarchisches und asymmetrisches Verhältnis zueinander setzt. Die paradoxe >Sexuierung< des männlichen Individuums wird hier in eine >paradoxe Sexualisierung übersetzt: Im Unterschied zum Gattungswesen Frau, deren ganzes psychisches Dasein durch die Sexualfunktion bestimmt ist, die sich jedoch nicht als sinnliches Begehren, sondern als Mutterliebe äußern soll, tritt diese beim Individuum Mann nur temporär in Erscheinung. Mit Blick auf die Stärke des männlichen Sexualtriebs erscheint die - stets gefährdete - Balance zwischen »Sinnlichkeit und Sittlichkeit« (ebd.: 5) gleichermaßen als Voraussetzung für die Kontrolle über die Frau wie für jene weitgehende geschlechtliche Entbindung, die den Mann zur Verkörperung des allgemein-menschlichen Individuums macht und zum Träger der Kultur erhebt. >Normale<, d.h heterosexuelle Männlichkeit muss sich jedoch nicht nur von der Frau, sondern von der >innergeschlechtlichen< Negativfigur des >verweiblichten Homosexuellen abheben, die vollständig durch ihre >verkehrte Sexualität bestimmt ist. Die Konstruktion der konträren Sexualempfindung, die als >rätselhafte< Inkongruenz zwischen Keimdrüsen und Gehirn codiert wird, markiert zugleich eine Erosion der anatomisch-physiologischen Begründung der Geschlechtscharaktere, die den sexuierten Körper als zuverlässigen Referenten geschlechtlicher Identität zu unterminieren droht (vgl. Heidel 2001: 304).

\section{Erosionen und IUmschriften, der Geschlechterdifferenz}

Um 1900 spitzen sich diese Erosionstendenzen angesichts einer expansiven Vervielfältigung sexueller und geschlechtlicher Abweichungen in den sexualwissenschaftlichen Debatten über die Ätiologie von Homosexualität und Hermaphroditismus zu. ${ }^{6}$ Das Problem der >Unzuverlässigkeit des

6| Die Vielzahl der »Abweichungen der Natur von sich selbst« (Runte 2001: 267) wirft grundsätzliche Fragen nach dem Verhältnis von Natur und Kultur, der 
Körpers (vgl. Mehlmann 2006), das sich in einer »Krise des Geschlechterwissens« (Schäffner 1995) manifestiert, erscheint dabei umso drängender, da sich zugleich eine Erosion der >natürlichen< Geschlechterordnung durch die Forderungen der Frauenbewegung nach gleichberechtigter Teilhabe an Politik, Erwerbsleben und Wissenschaft (vgl. Bublitz 1998: 45) sowie durch die um gesellschaftliche Anerkennung sexueller Minderheiten kämpfende Homosexuellenbewegung (vgl. Mosse 1997: 118) abzeichnet. Vor diesem Hintergrund möchte ich abschließend auf die Geschlechtertheorien Weiningers und Freuds eingehen, die durch eine Verlagerung von einer biologischen auf eine psychologische Argumentation gekennzeichnet sind. Im Vergleich beider Positionen möchte ich zeigen, dass dieser geschlechtertheoretische >Paradigmenwechsel $<$ mit unterschiedlichen Strategien der Wiederherstellung eines asymmetrisch-hierarchisch strukturierten Zweigeschlechtermodells verbunden ist, die in je spezifischer Weise auf die skizzierten Konstruktionslogiken des mann-menschlichen Individuums rekurrieren.

\section{Weininger: Sexuelle Mannigfaltigkeit und geschlechtliches 'Sein,}

In seiner 1903 erschienenen antifeministischen (und antisemitischen) Dissertationsschrift »Geschlecht und Charakter« sieht sich Otto Weininger (1997: V) vor die Aufgabe gestellt, die »geistigen Differenzen der Geschlechter in ein System« zu bringen. Diese Aufgabe ergibt sich für Weininger aus dem Problem der Unbestimmtheit bzw. Unbestimmbarkeit der Geschlechterdifferenz. Weiningers psychologische Wendung ist dabei bekanntlich mit einem expliziten geschlechterpolitischen Interesse verbunden: Es geht um die Frauenfrage als zentrales »Kulturproblem« (ebd.: VII), das durch eine >Neubewertung < des Wesens der Frau und deren Bedeutung im »Weltganzen « einer endgültigen Lösung zugeführt werden soll, die sich allerdings, wie Weininger im ersten biologisch-psychologischen Teil seiner Arbeit vorführt, nicht länger auf `natürliche< Geschlechtergrenzen stützen kann. Hier bestreitet er die Existenz von »ein- und bestimmt-geschlechtlich $\mathrm{zu}$ bezeichnenden Lebewesen « (ebd.: 12) und weist die anthropologische Norm >reiner< Männlichkeit und Weiblichkeit als idealtypische Konstruktion aus, die in der Wirklichkeit nicht vorkomme. Demgegenüber postuliert er ein psychophysisches Kontinuum von »unzählige[n] Abstufungen zwischen Mann und Weib« (ebd.: 9), die durch je spezifische Mischungsverhältnisse männlicher und weiblicher Anteilen ( $\mathrm{m}$ und w) gekennzeichnet sind. Gestützt auf das Theorem einer ursprünglichen phylo- und ontoge-

inneren Verbindung von Körpergeschlecht, Sexualtrieb und Psyche (vgl. Schmersahl 1998), einem gesicherten Bezugspunkt für die Bestimmung der Geschlechtergrenzen (vgl. Schäffner 1995; Bublitz 2000) sowie der Grenzen geschlechtlicher Normalität auf (vgl. Link 1997; Dornhof 1998; Mehlmann 2000; Bublitz 2001). 
netischen Bisexualität wird nunmehr eine >dauernde Doppelgeschlechtlichkeit< zum >Normalfall< des Geschlechts erhoben. Ausgehend von der konstitutiven Kopplung von Sexualität, Geschlecht und Identität, die im Horizont der sexuellen Matrix zu einem Gesetz der sexuellen Anziehung der jeweiligen männlichen und weiblichen Anteile ausgearbeitet wird, werden alle geschlechtlichen Mischformen, einschließlich der Homosexualität, als normale, nicht-pathologische Phänomene ausgewiesen. Anatomisch physiologische Basis des >Prinzips « sexueller Zwischenformen, das Magnus Hirschfelds Theorie der sexuellen Zwischenstufen ${ }^{7}$ radikalisiert, ist ein Modell unzähliger Zellgeschlechter, die in ihrer sexuell-geschlechtlichen Ausprägung nicht nur graduell und lokal, sondern auch temporär variieren. Aus diesen >sexu(alis)ierten< Körpern lassen sich weder eindeutige und noch dauerhafte geschlechtliche Zuordnungen und Identitäten mehr ableiten (vgl. Schäffner 1995: 286).

Weininger begegnet diesen Problemlagen im zweiten philosophischpsychologischen Hauptteil seines Werkes zunächst mit dem Postulat eines

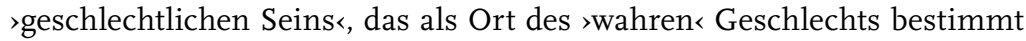
wird: »Trotz allen sexuellen Zwischenformen ist der Mensch am Ende doch eines von beiden, entweder Mann oder Weib « (Weininger 1997: 98). ${ }^{8}$ Mit diesem geschlechtlichen Identitätsprinzip wird ein fixer Bezugspunkt für eine metaphysisch-ontologische Neubestimmung der Geschlechterdifferenz eingeführt, in der der (ideale) Mann (m) zum >rein geistigen< Repräsentanten eines Allgemein-Menschlichen Seins erhoben, während das (ideale) Weib (w) demgegenüber als Verkörperung des Sexuell-Geschlechtlichen, rein materiellen Nicht-Seins entworfen wird. Basis seiner sexuellen Typenlehre, die den Mann als eigentliches >Rätsel< der Geschlechterpsychologie ausweist (vgl. ebd.: 277), ist die Figur des vom Geschlechtlich-Sexuellen nur temporär affizierten männlichen Individuums, der nun allerdings die Figur einer vollständig vom Sexuellen durchdrungenen Frau gegenübergestellt wird. ${ }^{9}$ Weininger wendet sich damit zugleich gegen eine Sexualisierung des männlichen, kulturschaffenden Geistes, die er in Darwins Theorie der geschlechtlichen Zuchtwahl und in den Sexualwissenschaften ausmacht. In seiner philosophischen Argumentation, in der >Sex< und >Geist< (wieder) als Antagonismen definiert werden, greift Weininger auf den gesamten abendländischen Bestand geschlechtlich codierter Binär-

7| Zu Hirschfelds Zwischenstufentheorie, vgl. wiederum den Beitrag von Rainer Herrn.

8| Weininger stützt sich bei dieser Grenzziehung auf die Figuren des/der Homosexuellen, die - auf der Folie der heterosexuellen Matrix der geschlechtlichen Anziehung - als Beleg für die (subjektive, innerpsychische) Unhintergehbarkeit des Mann- oder Frauseins (vgl. Spörri 2000: 38) und zugleich als Modell für eine Entkopplung von Physis und Psyche eingesetzt werden.

9| Zur »Neu-Entdeckung« der sexualisierten Frau um 1900, vgl. von Braun 1990: $186 f$. 
oppositionen zurück, wobei w als Negation der durch das Prinzip m vertretenen - menschlichen - Charakteristika des Bewusstseins, der Seele, des Willens, der Logik und der Moral (vgl. ebd.: 378) ausgewiesen wird. Vor dem Hintergrund dieser - wie Weininger selbst einräumt - vollständigen Entwertung des Weiblichen, wird das gesamte Spektrum sexuellgeschlechtlicher Zwischenformen, das bislang als >normal< ausgewiesen wurde, pathologisiert, wobei jede >Mischung $<$ mit w mit dem Stigma - sittlicher - Entartung belegt wird. Die >Neuerfindung< des idealen, d.h. zugleich genialen Mannes als Raum, Zeit und Materie transzendierendes intelligibles und wertsetzendes Subjekt bildet zugleich die Folie für eine asymmetrische Neukonstruktion der Geschlechtergrenze, die wiederum mit einer für Mann und Frau je unterschiedlichen Konzeption des Verhältnisses zwischen Physis und Psyche verknüpft wird: Da Weininger (ebd.: 241) in der Seele des Mannes alle Möglichkeiten des Seins angelegt sieht, könne dieser »zur höchsten Höhe hinaufgelangen und auf tiefste entarten, er kann zum Tiere, zur Pflanze, er kann auch zum Weibe werden, und darum gibt es weibliche, weibische Männer«. Umgekehrt aber, könne »die Frau [...] nie zum Manne werden«. Während Weininger das Prinzip des psychophysischen Parallelismus für den Mann außer Kraft gesetzt sieht, bleibt das Weib »[t]rotz aller Bisexualität« an ihre körperliche Geschlechtlichkeit gebunden, womit dem Emanzipationsbedürfnis der Frauen, das er auf deren männliche Anteile zurückführt (vgl. ebd: 5of.), wieder >natürlicheく Grenzen gesetzt sind.

Neben der >Neubestimmung « der Geschlechterdifferenz spielt die Übertragung der charakterlogischen Typenlehre auf das Judentum eine zentrale Rolle in Weiningers Arbeit, wobei Misogynie und Antisemitismus in der These von der Weiblichkeit des Juden untrennbar miteinander verknüpft werden (vgl. Brunotte 2004: 109). Dem >feminisierten< Homosexuellen, den Weininger im ersten Teil im Rahmen seiner Theorie sexueller Zwischenformen entwirft, wird nun der >feminisierte< Jude zur Seite gestellt, dem im zeitgenössischen Diskurs ebenfalls eine zentrale Bedeutung als Negativfigur zur >normalen< Männlichkeit zukommt (vgl. Mosse 1996: 98). ${ }^{10}$

Die Weiblichkeit, von der das Judentum »durchtränkt« (Weininger 1997: 409) sei, ist bei Weininger, der selbst explizit auf seine jüdische Herkunft verweist (vgl. ebd.: 406 Anm. 1), in zweifacher Weise bestimmt: Im Horizont seiner sexuellen Typenlehre wird der Jude in Abgrenzung zum Arier gleichzeitig als »sexuell weniger potent« und »stets lüsterner, geiler« (ebd.: 417) beschrieben. Bemisst sich das >Weibische< des Juden im Vergleich zum arischen Mann am Grad der >Virilität<, ergibt sich die

10| Wobei, wie Mosse mit Blick auf die vielfache Bezichtigung von Juden als homosexuell feststellt, das Bild des Juden und das des Homosexuellen einander ergänzten (vgl. Mosse 1996: 95). Diese Verbindung wird in der Person Weiningers, der nicht nur als Jude, sondern auch als Homosexueller identifiziert wurde, geradezu exemplarisch >verkörpert<. Vgl. hierzu den Beitrag von Jay Geller. 
spezifische Verbindung zum >Wesen< des Weibes insbesondere über die Zuschreibung des übergroßen sexuellen Begehrens, das sich im »Drang zum >Koitus und zur >Kuppelei« (Brunotte 2004: 109) sowie im »Unverständnis für alle Askese« (ebd.: 110) spiegele. Im Horizont seiner philosophischen Deduktionen erscheint der >echte< Jude ebenso wie das >echte< Weib als ich- und geistloses Wesen ohne jeden »Eigenwert« (Weininger 1997: 412). Beide »leben nur in der Gattung, nicht als Individualitäten« (ebd.: 416).

Spiegelt Weiningers inhaltliche Argumentation »eine von ihm in klassischer Identifikation mit dem Aggressor >akzeptierte< Stigmatisierung als >Jude< im Sinne der antisemitischen Propaganda « (Link 1997: 375), ergeben sich aus seinen geschlechtertheoretischen Überlegungen entscheidende Differenzen zur Rassenanthropologie: Während Weininger zunächst die Anwendung des Prinzips der sexuellen Zwischenstufen diskutiert und einräumt, dass über einige >Völker< bzw. >Rassenく »ein größeres Quantum von Weiblichkeit insgesamt ausgestreut« (Weininger 1997: 404) zu sein scheint, wird das Judentum im Weiteren jedoch nicht als >Rasse< oder >Volk<, sondern als »eine Geistesrichtung, [...] eine psychische Konstitution« definiert, »welche für alle Menschen eine Möglichkeit bildet« (ebd.: 406). Der Konzeption der Prinzipien von $\mathrm{m}$ und $\mathrm{w}$ als platonische Ideen folgend, weist Weininger nicht nur die Vorstellung eines >absoluten $<$ Juden und eines >absoluten < Christen (vgl. ebd.: 418), sondern ebenfalls die Vorstellung biologisch fixierter >Rassencharaktere < und -grenzen zurück (vgl. Thorson 2000: 74f.): »Es gibt Arier, die jüdischer sind als mancher Jude, und es gibt wirklich Juden, die arischer sind als gewisse Arier« (Weininger 1997: 407). Analog zur Weiblichkeit, die in der Seele des Mannes als Möglichkeit >tiefster Entartung < angelegt ist, wird auch das Judentum als etwas entworfen, vor dem sich der arische Mann hüten müsse: »als Möglichkeit in ihm selber« (ebd.: 409).

Umgekehrt eröffnet die Konstruktion des von Naturgesetzen >befreiten intelligiblen männlichen Subjekts, das - so Weininger - seinen Körper im Unterschied zum >passiven<, >formbaren< Weib >aktiv < nach seinem eigenen Willen schaffen und umschaffen kann (vgl. ebd.: 396), nicht nur die Option einer Überwindung des Weiblichen und der damit verknüpften Sphäre des Sexuell-Geschlechtlichen, sondern (zumindest prinzipiell) auch des >Jüdischen< (vgl. ebd.: 438). Diese nunmehr als moralischer Imperativ formulierte Option wird schließlich mit der - eingeschlechtlichen - Vision eines >reinen<, d.h. am christlich-asketischen Ideal der Keuschheit orientierten (männlichen) Menschen verknüpft (vgl. ebd.: $456 \mathrm{f}$.). ${ }^{11}$

11 Mit Blick auf Weininger selbst, der nach Erscheinen seines Werkes Selbstmord beging, lässt sich diese Konstruktion als Versuch der Abwehr eines doppelten - mit Verweiblichung assozierten und am bzw. im Körper verankerten - Stigmas des feminisierten homosexuellen Juden lesen. Weiningers $>$ Bruch $<$ mit der biologischen Begründung der Geschlechtscharaktere stellt sich in dieser Perspektive 


\section{Freud: Geschlechterdifferenz und psychosexuelle Entwicklung}

Anders als bei Weininger, der auf das Problem geschlechtlicher >Grenzüberschreitungen< fokussiert, stehen in Freuds erstmals 1905 veröffentlichten »Drei Abhandlungen zur Sexualtheorie« die saußerordentliche< Verbreitung und Mannigfaltigkeit sexueller Abirrungen im Vordergrund, die die >Natur des Sexualtriebs im Sinne eines angeborenen Fortpflanzungstriebs (vgl. Freud 1905: 47) ebenso wie die Möglichkeit einer klaren Grenzziehung zwischen dem Normalen und dem Pathologischen in Frage stellen (vgl. ebd.: 7of.). In seiner Kritik der »Inversion « als geschlechtliche >Sondernatur< grenzt sich Freud gleichermaßen von degenerationstheoretischen Begründungen wie der Konzeption eines >dritten< Geschlechts einschließlich gehirnlokalistischer Spekulationen ab und stellt die kausale Beziehung zwischen anatomischen und psychischen Geschlechtscharakteren einerseits und die Verknüpfung von geschlechtlicher Identität mit der Ausrichtung des sexuellen Begehrens andererseits zur Disposition (vgl. ebd.: 48-58). Darüber hinaus werden angesichts der »Verhältnisse beim Weibe« und »beim Kinde« (ebd.: 118) sowie der widersprüchlichen Befunde von Kastrationen, die darauf verweisen, dass die Sexualerregung und die Geschlechtscharaktere »in beachtenswertem Grade unabhängig von der Produktion der Geschlechtsstoffe« (ebd.) sein können, auch die Keimdrüsen als organische Grundlage der Geschlechtlichkeit verworfen (vgl. ebd.: 120 Anm. 1, editorische Anmerkung). Die Freud'sche >Lösung< dieser Problemlagen besteht in zwei zentralen Perspektivverschiebungen: Erstens wird in seiner Theorie der psychosexuellen Entwicklung die normale, fortpflanzungsbezogene Heterosexualität zum erklärungsbedürftigen Phänomen erhoben und an die Umgestaltung einer ursprünglichen infantilen polymorph-perversen und bisexuellen Anlage gebunden. Zweitens wird die anatomisch-physiologische Begründung der Geschlechtscharaktere durch eine psychologische Argumentation ersetzt: Die psychosexuelle Differenzierung, die ausgehend von der These einer >primären< Männlichkeit beider Geschlechter bekanntlich einen zweifachen Geschlechtswechsel des weiblichen Kindes voraussetzt, wird als Ergebnis eines konfliktträchtigen und störungsanfälligen Prozesses gefasst, in dem die Kohärenz von Körpergeschlecht, Psyche und Sexualtrieb auf innerpsychischem Wege hergestellt wird. Grundlage dieses Prozesses bildet die psychische Aneignung des anatomischen Geschlechts, die in Gestalt von Kastrationsangst und Penisneid als Movens und Motiv für die - kulturell eingeforderte - Umwandlung infantiler libidinöser Objektbesetzungen in gleichgeschlechtliche Identifizierungen und heterosexuelle Objektwahlen

auch als ein Versuch der Einschreibung in das Modell der hegemonialen, d.h. hier: christlich-arischen Männlichkeit dar. Für diesen Hinweis danke ich Ulrike Brunotte. 
im Rahmen des ödipalen Familiendramas konstruiert wird. ${ }^{12}$ An der Nahtstelle von Kastrations- und Ödipuskomplex wird der >unzuverlässige Körper< über die Wendung ins Imaginäre als Bezugspunkt eines asymmetrisch-hierarchischen Zweigeschlechtermodells wieder eingesetzt. Im Freud'schen Konzept der psychosexuellen Entwicklung wird die >geistigmoralischeく Überlegenheit des Mannes, aus der - im Idealfall - vollständigen Auflösung des Ödipuskomplexes sowie den Sublimierungen des Sexualtriebs abgeleitet; eine Leistung, die wiederum auf die Signifikanz des männlichen Genitals verweist, das als >Phallus « zum Zeichen und Maß des Geschlechterverhältnisses erhoben wird (vgl. Breidenstein 1996: 235). Im Diktum der »Anatomie als Schicksal« (vgl. Freud 1924: 249), das die Frau nicht nur zum Mangelwesen macht, sondern auch als Kulturträgerin disqualifiziert, verblasst auch die >Unzuverlässigkeit des Körpers< als stabile und eindeutige Grundlage der Geschlechterdifferenz.

Mit Blick auf die eingangs formulierte These einer >Vergeschlechtlichung des mann-menschlichen Individuums zeichnen sich im Vergleich der Positionen Weiningers und Freuds zwei unterschiedliche Modelle ab, die wiederum in unterschiedlicher Weise auf die beiden Konstruktionsmodi >männlicher Hegemonie< Bezug nehmen: Während Weininger in seiner charakterologischen Typenlehre, die der >bedrohlichen< Sexualisierung des Männlichen mit dem Versuch der (Wieder-)Einsetzung des (idealen) Mannes als - nun allerdings explizit geschlechtlich markierten - Repräsentanten eines vom Sexuellen >gereinigten allgemein-menschlichen Individuums und einer vollständigen Sexualisierung und Ent-Individualisierung des Weiblichen begegnet, liegt das Spezifische der Freud'schen Psychoanalyse darin, dass sie die These von der >überlegenen sexuellen Potenz « mit der These der >geistig-moralischen Überlegenheit des Mannes auf neuartige Weise verknüpft (vgl. Bruns 2002: 121 Anm. 42). ${ }^{13}$ In der an das Konzept des Unbewussten gebundenen Libidotheorie wird der Mann als sexuell bestimmtes Individuum entworfen, das zwar nicht mehr >Herr im eigenen Hause < ist, aber seinen Anspruch auf >Kulturträgerschaft $<$ als erstes - bzw. im Horizont eines sexuellen und phallischen Monismus als einziges - Geschlecht erneuern kann. Beide Modelle überschneiden sich in der asymmetrischen Konstruktion der Geschlechterdifferenz, die darü-

12| Zur Situierung der Freud'schen Theorie der psychosexuellen Entwicklung und speziell des Kastrationskomplexes im Spannungsfeld von Antisemitismus, Homophobie und maskulinem Judentum, vgl. Geller in diesem Band. Freuds psychologische Wendung kann vor diesem Hintergrund ebenfalls als >Reaktion auf die Stigmatisierung des >jüdischen Körpers $<$ gelesen werden (vgl. von Braun 2000: 43).

13 Freud schließt dabei - wie Christina von Braun feststellt - an Darwins Konzept der geschlechtlichen Zuchtwahl an, insofern bei beiden die »Überlegenheit< des männlichen Geistes [...] mit der >Männlichkeit< des Geschlechtstriebs« (von Braun 1990: 179) erklärt wird. 
ber definiert wird, was der Mann hat und der Frau fehlt (bei Weininger ist es das - männliche - Bewusstsein, bei Freud der Phallus), eine Konstruktion, die zugleich sicherstellt, dass die Frau nie zum Mann werden bzw. nicht Mann sein kann.

\section{Literatur}

Bergmann, Anna (1998): Die verhütete Sexualität. Die Anfänge der modernen Geburtenkontrolle, Berlin: Aufbau.

Braun, Christina von (1990): Nicht ich: Logik, Lüge, Libido, Frankfurt a.M.: Verlag Neue Kritik.

Braun, Christina von (2000): »Gender, Geschlecht und Geschichte«. In: dies./Inge Stephan (Hg.), Gender Studien: eine Einführung, Stuttgart/ Weimar: Metzler, S. 16-57.

Breidenstein, Georg (1996): »Geschlechtsunterschied und Sexualtrieb im Diskurs der Kastration Anfang des 20. Jahrhunderts«. In: Christiane Eifert/Angelika Epple/Martina Kessel/Marlies Michaelis/Claudia Nowak/Katharina Schicke/Dorothea Weltecke (Hg.), Was sind Frauen? Was sind Männer? Geschlechterkonstruktionen im historischen Wandel, Frankfurt a.M.: Suhrkamp, S. 216-239.

Brunotte, Ulrike (2004): Zwischen Eros und Krieg. Männerbund und Ritual in der Moderne, Berlin: Wagenbach.

Bruns, Claudia (2002): »Subjekt, Gemeinschaft, Männerbund. Hans Blühers Wandelvogelmonographien im Wilhelminischen Kaiserreich«. In: Gabriele Boukrif/Claudia Bruns/Kirsten Heinsohn/Kathrin Schmersahl/KatjaWelle (Hg.), Geschlechtergeschichte des Politischen. Entwürfe von Nation und Gemeinschaft, Münster/Hamburg/Berlin/Wien/ London/Zürich: LIT, S. 107-140.

Bublitz, Hannelore (1998): »Das Geschlecht der Moderne - Zur Genealogie und Archäologie der Geschlechterdifferenz«. In: dies. (Hg.), Das Geschlecht der Moderne - Zur Genealogie und Archäologie der Geschlechterdifferenz, Frankfurt a.M./New York: Campus, S. 26-48.

Bublitz, Hannelore (2000): »Zur Konstitution von >Kultur und Geschlecht«. In: dies./Christine Hanke/Andrea Seier (Hg.), Der Gesellschaftskörper. Zur Neuordnung von Kultur und Geschlecht um 1900, Frankfurt a.M./ New York: Campus, S. 19-96.

Bublitz, Hannelore (2001): »Geschlecht als historisch singuläres Ereignis: Foucaults poststrukturalistischer Beitrag zu einer Gesellschaftstheorie der Geschlechterverhältnisse«. In: Gudrun-Axeli Knapp/Angelika Wetterer (Hg.), Soziale Verortung der Geschlechter: Gesellschaftstheorie und feministische Kritik, Münster: Westfälisches Dampfboot, S. 256287 . 
Bührmann, Andrea Dorothea (1995): Das authentische Geschlecht. Die Sexualitätsdebatte der Neuen Frauenbewegung und die Foucaultsche Machtanalyse, Münster: Westfälisches Dampfboot.

Connell, Robert W. (1999): Der gemachte Mann. Konstruktion und Krise von Männlichkeiten, Opladen: Leske + Budrich.

Darwin, Charles (1951): Die Abstammung des Menschen und die geschlechtliche Zuchtwahl, Neudruck der 1. Aufl., Stuttgart 1871, Leipzig: Philipp Reclam jun.

Dornhof, Dorothea (1998): »Inszenierte Perversionen. Geschlechterverhältnisse zwischen Pathologie und Normalität um die Jahrhundertwende«. In: Antje Hornscheidt/Gabriele Jähnert/Annette Schlichter (Hg.), Kritische Differenzen - Geteilte Perspektiven. Zum Verhältnis von Feminismus und Postmoderne, Opladen/Wiesbaden: Westdeutscher Verlag, S. 253-277.

Foucault, Michel (1989): Der Wille zum Wissen. Sexualität und Wahrheit, Bd. 1, Frankfurt a.M.: Suhrkamp.

Freud, Sigmund (achte, korrigierte Auflage 1997): »Drei Abhandlungen zur Sexualtheorie« (1905). In: Studienausgabe, Bd. 5, Frankfurt a.M.: Fischer, S. 43-145.

Freud, Sigmund (achte, korrigierte Auflage 1997): »Der Untergang des Ödipuskomplexes« (1924). In: Studienausgabe, Bd. 5, Frankfurt a.M.: Fischer, S. 245-251.

Hark, Sabine (1999): Deviante Subjekte. Die paradoxe Politik der Identität, Opladen: Leske + Budrich.

Hausen, Karin (1976): »Polarisierung der >Geschlechtscharaktere Spiegelung der Dissoziation von Erwerbs- und Familienleben«. In: Werner Conze (Hg.), Sozialgeschichte in der Neuzeit Europas: neue Forschungen, Stuttgart: Klett, S. 161-191.

Heidel, Ulf (2001): »In Verteidigung der Männlichkeit. Sexualpsychiatrische Bestimmungen der Konträrsexualität in der Geschlechterordnung des späten 19. Jahrhunderts«. In: ders./Stefan Micheler/Elisabeth Tuider (Hg.), Jenseits der Geschlechtergrenzen. Sexualitäten, Identitäten und Körper in Perspektiven von Queer Studies, Hamburg: MännerschwarmScript Verlag, S. 291-310.

Honegger, Claudia (1991): Die Ordnung der Geschlechter. Die Wissenschaften vom Menschen und das Weib, Frankfurt a.M./New York: Campus.

Klinger, Cornelia (2005): »Feministische Theorie zwischen Lektüre und Kritik des philosophischen Kanons«. In: Hadumod Bußmann/Renate Hof (Hg.), Genus. Geschlechterforschung/Gender Studies in der Kulturund Sozialwissenschaften, Stuttgart: Kröner, S. 328-364.

Krafft-Ebing, Richard von (1886): Psychopathia sexualis. Eine klinisch-forensische Studie, Stuttgart: Ferdinand Enke.

Laqueur, Thomas (1992): Auf den Leib geschrieben. Die Inszenierung der Geschlechter von der Antike bis Freud, Frankfurt a.M.: dtv. 
Link, Jürgen (1997): Versuch über den Normalismus. Wie Normalität produziert wird, Opladen: Westdeutscher Verlag.

Mehlmann, Sabine (1998): »Das vergeschlechtlichte Individuum - Thesen zur historischen Genese des Konzepts männlicher Geschlechtsidentität«. In: Hannelore Bublitz (Hg.), Das Geschlecht der Moderne. Genealogie und Archäologie der Geschlechterdifferenz, Frankfurt a.M./New York: Campus, S. 95-118.

Mehlmann, Sabine (2000): »Das doppelte Geschlecht. Die konstitutionelle Bisexualität und die Konstruktion der Geschlechtergrenze«. In: Feministische Studien 1, S. 36-51.

Mehlmann, Sabine (2006): Unzuverlässige Körper - Zur Diskursgeschichte des Konzepts geschlechtlicher Identität, Königstein/Taunus: Helmer.

Meuser, Michael/Scholz, Sylka (2005): »Hegemoniale Männlichkeit. Versuch einer Begriffsklärung aus soziologischer Perspektive«. In: Martin Dinges (Hg.), Männer - Macht - Körper. Hegemoniale Männlichkeiten vom Mittelalter bis heute, Frankfurt a.M./New York: Campus.

Mosse, George L. (1997): Das Bild des Mannes. Zur Konstruktion der modernen Männlichkeit, Frankfurt a.M./Wien: Büchergilde Gutenberg.

Müller, Klaus (1991): Aber in meinem Herzen sprach eine Stimme so laut. Homosexuelle Autobiographien und medizinische Pathographien im neunzehnten Jahrhundert, Berlin: Rosa Winkel.

Runte, Annette (2001): »Zwischenstufen, Häufungskurven, Drehpunktund Pfadwegmodelle. Über moderne Topographien geschlechtlicher Devianz und ihre >transsexuelle< Normalisierung«. In: Ute Gerhard/ Jürgen Link/Ernst Schulte-Holtey (Hg.), Infografiken, Medien, Normalisierung. Zur Kartografie politisch-sozialer Landschaften, Heidelberg: Synchron Wissenschaftsverlag der Autoren, S. 265-293.

Schäffner, Wolfgang (1995): »Transformationen. Schreber und die Geschlechterpolitik um 1900«. In: Elfi Bettinger/Julika Funk (Hg.), Maskeraden: Geschlechterdifferenz in der literarischen Inszenierung, Berlin: Erich Schmidt, S. 273-291.

Schäffner, Wolfgang/Vogl, Joseph (1998): »Nachwort«. In: dies. (Hg.), Herculine Barbin. Michel Foucault über Hermaphrodismus, Frankfurt a.M.: Suhrkamp, S. 215-246.

Schmersahl, Katrin (1998): Medizin und Geschlecht. Zur Konstruktion der Kategorie Geschlecht im medizinischen Diskurs des 19. Jahrhunderts, Opladen: Leske + Budrich.

Soine, Stefanie (2002): »Das heterosexistische Geschlechterdispositiv als Produktionsrahmen für die Gewalt gegen lesbische Frauen«. In: Regine-Maria Dackweiler/Reinhild Schäfer (Hg.), Gewalt-Verhältnisse. Feministische Perspektiven auf Geschlecht und Gewalt, Frankfurt a.M./New York: Campus, S. 135-159.

Spörri, Miriam (2000): Die Diagnose des Geschlechts. Hermaphroditismus im sexualwissenschaftlichen Diskurs zwischen 1886 und 1920, Zürich: unveröffentlichte Lizentiatsarbeit. 
Thorson, Helga (2000): »Confronting Anti-Semitism and Antifeminism in Turn of the Century Vienna: Grete Meisel-Hess and the Modernist Discourses on Hysteria«. In: Klaus Hödl (Hg.), Jüdische Identitäten. Einblicke in die Bewußtseinslandschaft des österreichischen Judentums, Innsbruck/Wien/München: StudienVerlag.

Weininger, Otto (1997): Geschlecht und Charakter. Eine prinzipielle Untersuchung, Nachdruck der 1. Aufl., Wien 1903, München: Mattes \& Seitz. 



\section{Das Militär als Schule der Männlichkeiten}

Ute Frevert

\section{Im postheroischen Zeitalter}

Das Militär als Schule der Männlichkeiten - dieser Titel und seine These verweisen auf Vergangenes. Sie nehmen eine Formulierung auf, die der Berliner Philosophieprofessor Friedrich Paulsen 1902, damals noch im hegemonialen Singular, gebrauchte, um die geläufige Rede vom Militär als »Schule der Nation« zu ergänzen und zu präzisieren. Für die Gegenwart passt die These nicht mehr. Denken wir über Männlichkeit heute nach, fällt uns vieles ein: der Fußballplatz und die Autobahn, die Cebit-Ausstellung und der Pornoshop, die Businessclass und das Gefängnis. Das Militär fehlt in dieser Aufzählung, steht jedenfalls nicht an prominenter Stelle. Kaum jemand würde behaupten wollen, dass das Militär in der aktuellen Gesellschaft eine formgebende Institution sei, die an der Produktion von Männlichkeit entscheidenden Anteil habe.

Woran liegt das? Immerhin haben in den letzten fünfzig Jahren, seit es die Bundeswehr gibt, acht Millionen junge Männer >gedient< und diese Einrichtung über Jahre und Monate intensiv kennen gelernt. Auch die Nationale Volksarmee der DDR hat hunderttausende Soldaten ausgebildet, proportional zur Bevölkerungszahl sogar mehr als die Bundeswehr. Nach wie vor gilt die Wehrpflicht ausschließlich für Männer, und zweifellos ist die Bundeswehr eine der männlichsten Institutionen, die es in unserer Gesellschaft gibt: Lediglich sieben Prozent aller Berufs- und Zeitsoldaten sind Frauen - 13.500 bei einer Gesamtstärke von über 250.000. Während andere Organisationen und Einrichtungen sich in den letzten Jahrzehnten deutlich feminisiert haben - man denke etwa an die Berliner Philharmoniker -, hält das Militär an seinem männlichen Image fest. Es bedarf höchstrichterlicher europäischer Intervention, Frauen außerhalb der Schreibstuben, des Sanitätsdienstes und des Musikkorps in seine Reihen aufzunehmen. Und dennoch hält sich der militärische Einfluss auf das, was man als männlichen Code oder Habitus bezeichnet könnte, deutlich in Grenzen. 
Das liegt zum einen daran, dass immer weniger Wehrpflichtige tatsächlich in der Kaserne landen. Im Jahre 2000 wurden 390.000 junge Männer gemustert, aber nur 145.000 eingezogen. Fünf Jahre später waren es nur noch 68.000, die eine Kaserne von innen kennen lernten - der Bedarf war damit gedeckt. Gemessen an den $1960 e r$ Jahren, als 90 Prozent aller tauglich Gemusterten tatsächlich einberufen wurden und doppelt so lange wie heute, nämlich achtzehn Monate bei der Truppe blieben, spielt die Militärerfahrung daher für heutige Jugendliche eine viel geringere Rolle.

Zum anderen steigt die Zahl derer, die sich bewusst gegen diese Erfahrung entscheiden. In den $1960 e r$ Jahren hatten erstmals mehr junge Männer Zivildienst als Wehrdienst. Für mindestens jeden zweiten, der tauglich gemustert wird, ist das Militär folglich keine attraktive Option. Drittens schließlich leidet das Militär unter dem, was Bundespräsident Horst Köhler 2005 »positives Desinteresse« nannte. »Ein wirkliches Interesse« an der Bundeswehr »oder gar Stolz auf sie«, meinte Köhler zu Recht, seien in der Bevölkerung »eher selten «. ${ }^{1}$ Dafür gibt es mehrere Gründe. Die lange Friedenszeit gehört dazu, der Mangel an Bewährung (über den wir froh sein können), ein abnehmendes Bedrohungsgefühl. Das postheroische Zeitalter (zuletzt Münkler 2006), in das alle westlichen Gesellschaften, selbst die USA, inzwischen eingetreten sind, macht sich geltend. Aber auch der massive Traditionsbruch nach dem Zweiten Weltkrieg spielt eine Rolle, speziell in Deutschland.

Es bleibt festzuhalten, dass wir heute, in der >zweiten Moderne<, das Militär nicht mehr als >Produzenten hegemonialer Männlichkeit< betrachten können - weder quantitativ noch qualitativ besitzt es diese Macht. $\mathrm{Ob}$ eine andere Institution an die Stelle des Militärs getreten ist und heute »hegemoniale Männlichkeitsbilder« (Connell 1999; Mosse 1996) verbreitet, ist überaus fraglich. Genauer betrachtet, gibt es in der heutigen Gesellschaft keine vergleichbar einflussreichen, sozial inklusiven und politisch mächtigen >Männlichkeitsproduzenten< mehr. Allenfalls lässt sich von einer Vielzahl konkurrierender, sozial und generationell stark differenzierter und in ihrer Reichweite ausgesprochen begrenzter Institutionen sprechen.

\section{Militär und Gesellschaft im Kaiserreich}

In der >ersten Moderne anders. An der vorletzten Jahrhundertwende, um 1900 herum, nahm das Militär einen zentralen Platz in der Gesellschaft ein. Es wurde geachtet und verehrt, aber auch gehasst und gefürchtet. In jedem Fall band es starke Emotionen und ließ niemanden kalt; von >Desinteresse $<$, positivem oder

1| http://www.uni-kassel.de/fb5/frieden/themen/Bundeswehr/50-jahre-koeler. 
negativem, konnte nicht die Rede sein. Städtische Magistrate schätzten sich glücklich, eine Garnison zu beherbergen - nicht nur wegen der wirtschaftlichen Vorteile, die dem Stadtsäckel zugute kamen. Auch sozial und kulturell war das Militär wohl gelitten: Viele Bürger waren Reserveoffiziere und suchten den gesellschaftlichen Verkehr mit ihren hauptberuflichen Kameraden. Ihre Töchter freuten sich auf jeden Ball, auf dem Offiziere zugegen waren, denn das bürgte für gute und willige Tänzer. Ihre Dienstmädchen träumten von Unteroffizieren, die nicht nur eine schmucke Uniform, sondern auch den Zivilversorgungsschein in der Tasche trugen. Und die alten Soldaten, die nach ihrer aktiven Dienstzeit einem Kriegerverein beitraten - fast drei Millionen waren es kurz vor dem Ersten Weltkrieg -, waren stolz darauf, bei Militärparaden mitzumarschieren. Solche Paraden zogen regelmäßig ein großes Publikum an, jung und alt, männlich und weiblich, bürgerlich und proletarisch - ebenso wie die Militärkapelle, die am Sonntagnachmittag auf der Promenade oder im Kurpark aufspielte. ${ }^{2}$

Der gesellschaftlichen Wertschätzung entsprach die politische Bedeutung. Die Armee des deutschen Kaiserreichs zehrte von dem Prestige, das sie 1870/71 erworben hatte. Mit dem Sieg über Frankreich erntete sie militärische Lorbeeren; zudem hatte er einen Vorschein jener nationalen Einheit abgegeben, die seit langem auf der politischen Agenda stand. Als der preußische Ministerpräsident Otto von Bismarck im Spiegelsaal von Versailles die Gründung eines deutschen Kaiserreichs proklamierte, waren außer ihm und den deutschen Fürsten nur Offiziere anwesend - und der Hofmaler Anton von Werner, der den Moment in zahlreichen Gemälden festhielt. Vielfach reproduziert und sogar als Postkarten vertrieben, wurde das Bild zur politischen Ikone. Die Waffenbrüderschaft der Soldaten, so die klare Botschaft, hatte den neuen Staat ermöglicht und begründet - und vergessen lassen, dass fünf Jahre zuvor bayerische, badische und württembergische Truppen an der Seite Österreichs gegen preußische gekämpft und verloren hatten (vgl. dazu Gaehtgens 1990).

Fortan sonnte sich das Militär im Glanz seines Erfolges. Der preußische Leutnant, erinnerte der 1862 geborene Friedrich Meinecke, ging damals »als junger Gott« durch die Welt (Meinecke 1965: 25). Immer mehr Bürgersöhne träumten denn auch von einer Offizierskarriere, die in Preußen klassischerweise jungen Männern aus adligem Hause vorbehalten war. Viele konnten ihren Traum verwirklichen, nachdem Kaiser Wilhelm II. 1890 den entscheidenden Schritt tat: Er stellte dem »Adel der Geburt« den »Adel der Gesinnung« offiziell zur Seite und lud die Söhne »solcher ehrenwerten bürgerlichen Häuser, in denen die Liebe zu König und Vaterland, ein warmes Herz für den Soldatenstand und christliche Gesittung gepflegt und anerzogen werden«, zu einer militärischen Laufbahn ein

2| Sie gehört zum städtischen Leben wie die Straßenbahn und der Fahnenschmuck zu Kaisers Geburtstag. Vgl. dazu und zum Vorgesagten Vogel 1997; Frevert 2001; Ulrich/Vogel/Ziemann 2001. 
(Deist 1977: 322). Dreiundzwanzig Jahre später stammten dann bereits sieben von zehn preußischen Offizieren aus bürgerlichen Familien.

Die soziale Öffnung kam nicht von ungefähr. Das Militär brauchte dringend Nachwuchs und konnte ihn nicht mehr aus dem traditionellen Reservoir decken. Die seit den 189 oer Jahren forcierte Aufrüstung betraf nicht nur die Ausstattung mit neuen Waffen, sondern auch und vor allem die Mannschaftsstärke. Sie stieg zwischen 1880 und 1914 von 400.000 [Soldaten und Unteroffiziere] auf 760.000 , verdoppelte sich also annähernd. Parallel dazu wuchs das Offizierkorps von 17.000 auf 31.000 Mann. Diese Zahlen beziehen sich nur auf das Heer; die Marine, das Lieblingskind Wilhelms II., verzeichnete sehr viel höhere Wachstumsraten und konnte ihren Personalbestand zwischen 1880 und 1910 glatt verfünffachen.

Kurz vor Ausbruch des Ersten Weltkrieges standen demnach in Deutschland knapp 900.০०० Mann unter Waffen. Hinzu kamen Millionen von Männern, die in ihrer Jugend >gedient < hatten, sowie Hunderttausende von Reservisten, deren aktive Dienstzeit bereits hinter ihnen lag, die aber im Mobilisierungsfall jederzeit einberufen werden konnten. Hinzu kamen auch Zehntausende von Reserveoffizieren - jene »Halbgötter« (Meinecke), die im Hauptberuf Lehrer, Rechtsanwälte, Ärzte oder Kaufleute waren, daneben aber regelmäßig militärische Übungen abhielten und im Krieg Kommandopositionen besetzen würden.

Wir sehen also »ein Volk in Waffen«, wie es Generalstabsoffizier Colmar von der Goltz 1883 beschworen hatte. Selbstredend stand nicht das ganze Volk unter Waffen, Frauen und Kinder nicht, und nicht einmal alle Männer. Auch im Kaiserreich schöpfte das Militär den Pool der Wehrpflichtigen nicht aus. Aber der Kontrast zu heute ist gleichwohl beachtlich: bei einer Gesamtbevölkerung von ca. 65 Millionen zogen 1913 380.000 Rekruten die Uniform an, 2005, bei 80 Millionen, 68.000.

Rein quantitativ war also das Militär um 1900 sehr viel sichtbarer und inklusiver. Darüber hinaus war es sehr viel mächtiger. Das Militär besaß im Kaiserreich einen annähernd extrakonstitutionellen Status. Es war zwar nicht vollkommen unabhängig vom Zugriff des Parlamentes, das immerhin über sein Budget befand. Seine Interna aber blieben politischer Kontrolle weitgehend verschlossen, getreu dem Grundsatz, den Generalstabschef von Waldersee 1890 so formulierte: »Die Armee ist eine Korporation wie eine Familie, deren intime Fragen nicht vor die Öffentlichkeit gehören« (Waldersee 1923: 124). Das Offizierkorps beanspruchte, diese Fragen allein zu regeln, und konnte sich dabei auf das Wohlwollen des Obersten Kriegsherrn, des Kaisers, verlassen. Hohe Offiziere besaßen Immediatrecht, sie konnten sich jederzeit direkt an den Kaiser wenden. Die Kommandogewalt des Monarchen war unbeschränkt; nicht einmal der Kriegsminister wurde gefragt.

Diese innige Beziehung zwischen Militär und Monarch, so problematisch sie für die politische Verfassung des Kaiserreichs war, trug erheblich dazu bei, das gesellschaftliche Ansehen der Offiziere und Soldaten 
zu heben. Wer »des Kaisers Rock« trug, war dem Kaiser nah. Das war nicht nur symbolisch zu verstehen. Jeder Offizier, unabhängig von seinem Rang, durfte bei Hofe erscheinen. Zivilisten wurde dieses Privileg erst dann zuteil, wenn sie eine hohe Position im Staatsdienst bekleideten oder sich durch große persönliche Leistungen hervorgetan hatten [und deshalb »bei Hofe vorgestellt« wurden]. Hermann Helmholtz, der 1871 nach Berlin berufen wurde und damals bereits weltberühmt war, wurde erst sechs Jahre später, in seiner Eigenschaft als Rektor der Universität, hoffähig; jedem Sekondeleutnant, der gerade die Kadettenanstalt hinter sich gebracht hatte, stand dieses Recht selbstverständlich zu, auch wenn ihm noch kein Bart wuchs. Das Hofrangreglement war militärisch geprägt: Generäle rangierten vor Ministern, jeder Major lief einem Parlamentarier den Rang ab (Röhl 1987: 95ff.).

Viele Politiker zogen es deshalb vor, im Amt Uniform zu tragen, um ihren Status zu erhöhen. Angehende Juristen oder Mediziner, die zugleich Reserveoffiziere waren, warfen sich gleichfalls in Uniform, wenn sie beim Schwiegervater um die Hand der Angebeteten anhielten. Das Ansehen eines Hauses hing davon ab, ob Offiziere auf der Einladungsliste standen und die Einladung annahmen. Dabei spielten das Regiment und die Waffengattung eine zusätzliche und erhebliche Rolle. Kavallerieoffiziere besaßen ein höheres Prestige als diejenigen, die bei der Infanterie, Artillerie oder Marine dienten. Garderegimenter, in denen der Adel besonders stark vertreten war, standen in der Rangskala ganz oben; ihre Mitglieder waren begehrte Tänzer auf den zahlreichen Hof- und Hausbällen, die die lange Wintersaison aufhellten. Als die 17-jährige Marie von Bunsen, Tochter eines liberalen Reichstagsabgeordneten und seiner englischen Frau, ihre Berliner Ballkarriere 1877 begann [übrigens kurz bevor sie ihr Lehrerinnenexamen ablegte, damals noch eine Seltenheit], kannte sie sich in den feinen Abstufungen der militärischen Hierarchie bestens aus. In den großbürgerlichen Häusern, in denen sie verkehrte - bei Bleichröder, Siemens, Mendelssohn-Bartholdy etc. -, galt der Gardeleutnant als beliebtester Tänzer. Auf Kavalleristen musste sie zwar verzichten, denn diese walzten nur beim Adel. Stattdessen »herrschte « bei Bunsens und in den befreundeten Familien der Gardeinfanterist, demgegenüber Gardeartilleristen »etwas abfielen«. Gardeingenieure hingegen »gab es für uns nicht«, ebenso wenig die »provinzmäßigen Marinetänzer« (Bunsen 1959: 49ff.). ${ }^{3}$

\section{Militär und Geschlechterverhältnis}

Die klaren Vorlieben dieser jungen Dame [und ihrer Freundinnen] sagen nicht nur etwas aus über die soziale Wertschätzung der Offiziere und über

3| Maries Bruder war selber bei der Marine - man stelle sich die Kränkung des brüderlich-männlichen Egos vor. 
die Rangunterschiede zwischen den einzelnen Waffengattungen und Regimentern. Sie beleuchten auch ein allgemeineres Phänomen: die Attraktivität militärischer Männer für Frauen. Diese Attraktivität ist breit überliefert, von weiblicher wie von männlicher Seite. Legionen von Zivilisten haben wortgewaltig darüber geklagt, dass die militärische Uniform auf Frauen eine besondere Anziehungskraft ausübe, der der grau-schwarze bürgerliche Anzug nichts entgegenzusetzen habe. Offenbar verlieh sie ihrem Träger eine erotische Aura, die auf viele Frauen unwiderstehlich wirkte (Brändli 1997; Frevert 2003). Wie ist das zu erklären? Zum einen reagierten Frauen zweifellos positiv auf das hohe Sozialprestige des Militärs. Ihre Wertschätzung der Uniform reflektierte die allgemeine Wertschätzung, die die deutsche Gesellschaft - und nicht nur die deutsche - ihrer Armee entgegenbrachte. Sie lag folglich im Trend und war nichts Ungewöhnliches. Zum anderen aber gaben Frauen jenem Trend eine spezifische Wendung. Sie erweiterten das Prestige des Militärs um eine symbolisch-kulturelle Dimension, indem sie ihm eine prononciert sexuelle Konnotation beilegten. Die Macht der Soldaten und Offiziere beschränkte sich damit nicht nur auf Politik und Gesellschaft. Sie erstreckte sich auch auf das Feld der Geschlechterbeziehungen, auf Erotik und Sexualität. Für Frauen, so schien es den Zeitgenossen, war der militärische Mann der Mann schlechthin: der Mann an sich, das Vorbild, der Prototyp eines Mannes. Vor ihren Augen stellte er alle anderen Männer, alle Zivilisten also, in den Schatten.

Nicht alle Frauen dachten so. Und nicht alle wollten militärische Ehemänner. Bürgerliche Mütter und Väter waren nicht immer begeistert, wenn die Tochter einen Offizier heiraten wollte. Man verdiente nicht viel im Militär - und hatte hohe Ausgaben. Viele junge Offiziere waren hochverschuldet und hofften dementsprechend auf eine reiche Braut. Ihre Aussichten auf Avancement waren unsicher, die meisten scheiterten an der Majorsecke. Das alles empfahl sie nicht unbedingt als Schwiegersöhne. Im unterbürgerlichen Milieu sah es etwas anders aus. Besonders Unteroffiziere waren nicht ohne ökonomischen Reiz: Auch wenn ihr Sold nicht hoch war, boten sich ihren Ehefrauen in der Kaserne zahlreiche Möglichkeiten, das Familieneinkommen aufzubessern. Nach dem militärischen Dienst wechselten sie gemeinhin in untere Beamtenpositionen bei der Bahn oder Post. Das brachte zwar ebenfalls kein hohes Salär, aber doch eine regelmäßige Versorgung und eine auskömmliche Alimentation im Alter.

Jenseits solch prosaisch-materiellen Kalküls aber stand etwas anderes: die Begeisterung junger Frauen aller sozialer Schichten für die Träger militärischer Uniformen. Diese Begeisterung war genuin, immateriell, schwärmerisch. Sie folgte keiner ökonomischen Bilanz von Soll und Haben, sondern richtete sich an anderen Zeichen aus: an einem in bestimmter Weise modellierten Körper; an der Fähigkeit, diesen Körper zum Ausdruck zu bringen [etwa beim Tanzen]; an einem Auftreten, das sowohl höflich-zuvorkommend als auch forsch und bestimmt war. Es waren individuelle Zei- 
chen, die an der einzelnen Person hafteten; zugleich aber verwiesen sie auf das Kollektiv, dem die Person angehörte und das ihren Habitus prägte.

Dieser Zusammenhang wurde bereits beim ersten Blickkontakt deutlich. Militärische Männer waren schöne Männer - schön im zeitgenössischen Verständnis. Die strengen Tauglichkeitsstandards der Armee sorgten dafür, dass nur große, kräftige, gerade gewachsene und gesunde Männer rekrutiert wurden, ohne Schweiß- und Plattfüße, ohne Buckel und Brille. Sie gehörten, und das wurde ihnen immer wieder eingeprägt, »zu den Besten des männlichen Nachwuchses« und waren dem Gros ihrer Altersgenossen - die Untauglichkeitsrate lag bei 70 bis 80 Prozent - physisch überlegen. Das Körpertraining in der Armee trug seinerseits dazu bei, »schöne Leute « in noch schönere zu verwandeln. Soldaten bewegten sich anders als Nichtgediente, selbstbewusster, sicherer, disziplinierter. Sie konnten auftreten, im doppelten Wortsinn: Sie hatten gelernt, ihre Füße so auf den Boden zu setzen, dass sie fest standen, und sie wussten, wie sie sich Respekt verschaffen konnten.

Darüber hinaus waren sie von ihren Vorgesetzten genau instruiert, die »militärischen Formen« zu beachten, um jenen Respekt auch zu wahren. Offizierburschen in Uniform war untersagt, große Marktkörbe oder auffallende Pakete zu schleppen, weil dies dem militärischen Habitus abträglich schien. Streng verboten war es auch, sich »auf der Straße bei weiblichen Personen einzuhängen. Militärpersonen dürfen Damen am Arm führen, nicht aber sich von Damen führen lassen.« Außerdem durften sie auf der Straße weder essen noch Schirme oder Stöcke tragen. Stattdessen mussten sie überall ihren Säbel mitnehmen, auf Spaziergängen ebenso wie ins Wirtshaus. Allenfalls auf dem Tanzboden durfte er kurzzeitig abgeschnallt werden. Als in den 18 goer Jahren das Radfahren beim Heer eingeführt wurde, machten sich die zuständigen Stellen monatelang darüber Gedanken, wo der Säbel am besten zu befestigen war. Eine Instruktion des Münchner Kriegsministeriums befand schließlich, dass er entweder in einer »Schlinge am linken Handgriff der Lenkstange anzubringen« sei oder »soweit um den Leib herum nach vorn geschoben wird, dass es dem Fahrer nicht hinderlich ist (Frevert 2001: 240, 405).

Von größter Bedeutung war zudem die Uniform, die in perfekter Ordnung gehalten werden musste. Ihr Stoff und Schnitt modellierten den ohnehin schon »schönen« Körper der Soldaten in besonderer Weise. Die Uniform war in der Regel aus festem, bei den Mannschaftssoldaten oft kratzigem Wolltuch geschneidert, das sich nicht etwa dem Körper anschmiegte, sondern seinerseits den Körper formte. Der Uniformschnitt betonte die gerade Haltung; er zwang zum Aufrichten und zur Zackigkeit. Hochgeschlossene Kragen und Halsbinden legten eine gestreckte Kopfund Rückenhaltung nahe. Ausladende Ober- und schmale Hüftpartien erzeugten, in den Worten eines Offiziers, »die Illusion einer Wespentaille 
und gigantischer Schultern «. Das erweckte, so der Offizier weiter, den Eindruck »strotzender Kraft« (Wilke 1930: 96).

Diese Kraft aber trat gezügelt auf, eingehegt und kontrolliert. Gerade das machte sie attraktiv. Sie kam nicht im wilden oder rohen Zustand daher, sondern gebändigt, gleichsam zivilisiert. Von Offizieren und Soldaten erwartete man, dass sie sich an Regeln hielten, Befehlen Folge leisteten. Fehltritte zogen Konsequenzen nach sich, im Dienst ebenso wie außerhalb des Kasernenhofs. Der Comment war strikt, die Disziplin eisern. Selbst wenn sie nur von außen oktroyiert war, tat sie der Gesellschaft gute Dienste. Das Militär stand im Ruf, streng, aber gerecht zu sein und auch auf pädagogischem Gebiet Wunderdinge zu vollbringen. Mütter, die bei der Erziehung ihrer Söhne am Ende ihrer Weisheit angelangt waren, griffen zur letzten Drohung: »Wart<, bei die Soldatens werden sie Dich das Gehorchen schon beibringen!« (Gregory 1944: 41). Die Münchnerin Anna Meyr beklagte sich 1906 beim bayrischen Kriegsminister über ihren unzuverlässigen und gewalttätigen Liebhaber und fügte hinzu: »Es wäre gut, einen solchen Menschen in das Militär befördern zu können « (Frevert 2001: 272). Das Militär war der Ort, an dem Wildheit gebändigt und kaserniert wurde, in dem Männer nicht nur >geschliffen<, sondern auch abgeschliffen wurden.

\section{Körper, Sexualität, Gewalt}

Zunächst jedoch produzierte das Militär Bedingungen, die, in der Sprache der Zeit, unsittliches Betragen wahrscheinlicher machten. Als eine Institution, die junge, adoleszente Männer in großer Zahl zusammenfasste und für mehrere Jahre bei sich behielt, sah es sich mit geballten geschlechtsund alterstypischen Problemen konfrontiert: Alkohol, Sexualität, körperliche Auseinandersetzungen. Letztere kamen gehäuft in der Kaserne selber vor, oft in ritualisierter Form. Ältere Jahrgänge kujonierten jüngere und machten ihnen ihren Platz in der Hierarchie klar. Es war üblich, Neuankömmlinge nachts in ihren Betten zu verprügeln, »der Kasernengeist«, hieß es dann, sei "gekommen und habe sie ordentlich gewickelt« (Frevert 2001: 250). Stellten sich Rekruten bei ihrer militärischen Abrichtung ungeschickt an - wofür nicht selten die ganze Gruppe zur Verantwortung gezogen wurde -, bekamen sie den Zorn ihrer Kameraden hautnah zu spüren. Darüber hinaus bot das tagtägliche und nachtnächtliche Zusammensein genügend Zündstoff für persönliche Streitigkeiten, die mittels physischer Gewalt ausgetragen wurden. Unter dem Einfluss des Alkohols, der bei Wirtshausbesuchen am ausgehfreien Wochenende reichlich floss, waren Schlägereien untereinander, aber auch mit Zivilisten kaum zu vermeiden. Die Tatsache, dass Soldaten auch außerhalb der Kaserne meist in Gruppen auftraten, trug zur Eskalation der Streitlust bei.

Raufereien und Prügeleien waren in der männlichen Jugendkultur 
ländlicher ebenso wie städtischer Provenienz nichts Ungewöhnliches. Unter den Bedingungen der Militärzeit traten sie allerdings gehäuft und potenziert auf - potenziert durch die Allgegenwart des Säbels, den die Soldaten stets mit sich führen mussten. Auf der anderen Seite wurden sie auch schärfer beobachtet und sanktioniert. Die Kontrolle durch Vorgesetzte und Militärpolizei war dicht, die Strafen harsch. Im Dienstunterricht wurde immer wieder betont, dass die Uniform, der Rock des Königs, ihre Träger zu Disziplin und Anstand verpflichte. Als Soldat habe der junge Mann nicht nur seine eigene, persönliche Ehre zu wahren, sondern auch die der Armee und ihres Obersten Kriegsherrn. ${ }^{4}$

Gerade jene Mahnung aber gab wiederum Anlass zu vermehrten und militärspezifischen Konflikten. Denn im Umgang mit männlichen Zivilisten, wie er bei den wochenendlichen Tanzvergnügungen und Wirtshausbesuchen unvermeidlich war, konnten alle möglichen Bemerkungen, Gesten, Grimassen als Angriffe auf die soldatische Ehre (miss)verstanden und mit Waffengewalt geahndet werden. Die Allgegenwart der militärischen Gruppe verstärkte die Neigung, in der Öffentlichkeit forsch aufzutreten und dem »Zivilpack« nichts durchgehen zu lassen. Zwar schärften die Kriegsartikel jedem einzelnen Soldaten ein, »bedacht« zu handeln; keinesfalls sei er berechtigt, »jemanden sofort niederzustechen, der ihn >angerempelt $<$ hat«. Die Praxis jedoch zeigte, dass der Säbel locker saß (Henseling 1902: 46).

Soldatisches Verhalten war demnach von einer eigentümlichen Ambivalenz geprägt: Einerseits trug es deutliche Zeichen standesbedingter Machtanmaßung, gepaart mit einer spannungsvollen Mischung aus jugendlich-männlicher Statusunsicherheit und physischer Selbstbestätigung; andererseits unterlag es einem engmaschigen System militärischer Kontrolle und Disziplinierung. Unverkennbar aber war die Frontstellung gegen (junge) Männer, die die Uniform nicht trugen; ihnen fühlte man sich überlegen und verlieh diesem Gefühl offensiv Ausdruck.

Wie aber verhielten sich Soldaten gegenüber dem anderen Geschlecht? Gab es überhaupt einen militärtypischen und verallgemeinerbaren Umgang mit Frauen? Die Dienstinstruktionen sprachen eine ebenso lakonische wie deutliche Sprache: »Unehrenhaft ist es, ein sittsames Mädchen zu verführen, widerlich und gesundheitsgefährlich der Verkehr mit liederlichen Frauenzimmern« (Schmidt 1894: 17; Menzel 1894: 47). Garnisonskommandanten stellten den Besuch von Wirtshäusern, in denen Prostituierte und Zuhälter verkehrten, unter Strafe; sie warnten die Mannschaften vor »Ausschweifungen « und übten Druck auf Gastwirte aus, ihr weibliches Personal sorgfältig auszuwählen. Andererseits wehrten sie sich dagegen, die jungen Männer wie die Zöglinge eines Mädchenpensionats zu behandeln und zu »Temperenzlern oder Kopfhängern« zu erziehen. Als

4 | Vgl., pars pro toto, aus der Fülle publizierter Dienstratgeber Menzel 1910 - ein vielfach aufgelegtes Buch, von dem 1907 ca. 400.000 Exemplare kursierten. 
das erzbischöfliche Ordinariat München-Freising das bayerische Kriegsministerium 1910 darauf aufmerksam machte, dass unter Soldaten Bücher mit »höchst anstößigen, rohgeschlechtlichen Schilderungen« kursierten, erklärte sich das Ministerium nicht für zuständig. Den Leuten mit Moralpredigten zu kommen, helfe nicht weiter; »auch ist das hier weniger am Platze, denn auf diesem Gebiete wird die Natur sich stets zuletzt bändigen lassen« (Frevert 2001: 233, 404).

$\mathrm{Ob}$ eine >Bändigung< sexueller Phantasien und Handlungen unter den Umständen kasernierter Gruppenbildung überhaupt hätte gelingen können, bleibt dahingestellt. Sicher, es mangelte nicht an einschlägigen Ermahnungen und Verboten, und Frauen durften generell nicht aufs Kasernengelände gebracht werden. Aber diese Verbote wurden ebenso missachtet wie die Warnungen, sich mit Prostituierten abzugeben. Unter den Mannschaften aller Waffengattungen und jeglicher sozialen Herkunft gehörten Bordellbesuche, oft im Kameradenkreis, zum guten Ton. Auch diejenigen, die beim Dienstantritt noch sexuell unerfahren waren, verließen die Kaserne zwei oder drei Jahre später als ganze oder richtige Männer. ${ }^{5}$

Aber wie sah es mit Beziehungen zu »sittsamen Mädchen« aus, deren »Verführung« als »unehrenhaft« galt? Hier sind wir bislang weitgehend auf Spekulationen und Plausibilitätserwägungen angewiesen. Wir wissen einiges über die erotische Selbststilisierung der Soldaten, wie sie uns in den verbreiteten und beliebten Soldatenliedern begegnen: »Wenn Trompeten lustig schallen,/Manches Mädchen kommt in Gluth,/Denn die Mädchen sind vor allen/Den Soldaten innig gut./Kühn und mutig in der Liebe,/Wie im Feld, ist der Soldat;/[...] Liebesblicke, Liebesthränen/Dem Soldaten eigen sind,/und der Mädchen Herzensthüre/findet er gar sehr geschwind.«Ebenso schnell wie er die Tür zum Mädchenherzen zu öffnen wusste, schlug er sie auch wieder zu, denn zur Treue, hieß es, seien Soldaten nicht geschaffen: »Heute Jettchen, morgen Bettchen, immer neu, Das ist Soldatentreu « (beide Göttsch 1998: 150f., 138).

Aber waren das nicht bloße Projektionen und männliche Wunschvorstellungen? Wie belastbar, wie realitätsnah waren solche soldatischen Selbstbilder? Immerhin deckten sie sich mit dem öffentlichen Ruf von Soldaten als Männern, »die frisch und fröhlich in die Welt« zögen (Schmidt 1894: 133). Kehrten sie nach der Dienstzeit in ihren Heimatort zurück (was viele nicht taten), brachten sie, zum Verdruss lokaler Honoratioren, »lose Sitte und unzüchtige Rede« mit, die sie »von den älteren Kameraden oder auch von manchen Vorgesetzten« gehört hätten (Meyer 1984: 240). Allgemein galten sie als lustige Gesellen, die in der Kaserne ein kontrolliertes, aber sorgenfreies Leben führten und sich, anders als ihre zivilen Altersgenossen, weder um ihr Einkommen noch um ihr Fortkommen kümmern mussten.

5| Beispiele aus der autobiographischen Literatur: Rehbein 1911/1985: 192f.; Müller 1958: 214-217. 
Zugleich aber war die Kaserne nicht nur eine Chiffre für lose Sitte und Jungmännerkameradschaft. Sie stand mindestens ebenso sehr für Manneszucht, für Disziplin, Gehorsam und Regelkonformität. Wer sich hier auszeichnete, konnte beim Militär bleiben und zum Unteroffizier aufsteigen, eine Karrieremöglichkeit, die für Männer aus sozialen Unterschichten - und ihre potentiellen Ehefrauen - durchaus attraktiv war. Aber auch diejenigen, die lieber wieder ins Zivilleben zurückkehrten, hatten in der Kaserne nicht nur »unzüchtige Rede« gelernt. Sie wussten zudem, wie man Knöpfe annähte, seine Kleidung in Ordnung hielt und eine Dusche benutzte.

Auch damit konnten sie jungen Frauen imponieren. Ob sie es taten und wie weit die vielfach bezeugte Attraktivität der Uniform reichte, wissen wir nicht genau. Wollen wir uns nicht allein auf literarische Quellen verlassen - Arthur Schnitzlers »Reigen« kommt hier in den Sinn -, bleibt wenig mehr als das Gegenlesen gerichtlicher Fallakten. Obwohl solche Akten ausschließlich Konflikte zwischen Frauen und Soldaten, meist Vergewaltigungen oder Vergewaltigungsversuche, dokumentieren und damit ein einseitig negatives Bild zeichnen, enthalten sie auch Hinweise auf normale Umgangsformen und Einstellungen. Beispielsweise lassen sie nicht erkennen, dass junge Frauen generell Angst vor Soldaten gehabt hätten und ihnen deshalb von vornherein aus dem Weg gegangen wären. Bauernmägde, Dienstmädchen und Fabrikarbeiterinnen fanden nichts dabei, sich von einem Soldaten nach Hause begleiten zu lassen; sie schätzten ihn als Tanzpartner und waren auch nicht abgeneigt, sich auf ein erotisches oder sexuelles Verhältnis einzulassen - solange es eigenen Wünschen entsprach. Tat es das nicht und setzte ein Soldat sein Begehren mit Gewalt durch, konnte er, sofern die Frau Anklage erhob, militärgerichtlich belangt werden.

Nichts deutet bislang darauf hin, dass Vergewaltigungen bei Soldaten signifikant häufiger vorkamen als bei gleichaltrigen Männern in zivilen Milieus (Hommen 1999). Es ist auch nicht bezeugt, dass Soldaten ein entsprechendes Image anhaftete. Das galt selbst für kriegerische Zeiten. Obwohl Vergewaltigungen als Zweck, Mittel oder Nebenprodukt der Kriegführung seit der Antike bekannt waren ${ }^{6}$, spielten sie im 19. Jahrhundert keine Rolle, genauer: Sie waren kein Thema, das öffentliche Aufmerksamkeit erregte. Aus dem 1870 or Feldzug gegen Frankreich etwa wurden nur wenige Fälle bekannt, die in Deutschland gar nicht und in Frankreich kaum diskutiert wurden. Französische Quellen (Zeitungen, Karikaturen,

6| Man denke an den »klassischen« Fall der geraubten Sabinerinnen, der, da für die Gründungsgeschichte Roms wichtig, in allen Gymnasien des 19. Jahrhunderts auf dem Lehrplan stand. Leider liegen zum Thema »Vergewaltigung und Krieg « kaum historische Studien vor; die Pionierin der Vergewaltigungsforschung, Susan Brownmiller, bietet dazu nur wenige und disparate Anhaltspunkte (Brownmiller 1975: 31ff.). 
Polizeiberichte) enthielten so gut wie kein einschlägiges Material. Als der Historiker Ernest Lavisse 1871 eine hasserfüllte Anklage der »tierischen« Übergriffe publizierte, die sich die deutschen Truppen in Frankreich hatten zu schulden kommen lassen, fehlte jeder Hinweis auf Vergewaltigungen. Während der preußische Terror - Exekutionen, Verstümmelungen, Morde - ausladend geschildert wurde, ließ der Autor seinen Feinden auf sexuellem Gebiet Gerechtigkeit widerfahren: »Il faut savoir rendre justice à ses ennemis: les notres ont donné un exemple unique dans l'histoire des guerres en respectant et en faisant respecter partout les honnetes femmes « (Audoin-Rouzeau 1995: 45).

War das ehrenwerte Verhalten der Deutschen 1870/71 eine Ausnahme? Lavisse nannte es schließlich ein »einzigartiges Beispiel in der Geschichte der Kriege«. Aus dem Ersten Weltkrieg sind andere Vorfälle dokumentiert; hier steht außer Frage, dass deutsche Militärangehörige Frauen vergewaltigten und die Ehre belgischer und französischer honnetes femmes verletzten (Horne/Kramer 2001: 75; Audoin-Rouzeau 1995; Harris 1993). Britische, belgische und französische Untersuchungen der »German outrages « und »atrocités allemandes « sprachen diese Übergriffe explizit an, und die alliierte Propaganda machte sie sich weidlich zunutze (Morgan 1916: 57ff.; Bryce 1915: 253, 255). Völkerrechtlich aber wurden Vergewaltigungen im Krieg erst 1949 geächtet; die Haager Landkriegsordnung von 1907 hatte lediglich verfügt, dass die »Familienehre « zu respektieren sei (Bryce 1915: 276; Gullace 1997: 733f.). Es ist weitgehend unerforscht, wie die Militäradministration selber das Thema behandelte. Erteilten Kommandeure, wie Lavisse die Aussage eines deutschen Unteroffiziers aus dem 1870er Krieg wiedergab, dezidierte Befehle, »die Frauenzimmer zu respektieren«, um keinen französischen Widerstand zu provozieren? Ließen sie umgekehrt 1914 ihren Soldaten freien Lauf, ohne sich um die Folgen $\mathrm{zu}$ scheren? Dieses Kapitel der Kriegsgeschichte muss noch geschrieben werden.

\section{Das militärische Curriculum: schulbildend und normsetzend}

Besser informiert sind wir über den Anspruch des Militärs, »Schule der Nation« zu sein. Bereits das Gesetz, das 1814 die Wehrpflicht dauerhaft in Preußen einführte, sprach von der Armee als »Haupt-Bildungsschule der ganzen Nation für den Krieg«. Zwei Jahre später präzisierte der Kriegsminister, sie sei darüber hinaus auch als »Schule für alle dazu nötigen Tugenden des Staatsbürgers « anzusehen (Frevert 2001: 100). Ihr Bildungsprogramm enthielt demnach nicht nur das, was einen Mann kriegstüchtig machte, sondern auch das, was ihn gesellschafts- und politikfähig sein ließ. Darüber hinaus verstand sich das Militär als »Schule der Männlichkeit« - eine Formulierung, die der Berliner Philosophieprofessor Friedrich Paulsen 1902, seines eigenen Militärjahrs eingedenk, gebrauchte (Paulsen 
1902: 471). Auch militärintern war immerzu davon die Rede, dass man die Wehrpflichtigen nicht nur zu guten Soldaten, sondern auch zu richtigen Männern erziehen wollte. Und es war klar, dass diese Erziehung Standards setzte. Die Armee (und Marine) sah sich nicht als eine Erziehungsanstalt unter vielen anderen, sondern als die normgebende Schule überhaupt.

Angesichts ihrer starken politischen und sozialen Stellung war dieser Anspruch wohlbegründet. Allerdings gab es durchaus Konkurrenz: Schulen arbeiteten mit einem anderen Lehrplan - nicht so sehr die Volksschulen, aber doch die Gymnasien, die viel mehr Wert auf intellektuelle Fähigkeiten, auf musische und ästhetische Erziehung legten und ihre Absolventen mit Literatur versorgten, die Männer und Männlichkeiten mehrdimensional entwarf. Auch die Universitäten, bis 1908 frauenlose Räume, waren einflussreiche Schulen der Männlichkeit und vermittelten teils konträre, teils komplementäre Botschaften. Wer einer studentischen Verbindung beitrat, machte dort ähnliche Erfahrungen wie im Militär und lernte eine Schneidigkeit, die militärische Vorbilder nicht verleugnete. Und wer Heinrich von Treitschkes Vorlesungen hörte, bekam ebenfalls ein wenig differenziertes Bild seiner männlichen Rechte und Pflichten serviert. »Obrigkeit ist männlich«, dozierte der Professor, und da staatliche Macht auf militärischer Macht beruhe, seien die Dinge klar. Politik und Kriegshandwerk hatten ausschließlich in männlichen Händen zu liegen; und nur wer in der Armee gehorchen gelernt hatte, konnte später befehlen (Treitschke 1899: 252f.).

Allerdings umfasste der universitäre Lehrplan mehr als Befehl und Gehorsam, und selbst unter Studenten regte sich Ende des 19. Jahrhunderts Widerstand gegen das Treiben schlagender Verbindungen und deren antiintellektuellen Habitus. Auch andere Bildungsinstitutionen [im weitesten Sinn] fügten sich nicht nahtlos in das vom Militär vorgegebene Muster ein. Kirchliche Jugend- und Jungmännerorganisationen hielten andere Rollenvorbilder hoch, ebenso wie die sozialdemokratische Arbeiterbewegung zivile Gegenmodelle entwarf (Ruppert 1986, Kap. 4).

Gleichwohl spricht viel dafür, dass das militärische Curriculum nicht nur vom Anspruch her, sondern auch in der gesellschaftlichen Wirklichkeit einflussreich und normsetzend war. Zum einen war die Armee sozial sehr viel inklusiver als alle anderen genannten Organisationen: Sie rekrutierte ihre Soldaten quer durch alle Schichten, aus Stadt und Land. Zum anderen hantierte sie mit anderen Zahlen als Universitäten, Gymnasien oder katholische Jünglingsvereine. Drittens fanden sich die von ihr favorisierten Werte und Verhaltensmodi in der einen oder anderen Form auch in zivilen Institutionen wider, wobei der Transfer durchweg nur in einer Richtung verlief. Ebenso wie Unternehmer gern >gediente< Arbeiter einstellten, verdankte manch ein Jurist seine Beförderung nicht nur seinen professionellen Leistungen, sondern der Tatsache, dass er als Reserveoffizier »Haltung gelernt« hatte (Wermuth 1922: 7of.). Last but not least: Selbst dann, wenn etwa in Teilen der Jugendliteratur dezidiert zivile Rollenvor- 
bilder propagiert wurden - der sozialdemokratische Arbeiterführer, der Missionar im Urwald, der Arzt im Labor oder der Forschungsreisende in der Antarktis -, waren die ihnen beigelegten Eigenschaften und Passionen militärisch grundiert: Sie alle waren Helden, Kämpfer voller Mut, Stärke, Selbstüberwindung, Aufopferung und Disziplin (Frevert 1998: 335-337).

Diese Eigenschaften machten den Kern dessen aus, das wir als Ziel militärischer Männlichkeitserziehung beschreiben können. Im Mittelpunkt stand die Figur des Helden, der über sich selber hinauswuchs und sein Leben für ein hohes Gut in die Schanze schlug. Das höchste Gut im Militär war die Ehre des Vaterlandes, aber es gab auch Handfesteres: das Leben des verwundeten Kameraden, die sexuelle Integrität der Schwester. Mut und Opferwille waren nötig, um dieses Heldentum zu praktizieren, außerdem Disziplin, Selbstbeherrschung, Zuverlässigkeit und Gehorsam. Umrahmt wurde dieser Kern von einem Kranz bürgerlicher Sekundärtugenden: Sauberkeit, Fleiß, Ordnungssinn, Pünktlichkeit, Sparsamkeit.

Das Feld, auf dem die Primärtugend des militärischen Mannes am besten zur Geltung kam, war selbstverständlich das Schlachtfeld, der Krieg. Diese Beziehung war den Zeitgenossen um 1900 absolut gegenwärtig, den aktiven Soldaten ebenso wie den Zivilisten und Veteranen. Die Erinnerung an siegreiche Kriege - 1870/71, aber auch 1813/15 - ging einher mit der mentalen und materiellen Vorbereitung auf zukünftige Waffengänge. Hochrüstung und ein dynamisches außenpolitisches Krisenszenario hielten den Krieg dauerhaft präsent. Auch das trug dazu bei, die normative Hegemonie des Militärs zu stabilisieren.

Von »Krise« war dabei wenig zu spüren. Sicher, es gab im Militär verschiedene Gruppen und Abteilungen; die Marine wurde selbstbewusster, das Heer reagierte empfindlich, die Waffengattungen konkurrierten um Prestige und Sold. Es gab Offiziere, die zurückblickten und alte preußische Tugenden hochhielten; es gab andere, die auf Modernisierung setzten und die Konsequenzen der neuen Waffentechnik - MGs, verbesserte Artillerie, Panzer - bedachten. Das wirkte sich auf die Ausbildungsziele und -praktiken aus. Die reformierten Exerzierreglements ließen erkennen, dass reiner Drill und mechanisches Abrichten nicht mehr ausreichten. Neue Felddienstordnungen betonten die Erziehung des Infanteristen zum »selbständig und überlegt handelnden Schützen«, der auch ohne Intervention des Vorgesetzten »seine Waffe gewissenhaft handhabt«. Der »heutige Krieg«, hieß es 1900, stelle »erhöhte Ansprüche« an die »intellektuelle Entwicklung des gemeinen Mannes«. Er lege eine stärkere »Individualisierung« der Ausbildung nahe, favorisiere also den innengeleiteten vor dem außengeleiteten Soldaten (Frevert 2001: 262f.)

Das waren neue Töne - von denen nicht klar ist, ob sie tatsächlich in neue Ausbildungspraktiken umgesetzt wurden. In jedem Fall aber ist der Begriff der Krise hier fehl am Platz. Das Militär war sich seiner selbst sicher. Es wusste, was es wert war, badete in der Zustimmung des Kaisers und der breiten Bevölkerung. Kritik, die in der (links)liberalen und sozia- 
listischen Presse sowie zuweilen auch im Reichstag laut wurde, prallte ab und wurde zur Seite gelegt. Funktions- und Operationsweisen des Militärs entzogen sich öffentlicher Einflussnahme und standen nicht zur Debatte. Wenn Krise, dann fand sie, aus militärischer Sicht, außerhalb der Kasernen statt: in den Arbeiterbezirken der großen Städte, in denen die staatsfeindliche Sozialdemokratie immer stärker Fuß fasste; in manchen Intellektuellenkreisen, die das Individuum höher schätzten als die Gemeinschaft; in den Frauenbewegungen, die politische und soziale Partizipation forderten und die bürgerliche Moral in Frage stellten. Das waren in der Tat bedrohliche und als bedrohlich wahrgenommene Entwicklungen. Ihnen stellte sich das Militär als festes Bollwerk entgegen, wenn es nicht vorzog, sie schlicht zu negieren.

Ein aufschlussreiches Indiz dafür ist die Frage, genauer: das Tabu der Homosexualität. In der zeitgenössischen Gesellschaft intensiv diskutiert wurde sie anlässlich der sogenannten Eulenburg-Prozesse, die zwischen 1906 und 1909 stattfanden (vgl. Bruns in diesem Buch). Im Militär aber fand die Diskussion nicht statt. Militärische Zeitschriften, Dienstreglements, Instruktionsbücher, Autobiographien und Gerichtsprotokolle enthalten so gut wie keinen Hinweis auf Homosexualität. Diese Leerstelle spricht Bände - ebenso für die heutige Forschung. Wenn wir davon ausgehen, dass es homosexuelle Beziehungen auch unter Soldaten und Offizieren gegeben haben muss - die entsprechenden Mitteilungen »Aus der Kriegszeit« im von Magnus Hirschfeld herausgegebenen »Jahrbuch für sexuelle Zwischenstufen« (1914-1918) belegen das ebenso unzweifelhaft wie die entsprechenden Kapitel seiner »Sittengeschichte des Weltkrieges « (Hirschfeld 1930: 273-304) -, ist gleichwohl festzustellen, dass es keine Sprache, keinen Raum gab, sie zu thematisieren - weder als drohende Gefahr noch als soziale Tatsache.

Aber ist das ein Beleg für Krise? Eher lässt sich umgekehrt argumentieren, dass das Militär es sich schlicht leisten konnte, Homosexualität zu ignorieren - trotz aller Anfeindungen der liberalen Presse, trotz der Gerichtsverhandlungen um hohe Offiziere und den Freundeskreis des obersten militärischen Dienstherrn, trotz der Debatten im Reichstag. Es war selbstbewusst genug, solche Tendenzen mit Nichtachtung zu strafen. Solange es die allgemeine Wehrpflicht gab - und dagegen opponierte damals kaum jemand -, behielt es alle Trümpfe in der Hand: Es blieb »Schule der Nation« und »Schule der Männlichkeit«.

\section{Männlichkeit im Plural}

Aber war die Männlichkeitserziehung im Militär tatsächlich einlinig und eindimensional? Muss man nicht eher von Männlichkeit im Plural sprechen, und zwar sowohl in synchroner als auch in diachroner Perspektive? Bereits die neuen, seit den späten 188 oer Jahren eingeführten Ausbil- 
dungsdirektiven deuteten darauf hin, dass es verschiedene, zeitlich und sozial differenzierte Konzepte gab. Man wollte den befehlsgehorsamen und disziplinierten Soldaten, aber erwartete zunehmend mehr Selbsttätigkeit und Selbständigkeit. Hier klopfte ein intellektuelleres Männerbild an und stand im Einklang mit modernisierenden Entwicklungen, die sich auch in anderen Bereichen von Wirtschaft und Gesellschaft abzeichneten.

Pluralisierung gab es zudem im Hinblick auf soziale Adressaten. Zwischen Mannschaften und Offizieren klafften Welten, und die Hierarchie war überall sichtbar. Die Ausbildung der Berufsoffiziere prämierte andere Fähigkeiten als die der Soldaten - ihnen brachte man zusätzlich zum Gehorsam auch das Befehlen bei und das Tanzen. Darüber hinaus erzog man ihnen ein empfindliches Ehrgefühl an und gab ihnen Mechanismen an die Hand, dieses Ehrgefühl zum Ausdruck zu bringen [Ehrengerichte, Duelle]. All das kam für gemeine Soldaten nicht in Frage. Dafür lernten sie Knöpfe annähen, Uniformstücke flicken, Wäsche waschen. Sie lernten sich selber organisieren, ihre Dinge in Ordnung halten - auch wenn solche Funktionen in der Außenwelt Frauensache waren. Es ist nicht überliefert, dass sie daran Anstoß genommen hätten. Offenbar erlaubte ihnen die Männergesellschaft des Militärs, Grenzüberschreitungen gelassen anzugehen. Sie gewannen auf diese Weise eine Selbständigkeit und Unabhängigkeit, die sie in der Außenwelt nicht besaßen. Sie lernten, ohne Frauen und deren Dienstleistungen auszukommen - sofern sie nicht das Geld hatten, sich diese Dienstleistungen zu kaufen.

Das Militär präsentierte sich demnach als eine Institution, die verschiedenen Männlichkeiten Platz bot: solchen der Offiziere und der Mannschaften, solchen der Hierarchien und der egalitären Kameradschaft. So geschichtet und gestaffelt die hier vermittelten Rollenbilder waren, wurden sie doch überwölbt von etwas Gemeinsamem, das gerade im Vergleich zu nicht-militärischen Männlichkeitsbildern klar hervorsticht: von der Nähe zur staatlichen Macht und der Verfügung über legitime Gewaltmittel. Paradigmatisch dafür stehen die Uniform und der Säbel. Die Uniform war zwar durch vielerlei Zeichen differenziert - durch die Qualität des Stoffes, den Schnitt und die Abzeichen, die den Rang ihres Trägers abbildeten. Zugleich aber war sie ein gemeinsames Charakteristikum aller Angehörigen der bewaffneten Macht, ein Signalzeichen für diejenigen, die an dieser Macht nicht teilhatten. Feindifferenzierung nach innen und Homogenisierung nach außen - das war ihre Devise.

Neben der Uniform gehörte der Säbel zu den Inkunabeln. Auch ihn trugen Offiziere ebenso wie Mannschaften, und zwar immerzu und auch und gerade in der Öffentlichkeit. Der Säbel zeichnete sie noch stärker als die Uniform als Mitglieder der Institution Militär aus und machte auf die spezifische Funktion dieser Institution aufmerksam: das Töten. Der Säbel stand für das Waffenarsenal, über das die Armee gebot und das sie gegen die inneren und äußeren Feinde des Vaterlandes, des Staates, der Nation einsetzte. Diese Waffen waren scharf bewacht, und ihre Anwendung folgte 
strengen Regeln. Auch der Gebrauch des Säbels war genau umschrieben und kontrolliert. Keinesfalls durfte man mit ihm herumfuchteln oder ihn anders als bei Gefahr benutzen. Aber selbst dann, wenn er nicht in Aktion trat, war er überaus sichtbar. Er rief die exponierte Macht in Erinnerung, die sein Träger verkörperte: Letzterer konnte sich zum Herrn über Leben und Tod aufschwingen. Die legitime Verfügung über Tötungsgewalt - schärfer noch: Das legitime Monopol von Tötungsgewalt war es, das das Militär und seine Angehörigen exklusiv auszeichnete. Es verlieh Soldaten einen besonderen, hervorgehobenen Status und die entsprechende Aura von Schutz und Bedrohlichkeit, von Gefahr und Kontrolle. Anders als heute wurden dieser Status und diese Aura politisch und gesellschaftlich hervorgehoben und hochgeschätzt.

Das Gewaltmonopol und die ihm beigegebenen Attribute unterschieden und unterscheiden das Militär von allen anderen Einrichtungen der modernen Gesellschaft. Da es ausschließlich in männliche Hände gelegt wurde, konstituierte es zugleich die wesentliche und unhintergehbare Differenz gegenüber Frauen. Wie gesagt: Nicht alle Männer waren Soldaten, und neben dem Militär gab es andere Institutionen, die Männlichkeit formten und prägten. Aber Soldaten waren immer nur Männer - Frauen blieben aus diesem Bereich kategorisch ausgeschlossen. Ihre systematische, prinzipielle Abwesenheit gehört zu den wichtigsten und dauerhaftesten Markierungen militärischer Männlichkeiten. Um 1900 gab es niemanden, der diese Abwesenheit in Frage gestellt hätte. Selbst die mutigsten, radikalsten Frauenrechtlerinnen dieser Zeit schreckten davor zurück, Gleichheit auch auf dem Gebiet militärischer Inklusion zu fordern.

Auch in dieser Hinsicht erwies sich das Militär als krisenfest. Seine Rolle als »Schule der Nation« und »Schule der Männlichkeiten« war stabil und hegemonial. Das verdankte es einerseits seiner substantiellen Macht [über Leben und Tod], andererseits der politischen und gesellschaftlichen Akzeptanz jener Macht. Um 1900 stand die Akzeptanz außer Frage, und das Militär hatte es nicht nötig, seine Männlichkeitsstandards gegenüber anderen Institutionen zu verteidigen, $\mathrm{zu}$ legitimieren oder gar $\mathrm{zu}$ revidieren. Das änderte sich entscheidend erst nach der Epoche zweier Weltkriege - in einer anderen Moderne.

\section{Literatur}

Audoin-Rouzeau, Stéphane (1995): L'enfant de l'ennemi 1914-1918, Paris: Aubier.

Brändli, Sabina (1997): »Von >schneidigen Offizieren und >Militärcrinolinen : Aspekte symbolischer Männlichkeit am Beispiel preußischer und schweizerischer Uniformen des 19. Jahrhunderts«. In: Ute Frevert (Hg.), Militär und Gesellschaft im 19. und 20. Jahrhundert, Stuttgart: Klett, S. 201-228. 
Brownmiller, Susan (1975): Against Our Will: Men, Women and Rape, New York: Fawcett Columbine.

Viscount Bryce (1915): Evidence and Documents laid before the Committee on Alleged German Outrages, New York: MacMillan.

Bunsen, Marie von (1959): Die Welt in der ich lebte 1860-1912, Biberach: Koehler (Erstveröffentlichung 1929).

Deist, Wilhelm (1977): »Die Armee in Staat und Gesellschaft 1890-1914«. In: Michael Stürmer (Hg.), Das kaiserliche Deutschland. Politik und Gesellschaft 1870-1918, Kronberg: Athenäum, S. 312-339.

Frevert, Ute (1998): »Herren und Helden. Vom Aufstieg und Niedergang des Heroismus im 19. und 20. Jahrhundert«. In: Richard van Dülmen (Hg.), Erfindung des Menschen, Köln: Böhlau, S. 323-344.

Frevert, Ute (2001): Die kasernierte Nation. Militärdienst und Zivilgesellschaft in Deutschland, München: C.H. Beck.

Frevert, Ute (2003): »Männer in Uniform: Habitus und Signalzeichen im 19. und 20. Jahrhundert«. In: Claudia Benthien/Inge Stephan (Hg.), Männlichkeit als Maskerade, Köln: Böhlau, S. 277-295.

Gaehtgens, Thomas W. (1990): Anton von Werner, Die Proklamierung des Deutschen Kaiserreiches. Ein Historienbild im Wandel preussischer Politik, Frankfurt a.M.: Fischer.

Göttsch, Silke (1998): »>Der Soldat, der Soldat ist der erste Mann im Staat...< Männerbilder in volkstümlichen Soldatenliedern 1855-1875«. In: Wolfgang Schmale (Hg.), Mann-Bilder, Berlin: A. Spitz Verlag, S. 131-154.

Gregory, Mathilde Freifrau von (1944): Dreißig Jahre preußische Soldatenfrau, Brünn: Rohrer.

Gullace, Nicoletta F. (1997): »Sexual Violence and Family Honor: British Propaganda and International Law during the First World War«. In: American Historical Rreview 102, S. 714-747.

Harris, Ruth (1993): »The >Child of the Barbarian<: Rape, Race and Nationalism in France during the First World War«. In: Past \& Present 141, S. 170-206.

Henseling, Wilhelm (1902): Die Kriegsartikel mit Erläuterungen, 4. Aufl., Berlin

Hirschfeld, Magnus (Hg.) (1930): Sittengeschichte des Weltkrieges. Bd. 1, Leipzig: Verlag für Sexualwissenschaft Schneider \& Co.

Hommen, Tanja (1999): Sittlichkeitsverbrechen. Sexuelle Gewalt im Kaiserreich, Frankfurt a.M.: Campus.

Horne, John/Kramer, Alan (2001): German Atrocities, 1914: A History of Denial, New Haven: Yale University Press.

Meinecke, Friedrich (1965): Die deutsche Katastrophe. Betrachtungen und Erinnerungen, 6. Aufl., Wiesbaden: F.A. Brockhaus (Erstveröffentlichung 1946).

Menzel, Max (1894): Der Deutsche Infanterist, 4. Aufl., Hofgeismar: Keseberg. 
Menzel, Max (1910): Dienstunterricht des deutschen Infanteristen, Berlin: Eisenschmidt.

Meyer, Elard Hugo (1984): Badisches Volkesleben im neunzehnten Jahrhundert, Stuttgart (Erstveröffentlichung 1900: Konrad Theiss Verlag)

Morgan, J.H. (1916): German Atrocities: An Official Investigation, London: T. Fischer Unwin.

Müller, Karl Alexander von (1958): Aus Gärten der Vergangenheit. Erinnerungen 1882-1914, Stuttgart: G. Kilpper.

Münkler, Herfried (2006): Der Wandel des Krieges. Von der Symmetrie zur Asymmetrie, Weilerswist: Velbrück.

Paulsen, Friedrich (1902): Die deutschen Universitäten und das Universitätsstudium, Berlin: A. Asher \& Co.

Rehbein, Franz (1985): Das Leben eines Landarbeiters, Hamburg: Christians (Erstveröffentlichung 1911).

Röhl, John C.G. (1987): Kaiser, Hof und Staat. Wilhelm II. und die deutsche Politik, München: C.H. Beck.

Ruppert, Wolfgang (Hg.) (1986): Die Arbeiter. Lebensformen, Alltag und Kultur von der Frühindustrialisierung bis zum Wirtschaftswunder, München: C.H. Beck.

Schmidt, Paul von (1894): Die Erziehung des Soldaten, Berlin: Liebel.

Treitschke, Heinrich von (1899): Politik, Bd. 1, Leipzig: S. Hirzel.

Ulrich, Bernd/Vogel, Jakob/Ziemann, Benjamin (Hg.) (2001): Untertan in Uniform. Militär und Militarismus im Kaiserreich 1871-1914, Frankfurt a.M.: Fischer.

Vogel, Jakob (1997): Nationen im Gleichschritt. Der Kult der >Nation in Waffen < in Deutschland und Frankreich, 1871-1914, Göttingen: Vandenhoeck \& Ruprecht.

Waldersee, Alfred Graf von (1923): Denkwürdigkeiten, hg. v. Heinrich Otto Meisner, Bd. 2, Stuttgart: DVA.

Wermuth, Adolf (1922): Ein Beamtenleben. Erinnerungen, Berlin: A. Scherl. Wilke, Adolf von (1930): Alt-Berliner Erinnerungen, Berlin: Schröder. 



\section{Männlichkeit, Politik und Nation -}

\section{Der Eulenburgskandal im Spiegel europäischer}

\section{Karikaturen}

Claudia Bruns

In mehr als 350 politischen Karikaturen und einer noch wesentlich höheren Anzahl von ausführlichen Prozessberichten wurde die deutsche Öffentlichkeit in den Jahren 1906 bis 1908 täglich mit neuen Enthüllungen über die vermeintlich sanormale < und effeminierte Sexualität des kaiserlichen Freundes- und Beraterkreises, der Generalität und des Reichskanzlers konfrontiert. »Was mittags um 1/2 2 Uhr sich unter Ausschluß der Öffentlichkeit und der Presse im Gerichtssaal abspielte «, so der medizinische Sachverständige Magnus Hirschfeld in seinem Prozessbericht, »[...] ging am andern Tage mit weitern Zusätzen versehen in einen großen Teil der rechts und links stehenden Presse über, [...] mündete schließlich in einer Unmenge von Winkelblättchen, wurde [...] von der Skandalpresse aufgegriffen und [...] entfaltete so in allen Kreisen eine Suggestion von immenser Wirksamkeit« (Hirschfeld 1908: 4).

Doch nicht nur im Kaiserreich, auch im europäischen Ausland spottete man über die vermeintlich gleichgeschlechtlichen Neigungen des deutschen Adels und führender Militärs. So etwa in einer österreichischen Karikatur vom November 1907, die mit zwei vor einer verschlossenen Tür stehenden Reiterstiefelpaaren andeutet, dass hier ein Rendezvous zweier Männer stattfindet, während es in der weniger dekadenten, aber offenbar weit zurückliegenden Vergangenheit - »einst « - noch ein heterosexuelles (Schuh-)Paar gegeben hatte (vgl. Abb. 1). Tatsächlich habe nichts, so Hirschfeld, »in weitesten Kreisen so tief verstimmend gewirkt, wie der Umstand, daß im Zusammenhang mit [...] [den Prozessen, C.B.] ein Flecken auf den Ehrenschild unseres Heeres und die Disziplin fiel, in der seine Größe und sein Ansehen wurzeln « (Hirschfeld 1908: 20). Das Selbstverständnis und das Ansehen des Kaiserreichs schienen auf dem Spiel zu stehen. Offenbar 
wurde die »Ehre« der Nation an bestimmten Formen »männlichen« Verhaltens festgemacht, welche im Zuge der Prozesse präzisiert und zugleich sexualisiert wurden.

Abbildung 1: »Einst. Jetzt« (1907) In: Der Floh (Wien), 39/40 (November), S. 4 .

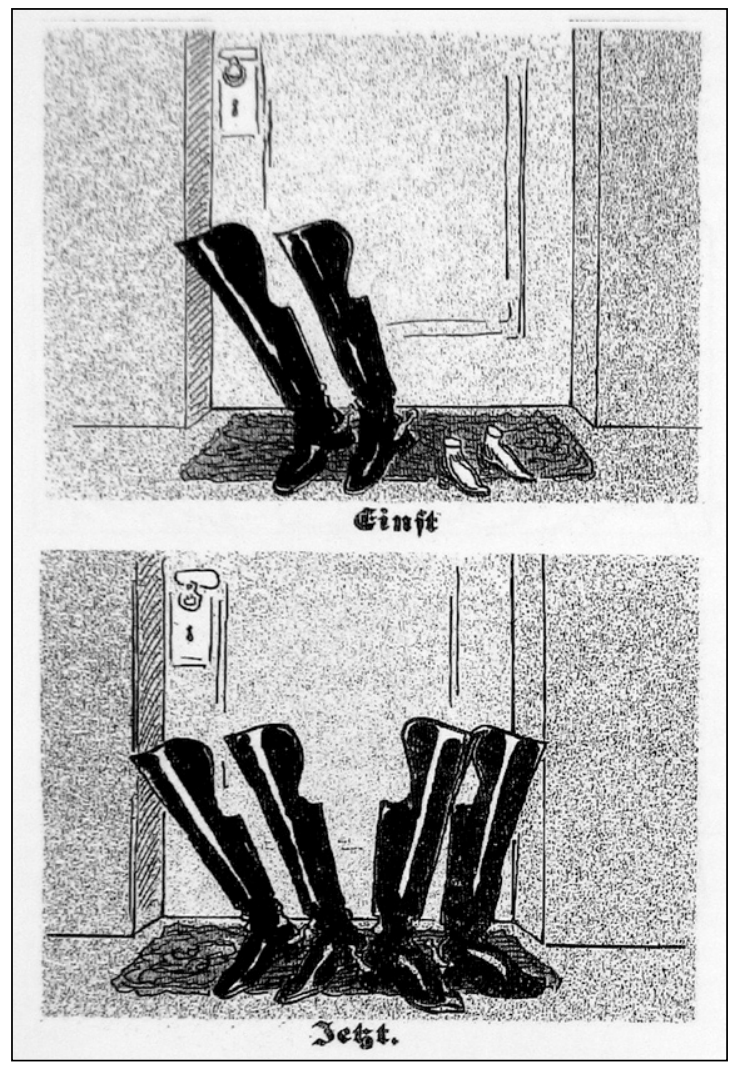

Die Unterstellung und Aufdeckung »homosexuellen« Begehrens im Führungskreis um Kaiser Wilhelm II. diente dazu, einen bestimmten, stark auf die Person des Kaisers und seinen Adelskreis zugeschnittenen, unparlamentarischen Politikstil entlang geschlechtlicher Codes als fehlende Männlichkeit des Staates zu kritisieren. Wie zu zeigen ist, wurde der Mangel an »echter Männlichkeit« nicht nur mit dem dekadenten Adelsstand verknüpft, sondern auch als sexualpathologische »Anormalität« und fehlende Gesundheit ausgewiesen. Das Bürgertum avancierte im Umkehrschluss zu einem Garant soldatisch-gesunder »Männlichkeit«, »Sittlichkeit« und zum »Retter des Vaterlands«. Als prototypisches Gegenmodell diente nicht nur der Adel, sondern zugleich auch die Figur des »Homosexuellen«, die im Verlauf nur weniger Jahre zum Symbol einer drohenden 
»Verweiblichung « des Staates und der deutschen Nation avancierte (zur Nieden 2004: 329ff.; Baumgardt 1992: 21). Neben den Anspielungen auf männliche Homosexualität werden in den Karikaturen, die die Skandalprozesse begleiten, jedoch auch antisemitische Reaktionen sichtbar, was auf eine Verbindung beider Ausgrenzungsstrategien hinweist und deutlich macht, in welch hohem Maß die Kategorien von race, class und gender selbst den Raum >hoher< Staatspolitik durchzogen.

Im Folgenden möchte ich zunächst die Angriffe des bürgerlichen Journalisten Harden gegen die »Liebenberger Tafelrunde« um Fürst Philipp von Eulenburg-Hertefeld vorstellen, anschließend die zentralen Prozessverläufe analysieren und schließlich die ambivalenten Effekte und Folgen derselben für die Verbindung von Männlichkeit, Sexualität und Politik darlegen.

\section{Hardens Angriffe auf die "Liebenberger Tafelrunde"}

Seit 1902 begann der Berliner Journalist und Verleger einer der einflussreichsten politischen Wochenzeitschriften des Kaiserreichs, Maximilian Harden (eigtl. Maximilian Witkowski, 1861-1927), gezielt Material gegen Fürst Eulenburg und seinen Kreis zu sammeln, dessen Einfluss auf den Kaiser er, ähnlich wie Bismarck, seit langem für politisch bedenklich hielt. Im November 1906 kritisierte Harden nicht nur Eulenburgs Mitwirkung bei der Besetzung hoher politischer Ämter (Harden 1906b: 265), sondern auch, dass er den Kaiser in seiner Tendenz zu einer »absolutistischen « Politik des »persönlichen Regiments« (Harden 1906c: 302, 1906b: 266) bestärke und maßgeblich zu einer unvorsichtigen, pazifistischen und Frankreich-freundlichen Politik des Kaisers beitrug.

Tatsächlich hatte der Gardeoffizier Philipp Friedrich Karl Alexander Botho Fürst zu Eulenburg und Hertefeld Graf von Sandels (1847-1921), Sohn eines preußischen Majors und Königsberger Gutsherrn, bereits während seines Studiums einen adeligen Freundeskreis um sich versammelt, der durch seine Kontakte zum Kronprinzen Wilhelm Viktor Albert (dem späteren Kaiser Wilhelm II.) schnell einflussreich wurde. Neben dem späteren Botschaftssekretär Axel von Varnbüler gehörte u.a. General Kuno von Moltke zum Kern des Kreises. ${ }^{1}$ Moltke war bis 1902 »Flügeladjutant seiner Majestät«, dann zwischen 1905 und 1907 Stadtkommandant von Berlin. Die Männer verband eine überaus gefühlvolle und romantische Freundschaft. Man musizierte, komponierte und dichtete ${ }^{2}$ gemeinsam

1। $\mathrm{Zu}$ den Mitgliedern des Freundeskreises vgl. Hull 1992: 84f.

21 Eulenburgs Rosenlieder machten ihn in den 188 oer und 189 oer Jahren in Deutschland berühmt. Moltke komponierte Orchester- und Regimentsmusik. Görtz und Hülsen inszenierten Dramen und Belustigungen (Hull 1992: 86). 
und sprach sich gegenseitig mit zärtlichen Kosenamen an - wie die Gerichtsprozesse später enthüllten.

Nach dem Regierungsantritt Wilhelms II. im Jahr 1888 entwickelte sich Eulenburg zu einem der wichtigsten Berater des Kaisers und zu seinem persönlichen Vertrauten (vgl. Röhl 1992: 134; Hull 1992: 10of.). Er hatte großen Einfluss auf die Weltanschauung des Kaisers, nicht zuletzt auf dessen Antisemitismus (Hull 1992: 116), und es gelang ihm, wichtige politische Posten mit seinen Freunden zu besetzen. So unterstützte er erfolgreich die Ernennung Bernhard von Bülows zum Reichskanzler.

Auf seinem uckermärkischen Gut Liebenberg bei Templin (nördlich von Berlin) bot Eulenburg dem Kaiser Entspannung und Unterhaltung bei Jagd, Gesang und Theateraufführungen, die nicht selten in travestieartige Darbietungen übergingen. In den Briefen dieses Freundeskreises wurde der Kaiser oft vertraulich »das Liebchen« genannt (Röhl 1992: 128f.). Dieser suchte im »Liebenberger Kreis« Resonanz für seine empfindsame, kultivierte Seite, während er sich nach außen hin gern mit dem Glanz soldatischer Männlichkeit und Militärs umgab (Hull 1992: 99).

Durch eine Serie von Artikeln, in denen Harden auf die sogenannten »abnormen« Neigungen Eulenburgs etwa dadurch hinwies, dass er ihn in Anspielung auf die Gepflogenheiten des Liebenberger Freundeskreises süffisant als »Phili« bezeichnete, versuchte er ab 1906 verstärkt Druck auf ihn auszuüben (Harden 1906b: 264f.). Dabei ging es Harden nach eigenem Bekunden nicht darum, Vergehen gegen den Paragrafen 175 im Sinne des Strafgesetzbuches zu verfolgen und aufzudecken. Tatsächlich war er 1898 der erste deutsche Verleger gewesen, der die Petition des Wissenschaftlichhumanitären Komitees zur Aufhebung des Paragrafen unterzeichnet hatte (Steakley 1991: 254). In seinem »Schlussvortrag « zum Moltke-Harden-Prozess grenzte er sich sehr grundsätzlich von Hirschfelds Perspektive der »Gleichwerthigkeit homosexueller Menschen«ab:

»Sie können, wo mehrere sich zusammenfinden, unbewusst Schaden stiften. Besonders an Höfen, wo die ganzen Männer es schwer genug haben. Und wenn man, wie es heute schon Mode geworden ist, die Abnormen als die besseren, edleren Menschen preist, dann treibt man Gesunde ins Verderben.« (Harden 1907: 185)

Harden behauptete, dass »derjenige, der etwas feminin veranlagt ist, absolut nicht für politische Geschäfte passt«, womit er nicht nur auf die Theorie vom »Dritten Geschlecht« (von weiblicher Seele im männlichen Körper) rekurrierte, sondern auch auf den antifeministischen Konsens des Kaiserreichs. Es sei seine patriotische Pflicht, den Kaiser von den »unmännlichen, weichlich-weibischen Beratern « zu befreien, die ihn von der Realität fernhielten und ihn daran hinderten, aktive »Realpolitik« zu machen (Harden 1907: 196). »Wir treiben im Deutschen Reich eine viel zu süßliche und weichliche Politik«, schrieb Harden in der Zukunft und forderte: »Um den deutschen Kaiser sollen und müssen ganze Männer sein!« (Zit.n. Sombart 
1997 [1991]: 4of.) Eulenburg sollte politisch entmachtet werden und aus dem »Lichtkreis deutscher Politik verschwinden« (Harden 1907: 192).

Eine Karikatur der Münchener Zeitschrift die »Jugend« (vgl. Abb. 2) zeigt den »Liebenberger Entwurf« des preußischen Wappens und spielt damit auf die Effeminierung des Staates durch Eulenburgs Kreis an: Zwei puttenartige Engelsgestalten, die das preußische Wappen flankieren, kitzeln, necken und herzen sich gegenseitig. Sie sind nackt, nur von Rosenkränzen bedeckt; die linke Figur trägt eine Harfe in der Hand, die auf die romantische Freundschaftskultur der Liebenberger Runde anspielt, wurde doch Eulenburg selbst oft als »Harfner« dargestellt. Unterhalb des Wappens befindet sich eine Banderole auf der die Kosenamen des Kreises zu lesen sind: »meine Seele, mein Alterchen, mein einziger Dachs«. Das Bild verweist zugleich auf die (verletzte) Norm soldatischer Männlichkeit und preußischer Tugenden wie Strenge, Härte und Disziplin.

Abbildung 2: »Neues Preußisches Wappen « (1907) In: Jugend, München: Verlag der Jugend, 45 (28. Oktober), S. 1028.

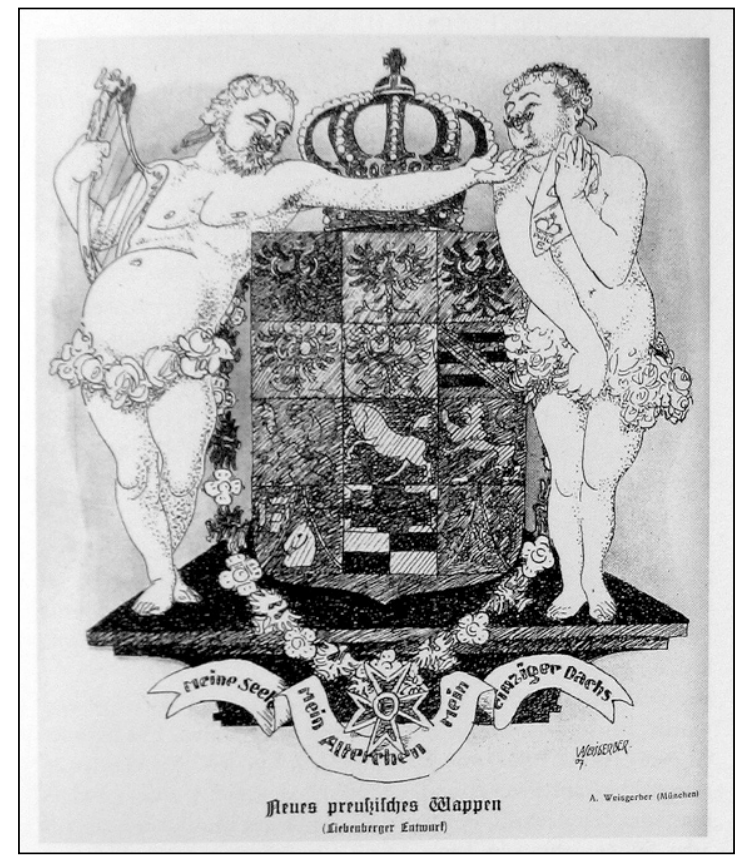

Hardens politische Kritikpunkte verdichteten sich im Bild des effeminierten Homosexuellen, das er in einer Serie von Artikeln immer plastischer werden ließ. Diese »abnorm« veranlagten Männer im Umfeld Eulenburgs seien gezwungen, »ihre wahre Veranlagung vor der Welt durch eine Maske zu verbergen«, und hätten daher ein gestörtes Realitätsverhältnis (zit.n. Sombart 1997 [1991]: 42). Ihr verzerrtes Wahrnehmungsvermögen 
und ihr enger Kontakt zu dem französischen Diplomaten Raymond Lecomte, der ebenfalls »geschlechtlich abnorm« sein sollte, mache sie unfähig, das »reale« Ausmaß der Bedrohung der eigenen Nation durch andere europäische Großmächte zu erkennen und entsprechend aggressiv nach außen aufzutreten, wie sich in der Marokkokrise gezeigt habe. Zudem würde die Tafelrunde den Kaiser umschließen, ihn von anderen Beratern abschirmen und zu einem neuen Absolutismus beflügeln:

»Wenn an der sichtbarsten Stelle des Staates Männer von abnormen Empfinden einen Ring bilden und eine durch Erfahrung nicht gewarnte Seele einzuklammern suchen, dann ist's ein ungesunder Zustand. Ein höchst gefährlicher, wenn in dieser Geisterringbildung der Vertreter fremder Machtinteressen aufgenommen ward.« (Harden 1907: 201)

Abbildung 3: »Der Retter des Vaterlandes« (1908).

In: Der wahre Jakob. Illustrierte Zeitschrift für Satire, Humor und Unterhaltung, Stuttgart (später: Berlin: Dietz), (19. Dezember), S. 671

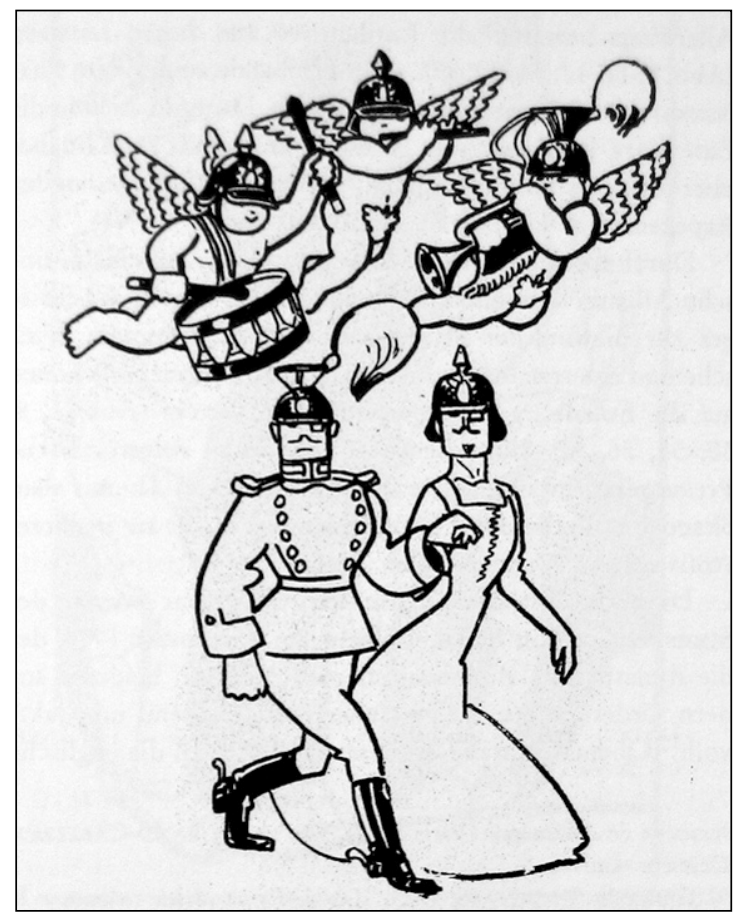

Vor den Augen der staunenden Öffentlichkeit wurde so die Idee von einem erotisch motivierten Freundschaftsbund, der den Staat leitete, in die politische Realität des Kaiserreichs überführt. Dies wurde auch im Ausland wahrgenommen. In der Pariser Zeitschrift »Fantasio« (Abb. 4) nahm im 
November 1907 der deutsche Männerbund als ein gleichgeschlechtliches Hochzeitspaar Gestalt an, dem zur Vermählung nackte Engel mit Militärhelmen aufspielen.

Im Stuttgarter »Wahren Jacob« sollte Maximilian von Harden ein Jahr später spöttisch in Gestalt eines strengen, hochmütigen Lehrers zum »Der Retter des Vaterlands« (Abb. 3) ausgerufen werden, der nicht mit (sozialdemokratischer) Gesellschaftskritik, sondern mit den skandalösen Enthüllungen in seiner Zeitschrift »Die Zukunft« Politik zu machen sucht.

Abbildung 4: [Karikatur ohne Titel] (1907). In: Fantasio

(Paris), 2/32 (15. November), S. 473. [zit.n. Steakley].

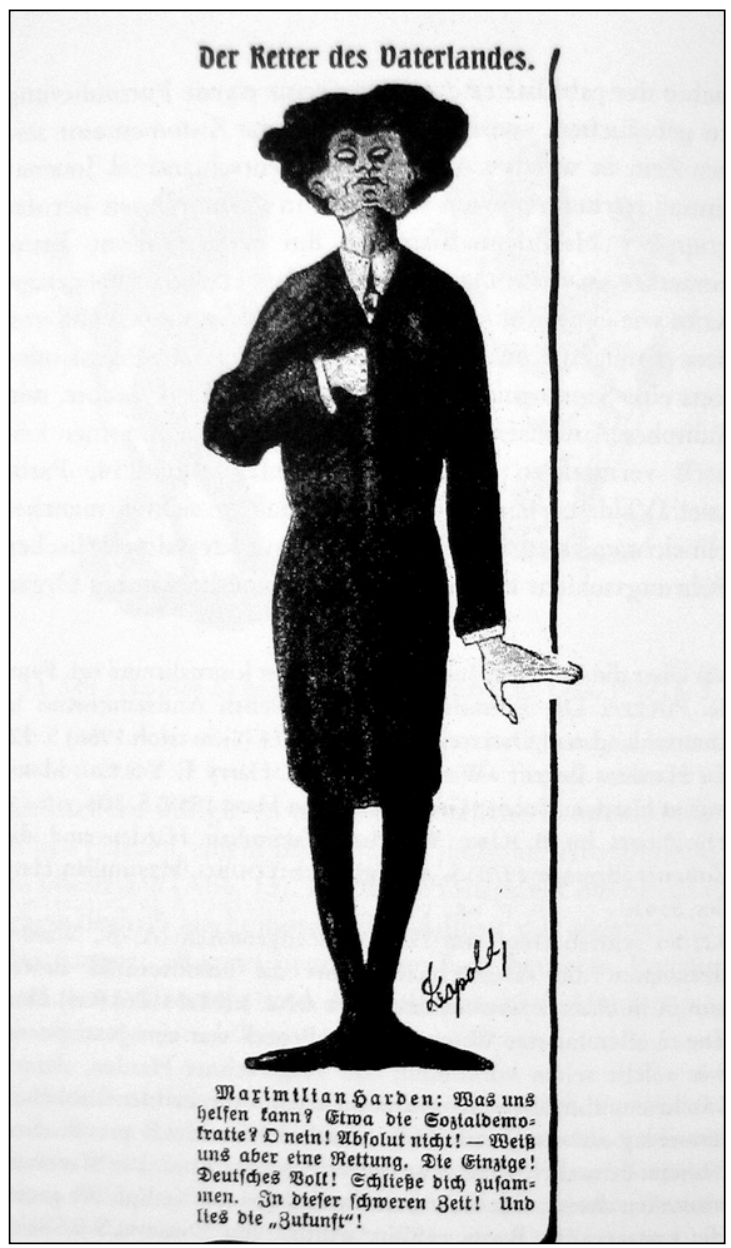




\section{Die Skandal-Prozesse}

Die Insinuationen in der »Zukunft« wurden sogleich zum Tagesgespräch in den Salons der Berliner Aristokratie. Das Ansehen der Hofgesellschaft und ebenso des Offizierskorps schien ernstlich gefährdet. Nach anfänglichem Zögern des Reichskanzlers von Bülow wurde der Kaiser jedoch erst Anfang Mai 1907 über die Vorwürfe gegen seine engsten Freunde informiert (Hull 1982: 140-143; Mommsen 1996: 282). Er reagierte entsetzt, und forderte einigermaßen unbedacht schleunige Remedur, noch bevor die Dinge überhaupt geklärt waren. So wurde die einstweilige Entlassung Moltkes und Eulenburgs verfügt. Glaubt man Hardens Bericht, dann entstand erst dadurch eine breitere Aufmerksamkeit für das Geschehen:

»Und nun entstand schnell die Meinung, da müsse Abenteuerliches ans Licht gekommen sein, ganz Ungeheuerliches; sonst wären diese Günstlinge, diese angesehenen Herren nicht gezwungen worden, aus ihren Aemtern zu scheiden. [...] Nun ging es in raschem Tempo weiter und wir erlebten einen Höllenlärm. In hundert Zeitungen stand, die Herren seien Hundertfünfundsiebziger; und Aehnliches. Plötzlich hatte Jeder Alles längst gewusst.« (Harden 1907: 200)

Eulenburg und Moltke wurden vom Kaiser aufgefordert, ihre verletzte Ehre in angemessener Weise wiederherzustellen (Mommsen 1996: 283). Nach einigem Zögern forderte Moltke Harden zum Duell heraus, was dieser jedoch ablehnte (Röhl 1992: 129). Moltke erhob daraufhin eine Privatklage wegen verleumderischer Nachrede gegen Harden, wodurch der Aufsehen erregende Prozess >Moltke gegen Harden< in Gang kam. Eulenburg suchte die Wiederherstellung seiner angegriffenen Ehre zunächst etwas vorsichtiger über eine Selbstanzeige in seinem Heimatort Prenzlau - ein Verfahren, das erwartungsgemäß folgenlos verlief (Mommsen 1996: 283).

Am 23. Oktober 1907 begann vor dem Schöffengericht Berlin-Mitte das Gerichtsverfahren Moltke gegen Harden, in dessen Verlauf die geschiedene Ehefrau ihren Mann stark belastete und Hirschfeld ihm als Sachverständiger eine »ihm selbst nicht bewusste homosexuelle Veranlagung « bescheinigte. ${ }^{3}$ Im Zuge der Beweiserhebung kam auch zur Sprache, dass in einzelnen Garderegimentern sexuelle Handlungen unter Männern stattgefunden hatten.

3| Dass Hirschfeld sich bemühte, einen feinen Unterschied zwischen dem »ausgesprochen seelisch-ideellen Charakter« von Moltkes »Homosexualität« und körperlich ausgeübter Sexualität zu machen, wurde kaum wahrgenommen (Hirschfeld 1908: 8). 
Abbildung 5: »Themis (reißt sich die Binde von den Augen)« (1907). In: Kladderadatsch. Humoristisch-satirisches Wochenblatt, Berlin: Hofmann, 6o/44 (3. November), 1. Beiblatt, S. 1.

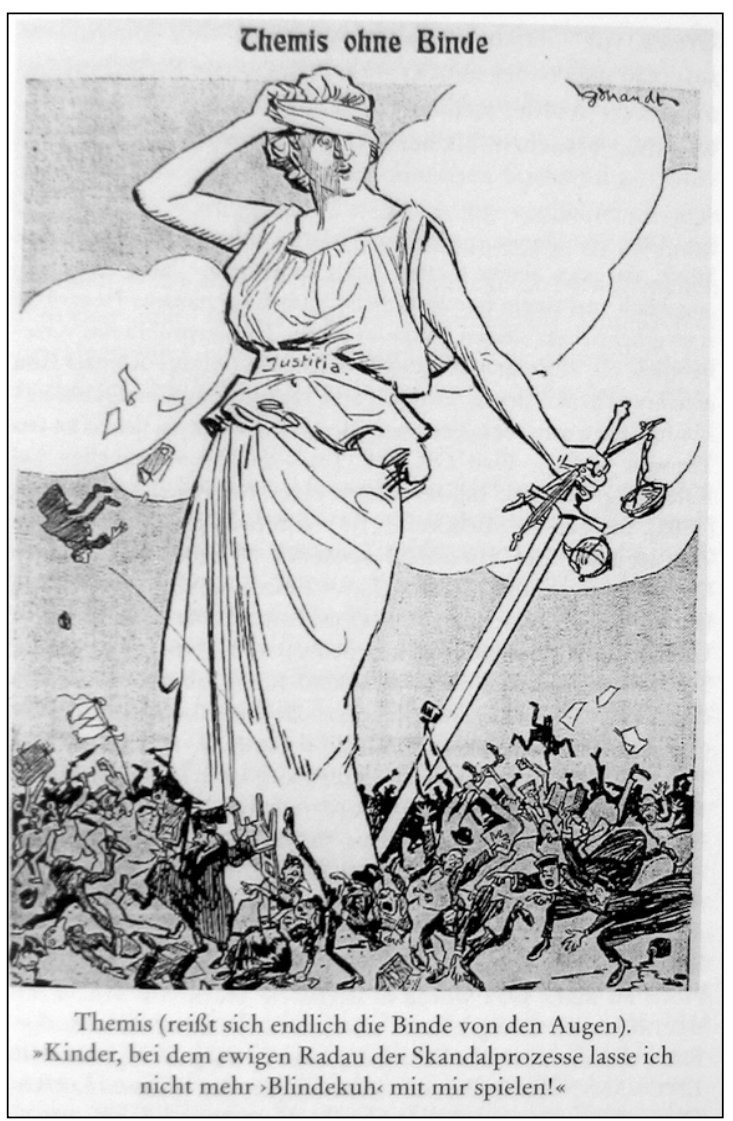

So wurde Harden am 29. Oktober 1907 vom Vorwurf, Moltke als »Homosexuellen « verleumdet zu haben, freigesprochen; der Skandal war perfekt und die Erregung nicht nur in der Berliner Aristokratie groß (Mommsen 1996: 283). Der Kaiser selbst wurde zur Zielscheibe ausländischer Karikaturen. In der Turiner Zeitung »Pasquino« vom 2. November 1907 sieht man Kaiser Wilhelm II. in einen langen Mantel gehüllt, Stufen hinaufeilend (Abb. 6). Ein kleines fettes Schwein in Militäruniform, das auf dem langen Ende seines königlichen Mantels sitzt und diesen einkotet, verhindert jedoch sein zügiges Voranschreiten. Seine Majestät ist gezwungen, mit Gewalt am Mantel ziehen, der nun unwiderruflich verschmutzt ist. Darunter ist zu lesen: »Gar nicht so übel [...] wenn der kaiserliche Mantel passend verkürzt wird - wo er auf den Stufen des Thrones so versaut wurde.« 
Abbildung 6: »Non sara un gran male se ...« (1907). In: Pasquino. Revista umoristica della settimana, (Turin) 52/44 (3. November), S. 4.

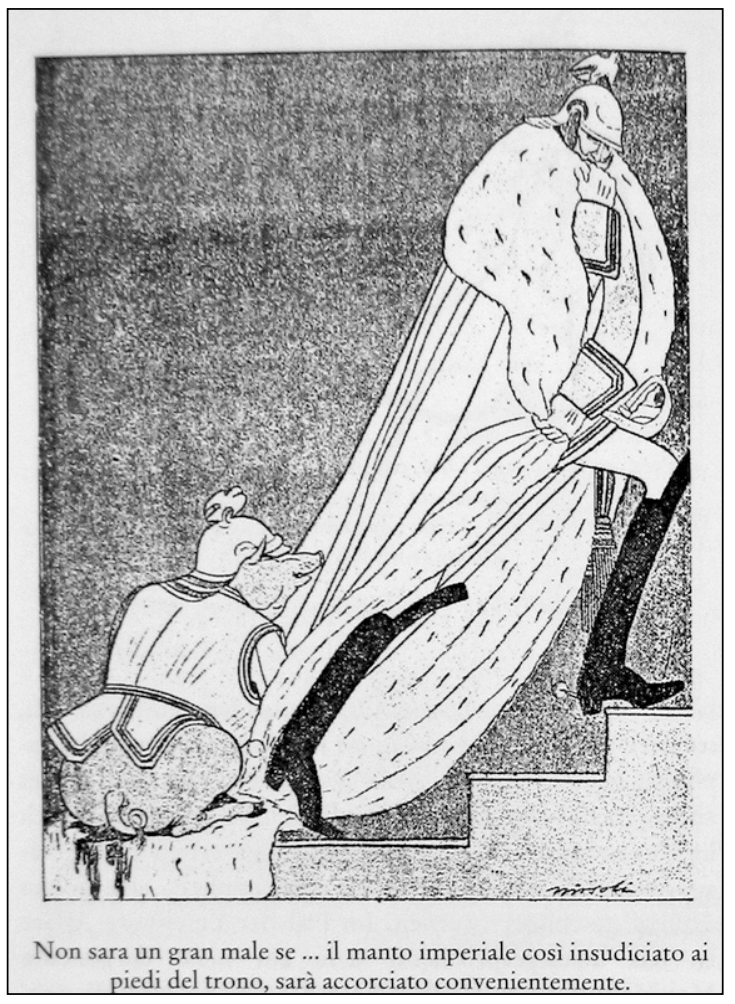

Die »Tägliche Rundschau« kommentierte die Vorgänge wie folgt:

»Wohl selten hat die Rechtspflege eines modernen Staates einen Prozeß geführt, der in der gleichen Weise die öffentliche Sittlichkeit verpestet, das Vertrauen der unteren Klassen zu den höheren, ja zum Throne erschüttert und das eigene Land vor dem Auslande rücksichtsloser an den Pranger gestellt hat, wie dieser MoltkeHarden-Prozeß.« (Zit.n. Rogge 1959: 234)

So fühlte sich Kanzler Bülow in seiner Rede vor dem deutschen Reichstag vom 28. November 1907 genötigt, die Angriffe der Parlamentarier zu entkräften und das Deutsche Reich demonstrativ von Zuständen im sinkenden Rom abzuheben:

»[...I]ch wende mich gegen die Auffassung, als ob das deutsche Volk und das deutsche Heer in ihrem innersten Kern nicht vollkommen gesund wären. So wie es niemand gibt, der an dem sittlichen Ernst unseres Kaiserpaares zweifelt, das in seinem Familienleben dem ganzen Lande ein schönes Vorbild gibt, so ist auch das 
deutsche Volk kein Sodom, und in der deutschen Armee herrschen nicht Zustände wie im sinkenden römischen Kaiserreich. Und Sie können sich darauf verlassen, daß gerade unser Kaiser mit scharfen Besen alles ausfegen wird, was nicht zur Reinheit seines Wesens und seines Hauses passt.« (Zit.n. Hötzsch 1909: 66)

Die Entrüstung der Öffentlichkeit richtete sich paradoxerweise sowohl gegen die »dekadenten« höheren Klassen wie auch mit antisemitischer Stoßrichtung gegen die Überbringer schlechter Nachrichten, Harden und Hirschfeld, welche aus jüdischen Elternhäusern stammten (Steakley 1991: 242).

Vielleicht ist es kein Zufall, dass gerade in der österreichischen Presse, die in ihrem Antisemitismus offener war (Steakley 2004: 112), am 10. November 1907 eine Zeichnung abgedruckt wurde, die Harden (der seit 1878 zum Protestantismus konvertiert war) als Juden markierte und ihm unterstellte, den vormals ehrbaren deutschen Männerbund zu einem Bund von Juden »umschmieden « zu wollen (Abb. 7). Im oberen Teil des Bildes sieht man Harden etwas erhöht, mit verschränkten Armen und strenger Mimik, als Mittelpunkt und Drahtzieher eines Kreises von Adeligen, der um ihn herumtanzt.

Abbildung 7: »Die Politik des Juden Harden « (1907).

In: Kikeriki. Humoristisch-politisches Volksblatt (Wien)

47/90 (10. November), S. 2..

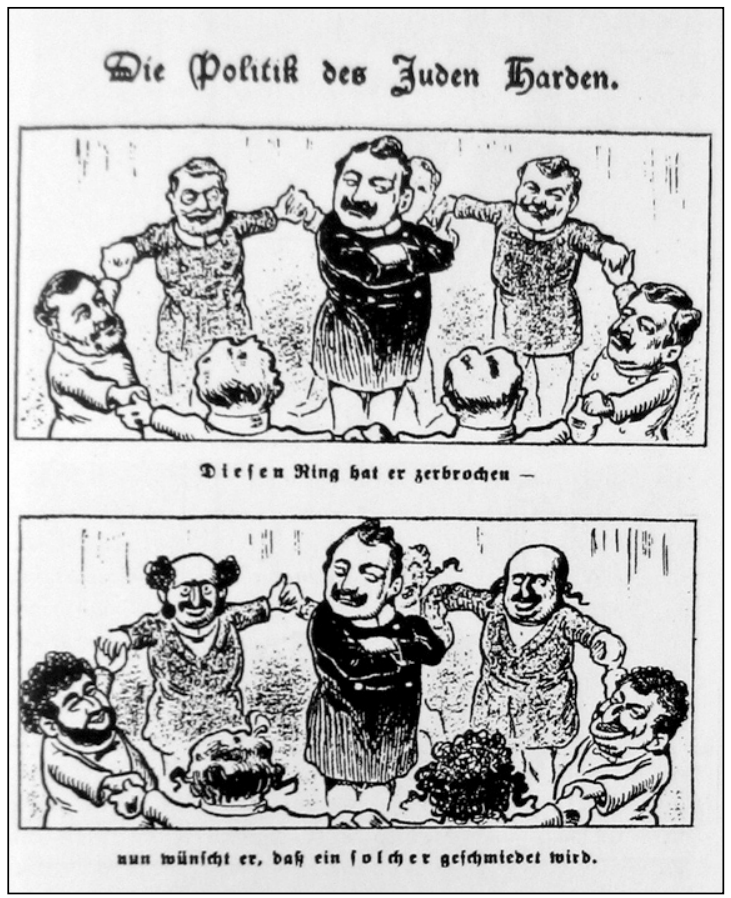


Diese Anspielung auf antisemitische Verschwörungstheorien wird durch die darunter abgedruckte Zeile unterstrichen: »Diesen Ring hat er zerbrochen -«. Harden wird also als Zerstörer einer heilen deutschen Welt dargestellt. Im unteren Teil des Bildes, das die Unterschrift trägt: »nun wünscht er [Harden], dass ein solcher geschmiedet werde«, haben sich die deutschen Adeligen in Männer verwandelt, die auf stereotype Weise mit den negativen Merkmalen des Jüdischen behaftet sind: Hakennasen, Locken und aufgeworfene Lippen. Zudem tragen die im Kreis tanzenden Männer Morgenmäntel, was sie zusätzlich sexualisiert. Während die Adeligen im oberen Bild in keiner Weise als »homosexuell« markiert sind, geht mit der unten dargestellten »Verjudung « auch eine Verknüpfung zur sexuellen Abweichung von der Norm einher. Die Verbindung von Jüdischsein mit Krankheit und (sexueller) Perversion wird hier - im Kontext des noch relativ jungen medizinischen Konzepts von »Homosexualität« - erneut befestigt, modernisiert und zugleich in seiner negativen Folge für den deutschen Staat ausgewiesen, in dem bald allein die (lasterhaften) Juden regieren würden.

Angesichts der sich zuspitzenden Krise wurde Kaiser Wilhelm II. aktiv. Er sorgte für die Rehabilitierung Moltkes, indem er persönlich die Kassation des Urteils anordnete und die Neuaufnahme des Verfahrens, diesmal als Strafprozess, verlangte. Dieser krasse Rechtsbruch, der auch in den Karikaturen als solcher aufs Korn genommen wurde (vgl. Abb. 6), schien wohl auch den Behörden im Interesse der Krone gerechtfertigt und führte zu der gewünschten Urteilsrevision.

In dem zweiwöchigen Prozess, der am 18. Dezember 1907 begann, wurde nun die Hauptzeugin für hysterisch und daher unglaubwürdig erklärt. Moltke und Eulenburg verteidigten den Geist männlicher Freundschaft (Steakley 1991: 244), der Berliner Mediziner Albert Moll - ein Opponent von Hirschfelds sexualwissenschaftlichen Positionen - schrieb als neu herangezogener Sachverständiger ein forensisches Gutachten (Röhl 1992: 128), das Moltke vom Vorwurf der Homosexualität freisprach und Hirschfeld revidierte das seinige. 4

Diesmal wurde Harden zu vier Monaten Gefängnis und der Übernahme der Prozesskosten verurteilt. Um eine Revision des Prozesses durch Harden zu verhindern, griff Reichskanzler Bülow ein und erreichte, dass Moltke eine öffentliche Ehrenerklärung abgab, wonach Harden ausschließlich im nationalen Interesse gehandelt habe. Die 40.000 Mark Prozesskosten, die eigentlich Harden $\mathrm{zu}$ tragen hatte, wurden aus den Mitteln der Reichskanzlei bereitgestellt. General Kuno von Moltke war in den Augen des Kaisers rehabilitiert.

Harden gab allerdings die Verfolgung Eulenburgs nicht auf und provozierte am 21. April 1908 ein weiteres Gerichtsverfahren in München, das

4| Hirschfelds widersprüchliche Gutachten über Moltkes Homosexualität provozierten öffentlichen Spott (Hirschfeld 1908: 4, 6, 21). 
der Einwirkung des Reichskanzlers entzogen war und das Eulenburg des Meineids überführen sollte. Es gelang Harden, zwei Starnberger Bauern ausfindig zumachen, die tatsächlich homosexuelle Handlungen mit dem Fürsten bezeugten (vgl. Mommsen 1996: 287). ${ }^{5}$ Nachdem das Verfahren gegen Eulenburg am 29. Juni 1908 daraufhin in Berlin wieder aufgenommen wurde, konnte sich Eulenburg seiner drohenden Verurteilung nur noch durch ärztliche Atteste entziehen, die ihm eine dauerhafte Verhandlungsunfähigkeit bescheinigten.

Das Verfahren wurde schließlich am 17. Juli 1908 suspendiert und nach einem vergeblichen Wiederaufnahmeversuch im folgenden Jahr (7. Juli 1909), während dessen Eulenburg vor Gericht einen Herzanfall erlitt, beendet. Eulenburg zog sich endgültig politisch diskreditiert und isoliert auf sein Gut Liebenberg zurück (Röhl 1992: 132).

\section{Die Effekte der Skandale}

Die infrage gestellte Männlichkeit der obersten Regierungskreise des Deutschen Reiches, der symbolischen Repräsentanten der deutschen Nation, war im Laufe der Skandale zu einem politisch virulenten Problem geworden. Die Auflagen von Hardens Zeitschrift »Die Zukunft« waren in die Höhe geschnellt. »Homosexualität« wurde in Frankreich jetzt spöttelnd »vice allemand « genannt, das deutsche Laster. In der internationalen Presse, aber auch im Deutschen Reich entstanden zahlreiche Satiren und Karikaturen, die auf das Thema anspielten und die gesündere Vergangenheit mit der dekadenten Gegenwart kontrastierten. Die schleichende Verweiblichung der Armee und eine drohende Entmännlichung des Staates wurden zu zentralen Themen der wilhelminischen Gesellschaft.

Überdies trugen die Skandalprozesse wesentlich dazu bei, die drei diskursiven Felder Politik, Homosexualität und männliche »Verbündelung « miteinander zu verknüpfen. Zunächst randständige Diskurse, wie die Männerbund- und Homosexualitätsdiskurse, die vor allem in wissenschaftlichen Kreisen und von den Betroffenen entwickelt und wahrgenommen worden waren, wurden nun mit einer größeren Bedeutung für die Nation aufgeladen und zu einem Teil des politischen Alltagswissens. Das neue Wissen vom homoerotischen Männerbund erhielt mit den Gerichtsprozessen eine ungeahnte Realität und Materialität, indem die preußische Justiz gleichsam amtlich die Klassifizierung politisch einflussreicher Adeliger zu homosexuellen Persönlichkeiten vollzog. Die Kraft zu solcher politischen »Verbündelung« schien sich direkt aus der »abnormen« Sexualität

5| Mitte der 188oer Jahre war Eulenburg als Sekretär der Preußischen Gesandtschaft in München tätig gewesen und hatte vertrauliche Berichte über die gleichgeschlechtlichen Neigungen von Ludwig II. an Herbert von Bismarck, den Sohn Otto Fürst von Bismarcks, weitergeleitet (vgl. Herrn 2004: 49). 
der beteiligten Männer abzuleiten. Die sexuelle Grundstruktur sozialer und politischer Ordnung erhielt so einen hohen Grad an Plausibilität.

Allerdings hatte die Verschiebung der politischen Auseinandersetzung auf das Feld von Normalität, Biologie und Geschlecht nicht in allen Teilen die von Harden gewünschte Wirkung. Zwar gelang es, den politisch unliebsamen Ratgeber Eulenburg zu entmachten. Hardens Forderung einer fortschrittlicheren Verfassung, die 1906 durchaus auch Thema der Tagespresse gewesen war (z.B. bei Harden 1906c: 291f.), trat jedoch nach den Skandalen stärker denn je in den Hintergrund. Nun galt es, die angegriffene Monarchie zu restituieren.

Der >nationalen Gefahr der Effeminierung war gemäß der binären Geschlechter-Logik nur mit einer verstärkten Remaskulinisierung der staatlichen Politik zu begegnen. Der öffentliche Druck stärkte nicht zuletzt die Hardliner der militärischen Ratgeber um Kaiser Wilhelm II. (Hull 1992: 113f.). Er trug zur Festigung eines aggressiven Politikstils bei, in dem kriegerische Männlichkeit in dem Maße demonstriert werden musste, wie andere Formen der Politik delegitimiert und mit dem Verdacht latenter Verweiblichung belegt worden waren (vgl. Hull 1982: 296; Steakley 1991: 233ff.; Röhl 1992: 140).

Die Skandalprozesse reflektierten über dies den virulenten Konflikt zwischen Bürgertum und Adel um politischen Einfluss, der nicht zuletzt im Medium gegensätzlicher Männlichkeitscodes und Identitätskonstruktionen ausgetragen wurde (Mosse 1997 [1996]: 27-36). Was nach den Moralgesetzen der bürgerlichen Gesellschaft als unmännliches, »homosexuelles«, auf jeden Fall kriegsuntaugliches Verhalten gedeutet werden konnte, war für die adeligen Offiziere oft nichts anderes als traditionell höfisches Verhalten und aristokratische Etikette, die genauso minutiös beherrscht werden musste wie der Militärdienst. ${ }^{6}$

Im Gegensatz zur Genealogie des Blutes hatte das Bürgertum im Laufe des 18. Jahrhunderts seine wachsenden gesellschaftlichen Herrschaftsansprüche gegenüber der Aristokratie (wie auch den Unterschichten) entlang sexualmoralischer Kriterien wie bürgerlicher Reinheit, Triebkontrolle und Sittsamkeit geltend gemacht, die es adeliger »Ausschweifung « und »sexueller Amoral« gegenüberstellte (Steakley 1991: 253). Hardens >Aufdeckung von nur einem »Halbdutzend Degenerirter« aus dem Adelsstand konnte wie ihm sehr wohl bewusst war - in der bürgerlichen öffentlichen Meinung durchaus »gegen die Gesundheit einer Klasse zeugen« (Harden 1907: 201).

6I So war es um 1900 nicht ungewöhnlich, dass in den Offizierskasinos hofnaher Regimenter Tanzstunden stattfanden, in denen zwei Männer miteinander tanzten. In solchen aristokratisch geprägten Luxusregimentern konnte der männliche Körper unter Gleichen, nicht aber in der Öffentlichkeit, zur Schau gestellt werden (Funck 2001: 73-75). 
Das enge emotionale Verhältnis unter Männern war für Eulenburg und Moltke solange mit den Verhaltenscodes der Adelsgesellschaft vereinbar gewesen, wie das »ritterliche« Verhalten gegenüber der standesgemäß geheirateten Frau beibehalten und sexuelle Handlungen allenfalls mit Angehörigen unterer Schichten vollzogen wurden (Steakley 1991: 253).

Abbildung 8: »Das Bildnis des Dorian Gray«.

In: Lustige Blätter. Schönstes buntes Witzblatt Deutsch lands, Berlin: Verlag der Lustigen Blätter, 22/28 (9. Juli), S. 1.

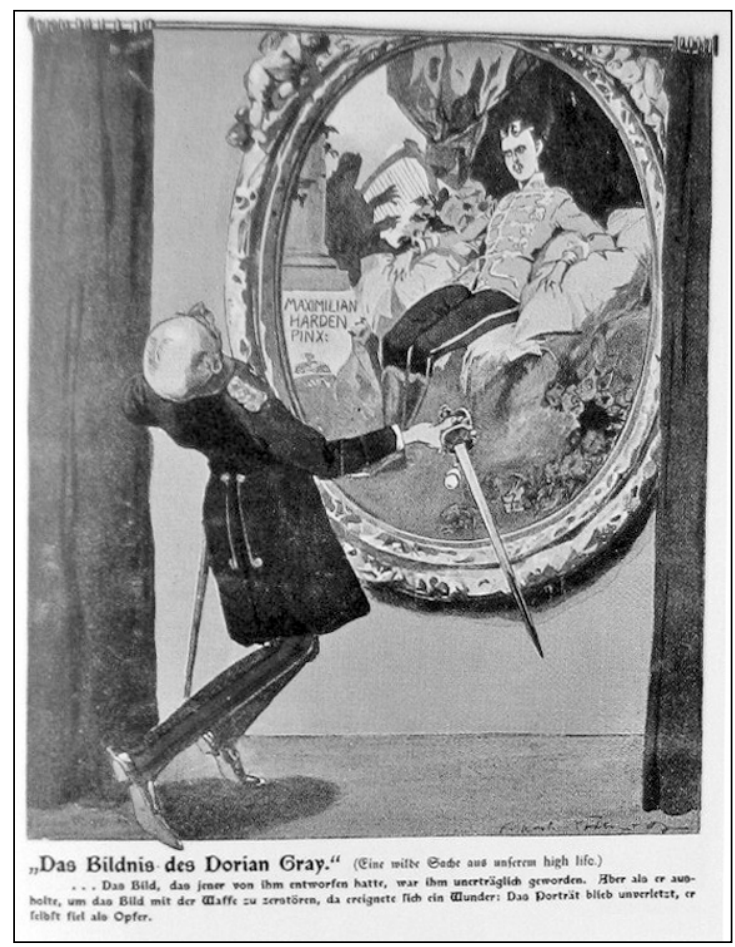

Eulenburg wollte oder konnte sich selbst nicht in den modernen Kategorien einer »homosexuellen Persönlichkeit« fassen, weil er dieses am sexuellen Begehren orientierte Identitätskonzept für sich nicht als gültig betrachtete. Dies wird in einer Passage eines Briefes deutlich, den Eulenburg am 10. Juni 1907 an Moltke richtete:

»In dem Augenblick, da der frechste Repräsentant der modernen Zeit, ein Harden - in der Presse unser Wesen kritisierte, unsere ideale Freundschaft herabzog, unser Denken und Fühlen der Form entkleidete, die wir als vollberechtigt so lange Jahre unseres Lebens anerkannt von den Zeitgenossen, als eine selbstverständliche, natürliche kaum beachtet hatten, brach die neue Zeit uns kaltlächelnd den Hals. [...] Auch die neuen Begriffe über Sinnlichkeit und Liebe stempeln unser Wesen zur 
Schwäche oder gar zu ungesunder Schwäche. Und doch waren auch wir sinnlich; gewiß nicht minder als die Neuen. Aber dieses Gebiet lag streng gesondert, drängte sich nicht als Selbstzweck vor [...].« (Zit.n. Hull 1992: 91)

Die Codierung der männlichen Identität über die richtige Form des Begehrens bzw. die »normale« Sexualität hatte um die Jahrhundertwende derart normierende Macht bekommen, dass selbst die Berufung auf den höheren Stand und die adelige Herkunft Eulenburg nicht mehr davor schützte, entlang der neuen Kategorien als »unmännlich« und »abnorm« beurteilt zu werden. Auch das machten die Skandale deutlich. In einer auf Oskar Wildes Leben und Werk anspielenden Karikatur aus den »Lustigen Blättern« vom Juli 1907 sinkt ein Adeliger im Versuch, das »unerträglich« gewordene Bild von sich selbst niederzuringen, mit dem Schwert in der Hand zu Boden (Abb. 8). Eine treffendere Verbildlichung der Niederlage des Adels lässt sich kaum finden.

Männliche Homosexualität mutierte - nun auch für breite Teile der Bevölkerung sichtbar - zu einer »Krankheit«, die die Gesellschaft mit

Abbildung 9: »Helden des Tages. III. Dr. Magnus Hirschfeld«. In: Lustige Blätter. Schönstes buntes Witzblatt Deutschlands, Berlin: Verlag der Lustigen Blätter, 22/48 (26. November), S. 3 .

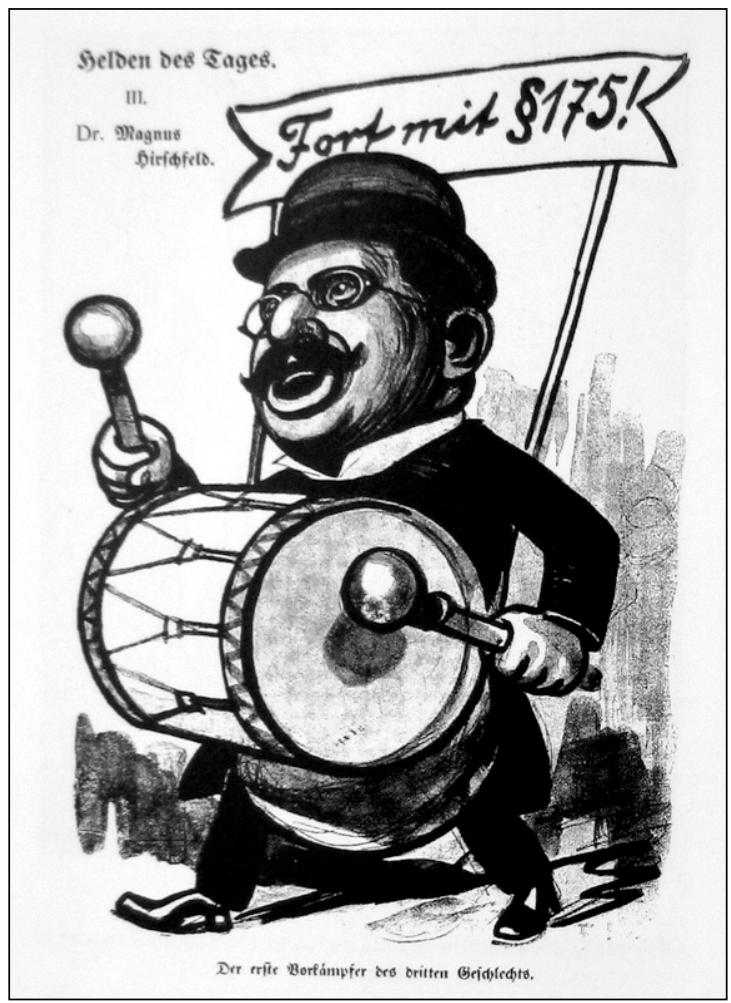


einem kulturellen und politischen Niedergang bedrohte (Steakley 1991: 253f.). Man beklagte, dass Zeitungsartikel erstmals pornographische Qualität annahmen und sah darin vor allem eine Gefahr für die moralische »Reinheit« der Jugend. Insbesondere die vielen Karikaturen machen deutlich, wie stark Homosexualität mit nationalem Verrat und Degeneration verknüpft wurde (vgl. weitere Abb. bei: Steakley 1991: 258-263).

Abbildung 10: »Garde du corps«. In: Ulk. Illustriertes

Wochenblatt für Humor und Satire, Berlin: Mosse, 36/45

(8. November), S. 1 .

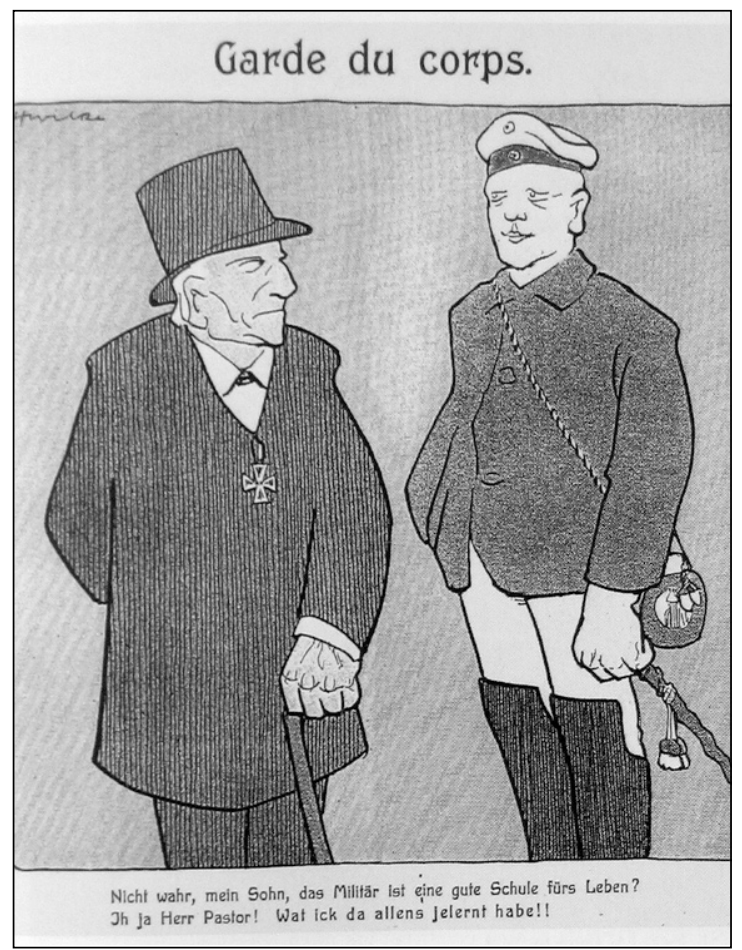

Dies wirkte sich auch auf die Homosexuellen-Emanzipationsbewegung aus, die empfindliche Rückschläge erlitt. Statt einer Aufhebung des Paragrafen 175 RStGB wurde nun seine Verschärfung und Ausdehnung auf Frauen diskutiert. Die Sittlichkeitsbewegung ging hingegen gestärkt aus den Jahren der Prozesse hervor und attackierte nicht nur die Emanzipationswünsche der Homosexuellen, sondern auch die der Frauen schärfer denn je.7 Eine Berliner Karikatur vom 26. November 1907 (Abb. 9) weist Hirschfeld als jüdisch markierten Antihelden des Tages aus, der in Kinder-

7| Gegen Ende der Skandalserie hatte sich die Stimmung auch in der ganz Linken zuungunsten der Homosexuellen gewendet (Steakley 1991: 254f.). 
gestalt mit großer Trommel - einem mechanischen Spielzeugmännchen gleich - für die Aufhebung des »Paragraphen 175 « wirbt.

Überdies brachte die Eulenburg-Affäre Männer und Frauen dazu, sich im Licht des neuen Wissens zu reflektieren. Lili von Elbe, die geschiedene Frau des Grafen Moltke, sprach für viele, als sie aussagte, dass sie ihren Ehemann anfänglich nicht der Homosexualität verdächtigt hätte, weil sie von der Existenz eines solchen Phänomens nichts gewusst habe. Auch der bayerische Fischer Jakob Ernst sagte vor Gericht aus, dass er keinen wirklichen Namen für »es« gehabt hätte. Verhaltensweisen und Einstellungen, die zuvor in den Bereich persönlicher Heimlichkeiten oder der Sünde gefallen waren, erschienen in einem völlig neuen Licht. Sie wurden nun vielen Menschen nicht nur bekannt, sondern auch höchst suspekt. Es gab Eltern, die plötzlich Bedenken hatten, ihre Söhne zum Militär oder auch nur vom Land in die Stadt zu schicken. In einer Karikatur des Berliner »Ulk«-Blatts (Abb. 10) wird aus dem Militär als »Schule fürs Lebens«, eine Möglichkeit, außergewöhnliche sexuelle Erfahrungen mit Männern zu machen, wie aus der zweideutigen Antwort des jungen Militärdienstleistenden hervorgeht: »Wat ick da allens jelernt habe!!«

Trotz der Kampagne für moralische Erneuerung, der antisemitischen Untertöne, der Erhöhung der militärischen Disziplin, der Sorge um den Niedergang der Nation und der bürgerlichen Moral lag dieser Entwicklung auch eine subtile Dialektik zugrunde (Steakley 1991: 257). Denn mit den neuen Restriktionen vervielfältigten sich zugleich auch die Möglichkeiten, sich als ein besonderes sexuelles Subjekt zu entwerfen. Dies schlug sich nicht zuletzt in einer Vielzahl neuer sexualwissenschaftlicher Publikationen und Subjektivierungspraktiken - besonders im Kontext der Reformbewegungen - nieder.

Auch die Wandervogelbewegung wurde seit dem Jahr 1908 sehr viel aufmerksamer gegenüber vermeintlich »homosexuellem« Verhalten in den eigenen Reihen, nachdem sie im Kontext des Skandal-Prozesses öffentlich als »Päderastenclub« bezeichnet worden war. In Umkehrung der negativen gesellschaftlichen Bewertung von Homosexualität deutete der Berliner Student Hans Blüher die Wandervogelbewegung als »homoerotisches Phänomen«, als eine erotische Kulturrevolution der männlichen Jugend gegen wilhelminische Bildungsanstalten und Elternhäuser. Die >männerbündische Erfahrung ‘ avancierte so zu einem prägenden Element der Selbstwahrnehmung und Selbstbeschreibung der jungen Generation (vgl. Brunotte 2004; Bruns 2007).

\section{Literatur}

Baumgardt, Manfred (1992): Magnus Hirschfeld. Leben und Werk. Ausstellungskatalog aus Anlass seines 50. Todestages, veranstaltet von der Magnus-Hirschfeld-Gesellschaft, mit einem Nachwort von Ralf Dose, 2. erw. 
Aufl., Hamburg: v. Bockel (Schriftenreihe der Magnus-Hirschfeld-Gesellschaft 6).

Brunotte, Ulrike (2004): Zwischen Eros und Krieg. Männerbund und Ritual in der Moderne, Berlin: Wagenbach.

Bruns, Claudia (2007): Politik des Eros. Der Männerbund in Wissenschaft, Politik und Jugendkultur 1880-1934, Köln u.a.: Böhlau (Diss. Hamburg, 2004).

Duberman, Martin/Vicinus, Martha/Chauncey, George (1991) (Hg.): Hidden From History. Reclaiming The Gay And Lesbian Past, London u.a.: Penguin.

Funck, Marcus (2002): »Entwurf und Praxis militärischer Männlichkeit im preußisch-deutschen Offizierkorps vor dem Ersten Weltkrieg«. In: Hagemann/Schüler-Springorum (Hg.), S. 69-77.

Hagemann, Karen/Schüler-Springorum, Stefanie (2002) (Hg.): HeimatFront. Militär und Geschlechterverhältnisse im Zeitalter der Weltkriege, Frankfurt a.M.: Campus.

Harden, Maximilian (1906a): »Enthüllungen. III. Bismarcks Entlassung«. In: Die Zukunft 57 (3. Nov.), S. 169-198.

Harden, Maximilian (1906b): »Präludium«. In: Die Zukunft 57 (17. Nov.), S. 251-266.

Harden, Maximilian (1906c): »Dies Irae. Momentaufnahmen«. In: Die Zukunft 57 (24. Nov.), S. 287-302.

Harden, Maximilian (1907): »Schlussvortrag«. In: Die Zukunft 61/9 (Nov.), S. 179-210.

Hewitt, Andrew (1999): »Die Philosophie des Maskulinismus«. In: Zeitschrift für Germanistik, Neue Folge 1, S. 36-56.

Hirschfeld, Magnus (1908): Sexualpsychologie und Volkspsychologie. Eine epikritische Studie zum Harden-Prozess, Leipzig: Wigand's Verlag.

Herrn, Rainer (2004): »Ein historischer Urning. Ludwig II. von Bayern im psychiatrisch-sexualwissenschaftlichen Diskurs und in der Homosexuellenbewegung des frühen 20. Jahrhunderts«. In: Sykora (Hg.), S. 48-89.

Hull, Isabel V. (1982): The Entourage of Kaiser Wilhelm II 1888-1918, Cambridge u.a.: Cambridge University Press.

Hull, Isabel V. (1992): »Kaiser Wilhelm II. und der >Liebenberger-Kreis « . In: Lautmann/Taeger (Hg.), S. 81-117.

Jungblut, Peter (2003): Famose Kerle. Eulenburg - Eine wilhelminische Affäre, Hamburg: Männerschwarm.

Kotowski, Elke Vera/Julius H. Schoeps (2004) (Hg.): Der Sexualreformer Magnus Hirschfeld (1868-1935). Ein Leben im Spannungsfeld von Wissenschaft, Politik und Geschichte, Berlin: Bebra Wiss.

Lautmann, Rüdiger/Taeger, Angela (1992) (Hg.): Männerliebe im alten Deutschland. Sozialgeschichtliche Abhandlungen, Berlin: rosa Winkel (Sozialwiss. Studien zur Homosexualität 5). 
Mommsen, Wolfgang J. (1996): »Homosexualität, aristokratische Kultur und Weltpolitik. Die Herausforderung des wilhelminischen Establishments durch Maximilian Harden 1906-1908«. In: Schultz (Hg.), S. 179288.

Mosse, George L. (1997) [1996]: Das Bild des Mannes. Zur Konstruktion der modernen Männlichkeit, Frankfurt a.M.: Fischer.

Nieden, Susanne zur (2004): »Die >männerheldische, heroische Freundesliebe < bleibt >dem Judengeiste fremd nismus«. In: Kotowski/Schoeps (Hg.), S. 329-342.

Röhl, John C.G. (1992): »Fürst Philipp zu Eulenburg. Zu einem Lebensbild«. In: Lautmann/Taeger (Hg.), S. 119-140.

Rogge, Helmuth (1959): Holstein und Harden. Politisch-publizistisches Zusammenspiel zweier Außenseiter des Wilhelminischen Reiches, München: Beck.

Schultz, Uwe (1996) (Hg.): Große Prozesse. Recht und Gerechtigkeit in der Geschichte, München: Beck.

Sombart, Nicolaus (1997) [1991]: Die deutschen Männer und ihre Feinde. Carl Schmitt - ein deutsches Schicksal zwischen Männerbund und Matriarchatsmythos, Frankfurt a.M.: Fischer.

Steakley, James D. (1991): »Iconography of a scandal. Political cartoons and the Eulenburg affair in Wilhelmin Germany«. In: Duberman/Vicinus/ Chauncey (Hg.), S. 233-263.

Steakley, James D. (2004): Die Freunde des Kaisers. Die Eulenburg-Affäre im Spiegel zeitgenössischer Karikaturen, Hamburg: Männerschwarm.

Sykora, Katharina (2004) (Hg.): »Ein Bild von einem Mann«. Ludwig II. von Bayern. Konstruktion und Rezeption eines Mythos, Frankfurt a.M.: Campus. 


\title{
Komplizen und Klienten.
}

\section{Die Männlichkeitsrhetorik der Homosexuellen-}

\section{Bewegung in der Weimarer Republik als}

\section{hegemoniale Herrschaftspraktik}

\author{
MARTIN LÜCKE
}

Spürt man den Mechanismen der Konstruktion und >Krise< von hegemonialer Männlichkeit in der Moderne nach, so ist ein Blick auf die Zeit der Weimarer Republik besonders reizvoll. Sowohl aus der Sicht der Zeitgenossen als auch aus der retrospektiven Warte von Historiker/-innen erscheinen die Jahre der ersten deutschen Demokratie vor allem als eine Zeit der >Krise < und der Krisenerfahrung: Das Reden von >Krisen < war bei den Zeitgenossen omnipräsent und sie übertrugen »in inflationärer Weise die Krisenrhetorik auf ihre Analysen nahezu aller Lebensbereiche, von Staat und Recht über die Geistes- und Naturwissenschaften bis hin zu Kultur und Religion« (Föllmer/Graf/Leo 2005: 11). Diese zeitgenössische Wahrnehmung aufgreifend, besaß deshalb lange Zeit Detlev Peukerts historiografische Interpretation Gültigkeit, die Weimarer Jahre als die »Krisenjahre der klassischen Moderne (Peukert 1987) schlechthin anzusehen.

Mittlerweile hat sich das Erkenntnisinteresse der Geschichtswissenschaft gewandelt: Nicht mehr die Suche nach vermeintlich sechten Krisen « steht im Mittelpunkt, vielmehr wird Krisenrhetorik - zeitgenössische wie historiografische - als Mittel einer »strategischen Dramatisierung« begriffen, die von den Weimarer Zeitgenossen zur Einordnung von oft widersprüchlichen Gegenwartserfahrungen verwendet wurde und den Historiker/-innen zu einer »dramatischen Ordnung des historischen Materials« (Föllmer/Graf/Leo 2005: 22) diente. Gerade für die Männlichkeitsgeschichte ist ein solcher Umgang mit dem Krisenbegriff eine vielversprechende Perspektive. Krise und Hegemonie werden hier als ein wechselseitig aufeinander bezogenes Begriffspaar aufgefasst: Bei der Analyse von 
historischen Prozessen der Generierung von hegemonialer Männlichkeit wird zunehmend der Blick darauf gerichtet, welche Krisenrhetorik diese Prozesse begleitet hat und auf welche Weise das Reden von Krisen die Maßnahmen zur Durchsetzung von hegemonialen Männlichkeitskonstrukten flankieren konnte (Martschukat/Stieglitz 2005: 81-90).

Auch das Reden über männliche Homosexualität war in den Weimarer Jahren von einer steten Krisenrhetorik begleitet. So sprach Justus Erhardt, Leitender Fürsorger des Landesjugendamts Berlin, - um hier nur eine Stimme von vielen zu nennen - 1928 von einer »Krise der Fürsorgeerziehung «, die er besonders darin erkannte, dass seiner Auffassung nach die mann-männliche Sexualität zu einem grassierenden Problem in den Erziehungsanstalten wurde. In dem von ihm entworfenen Krisenszenario befürchtete er, dass nun auch die nicht-homosexuellen Jungen in den Anstalten zu einer homosexuellen Sexualneigung verführt werden könnten, und nahm diese Analyse zum Anlass, eine Neuorganisation des Anstaltswesens zu fordern (vgl. Ehrhardt 1928/29, 1930).

In diesem Beitrag soll jedoch nicht aufgezeigt werden, wie Vertreter hegemonialer Instanzen mit dem Thema der als bedrohlich wahrgenommenen männlichen Homosexualität umgegangen sind. Hierzu liegen bereits zahlreiche Studien vor. ${ }^{1}$ Stattdessen wird in den Blick genommen, wie in den Weimarer Interessenverbänden der Homosexuellen mit männlichen Leitbildern agiert wurde, von welchen Rhetoriken ihr politisches Agieren geprägt war und auf welche Weise sie an Weimarer Krisenszenarien anknüpften. Indem hier gerade kein gesellschaftlicher Hegemon wie die Jugendfürsorge oder die Strafgerichte, sondern die Interessenvertretung einer vermeintlichen >Randgruppe < zum Gegenstand der Analyse wird, kann deutlich werden, welche gesellschaftliche Reichweite hegemoniale Männlichkeitsentwürfe entfalten konnten. Trug die Politik der Weimarer Homosexuellen-Bewegung zu einer Aufweichung des hegemonialen Männlichkeitsbildes bei oder kann ihr Agieren als ein Unterfangen interpretiert werden, durch das das hegemoniale Männlichkeitsbild noch gestärkt werden konnte?

In diesem Zusammenhang lohnt sich insbesondere eine Analyse der politisch motivierten Männlichkeitsrhetorik des Homosexuellen-Aktivisten Friedrich Radszuweit (1876-1932), dessen Engagement sich durch rege Verbandsaktivitäten und eine lebhafte Publikationstätigkeit ausgezeichnet hat. Männlichkeitsrhetorik soll hier aufgefasst werden als das planvolle, vor dem Hintergrund der eigenen politischen Interessen und der diskursiven Rahmenbedingungen bewusst konzipierte Reden über Männlichkeit.

1| Vor allem die zahlreichen Arbeiten zur Entwicklung der Strafbarkeit von mann-männlicher Sexualität stellen dar, wie der Staat als hegemoniale Instanz mit Hilfe von Rechtsnormen das Sexualverhalten von gleichgeschlechtlich begehrenden Männern zu reglementieren wusste. Vgl. hierzu Sommer 1998; Lautmann/ Taeger 1992 
Nach kurzen biografischen Ausführungen über Radszuweit wird zunächst aufgezeigt, innerhalb welcher durch die Zensur gesetzten Grenzen ein Reden über männliche Homosexualität überhaupt möglich war, im Anschluss werden aussagekräftige Textstellen aus Radszuweits publizistischen Werk vorgestellt, anhand derer sein Umgang mit hegemonialen und marginalisierten Männlichkeitsbildern rekonstruiert werden kann. Im Anschluss daran wird der Versuch unternommen, Radszuweits Männlichkeitsrhetorik unter Verwendung aktueller Theorieangebote zu analysieren. Als heuristische Folien dienen hierbei Robert W. Connells Einteilung von Männlichkeiten in die Kategorien der Hegemonie, Unterordnung und Komplizenschaft (vgl. Connell 2000: 97-102) sowie Überlegungen, die Pierre Bourdieu im Anhang seines Werkes »Die männliche Herrschaft« zur Schwulen- und Lesbenbewegung anstellt (vgl. Bourdieu 2005: 201-211). Während die heuristische Verwendung der Connell'schen Begriffe mittlerweile zum Standardrepertoire der Männlichkeitsforschung gehört, ist Bourdieus Textfragment »Einige Fragen zur Schwulen- und Lesbenbewegung « vom deutschen Publikum bisher kaum rezipiert worden. Bourdieu begreift die gesellschaftliche und juristische Unterdrückung von homosexueller Männlichkeit als eine »Unterdrückung als >Unsichtbarmachen« (ebd.: 202), als eine Herrschaftspraxis also, durch die den Homosexuellen ihr Recht auf eine öffentliche Sichtbarkeit streitig gemacht wird. Im Gegenzug ist es nach Bourdieu das Ziel der Schwulen- und Lesbenbewegung »durch eine symbolische Destruktions- und Konstruktionsarbeit neue Wahrnehmungs- und Bewertungskategorien durchzusetzen« (ebd.: 209f.). Bourdieu betont dabei den subversiven Charakter der Schwulen- und Lesbenbewegung: Ihr Ziel sei es, tatsächlich »neue« Muster zur Bewertung von gleichgeschlechtlicher Sexualität zu propagieren und in emanzipatorischer Absicht von den konventionellen Sexualitäts- und Geschlechterkonzepten abzugrenzen. Bourdieu geht dabei über die Theoriebildungen von Connell, aber auch von George L. Mosse hinaus: Mosse zum Beispiel spricht davon, dass marginalisierte Männer bei den Versuchen, ihre Marginalisierung zu überwinden, häufig lediglich den Idealtypus von Männlichkeit imitieren, dass sie also den Versuch unternehmen, hegemoniale Männlichkeitsvorstellungen für sich selbst als Leitbild annehmen (vgl. Mosse 1997: 21f.), einen Sachverhalt, den Connell mit dem Terminus der Komplizenschaft hegemonialer Männlichkeit beschreibt. Eine Analyse der Männlichkeitsrhetorik von Friedrich Radszuweit kann aufzeigen, ob die Weimarer Homosexuellen-Bewegung traditionellen Sexualitäts- und Geschlechterkonzepten verhaftet blieb und diese lediglich imitierte oder ob es ihr gelang, neue Wahrnehmungs- und Bewertungskategorien durchzusetzen. 


\section{Friedrich Radszuweit und der Bund für Menschenrecht}

Friedrich Radszuweit war Medienunternehmer und Homosexuellen-Aktivist zugleich. Er kam 1876 im ostpreußischen Königsberg zur Welt und betrieb ab 1901 in Berlin einen Betrieb für Damenkonfektion sowie ein Einzelhandelsgeschäft. Nach dem politischen Umbruch der Jahre 1918/19 konnte er zur führenden Figur der Homosexuellen-Bewegung werden: 1922 ließ er sich zunächst zum Vorsitzenden der Homosexuellen-Organisation Vereinigung der Freunde und Freundinnen wählen; aus dieser Position heraus betrieb er eine Fusion mit dem 1920 gegründeten Deutschen Freundschaftsverband zum sogenannten Bund für Menschenrecht E.V. (BfM), dessen erster Vorsitzender er 1923 wurde. Der Bund für Menschenrecht war eine Massenorganisation, die 1929 angeblich sogar 29.000 Mitglieder verzeichnen konnte (vgl. Hergemöller 1998: 568). Zahlen dieser Größenordnung können heute jedoch nicht mehr eindeutig überprüft werden und dürften sich eher auf die Abonnenten und regelmäßigen Leser der Periodika beziehen, die in Radszuweits Verlag seit 1923 erschienen. Damit unterschied sich der BfM jedoch deutlich von anderen Organisationen der Homosexuellen-Bewegung in der Weimarer Zeit. Das Wissenschaftlich-humanitäre Komitee um Magnus Hirschfeld etwa sprach primär ein akademisches Publikum an; auch die maskulinistisch orientierte Gemeinschaft der Eigenen um den Publizisten Adolf Brand, die der Jugendbewegung nahestand, konnte keine so große Reichweite entfalten.

Neben Zeitschriften für männliche Homosexuelle wie den »Blättern für Menschenrecht«, dem »Freundschaftsblatt« oder der »Insel« gab Radszuweit als Erster auch Periodika für lesbische Frauen wie die Zeitschriften »Die Freundin« und »Ledige Frauen« heraus; auch ein Blatt für Transvestiten konnte im Zeitraum von 1930-33 unter dem Titel »Das Dritte Geschlecht. Die Transvestiten« erscheinen, und Radszuweit unterstützte - nicht ohne kommerzielles Eigeninteresse - deren Selbstorganisation. Die Herausgabe einer so üppigen Anzahl von Zeitschriften durch Radszuweit ist jedoch nicht ausschließlich als Folge einer gesellschaftlichen Pluralisierung in der Weimarer Zeit anzusehen oder allein Ausdruck von Radszuweits unternehmerischem Talent, sondern auch das Ergebnis eines rigiden Zensurwesens. So erschienen manche Zeitschriften nur in wenigen Ausgaben, bis die Zensurbehörden im Rahmen von sogenannten »Schundund Schmutzverfahren« Anstoß an deren »homosexueller Propaganda« nahmen, andere wechselten den Namen oder die Erscheinungsweise, um einer solchen Zensur zu entgehen. Die publizistische Vielfalt war also eher das Kennzeichen der Zensurpolitik als Ausdruck einer pluralistischen Zeitungslandschaft für sexuelle Minderheiten.

Radszuweits Bund für Menschenrecht verstand sich zunächst als parteipolitisch ungebundene Organisation. Nach 1930 lässt sich jedoch ein starker Rechtsruck beobachten: Radszuweit interpretierte die ablehnende 
Haltung der NSDAP zur Homosexualität als eine Folge der Politik des in seinen Augen jüdisch dominierten Wissenschaftlich-humanitären Komitees um Magnus Hirschfeld. Indem er auf diese Weise bewusst antisemitische Töne anschlug, hoffte er wahrscheinlich, die NSDAP für seine politischen Ziele gewinnen zu können. Radszuweits überraschender Tod am 15. März 1932 infolge einer Tuberkulose-Erkrankung ließ ihn nicht mehr erfahren, dass ein solches Taktieren nicht aufgehen konnte (vgl. Hergemöller 1998: 568).

\section{Historische Befunde}

Die Analyse von Radszuweits Männlichkeitsrhetorik darf nicht außer Acht lassen, welchen Begrenzungen das Reden über männliche Homosexualität in den Weimarer Jahren unterworfen war. Akten aus Verfahren nach dem »Gesetz zur Bewahrung der Jugend vor Schund- und Schmutzschriften« (R.G.Bl. 1926: I, 505), das von 1926 bis 1935 die wesentliche Rechtsgrundlage für umfangreiche Zensurmaßnahmen darstellte, können zeigen, welche Freiräume der politische Publizist Radszuweit beim Verfassen seiner Texte überhaupt hatte und welche Möglichkeiten es gab, der Zensur zu entkommen. Zur genauen Bedeutung der Begriffe »Schund- und Schmutzschriften« merkt der Historiker Jens Dobler an, dass das Gesetz selbst keine eindeutige Definition festlegte und es deshalb zur Aufgabe der sogenannten »Oberprüfstelle für Schund- und Schmutzschriften« in Leipzig wurde, durch Präzedenzfälle festzulegen, wann Schriften als »schundig« bzw. »schmutzig« gelten konnten. Die Leipziger Kasuistik zusammenfassend führt Dobler aus:

»Demnach war eine Schrift als >Schundschrift< einzustufen, wenn sie >in jeder Beziehung objektiv wertlos und schädigend « sei, wenn sie dem Leser keine positiven Werte und ein >vollständig verzerrtes Weltbild < vermittele, wenn sie die >niedrigen Instinkte anreizt< und wenn übermäßig viele Sprach- und Rechtschreibfehler vorkämen. Um eine Schrift als >Schmutzschrift < zu klassifizieren, musste sie >wertlos sein und wegen der Unreinlichkeit des Inhaltes Widerwillen erregen<, sie müsse >die gemeine geschlechtliche Lüsternheit erregen<, wobei es keinen Unterschied mache, ob >die Lüsternheit zu normaler oder anormaler bzw. perverser Geschlechtlichkeit erregt< würde.« (Dobler 2000: 86)

Setzte die Prüfstelle eine Veröffentlichung auf die Liste der »Schmutz- und Schundschriften«, so war deren Verkauf an Jugendliche unter 18 Jahren verboten und die Schrift durfte nicht öffentlich beworben oder ausgelegt werden, lediglich ein Verkauf unterhalb der Ladentheke war gestattet (vgl. Dobler 2000: 89). Im Falle von Radszuweit, der in erster Linie ein erwachsenes Publikum ansprach, hätte eine solche Maßnahme gewiss nicht seinen finanziellen Ruin bedeutet, ein Verbot der öffentlichen Bewerbung 
eines Periodikums wäre aber in jedem Fall ein herber Rückschlag für einen öffentlichkeitswirksamen Kampf gegen die Marginalisierung von Homosexualität gewesen.

Mit Entscheidung vom 30. Oktober 1930 setzte die Leipziger Oberprüfstelle auf Antrag des Landesjugendamtes Rheinprovinz drei Nummern des sechsten Jahrgangs (1928) von Radszuweits »Freundschaftsblatt« sowie drei Hefte der »Insel« auf den Index der Schund- und Schmutzschriften. In ihrer Begründung nahm die Prüfstelle insbesondere Anstoß an einem literarischen Text, in dem geschildert wurde, wie sich die fiktiven Figuren >Angelo< und >Hinrich< sexuell begegneten. Hier hieß es unter anderem:

»Wortlos, in bebender Inbrunst suchten sie die Erlösung, brennend in des anderen Nähe wie ein langentbehrtes kostbares Labsal fühlend. Ihre Leiber wühlten sich ineinander, sie umklammerten sich in wilder keuchender Umarmung, stöhnend und lachend zugleich [...].« (Oberprüfstelle 1928: 4)

Die Prüfstelle erkannte völlig richtig, dass hier sexuelle Handlungen dargestellt wurden, die unter die Strafbarkeit nach $₫ 175$ RStGB fielen. Bei dieser Feststellung, die bereits ausgereicht hätte, um die Schrift zu indizieren, beließ die Prüfstelle es jedoch nicht, sondern kommentierte das Beschriebene mit deutlichen Worten. Sie hielt »die Art der Darstellung brünstiger Liebesgefühle innerlich besonders unrein, Widerwillen und Abneigung erregend « und stellte fest, »dass durch die Lektüre der Schriften die Jugend in sittlicher Hinsicht sowie mit Bezug auf andere Lebensgebiete gefährdet wird « (ebd.).

Nicht jedoch nur die literarische Formung von mann-männlicher Erotik, auch die zahlreichen Werbeanzeigen für Homosexuellen-Lokale, beunruhigten die Zensoren. Aus diesem Grund geriet das »Freundschaftsblatt« im Oktober 1931 erneut in das Visier der Prüfstelle. Die Prüfer führten aus:

»Die Häufung der Ankündigungen und Anzeigen in einem homosexuelle Tendenz verfolgenden Blatt lassen keinen Zweifel darüber, welchem Zweck sie dienen, und wirken in ihrer für den homosexuellen Verkehr unmissverständlich werbenden Weise auf den normalen Leser widerwärtig. Daß derartige Schund- und Schmutzschriften geeignet sind, die Jugend zu gefährden, bedarf keiner Begründung.« (Oberprüfstelle 1931: 2f.)

Die Argumentation der Prüfstelle erfolgt hier in zwei Schritten: Zunächst sei das Abdrucken von Werbung für Lokale homosexueller Frauen und Männer als ein Grund für die Indizierung des »Freundschaftsblattes « anzusehen. Dies plausibilisierten die Zensoren, indem sie diese Annoncen mit dem Attribut der Widerwärtigkeit versahen. Dabei mussten sie nicht im Detail begründen, worin sich eine solche Widerwärtigkeit konkret zeigte, ihr Empfinden fungierte also als selbstverständlicher Subtext hin- 
ter der Argumentation. Eine solche selbstredend attestierte Widerwärtigkeit ließ es dann in einem zweiten Schritt umso dringlicher erscheinen, in den Inseraten erst recht eine Gefährdung der Jugend zu erkennen.

Nicht alle Prüfverfahren gegen homosexuelle Periodika mussten mit einer Indizierung enden. Als die Berliner Prüfstelle über die Indizierung des Blattes »Die Freundschaft«, das bei Radszuweits Konkurrenz, der Karl-Schultz-Verlagsgesellschaft, erschien, verhandelte, ließen sich die Zensoren von der Argumentation des Redakteurs Georg Plock (1865-1930) überzeugen. Der ausgebildete Theologe Plock hatte sich von 1908 bis 1926 im Wissenschaftlich-humanitären Komitee um Magnus Hirschfeld engagiert und übernahm ab 1922 die Chefredaktion der »Freundschaft« (Hergemöller 1998: 558f.). Gegenüber der Prüfstelle führte er über seine Zeitschrift aus:

»Die Zeitschrift sei seit dem Kriege die älteste dieser Art und sei grundsätzlich peinlichst bestrebt, dezent zu sein. Bei Novellen oder Erzählungen habe der Redakteur die Pflicht zu prüfen, ob sie anstößig oder anfechtbar seien [...]. Die Anzeigen von Lokalen als Treffpunkte seien erst auf Wunsch der Leserschaft aufgenommen, die Anzeigen von Büchern aber könnten doch nicht beanstandet werden, solange die Bücher selbst nicht verboten seien. [...] Vermittlungsanzeigen seien wegen verschiedentlichen Mißbrauchs aus der öffentlich erscheinenden Auflage jetzt verschwunden und würden nur den Abonnenten als Mitteilungsblatt beigelegt. Die Abonnenten müßten über 20 Jahre alt sein und eine Bescheinigung ausstellen.« (Prüfstelle Berlin 1928: 1f.)

An Plocks Argumentation ist auffällig, dass er explizit auf den dezenten Charakter seines Blattes hinwies. Eine Anbahnung von Kontakten unter Homosexuellen sollte dem Aktivisten zu Folge am besten in der verborgenen Sphäre eines Abonnentenkreises stattfinden, nicht jedoch in einem öffentlich zugänglichen Periodikum.

Nachdem durch einen Blick auf die Zensurpraxis der diskursive Rahmen für Radszuweits Männlichkeitsrhetorik aufgezeigt wurde, sollen nun aussagekräftige Texte aus seinen Zeitschriften »Die Insel« und »Das Freundschaftsblatt« betrachtet werden. Auch eine Analyse von Radszuweits Roman »Männer zu verkaufen«, den er 1931 vorlegte, um die BfMStrategie einer Strafverschärfung für männliche Prostituierte zu untermauern, wäre eine geeignete Quelle, um seiner Männlichkeitsrhetorik aufzuspüren. Hierzu liegen bereits an anderer Stelle Ergebnisse vor, die im resümierenden Teil dieses Beitrags im Überblick referiert werden (vgl. Lücke 2005: 312-315).

Eine nicht zu vernachlässigende Aufgabe des homosexuellen Zeitschriftentums bestand für Radszuweit darin, auch die Heterosexuellen in positiv aufklärerischer Absicht über die Lebensstile von Homosexuellen zu informieren, um auf diese Weise für deren Akzeptanz zu werben. Die Formulierung einer solchen Aufgabe für ein Homosexuellen-Blatt erstaunt 
zunächst, denn Heterosexuelle dürften kaum zur Leserschaft von Radszuweits Periodika gezählt haben. So wird es sich hierbei wohl eher um eine Scheinbegründung gehandelt haben, mit dessen Hilfe Radszuweit eine disziplinierende Wirkung auf die homosexuelle Publikationslandschaft erzielen wollte. In der »Insel« musste er jedoch feststellen, dass sich längst nicht alle Homosexuellen-Zeitschriften an Bemühungen dieser Art beteiligten. Unter der Überschrift »Der Krebsschaden in der homosexuellen Bewegung« klagte er am 12. Dezember 1924 darüber, dass in manchen Homosexuellen-Zeitschriften, die nicht aus seinem Verlagshaus kamen,

»die homosexuellen Menschen mit folgenden Namen belegt werden: Knochenmotte, Grenadiertrude, Kanalerna, Pinkelpaula, Straßburger Rosa, Irene, Ossi, Karola usw.« (Radszuweit 1924: 2)

Nicht etwa die negativ besetzten Wortbestandteile wie Kanal oder Pinkel riefen dabei die Missbilligung Radszuweits hervor, sondern die Verwendung weiblicher Namensgebungen für männliche Homosexuelle. Auf diese Weise könnten, so der Homosexuellen-Aktivist, »Wogen der Entrüstung über die Homosexuellen« (ebd.) hereinbrechen. Trotz der hier klar zu Tage tretenden humoristisch-satirischen Sprachverwendung schien der von ihm beobachtete Verstoß gegen die etablierte Ordnung der Geschlechter ein so großes Hindernis bei einer gesellschaftlichen Entstigmatisierung der Homosexualität zu sein, dass es ihm sogar gerechtfertigt erschien, hierfür die sehr drastische Formulierung »Krebsschaden« zu verwenden.

Ganz Ähnliches zeigte sich, als dem Bund für Menschenrecht am 2. Juli 1925 eine Audienz im Preußischen Innenministerium gewährt wurde. Radszuweit wurde bei seinen Gesprächen mit den Ministerialbeamten mit dem Vorwurf konfrontiert, Homosexualität sei eine krankhafte Veranlagung und deshalb habe mann-männliche Sexualität keinen Anspruch auf juristische Gleichstellung. Als Radszuweit dies energisch zurückwies und auf sich selbst als positives homosexuelles Vorbild verwies, entgegnete ihm ein Vertreter der Ministerialbürokratie nach Überlieferung des »Freundschaftsblattes«:

»Wenn man aber, wie das vor einigen Tagen hier Unter den Linden passierte, Ihre Leute in karierten Breecheshosen, langen seidenen Strümpfen und hohen Stöckelschuhen umherlaufen sieht, so werden Sie doch zugeben müssen, daß dieses krankhaft ist.« (Radszuweit 1925: 1)

Dieser Argumentationsweise der Ministerialbürokratie begegnete Radszuweit, indem er anmerkte,

»daß er mit solchen Auswüchsen nicht sympathisiere und daß er auf dem Standpunkt stehe, daß alle Auswüchse im öffentlichen Leben, gleichviel von welcher Seite, auf das Energischste bestraft werden müssen.« (Ebd.) 
Diese Kritik an sichtbarer Effemination von Männern trug die Organisation jedoch nicht nur aus taktischen Motiven intern im Rahmen ihrer Behördenkonsultationen vor. Indem Radszuweit seine Stellungnahme im »Freundschaftsblatt« publizierte, konnte er dafür sorgen, dass seine zunächst nur behördenintern verwendete Redeweise auch der homosexuellen Klientel seiner Periodika zugänglich gemacht wurde. So hatte seine Männlichkeitsrhetorik zwei Adressaten: die hegemoniale Staatsmacht und die marginalisierte Leserschaft seiner Zeitschriften.

Welche Tugenden stattdessen gleichgeschlechtlich begehrende Männer auszeichnen sollten, lässt sich anhand Radszuweits Argumentation zu Homosexuellen in der Reichswehr erkennen. Im Februar 1926 stellte Radszuweit fest, dass homosexuelle Männer aus den Reihen der Armee ausgeschlossen würden, wenn man ihrer Sexualneigung auf die Spur kam. Diese Vorgehensweise kritisierend, führte er aus:

»Die Militärbehörde, die freiwillig sich meldende Rekruten zur Einstellung in das Heer annimmt, fragt nicht nach dem Seelen- und Empfindungsleben derselben, und mit Recht, denn der Soldat muss, will er dem Vaterlande Dienste leisten, vor allen Dingen körperlich gesund sein. Wir erleben aber daß, wenn sich später herausstellt, ein Angehöriger der Reichswehr homosexuell veranlagt ist, er ohne weiteres aus dem Heere wieder entlassen wird, trotzdem er nach jeder Richtung hin seine dienstlichen Pflichten erfüllt hat.« (Radszuweit 1926: 1)

Während Radszuweit die gleichgeschlechtliche Sexualneigung von Rekruten hier als - unsichtbaren - Ausdruck ihres Seelen- und Empfindungslebens darstellte, verfügten sie hingegen genau wie ihre heterosexuellen Kameraden über eine solide körperliche Gesundheit, also über Merkmale von einwandfrei zu attestierender männlicher Körperlichkeit. Darüber hinaus zeichneten sie sich durch dienstliches Pflichtbewusstsein aus: populären Vorstellungen über Gefahren durch homosexuelle Verbündelungen oder eine homosexuelle Cliquenwirtschaft in geschlechtergleichen Männergemeinschaften, die den Zeitgenossen seit dem Eulenburg-Skandal als überaus plausibel erschienen, konnten so präventiv zerstreut werden. (Zur Eulenburg-Affäre vgl. den Beitrag von Claudia Bruns in diesem Band.) Radszuweits homosexuelle Klientel war also durchaus in der Lage, das Militär als eine >Schule der Männlichkeit< zu besuchen.

\section{Heuristische Folien}

Liest man Radszuweits Texte aus der Perspektive des Konzeptes der hegemonialen Männlichkeit von Robert W. Connell, so kann seine Rhetorik als ein Versuch der Teilhabe an hegemonialer Männlichkeit interpretiert werden: Radszuweit griff vermeintlich effeminierte Elemente homosexueller Männlichkeitskonstrukte in seinen Medien, aber auch bei Konsul- 
tationen mit Behörden, scharf an. Auch wies er explizit darauf hin, dass auch gleichgeschlechtlich begehrende Männer Soldaten sein können. Auf diese Weise ordnete er sich selbst als Homosexuellen-Aktivisten und seine Klientel in die Gruppe der »Komplizen hegemonialer Männlichkeit« (vgl. Connell 2000: 100f.) ein: Er entwarf das Idealbild eines Homosexuellen, das sich möglichst eng an das hegemoniale Leitbild von Männlichkeit anlehnen sollte. Von Elementen homosexueller Identitätsentwürfe, die hierzu inkompatibel waren, grenzte er sich im Gegenzug ab.

Gerade, wenn sich untergeordnete Männlichkeiten aufmachen, zu solchen Komplizen hegemonialer Männlichkeit zu werden, lassen sich äußerst ambivalente Mechanismen beobachten, über die die Männlichkeitshistoriker Jürgen Martschukat und Olaf Stieglitz ausführen,

»dass marginalisierte Männer nicht selten den hegemonialen Entwurf von Männlichkeit für sich als Leitvorstellung annehmen. Durch ihr Streben, die Marginalisierung zu überwinden, indem sie die Kriterien der Hegemonie erfüllen, bestätigen sie dann das hegemoniale Konzept selbst, und auf diesem Wege bestärken sie wiederum einen wesentlichen Faktor für ihre eigene Kennzeichnung als defizitär. Möglicherweise führt das Streben marginalisierter Männer nach einem Dasein als sechte Männer< und zu einer Akzentuierung von Differenz gegenüber Frauen.« (Martschukat/Stieglitz 2005: 83f.)

Die theoretischen Aussagen von Martschukat und Stieglitz lesen sich zunächst wie eine Interpretation, die auf frappierende Weise auf das Agieren von Radszuweit zutrifft. Denn in der Tat werden die Kriterien der Hegemonie auch auf die Homosexuellen angewendet und es lässt sich beobachten, dass Radszuweit eine Differenz gegenüber Frauen und Weiblichkeit akzentuiert, um seine Klientel als >echte Männerく erscheinen zu lassen. Ganz Ähnliches lässt sich bei einem Blick in das belletristische Schaffen von Radszuweit beobachten. In seinem bereits erwähnten Roman »Männer zu verkaufen« grenzte er die >gewöhnlichen Homosexuellen< scharf von männlichen Prostituierten ab, indem er diese ebenfalls mit weiblich kodierten Eigenschaften versah, während sich die sgewöhnlichen Homosexuellen< durch Werte wie platonische Freundschaftlichkeit und sexueller Treue ausgezeichnet haben (vgl. Lücke 2006: 312-315).

Auffällig ist, dass das Konstrukt einer hegemonialen Männlichkeit, wie es Martschukat und Stieglitz hier entwerfen, nach ihrer Lesart der Connell'schen Theoriebildung als ein überaus stabiles und unflexibles Gebilde erscheint. Diese Stabilität kam in dem hier betrachteten historischen Zusammenhang jedoch erst durch das Wirken strenger Zensurmaßnahmen zur Entfaltung. Die Zensoren wiesen in ihren Begründungen stets darauf hin, dass sie in einer allzu öffentlichen und freizügigen Publikationspraxis von Homosexuellen-Zeitschriften eine Gefährdung vor allem der Jugendlichen erkannten. Während die Männlichkeitsrhetorik von Radszuweit als Komplizenschaft hegemonialer Männlichkeit interpretiert 
werden kann, erscheinen die Begründungen der Zensoren als Texte, die als Krisenrhetorik die Durchsetzung eines hegemonialen Männlichkeitsbildes unterstützen konnten.

Bei einer Analyse von Männlichkeitspolitik mit Hilfe der Vokabeln des Konzeptes der hegemonialen Männlichkeit gerät in erster Linie in den Blick, was mit Männlichkeitsentwürfen passiert, wenn sich marginalisierte Männer aufmachen, ihre Marginalisierung zu überwinden. Wie Mechanismen dieser Art wirken, kann anhand von Pierre Bourdieus »Fragen zur Schwulen- und Lesbenbewegung « deutlich werden. Bourdieu beschäftigt sich in seinem Textfragment zunächst grundsätzlich mit der Frage, warum Homosexuelle überhaupt Opfer von Unterdrückung werden. Er führt aus, dass das Stigma, das die Gesellschaft den Homosexuellen zuweist, ein Stigma ist, das im Gegensatz etwa zur Hautfarbe oder zum Geschlecht von den Betroffenen verborgen gehalten werden und unsichtbar bleiben kann. Stigmatisierung von Homosexualität bedeutet bei Bourdieu »die Bestreitung des Rechts auf eine sichtbare öffentliche Existenz« der Homosexuellen und ihrer politischen Verbände; die Unterdrückung von Homosexualität ist bei ihm demzufolge eine »Unterdrückung als >Unsichtbarmachen««, sie äußert sich »in einer Verweigerung der öffentlichen, legitimen, d.h. anerkannten Existenz« (Bourdieu 2005: 201f.). Gerade dann, so Bourdieu weiter, wenn die Homosexuellen-Bewegung Sichtbarkeit fordere, wird sie deshalb zur Diskretion gemahnt, also dazu, das Stigma der Homosexualität auch weiterhin verborgen zu halten.

Die von Bourdieu hier skizzierte Strategie einer »Unterdrückung durch Unsichtbarmachung « als Mechanismus zur Marginalisierung von Homosexualität wird auch in den Begründungen der Zensur-Prüfstellen deutlich: Das Recht auf eine sichtbare, weil in Zeitschriften veröffentlichte Darstellung homosexueller Lebensweisen machten die staatlich-hegemonialen Instanzen der Homosexuellen-Bewegung streitig. Eine literarisch geformte Darstellung von mann-männlicher Sexualität sollte dabei genauso unsichtbar bleiben wie die Treffpunkte und Lokale der Homosexuellen: Sichtbare Werbeanzeigen, die dazu führen konnten, dass solche Orte innerhalb Berlins wahrnehmbar wurden, erregten die besondere Ablehnung der Prüfstelle. Aufschlussreich ist in diesem Zusammenhang gerade die Argumentation des Chefredakteurs der »Freundschaft« Plock, der die Prüfstelle von einer Indizierung abhielt, indem er insbesondere auf den dezenten Umgang seines Blattes mit dem Thema der Homosexualität hinwies und explizit betonte, dass Kontakt- und Werbeanzeigen für Jugendliche erst dann einsehbar würden, wenn sie das 21. Lebensjahr vollendet hätten.

Mit Hilfe der von Bourdieu angebotenen theoretischen Folie lässt sich auch die Strategie von Radszuweit beschreiben, wie es in seinen Texten in der »Insel« und im »Freundschaftsblatt« deutlich wird: Indem er sich gegenüber der Ministerialbürokratie scharf von sichtbaren >Auswüchsen ২ homosexueller Lebensstile distanzierte, deutete er die hegemoniale Strategie 
einer >Unterdrückung durch Unsichtbarmachung « um: Durch eine NichtSichtbarmachung homosexueller Stereotype hoffte er, auf eine Nicht-Unterdrückung homosexueller Männlichkeit hinzuwirken. Indem er seine behördenintern vorgetragenen Äußerungen einem breiten homosexuellen Publikum zugänglich machte, trat der Homosexuellen-Aktivist selbst als jemand auf, der sich einer Herrschaftsstrategie zur >Unterdrückung durch Unsichtbarmachung bediente: Er rief seine Klientel dazu auf, die ihrem Sexualbegehren klischeehaft zugeschriebenen sichtbaren Attribute in die Sphäre des Unsichtbaren zu verbannen.

Es ist kein Zufall, dass die Strategie einer >Unterdrückung durch Unsichtbarmachung< durch die Zensurbehörden und die bei Radszuweit und Plock deutlich werdende Um-Interpretation in ein >Nicht-Sichtbarwerdenlassen zum Zweck der Nichtunterdrückung in der Weimarer Republik zum Tragen kam, die im kollektiven Bewusstsein häufig als eine Epoche besonderer Liberalität und sexueller Freizügigkeit gilt. Gerade während der Weimarer Jahre, das zeigen die zahlreichen Aktivitäten Radszuweits, konnte die Homosexuellen-Bewegung mit ihrem Projekt einer Entstigmatisierung von Homosexualität eine rege Tätigkeit entfalten und ein facettenreiches Publikationswesen hervorbringen. Besonders in Zeiten lebhafter Agitation, so führt Bourdieu aus, werden die Homosexuellen als »Angehörige der symbolischen Minderheiten« durch staatliche Instanzen »zur Ordnung gerufen« (Bourdieu 2005: 209). An der Männlichkeitsrhetorik von Radszuweit ist auffällig, dass er nun selbst zu jemandem wurde, der seine Klientel zur Ordnung rief, sich also die Herrschaftsstrategie der >Unterdrückung durch Unsichtbarmachung aneignete. Vorstellungen von hegemonialer Männlichkeit waren also noch so wirkmächtig, dass in der historischen Situation der Weimarer Republik noch nicht daran zu denken war, dass die Homosexuellen-Bewegung »durch eine symbolische Destruktions- und Konstruktionsarbeit neue Wahrnehmungs- und Bewertungskategorien durchzusetzen« vermochte (Bourdieu 2005: 209f.). Die Körperkonzepte etwa Magnus Hirschfelds, die Rainer Herrn in seinem Beitrag in diesem Band darstellt und die wesentlich davon ausgingen, dass homosexuelle Männlichkeit eine sichtbare körperliche Erscheinung war, konnten eben nicht massenwirksam in politische Männlichkeitsrhetorik übersetzt werden. Das gerade dem Hirschfeld'schen Köperentwurf innewohnende subversive Element, das im Sinne Bourdieus in der Tat als ein Versuch gelesen werden kann, durch symbolische Destruktions- und Konstruktionsarbeit neue Wahrnehmungs- und Bewertungskategorien für das Sexuelle und die Geschlechtlichkeit zu entwerfen, wurde eben nicht zur intellektuellen Grundlage der massenhaft organisierten HomosexuellenBewegung in der Weimarer Republik.

Erst der Schwulen- und Lesbenbewegung in den 1970er Jahren sollte es gelingen, eine bewusst als subversiv konzipierte Strategie beim Umgang mit Männlichkeits- und Weiblichkeitsbildern zu entwickeln. Für die Zeit der Weimarer Republik erweist sich der hegemoniale Entwurf von Männ- 
lichkeit jedoch noch als überaus machtvolles und weitreichendes Herrschaftsinstrument, das sich auch in das Handeln des Homosexuellen-Aktivisten Radszuweit einschreiben konnte. Für die Wirkmächtigkeit von hegemonialer Männlichkeit in den »Krisenjahren der klassischen Moderne« (Peukert 1987) scheint das Foucaultsche Diktum zu gelten:

»Nicht weil sie alles umfasst, sondern weil sie von überall kommt, ist die Macht überall.« (Foucault 1983: 114)

\section{Literatur und Quellen}

\section{Quellen und Archivalien}

Das Freundschaftsblatt. Wochenschrift des Bundes für Menschenrecht, Berlin: Radszuweit, Jg. 1 (1922)-Jg. 11 (1933).

Die Freundschaft. Freundschaft und Freiheit. Monatsschrift für ideale Freundschaft, Berlin, Jg. 1 (1919)-Jg. 15 (1933).

Die Insel. Das Magazin der Einsamen, Berlin: Radszuweit 1926-1931.

Radszuweit, Friedrich (1924): »Der Krebsschaden in der homosexuellen Bewegung«. In: Die Insel 2, Nr. 6 (12.12.1924), S. 1f.

Radszuweit, Friedrich (1925): »Merkwürdige Ansichten im Ministerium des Innern über die Homosexuellen«. In: Das Freundschaftsblatt 3, Nr. 6, S. if.

Radszuweit, Friedrich (1926): »Reichswehr und Homosexualität«. In: Das Freundschaftsblatt 4, Nr. 6 (5.2.1926).

Oberprüfstelle für Schund- und Schmutzschriften Leipzig (1928-1931): Verfahren nach dem »Gesetz zur Bewahrung der Jugend vor Schund- und Schmutzschriften« gegen Periodika aus dem Verlag Radszuweit, in: Landesarchiv Berlin, A Pr. Br. Rep 030, Tit. 121, Nr. 17066.

Prüfstelle Berlin für Schund- und Schmutzschriften: Verfahren nach dem »Gesetz zur Bewahrung der Jugend vor Schund- und Schmutzschriften« gegen Periodika aus der Karl-Schultz-Verlagsgesellschaft m.b.H., in: Landesarchiv Berlin, A Pr. Br. Rep 030, Tit. 121, Nr. 17065.

\section{Zitierte Literatur}

Bourdieu, Pierre (2005): Die männliche Herrschaft, Frankfurt a.M.: Suhrkamp.

Connell, Robert W. (2000): Der gemachte Mann. Konstruktion und Krise von Männlichkeiten, Opladen: Leske und Budrich.

Dobler, Jens (2000): »Zensur von Büchern und Zeitschriften mit homosexueller Thematik in der Weimarer Republik«. In: Invertito. Jahrbuch für die Geschichte der Homosexualitäten 2, S. 85-104. 
Erhardt, Justus (1928/29): »Straffällige Fürsorgezöglinge. Ein Beitrag zur Krise der Fürsorgeerziehung«. In: Zentralblatt für Jugendrecht und Jugendwohlfahrt 20, S. 143-146.

Erhardt, Justus (1930): »Männliche Prostitution und Jugendverwahrlosung«. In: Zentralblatt für Jugendrecht und Jugendwohlfahrt 22, Heft 7 , S. $217-223$.

Föllmer, Moritz/Graf, Rüdiger (2005): Die »Krise« der Weimarer Republik. Zur Kritik eines Deutungsmusters, Frankfurt a.M.: Campus.

Föllmer, Moritz/Graf, Rüdiger/Leo, Per (2005): »Einleitung: Die Kultur der Krise in der Weimarer Republik. In: Moritz Föllmer/Rüdiger Graf (Hg.): Die »Krise«der Weimarer Republik. Zur Kritik eines Deutungsmusters, Frankfurt a.M.: Campus, S. 9-41.

Foucault, Michel (1983): Sexualität und Wahrheit, Bd. 1: Der Wille zum Wissen, Frankfurt a.M.: Suhrkamp.

Hergemöller, Bernd Ulrich (1998): Mann für Mann. Biographisches Lexikon zur Geschichte von Freundesliebe und mannmännlicher Sexualität im deutschen Sprachraum, Hamburg: MännerschwarmSkript.

Herzer, Manfred (1982): Bibliographie zur Homosexualität. Verzeichnis des deutschsprachigen nichtbelletristischen Schrifttums zur weiblichen und männlichen Homosexualität aus den Jahren 1466 bis 1975, Berlin: rosa Winkel 1982.

Lautmann, Rüdiger/Taeger, Angela (Hg.) (1992): Männerliebe im alten Deutschland. Sozialgeschichtliche Anhandlungen, Berlin: rosa Winkel.

Lücke, Martin (2005): »Beschmutzte Utopien. Subkulturelle Räume, begehrte Körper und sexuelle Identitäten in belletristischen Texten über männliche Prostitution«. In: Sabine Grenz/Martin Lücke (Hg.), Verhandlungen im Zwielicht. Momente der Prostitution in Geschichte und Gegenwart (Gender Codes - Transkriptionen zwischen Wissen und Geschlecht Bd. 1), Bielefeld: transcript.

Martschukat, Jürgen/Stieglitz, Olaf (2005): »Es ist ein Junge!« Einführung in die Geschichte der Männlichkeiten in der Neuzeit, Tübingen: edition diskord.

Mosse, George L. (1997): Das Bild des Mannes. Zur Konstruktion der modernen Männlichkeit, Frankfurt a.M.: Fischer.

Peukert, Detlev J.K. (1987): Die Weimarer Republik. Krisenjahre der klassischen Moderne, Frankfurt a.M.: Suhrkamp.

Sommer, Kai (1998): Die Strafbarkeit der Homosexualität von der Kaiserzeit bis zum Nationalsozialismus, Frankfurt a.M.: Peter Lang. 


\title{
Proletarische und bürgerliche Jünglinge
}

\author{
in der Moderne. Jugendkult als Emanzipations- \\ strategie und Krisenreaktion um 1900
}

BiRgit DAHLKE

\section{Verjüngendes Licht}

Kein Kaiser war im Bildgedächtnis der deutschen Nation so präsent wie der letzte. Eine Postkarte mit dem Bild Wilhelms II. hatte um 1900 wohl jedes Kind schon mal gesehen. In die Geschichtsbücher sind vor allem Fotografien eingegangen, welche den Kaiser als einen melancholisch in die Ferne blickenden jungen Mann in Uniform mit akkuratem Haarschnitt und gestutztem »Kaiser-Wilhelm-Bart« zeigen. Die Profilansicht von rechts lässt seine lädierte linke Seite im Dunklen, während die rechte Schulter und der rechte Arm vom hell glänzenden Tressenschmuck betont werden. Das selbstbewusst gereckte Kinn, die aufrechte Körperhaltung und die Präsenz der Schulter stehen in Widerspruch zum ernsten Blick, der aus dem Bild hinausweist. Die Statik des traditionellen Arrangements bildet einen Gegensatz zur hellen aufsteigenden und nach oben rechts aus dem Bild herausführenden Linie von Schulter, Hals und Gesicht. Dieser junge Herrscher ist unterwegs in die Zukunft, aber nicht abenteuerlustig. Seine Gestalt erfüllt die Erwartung der traditionellen Herrscherinszenierung, ihr fehlt jedoch jeglicher Anflug von Kraft, Virilität und jugendlichem Übermut. Von Macht künden hier eigentlich nur äußere Insignien wie Schärpe, Ordenskette und Offiziersuniform (Sombart 1996: 21). Obwohl Wilhelm II. 1888 bei Herrschaftsantritt mit 29 Jahren durchaus kein Jüngling mehr war, lassen zeitgenössische Quellen eine Wahrnehmung des Herrschers im Zeichen jugendlichen Elans erkennen: Ein >Jüngling< übernimmt die Verantwortung für das erst zwanzig Jahre bestehende Reich und liquidiert als erstes den Reichsgründer. Die Medialisierung spielt für die Verdichtung dieser Wahrnehmung eine entscheidende Rolle: Nie zuvor hatte es so 
viele Zeitungen und Illustrierte gegeben, nie zuvor waren so viele Nachrichten so schnell über ganze Kontinente transportiert worden, nie zuvor gab es so viele ZeitungsleserInnen. Fotografien, Pressemeldungen, Kommentare, Karikaturen und abgedruckte Reden waren somit in bislang unüblicher Weise an der Verfestigung und massenhaften Verbreitung des inszenierten Kaiserbildes beteiligt. Vor allem aber führte die Medienrevolution zur Herausbildung nationaler Kommunikationsgemeinschaften. Das Herrscherbildnis behielt paradoxerweise aufgrund der damit verbundenen Visualisierungsschübe seinen traditionellen Status auch unter Bedingungen der Modernisierung. In einem in der Zeitschrift »ugend « vom 28. Mai 1900 veröffentlichten Aufsatz zeichnet Houston Stewart Chamberlain ein Bild von der Regierung Wilhelms II. als einer, welche »den Charakter eines aufgehenden Morgens « trage, während »die junge Zeit auf feurigem Rosse dem neuen Morgen« entgegenbrause (Kohlrausch 2006: 54).

Die Betonung der Jugendlichkeit des Herrschers, die nicht allein Thomas Mann in seinem Roman »Königliche Hoheit« unter Einschluss des Kompensationsproblems der Körperbehinderung ironisch reflektierte, ist gleichwohl nicht identisch mit seiner ungebrochenen Männlichkeit. Denn Wilhelm II. wurde nicht erst anlässlich der Affäre um die Homosexualität eines seiner nächsten Freunde (vgl. Beitrag Bruns) zum Ziel von Satiren, die seine unzureichend ausgeprägte soldatische Männlichkeit aufs Korn nahmen.

»Wilhelm II. hat bewiesen, daß er zur Erledigung politischer Geschäfte ganz und gar ungeeignet ist«, »Deutschland ersehnt sich nur einen Mann«, ein »Mannesgenie«, das »wie kein anderer seit den mythischen Tagen Siegfrieds und des grimmigen Tronjerjunkers germanische Männlichkeit verkörpert« (Dahlke 2006: 6), ist ausgerechnet in Maximilian Hardens Zeitschrift »Die Zukunft« zu lesen (ebd.).

Maskulinität wird zur rhetorischen Keule und ihre Verschmelzung mit nationaler Führungsstärke und Germanenmythos zu einem Topos, der auch in Gedichten von Stefan George, Essays von Rudolf Borchardt, dem Roman von Walter Flex oder der Geschichte des Wandervogels von Hans Blüher anzutreffen ist. Die Ambivalenz des Jugendkults allerdings, der eine sunsichere< Männlichkeit transportiert, wird sich in den sexualisierten Kulturkrisendebatten und nicht zuletzt den Reden von der Krise der Maskulinität ebenso spiegeln wie in den Utopien eines neuen Geschlechts jenseits der Sexualität.

Die Inszenierung des jugendlichen Herrschers bleibt allerdings zentraler Ausdruck einer um 1900 im Zuge der beschleunigten Modernisierungsprozesse erfolgenden allgemeinen Aufwertung der Jugend gegenüber dem Alter. Jugend wurde zur Signatur der kommenden Epoche, Wilhelm II. zur Verkörperung der Vitalität eines »jungen Volkes«, wie es Moeller van den Bruck später bezeichnen sollte (Moeller van den Bruck 1919). Als Gegensymbol zu >Alter/Tradition wurde >Jugend< sowohl für konservativ-kulturkritische als auch für linksbürgerliche und proletarische politische Bewegungen attraktiv. Lebensreformbewegung, Naturheilkun- 
de, Siedlungsbewegung, Freikörperkultur, Reformpädagogik - auch die Reformbewegungen um 1900 gestanden der neuen Generation eine gesellschaftliche Bedeutung in bisher unbekanntem Maße zu, ja sie erklärten diese zum sozialen Träger der jeweiligen Bewegung, wie am Beispiel von Ludwig von Hofmanns bildlicher Darstellung »Der Frühlingssturm« von 1894/95 erkennbar wird.

Abbildung 1: Ludwig von Hofmann:»Der Frühlingssturm« (1894/95).

In: Die Lebensreform. Entwürfe zur Neugestaltung von

Leben und Kunst, Bd. 2, Darmstadt 2005: Häusser, S. 11.

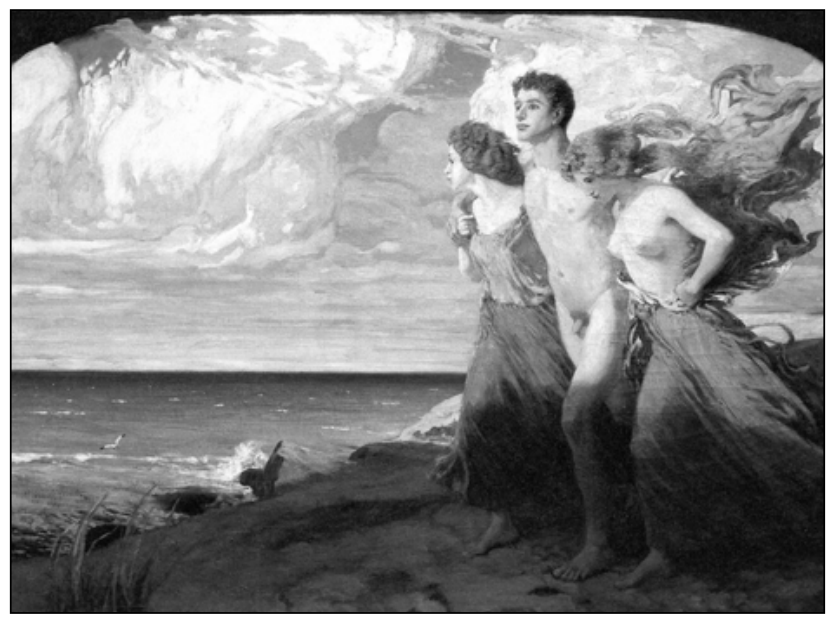

Innerhalb dieser Umorientierungsprozesse erscheinen die Position und die Diskursivierung des kulturellen Phänomens »Jugendstil« als ebenso einzigartig wie widersprüchlich. Nur in Deutschland wird die künstlerische Bewegung mit dem Wort Jugend verbunden, in England spricht man vom »Modern Style«, in Frankreich von »Art Nouveau«.

Die im Ölbild, der Druckgrafik, der Buchillustration und der Massenpostkarte unter die Leute gebrachten androgynen Lichtbringer lassen sich als Gegenentwurf zu etablierten Männlichkeitsmodellen der Gründerzeit deuten. »Passage«, »Gemeinschaft«, »neuer Mensch«, »Licht« antworten als Phantasmagorien auf die Erfahrung eines Bruchs aller Überlieferung und die Untauglichkeit aller vertrauten Formen der Daseinsinterpretation und -bewältigung.

In den emphatischen Gesamtkunstwerken des Jugendstils fungiert Jugend als Mythos im Sinne Roland Barthes $<$ in dem Geschichte in Natur verwandelt und Ambivalenz verdrängt wird. Modernisierungsangst und die beunruhigende Dynamik der Geschlechterverhältnisse werden »gereinigt« und »unschuldig gemacht« (Barthes 1957: 131), Anthropologie und Geschichtsutopie miteinander vermittelt. 
Abbildung 2: Walter Crane: »Illustration zu A Floral fantasy in an old English Garden (Detail), London 1899«. In: Hans H. Hofstätter, Jugendstil. Graphik und Druckkunst, St. Gallen 2003: Otus, S. 85 .

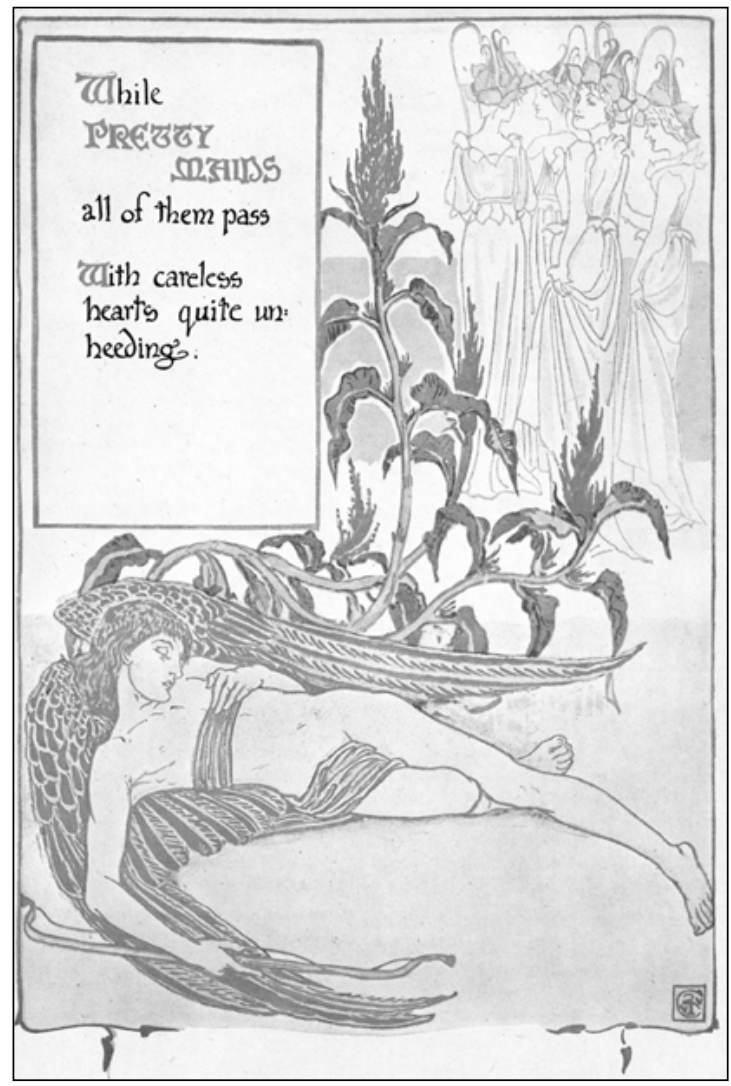

In den Aktdarstellungen verschmelzen naturphilosophische, erotische und religiöse Symbolik zum Erhabenen, wobei paradoxer Weise das Hinausschieben pubertärer Sexualität selbst sexualisiert wird. Die massenweise Inszenierung des Aufschubs und die Ikonisierung des reinen Jünglings in Bild und Text zwingen die RezipientInnen geradezu in eine voyeuristische und damit sexualisierte Position. In den Ansichtskartenalben von Peter Altenberg hebt das rituelle Arrangement mit Hintergrund und Rahmen die Figuren ins Überzeitliche und entkleidet sie jeglichen historischen und sozialen Umfeldes. Idealisierung und Enthistorisierung können die Nähe der Bilder zur Pornografie jedoch kaum verdecken. Die Perspektive auf das fotografierte Objekt unterscheidet sich nur unwesentlich von den Männerakten in zeitgenössischen Homosexuellen-Zeitschriften wie »Der Eigene«. Einzig der mediale Rahmen, der Charakter des Ansichtskartenalbums als 
Unikat, sichert den Abstand. Der entsexualisierte reine Jünglings- oder Mädchenakt wird zum Fetisch und zum Ausgangspunkt einer erotischsexuellen Kultpraxis.

Zur Dominanz der idealisierten Wahrnehmung des Jungseins trägt nicht zuletzt der Siegeszug der neuen Medien bei, wird doch im Kino die Jugendlichkeit des Stars für immer stillgestellt und die ewige Jugend damit zur massenwirksamen Illusion. Dass ehemals getrennte Bereiche kultureller Aktivität einander zunehmend durchdringen, ist eine Entwicklung, die auf das engste mit den medialen Wandlungsprozessen zu Beginn des 20. Jahrhunderts verbunden ist (Faulstich 2006). So verweist die Jugendstilrhetorik der Lichtgestalten nicht zufällig auf die Terminologie der Fotografie und des Films. Stefan George etwa, den viele Zeitgenossen als Dichter der Jugend wahrnahmen, dessen frühe Dichtung voller Keuschheits- und Reinheitssymbolik war und von Walter Benjamin zu Recht dem Jugendstil zugeordnet wurde, wusste sich des neuen Mediums Fotografie überaus gut zu bedienen. Auf den mehr als hundert autorisierten Lichtbildern des »Meisters « wird das Licht tatsächlich überaus zielgerichtet eingesetzt. Die minimalistische Ästhetik (man sieht meist nur Kopf, Oberkörper und Hand) erzwingt eine maximale Deutungsanstrengung (vgl. Blasberg 2000: 140), zumal George dem Jugendkult in seiner Privatreligion um den früh verstorbenen Freund Maximin zwar eine weitere Ikone bereitstellt, sich in seiner Selbstinszenierung jedoch von früh an als jugendlicher Greis präsentiert. George stellt sich als einer der ersten erfolgreichen Strategen im Umgang mit dem neuen Medium Fotografie heraus, es gelingt ihm tatsächlich, sich die Macht über das eigene Bild zu sichern. Die Inszenierung funktioniert auch im Zusammenhang des Jugendkults, denn ein jugendlicher Greis altert nicht. In Georges Dichtung tritt an die Stelle des Generationenkonflikts, der andernorts damals sehr wohl thematisiert wurde, ein aus der Pflanzenwelt übernommenes Geschichtsmodell von Verfall und Wiedergeburt, das sich im Paradigma der symbolisch überhöhten Erbfolge alles Sexuell-Geschlechtlichen entledigt hat. Von dem Lyrikband »Das Jahr der Seele« (1897) bis zu »Der Stern des Bundes« (1913) tritt einem eine Verbindung aus sakraler Geburtsmetaphorik (»heiliger schooss «) und floralen Gleichnissen entgegen, wenn etwa vom »spross aus unsrem eignen stamm« die Rede ist oder es etwa heißt:

»Da schon Dein same den ich trug in fahr

Und aus mir nährte und erzog in nöten

Heut unausrottbar grünt [...].« (George 1913: 20)

Im Zuge von Allmachtsphantasien fallen die Grenzen zwischen Ich und Welt, Natur und Mensch, Männlichkeit und Weiblichkeit:

»ich bin der Eine und bin Beide

Ich bin der zeuger bin der schooss 
Ich bin der degen und die scheide

Ich bin das opfer bin der stoss [...].« (George 1913: 27)

Väter und Mütter werden symbolisch entmachtet, an die Stelle familiärer Genealogien Phantasmen vom »Umgebären« in einem rein männlichen »Reich des Geistes« gesetzt:

»Dies ist reich des Geistes: abglanz

Meines reiches · hof und hain.

Neugestaltet umgeboren

Wird hier jeder: ort der wiege

Heimat bleibt ein märchenklang.

Durch die sendung durch den segen

Tauscht ihr sippe stand und namen

Väter mütter sind nicht mehr.

Aus der sohnschaft · der erlosten .

Kür ich meine herrn der welt.« (George 1913: 83)

In der letzten Zeile der Strophe gibt sich ein monströs überhöhtes Ich als Verursacher der gewaltigen und gewaltsamen Metamorphose der »sohnschaft« zu erkennen. Das Reich des Geistes ist ein explizit männliches (George 1913: 97), in dem Sexualität ins Metaphysische verschoben wird und erotische und religiöse Erweckungsrhetorik ineinander übergehen.

Die Verbindung von moderner Medienpolitik und kalkuliertem Anachronismus der Exklusivausgaben der »Blätter für die Kunst« und des Lyrikbandes »Jahr der Seele« (1897) ist Teil einer gelungenen Sakralisierungs- und Distinktionsstrategie. Syntax und Kleinschreibung der Gedichte signalisieren den Bruch mit der Tradition, während Jugend mit Aufbruch, Zukunft, Schönheit, mit ästhetischer Innovation, aber auch mit nationaler Erneuerung in einen semantischen Zusammenhang gerückt wird. Entsexualisierte männliche, weiße Jugendlichkeit wird zum Ausdruck einer höheren Lebensart: »Die jugend die wir vor uns sehen gestattet uns den glauben an eine nächste zukunft mit höherer lebensauffassung vornehmerer führung und innigerem schönheitsbedürfnis«, heißt es in den »Einleitungen und Merksprüchen der Blätter für die Kunst« von 1901. Unter rückwärtsgewandtem Bezug auf eine imaginierte frühere Jugend, die es so nie gab, wird von Erneuerung, Fortschritt und Zukunft geredet. Das autoritäre Gefolgschaftsverhältnis im Georgekreis wird in der Rede von den »)üngern « einer christlichen Interpretation unterzogen, der früh verstorbene (und also ewig junge) Freund Maximin zur privatreligiösen Erlösergestalt erhoben. $\mathrm{Zu}$ den Paradoxien der Jahrhundertwende passt, dass der Ausschluss von Frauen, »Fremdrassigen« und Demokraten unter dem Gebot der »Reinheit« zum konstitutiven Moment des George'schen Männerbundes wurde, die favorisierten Männlichkeitsbilder jedoch un- 
ausgesprochen das »orientalisch«-konnotierte kontemplative Subjekt an die Stelle des aktivistisch-»abendländischen « setzen.

So wie alles Weibliche explizit ausgeschlossen und zugleich in ein erweitertes Männlichkeitsmodell integriert wird - wie anhand der Geburtsmetaphorik in Georges Gedichten zu sehen ist -, so wird auch das »rassisch« markierte Andere zugleich abgewehrt und inkorporiert. In den Jugendstil-Massenpostkarten wird die Farbsymbolik christlicher Gottesdarstellungen ins alltäglich-säkulare kollektive Bewusstsein überführt und sozusagen naturalisiert, denn sakralisiert werden ganz selbstverständlich ausschließlich gesunde, schöne weiße Mädchen und Jünglinge.

Die rassisierte bzw. nationalisierte Lichtmetaphorik, von Fidus in Manifesten und Bildunterschriften bis zu Formulierungen wie »lichtdeutsch « und »lichtheil« getrieben, begegnet uns in Walter Flex Bestseller »Der Wanderer zwischen beiden Welten« (1916) wieder. Auch dessen Hauptfigur, eine Mischung aus Christus, Zarathustra und Goethes Wanderer, ist ständig von einer Metaphorik der Helligkeit umgeben. Die zwei Welten, zwischen denen der »reine«, nackte Heros sich bewegt, sind die romantisierte Jugendbewegung des Wandervogels und der idealisierte Militärdienst. In die narrative Konstruktion gehen Elemente unterschiedlicher zeitgenössischer Diskurse von der romantischen Naturnähe, dem homosozialen Gemeinschaftserlebnis und der antimodernen Innerlichkeit bis zur pietistischen Herzensfrömmigkeit ein. Während der Held, ein Kriegsfreiwilliger, nach der realen Gestalt des gefallenen Leutnants Ernst Wurche entworfen, in der Wahrnehmung des Ich-Erzählers bis zu seinem frühen Tod sexuell »rein« bleibt, »flutet« die Maisonne, »zuckt« die Luft vor dem Gefecht und »schwillt« der Nachtsturm:

»Der junge Mensch, der auf uns zuschritt, war von diesem Frühling trunken. Mit rückgeneigtem Haupte ließ er die Maisonne ganz über sich hinfluten, er hielt ihr stille und stand mit frei ausgebreiteten Armen und geöffneten Händen da [...]. Feucht von den Wassern und von der Sonne und Jugend über und über glänzend stand der Zwanzigjährige in seiner schlanken Reinheit da, und die Worte des Ganymed kamen ihm schlicht und schön [...] von den Lippen.« (Flex 1916: 31f.)

Während das Kriegsgeschehen hier wie auch in literarischen Texten Ernst Jüngers und Franz Schauweckers oder etwa in der 1908/09 von Hans Breuer herausgegebenen Liedersammlung »Zupfgeigenhansel« sexualisiert wird, scheint der jugendliche Heros über allem Geschlechtlich-Sexuellen zu stehen. Es sind entsexualisierte Figuren der Reinheit (vgl. Brunotte 2004), die, um mit George Mosse zu sprechen, eine »libidinöse Beziehung zum Krieg« eingehen (Mosse 1985: 160). Im Krieg wird somit das Unmögliche möglich, die männliche Virilität im Dienste der Nation gegen alle Verweiblichungsgefahren der Moderne zu sichern und zugleich die als gefährlich wahrgenommene Sexualität abzuspalten. Das reale Kriegsgeschehen bleibt trotz realistischer Ortsangaben im Roman außerhalb des 
Erzählten, stattdessen wird das Erweckungserlebnis zwischen Natur- und Kameradschaftsromantik ebenso ins Vorgeschichtlich-Mystische verlegt wie der frühe Kriegstod. Die Dramaturgie des Textes folgt der Passionsgeschichte, die letzte Begegnung zwischen >Heiland < und Evangelisten, als welcher der Ich-Erzähler fungiert, findet entsprechend unter einem Wegekreuz statt. Jugendkult, Ästhetisierung des Krieges und eine morbide Ästhetik des Selbstopfers gehen in diesem Männlichkeitsnarrativ eine politisch gefährliche und langfristig wirksame Verbindung ein.

Die Lichtmetaphorik, die bereits hier auratisch-kultischen Charakter annimmt, wird später sowohl von der nationalsozialistischen als auch von der Arbeiterjugendbewegung aufgegriffen. Noch in DDR-Liederbüchern der Freien Deutschen Jugend finden sich Ausläufer solcher Heilsrhetorik. Die Umformungen der Lichtmetapher indizieren, wie Hans Blumenberg gezeigt hat, »die Wandlungen des Welt- und Selbstverständnisses« deutscher Intellektueller (Blumenberg 1957: 140). Als Metapher der Wahrheit wird das Licht etwa bei Fidus zur Basis einer Metaphysik. Die Kehrseite der eklektizistischen Vermischung neuplatonischer, aufklärerischer, christlicher und moderner Schichten der Lichtmetapher bilden die Luzifergestalten als Selbstbild deutscher Intellektueller und Künstler. Den Aquarellen und Ölgemälden von Fidus »Tempel des Luzifer« (1892), »Grollender Luzifer« (1893) oder »Luzifers Erwachen« (1913) und dem Aufsehen erregenden »Lucifer«-Gemälde von Franz von Stuck (1890) steht beispielsweise die ab 1902 von Rudolf Steiner und Marie von Sivers unter dem Namen »Lucifer« herausgegebene Monatszeitschrift der deutschen Sektion der Theosophischen Gesellschaft zur Seite. Der Erzengel Luzifer gehört wie Wotan, Prometheus, Parsifal, Tristan und Michael zu den Hauptfiguren der Monumentalporträts von Fidus. In der Gestalt des Lichtbringers etwa in »Luzifer Morgenstern« (1894) wird die Auflehnung gegen göttliche Autorität mit dem Schuldgefühl des Aufrührers verschmolzen, einmal mehr werden soziale Konflikte remythisiert (Osterkamp 1979). Immer wieder stellt Fidus seinen androgynen Jünglingen, die den kulturellen Diskurs der Männlichkeitskrise im Wilhelminischen Kaiserreich begleiten, allerdings auch germanische Helden mit Schwertern oder Spaten zur Seite. Die zeitgenössischen Verweiblichungsängste fordern offensichtlich auch von diesem Künstler ihren Tribut.

\section{Wissenschaftliche Entdeckung der Adoleszenz}

Um den widersprüchlichen Assoziationen, welche die Wende vom 19. zum 20. Jahrhundert im Unterschied $\mathrm{zu}$ früheren und späteren Jahrhundertwenden bei den ZeitgenossInnen auslöste, Raum zu geben, musste der Jugendmythos um ein entscheidendes Element erweitert werden, das der Ambivalenz. Verfügbar wurde es mit der Entdeckung der Adoleszenz durch den amerikanischen Kinderpsychologen Stanley Hall. Zugleich 
erhielt der Begriff Adoleszenz in der entstehenden Jugendforschung und ganz im Gegensatz zum ahistorischen Gebrauch des Terminus Jugend im Jugendstil wieder Anschluss an die ambivalenten Modernisierungserfahrungen selbst. Vermittelt über den jungen Jugendforscher und Psychoanalytiker Siegfried Bernfeld fand Halls zweibändige Schrift von 1904 Eingang zunächst in die deutsche Jugendforschung. Die anschließend erfolgende Übernahme des neuen Begriffs in den breiteren öffentlichen Diskurs erweiterte das anthropologische Grundmuster Jugend entscheidend: die Idealisierung der Jugend wurde ergänzt durch Anerkennung der mit dieser Lebensphase verbundenen Ambivalenz. Erst damit wurde das schon bei Aristoteles zu findende Kulturmuster »Jugend « anschlussfähig für die kulturkritischen Diskurse der »heißen Kulturphase« (Levi-Strauss 1962: 272) in Deutschland um 1900. Die Anerkennung der mit den Entwicklungsprozessen der Adoleszenz verbundenen Dynamiken löste allerdings vor allem unter PädagogInnen und PolitikerInnen auch neue Verunsicherungen aus, was bis zur Kriminalisierung und Pathologisierung der unkontrollierbar werdenden Jugend führen konnte. Insbesondere galt dies, sobald wie im Falle der Arbeiterjugend Generationen- und soziale Konflikte aufeinander trafen.

In einer Gesellschaft beschleunigter Modernisierung wird der Jugend eine verlängerte Adoleszenz eingeräumt, die Pubertät endet nicht wie früher mit der gewaltsamen Durchsetzung der Tradition und Verinnerlichung des Prinzips der Unterordnung, sondern in der Einheit von Erneuerung und Kontinuität (Erdheim 1982: 316). Was lange als Defizit der jungen Generation bewertet wurde, deren Erfahrungslosigkeit, erfährt innerhalb des neuen zukunftsorientierten Gesellschaftstypus zunächst einmal eine enorme Aufwertung. Jugend ist nun als ein »Konflikt- bzw. Avantgardehabitus akzeptiert, dem gesellschaftlich die Lizenz der Innovation und Konventionsverletzung eingeräumt wird« (Oesterle 1997: 14). Die Umorientierung von alt auf jung bringt als Extrem groteske medizinische Verjüngungstechniken hervor. Das »Steinachen«, das Verjüngen durch Abbinden von Samensträngen, wird selbst von Akademikern positiv aufgenommen und ausprobiert (vgl. Stoff 2004).

\section{Jugendbewegungen}

Wendet man sich der lebensweltlichen Seite der Aufwertung von Jugendlichkeit zu, den Jugendbewegungen der Zeit, so wird die andere Seite der Aufwertung sichtbar, die Angst vor der nun sichtbar gewordenen neuen sozialen Kraft. Jugendbewegungen entstehen immer dann, wenn gesellschaftliche Werte der Erwachsenenwelt ihre unbefragte Verbindlichkeit verlieren. Die Wandervogelbewegung wurde zu einer Massenbewegung, befreite sich jedoch nie von der pädagogischen Führung und Kontrolle, sie wurde nie zu einer autonomen jugendkulturellen Bewegung. Die lin- 
ke Jugendkulturbewegung um die Zeitschrift »Der Anfang« entwickelte zwar eine radikalere Protesthaltung, erreichte jedoch keine Breitenwirkung. Dennoch wurde sie polizeilich observiert und mit Verboten belegt. $\mathrm{Da}$, wo nicht idealisierend über Jugend gesprochen wurde, sondern wo Jugend selbst sprach - wie etwa in dem spektakulären Berliner »Sprechsaal« (Dahlke 2006: 229ff.) -, endete die staatliche Toleranz. Epochensignatur hin und her, der realen jungen Generation begegnete man misstrauischer denn je. Das lässt schon die Begriffsgeschichte des Wortes »Jugendlicher« erkennen, die nicht zufällig im kriminologisch-juristischen Kontext zu suchen ist. Bereits im letzten Drittel des 18. Jahrhunderts hatten Kindheits- wie Jugendbegriff einen Wandel erfahren und sich polarisiert. Das Konzept Kindheit ließ die Jugend (als Lebenszeit zwischen zwölf und achtzehn Jahren) mehr und mehr als gefährdet erscheinen (Wild 1993; Oesterle 1997). Die neue Semantik des Begriffs »Jugend« ist eng mit den sozialen Wandlungsprozessen im Zuge der Industrialisierung und Verstädterung verbunden (Dahlke 2006: 24-34). Die mit der industriellen Arbeitsteilung einhergehende Polarisierung der Geschlechtercharaktere (Hausen 1976) wirkte sich direkt auf die Erziehung der Jugend aus. Die parallel zur Schulpflicht entstehende Familienpolitik stellte vor allem die Jugend aus unteren Schichten unter staatliche Aufsicht, um die Mitte des 19. Jahrhunderts bildete sich denn auch ein spezielles Jugendstrafrecht heraus (Beulke 1991). Im Umkreis dessen lässt sich um 1875 erstmals der Gebrauch des Wortes »ugendlicher« nachweisen, ab da existieren mit dem idealisierten »üngling « und dem kriminalisierten »Jugendlichen« zwei divergente Deutungsmuster nebeneinander.

Mit dem Reichsvereinsgesetz von 1908 wurde Jugendlichen unter 18 Jahren jede politische Betätigung verboten. Unter allen westlichen Industrieländern kam es nur in Deutschland vor dem Ersten Weltkrieg zu Ansätzen einer Jugendbewegung. »Wenn anderswo in Europa Revolutionen stattfinden, gibt es in Deutschland Jugendbewegung «, kommentiert Gert Mattenklott treffend (Mattenklott 1997: XXVI). Der ehemalige Wandervogel und Aktivist der Berliner Sprechsaalbewegung Walter Benjamin sollte den entpolitisierenden Effekt des Jugendaufbruchs aus der Distanz der 1930er Jahre selbstkritisch als »Regression aus der sozialen in die natürliche und biologische Realität« bewerten (Benjamin 1933: 392f.).

\section{Adoleszenz als Krise hegemonialer Männlichkeit?}

War schon in der Genieästhetik des Sturm und Drang als selbstverständlich vorausgesetzt worden, dass die metaphysische Koalierung von Schönheit, Ästhetik und Jugend nur für männliche Junggenies galt, so wird auch zu Beginn des 20. Jahrhunderts der Zeitraum zur Entfaltung von Subjektivität, ihrer Krisen und Risiken, nur der männlichen bürgerlichen und verbürgerlichten aristokratischen Jugend zugestanden. Die Mehrheit der 
JugendforscherInnen - AktivistInnen einer Disziplin, die sich zu Beginn des 20. Jahrhunderts herausbildet - richtet ihre wissenschaftliche Aufmerksamkeit auf die männliche bildungsbürgerliche Jugend. Stanley Hall bildet keine Ausnahme, wenn er die Adoleszenz von Mädchen in nur zwei Kapiteln seiner 760-seitigen Darstellung als Sonderfall abhandelt. Seine Wahrnehmung des männlichen Adoleszenten als gesellschaftliche Gefahr wird in deutschen Debatten beinahe kritiklos übernommen. Für Hall ist die Adoleszenz die gefährlichste Phase des Lebens, nicht nur für das jugendliche Individuum, sondern auch für die Nation. Er greift alle zeitgenössischen Krisendiskurse von der Neurasthenie bis zur Hysterie auf und setzt ihnen eine radikale Normalisierungsstrategie entgegen. Die größte Gefahr für junge Männer, aber zugleich auch für die Nation, sieht Hall in der Verweichlichung/Verweiblichung der Großstadtjugend. Diese Argumentation tritt neu zur oben erwähnten kriminalisierenden und vor allem jugendliche Sexualität pathologisierenden hinzu: »Sex and Crime« werden schon im Untertitel dieser konservativ-kulturkritischen Darstellung in den Kontext der Adoleszenz gerückt. Zu begegnen sei den »ungesunden« (so wörtlich) Erscheinungen mit körperlicher Ertüchtigung und einer Kultur des Willens, wobei Muskeln vor dem Verstand und der Wille vor der Intelligenz kämen (Hall 1904: I, 243). Ein ganzes Kapitel widmet Hall den Biografien und Autobiografien berühmter Männer von Goethe über Rousseau zu Napoleon. Die literarischen Texte sind ihm authentische Quellen für den Verlauf der Adoleszenz. Den Zeitgeist-Forderungen nach gleichen Bildungschancen für Mädchen hält Hall das »Ewig-Weibliche« (deutsch im Original) entgegen, das eben darin bestehe, dass Frauen die Phase der Adoleszenz nie hinter sich ließen. Während Mädchen paradoxerweise im selben Denkmodell zugleich bereits als Frauen auf die Welt kommen, müssen Jungen die gefährliche Durchgangsphase der Instabilität, Emotionalität und sexuellen Perversionen passieren und in einem Willensakt beenden, um Männer zu werden. Damit wird am tradierten Männlichkeitsnarrativ der romantischen Krisenhelden seit Tiecks »Der blonde Eckbert« weiter geschrieben. Männlichkeit wird erworben, so Hall, indem das »feminisierte« (!) Stadium der psychischen Entwicklung überwunden wird. Koedukation bildet eine Gefahr für die Mannwerdung. Anders als die Propheten des Jugendkults sieht der Modernekritiker Hall die Jugend demnach keineswegs als Träger und Garanten gesellschaftlicher Erneuerung, sondern als gefährdet und als Gefahr. Auf die seltsame Abstinenz Freuds, der schließlich nicht wenige PatientInnen im entsprechenden Alter hatte, sich jedoch theoretisch kaum für die Lebensphase der Jugend interessiert, sei hier nur verwiesen. Von Interesse ist in unserem Zusammenhang jedoch ein Denkmuster, das sich mit dem Halls kreuzt: Freud stellt nämlich wie dieser einen Zusammenhang zwischen pubertärer Masturbation als Ursache der Neurasthenie und der Konstitution der Nation her. In einem 1898 publizierten Aufsatz artikuliert er "geradezu ein Volksinteresse daran, dass die Männer mit voller Potenz in den Sexualverkehr eintreten« (Freud 1898: 
28f.). Die Metaphorik von der »Entfesselung« der »aufgespeicherten« sexuellen Triebkräfte des Kindes zur Zeit der Pubertät lässt ahnen, was für ein dämonisches Wesen der Jugendliche für den Psychoanalytiker darstellt. In den späten Schriften wird Freud vor allem die kulturelle Leistung des Jünglings hervorheben, dessen Ablösung von der Autorität der Familie erst den für den Kulturfortschritt so wichtigen Gegensatz der neuen zur alten Generation schaffe (Freud 1905: 130).

\section{Erschöpfte Bürgersöhne - erwachende Jungproletarier}

Die Erschöpfungsrhetorik des Fin de Siècle wird innerhalb der deutschen Literatur von einem eigenen Genre getragen, dem Adoleszenzroman (Gansel 2004; Steinlein 2004). Um 1900 bringt die Zuspitzung der mit der Übergangsphase verbundenen psychischen und sozialen Konflikte eine Welle von Schulromanen, bildungskritischen Erzählungen und Jugenddramen hervor. Die Texte von Max Halbe, Emil Strauß, Friedrich Huch, Hermann Hesse, Frank Wedekind und Robert Musil sind zugleich entscheidend an der Herausbildung von zeitgenössischen Verständnismustern der familiären und schulischen Situation der Jugend beteiligt. Literatur funktioniert einmal mehr als Ort der Zirkulation sozialer Energien im Sinne Stephen Greenblatts, sie ist geprägt von kollektiven physischen und mentalen Empfindungen einer Zeit, sie kann diese jedoch auch hervorrufen, gestalten und ordnen (Greenblatt 1990: 15).

Anders als im klassischen Bildungs- und Entwicklungsroman zeigen die jungen Autoren der Jahrgänge 1864 bis 1877 ihre bildungsbürgerlichen Hoffnungsträgerfiguren als überfordert und existenziell gefährdet. Unter den Vorgangsfiguren ihrer Texte dominieren erschöpfte Hysteriker, lebensunfähige Melancholiker und fiebergeschwächte Neurastheniker wie Hans Giebenrath, Herrmann Heilner, Heinrich Lindner und Karl Notwang aus Rilkes Erzählung »Die Turnstunde« (1899/1902), Hermann Hesses »Unterm Rad« (1906), Robert Musils »Verwirrungen des Zöglings Törleß « (1903/06) oder Hanno Buddenbrook aus Thomas Manns Roman »Buddenbrooks« (1901), um nur wenige zu nennen. Das Plädoyer für die Rettung des sensiblen kunstsinnigen Jünglings vor den Forderungen der Erzieher und Väter, also die Erweiterung der tradierten Männerrolle wie sie bereits von den Romantikern modelliert worden war, geht einher mit der Wiederbelebung gänzlich konservativer Konstruktionen von Weiblichkeit. Die Schwestern, Mütter, Zofen und Huren sind in diesen Männlichkeitsnarrativen Figuren im Dienste der männlichen bürgerlichen Initiation. Ihnen wird mit wenigen Ausnahmen wie etwa in Frank Wedekinds spektakulärem Drama »Frühlings Erwachen « (1891, 1906 in Berlin uraufgeführt) kein psychologisches Innenleben zugestanden. Die Geschlechtertopografie bleibt genauso traditionell wie die Geschlechterdramaturgie: es ist der 
junge Hans Hartwig, der in Max Halbes Liebesdrama »Jugend « (1893) in die Welt zieht, während das gleichaltrige »Annchen« (!) sich höchstens sehnsuchtsvoll aus dem Fenster lehnen darf. Wedekinds Wendla, Thomas Manns blonde Inge und Lisaweta Iwanowna aus »Tonio Kröger« (1903) und Walter Hasenclevers Fräulein in »Der Sohn« (1914) eint ihre instrumentelle Funktion innerhalb des konflikthaltigen Reifungsprozesses der männlichen Hauptfigur. Der von männlichen Autoren dominierte literarische Diskurs über Männlichkeit unterscheidet sich überraschend gering von dem wissenschaftlichen Stanley Halls, gerade die Erweiterung der Rollenbilder belebt alte Ängste vor der Verweiblichung des Mannes wieder. Erschwert wird die seit Freud ödipal imaginierte Mannwerdung dadurch, dass die Position des Vaters durch den Statusverlust der bürgerlichen Kernfamilie bereits lange vor dem verlorenen Ersten Weltkrieg unbesetzt ist. Naturalistische Dramen von Gerhart Hauptmann, Arno Holz und Johannes Schlaf enthalten die Vaterposition nur noch als Leerstelle. Wie in Maeterlinks Drama »Die Blinden« (1890) sind es in Hofmannsthals »Der Tod des Tizian« (1892) die Söhne, welche dem Vater eine patriarchale Machtposition einräumen, die er längst nicht mehr ausfüllen kann (vgl. Streisand 2001: 250-261). Zu den widersprüchlichen Reaktionen auf die Dynamik des sozialen Wandels einschließlich der rasanten Veränderungen der Geschlechterverhältnisse gehört der befremdliche Sohneskult, den gerade emanzipierte Autorinnen wie Else Lasker-Schüler und Franziska zu Reventlow oder auch die bekannte Sozialistin Lily Braun betrieben (Dahlke 2006: 105ff.).

Die krisengeschüttelten Jünglinge verkörpern als ewige Söhne die Dekadenzängste der verunsicherten Bürger und die damit verbundene grundlegende Verunsicherung der hegemonialen bürgerlichen Männlichkeit. Den müden Helden Hofmannsthals, Andrians, Beer-Hofmanns, den Melancholikern Rilkes, Georges, Robert Walsers und Rudolf Borchardts, den ewigen Söhnen der Adoleszenzromane von Musil bis Hesse, den entsexualisierten Lichtanbetern des Jugendstils und vergeistigten hommes fragiles des verunsicherten Bürgertums stehen überraschend juvenile proletarische Heroen gegenüber. In der allegorischen Bildpublizistik der Arbeiterbewegung erfreut sich der kräftige nackte Jüngling als Heros der Freiheit und Arbeit großer Beliebtheit. Gern wird auch die mythische Gestalt des Jung-Siegfried in Dienst genommen (Lerch 1988: 364; Hickethier 1979: 79ff.). In dem Arbeitersatireorgan »Der wahre Jakob« von 1893 wird der proletarische Siegeszug im Bild des jugendlichen Reiters gestaltet.

War in Rilkes wirkungsmächtigem Narrativ des jugendlichen Reiters in »Die Weise von Liebe und Tod des Cornets Christoph Rilke« (1904/1906) die kriegerische mit der sexuellen Initiation verschränkt worden, so greift die Karikatur auf das etablierte Motiv zurück, entledigt sich jedoch der darin enthaltenen Todeseuphorie, die bei Rilke subjekt-konstituierend ist. An die Stelle des jugendlichen Selbstopfers (bei Rilke, bei Flex, vor allem aber auch in Liedern der Sammlung »Zupfgeigenhansel«) tritt hier die jugend- 
liche Siegergestalt. Die Nacktheit der proletarischen Heroen unterscheidet sich in ihrem Reinheitskult nur unwesentlich von den entsexualisierten Jugendstil-Ikonen. Die Körperbilder bieten eine glatte Oberfläche, welche innere (seien es psychische oder sexuelle) Konflikte der Individuation verdeckt. Die typisierende bildliche Allegorie macht die Widersprüche der Lebenswelt unsichtbar, wenn sie etwa >Freiheit< und >Arbeit< oder Reinheit und Virilität scheinbar problemlos integriert. Dabei stoßen die jungen ArbeiterInnen sehr wohl auf Konflikte, die mit ihrem Lebensalter zu tun haben, schließlich wird ihnen selbst innerhalb der Arbeiterbewegung ebenso wenig ein politischer Subjektstatus zugestanden wie in den konservativen oder liberalen bürgerlichen Parteien. Auch im Rahmen der proletarischen Kultur treffen wir demnach auf den für den bürgerlichen Jugendkult geltenden Gegensatz zwischen symbolischer und sozial-lebensweltlicher Sphäre.

Abbildung 3: »Hurrah, dem Sieger!« (Anonym). In: Peter von Rüden (Hg.), Beiträge zur Kulturgeschichte der Arbeiterbewegung, Frankfurt a.M. 1979: Büchergilde Gutenberg, S. 114.

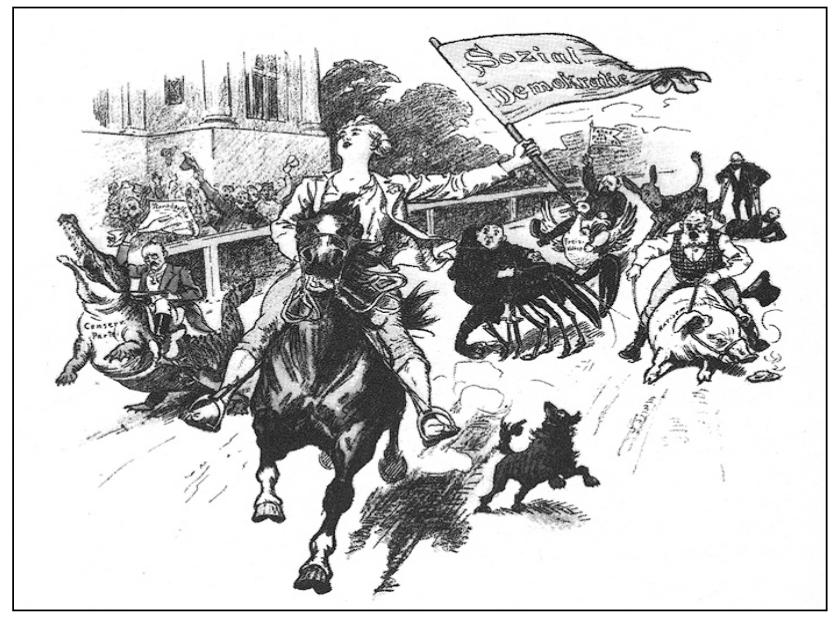

Bis in die 1920er Jahre hinein ließen die lange Arbeitszeit und die beengte Wohnsituation jungen ArbeiterInnen weder Zeit noch Raum, Adoleszenz überhaupt auszuleben, von einer verlängerten gar nicht zu reden. Viele wohnten als »Schlafgänger« in fremden Großstadtfamilien. In den Arbeiterlebenserinnerungen, einem literarischen Genre, das sich Ende des 19. Jahrhunderts herausbildet, wird der Jugendphase so gut wie gar kein Raum gegeben. Dabei wuchs genealogischen Narrativen innerhalb der minoritären Arbeiterliteratur zur selben Zeit Bedeutung zu, da diese in der bürgerlichen Literatur in die Krise gerieten. Obwohl die Texte von Adelheid Popp, Max Hoelz, Adam Scharrer oder Hans Marchwitza alle das Wort »Jugend « im Titel tragen, nimmt diese Lebensphase in der Erzählung 
keinen Raum ein. Auch aus der Distanz der erwachsenen Schreibenden werden die Jugendjahre nicht mit Sinn aufgeladen, sondern als tote, dem erzählenden Ich nicht gehörende Zeit erzählt. Zeit wird nicht zur Messachse der Entfaltung einer Persönlichkeit, sie gewinnt im fremdbestimmten Alltag keine Gerichtetheit. Im Arbeitertheater gehen die Figuren schnell und selbstverständlich aus dem Kinderstatus in den Stand der Erwachsenen über, dem populären Vater-Sohn-Konflikt, Dreh- und Angelpunkt expressionistischer Dramen, wird im proletarischen Drama von Ernst Preczang oder Paul Bader eher untergeordnete Bedeutung beigemessen.

Abbildung 4: »Der letzte Hosenschlupf«. Nach einer Zeichnung von H.G. Jentzsch (1901). In: Peter von Rüden (Hg.)

Beiträge zur Kulturgeschichte der Arbeiterbewegung, Frankfurt a.M. 1979: Büchergilde Gutenberg, S. 115.

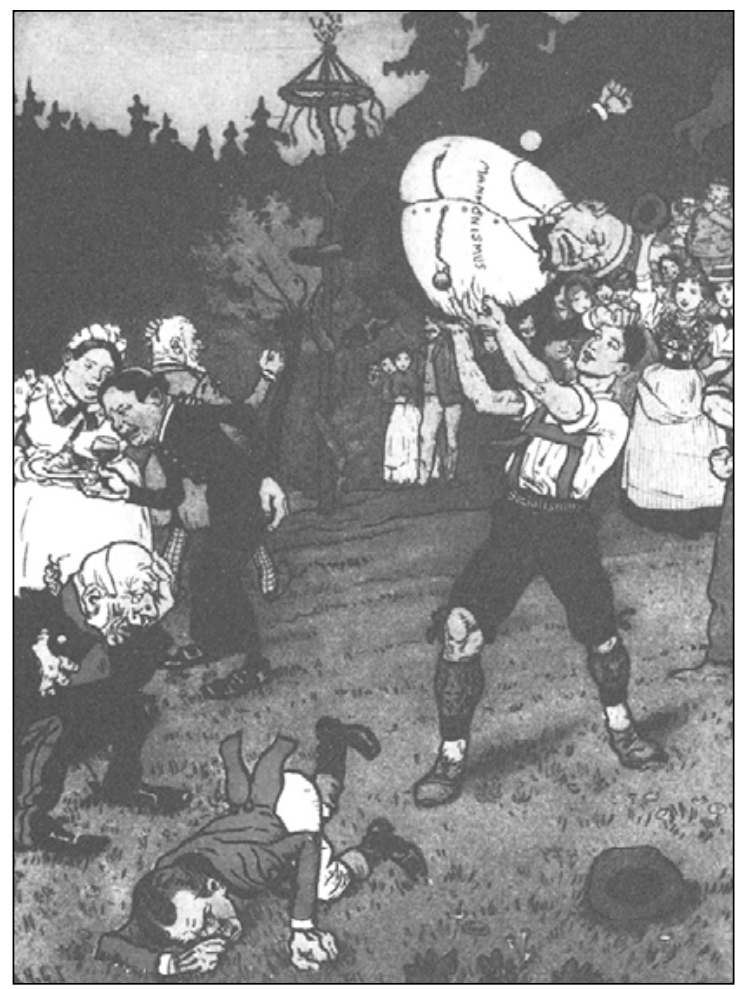

Klassenkonflikte drängen Generationenkonflikte ebenso in den Hintergrund wie Geschlechterkonflikte, das Durchleben von adoleszenten Krisen ist ein Privileg, über das junge Arbeiter ebenso wenig verfügen wie Arbeiterinnen. Der Verlauf des individuellen Lebens ist, so lassen die Lebenserinnerungen und Dramen erkennen, weit mehr durch die sozialen Verhältnisse determiniert als durch die persönlich-familiären, was die Ersetzung 
des individuellen durch eine Art kollektiven Lebenslauf (Bogdal 1991: 227) in dieser Literatur erklärt. Wo im Rahmen hegemonialer Männlichkeiten Krisenphasen als Reifungsprozesse durchlebt werden können und letztendlich der Selbstrettung und Selbsterhebung des weißen männlichen bürgerlichen Subjekts dienen, erfolgt hier eine Art Fluchtbewegung aus den Schwierigkeiten der Individuation in die Zugehörigkeit zum Kollektiv. Dass diese Struktur wenig Raum für die Thematisierung etwa von Konflikten zwischen den Geschlechtern und Generationen, für die Auseinandersetzung mit Homosexualität oder mit rassistischen Verhaltensmustern bietet, versteht sich von selbst.

Abbildung 5: Gedenkblatt »Zur Erinnerung an den 1. Mai 1892«. In: Peter von Rüden (Hg.), Beiträge zur Kulturgeschichte der Arbeiterbewegung, Frankfurt a.M. 1979: Büchergilde Gutenberg, S. 97.

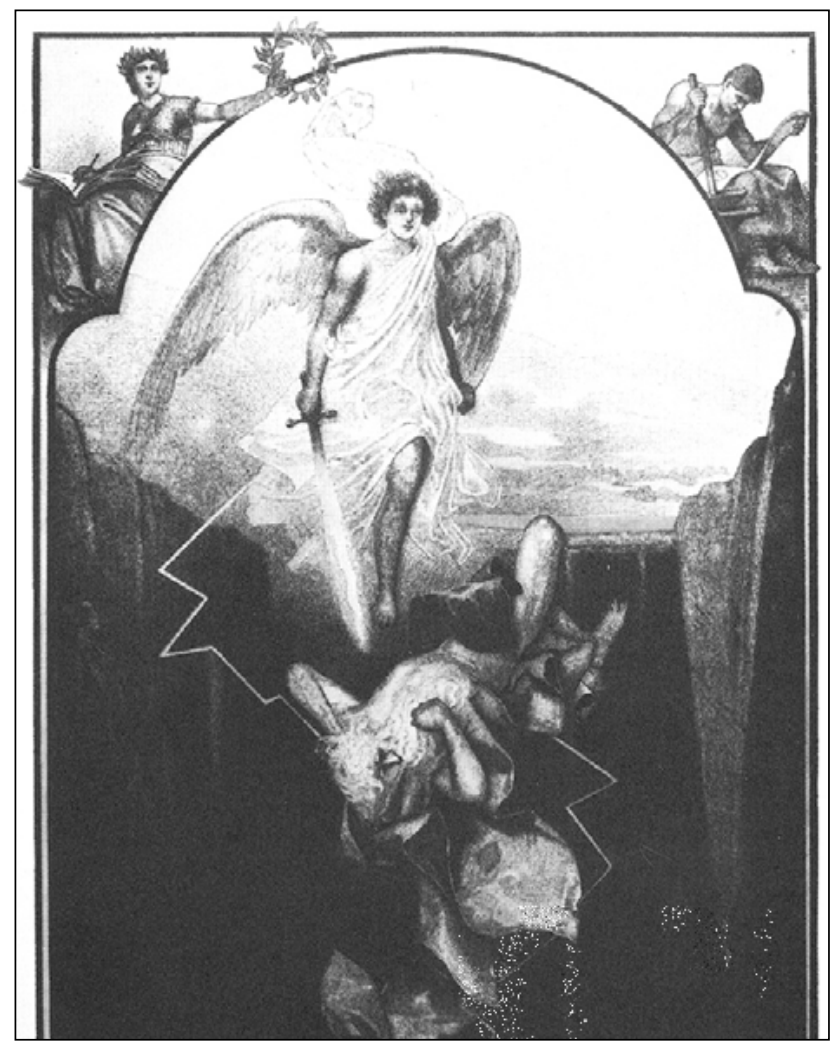

Während der Wohn- und Arbeitsalltag den realen jungen ArbeiterInnen keinen Platz zum Ausleben einer Lebensphase der Adoleszenz lässt, funktioniert auf der Ebene der Symbolisierung das Modell Jugend - Frühling - gesellschaftlicher Aufbruch ungebrochen und wird Teil einer antikapi- 
talistischen Emanzipationskultur. In überraschender Nähe zum bürgerlichen Jugendkult werden Natürlichkeit, Virilität, Muskelkraft und von allen Konflikten gereinigte jugendliche Leidenschaft der jungen Männer aus der Unterschicht mal dem verfetteten Mammon, mal dem verrottetdekadenten Zentauren gegenübergestellt. In einer Karikatur von 1901 hebt »der Jüngling Sozialismus [...] den fetten Mammonismus in die Höhe«.

Dass es sich bei diesem >Jüngling neuen Typus< keineswegs um eine Krisenfigur, sondern um eine politisch-kulturelle Erfolgsfigur von anhaltender Wirksamkeit handelte, zeigt die Kontinuität ihrer Verwendung in Kalendern, Liedern und Flugblättern der Arbeiterbewegung.

Das Gedenkblatt zum 1. Mai, erst 1890 als Kampftag der internationalen Arbeiterbewegung um den Achtstundenarbeitstag eingeführt, nutzt die Jugendstilvorlage für die eigenen politischen Zwecke. Die Spezifik des deutschen Jugendstils, eine Leerstelle an Sinnproduktionen durch den Rückgriff auf ahistorisch-mystifizierende Bildwelten verbunden mit der Etablierung neuer Modelle des entsexualisierten Androgyns zu kompensieren und massenkonsumierbar zu machen, ist anschlussfähig für die unterschiedlichsten Ideologien. Statt die konkreten sozialen Kämpfe der ersten Massenstreiks der 189 oer Jahre künstlerisch zu gestalten, wird von der jungen Emanzipationsbewegung auf die diffuse enthistorisierende Bildwelt und ästhetische Praxis der antimodernen und zugleich modernen »bürgerlichen Fluchtbewegung « (Frecot u.a. 1997: 192) zurückgegriffen. Die Spannung zwischen Bildinhalt und Bildunterschrift lässt sich als Zeichen der noch ungesicherten Position der neuen sozialen Schicht des Großstadtproletariats im Machtfeld des Symbolischen interpretieren: das Potential tradierter Gedenkkulturen und moderner Medien wird genutzt und gegebenenfalls gereinigt oder uminterpretiert, weil eigene Symbolwelten nicht zur Verfügung stehen.

Im Jüngling als Alter Ego des Krisendiskurses und als Verkörperung von Möglichkeiten und Gefährdungen der Mannwerdung gehen Modernisierungsängste und Emanzipationsstrategien eine paradoxe Verbindung ein. Die »junge Bewegung « der Nationalsozialisten, die sich dann selbst einfach »die Bewegung « nannte, wird auf das soziale und politische Integrationspotential der Kultfigur zurückgreifen. Sie wird das Vitalitäts- und Erneuerungspathos der Arbeiterbewegung freilich auf neue Weise mit einem nun nicht mehr bürgerlich-müden Totenkult (Brunotte 2004) verbinden.

\section{Literatur}

Barthes, Roland (1957): Mythen des Alltags, Frankfurt a.M.: Suhrkamp. Benjamin, Walter (1933): »Rückblick auf Stefan George«. In: Rolf Tiedemann u.a. (Hg.), Gesammelte Schriften, Bd. III, Frankfurt a.M. 1991: Suhrkamp, S. 392-399. 
Beulke, Werner (1991): Jugendstrafrecht, Stuttgart: Kohlhammer.

Blasberg, Cornelia (2000): »Charisma in der Moderne. Stefan Georges

Medienpolitik«. In: Deutsche Vierteljahresschrift für Literaturwissenschaft und Geistesgeschichte 74, S. 111-114.

Blumenberg, Hans (1957): »Licht als Metapher der Wahrheit. Im Vorfeld der philosophischen Begriffsbildung«. In: Hans Blumenberg, Ästhetische und metaphorologische Schriften, Auswahl und Nachwort von Anselm Haverkamp, Frankfurt a.M.: Suhrkamp, S. 139-171.

Bogdal, Klaus-Michael (1991): Zwischen Alltag und Utopie. Arbeiterliteratur als Diskurs des 19. Jahrhunderts, Opladen: Westdeutscher Verlag.

Bollenbeck, Georg (1994): Arbeiterlebenserinnerung. In: Simone Barck u.a. (Hg.), Lexikon sozialistischer Literatur. Ihre Geschichte in Deutschland bis 1945, Stuttgart/Weimar: Metzler, S. 31-35.

Brunotte, Ulrike (2004): Zwischen Eros und Krieg. Männerbund und Ritual in der Moderne, Berlin: Wagenbach.

Dahlke, Birgit (2006): Jünglinge der Moderne. Jugendkult und Männlichkeit in der Literatur um 1900, Köln/Weimar/Wien: Böhlau.

Emmerich, Wolfgang (1974): Proletarische Lebensläufe. Autobiographische Dokumente zur Entstehung der Zweiten Kultur in Deutschland, Bd. 1, Anfänge bis 1914, Reinbek bei Hamburg: Rowohlt.

Erdheim, Mario (1982): Die gesellschaftliche Produktion von Unbewusstheit. Eine Einführung in den ethnopsychoanalytischen Prozeß, Frankfurt a.M.: Suhrkamp.

Faulstich, Werner (Hg.) (2006): Das erste Jahrzehnt, Paderborn: Wilhelm Fink.

Flex, Walter (1916): Der Wanderer zwischen beiden Welten. Novelle, Kiel 1986: Orion-Heimreiter.

Freud, Sigmund (1898): »Die Sexualität in der Ätiologie der Neurosen«. In: Studienausgabe, Bd. V, Frankfurt a.M. 1972: S. Fischer, S. 11-35.

Freud, Sigmund (1905): »Drei Abhandlungen zur Sexualtheorie«. In: Studienausgabe, Bd. V, Frankfurt a.M. 1972: S. Fischer, S. 37-145.

Gansel, Carsten (2004): »Adoleszenz und Adoleszenzroman als Gegenstand literaturwissenschaftlicher Forschung«. In: Zeitschrift für Germanistik. Neue Folge 1, S. 130-149.

George, Stefan (1913): »Der Stern des Bundes«. In: Sämtliche Werke in 18 Bänden, Bd. VIII, Stuttgart 1986: Klett Cotta.

Greenblatt, Stephen (1990): »Die Zirkulation sozialer Energie. Einleitung«. In: ders., Verhandlungen mit Shakespeare. Innenansichten der englischen Renaissance, aus dem Amerikanischen von Robin Cackett, Frankfurt a.M.: Suhrkamp, S. 9-33.

Hall, G. Stanley (1904): Adolescence. Its Psychology And Its Relations to Physiology, Anthropology, Sociology. Sex, Crime, Religion and Education, 2 Bände, New York/London: D. Appleton.

Hausen, Karin (1976): »Die Polarisierung der >Geschlechtercharaktere Eine Spiegelung der Dissoziation von Erwerbs- und Familienleben«. 
In: Werner Conze (Hg.), Sozialgeschichte der Familie in der Neuzeit Europas, Stuttgart: Klett, S. 363-393.

Hickethier, Knuth (1979): »Karikatur, Allegorie und Bilderfolge - zur Bildpublizistik im Dienste der Arbeiterbewegung«. In: Beiträge zur Kulturgeschichte der deutschen Arbeiterbewegung, S. 79-82.

Klaus, Georg (1971): Sprache der Politik, Berlin: Deutscher Verlag der Wissenschaften.

Knilli, Friedrich/Münchow, Ursula (Hg.) (1970): Frühes deutsches Arbeitertheater 1847-1918. Dokumente, Berlin: Akademieverlag.

Kohlrausch, Martin (2006): Der Monarch im Skandal. Die Logik der Massenmedien und die Transformation der wilhelminischen Diplomatie, Berlin: Landtverlag.

Lerch, Edith (1988): »Die Maifeiern der Arbeiter im Kaiserreich«. In: Dieter Düding/Peter Friedemann/Peter Münche (Hg.), Öffentliche Festkultur. Politische Feste in Deutschland von der Aufklärung bis zum Ersten Weltkrieg, Reinbek bei Hamburg: Rowohlt, S. 56-77.

Levi-Strauss, Claude (1962): Das wilde Denken, Frankfurt a.M.: Suhrkamp. Mattenklott, Gert (1997): »Körperkult, Ökosophie und Religion. Ein kritisches Vorwort zur Neuauflage des Fidus-Buches von Janos Frecot, Johann Friedrich Geist und Diethart Krebs«. In: Janos Frecot/Johann Friedrich Geist/Diethart Krebs (Hg.), Fidus 1868-1948. Zur ästhetischen Praxis bürgerlicher Fluchtbewegungen, erweiterte Neuauflage mit einem Vorwort von Gert Mattenklott und einer Forschungsübersicht von Christian Weller, Hamburg: Rogner \& Bernhard, S. VII-XXVIII.

Mosse, George L. (1985): Nationalismus und Sexualität. Bürgerliche Moral und sexuelle Normen, aus dem Amerikanischen von Jörg Trobitius, Reinbek bei Hamburg: Rowohlt.

Oesterle, Günter (1997): »Einleitung«. In: ders. (Hg.), Jugend - ein romantisches Konzept?, Würzburg: Königshausen \& Neumann.

Osterkamp, Ernst 1979: »Lucifergestalten der wilhelminischen Ära. Der Lichtbringer im Prozeß der Zerstörung der Vernunft«. In: ders., Lucifer. Stationen eines Motivs, Berlin/New York: Peter Lang, S. 213-248.

Sombart, Nicolaus (1996): Wilhelm II. Sündenbock und Herr der Mitte, Berlin: Volk und Welt.

Stoff, Heiko (2004): Ewige Jugend. Konzepte der Verjüngung vom späten 19. Jahrhundert bis ins Dritte Reich, Köln: Böhlau.

Schwarze, Hans (Hg.) (1932), Moeller van den Bruck, Arthur: Das Recht der jungen Völker: Sammlung politischer Aufsätze (1919), Berlin: Verlag Der nahe Osten.

Steinlein, Rüdiger (2004): »Adoleszenzliteratur«. In: Zeitschrift für Germanistik. Neue Folge 1, S. 8-18.

Streisand, Marianne (2001): Intimität. Begriffsgeschichte und Entdeckung der >Intimität< auf dem Theater um 1900, München: Fink.

Wieland, Karin (1998): Worte und Blut. Das männliche Selbst im Übergang zur Neuzeit, Frankfurt a.M.: Suhrkamp. 
Wild, Reiner (1993): »Kind, Kindheit, Jugend. Hinweise zum begriffsgeschichtlichen Wandel im letzten Drittel des 18. Jahrhunderts«. In: Jugendliteratur und Gesellschaft, 4. Beiheft, S. 9-16. 


\title{
Le petit mal du grand Mâle
}

\author{
Christina von Braun
}

\section{Krise der Männlichkeit und Selbstermächtigung: Kunst}

Wer die Krise hegemonialer Männlichkeit in der Moderne verstehen will, wird um den Begriff der Hysterie nicht herumkommen. Die Hysterie verließ im 19. Jahrhundert ihren seit Jahrhunderten im kranken weiblichen Körper anberaumten Platz und ließ sich im männlichen Körper nieder. In >weiblichen $<$ Symptomen wie Migränen, Schwindel- und Ohnmachtsanfällen erfasste Künstler wie Novalis, Flaubert oder Mallarmé die Lust am Fallen und der Taumel der Begeisterung für die eigene Ohnmacht. »Seltsamer- und eigentümlicherweise«, so schrieb etwa Stéphane Mallarmé, »habe ich alles geliebt, was sich in diesem Wort Sturz zusammenfassen lässt« (Mallarmé 1876: 270). Baudelaire schrieb: »Ich bewohne für immer ein einstürzendes Gebäude, ein Gebäude, das von einer heimtückischen Krankheit zerfressen wird « (Baudelaire 1932: 37). Und Flaubert, der - vor allem während er an »Madame Bovary« arbeitete - an Schwindelanfällen und an >Fallsucht< litt (epilepsieähnlichen Anfällen, die im Französischen manchmal als >le petit mal< bezeichnet wurden), sagte von sich selbst: »Woher kommt es nur, daß ich so oft zum Spiegel ging, wenn ich weinte, um mich darin zu betrachten? Diese Lust, über sich selbst zu stehen, ist vielleicht die Quelle jeglicher Tugend « (Flaubert in: Nadeau 1964). Mag sein, dass die Lust, über sich selbst zu stehen, als Tugend zu begreifen ist, sie ließe sich aber auch als Versuch interpretieren, die eigene Weiblichkeit zu produzieren. Bei Flaubert steht ganz eindeutig hinter der >Lust< an der eigenen Ohnmacht auch die Lust an der Macht der schriftstellerischen Tätigkeit, die genau diese impliziert. Durch sie legt sich der Autor einen fiktiven, >simulierten< Körper zu: etwa in der Gestalt der Emma Bovary.

In einem Brief an Louise Colet schrieb Flaubert: »Die Tinte ist mein natürliches Element. Schöne Flüssigkeit, übrigens, diese dunkle Flüssigkeit! Und gefährlich! Wie man darin ertrinken kann! Wie sie einen an- 
zieht!« (Ebd.). Jean Starobinski verweist auf die enge Verbindung zwischen dem »schwarzen Stoff«, in dem Flaubert ertrinken möchte, und der Vergiftung, an der Emma Bovary stirbt. Als man den Kopf der Toten hebt, »quoll schwarze Flüssigkeit aus dem Munde hervor, als erbräche sie sich« (Flaubert in: Schurig 1976: 437). Damit, so Starobinski, offenbare Flaubert auch die tödliche Macht des >natürlichen Elements‘, das ihm so viel Lust bereitet:

»Die Heldin, deren Liebesglut in den Bildern der schlechten Literatur ihren Vorwand fand, gleitet hinüber in den Tod und endgültige Kälte mit dem Geschmack der Flüssigkeit im Munde, die ihre Existenz bestimmte. Spiegelbildliche Verdoppelung der Vergiftung: dieses durch den falschen Zauber der Lektüre fehlgeleitete Schicksal endet so, als würde mit ihm auch der falsche Zauber des Schreibens offenbart. Emma ist nicht etwa die Verkörperung des Autors im Roman (trotz des berühmten >das bin ich $<$ ), sie enthüllt vielmehr die tödliche Kraft dessen, was der Schriftsteller als sein >Element< bezeichnet.« (Starobinski 1991: 57f.)

Flauberts Lust an der Ohnmacht hängt also einerseits mit den Gefahren zusammen, in die ihn die Imagination führt; sie ist andererseits aber auch Ausdruck für die Machtgefühle, die ihm dieser Vorgang, den man auch als Simulation bezeichnen könnte, vermittelt. Es ist bekannt, dass die Hysterikerinnen - weil es keine organischen Ursachen für ihre Symptome gab - immer für Simulantinnen gehalten wurden. Daher also das Interesse so vieler Künstler und Schriftsteller des 19. Jahrhunderts für die Hysterie: Die Hysterie schien zu wissen, wie man es macht. Wie man aus dem Nichts - oder der reinen Imagination - Körper, Gefühle, Leiden fabrizieren kann. Um die hysterische Kunstfertigkeit zu erwerben, mussten sie die Krise in Kauf nehmen. Noch einmal Flaubert:

»Derjenige, der jetzt lebt und der ich bin, sinnt unaufhörlich über den anderen nach, der tot ist. Ich habe zwei sehr unterschiedliche Existenzen geführt. Äußere Ereignisse symbolisierten das Ende der ersteren und die Geburt der zweiten. All das ist Mathematik. Mein aktives Leben, leidenschaftlich, bewegt, voller entgegengesetzter Bocksprünge und vielschichtiger Empfindungen endete mit 22 Jahren. Zu dieser Zeit machte ich auf einmal große Fortschritte, und es ist etwas anderes gekommen. Also habe ich zu meinem persönlichen Gebrauch die Welt und mich klar in zwei Hälften geteilt: auf der einen Seite das äußere Element, das ich mir vielfältig, vielfarbig, harmonisch, großartig wünsche, von dem ich nichts anderes akzeptiere als das Schauspiel und das ich genießen will; auf der anderen Seite das innere Element, welches ich konzentriere, um es noch mehr zu verdichten und in das ich in vollen Strömen die reinsten Strahlen des Geistes durch das geöffnete Fenster der Intelligenz eindringen lasse.« (Flaubert in: Bruneau 1973: Bd. 1)

Mit solchen Bildern nimmt Flaubert einige der Phantasien vorweg, die mehr als hundert Jahre nach ihm unter den Begriffen Cyberspace und >vir- 
tueller Realität< gehandelt werden sollten. Dass diese Arten der Simulation in einem genealogischen Zusammenhang stehen, zeigt - unabhängig von der medientechnischen Entwicklung - schon die Etymologie des Wortes >virtuelk. Der Begriff ist sehr viel älter als der Computer, und er hatte auch nicht immer die heutige Bedeutung einer Schein- oder künstlichen Welt. Seine Geschichte geht bis in die Antike zurück: >virtuell bedeutet in etwa »der Anlage nach als Möglichkeit vorhanden«. Von vir, dem Mann, abgeleitet, konnotiert er Attribute wie »kräftig«, »tüchtig«, »mannhaft«. Der »Virtuose«, ein Begriff, der im 18. Jahrhundert entstand, um einen »großen Künstler«, vor allem in der Tonkunst, zu bezeichnen, ist eine direkte Ableitung von >virtuell in diesem Sinne. Eine weitere Ableitung von >vir< ist die Tugendhaftigkeit (auf die Flaubert auch anspielt), sie steht als >virtus ‘ für Männlichkeit, vor allem soldatische Männlichkeit. Auf Frauen bezogen, hatte der Begriff der >virtus < zwar ebenfalls die Konnotation von Sittlichkeit und sexueller Zurückhaltung, aber ohne die anderen Bedeutungen von >tatkräftig< und >schöpferisch $<$. Die >virtuelle Realität < ist mithin eine >mögliche< oder >denkbare< Wirklichkeit, die aus Männlichkeit und Tatkraft gepaart mit Enthaltsamkeit erschaffen wird: Sie entspricht einer creatio ex nihilo, wie sie auch der Hysterie eignet: In jeder dieser Konnotationen ist die >virtuelle Realität $<$ der >Wirklichkeit vergleichbar, die Flaubert schuf, als er, zurückgezogen in Croisset in den eigenen Worten als »hysterischer Eremit« (Sartre 1977: Bd. 5, 602) lebend, eine aus Worten und Zeichen bestehende >Realität< erzeugte.

»Schreiben ist etwas Köstliches, nicht mehr man selbst zu sein, sondern in der ganzen Schöpfung zu kreisen, von der man spricht. Heute zum Beispiel bin ich als Mann und Frau zugleich, als Liebhaber und Geliebte [...] durch einen Wald geritten.« (Flaubert in: Nadeau 1964)

Damit nahm Flaubert auch das Bild der >multiplen Persönlichkeit< (vgl. von Braun/Dietze 1999) mit ihren wechselnden Ichs voraus, die im 20. Jahrhundert ebenfalls den Stempel der >Frauenkrankheit< erhielt, andererseits aber auch zum Vorbild für den Surfer im Cyberspace werden sollte. In der virtuellen Welt, so schreibt Sherry Turkle,

»sind wir mit dem anderen Selbst nicht allein. Im cyberspace sind wir mit vielen anderen. Einige von ihnen sind Verkörperungen unserer selbst, Aspekte unseres Ich. Die Grenze zwischen virtuell und real, zwischen dem Lebendigen und dem Leblosen sind durchlässig geworden. Identität? Wir erfinden uns laufend selbst - unsere multiplen Selbst.« (Turkle 1996: 164)

Auch beim Cyberspace wird ein Eintauchen in eine gefährliche Flüssigkeit imaginiert, nur dass es sich um eine Flüssigkeit handelt, die nicht aus Tinte besteht, sondern die durch den binären Code erzeugt wird. Im modernen Medienjargon heißt diese Flüssigkeit immersive environment: Mit dem 
Begriff wird ein >Schnittstellendesign< bezeichnet, »dessen Realitätsfiktion derart suggestiv ist, daß es als solches gar nicht wahrnehmbar wird « (Matussek 2001: 291-320, 304). ${ }^{1}$ Anders ausgedrückt, ein immersive environment bezeichnet einen technisch erzeugten Raum, in den das Ich aktiv und passiv eintauchen kann. Dass beim Cyberspace das Eintauchen in eine >Flüssigkeit< phantasiert wird, geht auch aus dem Begriff des >Surfers < hervor, der auf - oder in - den Wellen reitet. Das ganze Vokabular des World Wide Web, das hat Bettina Mathes gezeigt (Mathes 2006), beruht auf der Metapher des Wassers und der Flüssigkeit, in die das Subjekt eintauchen und untergehen kann, wie Flaubert in seiner köstlichen Tinte. In beiden Fällen handelt es sich um einen Vorgang, bei der das Ich aktiv werden muss, um sich in den ersehnten Zustand der Passivität oder Ohnmacht zu versetzen. Mit der Aneignung von Weiblichkeitsmustern erhoben Künstler Anspruch auf eine bisexuelle schöpferische Potenz.

Wie eng die Krise der Männlichkeit mit Selbstermächtigungsstrategien zusammenhängt, lässt sich nicht nur am Beispiel von Künstlern zeigen. Der Zusammenhang zeigt sich auch auf der Ebene kollektiver Vorgänge und Phänomene: politisch-psychologischen wie ökonomischen. Den politisch-psychologischen Bereich möchte ich am Beispiel dieser seltsamen Wandlung darstellen, die sich um 1900 mit dem Begriff der Hysterie vollzog, als er eine Bedeutung annahm, die nicht mehr auf die >Krankheit $<$ des weiblichen Körpers - und damit auf Unangepasstheit und Anomalie - verwies und stattdessen einen Sinn annahm, der das völlige Eintauchen und Aufgehen des Subjekts in der Masse beinhaltete. Man kann die Idee der >Massenhysterie< als ein reales Phänomen der Moderne betrachten, man kann in ihr aber auch eine Selbstermächtigungsstrategie ihrer Theoretiker sehen.

\section{Krise der Männlichkeit und Selbstermächtigung: Psychologie}

Der bekannteste unter diesen Theoretikern war Gustave Le Bon, dessen »Psychologie der Massen« 1895 erschien, zeitgleich mit Freuds und Breuers »Studien zur Hysterie«. Le Bon beschreibt die »psychologische Masse« als

»ein unbestimmtes Wesen, das aus ungleichartigen Bestandteilen besteht, die sich für einen Augenblick miteinander verbunden haben, genau so wie die Zellen des

1| Wie für viele Begriffe, die dem Zeitgeist entsprechen, gibt es auch für den Begriff des >immersive environment< keinen Erfinder; er stammt aus der Subkultur der späten 7oer oder frühen 8oer Jahre des 20. Jahrhunderts. Näheres zu dem Begriff: Peter Matussek, Monika Fleischmann, Oliver Grau, Ernst Roland. 
Organismus durch ihre Vereinigung ein neues Wesen mit ganz anderen Eigenschaften als denen der einzelnen Zellen bilden.« (Le Bon 1973: 13)

Mit dem Begriff des >unbestimmten Wesens < griff er auf ein ähnliches Bild zurück wie Freud mit seinem >dunklen Kontinent<. In der Tat sahen beide in der Masse ein >weibliches Phänomen`, das sie einerseits anzog - wie die >dunkle, gefährliche Flüssigkeit<, in der Flaubert ertrinken möchte -, das sie andererseits aber auch beherrschen möchten. Flaubert zog sich auf das Schreiben zurück - als Schriftsteller konnte er als »Mann und Frau durch den Wald reiten«. Freud und Le Bon zogen sich auf >wissenschaftliche< Positionen zurück. Und sie können das nur, indem sie die Masse zu einem >weiblichen Phänomen< erklären. Hatte der Physiologe Rudolf Virchow erklärt: »Alles, was wir an dem wahren Weibe Weibliches bewundern und verehren, ist nur eine Dependenz der Eierstöcke« (Virchow in: Mayreder 1907: 17), so schreibt Le Bon:

»die Masse (wird) beinahe ausschließlich vom Unbewußten geleitet. Ihre Handlungen stehen viel öfter unter dem Einfluß des Rückenmarks als unter dem des Gehirns. Die vollzogenen Handlungen können ihrer Ausführung nach vollkommen sein, da sie aber nicht vom Gehirn ausgehen, so handelt der einzelne nach zufälligen Reizen.«(Le Bon 1973: 20)

Bei Le Bon unterliegt die Masse >Einbildungen<, und sie ist zugleich >Urnatur<, verfügt über einen >echten< Leib. Man sieht also deutlich, wie hier die traditionellen Beschreibungen der Hysterie - Nervosität, Irrationalität, Unberechenbarkeit, die Einbildung und deren Macht über die >Natur< - auf den kollektiven Körper übertragen werden. Freud, der Le Bons Thesen in »Massenpsychologie und Ich-Analyse« aufgriff und weiterentwickelte, hatte eine andere Vorstellung vom Unbewussten, und der Grundunterschied bestand darin, dass er es für notwendig erachtete, die Anziehungskraft des Unbewussten zu überwinden, während Le Bon die Masse zum Helden der Geschichte erklärte. In beiden Fällen ist das Unbewusste weiblich. Die Konsequenzen will ich kurz darstellen.

Bei Freud ist das Unbewusste der Gegenspieler des Über-Ich. Ersteres muss domestiziert werden, damit das Ich den Eintritt in die symbolische Ordnung vollziehen und Gemeinschaftsverantwortung übernehmen kann. Bei Le Bon hingegen kann das Gesetz nichts gegen die Macht des Unbewussten ausrichten.

»Die Massenpsychologie zeigt, wie außerordentlich wenig Einfluß Gesetze und Einrichtungen auf die ursprüngliche Natur der Massen haben und wie unfähig diese sind, Meinungen zu haben außer jenen, die ihnen eingeflößt wurden; Regeln, welche auf rein begrifflichem Ermessen beruhen, vermögen sie nicht zu leiten. Nur die Eindrücke, die man in ihre Seele pflanzt, können sie verführen.« (Le Bon 1973: 6) 
In »Der Mann Moses und der Monotheismus« entwickelte Freud das Konzept der Tatkraft des >großen Mannes<, der sich durch die »Entschiedenheit der Gedanken, die Stärke des Willens, die Wucht der Taten [...], Selbständigkeit und Unabhängigkeit« sowie eine »göttliche Unbekümmertheit, die sich zur Rücksichtslosigkeit steigern darf« (Freud 1952ff.: Bd. XVI, 101-246, 217) auszeichne. Dank dieser Eigenschaften gelinge es diesem >großen Mann<, die >Masse< auf den rechten Weg zu bringen. Aus der Psychologie des Einzelmenschen, so Freud weiter, wisse man, woher dieses Bedürfnis der Masse stamme: »Es ist die Sehnsucht nach dem Vater, die jedem von seiner Kindheit her innewohnt, nach demselben Vater, den überwunden zu haben der Held der Sage sich rühmt« (ebd.: 216). Ganz anders bei Le Bon, der die Masse einerseits als weiblich umschreibt - »Überall sind die Massen weibisch, die weibischsten aber die lateinischen Massen« (Le Bon 1973: 22) -, andererseits aber gerade dieser Weiblichkeit jene heldischen Eigenschaften zuschreibt, die für Freud den »großen Mann« charakterisieren.

»Gewiß ist die Masse oft verbrecherisch, oft aber auch heldenhaft. Man bringt sie leicht dazu, sich für den Triumph eines Glaubens oder einer Idee in den Tod schicken zu lassen, begeistert sie für Ruhm und Ehre, dass sie sich, wie im Zeitalter der Kreuzzüge, fast ohne Brot und Wasser zur Befreiung des göttlichen Grabes von den Ungläubigen oder wie im Jahre 1793 zur Verteidigung des vaterländischen Bodens fortreißen läßt.« (Ebd.: 17f.)

Zwar gibt es auch für Le Bon die Gestalt des >Führers «, doch anders als bei Freud zeichnet sich dieser nicht durch die >Entschiedenheit der Gedanken oder geistige Potenz aus, sondern gerade dadurch, dass er sich den Eigenschaften und der Irrationalität der >Masse< anpasst.

»Meistens sind die Führer keine Denker, sondern Männer der Tat. Sie haben wenig Scharfblick und könnten auch nicht anders sein, da der Scharfblick im allgemeinen zu Zweifel und Untätigkeit führt. Man findet sie namentlich unter den Nervösen, Reizbaren, Halbverrückten, die sich an der Grenze des Irrsinns finden.« (Ebd.: 83)

Sieht Freud in der »Wendung von der Mutter zum Vater [...] einen Sieg der Geistigkeit über die Sinnlichkeit, also einen Kulturfortschritt« (Freud 1952: 221), so verkehrt sich diese Blickrichtung bei Le Bon in das genaue Gegenteil:

»Ist es zu bedauern, dass die Massen nie von der Vernunft geleitet werden? Wir wagen es nicht zu behaupten. Der menschlichen Vernunft wäre es wahrscheinlich nicht gelungen, die Menschheit mit derselben Glut und Kühnheit die Bahnen der Kultur zu führen, zu der ihre Trugbilder sie fortgerissen haben. Die Trugbilder waren Erzeugnisse des Unbewußten, von dem wir geleitet werden, und sie waren wahrscheinlich notwendig.«(Le Bon 1973: 82). 
Beide, Le Bon und Freud, haben unterschiedliche Strategien, die >Masse - die an sich eine tiefe Kränkung hegemonialer Männlichkeit darstellt - in ein Phänomen zu verwandeln, das einerseits Anziehungskraft ausübt, andererseits aber auch von ihnen beherrscht wird. Beide nehmen die Gleichsetzung von Masse mit Unbewusstem vor - bei Le Bon wird daraus eine Art von >Urnatur<-, und beide versetzen sich als Theoretiker in die Situation, dieses Unbewusste zu steuern: Le Bon, indem er sich zum Theoretiker der >Massenpsychologie< erklärt; Freud, indem er den >Kulturfortschritt< als die >Wendung von der Mutter zum Vater darstellt. Für beide ist das Unbewusste die Macht, die über das Denken und die Handlungen des Individuums bestimmt. »Das göttliche Recht der Massen wird das göttliche Recht der Könige ersetzen« (ebd.: 3). Auch Freud bedient sich ähnlicher Bilder, wenn er vom Unbewussten spricht. Beide Theoretiker bekennen sich also zur Anziehungskraft, die das Unbewusste ausübt. Aber indem sie das Unbewusste verweiblichen, distanzieren sie sich auch von dessen Macht und machen es zu einer >köstlichen Flüssigkeit<, in die man beliebig eintauchen, der man sich aber auch wieder entziehen kann.

\section{Krise hegemonialer Männlichkeit: Das Geld}

Auch auf dem Gebiet der Ökonomie ist ab dem 19. Jahrhundert ein Zusammengehen von Hysterie und Selbstermächtigung zu beobachten. Verfügte die Hysterie über das Geheimnis, wie Gott aus dem Nichts sichtbare Wirklichkeit zu erschaffen, so galt das auch für das Geld, das im 19. Jahrhundert zunehmend aus dem Nichts - dem reinen Zeichen - materielle Wirklichkeit $\mathrm{zu}$ erschaffen vermochte. In seinem 1900 veröffentlichten Werk »Philosophie des Geldes« schrieb Georg Simmel: »Man macht sich im allgemeinen selten klar, mit wie unglaublich wenig Substanz das Geld seine Dienste leistet « (Simmel 1907: 185). Im Geld habe die Fähigkeit, »das Körperhafte zum Gefäß des Geistigen zu machen« (ebd.: 99), ihre höchsten Triumphe gefeiert.

Diese Macht des Geldes einer creatio ex nihilo - einer Schöpfung aus dem Zeichen - war schon in der Entstehungsgeschichte des Geldes angelegt, auf die ich hier nicht eingehen werde. ${ }^{2}$ Es genügt festzuhalten, dass sich das Geld - nachdem es über die Jahrhunderte von der nominalen Münze, über Wechsel, Schecks und Papiergeld immer abstrakter geworden war - im späten 19. Jahrhundert endgültig von jeder Bindung an materielle Tauschwerte gelöst hat. Das Geld wurde mit dem Industriezeitalter $\mathrm{zu}$ einem reinen Zeichensystem - und eben das war die Grundlage seiner Macht wie der Grund für diese seltsame sexuelle Aufladung, die es erfuhr, auch in dieser Hinsicht an die Hysterie anknüpfend. Marx und

2| Um die Entstehungsgeschichte des Geldes zu begreifen, vgl. das großartige Werk des Altertumsforschers Bernhard Laum. 
Engels sprachen von der ungewöhnlichen Fähigkeit des Geldes, Begierden auszulösen. Emile Zola, der in seinem 1891 veröffentlichten Roman »Das Geld« den kometenhaften Aufstieg und dem ebenso kometenhaften Konkurs einer neuen Bank, La Banque Universelle, beschrieb, sagt von seinem Roman: »Die Familie, die ich mir vorgenommen habe, zu studieren, ist durch ein Überschäumen der Begierden gekennzeichnet« (Zola 1983: 306). Die Hauptfigur in Zolas Roman, Saccard, ersetzt die Leidenschaft der Sexualität durch die des Geldes:

»Wenn er, auf seinen neun Millionen hockend, Verlangen nach einer Frau verspürte, dachte er nur daran, eine sehr teure zu kaufen, um sie vor ganz Paris zu besitzen, so als würde er sich einen sehr großen Brillanten schenken, um ihn sich lediglich aus Eitelkeit an die Krawatte zu stecken.« (Zola 1983: 195)

An der Börse wird das Geld zur göttlichen Maschine des Lebens. Hatte Hobbes zweihundert Jahre vorher das Geld mit dem Blutkreislauf des Staates verglichen, so erklärt der Spekulant des 19. Jahrhunderts den Aktienhandel zur Pumpe, die den Blutkreislauf in Gang hält:

»Begreifen Sie doch, die Spekulation, das Börsenspiel ist das zentrale Räderwerk, das Herz eines so großen Geschäftes wie des unseren. Ja, das Herz, das das Blut mobilisiert, es überall in kleinen Bächen aufnimmt, sammelt, in Strömen in alle Richtungen zurückfließen läßt und einen ungeheuren Geldumlauf bewirkt, der das Leben der großen Geschäfte ausmacht.« (Ebd.: 86)

Das Geld, für das, wie im Islam, auch einst im christlichen Europa keine Zinsen genommen werden durften, weil - so schon Aristoteles - eine geschlechtslose Fortpflanzung und Vermehrung >widernatürlich<sei, dieses Geld wurde im 19. Jahrhundert nicht nur potent, sondern sogar zeugungsfähig.

Saccard zu seiner Geliebten Caroline:

»)Ja, die Spekulation. Warum haben Sie Angst vor diesem Wort? Die Spekulation gibt dem Leben doch erst seinen Reiz, sie ist das ewige Begehren, das zu kämpfen und zu leben zwingt. [...] Wenn ich einen Vergleich wagen dürfte, könnte ich Sie überzeugen.< [...] Er lachte wieder, denn er wollte ihr nicht zu nahe treten. Doch als ein Mann, der sich vor Frauen gerne brutal gibt, wagte er seinen Vergleich dann trotzdem.

>Schauen Sie, glauben Sie denn, daß man ohne [...] wie soll ich es sagen? ohne Ausschweifungen viele Kinder zeugen würde? Auf hundert ungezeugte Kinder kommt eines, das man zustande bringt. Das Übermaß bringt das Notwendige hervor, nicht wahr?« (Ebd.: 102)

So erstaunt es nicht, dass nicht nur die Künstler wie Flaubert, die Masse (in den Augen ihrer Theoretiker), sondern auch das Geld begann, sich hys- 
terische Eigenschaften zuzulegen. Ist es ihre Fähigkeit zur vollendeten, d.h. die Natur nachahmenden Simulation, die die Aufmerksamkeit des homo oeconomicus auf die Hysterie lenkte? Ist es die Macht des hysterischen Körpers, aus der Einbildung materielle Wirklichkeit zu erschaffen, die eine solche Faszination auf ihn ausübt, dass der Markt nach den Grundsätzen der Hysterie funktioniert? Der Börsen-Guru Andras Kostolany hat einmal gesagt: »Der Teufel hat die Börse erfunden, damit der Mensch glaubt, dass er, wie Gott, aus dem Nichts etwas erschaffen könne.« Dass seine alte Komplizin, die Hysterie, deren Symptome lange als Zeichen von Besessenheit gelesen wurden, bei der Erfindung der Börse Modell gestanden hat, dafür spricht einiges. Anfang des 20. Jahrhunderts begannen die großen hysterischen Anfälle aus den Krankenhäusern der Industrieländer zu verschwinden - ein Phänomen, für das es keine plausible Erklärung gab. Unter dem Aspekt einer Krise der Männlichkeit als Selbstermächtigungsstrategie bietet es sich jedoch an, dieses Phänomen als Börsengang der Hysterie zu lesen. In dem Maße, in dem die Hysterie als >Frauenkrankheit< aus den psychiatrischen Praxen verschwand, setzten ihre großen Auftritte auf dem Geldmarkt ein. Je abstrakter das Geld wurde, je mehr es sich in Papier und elektronisch zirkulierende Zeichen verwandelte, desto dramatischer wurden die hysterischen Inszenierungen der Börse. Mit ihren schlechten Launen und grandiosen Hochstimmungen, mit ihrer Fähigkeit, freudiges Herzklopfen oder Depression zu bereiten, mit ihren zerrütteten Nerven und ihren nervösen Spannungen, mit ihrer Suggestibilität und ihrer synchronen Erregungszuständen verwirklicht die Börse das, wofür die eingebildeten Symptome der Hysterika nur eine Verheißung waren. Sie schafft eine Konsensgemeinschaft in jeder Bedeutung des Wortes: eine Gemeinschaft der Sinne, in der sich die Anleger ebenso unberechenbar wie einmütig verhalten. Die Börse hat die Erbschaft der alten Hysterika angetreten, aber sie agiert nicht mehr im einzelnen Frauenleib, sondern - wie die Masse - im Kollektivkörper eines globalen Nervensystems: endlich ein echter globus hystericus, der seinen Namen verdient!3 Mit ihrer lustvollen Spekulation auf Wertpapiere, die durch keine Produktionsmittel gesichert sind, hält sie fest an den Prinzipien der alten Hysterie mit ihren Symptomen ohne organische Ursache. Nur die Hysterika und die Börse bringen es fertig, >ein bisschen schwanger< zu sein. Doch mit ihrer zuverlässigen Unberechenbarkeit, mit ihren Scheinschwangerschaften - bei der hohe Werte und ganze Märkte als Spekulationsblasen platzen - repräsentiert die Börse nicht etwa die alte >Krankheit<, sondern die perfekte Umsetzung aller Phantasien von der Macht der Ohnmacht. Deshalb ist die Börse zu dem Ort des modernen Konversionssymptoms geworden - und es geht dabei

3| Mit dem >globus hystericus < bezeichneten die Hysterienosologen eine Art von Erstickungsangst, die während eines hysterischen Anfalls entstehen konnte und durch den Eindruck - die Einbildung - vermittelt wurde, dass etwas im Halse stecken bleibt. 
auch um die geschlechtliche Konversion: Ein >männliches< Zeichen versieht sich mit der Simulationsfähigkeit einer >weiblichen Natur<.

Kurz und gut: Wenn wir von der Krise hegemonialer Männlichkeit sprechen, sollten wir keine der köstlichen Flüssigkeiten, in der die Männlichkeit ihren Untergang und ihre Wiedergeburt sucht, aus den Augen verlieren: weder die Tinte noch die Theorie von der spsychologischen Massen und schon gar nicht das Geld.

\section{Literatur}

Baudelaire, Charles (1932): Euvres complètes, texte établi et annoté par Y.-G. Le Dantec, Paris.

Braun, Christina von/Dietze, Gabriele (Hg.) (1999): Die Multiple Persönlichkeit. Krankheit Medium oder Metapher, Frankfurt a.M.: Neue Kritik.

Flaubert, Gustave: Brief an Louise Colet, 8./9. Mai 1852. In: Fuvres de Gustave Flaubert, hg. v. Maurice Nadeau, Lausanne 1964: Édition Rencontre.

Flaubert, Gustave: Brief an Louise Colet, 14. August 1853. In: Euvres de Gustave Flaubert, hg. v. Maurice Nadeau, Lausanne 1964: Édition Rencontre.

Flaubert, Gustave: Brief an Louise Colet, 31. August 1846. In: Correspondance, hg. v. Jean Bruneau, Paris 1973: Gallimard.

Flaubert, Gustave: Madame Bovary. In: (revidierten Übersetzung) Arthur Schurig, Frankfurt a.M. 1976: Insel Taschenbuch.

Freud, Sigmund (1952ff.): Der Mann Moses und die monotheistische Religion, Gesammelte Werke, Frankfurt a.M.: S. Fischer.

Fleischmann, Monika (1996): »Virtualität und Interaktivität als Medium. Die Auflösung des Raumes«. In: GMD-Spiegel 1, S. 42-44.

Grau, Oliver (2000): »Verlust der Zeugen. Das lebendige Werk«. In: GötzLothar Darsow (Hg.), Metamorphosen, Gedächtnismedien im Computerzeitalter, Stuttgart/Bad Cannstatt: Frommann-Holzboog, S. 101-121.

Hobbes, Thomas (1999): Leviathan. Oder Stoff, Form und Gewalt eines kirchlichen und bürgerlichen Staates, eingeleitet von Iring Fetscher (Hg.), Frankfurt a.M.: Suhrkamp.

Laum, Bernhard (1924): Heiliges Geld. Eine historische Untersuchung über den sakralen Ursprung des Geldes, Tübingen; neu aufgelegt: Berlin 2006: Semele.

Le Bon, Gustave (1973): Psychologie der Massen (1895), deutsch mit einer Einführung von Helmut Dingeldey, Stuttgart: Alfred Kröner.

Mallarmé, Stéphane (1945): Plainte d'automne (1867). In: Guvres complètes, Paris.

Mathes, Bettina (2006): Under Cover. Das Geschlecht in den Medien, Bielefeld: transcript. 
Matussek, Peter (2001): »Performing Memory. Kriterien für einen Vergleich analoger und digitaler Gedächtnistheater«. In: Paragrana. Zeitschrift für Historische Anthropologie 10, Heft 1, S. 291-320.

Marx, Karl (1844): Ökonomisch-philosophische Manuskripte Marx-Engels Werke, Erg.-Bd. 1, Berlin 1968: Dietz.

Roland, Ernst (2000): »Jenseits der Immersion - Der hybride Raum«. In: Computer als Medium - >Hyperkultur IX<, Lüneburg.

Sartre, Jean Paul (1977): Der Idiot der Familie, Gustave Flaubert 1821-1857, deutsch von Traugott König, Reinbek bei Hamburg: Rowohlt.

Schober, Rita (1983): Das Geld - geschichtliche Befunde und erfundene Geschichte, Nachwort zu: Emile Zola, Das Geld, übersetzt von Wolfgang Günther, Berlin: Rütten \& Loening.

Simmel, Georg (1907): Philosophie des Geldes, 2. vermehrte Auflage, Leipzig: Duncker und Humblot.

Starobinski, Jean (1991): Kleine Geschichte des Körpergefühls, mit einer Einleitung von Hans Robert Jauß, aus dem Französischen von Inga Pohlmann, Frankfurt a.M.: Fischer.

Turkle, Sherry (1996): »Sex, Lies and Avatars«. In: Wired, April.

Virchow, Rudolf (1907): Das Weib und die Zelle, zitiert nach Rosa Mayreder, Zur Kritik der Weiblichkeit, 2. Auflage, Jena/Leipzig: Diederichs. 



\section{"Sollte dieser Mann verunglückt sein?"}

\section{"Doktor Faust" zwischen Freud und Busoni}

\section{(Bruchstücke eines Dialogs aus dem Off ${ }^{1}$ )}

Bettina Mathes

für Robert Kelly

Sigmund Freud (1856-1939) und Ferruccio Busoni (1866-1924) waren Zeitgenossen. Und doch scheinen der Begründer der Psychoanalyse, dessen Schriften und therapeutische Praxis ihn auch außerhalb psychologischer Zirkel weltbekannt gemacht hatten, und der kontroverse Musiktheoretiker, Komponist und berühmteste Pianist seiner Zeit, der schon im Knabenalter als Wunderkind gefeiert wurde, in parallelen Welten gelebt zu haben. Nichts deutet auf eine Begegnung, einen Briefwechsel, das Interesse an der Arbeit oder der Person des anderen hin. Freud wird in Busonis Werken und seinem schriftlichem Nachlass nicht erwähnt, die vieldiskutierten Bücher des Wiener Psychoanalytikers haben in der reichen, gut bestückten Bibliothek des ungemein belesenen Büchernarren keinen Platz gefunden; der Katalog, den das Antiquariat Max Perl (1925) anlässlich der Versteigerung von Busonis Bibliothek erstellte, listet kein einziges Buch Freuds. Umgekehrt bietet sich das gleiche Bild: bislang gibt es keine Anzeichen, dass Sigmund Freud, wie Busoni ein Büchernarr und passionierter Briefschreiber, den deutsch-italienischen Musiker, der mehrfach für längere Zeit in Wien lebte, wahrgenommen hat (Davies/Fichtner 2006). - Es ist schwer vorstellbar: zwei der berühmtesten und kontroversesten Intellektuellen des frühen 20. Jahrhunderts, die beide enge Beziehungen zu Wien und Berlin unterhielten, sollten keine Notiz voneinander genommen haben? Vielleicht trügt der Schein. Vielleicht ist dieser >Mangek an Anerkennung nur Symptom einer umso intensiveren >verdeckten< Kommunikation, die jenseits der üblichen Rituale (Briefwechsel, persönliche Begegnung, Zitat, Kom-

1| Gekürzte Fassung des Vortragsmanuskripts. 
mentar, Kritik) vonstatten ging. Möglicherweise waren Freud und Busoni sich näher als der >Mangel an Beweisen< zugibt, kommunizierten sie über Kanäle und Mittelsmänner, die keine eindeutigen Spuren hinterlassen haben. Ein solcher Mittelsmann, der Freud und Busoni in mannigfacher Hinsicht nahe stand, ist Faust. Machen wir also die Probe aufs Exempel. Inszenieren wir einen Dialog zwischen Sigmund Freud und Ferruccio Busoni via Faust.

Sowohl Freud als auch Busoni hat der Fauststoff über Jahrzehnte nicht losgelassen. Für beide war Faust Identifikationsfigur, Alter Ego, Wegweiser und Ausdrucksmedium; ein Verführer, an dem sich die prekäre Grenze zwischen Kunst und Wissenschaft, Realität und Traum, Weiblichkeit und Männlichkeit bearbeiten ließ (Prokhoris 1995; Morabito 2005). Die enge Bindung der beiden Intellektuellen an das Faustische ist auch ihrer Umwelt nicht entgangen. Im Jahre 1930 wurde Freud mit dem GoethePreis der Stadt Frankfurt a.M. ausgezeichnet. Sechs Jahre zuvor hatte man Ferruccio Busonis frühen Tod, dem die Vollendung seines Lebenswerks, die Oper »Doktor Faust«, zum Opfer fiel, mit seiner »faustischen Natur« erklärt. In einer Tagebuchnotiz zu Busonis Beerdigung am 30. Juli 1924 vermerkt sein Schüler Gottfried Galston: »Busoni kommt mir - wenn es etwas geschwollen ausgedrückt sein soll - wie der Faust - der unermüdliche Sucher, Forscher und Grübler - der rastlose Geist vor, der seine Seele dem Teufel verschrieb. Alkohol heißt der Böse. Und jetzt muss die Rechnung bezahlt werden« (zit. Levitz 2005: 96).

Natürlich sind Freud und Busoni nicht die Einzigen, die sich zu Beginn des 20. Jahrhunderts in Faust wiedererkennen. In Filmen, Theaterstücken, Romanen und politischen Abhandlungen wird Faust für die Formulierung so unterschiedlicher politischer Ideologien wie Sozialismus, Kommunismus, Nationalsozialismus und für die Artikulation von Gesellschafts- und Geschlechterkritik in Anspruch genommen (Hedges 2005). Wenn diese Stimmen hier ausgeblendet werden, dann deshalb, weil im fiktiven Dialog zwischen Freud und Busoni zum einen Austauschbeziehungen zwischen Oper und Psychoanalyse hörbar werden, die in der nicht zu bestreitenden These, die Psychoanalyse habe der Oper den Todesstoß versetzt (Kienlechner 2001; Žižek/Dolar 2002), unterschlagen werden. Zum anderen macht der Dialog zwischen Freud und Busoni auf Korrespondenzen aufmerksam, die es erlauben, den Fragmentcharakter des »Doktor Faust« als Kommentar zum nicht zuletzt durch Freud beeinflussten zeitgenössischen Männlichkeitsdiskurs zu deuten. Als der Ältere soll Freud den Vortritt haben.

Freuds Schriften sind durchzogen von (nicht immer als solche kenntlich gemachten) Zitaten aus Goethes »Faust«. Zu jedem Thema drängt sich ihm ein Zitat aus dem »Faust « auf. Ob »Erinnerungs-Zwang « und »Zwangszitieren« (Marcuse 1956: 85), Tatsache ist, dass kein anderer Schriftsteller und kein anderes literarisches Werk auch nur annähernd so oft aufgerufen werden, wie Goethes Faust. Faust wird meist dann ins Spiel gebracht, wenn der Wissenschaftler Freud, der sich vorgenommen hatte, 
die Prinzipien des Unbewussten zu entdecken und dabei doch weitgehend auf die Erforschung seiner selbst angewiesen war, mit seinem >Latein $<$ am Ende ist. Goethes »Faust« muss als >Beweis herhalten, dass Freuds subjektiv, an sich selbst gewonnene Einsichten, seine Verwandlung von Träumen und Traumassoziationen in eine wissenschaftliche Theorie, Beachtung, ja Anerkennung verdienen (Prokhoris 1995: 2, 76-107). Der Faust eröffnet einen (Übertragungs-)Raum, in dem Freuds Selbst-Analyse, ein Abenteuer, für das er kein Vorbild hatte, stattfinden konnte. Freud braucht Faust, um die Übertragung in Gang zu setzen (ebd.: 83): Freud und Faust - die Urszene der Psychoanalyse. ${ }^{2}$ Indem Freud den Faust als Gegenüber aufruft, findet er einen Weg, in seiner Selbst-Analyse, in der er Analysand und Analytiker zugleich ist, eine therapeutische Beziehung zu etablieren. Faust besetzt dabei jene Stelle, die in der psychoanalytischen Praxis der Psychoanalytiker, d.h. Freud höchstselbst, einnehmen sollte. Die auf diesem Weg gefundene Übertragungsbeziehung ist dem faustischen Pakt nicht unähnlich. So wie Faust seine Seele an den Teufel verkauft, so hat der Analysand (gegen Geld) seine Seele dem Analytiker zu überlassen. In beiden Fällen geht es darum, die Wissbegierde, der faustische >Trieb < par excellence, zur Wiederherstellung der Lebensfreude einzusetzen (ebd.: 57).

Ferruccio Busoni hat dem Fauststoff sein Lebenswerk, die Oper »Doktor Faust « gewidmet, an der er von 1910 bis zu seinem Tode 1924 arbeitete. »Eine hervorragende, historische und sprichwörtliche Figur«, so Busoni, »die mit dem zauberischen und Unenträtselten zusammenhinge, zum Mittelpunkt meines Opernspiels zu machen, war in mir Wunsch und Prinzip« (Busoni 1983a: 135). Busoni hatte ursprünglich Leonardo da Vinci, den >italienischen Faust<, ins Auge gefasst - dem auch Freud eine Studie gewidmet hatte -, entschloss sich dann aber für den Fauststoff. »Ich war aber nun einmal der Faust-Idee verfallen, und sie beherrschte mich weiter« (ebd.: 136). Zunächst von der Perfektion und >Autorität< des Goethe'schen Faust eingeschüchtert, wählte Busoni schließlich das alte (1864 von dem Germanisten Karl Simrock herausgegebene und überarbeitete) Puppenspiel als Ausgangspunkt für seine Oper, zu der er auch das Libretto schrieb. »Wie in einem Fieber und in sechs Tagen schrieb ich den ersten Entwurf des >Doktor Faust< nieder, zwischen dem Ausbruche des Krieges und den Vorbereitungen zu einer Ozeanfahrt, gegen Ende 1914« (ebd.: 136f.). In diesem >Befreiungsakt< vom >Übervater< Goethe gelingt es Busoni, der Musik seiner Epoche eine selbstreflexive Bedeutungsebene zu erschließen und der Oper eine neue Richtung zu geben. »Busoni erfindet >Oper< neu: als subjektive, offene Form, die alle bis dato verbindlichen dramaturgischen Verabredungen im Bewusstseinsstrom ihres Autors aufzulösen bestrebt ist« (Morabito 2005: 81): ein Vorhaben, mindestens so riskant wie die Psychoanalyse. Im Nationalsozialismus als »undeutsch« verboten, erging es

2| Auf Beispiele muss hier aus Platzgründen verzichtet werden; vgl. Prokhoris 1995 . 
Busonis Tonkunst ähnlich wie Freuds Schriften, die 1933 auf dem Bebelplatz öffentlich verbrannt wurden und aus den Regalen der Bibliotheken und Buchhandlungen verschwanden.

Busoni hat den »Doktor Faust «als Fragment hinterlassen. Eine Schlüsselszene - die Beschwörung der Helena - und das Ende sind nicht auskomponiert. Da die Oper in der von Busoni hinterlassenen Form als »unspielbar« (Beaumont 1986: 196) angesehen wurde, machte sich sein Schüler Phillip Jarnach unmittelbar nach Busonis Ableben an die >Fertigstellung< der Partitur, damit die Oper wie vorgesehen 1925 in Dresden uraufgeführt werden konnte. Danach wurde es still um den »Doktor Faust«. Jarnachs Zusätze empfand man als unbefriedigend, und Busonis >Fragment< galt noch vier Jahrzehnte nach dem Ende des Zweiten Weltkrieges, bis zu Antony Beaumonts »Rekonstruktion« der >fehlenden< Takte im Jahre 1986, als unzumutbar. Erst jetzt sollte der »Doktor Faust« ein Publikum finden. Beaumonts »Rekonstruktion « ist in Wirklichkeit eine Uminterpretation; die ergänzten Takte machen aus Faust einen tragischen Helden von übermenschlicher Größe, sie stülpen dem »Doktor Faust« ein Deutungsmuster über, das Busoni gerade verweigert hatte. Aber muss man wirklich davon ausgehen, dass Busoni sein >Lebenswerk « nicht vollenden konnte? Oder liegt es nicht viel eher nahe, »innere Gründe« (Morabito 2005: 87) anzunehmen; Gründe, die sich aus der Struktur der Oper sowie aus Busonis Interpretation des Fauststoffs ableiten. Im Dialog mit Sigmund Freud sollen einige dieser »inneren Gründe« hervorgeholt werden. Eine >talking cure<? Warum nicht?

\section{"... was in dem wirklichen Leben nicht zu finden ist ...". Doktor Faust}

»Es gibt einzelne Männer«, so Freud in seiner Fragment gebliebenen Schrift »Das Unbehagen in der Kultur«, »denen sich die Verehrung ihrer Zeitgenossen nicht versagt, obwohl ihre Größe auf Eigenschaften und Leistungen beruht, die den Zielen und Idealen der Menge durchaus fremd sind. Man wird leicht annehmen wollen, daß es doch nur eine Minderzahl ist, welche diese großen Männer anerkennt, während die große Menge nichts von ihnen wissen will. Aber es dürfte nicht so einfach zugehen, dank den Unstimmigkeiten zwischen dem Denken und dem Handeln der Menschen und der Vielstimmigkeit ihrer Wunschregungen« (Freud 1981: 67). Es scheint, Faust war (und ist) einer dieser Männer. Schauen wir uns also seine Wunschregungen etwas genauer an.

Der »Doktor Faust« besteht aus einem Prolog, drei Hauptbildern, mehreren Vorspielen und Intermezzi sowie einem Epilog, die auf den ersten Blick nicht unbedingt einen inneren Zusammenhang erkennen lassen. Die Handlung beinhaltet Fausts Teufelsbeschwörung, den Paktabschluss 
zu Ostern, die Ermordung von Gretchens Bruder, eine Gauklerszene am Hof zu Parma, wo Faust die Herzogin ver- und entführt, ein Kind mit ihr zeugt, und sie verlässt. Danach treffen wir Faust in einer Wittenberger Schänke; schließlich überbringt ihm Mephistopheles sein totes Kind und versucht, Faust mit der Beschwörung des Bildes der Helena zu trösten (diese Szene im Libretto ist ohne Musik geblieben). Doch schon ist Fausts Zeit abgelaufen, er erhält die Nachricht, dass er noch vor Mitternacht sterben werde. Letzter Szenenwechsel: Ostern, eine nächtliche Straße in Fausts Heimatstadt. Eine Bettlerin übergibt dem verloren umherirrenden Faust seinen toten Sohn; in einem letzten Anflug von Größenwahn, versucht der Vater den toten Sohn wiederzubeleben (hier bricht die Musik ab). Der Versuch misslingt. Mephistopheles in Gestalt des Nachtwächters findet den zusammengebrochenen Faust auf der Straße. »Sollte dieser Mann verunglückt sein?«-mit dieser Frage schließt das Libretto.

Die Form des »Doktor Faust« legt eine Nähe zum Traum nahe. Das Fragmentarische, Assoziative und Sprunghafte des Librettos, der stilistische Eklektizismus und die Zitatförmigkeit (Unoriginalität) der Musik, die Verweigerung gegenüber den chronologischen Ansprüchen der Narration, das >fehlende< Ende, das Übergewicht der Vorspiele und Intermezzi gegenüber der Haupthandlung: All diese Merkmale erzeugen den Eindruck des >Inkohärenten «, >Provisorischen « und >Unwahrscheinlichen<; sie insistieren darauf, dass das, was wir auf der Bühne sehen und hören, nicht dem Modus des Wachzustands verpflichtet ist, in dem das Realitätsprinzip regiert, sondern dem Modus des Traums, in dem Ratio und Vernunft außer Kraft gesetzt sind. »Welche Darstellung erfahren im Traum«, fragt Freud, »das >wenn, weil, gleichwie, obgleich, entweder - oder < und alle anderen Konjunktionen, ohne die wir Satz und Rede nicht verstehen können? Man muss zunächst darauf antworten, der Traum hat für diese logischen Relationen unter den Traumgedanken keine Mittel der Darstellung zur Verfügung. Zumeist läßt er all diese Präpositionen [gemeint sind Konjunktionen, B.M.] unberücksichtigt« (Freud 1972: 310f.). »Ebensowenig kennen die Ubw-Vorgänge eine Rücksicht auf die Realität. Sie sind dem Lustprinzip unterworfen « (Freud 1980: 146), sie kümmern sich nicht um logische Unvereinbarkeiten oder Widersprüche. Originalität ist dem Traumgeschehen fremd; der Traum recycelt erlebte Eindrücke aus der nahen oder fernen Vergangenheit, spielt aber stets in der Gegenwart. Die Partitur des »Doktor Faust« besteht zu hundert Prozent aus wiederverwendetem Material, das Busoni ursprünglich nicht für den Faust komponiert hatte. »Es dürfte in der ganzen Partitur keinen einzigen Takt geben, der nicht aus bereits existierendem, vorformuliertem Material generiert wäre (Morabito 2005: 82). Warum auch nicht? »Die Vorgänge des Systems $U b w$ sind zeitlos«, antwortet Freud; »sie sind nicht zeitlich geordnet, werden durch die verlaufende Zeit nicht abgeändert, haben überhaupt keine Beziehung zur Zeit« (Freud 1980: 145f.). Und dieses System - so scheint Busoni zu erwidern - verlangt nicht nur eine neue Form der The- 
rapie (die talking cure), sondern auch einen »Entwurf einer neuen Ästhetik der Tonkunst« (Busoni 1983b).

Busoni unterscheidet zwischen Musik, die er als unverfälschte, aber nicht durch die Notation abbildbare Sprache beschreibt, und Tonkunst, die dem Notationssystem entspringt. Nach Busoni existiert die Musik vor und außerhalb der Festlegung durch die Notation. »Sie ist fast unkörperlich «, ist »tönende Luft«, »fast die Natur selbst«, von »schwebender, expansiver« Leichtigkeit, sie gleicht einem Kind, das von den Gesetzen des Zeichensystems noch nicht erfasst wurde (Busoni 1983b: 51). Wenn Busoni die Musik mit der Natur vergleicht, dann deshalb, weil sie nicht den Regeln der Notation gehorcht. Musik verweise nur auf sich selbst, die Tonkunst könne sich dem Wesen der Musik bestenfalls interpretierend annähern, abbilden könne sie es nicht. Musik und Tonkunst verhalten sich wie Mündlichkeit und Schriftlichkeit, Freud würde sagen, wie das Lustprinzip zum Realitätsprinzip. Gerade weil die Musik der Natur angehört, erscheint sie aus der Perspektive der Tonkunst und des Realitätsprinzips als >unnatürlich und >widersinnig<. Die neue Tonkunst hat sich dieser Differenz zwischen Musik und Kunst bewusst zu sein. Eben weil die Tonkunst abstrakt ist, soll sie nicht dazu gebraucht werden, die Natur zu beschreiben. Tonkunst, geschriebene Musik, ist für Busoni eine Möglichkeit, den Menschen mit den Mitteln der Logik (der Notation) eine Ahnung von einer Welt zu vermitteln, die sich den Gesetzen der Logik widersetzt. Aber nicht, um den Verstand zu verlieren, sondern um der Verführungsmacht jener Gestalten, die das musikalische Imaginäre bevölkern, widerstehen zu können.

Dies gilt insbesondere für die Oper, die Busoni als die »oberste [...] Form musikalischen Ausdrucks« (Busoni 1983c: 124) bezeichnete.

»Und lasset Tanz und Maskenspiel und Spuk mit eingeflochten sein, auf daß der Zuschauer der anmutigen Lüge auf jedem Schritt gewahr bleibe und nicht sich hingebe wie einem Erlebnis. So wie der Künstler, wo er rühren soll, nicht selber gerührt werden darf - soll er nicht die Herrschaft über seine Mittel im gegebenen Augenblicke einbüßen -, so darf auch der Zuschauer, will er die theatralische Wirkung kosten, diese niemals für die Wirklichkeit ansehen, soll nicht der künstlerische Genuß zur menschlichen Teilnahme herabsinken.« (Busoni 1980: 59)

Hellwach also soll das Publikum bleiben. Das klingt nach einer Vorwegnahme von Brechts »Verfremdungseffekt«, ist aber zunächst Freuds Beharren, der Traum bedürfe einer Deutung, näher verwandt. Ähnlich der Traumdeutung macht die Oper für Busoni »Unausgesprochenes beredsam«, hebt »menschliche Erregungen aus der Tiefe, um sie den Sinnen zuzuführen« (Busoni 1983b: ${ }_{56} 6$ ). Die Oper, so wie Busoni sie konzipiert, ist also nicht mit dem Unbewussten identisch, sondern sie erzählt von Träumen und stellt dem Publikum eine Möglichkeit zur Verfügung, mit dem Unbewussten (der Kultur) in Beziehung zu treten. Wie die auf der Couch 
des Psychoanalytikers erzählten Träume bedürfen auch die Träume auf der Opernbühne der Deutung. Oper heißt Arbeit - am Traum. Im »Doktor Faust«, so schreibt Busoni, dient die Musik nicht der Illustration des Librettos oder dessen, was man auf der Bühne sieht. Vielmehr nähert sie sich dem an, was »in der Seele des Menschen währenddessen vorgeht, das Unsichtbare und Unhörbare« (ebd.: 57). Die Oper lauscht auf die Stimme aus dem Off, und das hat Konsequenzen für die Bespielung der Bühne:

»Ich habe in dieser Partitur den ersten (nicht völlig durchgeführten) Versuch unternommen, einen Klanghorizont eine akustische Perspektive zu schaffen, indem ich häufig Gesungenes und Gespieltes >hinter der Bühne r ertönen lasse, wodurch das Ungeschaute durch das Gehörte enthüllt werden soll.« (Busoni 1983a: 141)

Auf diese Weise werde die »Phantasie des Zuschauers aufgefordert, an der Ergänzung zu arbeiten« (ebd.: 140). Klangräusche à la Richard Wagner lehnt Busoni ab. »Daß die sensuelle oder >sexuelle< Musik (welche in einer Art Hartnäckigkeit, im Klangrausche besteht und so auf der Nervenklaviatur spielt) hier nicht am Platze ist, geht aus dem Wesen dieser Kunst, das rein abstrakt ist, eigentlich von selbst hervor« (Busoni 1983c: 126f.).

Diese >Intellektualität< stieß nicht nur auf Zustimmung. Der völkisch gesinnte Komponist Hans Pfitzner kritisierte Busoni als »kühlen, fluktuierenden Geist«, dem die Kunst »mehr Sache des Intellekts denn des Herzens« sei. »Deutsche Musik«, so Pfitzner, der 1933 in die NSDAP eintrat, »ist nicht bloß Gehirnsport, sondern auch Herzenskunst; und wenn ein Geist unserer Großen uns erscheinen will, so soll man ihm geziemend begegnen, ihn >Fürst, Vater< nennen können« (Pfitzner 1926: 202, 223). Es ist dieser mit Nationalstolz gepaarte Verehrungsgestus, den Busoni in seiner Oper verweigert (Applegate/Potter 2002). »Gegen die deutsche Musik halte ich mancherlei Vorsicht für geboten«, wendet er, Nietzsche zitierend, ein (Busoni 1983c: 80). Und so inszeniert er den Faust nicht als Tragödie eines großen deutschen Geistes, sondern stellt den Stoff der Traumarbeit anheim. Freud sagte es bereits: »Der Traum ist eine Wunscherfüllung« (Freud 1972: 140). Nicht dass Faust in der Oper scheitert ist das Anstößige - Geschichten gescheiterter Männlichkeit gehören genauso zum Kanon wie Siegergeschichten. Anstößig ist, dass der Komponist und Librettist das Publikum in diese Geschichte des Scheiterns mit einbezieht. Statt die Sehnsucht, sich diesem großen Verführer hinzugeben, zu befriedigen, zwingt Busoni das Publikum, sich dieser Sehnsucht bewusst zu werden: in den entscheidenden Momenten, als die Erfüllung der Wünsche zum Greifen nahe scheint, bricht die Musik ab. Die langersehnte Vereinigung mit dem Bild der Helena und die Auferstehung des toten Sohnes bleibt Faust und dem Publikum verwehrt. (So wie die Analyse niemals wirklich beendet ist, hat auch die Oper kein wirkliches Ende.) 


\section{"Mache mich frei!"}

Dass die Oper männliche Sehnsüchte auf die Bühne bringt, die das Lustprinzip gegen das Realitätsprinzip ins Spiel bringen, zeigt sich vielleicht am deutlichsten daran, dass Faust den Pakt deshalb eingeht, um in den Besitz einer »Vollkommenheitsgewalt« zu gelangen, über die er allein verfügen kann, die ihn von den Disziplinierungen befreit, die die Kultur den Lüsten und Bedürfnissen des Einzelnen auferlegt. Busonis Faust ist kein Gelehrter, kein Akademiker oder Ingenieur. Er ist ein Sinnenmensch, der von einer Wunscherfüllung zur nächsten schreitet. Er philosophiert nicht, baut nicht, führt keine Experimente aus, ist kein >Alchemist<, der Homunkuli im Reagenzglas erzeugt. Arbeit gehört dem Realitätsprinzip an, das Faust als Instrument männlicher Selbstzeugung aus seinem Leben vor dem Teufelspakt gut kennt: »Welchem Wahn gab ich mich hin«, bemerkt er in einem hellsichtigen Moment des Zweifels, kurz bevor er den Handel mit dem Teufel besiegelt, »Arbeit, heilende Welle, in dir bade ich mich rein « (Busoni 1980: 53). Oder sollte sich hier bereits eine ganz andere Arbeit ankündigen? Ist es die Traumarbeit, von der Busoni sich für Faust sowohl Heilung als auch Reinigung erwartet? Die heilende Welle - Symbol des Unbewussten und des Weiblichen. »Beschaffe mir für meines Lebens Rest die unbedingte Erfüllung jeden Wunsches, laß mich die Welt umfassen, den Osten und den Süden, die mich rufen « (ebd.: 57), verlangt Faust von Mephistopheles. Es sind die >weiblichen< Regionen, zu denen Faust sich hingezogen fühlt. Faust will Glück und Freiheit: »auf daß ich glücklich werde wie kein Anderer! ... Mache mich frei!« gebietet er seinem Geist, als er den Pakt am Ostersonntag unterzeichnet. Man kann es nicht oft genug wiederholen: »Der Traum ist eine Wunscherfüllung«.

»Es klingt nicht nur wie ein Märchen, es ist direkt die Erfüllung aller - nein, der meisten - Märchenwünsche, was der Mensch durch seine Wissenschaft und Technik auf dieser Erde hergestellt hat [...] Im Interesse unserer Untersuchung wollen wir aber auch nicht vergessen, daß der heutige Mensch sich in seiner Gottähnlichkeit nicht glücklich fühlt.« (Freud 1981: 87)

Der Widerspruch zwischen individuellen und gesellschaftlichen Glücksvorstellungen ist das große Thema, dem Freud sich in »Das Unbehagen in der Kultur« widmete. Warum ist der Mensch unglücklich? Weil die durch Wissenschaft und Technik erlangte Gottähnlichkeit keinem Individuum, sondern der Gesellschaft als ganzer zukomme; ihre Aufrechterhaltung dem Individuum jedoch ein hohes Maß an Trieb- und Lustverzicht abfordere. »Diese Ersetzung der Macht des einzelnen durch die der Gemeinschaft ist der entscheidende kulturelle Schritt [...] Die individuelle Freiheit ist kein Kulturgut« (ebd.: 90). Im »Mache mich frei«, welches Faust dem Teufel entgegenschleudert, artikuliert sich der Wunsch nach der Befreiung von den Zwängen der Kultur, denen der männliche Körper und Geist als Re- 
präsentant der Kultur unterworfen ist. Freud hat die Verinnerlichung dieser Zwänge als Kastrationsdrohung beschrieben, die den Knaben dazu veranlasse, sich der väterlichen (gesellschaftlichen) Autorität unterzuordnen. Dagegen zielt das, wonach Faust strebt, »daß die Tat/zugleich ins Leben trete mit der Absicht« (Busoni 1980: 73), auf die Aufhebung dieser Zwänge. »Ich, Faust,/ein ewiger Wille«, ruft der Teufelsbündler in größenwahnsinniger Verblendung. An dieser Stelle lässt Busoni Faust in eine Ohnmacht fallen, aus der er bis zum Ende der Oper nicht mehr erwachen sollte. Der Wille - jene männlichste Form der Arbeit - wird von der Welle der Bewusstlosigkeit getragen. Die (nachösterliche) Traum-Reise kann beginnen.

\section{Verführer und Verführte(r)}

»Von Menschensehnsucht ward vor Euren Blicken/den Abend durch ein tönend Bild entrollt«, heißt es im Epilog des »Doktor Faust«. »Der Traum ist eine Wunscherfüllung«, hören wir Freud flüstern. Einige der Wünsche, die Busonis Oper erfüllt, kreisen um Verführen und Verführtwerden und sie bedienen sich weniger des Wortes, das dem wachen Verstand zugehört, sondern dem Bild, das, nach Freud, das Unbewusste beherrscht. »Nun denkt der Traum hauptsächlich in Bildern, und man kann beobachten, daß mit der Annäherung an den Schlaf in demselben Maße, in dem die gewollten Tätigkeiten sich erschwert zeigen, ungewollte Vorstellungen hervortreten, die alle in die Klasse der Bilder gehören« (Freud 1972: 73). Wer die Herstellung der Bilder kontrolliert, beherrscht die Kunst der Verführung. Faust will verführen und er tut dies, indem er Bilder in die Luft zaubert, die das Begehren der Menschen anreizt und befriedigt.

»Er naht. Mit ihm das Wunderbare./Wir werden staunen und erschauern./Ringsum verborgene Geister lauern,/umranken trügerisch das Wahre./Das läßt uns ahnen, wie das Nächtliche zu Tage tritt,/so daß wir stumm geworden sind und zittern./Er sieht gebieterisch und schön!/Das Ungewohnte ist an ihm natürlich./Säh er nicht stolz, wir hielten ihn für zierlich,/er schüchtert uns, doch müssen wir ihn ansehn.« (Busoni 1980: 78 )

Ein scharfer Verstand mag bestechend sein, aber er wird auch als kalt und leblos empfunden. Es stimmt, die Studenten verehren den Professor Wagner, der einst bei Faust als Famulus begonnen hatte, aber sie spüren auch: seine »Weisheit fühlt sich an so kalt« (ebd.: 90). Faust dagegen »brenzelt gleichsam von unheiligem Feuer« (ebd.: 77). Nicht umsonst projiziert Faust am Hof des Herzogs und der Herzogin von Parma zwei der berühmtesten Verführungsgeschichten in die Luft: die aus dem Alten Testament stammende Geschichte von Samson und Dalila und die Verkörperung der femme fatale schlechthin: Salomé, deren »Tanz der sieben Schleier« Maler, Schriftsteller und Musiker im 19. und 20. Jahrhundert 
inspirierte. In beiden Geschichten setzen Frauen ihre Verführungsmacht ein, um Männer zu töten, und in beiden Geschichten ist die Tötung jeweils als symbolische Kastration interpretiert worden. Dalila verführt den Helden Samson, schneidet ihm im Schlaf das Haar, in dem seine übermenschliche Manneskraft ihren Sitz hat, und liefert ihn auf diese Weise seinen Feinden aus. Busoni lässt den Chor singen: »Sie hebt die Schere -/das ist bekannt -/die listige Mähre -/Ha, wird er entmannt?« (ebd.: 80). Aber bevor es dazu kommen kann, erlöscht die Szene und die Herzogin verlangt ein neues Bild - Salomé tritt auf den Plan. »Auf einen Wink Salomés«, so erklärt Faust der Herzogin, »fällt das Haupt!« Aber die Herzogin will auch Johannes nicht sterben sehen, was Faust als Liebesbeweis interpretiert: »Also liebt ihr mich«, entgegnet er der aufgewühlten Herzogin. Im Traum wird die Kastrationsdrohung - das Disziplinierungsinstrument schlechthin - abgewehrt. Stattdessen verfällt die Herzogin dem Verführer: »Faust,/du, mein Faust!/ich komme!« strebt sie ihm in einer ergreifenden Arie entgegen, mit der Faust nicht zuletzt sich selbst verführt. Mehr noch als der Herzogin verfällt Faust dem Bild der Helena, die Mephistopheles für ihn heraufbeschwört: »Maßlos an Schönheit, unerschöpft an Liebe,/an Jugend unvergänglich, Helena« (ebd.: 86). Ihr Bild verkörpert all das, wonach Faust strebt: »Traum der Jugend,/Ziel des Weisen!/Reinster Schönheit/Bildvollendung:/Dich zu üben,/Dich zu preisen,/Dich zu lehren/War mir Sendung « (ebd.: 87). Helena verkörpert die Anziehungskraft des Weiblichen als männliche Projektion; sie ist der Phallus, den Faust haben will. »Nur Faust berührte je das Ideal!« (ebd.), frohlockt der Teufelsbündler, aber er hat sich zu früh gefreut, es gelingt ihm nicht, die Ersehnte zu fassen: »Als er sie endlich zu halten wähnt«, so die Regieanweisung, »zerfließt die Erscheinung ins Nichts« (ebd.). Busoni hat für diese Szene keine Musik gesetzt und bescherte dem Publikum ein erstes Erwachen.

»Und nun will ich Dir sofort das große Geheimnis anvertrauen«, schreibt Freud im September 1897, kurz nach dem Tod seines Vaters, an Fließ: »Ich glaube an meine Neurotica [der Ausdruck für die Verführungsneurose] nicht mehr« (Freud 1986: 283f.). »Ich war aber nun mal der Faszination dieser Faust-Idee verfallen und sie beherrschte mich weiter« (Busoni 1983a: 136), hört man Busoni entgegnen. Im Gegensatz zu Freud, der in der »Traumdeutung« die Thematik der Verführung ausspart, räumt Busoni der Verführung in seiner Oper breiten Raum ein. Die Verführungstheorie als der verdrängte Ursprung der Psychoanalyse kehrt im »Doktor Faust« - also in der Gestalt jener Figur, der Freud seine Entdeckung der Traumarbeit verdankt und die es ihm erlaubt hatte, die mögliche Verführung durch seinen eigenen Vater nicht thematisieren zu müssen - auf die Bühne zurück. Handelt es sich beim »Doktor Faust« um den Wiedergänger jenes männlichen Verführers, an dessen Existenz Freud während der Arbeit an der »Traumdeutung « nicht mehr glauben mochte? Betritt in Busonis Oper dieser verdrängte Verführer, dessen Platz der Doktor Sigmund Freud besetzt hatte, die Bühne? 


\section{Aus der Traum?}

Die mit dem Pakt erkaufte Zeit ist im Nu verronnen und Faust steht als Gescheiterter da. Sein Sohn ist tot, er selbst ist ein Außenseiter, der nichts Bleibendes hinterlässt. Sein Famulus hat es inzwischen zum Professor in Wittenberg gebracht, während Faust als »Phantast« daherkommt. Doch halt! - im Traum ist es nie zu spät, wer keine Zeit kennt, kennt auch kein Ende. Busoni hält eine weitere Option für Faust bereit. Als Faust (eher widerwillig) versucht, sich der göttlichen Autorität zu unterwerfen, um der Verdammnis zu entgehen, schaltet die Oper erneut in den Modus des Traums. Am Fuße eines Kruzifixes kniend, blickt Faust zum Gekreuzigten auf und in diesem Moment wird jener vom Sehnsuchtsbild der Helena überlagert. »Hilf, Sehnsucht, Urzeugerin, zwingende Kraft, dich ruf ich an zu höchstem Tun« (Busoni 198: 133). Im anschließenden Schlussmonolog erleben wir einen >verblendeten «, größenwahnsinnigen Faust, der sein totes Kind zu neuem Leben erwecken will, um damit selbst Unsterblichkeit zu erlangen. »So sei das Werk vollendet [...] dir vermach ich mein Leben:/es schreite von der erdeingebissenen Wurzel/meiner scheidenden Zeit/in die luftig knospende Blüte/deines werdenden Seins./So wirk ich weiter in dir,/und zeuge fort/und grabe tiefer und tiefer/die Spur meines Wesens/bis an das Ende des Triebes [...] Ich Faust,/ein ewiger Wille!« (Ebd.: 135) Mit diesen Worten stirbt Faust.

Busoni hat für diese Allmachtsphantasie keine Musik gefunden, und damit alle späteren Interpreten (und Zuhörer) dazu gezwungen, ihren eigenen Standpunkt gegenüber Fausts Verführungskünsten zu erarbeiten. Die Regieanweisungen sehen vor, dass dort, wo das tote Kind gelegen hatte, »ein nackter, halbwüchsiger Jüngling aufgestiegen [ist], einen blühenden Zweig in der Rechten « (ebd.: 135). Dies ist gewiss das Ende der Ostergeschichte. Aber es ist nicht das Ende der Oper. Ein letztes Mal lässt Busoni Mephistopheles in Gestalt eines Wachmanns auftreten. Als dieser Fausts reglosen Körper auf der Straße findet, fragt er: »Sollte dieser Mann verunglückt sein?« (Busoni 1980: 136). Mit dieser Frage endet die Oper (in Busonis Fassung). Offen bleibt damit, ob Faust den Jüngling reanimiert hat. Und offen bleibt auch, ob Faust tatsächlich jener ewige Wille ist, als der er sich phantasiert.

Der Wachmann, der nach Fausts Tod den neuen Tag ankündigt, reißt die Zuschauer und Zuhörer gleichsam zu früh aus dem Schlaf. »Der innerlichen Logik gehorchend«, schreibt Busoni an seine Frau Gerda,

»ist dieser Schluß unvermeidlich. Dieser Mann ist weise genug, um eigene Gesetze haben zu dürfen; aber er hat seine Weisheit vergeblich gebraucht: Er ist mehrerer Morde schuldig und eigentlich keiner guten That verdienstlich. Überdies ist der Teufel als Nachtwächter vom Bösen sehr entfernt und ins Alltäglich-Menschliche gerückt, so daß die Situation kaum mehr symbolisch ist. [...] Heute morgen wachte ich auf, als der Sonnenball aus dem Wasser stieg gerade gegenüber meinem Bett.« (Zit. Morabito 2005: 90) 
Man kann dies sicherlich als frustrierenden Mangel empfinden; zugleich aber ruft dieses plötzliche Aufwachen dem Zuschauer in Erinnerung, dass Traum und Wachen, Lustprinzip und Realitätsprinzip zwei verschiedene Wahrnehmungszustände sind, die im Falle der faustischen Verführungskunst besser nicht zur Deckung gebracht werden sollten. Dass das Aufwachen vom Publikum als unangenehm empfunden wird, zeigt nicht zuletzt die Rezeptionsgeschichte der Oper.

Lassen wir Freud noch einen letzten Gedanken vorbringen. »Es ist gewiss verlockend für den jungen und eifrigen Psychoanalytiker, daß er viel von der eigenen Individualität einsetze, um den Patienten mit sich fortzureißen und ihm im Schwung über die Schranken seiner engen Persönlichkeit zu heben « (Freud 1994: 175, 177). Aber dieser »Verlockung « dürfe nicht nachgegeben werden: Der Analytiker müsse eine gewisse »Gefühlskälte« an den Tag legen, denn nur so werde er »befähigt, aus den ihm mitgeteilten Abkömmlingen des Unbewußten, dieses Unbewußte, welches die Einfälle des Kranken determiniert hat, wiederherzustellen« (ebd.: 175f.). Busoni scheint geahnt zu haben, dass dies auch für den Tonkünstler gilt. Tatsächlich weisen Busonis Biographen immer wieder mit einer gewissen Enttäuschung darauf hin, dass Busoni, der unbestritten größte Pianist seiner Zeit, mit dem Publikum nicht >warm < wurde, die Zuhörer auf Distanz zu seiner Person hielt. Busoni lag wenig daran, sein Publikum durch sein Spiel zu verführen. Sein Biograph Hans H. Stuckenschmidt, der Busoni persönlich kannte, beschreibt ihn als »den widerwilligen Virtuoso«:

»Seine Kunst war auf zu hohem intellektuellen Niveau. Am Flügel schien er zurückgezogen, beinahe abwesend. Sein Gesicht zeigte keinerlei Anzeichen [...] der enormen kreativen Energie, die jedes Detail seines Spiels antrieb. Wie eine schöne Marmorstatue [...] sogar seine Hände bewegten sich nur minimal - schien er das Sprachrohr jenes Geistes, den er aus den Tasten aufsteigen ließ.« (Stuckenschmidt 1970: 67$)^{3}$

Trotz der Vergleiche, die seine Schüler und Freunde nach seinem Tod anstellten, als Pianist war Busoni keine Faustgestalt. Und auch als Komponist besteht er darauf, sich nicht zum Erfüllungsgehilfen des faustischen Strebens zu machen. Fausts grandiosem Selbstbild - »Ich Faust,/ein ewiger Wille« - folgt Busoni nicht. Angezeigt wird diese Verweigerung nicht nur in der unvollendeten Partitur, die Fausts Größenwahn buchstäblich ins Leere laufen lässt, sondern auch in Mephistopheles< trockener Frage: Sollte dieser Mann verunglückt sein?

Im »Doktor Faust« wird mithin nicht die schwache, scheiternde und >weibliche<Seite der Männlichkeit dargestellt, wie sie etwa zeitgleich im Diskurs der Décadence oder im modernen Roman betont wird. Vielmehr arbeitet die Oper einige der machtvollsten (und höchst attraktiven)

3| Übersetzung Bettina Mathes. 
Wunschregungen heraus, die sich hinter dem Bild des tragischen Helden verbergen. Der »Doktor Faust« verweigert bewusst die Ansprüche der Narration und bringt so etwas vom Unbewussten der zeitgenössischen Männlichkeitskonstrukte zum Vorschein. Mit Bezug auf Freud heißt das: der Verführer ist tatsächlich keine reale Person, er ist ein Mannsbild, das im deutschsprachigen Raum auf den Namen Faust hört. Ein Verführer, von dem nicht nur einzelne Männer, sondern eine ganze Nation träumt. Hat man die fiktionale, einer kulturellen Sehnsucht folgende >Natur faustischer Männlichkeit akzeptiert, besteht kein Grund, Faust in die Verdammnis zu stürzen. »Sollte dieser Mann verunglückt sein?« fragt der Nachtwächter und Sigmund Freud scheint zu sekundieren, »Die Absicht, daß der Mensch glücklich sei, ist im Plan der Schöpfung nicht enthalten« (Freud 1981: 75).

»Sollte dieser Mann verunglückt sein?« - Warum eigentlich nicht?

\section{Literatur}

Antiquariat Max Perl (1925): Bibliothek Ferruccio Busoni, Berlin: Max Perl. Applegate, Cecilia/Potter, Pamela (Hg.) (2002): Music and German National Identity, Chicago: University of Chicago Press.

Beaumont, Antony (1986): »Busoni's >Doktor Faust<: A Reconstruction and Its Problems«. In: The Musical Times 127 (1718), S. 196-199.

Busoni, Ferruccio (1983a): »Über die Partitur des >Doktor Faust««. In: Von der Macht der Töne. Ausgewählte Schriften, Leipzig: Reclam, S. 135-142.

Busoni, Ferruccio (1983b): »Entwurf einer neuen Ästhetik der Tonkunst (1907/1916)«. In: Von der Macht der Töne. Ausgewählte Schriften, Leipzig: Reclam, S. 47-82.

Busoni, Ferruccio (1983c): »Über die Möglichkeiten der Oper (1921)«. In: Von der Macht der Töne. Ausgewählte Schriften, Leipzig: Reclam, S. 121134 .

Busoni, Ferruccio (1980): Doktor Faust. Dichtung für Musik, Programmheft der Oper Frankfurt, Frankfurt a.M..

Davies, Keith J./Fichtner, Gerhard (Hg.) (2006): Freud's Library: a comprehensive Catalogue, London/Tübingen: The Freud Museum/Edition Diskord.

Freud, Sigmund (1972): Die Traumdeutung, Frankfurt a.M.: Fischer.

Freud, Sigmund (1980): »Das Unbewusste (1915)«. In: Studienausgabe, Bd. III, Psychologie des Unbewußten, Frankfurt a.M., S. 119-161.

Freud, Sigmund (1981): »Das Unbehagen in der Kultur (1938)«. In: Abriss der Psychoanalyse. Das Unbehagen in der Kultur, Frankfurt a.M.: FischerTaschenbuch-Verlag, S. 63-129.

Freud, Sigmund (1986): Briefe an Wilhelm Fließ 1887-1904, hg. von J.F. Masson, Frankfurt a.M.: S. Fischer. 
Freud, Sigmund (1994): »Ratschläge für den Arzt bei der psychoanalytischen Behandlung [1912]«. In: Schriften zur Behandlungstechnik, Frankfurt a.M.: S. Fischer, S. 169-180.

Hedges, Inez (2005): Framing Faust: twentieth-century cultural struggles, Carbondale, Ill.: Southern Illinois University Press.

Kienlechner, Sabina (2001): »Tonlagen der Leidenschaft. Musik und Psychoanalyse oder Die Anatomie ist das Schicksal«. In: Lettre International 52/1, S. 95-100.

Levitz, Tamara (2005): »Der Invalide und seine Entourage«. In: Staatsoper Stuttgart (Hg.), Ferrucio Busoni: Doktor Faust, Stuttgart: Staatsoper Stuttgart, S. 92-99.

Marcuse, Herbert (1956): »Die deutsche Literatur im Werke Freuds«. In: The German Quarterly 29 (2), S. 85-96.

Morabito, Sergio (2005): »Selbstporträt des Künstlers als Doktor Faust«. In: Staatsoper Stuttgart (Hg.), Ferrucio Busoni: Doktor Faust, Stuttgart: Staatsoper Stuttgart, S. 81-91.

Prokhoris, Sabine (1995): The witch's kitchen: Freud, Faust, and the transference, Übers. G.M. Goshgarian, Ithaca/London: Cornell University Press.

Stuckenschmidt, Hans H. (1970): Ferruccio Busoni: Chronicle of a European, übers. v. Sandra Morris, New York: St. Martin's Press.

ŽIžEK, Slavoj/Dolar, Mladen (2002): Opera's second death, New York u.a.: Routledge. 


\section{The queerest cut of all: Freud, Beschneidung,}

\section{Homosexualität und maskulines Judentum}

JAy Geller

1909 begründete Sigmund Freud die erste psychoanalytische Zeitschrift, das »Jahrbuch für psychoanalytische und psychopathologische Forschungen«, mit einer Fallstudie, die Freuds Ansicht nach erstmals den Beweis für die infantile Sexualität als »[konstitutionelles] Gemeingut aller Menschen « (Freud 1909a: 13) erbringt. ${ }^{1}$ In seiner »Analyse der Phobie eines fünfjährigen Knaben« beschreibt Freud den Beginn, Verlauf und die scheinbare Lösung der pathologischen Angst eines Jungen, »daß ihn auf der Gasse ein Pferd beißen werde« (ebd.: 26; Hervorhebung S.F.). Als Erklärung für die Phobie des kleinen Hans präsentiert Freud ebenfalls zum ersten Mal eine ausführliche Erörterung des Kastrationskomplexes und seiner Konsequenzen für die traumatische Grundierung der Geschlechtsdifferenz. Er erörtert dabei die angsterzeugende Phantasie, die den anatomischen Unterschied der Geschlechter damit erklärt, dass der Penis einiger Kinder abgetrennt oder >ganz klein < [so der kleine Hans] ist.

Schon früh in der Fallgeschichte, als Freud die nachträgliche Wirkung einer Kastrationsdrohung als eine wahrscheinliche Ursache für die Symptome des kleinen Hans darstellt, fügt er seinen Ausführungen eine außergewöhnliche Fußnote an:

»Ich kann den Zusammenhang nicht so weit unterbrechen, um darzutun, wieviel Typisches an diesen unbewußten Gedankengängen ist, die ich hier dem kleinen Hans zumute. Der Kastrationskomplex ist die tiefste unbewußte Wurzel des Antisemitismus, denn schon in der Kinderstube hört der Knabe, daß dem Juden etwas am Penis - er meint ein Stück des Penis - abgeschnitten werde, und dies gibt ihm

1| So führt z.B. der Schriftsteller und Philosoph der deutschen Jugendbewegung Hans Blüher (1918: 125f.) den Fall des kleinen Hans als einen Beweistext für die sexuelle Ätiologie der Neurose (ebenso wie die infantile Sexualität) an. 
das Recht, den Juden zu verachten. Auch die Überhebung über das Weib hat keine stärkere unbewußte Wurzel. Weininger, jener hochbegabte und sexuell gestörte junge Philosoph, der nach seinem merkwürdigen Buche Geschlecht und Charakter (1903) sein Leben durch Selbstmord beendigte, hat in einem vielbemerkten Kapitel den Juden und das Weib mit der gleichen Feindschaft bedacht und mit den nämlichen Schmähungen überhäuft. Weininger stand als Neurotiker völlig unter der Herrschaft infantiler Komplexe; die Beziehung zum Kastrationskomplex ist das dem Juden und dem Weibe dort Gemeinsame.« (Freud 1909: 36 Anm. 2)

Diese Anmerkung ist mehr als nur ein psychoanalytischer Gemeinplatz über die symbolische Beziehung zwischen Beschneidung und Kastration. Indem sie Gender, Sexualität und Judentum an das Wirken des Unbewußten, der Neurose und den Kastrationskomplex anbindet, stellt sie eine Verdichtung zentraler Aspekte von Freuds zahlreichen Identitäts- und Theoriekonstruktionen (vgl. u.a. Gilman 1993; Boyarin 1997) dar. Noch bemerkenswerter als die Bedeutung dieser Notiz für psychoanalytische Theorie ist jedoch die Tatsache, dass sie überhaupt erscheint. Der Freud'sche Text beinhaltet keinerlei Hinweise auf Beschneidung oder andere sjüdische Angelegenheiten`, die die Einfügung dieser Fußnote erklären könnten. Zu keinem Zeitpunkt verweist Freud darauf, dass der kleine Hans, im wirklichen Leben Herbert Graf, Sohn des Musikologen Max Graf und Olga Honig, jüdisch gewesen ist. Warum unterbricht er also seine Erörterung des Falls mit einer Bemerkung, die eher als Demonstration von etwas un»typischen an diesen unbewußten Gedankengängen« erscheint? Warum wird hier etwas aufgedeckt, das im wahrsten Sinne des Wortes - es handelt sich um eine Fußnote - unter dem Textkörper liegt? Handelt es sich bei der Fußnote um eine Freud'schen Fehlleistung? Falls dies der Fall ist, über was genau ist Freud ungewollt gestolpert?

Um die Verdichtungen in Freuds ursprünglicher Fußnote $\mathrm{zu}$ entschlüsseln und dieses Rätsel zu lösen, soll die Notiz mit Freuds Vermeidung expliziter jüdischer Referenzen bzw. Selbstreferenzen in seinen zwischen $1905^{2}$ und 1916 veröffentlichten Schriften, ebenso jedoch mit seiner Verbindung zur Familie Graf, verschiedenen Argumenten aus der Fallgeschichte sowie dem nicht unwichtigen Detail der (Nicht-)Beschneidung von Herbert Graf in Beziehung gesetzt werden. Im Unterschied zu den Analysen von Gilman (1993) und Boyarin (1997) wird es zu zeigen sein, in welcher Weise der Antisemitismus als eine gelebte Realität für Freud und die Beschneidung als ein Dispositiv (Deleuze 2006) bzw. Apparat der Wis-

2| Außer zwei nur mit »Freud« unterschriebenen kurzen Notizen in 1911, »Die Bedeutung der Vokalfolge« und »Groß ist die Diana der Epheser«, und dem anonymen Aufsatz, »Der Moses der Michelangelo«, 1914. Obwohl viele Judenwitze in der Schrift »Der Witz und seine Beziehung zum Unbewußten« (Freud 1905) angeführt werden, hat sich Freud hier im Gegensatz zu früheren Schriften (z.B. Freud 1900) nicht als Jude zu erkennen gegeben. 
sens- und Identitätsproduktion in Bezug auf das Judentum sich mit einer durch Assimilation aufgezwungenen Homophobie und einer gleichermaßen auferlegten hegemonialen Männlichkeit verbinden. Diese Verbindung führt zur Konstruktion des psychoanalytischen Modells individueller Entwicklung wie zum Ideal des kämpfenden Juden - des maskulinen Judentums 3 (Geller 2007).

\section{Schweigen in der Judenschule}

Die vielleicht offensichtlichste Auffälligkeit dieser Fußnote ist die Tatsache, dass sie Juden ausdrücklich beim Namen nennt. Zwischen 1905 und 1916, den entscheidenden Jahren seines Bemühens um eine öffentliche Anerkennung und wissenschaftliche Legitimierung der psychoanalytischen Bewegung, vermied Freud in seinen analytischen Schriften - mit dieser einzigen Ausnahme - explizite Verweise auf das Judentum, während die Korrespondenz mit seinen jüdischen Anhängern durchzogen ist von der Sorge, dass die Praktiker, Patienten und Topoi der Bewegung als spezifisch jüdisch wahrgenommen werden könnten. In der Zeit der Analyse des kleinen Hans schreibt Freud seinem jüdischen Kollegen Karl Abraham über die Bedeutung von Jungs Verbindung mit der Wiener Psychoanalytischen Gesellschaft: »Ich hätte beinahe gesagt, dass erst sein Auftreten die Psychoanalyse der Gefahr entzogen hat, eine jüdisch nationale Angelegenheit zu werden« (Freud/Abraham: 34 [3.5.1908]). Die Bedeutung Jungs im Sinne einer >nicht-jüdischen Tarnung und eines Bollwerks gegenüber den antisemitischen Anfeindungen der Psychoanalyse unterstreicht Freud in einem weiteren Brief an Abraham, den er im gleichen Jahr, kurz vor der Publikation seiner Fallstudie schreibt. Besorgt darüber, dass seine Ausführungen zur kindlichen Sexualität in der »Analyse« einen Aufruhr erzeugen könnten, kommentiert Freud trocken: »Wieder einige deutsche Ideale in Gefahr! Unsere arischen Genossen sind uns doch ganz unentbehrlich, sonst verfiele die Psychoanalyse dem Antisemitismus« (Freud/Abraham: $64[26.12 .1908])$.

Über die bloße Vermeidung jüdischer Themen hinausgehend, scheint es, dass Freud in diesem Zeitraum bewusst Fallmaterial unbeachtet ließ und rhetorische Ausweichmanöver verwendete, um seine eigene jüdische Identität und die seiner Patienten zu verbergen und die Verbreitung anti-jüdischer Stereotypen zu vermeiden. So sind beispielsweise die Originalnotizen zum Fall vom »Rattenmann«, der heute als der jüdische Rechtsanwalt Ernst Lanzer bekannt ist, erhalten. Im Unterschied zu Freuds publizierten

3। Freuds fetischiertes Ideal verleugnet sowohl Herberts Performanz von Männlichkeit (insbesondere in Bezug auf die Mutter), von der sein Vater berichtet, als auch die kulturellen Repräsentationen jüdischer Maskulinität, die zugleich als weniger >virik und >sexualisiert< entworfen bzw. stigmatisiert wird. 
»Bemerkungen über einen Fall von Zwangsneurose « (1909b) sind diese Notizen durchsetzt mit jiddischen Ausdrücken (von Schügsenen [nicht-jüdische Mädchen] über Miessnik [schauderhafter, hässlicher Kerl] und gekoschiert zu Parch [blöder Kerl] oder Chonte [Hure]). Zudem findet sich hier eine Erörterung von Lanzers sehr jüdischer Verlobten (es gibt zahlreiche weitere Beispiele in diesem Fall und anderen; s. Freud 1907/08).

Freud verweist in dieser Periode allerdings einmal auf die Beschneidung, und zwar wiederum in einer Fußnote, die in seiner 1912/13 veröffentlichten Untersuchung zur Genese und Entwicklung von Religion, »Totem und Tabu«, erscheint, einer Untersuchung, die merkwürdigerweise direkte Bezüge auf das Judentum in Text und Anmerkungen vermeidet. Im Gegensatz zu späteren Darstellungen in »Der Mann Moses und die monotheistische Religion« führt Freud in seiner Erörterung der Transformation von einer Vater- zu einer Sohn-Religion die Entstehung des Christentums aus Kulten um jugendliche Gottheiten wie Attis und Adonis sowie auf die Konkurrenz mit dem persischen Mithras-Kult zurück. Weder das Judentum noch die jüdische Bevölkerung Palästinas werden erwähnt. Als einzige Anspielung auf jüdische rituelle Praktiken taucht eine verwirrende Fußnote im Zusammenhang mit dem Hinweis auf Attis' Tod durch Kastration auf, in der Freud einen Teil der eingangs zitierten Fußnote paraphrasiert: »Wenn unsere Kinder von der rituellen Beschneidung erfahren, stellen sie dieselbe der Kastration gleich « (Freud 1912/13: 436 Anm. 1). Allerdings wird die rituelle Beschneidung an dieser Stelle weder speziell an das Judentum gebunden, noch wird das Alter für die Operation angegeben. Im Folgenden lenkt Freud die Aufmerksamkeit der Leser weiter vom Judentum ab: »Die in der Urzeit und bei primitiven Völkern so häufige Beschneidung gehört dem Zeitpunkt der Männerweihe an, wo sie ihre Bedeutung finden muss, und ist erst sekundär in frühere Lebenszeiten zurück geschoben werden« (ebd.). Die Beschneidung als eine verbreitete Praktik und als Bedeutungsträger ist in keinem Fall bei den (ungenannten) Juden zu suchen. Alsdann fährt Freud fort, die Leser von jüdischen Praktiken wegzuführen, indem er das symbolische »Äquivalent der Kastration« von der Beschneidung auf das »Haarabschneiden und Zahnausschlagen« verlagert. Freud macht nunmehr »diese beiden Operationen « und nicht das Ritual der Beschneidung für die Kastrationsangst »unsere[r] Kinder« (ebd.) verantwortlich.

Was ist also das Motiv für die ungewöhnliche Anspielung auf die Beschneidung in der Fußnote zur »Analyse«? Möglicherweise besteht ein Zusammenhang durch (eine angebliche) Beschneidung definierte jüdischen Identität: nicht nur von Freuds Patient Herbert, sondern von zwei weiteren Personen, die durch jene Notiz geistern: Otto Weininger, der, wie die meisten von Freuds damaligen Lesern wussten, als Jude geboren und aufgewachsen war, und natürlich Freud selbst, der lange schon als Jude ausgemacht worden war. 


\section{"In [nur] acht Tagen vom Schwächling zum Mann “4}

In einem früheren Artikel, »The Godfather of Psychoanalysis« (Geller 1999) brachte ich die Fußnote mit einer Passage aus den Erinnerungen, die Herberts Vater nach Freuds Tod publizierte, in Verbindung:

»Als mein Sohn [1903] geboren wurde, fragte ich mich, ob es nicht besser wäre meinen Sohn im christlichen Glauben zu erziehen. Freud riet mir davon ab. >Wenn Du Deinen Sohn nicht als Juden aufwachsen lässt<, sagte er, wirst Du ihm eine Quelle der Kraft nehmen, die durch nichts anderes ersetzt werden kann. Er muss als Jude kämpfen, und Deine Aufgabe ist es, all die Energie in ihm zu entwickeln, die er für diesen Kampf brauchen wird. Nimm ihm diesen Vorteil nicht.« (Graf 1942: 473)

Während seines gesamten Lebens charakterisierte Freud das Schicksal eines Juden als einen virilen Kampf. So steht es in seiner »Selbstdarstellung«, so wiederholte er es in seiner Ansprache vor dem Wiener Verein B'nai B'rith: jüdisch zu sein, war »mir auf meinem schwierigen Lebensweg unerläßlich geworden [...] als Jude war ich dafür vorbereitet, in die Opposition zu sehen und auf das Einvernehmen mit der >kompakten Majorität< zu verzichten« (Freud 1926: 52).

In Freuds Darstellungen seiner Jugend wird das Jüdischsein als Männlichkeitstest beschrieben, der durch die antisemitische Mehrheit auferlegt wird. Dass Freuds Vater Jacob »nicht[s] Heldenhaftes« (Freud 1900: 208) vollbracht hatte, nachdem er als junger Mann von christlichen Rüpeln angegriffen worden war, ist - ebenso wie Freuds beschämte Reaktion angesichts der Unterwürfigkeit seines Vaters - aus der Perspektive der Genderforschung mittlerweile als Schlüsselereignis der jüdischen Identifizierung Freuds bestimmt worden. In den Briefen an seine Verlobte und spätere Frau Martha finden sich zahlreiche Episoden, in denen er oder andere jüdische Ärzte sich erfolgreich gegen antisemitische Übergriffe zur Wehr setzten und dabei sowohl ihre Ehre als auch die Rechtmäßigkeit ihrer Position verteidigten (s. Freud 1960: 92-94 [28.1.1884], 143f. [12.5.1885]). Die wohl anschaulichste Darstellung jüdischer Männlichkeit, die sich von nicht-jüdischer Feigheit absetzt, erscheint in den Erinnerungen von Freuds Sohn Martin an einen Sommerausflug 1901, etwa zwei Jahre vor der Geburt Herbert Grafs. Er beschreibt, wie sein Vater sich einer Menschenmenge entgegen stellte, die den Weg Martins und seines Bruder Oliver blockierte und beide mit antisemitischen Pöbeleien überschüttete:

»Vater, ohne die Spur eines Zögerns, sprang aus dem Boot und marschierte auf die feindliche Menge zu, wobei er immer schön in der Mitte der Straße blieb [...] zehn

4 | Deutsche Bearbeitung des Songtextes »In just [eight] days I can make you a man« aus The Rocky Horror Picture Show; www.rocky-horror-deutschland.de/ RHPSSongs/SONGS7d.HTM. 
Männer, bewaffnet mit Stöcken und Regenschirmen [und] die Frauen im Hintergrund, feuerten die Männer mit Rufen und Gesten an. In der Zwischenzeit, griff Vater seinen Stock schwingend die feindliche Menge an, die ihm nachgab und sich prompt verlief, womit ihm der Weg frei war.« (M. Freud 1958: 70f.)

Martin hätte keine »freudianischere« Darstellung einer geschlechtsspezifischen jüdischen Identität ausgewählt haben können, als das Bild des Juden Freud, der, die eigene, singulär phallische Maskulinität schwingend, seine polyphallischen, d.h. kastrierten Gegner überwindet. 5 Freuds Rat an Herberts Vater, seinen Sohn als Juden zu erziehen, ist daher mit dem Versprechen einer zwar schwierigen, aber am Ende unweigerlich erfolgreichen Entwicklung verbunden, die sich am bürgerlichen Ideal einer gesunden, virilen, heterosexuellen Männlichkeit des frühen 2o. Jahrhunderts orientiert.

Fast fünf Jahre nach Herberts Geburt erfährt Freud jedoch von Max Graf, dass dieser - entgegen seiner Prophezeiung - kein starkes, selbstbestimmtes Kind geworden, sondern dass der junge Knabe in die Fänge einer Phobie geraten war. Das Hauptproblem von Herberts Zustand scheint für Freud allerdings weniger in der - durch die Zähne oder den Penis eines Pferdes ausgelösten - Angst des Jungen zu liegen, sondern in dessen sexueller Orientierung. Anstatt des »prächtigen Jungen« (Freud 1907: 164) Herbert, eines »Muskeljuden« (Nordau) oder »kämpfenden Juden« (M. Freud 1967: 201), der bereit ist, ${ }^{6}$ es mit den Bedrohungen einer antisemitischen Welt aufzunehmen, und der bereits mehrere Beiträge zur psychoanalytischen Theoriebildung geleistet hatte - insbesondere in der Schrift »Über infantile Sexualtheorien « (Freud 1908; s. auch 1907), in der Freud die Theorie des sexuellen Unterschieds oder eher die Theorie der Abwesenheit des einzigen Unterschieds, der für Freud von Bedeutung ist,7 entwickelt und sich dabei auf Herbert bezieht, der »allen Menschen, auch den weiblichen Personen, einen Penis zusprach« (Freud 1908: 176, Hervorhebung S.F.; vgl. Freud 1909a: 95f. Anm. 3) -, sieht Freud sich nun mit dem kleinen Hans konfrontiert, einem neurotischen faygeleh, ${ }^{8}$ der sich fürchtet, in die bedrohliche Welt hinaus zu gehen.

5| Nach Freud (1922: 47) symbolisieren multiple Phalli oder phallische Bilder Kastration.

6| »Ich möchte ausdrücklich bestreiten, dass der kleine [Herbert] ein sinnliches oder gar ein pathologisch veranlagtes Kind sei«; Freud 1907: 164.

7| Freuds Privilegierung des Penis wird bereits in seiner Identifizierung von Hans' Terminus »Wiwimacher« als Penis offensichtlich: Silverman 1980; Glenn 1980.

8| Jiddisch: wörtlich - ein kleiner Vogel. Obwohl der Terminus als Kosename für kleine Kinder gebraucht wird, hat faygeleh die Konnotation eines verweichlichten bzw. effeminierten Homosexuellen. 
Für Freud ist jedes Kind zu einem bestimmten Zeitpunkt homosexuell (vgl. Freud 1909a: 95). Als Freud Hans' »ersten Zug von Homosexualität« entdeckt und auch hinzufügt »aber nicht den Letzten«, kommentiert er dies unbekümmert und mit väterlicher Ironie, die nicht zuletzt darauf zielt, seine nicht-jüdische Leserschaft an der Nase herumzuführen: »Unser kleiner Hans scheint wirklich ein Ausbund aller Schlechtigkeiten zu sein!« (Ebd.: 2of.). Gleichwohl ist es für Freud von Bedeutung, dass dieses Stadium überwunden wird. »Die weitere Entwicklung unseres kleinen Erotikers geht aber nicht zur Homosexualität, sondern zu einer energischen, sich polygam gebärdenden Männlichkeit« (ebd.: 96). Er wurde »ein rechter Mann« (ebd.: 22) und »ein kleiner Ödipus« (ebd.: 96; vgl. 86). Im Anschluss an diese, als neurotische Abweichung oder gar >perverses< Zwischenspiel abgewehrten homosexuellen Eskapaden, nimmt der kleine Hans also wieder die für ihn bestimmte Rolle ein: heroische Männlichkeit, die durch eine virile Heterosexualität gekennzeichnet ist. 9 Als Beleg hierfür verweist Freud auf Hans Polygamie und schreibt: »Das Sexualziel, das er bei seinen Gespielinnen verfolgte, bei ihnen zu schlafen [Hervorhebung S.F.], rührte bereits von der Mutter her; es ist in die Worte gefaßt, die es auch im reifen Leben beibehalten kann, wenngleich der Inhalt dieser Worte eine Bereicherung erfahren wird« (ebd.: 96).

Unglücklicherweise werden Freuds Schlussfolgerungen durch den Fall selbst widerlegt. Denn der kleine Hans verwendet die sexuell konnotierte Formulierung schlafen bei keineswegs in Bezug auf seine weiblichen Spielgefährten im Rahmen seiner weiteren Entwicklung. Vielmehr verwendet er sie in Bezug auf die Phase vor Beginn seiner Phobie, in der Hans, wie Freud festgestellt hatte, »homosexuellen Anwandlungen« (ebd.: 22) unterworfen war. Die Formulierung (d.i. schlafen bei) taucht lediglich gegen Ende der Fallgeschichte auf, und zu diesem Zeitpunkt schlafen sowohl Jungen als auch Mädchen bei ihm. So teilt Hans seinem Vater mit: »Bei mir hab' ich sie schlafen lassen, Mädeln und Buben« (ebd.: 83). Als Antwort auf die Frage seines Vaters, woher diese Kinder kamen, offenbart Hans seinen Wunsch bzw. seine Phantasie, Mutter zu sein und zu gebären:

»Ich: »Aber von wem hast du dir gedacht, daß du die Kinder bekommen hast?» Hans: »No, von mir« [Hervorhebung S.F.] ...

Ich: »Wenn du am Topf gesessen bist und ein Lumpf gekommen ist, hast du dir gedacht, daß du ein Kind bekommst?«

Hans: (lachend): »Ja ...« (Ebd.: 84)

9| In »Eine Kindheitserinnerung des Leonardo da Vinci« schreibt Freud: »Sieht es doch fast so aus, als ob das Vorhandensein eines starken Vaters dem Sohne die richtige Entscheidung in der Objektwahl für das entgegengesetzte Geschlecht versichern würde« (1910: 125). 
Einen Tag vor diesem Gespräch hatte Hans schon einmal seinen Wunsch, Mutter zu sein bzw. zu werden, ausgedrückt: »bis ich verheiratet sein werde, werde ich nur ein [Kind] kriegen, wenn ich will, wenn ich mit der Mammi verheiratet sein werde, und wenn ich kein Kind will, will der liebe Gott auch nicht, wenn ich geheiratet hab'« (ebd.: 82). In Vorahnung der nachfolgenden Offenbarungen aus Hans' Phantasiewelt fühlte Freud sich offenbar genötigt, eine beruhigende Randbemerkung in seinen Fußnoten anzubringen:

»Es ist keine Nötigung, hier bei Hans einen femininen Zug von Sehnsucht nach Kinderhaben anzunehmen. Da er seine beseligenden Erlebnisse als Kind bei der Mutter gehabt hat, wiederholt er diese nun in aktiver Rolle, wobei er selbst die Mutter spielen muß.« (Ebd.: 82 Anm. 1)

Als ob dieser präventive Kommentar nicht ausreichte, um die Leser vom »femininen Zug« bei Hans abzulenken, fügt Freud eine weitere Diskussion der Phantasien von Hans an, um diese Angelegenheit endgültig aus der Welt zu schaffen. Aus Hans' Behauptung, dass seine Kinder aus ihm selbst kommen, zieht Freud nunmehr den Schluss: »Es sind Phantasie-, d.h. Onaniekinder« (ebd.: 84 Anm. 2). Mit diesen Randbemerkungen bringt Freud seine Leser dazu, Hans' eigene Aussagen über sein Begehren zu ignorieren, und bereitet sie darauf vor, die Deckgeschichte einer bewältigten Neurose und einer normalen sexuellen Entwicklung zu akzeptieren, die Freud in seiner nachfolgenden Erörterung des Falls entwirft (vgl. Rudnytsky 1994).

Freuds ultimative Verleugnung von Hans' fortdauernden homosexuellen Neigungen lässt sich ebenfalls an der (Miss-)Deutung von Hans' zweiter Phantasie vom Installateur zeigen, mit der der Bericht seines Vaters endet: »Es ist der Installateur gekommen und hat mir mit einer Zange zuerst den Podl weggenommen und hat mir dann einen andern gegeben und dann den Wiwimacher« (1909a: 86). Hans hatte mehrere Wochen zuvor ein erstes Mal vom Installateur geträumt: »Ich bin in der Badewanne, da kommt der Schlosser und schraubt sie los. Da nimmt er einen großen Bohrer und stoßt mich in den Bauch« (ebd.: 6o; Freud verweist auf »den Schlosser« als »den Installateur« [ebd.: 87; vgl. 108]). Im Hinblick auf die Frage, ob die ödipale Interpretation des ersten Traums durch den Vater - der große väterliche Penis wirft den Sohn aus dem Bett der Mutter - angemessen ist, bemerkt Freud: »Wir wollen unser Urteil noch aufgeschoben halten« (ebd.: 6o). In Zusammenhang mit der Wiederkehr der InstallateurPhantasie gibt Freud den Ereignissen schließlich seine eigene, glückliche Wendung: »Mit der letzten Phantasie Hansens war auch die vom Kastrationskomplex stammende Angst überwunden, die peinliche Erwartung ins Beglückende gewendet« (ebd.: 88).

Die erste Phantasie - der Große Bohrer des Handwerkers stößt ihn in den Bauch, die als Penetration durch den Penis des Vaters gelesen werden kann - und die zweite Phantasie der Auswechslung der Schamteile (Podl 
und Wiwimacher) legen jedoch auch die folgende Deutung nahe: die einer »passiv-weiblichen Identifizierung (Silverman 1980: 109, 115; Frankiel 1992; Carvalho Ribeiro 1993; Cournut-Janin/Cournut 1993: 1374-1381) mit der Mutter bei gleichzeitigem Begehren nach dem Vater.

Die Verkennung von Hans' Mutter-Identifizierung wird klar ersichtlich in Freuds Diskussion von Hans' Phantasie der zwei Giraffen, von denen die eine als groß und die andere als >zerwutzelt Ursprünglich hatte Hans behauptet, dass die erste seine Mutter und die andere seine kleine Schwester darstellt; später akzeptiert Hans jedoch die Deutung seines Vaters, dass die große Giraffe er (d.h. der Vater) und die zerwutzelte seine Mutter sei (Freud 1909a: 38f.). Freud vermutet, dass die Wahl der Giraffe zumindest zum Teil »vielleicht auch durch eine unbewußte Vergleichung, die an den langen und steifen Hals der Giraffe anknüpft« (ebd.: 104), geschuldet ist, und fügt in einer Fußnote an: »Dazu stimmt die spätere Bewunderung Hansens für den Hals seines Vaters« (ebd.: 104 Anm. 1). Der einzige Verweis auf einen Hals im Text bezieht sich jedoch auf den der Mutter; obwohl er die Deutung seines Vaters akzeptiert, erhebt Hans gegen die anatomische Erklärung seines Vaters Einspruch. Als sein Vater feststellt, der lange Hals (der großen Giraffe) erinnere ihn an einen Penis, antwortete Hans: »Die Mammi hat auch einen Hals wie eine Giraffe, das hab' ich gesehen, wie sie sich den weißen Hals gewaschen hat (ebd.: 39). Hans' ursprünglicher Kommentar zur Giraffen-Phantasie kann vor diesem Hintergrund vielmehr als ein Ausdruck seines nach wie vor bestehenden Glaubens an den mütterlichen Penis gedeutet werden (und den »noch kleinen« Wiwimacher seiner Schwester; ebd.: 17).

Freuds Verkennung von Hans' Affekt weist auf eine Verlagerung des Schwerpunkts vom Kognitiven zum Sexuellen hin; der Vater wird zum Objekt der Lust. Freud hatte die Liebe, die Hans für seinen Vater empfand, bereits erkannt und Graf widersprochen, der trotz des Protests seines Sohnes an der Deutung einer ödipalen Feindseligkeit festhielt: »Warum hast du mir gesagt, ich hab' die Mammi gern, und ich furcht< mich deshalb, wenn ich dich gern hab?« (ebd.: 42; Hervorhebung S.F.). Statt seinen Kastrationskomplex zu bewältigen und zur Latenzphase und damit zur »normalen« psychosexuellen Entwicklung überzugehen, hat der kleine Hans seine »homosexuellen Anwandlungen« aufrechterhalten. Was Freud in seinem Text nicht sagen konnte, aber was der Text recht klar ausdrückt, nämlich die fortdauernden homo- oder besser bisexuellen Neigungen des kleinen Hans, taucht nun in der Fußnote zum Antisemitismus und zu Weininger auf. Während Hans' »angewachsener« (ebd.: 36) Penis Freud in der Fallgeschichte zur Erkenntnis der Nachträglichkeit der Kastrationsangst geführt hatte, führte Hans' »Fixierung « auf den mütterlichen Penis ihres Telos der Homosexualität (Freud 1908: 177) Freud möglicherweise dazu, ihn mit dem sexuell verwirrten Weininger in Verbindung zu bringen, der ebenfalls »völlig unter der Herrschaft infantiler Komplexe« stand. Vielleicht war Herbert nicht in der Lage, seine »infantilen Komplexe« zu überwinden, da 
der Grund, der seine Kastrationsangst hervorgerufen hatte, noch aktuell war: seine Beschneidung.

\section{Never mind}

Wie auch frühere Kommentatoren (Gilman 1993: 72; Boyarin 1997) hatte ich angenommen, dass Herbert beschnitten war, und dass diese körperliche Markierung entweder visuell oder ideell die reale Gefahr einer Kastration anzeigte. Unmittelbar vor der »Fallgeschichte und Analyse«, die Freud im Text präsentiert, zitiert Freud Max Grafs Notizen über eine Veränderung im Verhalten seines Sohnes vor dem Auftauchen phobischer Symptome:

»Gestern als ich Hans auf die Seite gehen ließ, sagte er mir zum erstenmal, ich solle ihn hinters Haus führen, damit niemand zuschauen könne, und fügte hinzu: >Voriges Jahr, wie ich Wiwi gemacht habe, haben mir die Berta und die Olga zugesehen ...< Ich beobachtete seither wiederholt, daß er beim Wiwimachen nicht gesehen werden will.« (Freud 1909a: 25)

Vielleicht hätten ihn seine nicht-jüdischen Freundinnen Berta und Olga, nachdem er ihnen seinen Wiwimacher gezeigt hatte, ja gefragt: »Warum ist Dein Wiwimacher anders als alle anderen Wiwimacher? « Im Lichte dieser Interpretation hatte der gebieterische Freud, indem er Graf geraten hatte, seinen Sohn jüdisch aufzuziehen, ihm faktisch befohlen, seinen Sohn zu beschneiden, und hatte Herbert demnach nicht bloß zur Neurose, sondern auch zur Verweichlichung und zur Homosexualität verdammt. Demzufolge könnte das Einfügen der Fußnote Freuds Sorge über die verbreitete Assoziation männlicher Juden mit den letzteren beiden Übeln (Mosse 1996) geschuldet sein.

Für viele Zeitgenossen stellte Weininger eine exemplarische Verkörperung des Status des Juden als homosexuell dar; darüber hinaus war die Anerkennung der Beziehung zwischen Herberts (oder Weiningers) homosexuellen Impulsen und der fortbestehenden Kastrationsangst, die von seiner eigenen Beschneidung herrührte, mit der Gefahr einer Verallgemeinerung des Phänomens für alle beschnittenen männlichen Juden und damit mit einer Bestätigung bestehender antisemitischer Vorurteile verbunden. Gleichwohl könnten besondere persönliche Motive noch dringlicher gewesen sein. Indem er den >Fall Weininger und den Hinweis auf die Beschneidung in seiner Fallstudie aufnahm, brachte Freud - der väterliche Berater (d.h. der väterliche Ersatz und Beschneider) - sein Gefühl der Verantwortung für Hans' problematische geschlechtliche und sexuelle Identität zum Ausdruck; gleichzeitig deutet Freud - der beschnittene Analyst -, beunruhigt über seine eigenen widersprüchlichen »homosexuellen Anwandlungen« (s. z.B. Koestenbaum 1988; Davis 1995; Boyarin 1997), 
damit nochmals seine Identifikation mit Hans, dem Forscher, an (Freud 1909a: 66 Anm. 1; 67 Anm. 1; 81 Anm. 1).

Das einzige Problem meiner früheren Schlussfolgerung war, dass Herbert Graf laut der erhaltenen Registrierliste der Wiener jüdischen Gemeinde nicht beschnitten wurde. Könnte Freud angenommen haben, dass Herbert beschnitten wurde? Wahrscheinlich nicht. Obwohl Freud selbst beschnitten wurde, ${ }^{\circ}$ wurden es seine als Juden erzogene und eingeschriebene Söhne nicht - zumindest nicht, wenn man denselben Listen Glauben schenken darf (vgl. Rice 1994: 251f.). Weder die Wiener Zivilregierung noch die zuständige Behörden der jüdischen Gemeinde hatten - spätestens seit 1871 - die Beschneidung für die Registrierung der Juden gefordert. Offenbar war es nicht der Anblick eines kleinen jüdischen Schmuck, der die Kastrationsangst hervorgerufen hat, sondern eher »ein Gerücht über die Juden« (vgl. Bronner 2000): »denn schon in der Kinderstube hört der Knabe, das dem Juden etwas am Penis [...] abgeschnitten werde« (Freud 1909a: 36 Anm. 2; s. 1912/13: 436 Anm. 1 und oben; Hervorhebung J.G.). Wie schon die stereotypische jüdische Nase, die Freud und seine Kollegen mit Hilfe einer statistischen Rhinoplastie als ein Produkt der Phantasie zu entlarven suchten (Efron 1994), so war auch jene unauslöschliche Markierung (männlicher) jüdischer Identität ein gefährliches Phantasiebild. Möglicherweise geblendet durch Freuds Betonung der Rolle von Scopophilia bei der potentiell traumatischen >Entdeckung< der Geschlechtsunterschiede (s. Freud 1910: 12of.), durch die ideologische Annahme, dass diese Unterschiede >natürlicherweise $<$ an den Genitalien festgemacht werden können und durch ein positivistisches Misstrauen - das leider gelegentlich von Freud geteilt wurde - gegenüber Allem außer »eine[r] reale[n] Wiederholung des Ereignisses« (Freud 1939: 548), und schließlich durch die Notwendigkeit, eine einzigartige jüdische Identität zu sichern, haben frühere Leser - mich selbst eingeschlossen - die Abwesenheit einer ersten voyeuristischen Episode übersehen und unsere eigenen phantastischen Konstruktionen darüber »wie es eigentlich war « erschaffen. ${ }^{11}$

Sowohl Daniel Boyarin (1997) als auch Sander Gilman (1993) beschwören die Beschneidung des Kleinen Hans aufgrund der Fußnote Freuds herauf, um jedoch völlig unterschiedliche Spiegel-Szenen zu erschaffen: Für Gilman wurden »normale« Juden wie der Kleine Hans (1993: 87) davon überzeugt, »that the real difference is not between their circumcised penises and those of uncircumcised males, but between themselves and

10I Seine bris (rituelle Beschneidung) am 13. Mai 1856 ist in der Familienbibel der Freuds vermerkt.

11| Herzlichen Dank an Anne Golomb Hoffman, deren Vortrag vom 18. Dezember 2005 für die Association for Jewish Studies zu Jewish Studies Perspektiven auf das Leben und Werk Sigmund Freuds und späteres Manuskript »Archival Bodies« mir halfen, meine Augen für die von Freud aufgezeichneten Kinderstubengespräche zu öffnen. 
castrated females [...] Jewish neurotics like Weininger focus on the negative difference of their bodies from ones that are >normal<, and use this difference, like their evocation of the bodies of women, to define themselves « (ebd.: 87, 8o; Hervorhebung J.G.). Boyarin andererseits schreibt, dass Hans »in fact, possessed such a >damaged penis< as did Freud himself. In presenting >Little Hans < and Weininger as if they were gentiles gazing ... at the Jewish penis and becoming filled with fear and loathing, Freud is actually [...] representing himself [...] gazing at his own circumcised penis and being filled with fear and loathing « (1997: 234). Demgegenüber verwendet Gilman Freuds Analyse des Kleinen Hans und den Entwurf des Kastrationsparadigmas des weiblichen Geschlechts, um zu zeigen, wie der Psychoanalytiker die Beschneidung als die damals antisemitisch codierte Unterscheidung zwischen dem jüdischen und dem arischen Männerkörper verdeckt und dem Körper der Frau einschreibt (vgl. ebd.: 72; von Schnurbein 2005). Für Boyarin hingegen akzeptiert Freud »the characterization of Jews as differently gendered, as indeed female, and tries to overcome this difference« (ebd.: 239) durch Verleugnung. Vor kurzer Zeit hat Frank Maciejewski (2002, 2003) argumentiert, dass letztlich die gesamte Angstneurose des Kleinen Hans ursprünglich aus seiner Beschneidung herrühre. Dabei basierte Maciejewskis »dichte Beschreibung « auf einer sehr dünnen Beweisbasis. Dennoch ist er es, der das bisher größte theoretische Gebäude auf den realia von Beschneidung, Trauma und Antisemitismus aufbaut: Kastrationsangst entsteht aus der Beschneidung. Hier geht es im Gegensatz zu diesen Spekulationen um das genaue Lesen von Freuds Text, um die Spezifität von Herbert Grafs Situation und Freuds Verstrickung in diese. Es geht auch um das Verhältnis von Freuds Sitz-im-Leben zur Entwicklung des psychoanalytischen Diskurses, das weder von der Macht empirischer Fakten, noch von der Wirkung traumatischer Urszenen allein abhängt (Geller 2007).

In Freuds >langer Jahrhundertwende<, einer Periode von Krisen sowohl individueller als auch kollektiver Identität und Differenz, wurde Hegemonie zugleich legitimiert und sichtbar gemacht, indem am Körper der unterworfenen Anderen natürliche Unterschiede fixiert wurden. Für den imaginierten jüdischen Körper war die herausragende Markierung der immer schon beschnittene Penis. In einem Text, der die sexuelle Identität eines jüdischen Knaben analysierte und dabei sowohl dessen endgültige sexuelle und ursprüngliche jüdische Identität verschleierte, einem Text der schlüssige Beweise für die damals vermutlich provokanteste Theorie der Psychoanalyse - die der kindlichen Sexualität - vorlegte und mit der ersten ausführlichen Darstellung des Kastrationskomplexes eine nicht weniger kontroverse Grundlage für alle weiteren psychischen Entwicklungen lieferte, mit anderen Worten, in einem Text, an dem so viel hing, überrascht es nicht, dass ein Knotenpunkt auftaucht, an dem all diese Erzählstränge zusammenlaufen - die Beschneidung. In seinem gesamten Textkorpus wird Freud diesen Algorithmus der jüdischen Differenz, die Beschnei- 
dung, oder zumindest dessen symbolischen Ersatz, die Kastration, sowohl als pathologisch als auch als universelles Charakteristikum ausweisen. Wie wir jedoch aus der Psychoanalyse und der Geschichte wissen, findet das Verdrängte einen Weg zu seiner Wiederkehr, so auch die verdrängte >Partikularität< der Beschneidung.

\section{Eine heroische Lösung}

Im Schlusswort seiner Studie argumentiert Freud: »Ich habe aus dieser Analyse, strenggenommen, nichts Neues erfahren« (1909a: 122). Jedoch fügt er hinzu, dass dieser Analyse »eine typische und vorbildliche Bedeutung«zukommt. Die Kennzeichnung als typisch und vorbildlich bezieht sich allerdings nicht auf die beobachteten Symptome, sondern auf deren Entstehung: »als ob die Mannigfaltigkeit der neurotischen Verdrängungserscheinungen und die Reichhaltigkeit des pathogenen Materials einer Ableitung von sehr wenigen Prozessen an den nämlichen Vorstellungskomplexen nicht im Wege stünden« (ebd.). Der Vorstellungskomplex, der in der Analyse angesprochen wird, ist der Kastrationskomplex. Noch 1909 suchte Freud nach Objektiven (realia), die ein Jahrzehnt zuvor mit der Aufgabe der sogenannten Verführungstheorie verloren gegangen waren; er benötigte objektive, äußere ätiologische Faktoren, um seine Wissenschaft als Wissenschaft rechtfertigen zu können.

In Bezug auf diese fehlenden realia bot sich nunmehr die Kastrationsdrohung an, die es zudem ermöglichte, das auslösende Ereignis bei der Mutter zu lokalisieren, statt es mit der allgegenwärtigen, aber niemals ausgesprochenen Erinnerung an den eigenen Rat in Verbindung zu bringen: Indem Herbert als Jude aufgezogen worden war, war dessen Identität unentrinnbar mit der Beschneidung verknüpft. Dennoch entwirft Freud in seiner Abschlussdiskussion den Kastrationskomplex als eine universelle Entwicklungsstruktur; die somit unabhängig von realer Bedrohung oder zufälliger Beobachtung ist.

Schließlich erklärt Freud Hans - allen Beweisen zum Trotz, die auf das Gegenteil hindeuten - als >normal<. Demnach stellten sich Hans' neurotische Abenteuer letztlich als Entwicklungsvorteil heraus. Als Fazit seiner Analyse erklärt Freud:

»Ich könnte mir also vorstellen, dass es heilsam für unseren Hans war, diese Phobie produziert zu haben [...] Vielleicht hat er nun vor anderen Kindern das voraus, dass er nicht mehr jenen Keim verdrängter Komplexe in sich trägt, der fürs spätere Leben jedes mal etwas bedeuten muss, der gewiss Charakterverbildung in irgendeinem Ausmaße mit sich bringt, wenn nicht die Disposition zu einer späteren Neurose.« (Ebd.: 119f)

Mit diesem abschließenden >Ausgleichsangebot< für die unintendierten 
Folgen des nicht anerkannten »Jüdischen « - ein Terminus der häufig euphemistisch für »Beschneiden « verwendet wurde (Bar Amitai 1843:12) - des kleinen Hans kehrt Freud an den Anfang des Falls zurück. In der Beschreibung der positiven Ergebnisse der erfolgreichen Bewältigung der Phobie des kleinen Hans, wiederholt Freud seinen früheren Rat an Max Graf. In dieser abschließenden Erzählung hat die Überwindung einer Neurose das zu Stande gebracht, was ihrer genetischen Ursache (d.h. das Jüdischsein, eine Identität, die durch »Beschneidung « vermittelt wird) zugedacht war. Freuds Vorgehen scheint damit gerechtfertigt zu sein. Dank dieses Kampfes (mit der Neurose) wurde Hans - Herbert - zu einem »kämpfenden Juden .

Übersetzt aus dem Amerikanischen von Anja Becker mit Sabine Mehlmann

\section{Literatur}

Bar Amitai (1843): Ueber die Beschneidung in historischer und dogmatischer Hinsicht, Frankfurt a.M.: J.S. Hermann'sche Buchhandlung.

Blüher, Hans (1918): Die deutsche Wandervogelbewegung als erotisches Phänomen. Ein Beitrag zur Erkenntnis der sexuellen Inversion, 3. Aufl. Berlin: Verlag Hans Blüher.

Boyarin, Daniel (1997): Unheroic Conduct. The Rise of Heterosexuality and the Invention of the Jewish Man, Berkeley: University of California Press.

Bronner, Stephen Eric (2000): A Rumor about the Jews. Reflections on Antisemitism and the Protocols of the Learned Elders of Zion. New York: St. Martin's Press.

Carvalho Ribeiro, Paulo de (1993): »Oedipe et castration selon le petit Hans«. In: Psychanalyse à l'université 18, S. 47-69.

Cournut-Janin, Monique/Cournut, Jean (1993): »La castration et le féminin dans les deux sexes «. In: Revue française de psychanalyse 57.

Davis, Whitney (1995): Drawing the Dream of the Wolves: Homosexuality, Interpretation, and Freud's »Wolf Man«, Bloomington: Indiana University Press.

Deleuze, Gilles (2006): »What is a Dispositif?« In: David Lapoujade (Hg.), Two Regimes of Madness. Texts and Interviews 1975-1995, New York: Semiotext(e), S. 338-348.

Efron, John M. (1994): Defenders of the Race. Jewish Doctors and Race Science in Fin-de-Siècle Europe, New Haven: Yale University Press.

Frankiel, Rita V. (1992): »Analysed and Unanalysed Themes in the Treatment of Little Hans«. In: International Review of Psycho-Analysis 19, S. 323-333.

Freud, Martin (1958): Sigmund Freud. Man and Father, New York: Vanguard Press. 
Freud, Martin (1967): »Who Was Freud?« In: Josef Fraenkel (Hg.), The Jews of Austria. Essays on Their Life, History and Destruction, London: Valentine Mitchell.

Freud, Sigmund (1900): Die Traumdeutung. In: Freud-Studienausgabe, hg. v. Alexander Mitscherlich/Angela Richards/James Strachey/Ilse Grubrich-Simitis, 11 Bde., Frankfurt a.M. 1969-1975: S. Fischer Verlag, Bd. 2.

Freud, Sigmund (1905): Der Witz und seine Beziehung zum Unbewussten. In: Freud-Studienausgabe, Bd. 4.

Freud, Sigmund (1907): »Zur sexuellen Aufklärung der Kinder«. In: FreudStudienausgabe, Bd. 5 .

Freud, Sigmund (1907/08): »Originalnotizen zu dem Fall von Zwangsneurose«. In: Gesammelte Werke, hg. v. Alexander Mitscherlich/Angela Richards/James Strachey, 19 Bde., 4. Aufl., Frankfurt a.M. 1993: S. Fischer Verlag, Bd. 19

Freud, Sigmund (1908): »Über infantile Sexualtheorien«. In: Freud-Studienausgabe, Bd. 5 .

Freud, Sigmund (1909a): »Analyse der Phobie eines fünfjährigen Knaben«. In: Freud-Studienausgabe, Bd. 8.

Freud, Sigmund (1909b): »Bemerkungen über einen Fall von Zwangsneurose «. In: Freud-Studienausgabe, Bd. 7.

Freud, Sigmund (1910): Eine Kindheitserinnerung des Leonardo da Vinci. In: Freud-Studienausgabe, Bd. 10.

Freud, Sigmund (1912/13): Totem und Tabu. In: Freud-Studienausgabe, Bd. 9 .

Freud, Sigmund (1916/17): Vorlesungen zur Einführung in die Psychoanalyse. In: Freud-Studienausgabe, Bd. 1.

Freud, Sigmund (1922): »Das Medusenhaupt«. In: Gesammelte Werke, Bd. 17.

Freud, Sigmund (1926): »Ansprache an die Mitglieder des Vereins B'nai B'rith«. In: Gesammelte Werke, Bd. 17.

Freud, Sigmund (1939): Der Mann Moses und die monotheistische Religion. In: Freud-Studienausgabe, Bd. 9.

Freud, Sigmund (1960): Briefe 1873-1939, hg. v. Ernst Freud, Frankfurt a.M.: S. Fischer Verlag.

Freud, Sigmund/Abraham, Karl (1965): Briefe, hg. v. Hilda C. Abraham/ Ernst L. Freud, Frankfurt a.M.: S. Fischer Verlag.

Geller, Jay (1999): »The Godfather of Psychoanalysis: Circumcision, Antisemitism, Homosexuality, and Freud's >Fighting Jew«". In: Journal of the American Academy of Religion 67, S. 355-385.

Geller, Jay (2007): On Freud's Jewish Body: Mitigating Circumcisions, New York: Fordham University Press.

Gilman, Sander L. (1993): Freud, Race and Gender, Princeton: Princeton University Press. 
Glenn, Jules (1980): »Freud's Advice to Hans' Father: The First Supervisory Sessions«. In: Mark Kanzer/Jules Glenn (Hg.), Freud and His Patients, New York: Jason Aronson.

Graf, Max (1942): »Reminiscences of Professor Sigmund Freud«. In: Psychoanalytic Quarterly 11, S. 465-476.

Koestenbaum, Wayne (1988): »Privileging the Anus: Anna O. and the Collaborative Origin of Psychoanalysis«. In: Genders 3, S. 57-81.

Maciejewski, Frank (2002): Psychoanalytisches Archiv und jüdisches Gedächtnis. Freud, Beschneidung und Monotheismus, Wien: Passagen.

Maciejewski, Frank (2003): »Zu einer >dichten Beschreibungく des kleinen Hans. Über das vergessene Trauma der Beschneidung«. In: Psyche 57, S. 523-550.

Mosse, George (1996): The Image of Man: The Creation of Modern Masculinity, Oxford: Oxford University Press.

Nordau, Max (1909): »Muskeljudentum«. In: Zionistische Schriften, Cologne/Leipzig: Jüdischer Verlag, S. 379-381.

Rice, Emanuel (1994): »The Jewish Heritage of Sigmund Freud«. In: Psychoanalytic Review 81.

Rudnytsky, Peter L. (1994): »>Mother, have you got a wiwimaker too?< Freud's Representation of Female Sexuality in the Case of Little Hans«. In: André Haynal/Ernest Falzeder (Hg.), One Hundred Years of Psychoanalysis. Contributions to the History of Psychoanalysis, London: Karnac Books.

Silverman, Martin (1980): »A Fresh Look at the Case of Little Hans«. In: Mark Kanzer/Jules Glenn (Hg.), Freud and His Patients, New York: Jason Aronson. 


\section{Magnus Hirschfelds Geschlechterkosmos:}

\section{Die Zwischenstufentheorie im Kontext}

\section{hegemonialer Männlichkeit}

RAINER HERRN

Robert Connells Konzept hegemonialer Männlichkeit bezieht sich zunächst auf kulturelle Praktiken, mit denen männliche Vorherrschaft über Frauen legitimiert und aufrecht erhalten wird. Darüber hinaus nimmt es auch die Regulation sich von der hegemonialen Männlichkeit unterscheidender, zeitgleich koexistierender Männlichkeitsformen in den Blick. Unter ihnen bildet die moderne männliche Homosexualität aufgrund diverser Weiblichkeitszuschreibungen eine spezifische wie charakteristische Form dem hegemonialen Ideal untergeordneter Männlichkeit (Connell 1999: 78f., 97ff.). Der männlichen Homosexualität kommt in Connells Ansatz seit ihrer konzeptuellen Einführung im späten 19. und Verbreitung im frühen 20. Jahrhundert eine herausragende Bedeutung zu. Durch ihre permanente diskursive Präsenz, aber vor allem durch die Formation einer politischen Homosexuellenbewegung stellt sie neben der Frauenbewegung und zeitgleich entstehenden zionistischen Bewegung eine nachhaltige Herausforderung hegemonialer Männlichkeit dar (ebd.: 216).

Auch in George Mosses Rekonstruktion der modernen Männlichkeit nimmt der Homosexuelle als deren Gegenspieler - Mosse bezeichnet ihn als »Anti-Typus« (Mosse 1997: 21f.) - neben dem Juden eine konstituierende Funktion ein. Hier dient er - ähnlich dem jüdischen Mann - als Projektionsfläche unmännlicher Attribute. In beiden Ansätzen also, bei Connell wie bei Mosse, ist die männliche Homosexualität ein fest sitzender Stachel im Fleisch hegemonialer Männlichkeit, der einerseits ständig bewusst macht, was sie nicht sein will und darf, andererseits aber auch herausfordert und bedroht, indem er alternative Fluchtpunkte der Männlichkeit offeriert.

Robert Connells Konzept hegemonialer Männlichkeit wurde zunächst 
als analytisches Instrument zur Beschreibung der Dynamik gegenwärtiger sozialer, politischer, ökonomischer und kultureller Praktiken der Machtsicherung und -teilhabe entwickelt und ist insofern handlungsorientiert. Seine skizzenhafte historische Verortung der Konstituierung hegemonialer Männlichkeit (Connell 1999: 205-219) regte seither dazu an, diesen Ansatz auch zur Analyse der Geschlechtergeschichte einzusetzen. Die sich daraus ergebenden Problemfelder hat Martin Dinges kürzlich umrissen (vgl. Dinges 2005: 13-22). In meinem Beitrag soll es aber nicht um die Darstellung von historischen Praktiken zur alltäglichen Herstellung hegemonialer Männlichkeit gehen, sondern vielmehr um deren Verhältnis zu Repräsentanten anderer Männlichkeitsformen (vgl. ebd.: 14). Im Vordergrund stehen die in Magnus Hirschfelds Zwischenstufentheorie paradigmatisch zusammengefassten untergeordneten Männlichkeiten (repräsentiert durch Homosexuelle, Transvestiten, Hermaphroditen) im Vergleich zur hegemonialen Männlichkeit.

Kerngedanken der vom Sexualreformer und -wissenschaftler Magnus Hirschfeld (1868-1935) vorgelegten Zwischenstufentheorie finden sich bereits im ersten Aufsatz des von ihm herausgegebenen »Jahrbuches für sexuelle Zwischenstufen« von 1899. Wenngleich er seine Vorstellungen danach erweiterte, ergänzte und präzisierte, vertrat er diesen Ansatz bis er Deutschland, aufgrund der Machtübernahme der Nationalsozialisten, verlassen musste. Die dreißig Jahre, in denen Hirschfeld die Zwischenstufentheorie in zahlreichen wissenschaftlichen und populären Büchern und Broschüren, in Aufsätzen und Zeitungsartikeln, in Vorträgen und Filmen verbreitete und auf diese Art weithin implementierte, schließen das Fin de Siècle, den Ersten Weltkrieg und die gesamte Weimarer Zeit ein. In diesen Perioden veränderten sich die Geschlechterbilder gravierend, moderne Figuren - wie die neue Frau - betraten die Geschlechterbühne (vgl. Ankum 1997), Bilder von und Einstellungen gegenüber Homosexuellen änderten sich (vgl. Herrn 2004; Micheler 2005: 106-116 und 117-282). Dennoch markieren diese Perioden zusammen den Höhepunkt hegemonialer Männlichkeit, wie Connell und Mosse übereinstimmend feststellen. Obgleich der Erste Weltkrieg dem Männlichkeitsstereotyp »weitere wichtige Elemente« (Mosse 1997: 143) hinzufügte, vertiefte und verstärkte er paradoxerweise insgesamt dessen Konturen. Auch Dinges bezeichnet diese Abschnitte als »Zeiten der massivsten Geltung moderner hegemonialer Männlichkeit« (Dinges 2005: 20).

\section{Die Formation der Anti-Typen}

1896, ein Jahr vor Gründung der ersten Homosexuellenorganisation, dem Wissenschaftlich-humanitären Komitee (WhK), trifft Hirschfeld eine folgenreiche strategische Entscheidung im Hinblick auf das Männlichkeitsbild, mit dem die Entkriminalisierung sexueller Handlungen zwischen 
Männern erreicht werden soll. In seinem unter dem Pseudonym »Th. Ramien« veröffentlichten Erstling »Sappho und Sokrates« stellt er zwei, im Männlichkeitsverständnis grundverschiedene und vor allem unvereinbare Erklärungen der Homosexualität vor: Das seinerzeit vorherrschende sexualpathologische Konzept Krafft-Ebings, dessen Kern auf Karl-Heinrich Ulrichs' These der weiblichen Seele im männlichen Körper zurückgeht; und das Konzept von Gustav Jaeger, nach dem der Homosexuelle als »superviriler Mann« die gesellschaftliche Elite konstituiert. Hirschfeld musste sich entscheiden, ob ein Konzept inferiorer oder eines superiorer Männlichkeit als Instrument für die Entkriminalisierung homosexueller Handlungen besser geeignet ist. Er musste zwischen zwei Männlichkeitskonstruktionen wählen, die ganz verschiedene Positionen zum hegemonialen Ideal markieren.

Zunächst möchte ich Ulrichs' Konstruktion des sogenannten Urnings in seinem Verhältnis zur hegemonialen Männlichkeit kurz umreißen. Schließlich stellt er die Vorlage der sexualpathologischen Figur des modernen Homosexuellen dar, die erst im Prozess der »Einpflanzung der Perversionen«, wie Foucault es nannte (Foucault 1983: 64), entstand. Danach werde ich auf das Homosexualitätskonzept Gustav Jaegers eingehen, weil es von Hirschfeld als Alternative ausdrücklich verworfen wurde, um dann dessen >Zwischenstufen< im Verhältnis zur hegemonialen Männlichkeit zu betrachten.

Bereits in den Vorverhandlungen zur Reichsgründung 1871 wurde die Absicht erkennbar, das preußische Strafrecht, das gleichgeschlechtliche sexuelle Handlungen zwischen Männern unter Strafe stellte, auf das gesamte Territorium des Deutschen Reiches auszudehnen (vgl. Hutter 1990): ein symbolischer Akt der Unterwerfung mannmännlichen Begehrens unter die hegemoniale Männlichkeit und eine handfeste juristische Disziplinierungs- und Stigmatisierungspraxis, die fast das gesamte 20. Jahrhundert überdauerte.

Diese drohende Expansion einer reichsweiten Verfolgung stellte den konkreten Anlass für den Juristen Ulrichs dar, bereits in den Goer Jahren des 19. Jahrhunderts eine im Natürlichkeitsdiskurs angesiedelte medizinische Theorie des Männerbegehrens zu entwerfen. Ihr Kerngedanke besteht von Beginn an in der bereits zitierten These der weiblichen Seele im männlichen Körper: »Ich sage: >Wir sind geistig Weib« (Ulrichs 1862/1994a: 47). Urninge seien daher qua Geburt eine »zwitterähnliche besondere geschlechtliche Menschenklasse, ein eigenes Geschlecht, dem Geschlecht der Männer und dem der Weiber als drittes Geschlecht coordinirt« (Ulrichs 1864/1994a: 5; H.i.O.). Weil der mannmännliche Liebestrieb - analog dem mannweiblichen - naturgegeben sei, hätten Urninge auch »das Recht, ihn zu befriedigen « (Ulrichs 1862/1994a: 53; H.i.O.). Ulrichs' Natürlichkeitsverständnis schließt die - strafrechtlich präjudizierte - indi- 
viduelle Schuldhaftigkeit aus, weshalb er gegen die drohende Ausweitung der Verfolgung sexueller Handlungen zwischen Männern anschrieb und damit eine bis in die Gegenwart reichende biopolitische Strategie zum Abbau der Diskriminierung sozialer Minderheiten begründete.

Ulrichs leitete seine mischgeschlechtliche Konstruktion des Urnings aus den Mitte des 19. Jahrhunderts gängigen stereotypen medizin-anthropologischen Zuschreibungen von Männlichkeit und Weiblichkeit her, wie sie Claudia Honegger beschreibt (vgl. Honegger 1991), insbesondere übernahm er die aus den Geschlechtskörpern deduzierten sozialen und psychologischen Ausdeutungen. In seinen zwölf Schriften fällt dennoch die Absenz misogyner Untertöne auf. Auch zunehmend geäußerten pathologisierenden Zuschreibungen der Mannweiblichkeit trat Ulrichs von Beginn an ausdrücklich entgegen: »Uranismus und Hermaphroditismus sind durchaus nicht etwa Krankheitserscheinungen « (Ulrichs 1862/1994a: 50; H.i.O.). Und obgleich er die Urninge mit all ihren Unterformen ${ }^{1}$ gelegentlich »Halbmänner« nennt - ein Verweis auf ihr grundsätzliches Männlichkeitsdefizit -, traten sie durchaus selbstbewusst auf. Bei Ulrichs' konzeptueller Feminisierung der Urninge handelt es sich weder um eine Subordinationsgeste unter das herrschende Männlichkeitsideal noch um eine die Frauen abwertende Überlegenheitsattitüde. Er versuchte vielmehr eine gleichberechtigte alternative »urnische« Männlichkeit zu schaffen, die sich nicht ins Verhältnis zum hegemonialen Stereotyp setzte. Schon 1862 schrieb er seinen Verwandten:

»Hiernach wird es wahrscheinlich ein nie zu sühnendes Unrecht sein, wenn die Majorität noch länger ihre Uebermacht dazu missbrauchen wird, an die Uranier zwangsweise den Massstab der Männer anzulegen [...].« (Ebd.: 53)

Als Hirschfeld 1896, ein Jahr nach Ulrichs' Tod, begann, dessen wissenschaftliches Werk und politisches Vermächtnis zum Ausgangspunkt seiner reformerischen Aktivitäten zu machen, hatte die Urningstheorie bereits grundsätzliche Neuinterpretationen in der gerade aufkommenden Sexualpathologie erfahren. Dabei gab Ulrichs' Werk sogar Anstoß für die Begründung der Wissenschaft vom Sex, der »Psychopathia Sexualis« (vgl. Müller 1991: 119-134). So schrieb ihm Krafft-Ebing am 29. Januar 1879, »[...] die

1| Ulrichs' Schriften unter dem Aspekt hegemonialer Männlichkeit detailliert zu analysieren, ist sicher ein lohnendes Desiderat. Denn die Verfeinerungen des Konzeptes vom Urning wie auch dessen Vervielfältigung in geschlechtliche Unterformen, beispielsweise in den viril auftretenden »Mannling « und den effeminierten »Weibling«, sind ja erst in der dialogischen Rezeption seiner Schriften entstanden. Diese Figuren verweisen bereits auf jene sich ausdifferenzierenden Selbstbilder und daraus abgeleiteten verschiedenen Strategien im Umgang mit dem hegemonialen Ideal, die für die junge Homosexuellenbewegung zu Beginn des 20 . Jahrhunderts charakteristisch werden sollten. 
Kenntnis Ihrer Schriften allein war es, was mich veranlaßte zum Studium in diesem hochwichtigen Gebiet und zur Niederlegung meiner Erfahrungen [...]« (Ulrichs 1880/1994b: 92). Später spricht Krafft-Ebing Ulrichs allerdings aufgrund der vermeintlichen eigenen »Betroffenheit« die wissenschaftliche Objektivität bei der medizinischen Beurteilung des Männerbegehrens ab:

»Mitte der Goer Jahre trat ein gewisser Assessor Ulrichs, mit diesem Trieb behaftet, auf und behauptete, das geschlechtliche Seelenleben sei nicht an das körperliche gebunden, es gebe männliche Individuen, die sich als Weib dem Manne gegenüber fühlen (>anima muliebris in corpore virili inclusa $)$. Er nennt sie Urninge und verlangt nichts Geringeres als die Anerkennung der urnischen Geschlechtsliebe als einer angeborenen und damit berechtigten, sowie die Gestaltung der Ehe zwischen Urningen! Der Verfasser verschiedener dahin abzielender Broschuren bleibt nur den Beweis dafür schuldig, dass er als eine angeborene Erscheinung damit eo ipso eine physiologische und nicht vielleicht eine pathologische sei.« (Krafft-Ebing 1877: 305f.)

Diese Sequenz findet sich sinngemäß auch in den verschiedenen Ausgaben der »Psychopathia Sexualis«, beispielsweise in der 9. Auflage (KrafftEbing, 1894: 232f.). Während Ulrichs in seinen Schriften Sexualität und Fortpflanzung entkoppelt hatte, führte Krafft-Ebing zu dessen Verdruss mit der Behauptung, Ziel der Sexualität sei die Fortpflanzung, eine Rückkopplung ein. Nicht auf Reproduktion gerichtete sexuelle Praktiken und Formen galten als erworbene Perversität oder angeborene Perversion. In der von Krafft-Ebing aus der französischen in die deutsche Psychiatrie überführten Degenerationstheorie (vgl. Wettley 1959) wurde Mischgeschlechtlichkeit per se als atavistischer Rückschlag und Verfallssymptom der evolutiv entstandenen binären Geschlechterordnung gedeutet. Infolgedessen wurde aus Ulrichs' mischgeschlechtlichem, wenngleich selbstbewusstem Urning der perverse, kranke und nicht zuletzt degenerierte Homosexuelle - die Anhäufung von Negativzuschreibungen wirft ein Licht auf die ihm unterstellte Bedrohung der hegemonialen Männlichkeit. In dem historischen Moment also, indem sich der moderne Homosexuelle als fest umrissenes Subjekt konstituierte, erfolgte im Kontext der Medikalisierung seine Subordination unter das hegemoniale Ideal. Ulrichs' Strategie bezeichnet Sabine Mehlmann als »Naturalisierung des Männerbegehrens« (Mehlmann 1998: 46), während sie die überformende, mit den Namen Westphal und Krafft-Ebing verbundene, treffend als »Pathologisierungsstrategie« benennt. Nach der juristischen Sanktionierung ist die Pathologisierung eine gängige wie effektive Technik hegemonialer Unterwerfung, in deren Umsetzung der moderne Homosexuelle als Negativfigur, als George Mosses »Anti-Typus« entsteht.

In ausdrücklicher Abgrenzung von Ulrichs' Theorie und deren sexualpathologischer Vereinnahmung und Neuinterpretation legte der Physiologe 
Gustav Jaeger 1880 eine alternative Erklärung mannmännlichen Begehrens vor. Claudia Bruns nennt die Protagonisten dieser Strömung in Anlehnung an Hewitt »Maskulinisten«. Jaegers Theorie stellt sogenannte »physiologische Körperduftanziehungen« in den Mittelpunkt, die sexuelle Attraktion und Aversion sowie soziale Kohärenz erzeugten. Indem er nicht - wie Ulrichs - die Richtung des sexuellen Begehrens zum Ausgangspunkt wählt oder - wie die Sexualpathologen - die auf Fortpflanzung gerichtete Sexualität, sondern das Vorhandensein partnerbezogenen sexuellen Begehrens überhaupt, verwirft Jaeger sowohl die Weiblichkeitszuschreibungen Homosexueller als auch deren Pathologisierung. In seiner vertikalen Geschlechterhierarchie »erklimmen solche Supervirilen häufig die höchsten Stufen geistiger Entwicklung, sozialer Stellung und männlichen Könnens« (Hirschfeld 1896: 24; Jaeger 1884: 269). Deshalb ständen sie als uneingeschränkte >Hegemonen in Wirtschaft und Wissenschaft, Politik und Militär an der Spitze, gefolgt von den >Normalsexuellen<, den >eunuchengleichen Monosexualen und schließlich den Frauen (vgl. Bruns 2001). Weil Jaeger das Vorkommen solcher »Supervirilen« als »naturnotwendig« begreift, bezeichnet Hirschfeld dessen Theorie in »Sappho und Sokrates« als eine »nicht üble, von darwinistischem Geist getragene Erklärung«. Dennoch folgt er Jaeger nicht:

»[D]ass die Liebe zum eigenen genau so wie die zum anderen Geschlecht, zu großem befähigen kann, ist zweifellos. [...] [Homosexualität jedoch] als eine höhere Neigung zu preisen, wie die Liebe zwischen Mann und Weib, [...] schießt denn doch weit über das Ziel.« (Hirschfeld 1896: 24f.; H.i.O.)

Hirschfeld lehnt die aus Abwehr der Weiblichkeitszuschreibungen sowie der Kompensation gesellschaftlicher Ächtung hervorgegangene Überlegenheitsbehauptung Jaegers wohl aufgrund strategischer Erwägungen ab, denn im Natürlichkeitsdiskurs bewegt sich sowohl seine als auch Ulrichs Erklärung. Außerdem schien es ihm wohl weniger aussichtsreich, eine außerhalb medizinischer Theoriebildung liegende Homosexualitätskonstruktion zur Grundlage seiner Arbeit zu machen, als vielmehr innerhalb kanonisierter Theorien zur Revision medizinischer Dogmen im Sinne der Entpathologisierung beizutragen.

Jaegers Ansatz wurde dennoch weitergeführt, und zwar zur selben Zeit, in der Hirschfeld Ulrichs' Theorie aufgreift: dies zunächst durch Elisar von Kupffer und Edwin Bab, der übrigens 1903 in einem hirschfeldkritischen Text die Bezeichnung »Zwischenstufentheorie« prägte.

Denn der Begriff >Zwischenstufentheorie< wurde nicht von Hirschfeld in Umlauf gebracht, sondern vielmehr von jenen Rezipienten, die sein Konzept vom Homosexuellen als mischgeschlechtliche Konstruktion von Beginn an ablehnten oder sogar attackierten. Insofern ist er als >Kampfbegriffı aus einem Distanzierungsgestus der Hirschfeld-kritischen Fraktion der Homosexuellenbewegung entstanden. Erstmals verwendet ihn eben 
jener Medizinstudent Edwin Bab 1903 in seiner Abhandlung »Die gleichgeschlechtliche Liebe«, deren Untertitel »Lieblingminne« auf die Nähe zu Elisar von Kupffer verweist und die Adolf Brand gewidmet ist (Bab 1903: 31). Doch erst die Übernahme der Bab'schen Begriffsschöpfung durch den Hirschfeld-kritischen WhK-Mitstreiter und Biologen Benedikt Friedländer - ein konvertierter Jude mit antisemitischen Tendenzen (Boyarin 1997: 209 Anm. 69), und zwar in der Schreibweise »Zwischenstufen-Theorie«, führte $z u$ deren Verbreitung in der sexualwissenschaftlichen Literatur (Friedländer 1904, Aphorismen und Zusätze: 84). Da benutzt ihn der Schweizer Psychiater August Forel zuerst und nach ihm verschiedene andere Autoren, beispielsweise Iwan Bloch. Weil jene Autoren, die den Begriff zunächst prägten und verwendeten, eine »nicht ganz richtige Vorstellung« (Hirschfeld 1910a: 130 Anm.) von der »Zwischenstufentheorie« hätten - gemeint ist wohl die auf Homosexualität eingegrenzte Lesart -, versucht Hirschfeld diese »Missverständnisse « mit entsprechenden Veröffentlichungen auszuräumen. Er übernahm dazu den Begriff >Zwischenstufentheorie< relativ spät: 1906 verwendet er ihn erstmals im Text. Hier greift Hirschfeld auch die von den drei Autoren geäußerten Kritiken an der Zwischenstufentheorie auf (Hirschfeld 1906: 110ff.) und verwendet die Bezeichnung auch zum ersten Mal ohne distanzierende Anführungszeichen; 1910 dient sie dann auch als Kapitel- und Aufsatzüberschrift, doch lag das entsprechende Konzept - wie bereits dargestellt - spätestens seit 1899 vor.

Doch zurück zu Gustav Jaeger: Auch Adolf Brand mit seiner Gemeinschaft der Eigenen - das ist die zweite, um 1900 gegründete Homosexuellenorganisation - steht dessen Erklärung des Männerbegehrens und dem entsprechenden Männlichkeitsverständnis nahe (vgl. Steakley 1975: 44ff.; Keilson-Lauritz 1997: 142-153). Theoretisch ausgearbeitet und modernisiert wurde Jaegers Ansatz sodann von Friedländer, der auf dieser Basis eine Abspaltung von Hirschfelds WhK, die sogenannte Sezession, herbeiführte. Friedländers Arbeiten wiederum fließen schließlich in Hans Blühers Texte ein, die für die Jugendbewegung der Kaiserzeit und Weimarer Republik sehr einflussreich waren (vgl. Bruns 1998; Hergemöller 2004). Diese soeben aufgezählten Protagonisten eint die ausdrückliche Gegnerschaft zu Hirschfelds medizinisch argumentierender Zwischenstufentheorie. Der Disput um die Ex- und Inklusionen von Weiblichkeitsattributen in den verschiedenen Konstruktionen des homosexuellen Mannes blieb bis in die 3oer Jahre des 20. Jahrhunderts ein ständiger Konfliktherd der deutschen Homosexuellenbewegung. Und er ist untrennbar mit der Diskussion um die Geschlechterkonstruktion eines weiteren Anti-Typus verschränkt, nämlich des jüdischen Mannes. Auch ihm wurde eine partielle Weiblichkeit unterstellt (Gilman 1993; Mosse 1997; Boyarin 1997), für Otto Weininger verkörpert er sogar deren Äquivalent (vgl. Beitrag Mehlmann). Insofern überrascht es nicht, dass auch Magnus Hirschfeld aufgrund seiner jüdischen Herkunft nicht nur antisemitischen Attacken seiner Kon- 
trahenten ausgesetzt war. Ihm wurde »Unmännlichkeit« nachgesagt und sogar sein Status als Leitfigur der Homosexuellenbewegung von Konkurrenten abgesprochen. Umso bedeutsamer ist es, an dieser Stelle darauf hinzuweisen, dass Hirschfeld den Gedanken der Mischgeschlechtlichkeit auf die Rassenanthropologie übertrug und sogenannten Rassenmischungen zahlreiche Vorteile zuschrieb.

Hirschfeld, und darauf kommt es hier zunächst an, griff Ulrichs' Ansatz der mischgeschlechtlichen Homosexualität auf. Doch im Zuge seiner Medikalisierung verkörperte der moderne Homosexuelle 1900 keine gleichberechtigte Männlichkeit; vielmehr kam zu den bisherigen Stigmata des Sünders und des Verbrechers durch die sexualpathologische Neuinterpretation das des degenerierten Kranken hinzu. Der homosexuelle Mann war der hegemonialen Männlichkeit fraglos untergeordnet. Hirschfeld arbeitete sich in der Folgezeit an dieser sexualpathologischen Neuinterpretation Krafft-Ebings ab, um Homosexuelle in den vermeintlich wertfreien Natürlichkeitsdiskurs zu überführen. Dazu sollte ihm auch die Zwischenstufentheorie dienen. Inwiefern und in welchem Maße ihm diese Rückführung gelang, soll im Folgenden gezeigt werden, denn schließlich war er als Mediziner selbst dem medizin-anthropologischen Wertekanon der Geschlechtlichkeit verhaftet (vgl. Connell 1999: 238).

\section{Hirschfelds Geschlechter(neu)ordnung: Die Zwischenstufentheorie}

Hirschfeld konstatiert: »Den Ausgangspunkt für [mein] [...] Studium intersexueller Erscheinungen bildete die Homosexualität des Mannes und des Weibes« (Hirschfeld 1923: 11). Doch sehr schnell begann er, Homosexualität nicht als Einzelphänomen zu begreifen, sondern sie in den größeren Erklärungszusammenhang der Zwischenstufentheorie zu stellen, wie Mark Lehmstedt bereits an der Titelgebung des »Jahrbuches für sexuelle Zwischenstufen« belegt (Lehmstedt 2002: 103f.). Schließlich hatte bereits Ulrichs Uranismus und Hermaphroditismus analog gesetzt, wie auch die Sexualpathologen im Konzept der konträren Sexualempfindung verschiedene Formen von Mischgeschlechtlichkeit zusammenfassten (vgl. Herrn 2005: 25-30). Ich werde nun vier für das Konzept hegemonialer Männlichkeit relevante Aspekte der Zwischenstufentheorie benennen.

\section{Seine Positionen im Diskurs polarer Geschlechterbilder}

Zur Charakterisierung des Begriffs ssexuelle Zwischenstufen< schreibt Hirschfeld: »Wir verstehen unter sexuellen Zwischenstufen männlich geartete Frauen und weiblich geartete Männer« (Hirschfeld 1910a: 116). Insofern bezeichnet der Begriff keine sexuellen, sondern »geschlechtliche Zwi- 
schenstufen«, wie die Zwischenstufentheorie auch keine Sexualtheorie im engeren Sinne ist - eine solche hat Hirschfeld 1912 separat in seiner Arbeit »Naturgesetze der Liebe« vorgelegt (vgl. Herrn 2002) -, sondern eher eine Geschlechtersystematik darstellt. Denn sie beruht auf dem zeitgenössischen und in vieler Hinsicht durchaus konventionellen Verständnis der Geschlechter. In der Zwischenstufentheorie wird zunächst behauptet, dass es von jeder Eigenschaft, gleichgültig ob physisch, psychisch oder sozial, geschlechtsspezifische Ausprägungen gebe. Ihre Voraussetzung

»ist demnach eine genaue Erklärung dessen, was männlich und was weiblich ist, und hierin besteht die Hauptschwierigkeit und Strittigkeit, zumal es neben rein männlichen und weiblichen Eigenschaften auch solche gibt, die weder männlich noch weiblich oder, richtiger ausgedrückt, sowohl männlich als auch weiblich sind.« (Ebd.: 116)

Ungeachtet der Vielzahl Physis und Psyche überziehender geschlechtlicher Merkmalsausdeutungen gebe es also nicht nur eine »männliche« und eine »weibliche « Form jeder Eigenschaft, sondern noch zahlreiche Nuancen dazwischen, geschlechtliche Graduierungen auf der Merkmalsebene sozusagen. »Auf die Kenntnis gestützt, dass jeder Geschlechtscharakter für sich variieren kann, baute ich das System der sexuellen Zwischenstufen auf [...]« (Hirschfeld 1926: 548).

Nimmt man Hirschfelds diesbezügliche Texte zur Kenntnis, ist zunächst festzuhalten, dass er den tradierten medizinischen Geschlechterkanon weder verwirft, noch eine prinzipiell neue Lesart entsprechender Merkmale anbietet. Er greift vielmehr gängige stereotype Geschlechterzuschreibungen auf und macht sie zur Grundlage der Zwischenstufentheorie.

Zur Markierung seiner Position distanziert sich Hirschfeld ab 1904 unmissverständlich von den offen misogynen und antisemitischen Tönen Weiningers und bezieht sich auf eher moderate Sichtweisen (vor allem Rudolph Virchow und seine Schüler, aber auch Wilhelm Waldeyer, Havelock Ellis, Paolo Mantegazza u.a.). Auffällig ist dabei die Konstanz, mit der er viele dieser Befunde zwischen 1905 und 1930 immer wieder zitiert. Ungeachtet dessen wirbt er aber auch für neue feministische Positionen, wie beispielsweise in der gemeinsam mit seiner Schwester Franziska veröffentlichten Broschüre zum Frauenwahlrecht (Hirschfeld/Mann 1918). Außerdem setzt er sich in der Sexualreformbewegung für die Selbstbestimmung der Frauen und in der Sexualberatung und -aufklärung für die Verbreitung von Antikonzeptiva sowie Ende der 2oer Jahre auch für die Legalisierung der Abtreibung ein. Insofern modernisiert er auch die Geschlechterbilder. Als treffendes Beispiel für Hirschfelds ambivalente Haltung in der Frauenfrage sei hier auf den ersten Band seiner »Geschlechtskunde« verwiesen (Hirschfeld 1926: 479-542). Da referiert er die provokanten Thesen Mathilde Vaertings vom Kongress des Instituts für Sexualwissenschaft 1921 (Vaer- 
ting 1922) und benennt (s)ein zentrales Problem der Geschlechterdeutung, wenn er schreibt: »Man hat das soziologisch Gewordene viel zu wenig von dem biologisch Gegebenen getrennt« (Hirschfeld 1926: 488). Denn im Fluss dieses Textes entsteht ein Bruch an der Stelle, wo Hirschfeld auf seine aus früheren Veröffentlichungen stammenden, hergebrachten Lesarten zurückgreift und das Soziale - insbesondere die soziale und ökonomische Aufgabenteilung zwischen Frau und Mann - im Sinne einer Naturalisierung wieder biologisch deduziert (ebd.: 532 unten). Dieser Bruch verweist auf ein Oszillieren zwischen den Auffassungen aus der Kaiserzeit und der Weimarer Republik zwischen Traditionalismus und Moderne in der Geschlechterfrage. Die Annahme einer größeren Vielfalt merkmalsspezifischer Nuancierungen im Sinne eines Kontinuums bereichert jedoch die gewöhnlich binär gedachten Geschlechtereigenschaften. Doch insgesamt stellen die in Hirschfelds Schriften nachzulesenden akribischen Inventarisierungen und Gegenüberstellungen als männlich und weiblich geltender Eigenschaften vom ersten Jahrbuchaufsatz bis zur »Geschlechtskunde« weder die Geschlechterordnung noch die in der hegemonialen Männlichkeit getroffenen Idealisierungen ernsthaft in Frage (vgl. Hirschfeld 1918: 106-119). Im Gegenteil, sie wirken beglaubigend und bestärkend. Insofern besteht die Aporie der Zwischenstufentheorie zunächst darin, dass sie auf eben der Geschlechterpolarität aufbaut, die sie zu überwinden anstrebt. »Die Vermischung der Geschlechter hat immer wieder die Trennung der Geschlechter und die Geschlechtertrennung die Geschlechtervermischung zur Voraussetzung (Hirschfeld 1926: 545). Vergleichbar ist das - wie gezeigt wurde - mit Hirschfelds Position gegenüber dem Rassismus, den er ebenso ablehnt, wie er die anthropologischen Rassenunterschiede anerkennt.

\section{Die Systematisierung geschlechtlicher Vielfalt}

Die soeben erwähnte große Variabilität geschlechtlicher Merkmalsmanifestationen führt Hirschfeld auf der Grundlage von August Weißmanns Behauptung einer latenten Vererbung zu einer nahezu unendlichen Fülle ihrer Kombinationsmöglichkeiten. »Es kommen alle möglichen Verbindungen männlicher und weiblicher Eigenschaften, alle nur erdenklichen Variationen vor« (Hirschfeld 1926: 595).

»So gelangen wir bei einer [...] Betrachtung männlicher und weiblicher Individualtypen ganz von selbst zu einer großen Anzahl von Sexualtypen, die zwischen den extremen Vollmännern und Vollweibern eine lange Reihe bilden, in denen sich Mischformen männlicher und weiblicher Eigenschaften in größter Mannigfaltigkeit finden.« (Ebd.: 546)

Zur Systematisierung »dieser langen Reihe von Mischformen« nimmt Hirschfeld eine Unterteilung »in vier deutlich voneinander abgrenzbare 
Gruppen « (Hirschfeld 1910a: 122) von Geschlechtsmerkmalen vor: genitale, somatische, psychosexuelle und psychische, die sich in ähnlicher Form erstmals bei Römer (1904: 329) findet. Ihnen ordnet er Kategorien sie repräsentierender Formen von Mischgeschlechtlichkeit zu:

- den Zwischenstufen der Geschlechtsorgane die Hermaphroditen;

- den Zwischenstufen körperlicher Eigenschaften die Androgynen;

- den Zwischenstufen des Geschlechtstriebes die Homosexuellen und Metatropen; ${ }^{2}$

- und schließlich den Zwischenstufen seelischer Eigenschaften die Transvestiten.

Die Reihenfolge wählte Hirschfeld nicht zufällig, sie wird durch die Ontogenese bestimmt; jedes Geschlechtsmerkmal manifestiere sich zu einem bestimmten Zeitpunkt in der Individualentwicklung. Während die Differenzierung der Geschlechtsorgane bereits beim Embryo einsetze und sich der Körper im Folgenden ausdifferenziere, träten die psychosexuellen und psychischen Eigenschaften zuletzt in Erscheinung. Hirschfeld unterstellt mit dieser ontogenetischen Verklammerung aller Formen von Mischgeschlechtlichkeit stillschweigend die Analogisierbarkeit ihrer Kausalitäten, nämlich jene Erbanlagen und hormonellen Ursachen, wie sie in der zeitgenössischen Medizin gerade diskutiert wurden. Eben weil die vermeintlich evidente Mischgeschlechtlichkeit der Hermaphroditen medizinanthropologisch objektivierbar und unbestritten war, könne im Analogieschluss auch bei den Homosexuellen und Transvestiten davon ausgegangen werden; denn schließlich stellen sie gleichermaßen Geschlechtermischungen dar. Möglicherweise war die Option dieses Brückenschlags Anlass für Hirschfeld, diesen medizinisch etablierten Ansatz anderen vorzuziehen. Und entsprechend seiner 1905 in Anlehnung an Ernst Haeckels »biogenetisches Grundgesetz« ausformulierten »genogenetischen Gesetze« träten Zwischenstufen der jeweiligen Gruppen umso häufiger auf, je später sich die Merkmale manifestierten. Daher gebe es nur sehr wenige echte Hermaphroditen im Vergleich zu den schon zahlreicheren Pseudohermaphroditen, noch häufiger seien allerlei Formen körperlicher Mischgeschlechtlichkeit, und bereits in prozentualen Anteilen ließen sich die Bi- und Homosexuellen beziffern und ebenso die Fälle seelischer Mannweiblichkeit.

Weil sich für diese nach taxonomischem Vorbild vorgenommene Systematisierung ab 1903 die Bezeichnung »Zwischenstufentheorie« eingebürgert hatte, sah sich Hirschfeld veranlasst, überhöhten Erwartungen, die durch das Wort »Theorie« geweckt würden, entgegenzutreten. Zu seiner

2 I Mit seinem 1918 in der »Sexualpathologie« vorgelegten Konzept eines Metatropismus wollte Hirschfeld die Krafft-Ebingschen Konstruktionen des Sadismus und Masochismus ersetzen. Das Konzept wurde jedoch nur von seinem engen Mitarbeiterkreis im Institut für Sexualwissenschaft geteilt. 
Verteidigung schrieb er wiederholt: »Zunächst ist zu betonen, dass es sich bei der Lehre von den sexuellen Zwischenstufen [...] gar nicht um eine Theorie, sondern um ein Einteilungsprinzip handelt« (Hirschfeld 1910b: 275; H.i.O.). Sinn und Zweck seines Ansatzes fasst er wie folgt zusammen:

»Die intersexuellen Varianten in ihrer außerordentlichen Vielgestaltigkeit zu registrieren, sie historisch und biologisch zu erfassen, ethnologisch und soziologisch zu bewerten, sah ich als Aufgabe der Lehre [...] von den sexuellen Zwischenstufen.« (Hirschfeld 1923: 10; H.i.O.)

In einem seiner späten Beiträge zur Zwischenstufentheorie, die Hirschfeld nun schon in den Kontext der etablierten Konstitutionsbiologie stellte, findet sich die einzige, abstrakte Illustration, in der die Zwischenstufen zueinander ins Verhältnis gesetzt werden.

Abbildung 1: Aus: Magnus Hirschfeld, »Die intersexuelle Konstitution «. In: Jahrbuch für sexuelle Zwischenstufen XXIII, 1923, S. 24.

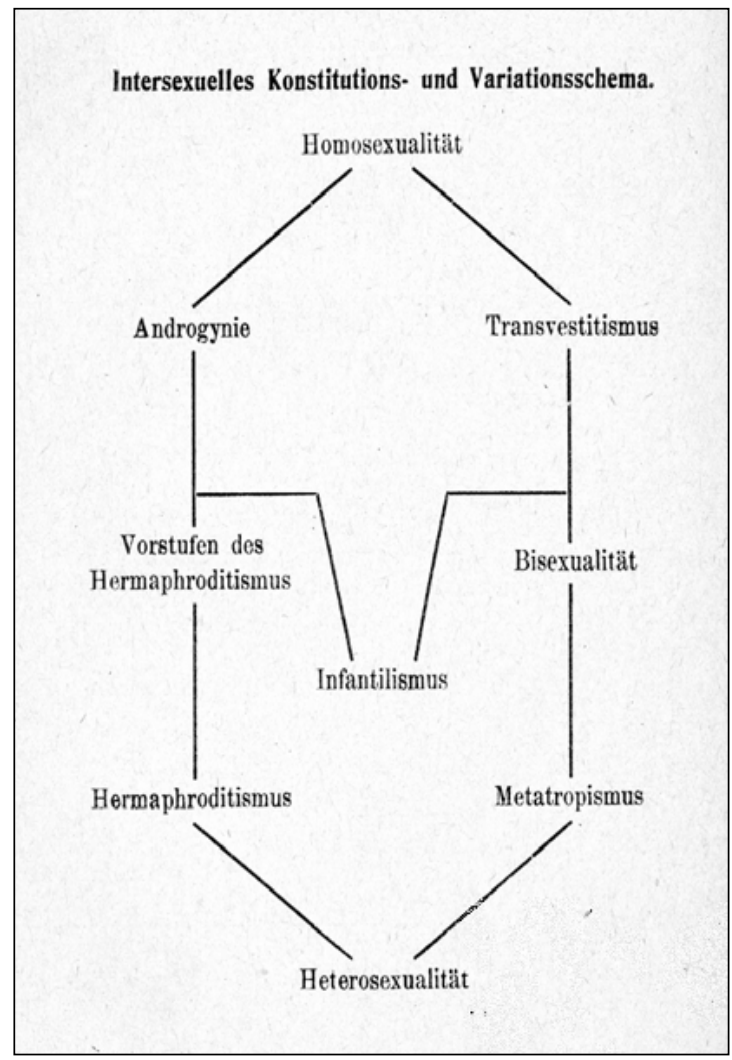


Zum Verständnis sei angemerkt, dass Hirschfeld sogenannte genitale, körperliche und psychische Infantilismen (hier mittig) auf eine andere Ebene seiner »Sexualpathologie« auslagerte.

Wie ein Kommentar zu diesem Schema liest sich der später von ihm niedergeschriebene Satz:

»Alle diese sexuellen Varietäten bilden einen geschlossenen Kreis, in dem gewisse Zwischenstufentypen nur besonders markante Punkte darstellen, zwischen denen aber [...] lückenlose Verbindungslinien [bestehen].« (Hirschfeld 1926: 599)

Hirschfeld stellt in seinem Schema zunächst phänomenologische Verwandtschaften der Zwischenstufenkategorien her, die er als geschlossenes System betrachtet. Auf deren rechtem Strang finden sich die psychischen Zwischenstufen aneinandergereiht, auf dem linken die körperlichen.

Obgleich es Hirschfeld hier um die Illustration kausaler und phänomenologischer Verbindungen zwischen den Kategorien geht und nicht um ihr hierarchisches Verhältnis zueinander, ist es dennoch kein Zufall, dass Homosexualität in der Vertikalen an oberster Stelle rangiert: ein deutlicher Hinweis auf ihre strukturelle Privilegierung gegenüber den anderen Zwischenstufen, die sich auch anhand Hirschfelds fotografischer Abbildungspraxis (z.B. Geschlechtsübergänge, Zwischenstufenwand) wie in entsprechenden Texten nachweisen lässt. Auffällig ist in diesem Zusammenhang aber auch, dass Homosexualität und Heterosexualität die auf den Kopf gestellten Pole der Vertikalen markieren, so dass sie hier als Gegenspieler - oder, um mit Mosse zu reden, als »Anti-Typen« - erscheinen.

Die in diesem Schema dargestellte konzeptuelle Verwandtschaft zwischen Homosexualität, Androgynie und Transvestitismus begründete Hirschfeld mit gemeinsamen Kausalitäten. Zur Erforschung phänomenologischer Beziehungen ließ er - nach dem Vorbild der Rassenanthropometrie - Körpervermessungen vornehmen, wie er auch mit einem eigens entworfenen und $\mathrm{zu}$ Tausenden verteilten Fragebogen die psychischen Ähnlichkeiten zu ermitteln trachtete.

Dabei haben die in der Abbildung durch Verbindungslinien dargestellten Verwandtschaften der Kategorien lange medizin-anthropologische Traditionen, die Hirschfeld kannte. Bereits in diversen mittelalterlichen und frühneuzeitlichen Konzeptionen des Hermaphroditismus - die letztlich auf rezeptionsbedingte Überlagerungen hippokratisch-sokratischer Sichten zurückgehen - wurden jene Mischgeschlechtlichkeitsformen phänomenologisch, kausal und semantisch in Verbindung gebracht, wenn auch nicht in der expliziten Weise Hirschfelds.

\section{Weiblichkeitszuschreibungen im Widerstreit}

Hirschfelds Verknüpfung der Zwischenstufenkategorien basiert auf den Zuschreibungen von genitaler, somatischer, psychosexueller und psychischer Mischgeschlechtlichkeit, die sie in spezifische Relationen zur 
hegemonialen Männlichkeit setzen. Das führte zu einer Reihe ganz massiver Konflikte, die sich - um in Connells Begrifflichkeit zu bleiben - um das Ausmaß der Teilhabe an der »patriarchalen Dividende« hegemonialer Männlichkeit im Sinne der Komplizenschaft drehten. Diese Konflikte entstanden aus den verschiedenen Geschlechterkonstruktionen sowohl zwischen den Kategorien als auch unter den Repräsentanten verschiedener Strömungen innerhalb einzelner Kategorien. Ein solcher Konflikt soll dies beispielhaft illustrieren: es handelt sich um das Verhältnis der Cross-Dresser, für die Hirschfeld 1910 die Kategorie »Transvestiten « einführte, zu den Strömungen der Homosexuellenbewegung:

Hirschfeld beschrieb die Transvestiten in seiner gleichnamigen Monografie als heterosexuelle Kategorie. Dem ging ein mehrjähriger Dialog zwischen Cross-Dressern und Sexualwissenschaftlern voraus, der die Entkoppelung des gleichgeschlechtlichen Begehrens von der Kleiderpräferenz zum Thema hatte. Cross-Dressing galt in der Sexualpathologie Westphals als Variante der »konträren Sexualempfindung « und in der Krafft-Ebings als Symptom der Homosexualität. Gegen diesen Konnex wandten sich ausschließlich männliche Cross-Dresser (vgl. Herrn 2005: 25-30). Ihre schriftlichen Äußerungen in sexualwissenschaftlichen Texten belegen eindrucksvoll, wie sie die ihnen zugeschriebene homosexuelle Neigung als Verkennung ihrer »Natur« dementierten und als Entwertung ihrer Männlichkeit ablehnten. So schreibt ein Cross-Dresser an Hirschfeld: »Leider werden wir fälschlich auch noch oft für Päderasten gehalten« (Hirschfeld 1910b: 73). Und ein anderer: »Urninge und effeminierte Männer verachte ich tief« (ebd.: 73; H.i.O.). Cross-Dresser waren darauf bedacht, ihre Eigenart auf den punktuellen, passageren oder permanenten Wunsch, das andere Geschlecht zu performieren, einzuschränken. Das war auch der Grund für ihre Sexualwissenschaftlern vehement vorgetragenen Separierungsbestrebungen, die schließlich zur kategorialen Abspaltung der Transvestiten führte. Nachdem sich das Transvestitismuskonzept vor dem Ersten Weltkrieg langsam durchzusetzen begann, setzten heterosexuelle männliche Transvestiten ihre Abgrenzung fort, indem sie Kontakte zu homosexuelle Transvestiten mieden und sie aus ihren Organisationen fernzuhalten suchten.

Aber auch die »homosexuellen« Maskulinisten drängten auf diese Separation. In der Tradition Gustav Jaegers, Elisar von Kupffers und Benedikt Friedländers lehnten sie nicht nur die sexualpathologische Verknüpfung zwischen Männerbegehren und Cross-Dressing ab, sondern überhaupt medizinische Erklärungen, die auf Weiblichkeitszuschreibungen rekurrierten. Männerbegehren wies in ihren Theoretisierungen keinerlei Korrelation zu Weiblichkeit auf und sei eine jedem mehr oder weniger zukommende Qualität. Daher wendeten sie sich von Beginn an gegen die von Hirschfeld und dem WhK propagierte Auffassung vom Homosexuellen als weiblichem Mann. Elisar von Kupffer und Adolf Brand karikierten Hirschfelds Homosexuellenkonstruktion als »urnische Unterröckchen« respektive »jammerbare Effeminierte«, die Hirschfeld »allen Gaffern und Lachern 
in Weiberkleidern« vorführe (Kupffer 1900: 3; Brand 1906: 30). Besonders war es jedoch die in der Zwischenstufentheorie vorgenommene Verknüpfung der Homosexualität mit der performativen Weiblichkeit der CrossDresser und der paradigmatischen Geschlechterambiguität der Hermaphroditen, die zumindest zu permanenten Angriffen gegen Hirschfeld und das WhK Anlass gab (vgl. Herrn 2005: 38-42; Hergemöller 2004).

Die Transvestiten wiesen den Homosexualitätsverdacht zurück; die Maskulinisten leugneten jede Form von Effemination. Beide versuchten demnach, ihre durch spezifische Weiblichkeitszuschreibungen beschädigt geglaubte Männlichkeit zu retten. Ihnen ging es um die Erhaltung ihrer Komplizenschaft zum hegemonialen Ideal. In Hirschfelds Konzept männlicher Homosexualität kulminierte hingegen die Feminität, die sie der hegemonialen Form eindeutig unterordnete, aber auch gegenüberstellte. Hirschfelds Homosexuelle sind keine Komplizen, sondern - wenn auch unfreiwillig - Opponenten. Das war ihm durchaus bewusst:

»Daß man auf die Männer, die sich weibliche Neigungen >zuschulden kommen ließen<, stets mit stärkerer Verachtung herabsah als auf Frauen, die nach Vermännlichung trachteten, hängt im letzten Grunde wohl mit der höheren Meinung zusammen, die die Männer von sich hatten; mehr oder minder unbewusst empfanden sie es als Erniedrigung ihres Geschlechts, wenn ein Mann mit und ohne seinen Willen Zeichen der Männlichkeit einbüßte.« (Hirschfeld 1910b: 341)

Das führte zu dem bereits geschilderten Dauerkonflikt. George Mosse beschreibt beide Strategien mit den Worten: »Diejenigen, die als Antitypus stigmatisiert wurden, versuchten entweder, den Idealtypus zu imitieren oder sich selbst in Widerspruch zum dominanten Stereotyp zu definieren« (Mosse 1997: 22). Letzteres scheint für Hirschfelds Homosexualitätskonzept zuzutreffen.

\section{Mischgeschlechtlichkeit als Norm}

Die Fülle möglicher Zwischenstufen veranschaulicht Hirschfeld zur Plausibilisierung anhand eines Rechenbeispiels, in dem er Merkmalszahlen und -variationen multipliziert und so auf eine utopische Zahl sogenannter »Sexualtypen« kommt. Dabei seien »Vollmänner« und »Vollweiber« als ausschließlich männliche und weibliche Eigenschaften repräsentierende Individuen lediglich »konstruierte Extreme, Abstraktionen, in Wirklichkeit sind sie bisher nicht beobachtet worden« (Hirschfeld 1910a: 122). Vielmehr trage grundsätzlich jeder Mensch Eigenschaften beider Geschlechter in sich, und infolgedessen sei jede[r] eine eigene und einmalige Zwischenstufe, ein Unikat der Mischgeschlechtlichkeit.

»Die Zahl der denkbaren und tatsächlichen Sexualtypen ist unendlich; in jedem Menschen findet sich eine verschiedene Mischung männlicher und weiblicher Subs- 
tanz, und wie wir nicht imstande sind, zwei gleiche Blätter an einem Baume ausfindig zu machen, so werden wir auch nie zwei menschliche Wesen auffinden können, in denen das Mischungsverhältnis des männlichen und weiblichen Prinzips nach Art und Menge vollkommen übereinstimmt.« (Hirschfeld 1926: 599; H.i.O.)

An dieser, 1899 erstmals sinngemäß geäußerten Auffassung offenbart sich eine neue Dimension der Zwischenstufentheorie. Sie stellt nicht nur eine Struktur und einen semantischen Zusammenhang zwischen den genannten vier Gruppen her, sondern weitet sich zu einer Erklärung universeller Mischgeschlechtlichkeit aus. Damit ist die Zwischenstufentheorie auch kein bloßes »Einteilungsprinzip« mehr, zu der sie Hirschfeld immer verteidigend herunterspielte, sondern tatsächlich eine neue Geschlechterdeutung. In ihr macht er die Mischgeschlechtlichkeit zur allgegenwärtigen Regel. Diese Denkfigur lässt aus den Vertretern vormals >abnormer< Geschlechtlichkeit, den Homosexuellen, Transvestiten und Hermaphroditen, kurzerhand hervorragende Exponenten der Geschlechternorm werden. Es handelt sich um einen Ansatz ihrer Rehabilitierung, eine Versöhnungsvision (vgl. Herrn 1996). Der Soziologe Stefan Hirschauer ordnet Hirschfelds Zwischenstufentheorie in diesem Kontext wie folgt ein:

»Hirschfelds humanistisches Projekt war das einer geschlechtlichen Konzeption von Individualität. [...] Die Zwischenstufentheorie war ein Gegendiskurs zum Differenzmodell der Geschlechter, der den darin artikulierten Denkstil unbeabsichtigt ad absurdum führte und noch in seinen antifeministischen Tönen auf seine Entstehungsgründe verwies. Die Homosexuellen wurden bei Hirschfeld eine Spezies unter vielen. Diese relative Entspezifizierung macht seine Theorie zu einem Wendepunkt.« (Hirschauer 1993: 84f.; H.i.O.)

Auch Gesa Lindemann ist der Ansicht: »Die Zwischenstufentheorie ist in diesem Jahrhundert [gemeint ist das 20.] der einzige große Versuch gewesen, die Konstruktion des Körpers in emanzipatorischer Hinsicht neu zu fassen« (Lindemann 1993: 103).

Hirschfelds Behauptung einer universellen Mischgeschlechtlichkeit stellt aber auch die hegemoniale Männlichkeit über ihre impliziten Weiblichkeitsanteile grundsätzlich in Frage, denn hegemoniale Männlichkeit setzt ja den kategorischen Ausschluss von Weiblichkeit voraus. Insofern bedeutete diese Dimension der Zwischenstufentheorie tatsächlich eine weitere, massive und neue Infragestellung hegemonialer Männlichkeit und damit eine Bedrohung.

Hirschfeld hat diese Konsequenz seines Ansatzes nie sonderlich betont oder gar in den Mittelpunkt gestellt - und in der Rezeption seiner Schriften wurde sie auch nur für kurze Zeit nach dem Ersten Weltkrieg gewürdigt. In der Regel wurde die Zwischenstufentheorie nämlich nur als Erklärung der Homosexualität wahrgenommen. Den Gedanken einer universellen 
Mischgeschlechtlichkeit hatte Hirschfeld, wie bereits erwähnt, vor 1900 niedergelegt - also einige Jahre vor Otto Weiningers mit großem Aplomb in Szene gesetzter Studie »Geschlecht und Charakter « (1903). ${ }^{3}$ Aber auch Weiningers Lesart der Mischgeschlechtlichkeit unterscheidet sich von der Hirschfelds: »Der wahre Mann« Weiningers müsse, so George Mosse, »anders als der Jude und der Homosexuelle, die weibliche Komponente seines Naturells überwinden« (Mosse 1997: 97). Insofern stellt Weiningers Arbeit die hegemoniale Männlichkeit nicht in Frage, sondern stabilisiert sie vielmehr. Der wahre Mann ist bei Hirschfeld jedoch eine Fiktion, er bezeichnet ihn als »imaginäres Gebilde«. Die weibliche Komponente gilt es bei ihm daher auch nicht zu überwinden, sondern zu entdecken und zu dechiffrieren - wo auch immer sie in Physis und/oder Psyche verborgen sein mag. Daher stellt diese Dimension der Zwischenstufentheorie tatsächlich eine Herausforderung hegemonialer Männlichkeit dar. - In diesem Zusammenhang ist nochmals daran zu erinnern, dass Hirschfeld seine Idee der Mischgeschlechtlichkeit auf die Rassenanthropologie übertrug und entgegen dem Zeitgeist noch in den 1930er Jahren die Vorteile der Rassenmischung verteidigte.

Der Religionswissenschaftler Edgar E. Bauer und der Hirschfeld-Biograf Manfred Herzer weisen Hirschfeld wegen dieser Lesart der Zwischenstufentheorie die Priorität des Gedankens einer universellen Mischgeschlechtlichkeit zu, um deren Herleitung und Auslegung eine detail- und faktenreiche Kontroverse im Gange ist. ${ }^{4}$

\section{Halbherzige Entpathologisierungen}

Ich hatte bereits angedeutet, dass Hirschfeld die Zwischenstufentheorie als Instrument zur Entpathologisierung der Homosexualität und ihrer Rückführung in eine Geschlechternormalität entwarf. In einer Reihe von Arbeiten aus seinen Anfangsjahren beschäftigt er sich ausführlich mit der Widerlegung jener von der Sexualpathologie getroffenen Zuschreibungen. Als Richard von Krafft-Ebing das pathologische Dogma der Homosexualität lockert (Krafft-Ebing 1901: 2, 5), faksimiliert Hirschfeld 1903 ein ent-

3| Es ist hervorzuheben, dass Hirschfeld schon 1903 - also im Jahr der Veröffentlichung von Otto Weiningers »Geschlecht und Charakter« - diese Gedanken klar und unmissverständlich formulierte: »Im Grunde genommen ist jeder Mensch erst durch das ihm innewohnende Mischungsverhältnis männlicher und weiblicher Teile verständlich. [...] Der Vollmann und das Vollweib sind in Wirklichkeit nur imaginäre Gebilde, die wir nur zur Hilfe nehmen müssen, um für die Zwischenstufen Ausgangspunkte zu besitzen« (Hirschfeld 1903: 126ff.).

4 | Vgl. dazu die entsprechenden Aufsätze in den letzten Nummern der Zeitschriften »Mitteilungen der Magnus-Hirschfeld-Gesellschaft« und »Capri. Zeitschrift für schwule Geschichte«. 
sprechendes Schreiben im »Jahrbuch für sexuelle Zwischenstufen«als Beleg für den Erfolg seiner Strategie.

Etwas später äußert er sich dazu wie folgt: »für einen darwinistisch geschulten Biologen« sei die generelle Pathologisierung sexueller Zwischenstufen ein »unhaltbarer Standpunkt«, wie auch die damals gängige Praxis, die Krankheitszuschreibungen von der Stärke der andersgeschlechtlichen Einschläge abhängig zu machen. Vielmehr plädiert er dafür, »alle diese Zwischenstufen als sexuelle Varietäten [aufzufassen] [...] und den Begriff des Pathologischen im Sexualleben von ganz anderen Momenten abhängig « zu machen, nämlich der »Geschlechtsreife«, also vom Alter und der Mündigkeit, und der »Geschlechtsfreiheit«, d.h. des freiwilligen Konsensus (Hirschfeld 1910a: 129; H.i.O.).

Dieser Vorschlag wurde von den Zeitgenossen keineswegs geteilt. Ein Großteil der Sexualwissenschaftler, darunter Albert Moll und Max Marcuse, kritisierten Hirschfeld gerade wegen dessen Verschiebung sexualpathologischer Grenzen, vor allem aber der Entpathologisierung der Zwischenstufen. Dabei ist Hirschfelds fast heutig anmutende Position in diesen Fragen bei weitem nicht so eindeutig, wie jenes Zitat zunächst vermuten lässt. Suchen wir in seinen Arbeiten, die er nach diesem Plädoyer 1910 veröffentlichte, nach Passagen, in denen er Zwischenstufen seinen Maßstäben zuordnet, ist Folgendes zu konstatieren:

Bei der konkreten Bewertung des Hermaphroditismus verfuhr Hirschfeld weit weniger großzügig in der Auslegung der Zwischenstufentheorie. Auch wenn er im Allgemeinen darum bemüht war, die sexuellen Zwischenstufen als nicht-pathologische Phänomene zu begreifen, ging er dennoch davon aus, dass Hermaphroditismus »Teilerscheinung eines degenerativen Zustandsbildes« sei, im Unterschied zu sogenannten »einfachen« Geschlechtermischungen. Die bei Hermaphroditen angeblich »sehr häufig« auftretenden »anderweitigen körperlichen und seelischen Störungen« veranlassten ihn $1918 \mathrm{zu}$ dem Schluss:

»Zwar sind [...] diese Begleiterscheinungen nicht durchgängig vorhanden, doch gehen wir wohl nicht fehl, wenn wir annehmen, dass an und für sich schon einer so hochgradigen Sexualstörung ein degenerativer Charakter innewohnt.« (Hirschfeld 1918: 13)

Schauen wir in seine Arbeiten über Homosexualität, so vergleicht er sie häufig mit sogenannten »Hemmungsbildungen«, zunächst mit Hasenscharte und Wolfsrachen (Hirschfeld 1896), später mit Farbenblindheit (Hirschfeld 1914), da Homosexuelle für bestimmte (weibliche) Sinnesreize unempfänglich seien. In der 1914 veröffentlichten Monografie »Die Homosexualität des Mannes und des Weibes« hebt er hervor, dass Homosexualität »auf einer spezifischen Konstitution von psychisch-hermaphroditischem Habitus« (Hirschfeld 1914: 370) beruhe, »letzten Endes [also] auf der Mannweiblichkeit des Menschen« (ebd.: 376). Aufgrund dessen 
sei sie keine Degenerationserscheinung an sich - eine Auffassung, die er mit Iwan Bloch und Sigmund Freud teilt. Hirschfeld hielt Homosexualität jedoch, wie er 1901 erstmals kund tut (Hirschfeld 1901: 55-61), für ein natürliches »Vorbeugungsmittel der Degeneration«, denn ihre Nachkommen trügen »vielfach den Stempel geistiger Minderwertigkeit«. Insofern sei »vom rassenhygienischen Standpunkt die Ehe eines oder einer Homosexuellen stets ein gewagtes Unterfangen « (Hirschfeld 1914: 391).

Trotz der beteuerten und ihnen von Hirschfeld zugestandenen Heterosexualität sei auch bei Transvestiten »der andersgeschlechtliche Einschlag besonders beträchtlich«. Deshalb äußerte sich Hirschfeld warnend »hinsichtlich der Zweckmäßigkeit dieser Ehen« (Hirschfeld 1910b: 303). Bei Transvestiten liege im Unterschied zu Homosexuellen »eine solche Abartung vom reinen Geschlechtstypus vor, dass sie zwar noch nicht als Entartung angesprochen werden soll, doch leicht bei der Nachkommenschaft zu psychisch uneinheitlichen, gelockerten, labil-degenerierten Individuen führen kann« (ebd.; vgl. auch Herrn 2005: 120-126).

Die soeben zitierten Einschätzungen Hirschfelds könnten noch mit vielen ähnlich lautenden untermauert werden. So lässt sich seine Stellung zur Pathologisierung der Zwischenstufen wie folgt zusammenfassen: Hirschfeld trat - kraft seiner medizinischen Autorität - für die Verschiebung sexualpathologischer Grenzen ein. Dennoch war er als naturwissenschaftlich orientierter Arzt so stark im eugenischen Diskurs verhaftet, dass er den Referenzrahmen der Degenerationstheorie nicht hinter sich lassen konnte. Obgleich er die primäre Pathologisierung der Zwischenstufen, die von der Mehrzahl seiner Zeitgenossen nicht in Frage gestellt wurde, zu überwinden sucht, führt er über ihre Rückbindung an einen eugenischen Wert im Reproduktionsprozess eine indirekte sekundäre Pathologisierung ein. Während er Hermaphroditen einen unmittelbaren »degenerativen Charakter« unterstellt, begreift er Homosexualität und Transvestitismus >nurく als natürliches Präventionsmittel vor Degeneration. Insofern gelang es Hirschfeld auch nur unvollständig, die Homosexuellen von den sexualpathologischen Zuschreibungen im Sinne Ulrichs zu befreien. Er bescheinigt den prominentesten Repräsentanten der Zwischenstufentheorie generell eine Minderwertigkeit, die sie der hegemonialen Männlichkeit wiederum hierarchisch unterordnet.

\section{Fazit}

Im Hinblick auf die hegemoniale Männlichkeit erweist sich Hirschfelds Konzept der Zwischenstufentheorie vielschichtiger, als es auf den ersten Blick scheinen mag. Schon sein Rückgriff auf Ulrichs' Konstruktion des Urnings als sich vom Männlichkeitsideal unterscheidende mann-weibliche Form stellt eine Herausforderung für die hegemoniale Männlichkeit dar, weil es ihr einen selbstbewussten »Anti-Typus« an die Seite stellt. Die 
Modernisierung, Popularisierung und nicht zuletzt Instrumentalisierung dieses Konzeptes für den sexualpolitischen Kampf des Wissenschaftlichhumanitären Komitees trug dazu bei, »das Ideal der Maskulinität und das, was es verkörperte, [...] allmählich [...] durch die zunehmende Selbstsicherheit unmännlicher Männer und unweiblicher Frauen « (Mosse 1997: 118) in Frage zu stellen. Wenn Gert Hekma meint, dass Ulrichs' und Hirschfelds mischgeschlechtliches Konzept des Homosexuellen ihm gleichsam die Bedrohlichkeit nimmt, weil es sich - im vorauseilenden Gehorsam - dem hegemonialen Ideal als »unmännlich « unterordnet (Hekma 1994: 234f.), ist das nur zum Teil zutreffend. Dass diese personalisierte Unmännlichkeit bereits durch ihre permanente Präsenz und ihr politisches Aufbegehren die hegemoniale Männlichkeit herausfordert, wird dabei freilich übersehen, ganz zu schweigen von den weitergefassten Deutungen der Zwischenstufentheorie, um die es in diesem Beitrag geht. Die soeben dargestellten, das Verhältnis der Zwischenstufentheorie zur hegemonialen Männlichkeit kennzeichnenden vier Aspekte, lassen sich wie folgt zusammenfassen:

Das Charakteristische an Hirschfelds Zwischenstufentheorie ist zunächst ihr vom Betrachter abhängiges Changieren zwischen Beglaubigung und Herausforderung der bestehenden Geschlechterordnung: auf der einen Seite finden wir - trotz der Übernahme einiger feministischer Positionen - die Fortschreibung der traditionellen geschlechterstereotypen Auffassungen, die klaren, an die biologische Taxonomie des 19. Jahrhunderts erinnernden Systematisierungen und Kategorienbildungen sowie deren Bewertung nach fortpflanzungsbiologischen Maßstäben.

Auf der anderen Seite finden wir Innovationen, wie die Einführung von Nuancierungen der binär gedachten Geschlechtseigenschaften im Sinne eine Kontinuums, die Durchlässigkeit von und die Übergänge unter den Zwischenstufenkategorien, die Flexibilisierung der sexualpathologischen Grenzen, vor allem aber die Behauptung einer universellen Mischgeschlechtlichkeit als grundsätzliche Infragestellung hegemonialer Männlichkeit.

Jürgen Link unterscheidet zwischen einem Protonormalismus als Verfahren strikter wie starrer Abgrenzungen und einem flexiblen Normalismus; während ersterer beispielsweise mit Polaritäten wie normal/abnorm oder krank/gesund operiert, geht letzterer von einem Kontinuum gradueller dynamischer Abstufungen aus (Link 1997). Andrea Bührmann nimmt diese Unterscheidung auf und beschreibt den Protonormalismus als typisch für die Sexualpathologie des 19. Jahrhunderts, während sie den flexiblen Normalismus einer empirischen Sexualwissenschaft im Sinne Kinseys zuordnet (Bührmann 1998: 214). Hirschfelds Zwischenstufentheorie markiert einen Übergang zwischen der protonormalistischen Sexualpathologie und dem flexiblen Normalismus der Sexualwissenschaft. Sie enthält Elemente beider Strategien, allerdings bereits ein halbes Jahrhundert vor Kinsey. 


\section{Literatur}

Ankum, Katharina von (Hg.) (1997): Women in Metropolis - Gender and Modernity in Weimar Culture, Berkeley: University of California Press.

Bab, Edwin (1903): Die gleichgeschlechtliche Liebe (Lieblingminne), Berlin: Hugo Schildberger Verlag.

Boyarin, Danial (1997): Unheroic Conduct. The Rise of Heterosexuality and the Invention of the Jewish Man, Berkeley: University of California Press.

Brand, Adolf (1906): »Afterkultur und Homosexualität«. In: Die Gemeinschaft der Eigenen, Flugschrift für Sittenverbesserung und Lebenskunst 3/3, S. 29-33.

Bruns, Claudia (2001): »(Homo-)Sexualität als virile Sozialität. Sexualwissenschaftliche, antifeministische und antisemitische Strategien hegemonialer Männlichkeit im Diskurs der Maskulinisten 1880-1920«. In: Ulf Heidel/Stefan Micheler/Elisabeth Tuider (Hg.), Jenseits der Geschlechtergrenzen - Sexualitäten, Identitäten und Körper in Perspektiven von Queer Studies, Hamburg: MännerschwarmSkript, S. 87-108.

Bührmann, Dorothea Andrea (1998): »Die gesellschaftlichen Konsequenzen der Wissensproduktion. Zum Verhältnis von (Sexual-)Wissenschaften und gesellschaftlichen Normalisierungsmechanismen«. In: Ursula Ferdinand/Andreas Pretzel/Andreas Seeck (Hg.), Verqueere Wissenschaft? - Zum Verhältnis von Sexualwissenschaft und Sexualreformbewegung in Geschichte und Gegenwart, Münster: LIT, S. 213-228.

Connell, Robert W. (1999): Der gemachte Mann - Konstruktion und Krise von Männlichkeiten, Opladen: Leske + Budrich.

Dinges, Martin (2005): »>Hegemoniale Männlichkeit< - ein Konzept auf dem Prüfstand«. In: ders. (Hg.), Männer - Macht - Körper - Hegemoniale Männlichkeiten vom Mittelalter bis heute, Frankfurt a.M.: Campus, S. 7-33.

Foucault, Michel (1983): Sexualität und Wahrheit, Bd. 1. Der Wille zum Wissen, Frankfurt a.M.: Suhrkamp.

Friedländer, Benedikt (1904): Die Renaissance des Eros Uranios, Schmargendorf-Berlin: Verlag »Renaissance

Gilman, Sander L. (1993): Freud, Race, and Gender, Princeton: Princeton University Press.

Hekma, Gert (1994): »>A Female Soul in a Male Body<: Sexual Inversion as Gender Inversion in Nineteenth-Century Sexology«. In: Gilbert Herdt (Hg.), Third Sex Third Gender - Beyond Sexual Dimorphism in Culture and History, New York: Zone Books, S. 213-239.

Hergemöller, Bernd-Ulrich (2004): »Hirschfeld und Blüher. Kontakte und Konflikte 1912-1922«. In: Vera-Elke Kotowski/Julius Schoeps (Hg.), Magnus Hirschfeld - Ein Leben im Spannungsfeld von Wissenschaft, Politik und Gesellschaft, Brandenburg: be.bra wissenschaft, S. 118-136.

Herrn, Rainer (1996): »Hirschfeld Magnus (1868-1935): >... es bedürfte der Feder eines Dante oder Goethe, um anschaulich zu schildern, wie die 
asketische Weltanschauung das Paradies körperseelischer Geschlechtlichkeit in eine Hölle auf Erden verwandelt hat.« In: Hans Erler/Ernst Ludwig Ehrlich/Ludger Heid (Hg.), Integration und Shoa - Jüdischer Geist und politische Humanität im 20. Jahrhundert, Frankfurt a.M.: Campus, S. 173-178.

Herrn, Rainer (2002): »Geschlechtsübergänge und Naturgesetze der Liebe«. In: Mitteilungen der Magnus-Hirschfeld-Gesellschaft 33/34, S. 52-56.

Herrn, Rainer (2004): »Ein historischer Urning. Ludwig II. von Bayern im psychiatrisch-sexualwissenschaftlichen Diskurs und in der Homosexuellenbewegung des frühen 20. Jahrhunderts«. In: Katharina Sykora (Hg.), »Ein Bild von einem Mann «. Ludwig II. von Bayern - Konstruktion und Rezeption eines Mythos, Frankfurt a.M.: Campus, S. 48-87.

Herrn, Rainer (2005): Schnittmuster des Geschlechts - Transvestitismus und Transsexualität in der frühen Sexualwissenschaft, mit einem Geleitwort von Volkmar Sigusch, Gießen: Psychosozial-Verlag.

Hirschfeld, Magnus [Pseudonym: Th. Ramien] (1896): Sappho und Sokrates oder Wie erklärt sich die Liebe der Männer und Frauen zu Personen des eigenen Geschlechts?, Leipzig: Max Spohr.

Hirschfeld, Magnus (1899): »Die objektive Diagnose der Homosexualität«. In: Jahrbuch für sexuelle Zwischenstufen I, S. 4-35.

Hirschfeld, Magnus (1901): \$Sind sexuelle Zwischenstufen zur Ehe geeignet?«. In: Jahrbuch für sexuelle Zwischenstufen III, S. 37-71.

Hirschfeld, Magnus (1903): »Ursachen und Wesen des Uranismus«. In: Jahrbuch für sexuelle Zwischenstufen VI, S. 1-193.

Hirschfeld, Magnus (1905): Geschlechtsübergänge - Mischungen männlicher und weiblicher Geschlechtscharaktere (Zwischenstufen), Leipzig: Verlag der Monatsschrift für Harnkrankheiten und sexuelle Hygiene, W. Malende.

Hirschfeld, Magnus (1906): »Vom Wesen der Liebe«. In: Jahrbuch für sexuelle Zwischenstufen VIII, S. 1-284. [1906 unter demselben Titel auch als Buch erschienen, Leipzig: Spohr.]

Hirschfeld, Magnus (1910a): »Die Zwischenstufen->Theorie«. In: Sexualprobleme 6, S. 116-136.

Hirschfeld, Magnus (1910b): Die Transvestiten - Eine Untersuchung über den erotischen Verkleidungstrieb, Berlin: Alfred Pulvermacher.

Hirschfeld, Magnus (1912): Naturgesetze der Liebe - Eine gemeinverständliche Untersuchung über den Liebes-Eindruck, Liebes-Drang und Liebes-Ausdruck, Berlin: Alfred Pulvermacher.

Hirschfeld, Magnus (1914): Die Homosexualität des Mannes und des Weibes, Berlin: Louis Marcus Verlagsbuchhandlung.

Hirschfeld, Magnus (1918): Sexualpathologie, Bd. 2, Sexuelle Zwischenstufen - Das männliche Weib und der weibliche Mann, Bonn: Marcus \& Weber.

Hirschfeld, Magnus (1923): »Die intersexuelle Konstitution«. In: Jahrbuch für sexuelle Zwischenstufen XXIII, S. 3-27. 
Hirschfeld, Magnus (1926): Geschlechtskunde, Bd. 1, Die körperseelischen Grundlagen, Stuttgart: Julius Püttmann.

Hirschfeld, Magnus/Mann, Franziska (1918): Was jede Frau vom Wahlrecht wissen muß!, Berlin: Alfred Pulvermacher.

Hirschauer, Stefan (1993): Die soziale Konstruktion der Transsexualität - Über die Medizin und den Geschlechtswechsel, Frankfurt a.M.: Suhrkamp.

Honegger, Claudia (1991): Die Ordnung der Geschlechter - Die Wissenschaften vom Menschen und das Weib 1750-1850, Frankfurt a.M.: Campus.

Hutter, Jörg (1990): Die gesellschaftliche Kontrolle des homosexuellen Begehrens - Medizinische Definitionen und juristische Sanktionen im 19. Jahrhundert, Frankfurt a.M.: Campus.

Jaeger, Gustav (1884): Entdeckung der Seele, Bd. I, 3. Aufl. Leipzig: Ernst Günthers Verlag.

Keilson-Lauritz, Marita (1997): Die Geschichte der eigenen Geschichte - Literatur und Literaturkritik in den Anfängen der Schwulenbewegung, Berlin: Verlag rosa Winkel.

Krafft-Ebing, Richard von (1877): »Ueber gewisse Anomalien des Geschlechtstriebes und ihre klinisch-forensische Verwerthung derselben als eines wahrscheinlich functionellen Degenerationszeichens des centralen Nervensystems«. In: Archiv für Psychiatrie und Nervenkrankheiten VII, S. 291-312.

Krafft-Ebing, Richard von (1894): Psychopathia Sexualis mit besonderer Berücksichtigung der conträren Sexualempfindung, 9. verbesserte und theilweise vermehrte Aufl., Stuttgart: Enke.

Krafft-Ebing, Richard von (1901): »Neue Studien auf dem Gebiet der Homosexualität«. In: Jahrbuch für sexuelle Zwischenstufen III, S. 1-36.

Kretschmer, Ernst (1921): Körperbau und Charakter, Berlin: Julius Springer.

Kupffer, Elisar von (1900): Lieblingminne und Freundesliebe in der Weltliteratur, Berlin-Neurahnsdorf: Adolf Brand's Verlag.

Lehmstedt, Mark (2002): Bücher für das »Dritte Geschlecht« - Der Max Spohr Verlag in Leipzig Verlagsgeschichte und Bibliographie (1881-1914), Wiesbaden: Harrassowitz Verlag.

Lindemann, Gesa (1993): »Magnus Hirschfeld«. In: Rüdiger Lautmann (Hg.), Homosexualität - Handbuch der Theorie- und Forschungsgeschichte, Frankfurt a.M.: Campus, S. 91-104.

Link, Jürgen (1997): Versuch über den Normalismus - Wie Normalität produziert wird, Opladen: Leske + Budrich.

Mehlmann, Sabine (1998): »Sexualität und Geschlechtlichkeit. Vom Geschlechtscharakter zur Geschlechtsidentität«. In: Ursula Ferdinand/ Andreas Pretzel/Andreas Seeck (Hg.): Verqueere Wissenschaft? - Zum Verhältnis von Sexualwissenschaft und Sexualreformbewegung in Geschichte und Gegenwart, Münster: LIT, S. 35-50. 
Micheler, Stefan (2005): Selbstbilder und Fremdbilder der »Anderen « - Eine Geschichte Männer begehrender Männer in der Weimarer Republik und der NS-Zeit, Konstanz: UVK Verlagsgesellschaft.

Mosse, George (1997): Das Bild des Mannes - Zur Konstruktion der modernen Männlichkeit, Frankfurt a.M.: S. Fischer.

Müller, Klaus (1991): Aber in meinem Herzen sprach eine Stimme so laut Homosexuelle Autobiographien und medizinische Pathographien im neunzehnten Jahrhundert, Berlin: Verlag rosa Winkel.

Römer, Lucien Sophie Albert Marie von (1904): »Vorläufige Mitteilungen über die Darstellung eines Schemas der Geschlechtsdifferenzierung«. In: Jahrbuch für sexuelle Zwischenstufen VI, S. 327-356.

Steakley, James, D. (1975): The Homosexual Emancipation Movement in Germany, New York: Arno Press.

Ulrichs, Karl Heinrich (1994a): Forschungen über das Räthsel der mannmännlichen Liebe, Bd. I-V, hg. v. Hubert Kennedy, Berlin: Verlag rosa Winkel.

Ulrichs, Karl Heinrich (1994b): Forschungen über das Räthsel der mannmännlichen Liebe, Bd. X-XII, hg. v. Hubert Kennedy, Berlin: Verlag rosa Winkel.

Vaerting, Mathilde (1922): »Neubegründung der Psychologie von Mann und Weib«. In: Arthur Weil (Hg.), Sexualreform und Sexualwissenschaft: Vorträge gehalten auf der I. Internationalen Tagung für Sexualreform auf sexualwissenschaftlicher Grundlage in Berlin, Stuttgart: Julius Püttmann, S. 121-128.

Weininger, Otto (1903): Geschlecht und Charakter, Wien: Wilhelm Braumüller.

Wettley, Annemarie (1959): Von der Psychopathia Sexualis zur Sexualwissenschaft, Beiträge zur Sexualforschung, Bd. 17, Stuttgart: Enke. 


\title{
Die männliche Kunst
}

\section{der jüdischen "Degeneration"}

\author{
MARILYN REIZBAUM
}

Dieser Beitrag untersucht die Rolle von Max Nordau (1849-1923), Cesare Lombroso (1835-1909) und Magnus Hirschfeld (1868-1935) im Kontext der Produktion und Krise von Männlichkeit in der Moderne. Alle drei wurden um 1900 mit einem bestimmten Modell - von Kunst und Übertreibung/ Exzess - oder mit einer Figur - wie dem Muskelmann, dem Kriminellen, respektive dem Homosexuellen - diskursiv verknüpft. Dass diese Konzepte und Figuren zu Beginn des 2o. Jahrhunderts >jüdisch < codiert waren, hatte seine Ursache nicht allein in der auf überderterminierte Weise mit der europäischen Modernisierung verknüpften Figur des Juden, sondern lag darüber hinaus in der Bedeutung der Juden in jenen neuen Wissenschaftsgebieten begründet, in denen Nordau, Lombroso und Hirschfeld eine zentrale Rolle spielten. Alle drei entwickelten je spezifische Männlichkeitstheorien und Figuren des Männlichen. In ihren Diagnosen einer Krise der Männlichkeit bezogen sie sich notwendigerweise auf die mehr oder weniger amorphen Degenerationstheorien der damaligen Zeit (frühes 20. Jahrhundert), deren »Rassesysteme« auf die darwinistische Infragestellung geltender Taxonomien reagierten. Die Schlagworte dieser Ära waren »Fortschritt« und »Ursprünglichkeit« oder »Ursprungstypus« (Morel 1857)', alles Kennzeichen zeitgenössischer Gesundheits- und Fitnesstypologien, die noch heute in Wissenschaft und Kunst gegenwärtig sind. Das Paradoxon, dass Juden sowohl Urheber als auch Gegenstand solcher Theorien waren, spielt - so die Ausgangsthese des Beitrags - eine entscheidende Rolle in den von ihnen, also von Nordau, Lombroso und Hirschfeld entwickelten Konzepten.

Im Kanon der modernen Jüdischen Studien wird bei diesem Thema immer auf Nordau verwiesen. Dabei wurde jedoch den Verbindungen

1| Morel definierte die berühmt-berüchtigte Degenaration als »krankhafte Abweichung vom Ursprungstypus«. 
zwischen den anscheinend völlig getrennten Aspekten seiner Karriere erst vor kurzem Beachtung geschenkt. Diese Verknüpfung geht über die Feststellung, dass er seinen Namen von Südfeld in Nordau geändert hat, weit hinaus. So werden in seinem Werk, mit dem Titel »Entartung« (Nordau 1892), Juden weder erwähnt noch diskutiert; und das, obwohl er darin Theorien vorstellt, die dazu verwendet werden können, Juden als >Degenerierte zu kennzeichnen oder die Degeneration selbst als genuin jüdisch zu markieren. Zehn Jahre später wurde derselbe Max Nordau zu einem der wichtigsten Befürworter des Zionismus, der als zweite Figur gleich hinter Theodor Herzl fungierte, von dem er nach dessen Tod das >Zepter der Führerschaft< übernahm. So betont Tod Samuel Presner zu Recht, dass »any study of Nordau's invention of the muscle Jew cannot be adequately understood apart from the paradoxical condensation of multiple discourses concerning the politics of regeneracy and the deployment of sexuality for the purposes of national formation« (Presner 2003: 275).

Um diese paradoxe Konstellation $\mathrm{zu}$ illustrieren, möchte ich einen Moment die Verbindungslinien zwischen Nordaus Konzeption von dekadenter Kunst, eine Kategorie, an deren Definition er maßgeblich beteiligt war, und der Rehabilitation des jüdischen männlichen Körpers durch die Figur des Neuen Juden des 20. Jahrhunderts betrachten. In »Muskeljudentum« (1900) bemüht sich Nordau angesichts seiner Nostalgie für die verlorenen Helden darum (der Zirkuskämpfer ist nach dem Vorbild des hellenischen Athleten modelliert), die Juden $\mathrm{zu}$ modernisieren oder $\mathrm{zu}$ »erneuern«. Wenden wir uns einem Werk zu, das einige Jahre nach dieser Abhandlung im Jahre 1905 (»Von Kunst und Künstlern«) geschrieben wurde, um den Widerspruch in seinem Denken zu rekonstruieren: Dabei handelt es sich um seinen Kommentar zu einer Skulptur Rodins, der die merkwürdige Wende in seinem Denken offen legt, eine Ambivalenz, die zudem wesentlich für die zionistische Ideologie von sjüdischer Fitness< war. Nordau untersucht Rodins künstlerische Gestaltung und kritisiert ihn heftig dafür, »Muskeln zu erfinden, die es nicht gibt und nie geben wird «. Er schreibt:

» The Thinker< excites in a spectator of uninitiated taste, not cheerfulness, but discomfort, which may give rise to loathing. >The Thinker is not only naked, but also flayed. Its anatomy is executed with obtrusive importance, without the covering epidermis with its vital warmth. The enormous exaggeration of the muscles, the impossible assertion of strengths which is expressed by the extreme contraction of the muscles, therefore also of the counteracting muscles, are well-known features of sculpture in the worst period of decline.« (Nordau 1905/1907: 289)

Nordaus kritische Abhandlung über das Unwirkliche der Künste oder die Kunst der Übertreibung beruht auf einem Unbehagen dieser Darstellung des Körpers, die ebenfalls als Zeichen des Verfalls oder vielmehr Zeichen eines Mangels interpretiert werden kann. (Jay Geller hat über diese Vor- 
stellungen Grundsätzliches veröffentlicht. ${ }^{2}$ ) Seine widersprüchliche Logik spiegelt sich in zwei konkurrierenden Bildern des jüdischen Körpers in der Moderne wider.

Abbildung 1: Adi Nes: »Untitled« (1996). (C) Adi Nes

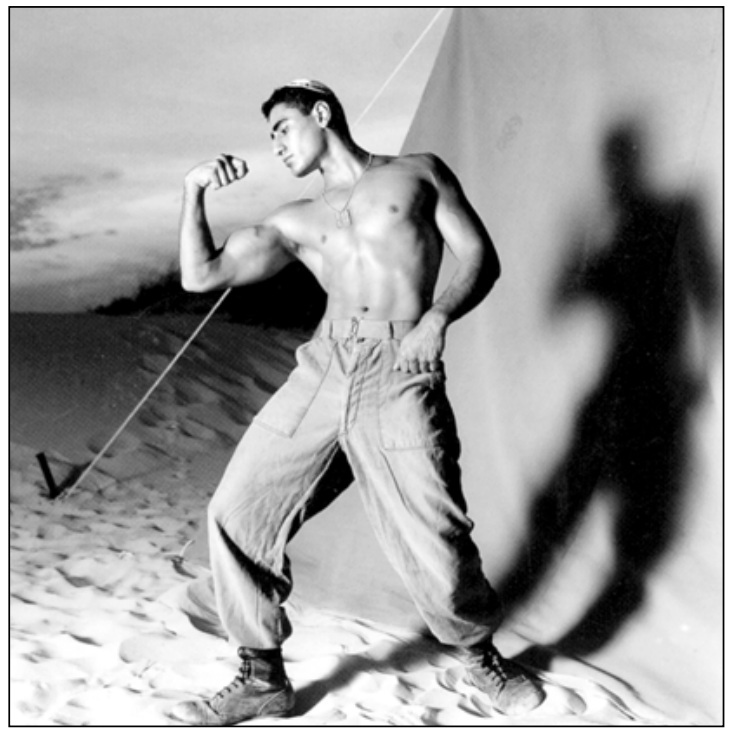

Für das erste Bild kann exemplarisch der in der Fotografie von Adi Nes behutsam und parodistisch dargestellte israelische Soldat herangezogen werden. Das zweite allseits präsente Bild des jüdischen Körpers ist das vom ausgemergelten Opfer/Inhaftierten, welches nicht gezeigt werden muss. Denn es ist jenes Bild, an das wir uns gewöhnt haben. Jedoch nicht - wie Susan Sontag vielleicht argumentieren würde - wegen seiner allgegenwärtigen Beziehung zu einem geschichtlichen Ereignis, sondern wegen seiner geschichtlichen Allgegenwart als exakte Darstellung des jüdischen Körpers bereits vor dem Holocaust: Der Ewige Jude. Nordau beabsichtigte, die Juden vom Diskurs und vom Bild der körperlichen Demütigung zu trennen und zwar entweder durch die Identifizierung eines solchen Ethos der Demütigung als genuin christlich oder durch das Beharren darauf, dass für Juden der »Akt« von anderen abgeschlachtet/vernichtet zu werden, eine historisch unauslöschliche Erfahrung sei. Bei Nordau liest sich das wie folgt:

»Lange, allzu lange haben wir die Fleischabtötung geübt. Ich drücke mich eigentlich ungenau aus. Die anderen haben Fleischabtötung an uns geübt, mit dem reichsten Erfolge, den hunderttausende von Judenleichen in den Ghettos, auf den Kirchenplätzen, an den Landstraßen des mittelalterlichen Europa bezeugen. Wir

2 | Von Jay Gellers Arbeiten sei beispielsweise auf die von 1993 verwiesen. 
selbst hätten auf diese Tugend recht gern verzichtet. Wir hätten unsern Leib lieber gepflegt als abgetötet oder - bildlich und unbildlich - abtöten lassen.« (Nordau 1900/1909: 379)

Sein Unbehagen, das sich in der Diskussion von Rodins muskelstrotzenden Figuren offenbart, könnte auch als indirekte Anerkennung einer Selbstdemütigung durch die Beschneidung gedeutet werden, die - seinem gleichzeitigen Aufruf zur stolzen Selbstpräsentation abermals widersprechend - den jüdischen Körper als unausweichlich unfit ausweisen würde. Man könnte auch argumentieren, dass der kriminelle Akt gegen den jüdischen Körper durch die Zurschaustellung des »kriminellen Körpers« gelindert werden sollte. ${ }^{3}$ Dabei muss allerdings vorausgesetzt werden, dass in der damaligen kulturellen Imagination, der »kriminelle Körper-Typus«, den Lombroso zeichnet, dem >degenerierten< Körper, wie ihn Nordau vorstellt, ähnelt.

Während Nordau gewöhnlich mit der Frage jüdischer Regeneration/jüdischen Muskeljudentums in Verbindung gebracht wird, gilt Cesare Lombroso als die eigentliche Quelle jener Taxonomien des kriminellen Körpers, die mit der Konstruktion von >Rasse< verknüpft wurden. Er ist der unbestrittene Vater der Kriminalanthropologie. Seine Vorstellungen von der >Natur< kriminellen Verhaltens - die der >degenerierte Typus< verkörpert - publizierte er erstmals in »Criminal Man« (1876). Die darin entwickelten Methoden der Identifizierung des >kriminellen Typus $<$, die die Messverfahren der Phrenologie und Physiognomie im Rahmen der zeitgenössischen Entartungslehre aufgreifen, waren ebenso wie seine Vorstellungen über das Strafsystem sehr einflussreich. Was über Lombroso zumeist unbekannt oder unbeachtet blieb, ist seine Zugehörigkeit zum Judentum. Obwohl er in seinem Essay »Anti-Semitism and Modern Science« (1894) den Antisemitismus als »Krankheit« diagnostiziert, argumentiert er gleichzeitig, dass Juden bestimmte Schlüsselrituale des Judentums als Zeichen und Ursprung ihres Atavismus verwerfen, ja sogar verurteilen müssten. Das Judentum stellte sich für ihn, wie auch für Nordau, als Doublebind dar, der drohte, sie von der Moderne auszuschließen, gleichzeitig wurden viele zentrale Qualitäten der Modernisierung von konservativen Kulturkritikern als $» j u ̈ d i s c h \ll$ gebrandmarkt.

Lombrosos >Entdeckung< der >Natur< der Kriminalität wurde u.a. von Bram Stoker in »Dracula« $(1896)$ aufgegriffen. Wie viele andere Romane des späten 19. und frühen 20. Jahrhunderts zitiert auch dieser sowohl Nordau als auch Lombroso, als wären sie die wissenschaftlichen Kronzeugen der Definition des Monsters der Perversion, des Vampirs. Lombrosos Anschauungen fungieren als zentrale Vorlage für die Figur des Dracula und

3| Vgl. dazu meine ausführliche Diskussion des Themas in Reizbaum 2003. 
ihren rassiierten Geschlechtscharakter. Judith Halberstam hat Wesentliches über die Verbindung zwischen »dem Juden« und dem Vampir geschrieben, warnt jedoch davor, die Verbindung zwischen der »identity of perversity and its relation to a particular set of traits « (Halberstram 1993: 334) zu stark zu verfestigen. Sie schreibt:

»Dracula is otherness itself, a distilled version of all others produced by and within fictional texts, sexual science and psychopathology. He is monster and man, feminine and powerful, parasitical and wealthy; he is repulsive and fascinating - Dracula is not simply a monster, but a technology of monstrosity.« (Ebd.)

Die Verknüpfung zwischen dem jüdischen Körper/Gesicht und der Kriminalität ist in der modernen Kultur allgegenwärtig. Das vielleicht bekannteste Beispiel für diese Lombroso'sche Verknüpfung zeigt sich im amerikanischen Film bei dem von Edward G. Robinson gespielten »Little Caesar«. Das Gangstergenre wurde bereits im Zusammenhang mit seinen jüdischen Protagonisten, bei denen es sich oftmals um tatsächliche historische Persönlichkeiten wie Meyer Lansky handelt, erforscht. Da rin fungierte auch Lombroso manchmal als Quelle für die Beschreibung von Kriminalität beim Gangstertypus. Erst bei dem Schauspieler Edward G. Robinson, dessen legendärer Auftritt als Rico in »Little Caesar« ihn lebenslang für derartige Rollen prägte, führte die Überschneidung zwischen Lombrosos Vorstellungen und seinem »Jüdisch-Sein« jedoch zu einer Hervorhebung des jüdischen Körpers und nicht mehr allein zur Codierung des kriminellen Handelns als jüdisch.

Auf den Iren James Cagney traf das eben Gesagte nicht zu. Er schaffte es trotz seines Irischseins, sich von seiner Rolle in »Public Enemy« zum gutartigen Helden in Filmen wie »Yankee Doodle Dandy« zu entwickeln. In einer Filmbeschreibung, die sich auf Robinson bezieht, wird darauf hingewiesen, dass er als Emanuel Goldenberg in Rumänien geboren wurde. Im gleichen Atemzug wird eindringlich beteuert, dass er kultiviert und gebildet war - ein völliger Gegensatz zu der Figur, die er in Rico verkörperte. Das Beharren auf seiner Authentizität als Rico und Robinsons Festgelegtsein auf diese bestimmte Art von Rolle, straft die Darstellung seiner good traits genauso Lügen wie die Erwähnung seiner rumänischen Herkunft, der berühmt-berüchtigten Heimat Draculas. Eine andere Filmbeschreibung bezieht sich auf die abnormen Eigenschaften in der Homosozialität von Gangstern. Er (»Little Caesar«) hat keine Gangsterbraut und sein Niedergang ist wohl das Ergebnis seiner Zuneigung für seinen Partner Joe. »Tipsy, Topsy Turvy« ist der emblematische Titel auf der Reklamewand unter der er am Schluss stirbt. Die »larvierte Figur« ist als Symbol des Jüdischen typisches Leitmotiv in der Arbeit des Juden Mervyn LeRoy, der bei Filmen wie »The Bad Seed «, »They Won’t Forget« (eine Neufassung des Lynchmordes an Leo Frank im Jahr 1913) und »The House I Live In«, ein Kurzfilm - in dem Frank Sinatra das Lied interpretiert, das zur Hymne 
amerikanischer Integrationsfähigkeit (1942) wurde -, Regie führte und sie produzierte. ${ }^{4}$

Abbildung 2: Filmstill aus Mervyn Leroy’s »Little Caesar«,
1931

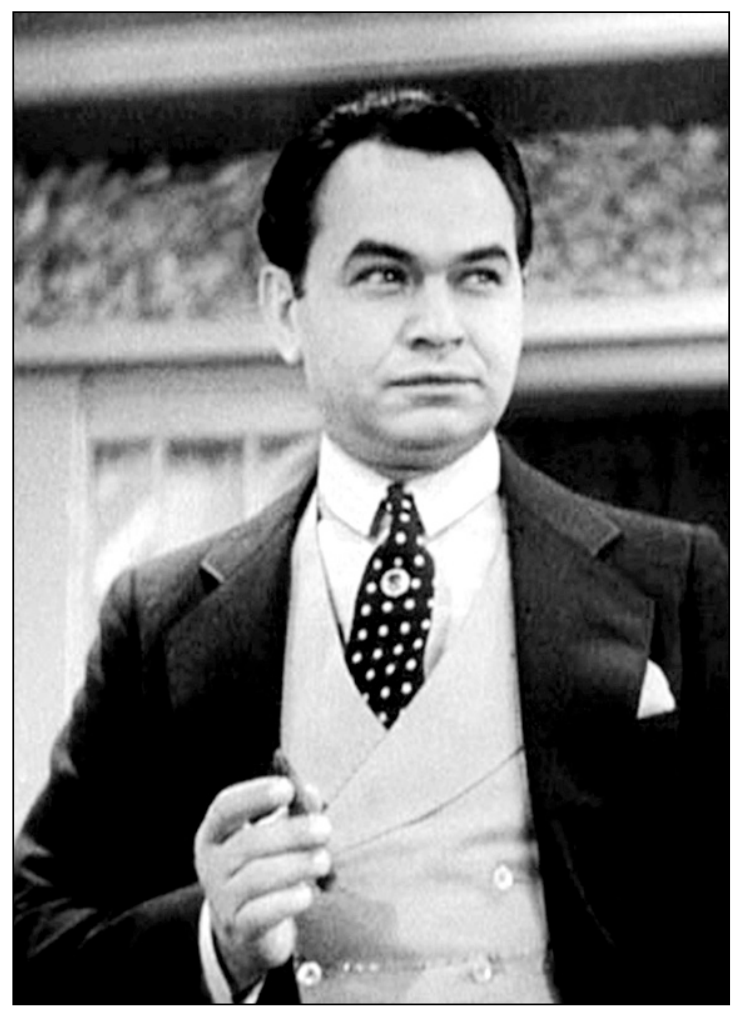

Der Beitrag zu Magnus Hirschfeld konzentriert sich auf das, was sich innerhalb seines Milieus als unentwirrbare Verbindung zwischen Homosexualität und Judentum entwickelt hat: Von Blüher, Brand, Friedländer, Weininger etc. stammt der Syllogismus, dass Juden weiblich sind und Homosexuelle unmännlich und demnach Juden = homosexuell seien. Hier wird es besonders um Hirschfelds Verwendung von Fotografien als Beweismittel gehen. Es ist nur ein kurzer Weg von der Indexikalität des Fotos

4| Das Lied stammt aus der Feder von Abel Meeropol, der unter dem Pseudonym Lewis Allen auch den Text zu Billie Holidays Lied »Strange Fruit« verfasste, welches zur Leitmelodie der Verfolgung der Schwarzen wurde. Ironischerweise lässt die bekannte Version von »The House I Live In« eine Strophe aus, die Schwarze zu einem Teil der harmonischen Gleichstellung machte. Meeropol war auch der Adoptivvater der Brüder von Ethel and Edgar Rosenberg. 
im Rahmen des wissenschaftlichen Fachgebiets hin zum Surrealismus in der Zeit, die mit Hirschfelds Arbeit zusammenfällt. So zeigt sich bei surrealistischen Fotografen wie Man Ray oder Claude Cahun das Vermächtnis Hirschfelds.

Hirschfelds Epigraf für sein Hauptwerk zum Wissen über die Sexualität, dem Bilderteil der »Geschlechtskunde« (1930) ist »Bilder sollen bilden«, ein großartiges Wortspiel hinsichtlich der Aufdringlichkeit des Mediums. Wie wir gesehen haben, erweisen sich Fotos als höchst anfällig für sogenannte Rahmungen. In ihrem hervorragenden Essay mit dem Titel »Umkleidekabinen des Geschlechts« (2004), in dem es um Hirschfelds Verwendung von Fotografien als medizinische Beweise geht, stellt Katharina Sykora die These auf, dass Hirschfeld seine eigene Theorie über das »dritte Geschlecht« durch seine Inszenierung von Subjekten und/oder die Anordnung von Fotografien auf ironische Art untergräbt, da er in seiner Analyse letzten Endes immer das eine oder das andere Geschlecht bevorzugt und dabei den Trugschluss in seiner Methode nicht bemerkt. ${ }^{5}$ Während Hirschfeld seine Klienten/Patienten ermutigte, sie selbst zu sein, vermittelte er selber angesichts möglicher Konsequenzen, ein »neutrales« Erscheinungsbild, indem er sich stets in üblicher professionell-männlicher Garderobe kleidete. Es scheint, als glaubte er, seine Wissenschaft und sein Anliegen verlangten danach.

Im Folgenden geht es um die Arbeiten von Adi Nes, jenem israelischen Fotografen, der das Vermächtnis Hirschfelds mit seiner homoerotischen Ästhetik des »neuen Juden«, der sich aus Nordaus »Muskeljuden« ableitet, so treffend ins Bild gesetzt hat.

Seine Arbeit findet Geschmack (wenn auch nicht direkt) an Blühers Behauptung, dass der »Jude die Umkehrung des invertierten Typs ist« (Blüher 1919/1921), wobei sich der Typus inversus auf den »Männerhelden« bezieht, der ihnen als Verteidigung gegen die effeminierte Version von Homosexualität ins Feld geführt wurde. Natürlich wird diese Vorstellung von Männerliebe als etwas Heroischem zu einer ironischen Reflexion in Nes' spielerischer Interpretation von Nordaus heldenhaften Charakteren. Der oben erwähnte »Muskelmann« und der, den ich an dieser Stelle einfüge (beide ohne Titel), stammen aus Nes' Soldatenserie, die er zwischen 1994 bis 2000 produzierte. Sie vermitteln sofort einen Eindruck von der Art seiner Arbeit - theatralisch und höchst selbstreflexiv hinsichtlich des nationalen Mythos jüdischer Muskelkraft.

Nes' Figuren sind Spiegelbilder der Auslassung, die Verstecktes sofort sichtbar machen, aber nicht dadurch, dass der Jude in den Text gebracht wird (was bei Hirschfeld fehlt), sondern dadurch, dass er queer dargestellt wird. Auf diese Weise bringt er das ans Licht, was sowohl die nationale

5| Ich verdanke Rainer Herrn diese Referenz und noch vieles andere für meine Untersuchung über Hirschfeld. 
Allegorie als auch die nationale Schande zu verschleiern sucht, die historische Gleichsetzung von Homosexuellen (Effeminierten) mit den Juden (den Unmännlichen), ohne jedoch diese Gleichsetzung wieder herstellen zu wollen. Dieses bemerkenswerte Foto zeigt die Inversion der Inversion, die in Nes' Inszenierung militärischer Glorie ebenso glorreich umgesetzt wird. Durch die Umkehr des Mythos vom Muskeljuden wird eher der Mythos als das Bild in gefährlicher Weise auf den Kopf gestellt. Auf diese Weise wird die Beständigkeit des Bildes vom männlichen Juden getestet. Oder, um es genauer zu sagen: Die Abbildung steht Kopf, als Kunststück und als Scherz.

Abbildung 3: Adi Nes: »Untitled« (1994). (C) Adi Nes

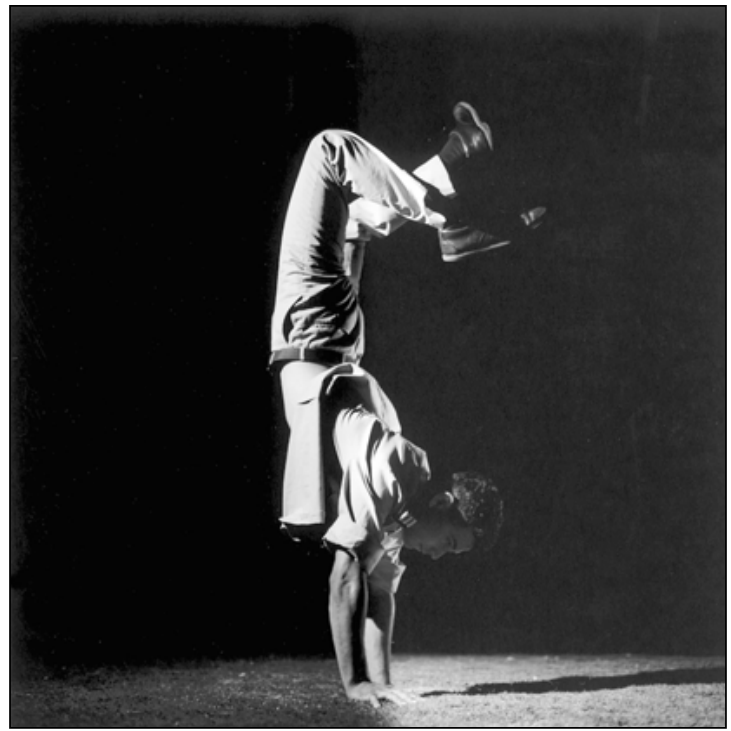

Nes' Arbeit gibt Anregungen dazu, wie die Nachwirkungen Nordaus >muskulöser Imperative ‘ für eine Analyse des heutigen Israels genutzt werden könnten. Ungeachtet dessen, wie sehr sie ein Ergebnis der Umkehr des »killing of the flesh « sein mögen, tragen Nordaus Theorien zur Darstellung von oder zum Spiel mit übertriebener Kraft bei, welche ironischerweise seinen eigenen Warnungen vor »degenerierten« Übertreibungen entspricht.

Übersetzung aus dem Amerikanischen von Ilka Krumholz, Sabine Mehlmann, Rainer Herrn und Ulrike Brunotte 


\section{Literatur}

Blüher, Hans (1919/1921): Rolle der Erotik in der männlichen Gesellschaft, Bb.: Der Typus Inversus, Jena: Eugen Diederichs Verlag.

Geller, Jay (1993): »A Paleontological View of Freud's Study of Religion: Unearthing the Leitfossil Circumcision«. In: Modern Judaism 13, S. 49-70.

Halberstam, Judith (1993): »Technologies of Monstrosity«. In: Victorian Studies 36, S. 333-353.

Hirschfeld, Magnus (1930): Geschlechtskunde, Bilderteil, Stuttgart: Julias Püttmann.

Lombroso, Cesare (1876): L'uomo deliquente studiato in rapporto all'antropologia, alla medicina legale ed alle discipline carcerarie, Mailand: Hoepli. Englisch: Criminal Man, übersetzt von Mary Gibson and Nicole Hahn Rafter, Durham/London 2006: Duke University Press.

Lombroso, Cesare (1894): L'antisemitismo e le scienze moderne, Turin: Roux. Zitiert nach einer Arbeitsübersetzung der Autorin: Anti-Semitism and Modern Science.

Morel, Bénedikt Auguste (1857): Traité des dégénérescences physiques, intellectuelles et morales de l'espèce humaine et des causes qui produisent ces variétés maladives, Paris: J.B. Ballière, H. Ballière.

Nordau, Max (1892): Entartung, 1. Teil, Berlin: Verlag von Carl Duncker.

Nordau, Max (1900): »Muskeljudentum«. In: Jüdische Turnerzeitung, Jg. 2. sowie in, ders.: Zionistische Schriften, Köln/Leipzig 1909: Jüdischer Verlag.

Nordau, Max (1905): Von Kunst und Künstlern, Berlin, zit.n. ders.: On Art and Artists, Übersetzung W.F. Harren, London 1907: T. Fisher.

Presner, Todd Samuel (2003): »Clear Heads, Solid Stomachs, and Hard Muscles: Max Nordau and the Aesthetics of Jewish Regeneration«. In: Modernism/Modernity, April 2003, S. 269-296.

Reizbaum, Marilyn (2003): »Max Nordau and the Generation of jewish Muscle«. In: Jewish Culture and History 6, Heft 1 (Summer 2003), S. $130-151$.

Stoker, Bram (1897): Dracula, New York: Penguin (1993). First published in Great Britain by Archibald Constable and Company.

Sykora, Katharina (2004): »Umkleidekabinen des Geschlechts, Sexualmedizinische Fotografie im führen 20. Jahrhundert«. In: Fotogeschichte 24 (92), S. 15-30. 



\section{Zwischen Übermacht und Ohnmacht:}

\section{Die Figur Simsons in der deutschen, völkischen und zionistischen Literatur um 1900}

als Medium des kulturpolitischen Kampfes

um hegemoniale Männlichkeit

JOSEPH CROITORU

Die folgende Untersuchung befasst sich mit der Rolle von Kastrationsfantasien $^{1}$ und Männlichkeitsbildern im Kontext der kulturellen Transformation der Figur Simsons in der deutschen und zionistischen Literatur zwischen 1894 und 1927. Simson, ein mächtiger Held der hebräischen Bibel und zugleich bezüglich seiner Körperkraft dem griechischen Herakles ähnlich, war ein Richter des Volkes Israel zur Zeit der Philisterkriegsherrschaft. Bekanntlich verlor er seine magische männliche Kraft, die sich in seinen Haaren konzentrierte, durch den Verrat seiner Geliebten, der schönen Philisterin Delila. Die Geschichte von Simson und Delila, die mit Simsons Blendung und einer von ihm dennoch vollbrachten Tötung des Feindes endet, gehört zu den bedeutendsten Geschlechterkampflegenden der Bibel. Sie fand neben den Erzählungen von Salome und Johannes dem Täu$\mathrm{fer}^{2}$, Judith und Holofernes oder dem Figurenpaar Ödipus und der Sphinx um 1900 ein bedeutendes Revival. Im Nachleben des israelitischen Helden Simson mischten sich freilich die geschlechterpolitischen und imaginären Kampf- und Effeminierungsszenarien der Moderne sowohl mit deutschnationalen wie mit zionistischen Entwürfen hyperviriler Männlichkeit.

1) Kastrationsfantasien sind um 1900 »als Negativ des Phallischen« (Böhme 2006: 382) zugleich Ausdruck erschütterter männlicher Identitäten.

2| Siehe den Beitrag »Feminisierung der Religion(swissenschaft)《 von Ulrike Brunotte in diesem Band. 
Der Beitrag basiert auf der Analyse von insgesamt sieben Werken. Es handelt sich dabei um drei Prosawerke (zwei Romane, eine Novelle) und vier Theaterstücke, die zwischen 1904 und 1917 entstanden sind; der zionistische Roman von Jabotinsky wurde 1928 veröffentlicht.

\section{Simson als frauenemanzipatorische Metapher für die Krise der Männlichkeit}

Es fällt auf, dass beide von Frauen verfassten Werke Prosawerke und - auch wenn sie mit »Simson und Delila « betitelt sind - keine historisierenden Erzählungen sind. Beide, sowohl der 1894 entstandene Roman von Annie Bock als auch die zehn Jahre später erschienene gleichnamige Novelle von Clara Viebig spielen im damaligen zeitgenössischen Deutschland.

Annie Bock beschreibt den gesellschaftlichen Aufstieg eines jungen, aus einfachen Verhältnissen stammenden Komponisten, dem mit seiner ersten Oper, in der er die biblische Erzählung von Simson und Delila verarbeitet, der künstlerische Durchbruch gelingt. Die Geschichte des Romanhelden Paul scheint eine Allegorie auf die biblische Erzählung zu sein: Paul, bereits so gut wie liiert mit einem Mädchen, das wie er aus kleinen Verhältnissen kommt, erliegt den Verführungskünsten einer älteren, verheirateten und wohlhabenden Mäzenin, der er sich immer mehr ausliefert. Diese setzt alles daran, ihn völlig zu beherrschen, was ihr schließlich auch gelingt - allerdings um den Preis seiner schöpferischen Kraft. Paul verliert die Fähigkeit zu komponieren und fristet fortan ein - wenn auch bequemes - Dasein als Klavierlehrer. Dass der Roman die Entmachtung des Mannes durch die Frau thematisiert, wird nicht zuletzt auch daran deutlich, dass der Hauptprotagonist von der Geliebten, mit der er später auch ein Kind hat, immer wieder Simson genannt wird und sich am Ende auch selbst als Simson bezeichnet (Bock 1894).

In der gleichnamigen, 1904 erschienenen Novelle von Clara Viebig gibt es, außer dem Titel, keine explizite Bezugnahme auf die biblische Erzählung. Der Hauptprotagonist ist der Sohn eines despotischen Försters, welcher hier wohl für das traditionelle Patriarchat steht, und von dem er gezwungen wird, in der Stadt bei einem Kaufmann in die Lehre zu gehen. Dort trifft Hubert, inzwischen ein stattlicher Soldat, nach Jahren seine Jugendfreundin Suss, die Tochter des bitterarmen Besenbinders, zufällig wieder und verliebt sich in sie. Diese Begegnung, die auch mit Grund dafür ist, dass Hubert seine in Liebe verbundene Mutter vor ihrem Tod nicht mehr sieht, wird dem jungen Mann zum Verhängnis. Als der Vater den Sohn um sein mütterliches Erbe betrügt, stachelt die Geliebte Hubert so lange auf, bis dieser den Vater zu zwingen versucht, ihm zumindest einen Teil des Geldes zu überlassen. Bei einer nächtlichen Begegnung im Wald kommt es im Streit zum Schusswechsel zwischen dem Förster und seinem Sohn, und Hubert, der irrtümlich glaubt, den Vater getötet zu haben, flieht. 
Da das Erbe nun endgültig verloren scheint, verrät die Geliebte schließlich das Versteck des Flüchtigen gegen die auf ihn ausgesetzte Belohnung.

Hubert verkörpert alles andere als das Idealbild eines aufstrebenden jungen Mannes seines Standes: Er versucht sich der väterlichen Autorität zu widersetzen, verzichtet auf die ihm in Aussicht gestellte Karriere beim Militär und verfällt einem nicht standesgemäßen geldgierigen Mädchen, das ihn einen Feigling schimpft und zum Vatermord treibt, um ihn am Ende gegen Geld seinen Verfolgern auszuliefern (Viebig 1904). Die Parallele zu Annie Bocks Roman ist unübersehbar: Auch in der Novelle wird der Hauptprotagonist seiner positiven Eigenschaften - hier Sensibilität und Gutmütigkeit, dort Kreativität - von einer Frau beraubt und bei Clara Viebig dazu noch schändlich verraten. In den beiden Werken entsprechen die männlichen Hauptfiguren keineswegs dem um die Jahrhundertwende herrschenden Ideal hegemonialer Männlichkeit, sondern liefern eher Beispiele - allerdings solche aus weiblicher Feder - für die vergeschlechtlichte Kulturkrisendebatte der Jahrhundertwende, in der die Rede von der Feminisierung der Kultur zugleich mit der Rede von den Krisen der Männlichkeit verknüpft war (Runte 2007: 9f.).

Dass die biblische Geschichte von Simson und Delila in dieser Zeit sehr populär wurde, darauf deutet auch die Tatsache, dass Annie Bocks Roman von 1894 bei dem gerade im Bereich der Populärliteratur sehr erfolgreichen Stuttgarter Engelhorn-Verlag erschienen war. Es handelte sich dabei um vor allem von Frauen konsumierte, relativ auflagenstarke Bücher. Für die Beliebtheit dieser verhängnisvollen Liebesgeschichte spricht zudem der Umstand, dass Clara Viebig noch zehn Jahre später ihrer Novelle den Titel »Simson und Delila« gab, ohne dass sich in dem Werk selbst auch nur irgendeine konkrete Spur dieser beiden biblischen Gestalten fand.

Die kulturelle Faszination des Themas zeigt sich allerdings besonders in seinen Bühnenbearbeitungen, die, anders als die genannte Prosa, eine so gut wie rein männliche Domäne darstellte. Das Theater war öffentlich, eine staatlich autorisierte und zensierte Institution und wichtiger Angelpunkt der bürgerlichen Kultur. Nicht zuletzt in diesem kulturellen Kontext diente die biblische Geschichte von Simson und Delila als mehr oder weniger prekäres Medium, mit dem die normativen Männlichkeits-, aber auch Weiblichkeitsbilder unterwandert oder gar umformuliert werden konnten. So ist es sicherlich kein Zufall, sondern Ausdruck >maskulinistischer< Reaktion auf die vermeintliche Krise der herrschenden Männlichkeit, dass die zwischen 1904 und 1917 entstandenen Theaterstücke nicht »Simson und Delila« hießen, sondern nur »Simson« - und gelegentlich mit einem Untertitel versehen waren. 


\section{Simson als wilhelminischer Held des Vaterlandes und als bürgerlicher Antiheld}

Eines dieser Werke »Simson. Tragödie in fünf Akten nach Worten des Alten Testaments « stammt aus dem Jahr 1904 und kommt aus der Feder von Hermann Wette (1857-1919), der als nationalkonservativer Vertreter des Wilhelminismus bezeichnet werden kann. Wette, ein Protestant, beschreibt Simson eingangs als eine Art Einsiedler, der sich vor der sündigen Welt zurückzieht und seinem Gott, der ihn mit dem Befehl »Umgürte deine Lenden wie ein Mann« ganz nach Art des religiös verbrämten wilhelminischen Militarismus in den Heiligen Krieg schickt, gehorcht: »Bis ich die Feinde alle zerschmettert, Jahwes Acker zu düngen mit ihrem Gebein!« (Wette 1904: 17). Im zweiten Akt ist der erste israelitisch-philistäische Krieg denn auch nach gut preußischer Manier schon vollbracht, Simson erscheint in Richtertracht - hier drängt sich unweigerlich das Bild des Reichsbeamten auf. Gleichzeitig fungiert er auch als Priester und vereinigt die Israeliten und die gefangenen Philister in einem »Sieges- und Versöhnungsfest « in der Stiftshütte zu einer Glaubensgemeinschaft. Vorher findet allerdings noch ein Disput statt, bei dem die israelitischen Frauen mit Simsons Mutter an der Spitze die Vorzüge ihrer Geistigkeit ins Feld führen, die über die vergängliche Schönheit und Sinnlichkeit der Philisterinnen triumphiert - ganz im Sinne des wilhelminisch-bürgerlichen Frauenbildes.

Simsons verbotene Liebe zu der schönen Philisterin Delila wird zum Teil legalisiert, da Delila bekehrt ist und mit Simson die versöhnte Gemeinde zum Opferaltar führt. Deshalb darf in Wettes Stück Delila, die im eigenen Volk zwar immer noch als moralisch zweifelhaft gilt, Simson ebenso lieben, wie der Zuschauer an die Aufrichtigkeit ihrer Liebe glauben darf. Und sie ist auch nur deshalb bereit, Simson an die Philister auszuliefern, weil der philistäische Priester, der sie verführen will und den sie nur abwehren kann, indem sie ein Messer zückt, Delila davon zu überzeugen vermag, dass Simson, sobald er seine übermenschliche Kraft verloren habe, ihr ganz und gar gehören würde. Hier sind die Anspielungen an die Heraklesmythologie und das tragische Ende des griechischen Heros durch das giftgetränkte Nessoshemd unübersehbar (zu Herakles vgl. Brunotte 1992). Auch dort glaubte eine liebende Frau an einen machtgebenden Liebeszauber, der sich dann freilich als ein tödlicher entpuppte. Simsons Mutter versucht noch das drohende Unheil von dem Sohn abzuwenden, indem sie ihn nicht nur an seine Amtspflichten als Richter erinnert, sondern auch vor den zerstörerischen Folgen seiner Liebe, die ihn blind mache, warnt. Die hier von den Philistern selbst betrogene und unwissend als Werkzeug benutzte Delila begehrt auf, als man den seiner Kraft beraubten Simson von ihr wegführt, und wird sogleich erstochen - weil sie nur eine Teilschuld trägt, darf sie einen ehrenhaften Tod sterben, der sie aus Sicht der Israeliten zur Heldin, aus der der Philister wiederum zur Vaterlandsverräterin macht. In beiden Fällen hebt der Autor auf die Tugend der 
Vaterlandstreue ab, die auch Simson, neben der Frömmigkeit, bis zuletzt leitet: Ehe er sich und die Philister tötet, besiegt er noch den »Satanas « und zerstört die Götzenbilder im Tempel Dagons. Insgesamt betrachtet haben Simson und Delila ihre bürgerlichen, religiösen und nationalen Pflichten weitgehend erfüllt, weshalb sie sich, wie vom Geist Delilas in einer der Szenen angedeutet wird, im Paradies wieder vereinen dürfen: »Komm, mein Geliebter,/Komm in den Garten!/Da will ich dein/Mit all meiner Liebe sein!« (Wette 1904: 65)

Von dieser bigotten wilhelminischen Prüderie ist in dem nur sechs Jahre später entstandenen Theaterstück »Simson. Eine Tragödie nebst einem Satyrspiel« von Herbert Eulenberg, der grob als Pazifist charakterisiert werden kann, nichts geblieben. Dessen Simson-Stück liest sich geradezu wie eine Gegenschrift zu Wettes Werk. Simson ist hier verheiratet und hat Kinder, kann sich jedoch weder mit der Rolle des Familienvaters noch mit der des Kriegshelden identifizieren. Seine Bestimmung als heldenhafter Erlöser empfindet er als Last, vom ewigen Töten fühlt er sich vergiftet und für die israelitischen Priester hat er nur Spott übrig: »Ihr seid nur heilig über euren Kleidern« (Eulenberg 1910: 20). Er will um seiner selbst willen geliebt werden, nicht als mit göttlicher Kraft gesegnetes Idol. Seinem nach Erlösung schreienden Volk wirft er vor: »Ihr liebt nur meine Zähne, nicht mich selbst« (ebd.: 23). Dass Eulenberg hier auch gegen die bürgerliche Sexualmoral seiner Zeit anschreibt, wird darin deutlich, dass Simson sich zwischen seiner treuen und liebenden israelitischen Ehefrau Rahel - die im Bibeltext bekanntlich nicht existiert - und der leidenschaftlichen Philisterin Delila, einer sexuell emanzipierten, männerverschlingenden Witwe mit schon fast nymphomanischen Zügen, entscheiden muss - erwartungsgemäß wählt er die Philisterin. Von den Pflichten seinem Volk gegenüber will der israelitische Held dann nichts mehr hören, er will nur noch sie: »Du Göttin mir!« (Ebd.: 65) Doch für die zahlreiche philistäische Liebhaber um sich scharende Delila ist Simson nur ein Werbender unter vielen. Diese wiederum, die der Autor Eulenberg als »reiche Nichtstuer unter den Philistern« bezeichnet, scheinen Simson eher als Mitbewerber denn als Volksfeind zu fürchten. Die aufgrund ihres zügellosen Lebensstils nur schwer zu verheiratende Delila zeigt auch nicht die geringsten Skrupel, gegen ein Heiratsversprechen des mächtigsten Philister-Fürsten Ammon, Simson das Geheimnis seiner Kraft zu entlocken. Ideale wie Patriotismus sucht man hier vergebens, denn für die als dekadent gezeichneten Philister, die unentwegt über ihre Siege und sich selbst als Anführer spotten, scheint Simson nicht viel mehr als eine Kriegstrophäe unter anderen zu sein, die Amüsement verspricht. Hier wird nicht zuletzt deutlich, dass bei der Analyse der Kritik an herrschenden Männlichkeitsvorstellungen auch schichtenspezifisch differenziert werden muss. ${ }^{3}$ So könnte die Persiflage Eulenbergs auf die Philister-Fürsten im übertragenen Sinn auch als die

3I Siehe etwa den Beitrag von Claudia Bruns in diesem Band. 
Kritik des bürgerlichen Theaterautors Eulenberg an Vertretern des preußischen Adels gelesen werden. Über Eulenbergs bürgerliche Herkunft - sein Vater besaß eine Maschinenfabrik - liefert seine Autobiographie Aufschluss (Eulenberg 1948: 7).

Da Eulenberg alle Männlichkeits- und Weiblichkeitsideale seiner Zeit wild durcheinander mischt, überrascht es kaum, dass er sich auch die Freiheit nimmt, mit den antisemitischen Vorurteilen seiner bürgerlichen Zeitgenossen zu spielen, um sie so kritisch zu durchleuchten. ${ }^{4}$ Dementsprechend findet in dem Stück immer wieder auch der keineswegs biblische, sondern zeitgenössische Begriff »Jude« Verwendung, und zwar fast immer mit einem ironischen Unterton. So etwa schmückt Delilas Lager eine Elfenbeinschnitzerei, die, wie einer der philistäischen Liebhaber, der sich unter ihrem Bett versteckt, entdeckt, »Der schmutz'gen Juden Zug durchs Rote Meer« (Eulenberg 1910: 57) zeigt. Als auf dem anlässlich des Sieges über Simson gegebenen Fest - das der Autor übrigens nicht, wie allgemein üblich, im Dagon-Tempel stattfinden lässt - einer der PhilisterFürsten in Kriegskleidung erscheint, wird er von seinen Gefährten ausgelacht: »Nun, Salah, Mensch aus Seide und Papier,/Du warst beim Heer, hast Judenblut getrunken?« Worauf Salah antwortet: »Aus Langeweile, es bekam mir nicht« (ebd.: 72). Simsons Freitod ist zwar auch hier die Rache Gottes, dennoch resultiert er auch aus einem Imageproblem: Er wolle zuhause nicht wie ein »Trümmerhaufen« (ebd.: 78) erscheinen, sagt Simson, dessen sehnlichster Wunsch sich mit seinem Selbstopfer erfüllt: »Mit edlem Angesicht/Von dieser Erde in die Welt zu kehren« (ebd.: 79).

Das bürgerlich-okzidentale Konzept maskuliner Hegemonie, das in Figuren des heroischen Kämpfers ebenso wie des patriotischen Selbstopfers und des nationalen Erlösers um 1900 (besonders 1914) auch in vielerlei Gestalten beschworen wurde und dem Wette in seinem Simson-Stück noch ganz und gar Rechnung trägt, ist bei Eulenberg weitgehend aufgegeben. Mann und Frau sind hier dem Anspruch nach zwar längst einander ebenbürtig - die Mythisierung der »heidnisch-orientalischen« Weiblichkeit findet allerdings in Delila dennoch eine weiterhin faszinierende Ikone. Zugleich sind - dem Dekadenzdiskurs der Zeit folgend - beide - Simson und Delila - bei Eulenberg Teil der Karikatur einer Welt, in der nur noch der Schein herrscht und die aus Sicht des Autors zum Untergang verurteilt ist. Nicht umsonst verkündet Simson kurz vor seinem Tod: »Ich richte mich mit meiner Zeit/Und schaffe Raum für bessere Geschlechter« (ebd.: 81).

4| Zu Eulenbergs Freunden, vor allem auch aus Künstlerkreisen, gehörten immer wieder auch Juden. Seine oben zitierte Autobiographie liefert dafür ebenso zahlreiche Belege wie für den Umstand, dass er ein entschiedener Gegner des völkisch und nationalsozialistisch gefärbten Antisemitismus war. 


\section{Die Feminisierung der Macht}

In Frank Wedekinds Theaterstück »Simson oder Scham und Eifersucht«, 1913 veröffentlicht, wird die alte Geschlechterhierarchie sogar auf den Kopf gestellt. Wedekind setzt dabei vor allem bei der Gestaltung der Figur Delilas offensichtlich indirekt die Arbeit an seiner vorangegangenen Bühnenfigur Lulu ${ }^{5}$ fort, einem freizügigen, die Männer in ihren Bann ziehenden Mädchen, das fast zu einer Dame der Gesellschaft aufsteigt, schließlich aber als Dirne endet und ermordet wird. Was Johannes G. Pankau, der Eva Demski zitiert, über Wedekinds Lulu schreibt, könnte ohne weiteres auch auf seine Delila, die eigentliche Hauptfigur seines Simson-Stücks, übertragen werden:

»Der literarische Bürgerschreck der Jahrhundertwende schuf eine Gestalt, deren Laszivität ebenso bannend wie schockierend wirkte. Wedekinds Lulu-Projekt ist das Märchen von der männermordenden Frau, der Hexe, die schließlich in den Ofen gestoßen wird. Es ist aber auch mehr, nämlich eine Geschichte der Männer, die sie erschaffen und projektiv aufladen. Denn natürlich ist Lulu keine Frau, sie ist, wie Eva Demski es ausdrückte, >ein Koordinatensystem, in das die Fieberkurven verschiedener männlicher Defekte sich eintragen lassen«.« (Pankau 2005: 139)

So lässt Wedekind auch in seinem Simson-Drama eine Frau vom Rande der Gesellschaft aufsteigen. Delila ist hier eine machtbesessene Dirne, die für ihren sozialen Aufstieg ihre Macht über Männer skrupellos einsetzt. Von der Entmachtung Simsons verspricht sie sich den höchsten Gewinn und sieht sich schon zu Beginn als Siegerin: Der Sieg erhebe sie, so prahlt sie, »Hoch über euch, ihr Fürsten .../Den Sieg, aus dessen Glanz, solang ich lebe,/Kein Sturz mich je dem niederen Volk vereint « (Wedekind 1913: 143). Die Philister-Fürsten sind vielmehr Karikaturen der Männlichkeit, Feiglinge und Schwächlinge, die nur noch an Geld denken. Sie regieren, halten sich aber gleichzeitig für regierungsunfähig und für klägliche Kreaturen, die nur noch Scham empfinden müssten. Aber dennoch sind sie nicht bereit, ihre Doppelmoral auf- und die Herrschaft abzugeben: »Solang ich herrsche, schäme/Ich überhaupt mich nicht«, verkündet Azav, einer von ihnen (ebd.: 156). Die zu blassen Schatten einstiger hegemonialer Männlichkeit verkommenen Figuren beklagen: »Hat uns Delila unsere Herrschermacht/Verliehen? Helden waren unsre Väter/Als Helden zeugten Heldensöhne sie« (ebd.).

Simson, der hier auffälligerweise als einziger Israelit auftritt, erweckt im Gegensatz zu den effeminierten Philistern, die in einem Matriarchat leben, eher den Eindruck eines hypervirilen >Körperhelden<, der wie Herakles gerne isst, trinkt und gerne Köpfe zerschmettert. Nachdem ihm seine

5| Lulu ist die Hauptfigur in Frank Wedekinds Dramen »Die Büchse der Pandora u und »Erdgeist« (Wedekind 1924). 
Kraft von Delila genommen wird, vollzieht der Heros >wilder< Männlichkeit eine Wandlung, die das vorläufige Ende seiner Virilität bedeutet. Denn geblendet und seiner Kraft beraubt, fühlt er sich nicht nur wie eine Frau, sondern wird zum Sprachrohr des still vor sich hin leidenden weiblichen Geschlechts:

»Durch meine Blindheit«, sagt er zu Delila, »sind wir so vertauscht,/Dass ich das Weib bin, und dass du der Mann bist/Blind weiß ich nicht, wie ich auf andre wirke./ Drum brauch' ich Liebe, brauch' Geborgenheit./Was Millionen Weiber schweigend leiden,/Das leid' ich jetzt. Ich schäme mich, Delila,/Wie in der Ehe nur das Weib sich schämt,/Unsicher seines Glücks, bei andern Männern.« (Ebd. 173)

Der geschwächte Muskelprotz Simson identifiziert sich jetzt so stark mit den Frauen, dass er sogar den Wunsch hegt: »Ich wollt', ich könnte Kinder dir gebären,/Delila. Beinahe glücklich dreht' ich dann/Die Mühle, wenn zur Seit' ein hilflos Kind/In sanftem Schlummer liegt« (ebd.: 174). Delila wird für ihre Tat nicht nur mit Ländereien und der Verheiratung mit dem Philisterkönig Og belohnt, sondern auch mit der Ernennung zur DagonPriesterin. Doch auch damit ist ihre Machtgier nicht befriedigt, Delila verlangt auch noch Simsons Tod, wird aber dann in einem Eifersuchtsanfall ihres königlichen Gemahls selbst erstochen. Simson weint erst um Delila - Wedekinds Regieanweisung lautet hier »Simson auf den Knien in Weinkrämpfen«-, bevor er den Dagon-Tempel zum Einsturz bringt. Sein Motiv scheint rein persönlicher Natur: »Dass ich mit einem Schlag für meine armen/Augen an den Philistern Rache nehme!« (Ebd.: 224).

Anhand der bislang behandelten Werke wird ersichtlich, dass in dem Zeitraum von 1894 bis 1913 die Figur Simson innerhalb des geschlechterpolitischen Diskurses deutscher Schriftsteller und Schriftstellerinnen unterschiedlich instrumentalisiert wird. Entwerfen die Prosaautorinnen Bock und Viebig ein antimilitaristisches und musisches Bild vom Mann, das sich gegen das herrschende, militärisch überformte Männlichkeitsideal des Wilhelminismus richtet, so scheint sich letzteres in der Theaterwelt der Zeit zunächst noch behaupten zu können, wofür Wettes 1904 entstandenes Bühnenwerk »Simson« den besten Beweis liefert. Aber nur sechs Jahre später werden mit Hilfe der Figur Simson auch im weitgehend männlich beherrschten Theaterbereich die wilhelminisch-maskulinistischen Ideale, wohlgemerkt durch männliche Autoren, demontiert. Dramenautoren wie Eulenberg und Wedekind kehren auf der Bühne die herrschende Geschlechterhierarchie geradezu um, indem sie nicht nur die Macht - durch die Figur der Delila - feminisieren, sondern, wie Wedekind, gar die traditionelle Männlichkeitsikone Simson als weiblich erscheinen lassen. Damit sind diese Lesarten allerdings Ausdruck eines in den Kulturkrisendebatten der Zeit fantasierten Verfalls der Geschlechterordnung und der »allgemeinen Krise der Unterscheidungen« (Koschor- 
ke 2000: 150), in der sich Geschlechter- und Moderne-Diskurs auf fatale Weise verbinden.

\section{Antisemitisch verweiblicht, jüdisch maskulinisiert: Simson im deutschen und zionistischen Protofaschismus}

Auch in dem nur vier Jahre nach Wedekinds Werk entstandenen Schauspiel von Hermann Burte, einem völkisch orientierten badischen Heimatdichter, wird Simson mit weiblichen Attributen belegt - freilich mit einer völlig anderen Intention. Der Antisemit Burte huldigt, anders als die genannten Kritiker des Wilhelminismus, den alten männlichen Tugenden, denen sein Simson nicht gerecht werden kann, da er eine Reihe von als jüdisch geltenden Eigenschaften in sich vereinigt. Die Philister sind es, die hier die Männlichkeit verkörpern, sie nennen Simson, den Burte schon eingangs als verweichlichtes Muttersöhnchen darstellt, »knabenhafter Mann/Und mädchenweich« (Burte 1917: 36). In ihren Augen ist er ein Mörder und Mädchenschänder, von seiner blonden philistäischen Frau Michal, die ihn liebt, erwarten sie, dass sie ihn verlässt. Dass Burte in seinem Schauspiel auch Simson mit blondem Haar ausstattet, scheint zunächst nicht in das völkische Schema zu passen. Jedoch kristallisiert sich im Laufe des Stücks immer mehr heraus, dass Simson im Grunde eine verlorene Seele ist, die sich vom jüdischen Joch zu befreien sucht. So beschimpft er die israelitischen Priester, derentwillen er sein Leben nicht opfern will, als Wucherer und wirft ihnen vor, an ihren Schulen Hass auf den Krieg zu predigen - man bedenke, wir befinden uns zeitlich im Ersten Weltkrieg. Dass Delila, auch hier eine Prostituierte, als Frau das philistäische Patriarchat vor Simsons Kraft erretten darf, hängt mit dem männlich-hegemonialen Frauenbild der Philister zusammen, demzufolge die Dirnen, so ein Philister-Fürst, »schützen manchen Mutterleib/Vor zeitigem Verderb« (ebd.: 108). Als Lohn soll Delila, die hier auch Werkzeug eines Glaubenskriegs zwischen dem philistäischen Heidentum und der jüdischen - und somit indirekt auch christlichen - Welt ist, zur Priesterin des Dagon erhoben werden.

Die völkischen, später nationalsozialistischen Elemente sind in dem Stück ebenso unübersehbar wie auch die ausdrücklich pejorative Bezeichnung Simsons als Jude; er wird von seinem Peiniger an der Mühle belächelt, weil er »Judenpsalmen« singt. Das Stück wird gegen Ende immer verworrener. Von einem Philister-Fürsten erfährt man, dass Dagon die »Mannheit als Gott« ist, dass also sein erwarteter Sieg den Triumph der Männerherrschaft bedeutet. Und diese fordert Delila heraus, als sie schließlich verlangt, dass das Götzenbild Dagons aus dem Tempel entfernt und stattdessen dort ihr goldenes Bildnis aufgestellt werde. Als die Philister dies natürlich verweigern, fordert sie, den Dagon-Tempel in einen 
jüdischen zu verwandeln und versucht sich noch mit Simson zu verbünden, der die Dirne allerdings abweist: »Du spielst und hegst ihn frech im Munde/Und lachst ihn an: Gott ist dein letzter Kunde« (ebd.: 264). Auch bei Burte bringt Simson den Tempel zum Einsturz, doch gibt es diesmal Überlebende, ein Mädchen, einen Knaben und einen Sklaven, die den Geist der Philister auferstehen lassen: »Kinder, kommt, wir wollen beten,/ Der Philister kann es nicht./Lasst uns auf die Berge treten,/Von den Bergen kam das Licht« (ebd.: 277). ${ }^{6}$

Spuren des aufkommenden Faschismus finden sich auch in Zeev Jabotinskys 1927 in einem russischen Exilverlag in Berlin zunächst auf russisch erschienenen Roman »Philister über dir, Simson«, der ein Jahr später ins Deutsche übertragen wurde (Jabotinksy 1928). Jabotinsky war der Begründer des »revisionistischen Zionismus«, einer ultranationalen und militanten Bewegung, aus der sich der Likud-Block im heutigen Israel ideologisch noch immer speist. Jabotinsky wollte aus den Juden der Diaspora ein Kämpfervolk machen, das seine angestammte Heimat, das Heilige Land, zurückerobern sollte. Die italienischen Faschisten, die ihn inspirierten, verkörpern in seinem Roman die Philister, sie werden den Israeliten gegenübergestellt. Es sind Jabotinskys Auffassung nach die »zwei Eroberervölker Kanaans«, Kolonisatoren also, die voneinander lernen sollten - vor allem aber müssen die Hebräer von den Philistern lernen. Genau das tut Simson auch, er lebt die meiste Zeit bei den Philistern und studiert sie - führt also ein Doppelleben. Simson trägt hier durchgehend männlich-heldenhafte, ja militaristische Züge: Er ist ein autoritärer Kommandant seiner Guerillakämpfer und will seine zerstrittenen Volksbrüder in einem Reich vereinen (Jabotinsky 1928: 61). Gleichzeitig tritt er auch als weiser Richter auf und wird vom Volk mit fast schon faschistischer Blindheit - als »Führer« (ebd.: 62) - verehrt, von einigen jedoch auch verspottet.

Das ist nicht die einzige Ambivalenz in diesem sehr komplexen Werk. So bewundert Jabotinskys Simson zwar die rigide Gesellschaftsordnung, die Disziplin der Philister sowie ihr Bemühen, die Rassenreinheit des eigenen Volkes zu bewahren (ebd.: 216f.). Aber er übersieht nicht, dass sie als Kolonisatoren das Volk der Kanaaniter unterdrücken. Seine Delila ist eine kultivierte und gebildete Frau, bekannt für ihre zum Teil in Ägypten erworbene Weisheit, die Simson bis zuletzt die Treue hält - ihre Magd ist es, die Simson verrät. Der seiner Kraft beraubte Simson, wegen seiner Heldentaten auch bei den Philistern geschätzt, erhält noch eine Chance: Er soll eine Art philistäisches Protektorat im Land der Israeliten errichten und so beide Völker zu einem großen mächtigen Reich zusammenschweißen

6| Hermann Burtes »Simson« erlebte eine breite Rezeption. Das Stück erreichte innerhalb von drei Jahren sechs Auflagen, von der Universität Freiburg wurde Burte 1924 die Ehrendoktorwürde verliehen. Zu Burtes Werdegang siehe Sarkowicz/Mentzer 2000: 121-123. 
helfen. Er lehnt jedoch ab und bleibt seinem Volk bis in den Tod treu. Ehe Simson den Philister-Tempel zertrümmert, tötet er die Geliebte und ihr gemeinsames Kind, das Delila, die inzwischen eine Belohnung vom Staat für die Dienste ihrer Magd erhalten hat, zum Hass auf das Volk seines Vaters zu erziehen trachtet.

\section{Der Kreis von Ent- und Re-Maskulinisierung}

Anhand der hier behandelten Werke lässt sich feststellen, dass einerseits die Figur Simson in Diskursen über Männlichkeitsvorstellungen, die sich gegen die Männlichkeitsideale des Wilhelminismus bis kurz vor Ausbruch des Ersten Weltkriegs richten, zwar unterschiedlich instrumentalisiert wird, dass dabei aber die Effeminierung der Figur dominiert. Andererseits dient jedoch ihre »Verweiblichung« nur wenige Jahre später dazu, aus völkisch-antisemitischer Sicht ein jüdisch kodiertes Gegenbild zu den als bedroht empfundenen, maskulinistisch-nationalistisch aufgefassten Tugenden zu konstruieren. Wird also die - feminisierte - Figur Simson als anti-wilhelminische Allzweckwaffe im Geschlechterkampfdiskurs der Vorkriegszeit eingesetzt, wird diese Feminisierung, wenn auch in abgewandelter Form, noch während des Ersten Weltkriegs Teil jener Re-Maskulinisierungs-Bewegung, die aus dem Vorstellungsarsenal maskulinistischer Reaktionsbildungen schöpft, wie sie sich damals etwa im Männerbunddiskurs konkretisierten und gerade durch die Kriegserfahrung verdichteten (Brunotte 2004). Betrachtet man aus dieser reaktiven Perspektive Hermann Burtes »Simson« als eine reaktionäre Antwort auf vorangegangene, den ideologisch-hegemonialen Männlichkeitskern des Wilhelminismus aushöhlenden Simson-Darstellungen, so muss zwangsläufig auch der Simson-Roman des militanten Zionisten Zeev Jabotinsky als eine Abwehrreaktion auf die antisemitische Darstellung der Juden als verweiblichte und kampfunfähige Schwächlinge ${ }^{7}$ gewertet werden. So bilden die unterschiedlichen literarischen Gestaltungen der biblischen Kämpferfigur Simson eine Art Seismograph, mit dem sich die kulturellen Schlachten um hegemoniale Männlichkeit, die im Spannungsfeld von Feminisierung und Re-Maskulinisierung in Deutschland seit dem ausgehenden 19. Jahrhundert und bis weit in die Weimarer Zeit hinein tobten, noch genauer verfolgen ließen.

7| Siehe den Beitrag von Marilyn Reizbaum in diesem Band. 


\section{Literatur}

Bock, Annie (1894): Simson und Delila. Roman, Stuttgart: Engelhorn.

Böhme, Hartmut (2006): Fetischismus und Kultur. Eine andere Theorie der Moderne, Reinbek bei Hamburg: Rowohlt.

Brunotte, Ulrike (1992): »Herakles, das Chaos und die Arbeit«. In: Heroisierungen, Kursbuch 108, Berlin: Rowohlt, S. 135-151.

Brunotte, Ulrike (2004): Zwischen Eros und Krieg: Männerbund und Ritual in der Moderne, Berlin: Wagenbach.

Burte, Hermann (1917): Simson: ein Schauspiel, Leipzig: Sarasin.

Eulenberg, Herbert (1910): Simson: eine Tragödie nebst einem Satyrspiel, Berlin: Rowohlt.

Eulenberg, Herbert (1948): So war mein Leben, Düsseldorf-Kaiserswerth: Die Faehre.

Jabotinsky, Zeev (1928): Philister über dir Simson. Roman, Weimar: Lichtenstein.

Koschorke, Albrecht (2000): »Die Männer und die Moderne«. In: Wolfgang Asholt/Wolfgang Fähnders (Hg.), Der Blick vom Wolkenkratzer. Avantgarden - Avangardekritik - Avantgardeforschung, Amsterdam/Atlanta: Rodopi, S. 141-162.

Pankau, Johannes G. (2005): Sexualität und Modernität. Studien zum deutschen Drama des Fin de Siècle, Würzburg: Königshausen \& Neumann.

Runte, Annette (Hg.) (2007): Feminisierung der Kultur? Krisen der Männlichkeit und weibliche Avantgarden, Würzburg: Königshausen \& Neumann.

Sarkowicz, Hans/Mentzer, Alf (2000): Literatur in Nazi-Deutschland. Ein biografisches Lexikon, Hamburg: Europa-Verlag.

Viebig, Clara (1904): Simson und Delila, Novelle, Leipzig: Hesse.

Wedekind, Frank (1913): »Simson oder Scham und Eifersucht: dramatisches Gedicht in 3 Akten«, in: Frank Wedekind, Ausgewählte Werke, Bd. 5, München 1924: Mueller.

Wedekind, Frank (1924): »Erdgeist. Die Büchse der Pandora. Der Kammersänger«, in: Frank Wedekind, Ausgewählte Werke, Bd. 2, München: Mueller.

Wette, Hermann (1904): Simson. Tragödie in 5 Akten nach Worten des Alten Testaments, Leipzig: Grunow. 


\title{
'Große Mutterı, Gräber und Suffrage.
}

\section{Die Feminisierung der Religion(swissenschaft)}

\author{
bei J.J. Bachofen und Jane E. Harrison
}

ULRIKE BRUNOTTE

\section{Religion und Kolonialismus}

In seinem Buch »Savage Systems« entwickelt der südafrikanische Religionswissenschaftler David Chidester (Chidester 1996) die These, dass die Kernkonzepte vergleichender Religionswissenschaft nicht allein aus der europäischen Aufklärung, sondern vor allem aus den kolonialen Grenzzonen stammen. Sie waren entscheidende Marker von Differenz und wurden als Instrumente der Kontrolle benutzt. Die kolonialen Kontakt- und Machtfelder bildeten somit einen bedeutenden Raum bei der Produktion konzeptioneller Kategorien von Religion und Religionen. Zugleich gehörte die vergleichende Wissensbildung in Sachen Religion zu den wichtigsten kolonialen Machtstrategien Europas und steht »at the forefront of the production of knowledge within these new power relations « (ebd.: 12). In dem Prozess des Othering, der im kolonialen Kontakt Jahrhunderte lang auch über die An- oder Aberkennung und die diskursive Produktion von »Religion« verlief, arbeitete die Strategie der Naturalisierung der indigenen Gesellschaften lange mit dem Verdikt ihrer Religionslosigkeit. In diesem Zusammenhang erhielten Codierungsprozesse durch imaginäre Geschlechter- und Rassebilder sowie durch ethnische Differenzierungen (Mc Clintock 1995) eine bedeutungsschaffende Funktion. David Chidesters Pionierarbeit von 1996 hat neben Michel Foucault in Edward Said einen bedeutenden Vorläufer. Edward Saids heute zunehmend kontrovers diskutierte (Castro Varela/Dhawan 2005) Studie »Orientalism« (Said 1978) ist somit nicht allein der »Gründungstext postkolonialer Theorie« (Dietze 2005: 208), sondern auch ein entscheidender Anstoß zur kritischen Selbstreflexion für die Religionswissenschaften. Das gilt freilich auch für die viel ältere religionskom- 
paratistische europäische Wissens- und Identitätsbildung. Denn »dieses Europa«, so Dipesh Chakrabarty, »ist ebenso wie der >Westen lich eine imaginäre Entität«, dessen Herstellung bereits »ein Stück globale Geschichte ist, von der die Geschichte des europäischen Imperialismus einen untrennbaren Teil bildet« (Chakrabarty 2002: 306). Zugleich allerdings müssen besonders die religions- und ritualtheoretischen Konzepte aus der Hochzeit des europäischen Überseekolonialismus um 1900 nicht allein als Produkte einer »imaginären Ethnographie« (Kramer 1977), sondern auch als Medien der z.T. unbewussten Selbst- und Modernereflexion gedeutet werden. Das hat zuletzt Hartmut Böhme in seiner Studie zum europäischen Fetischismusdiskurs gezeigt, der von 1830 bis 1920 aus dem Kanon religionswissenschaftlichen und ethnologischen Wissens als, so Jean Paul, »ungeheueres Reich des Unbewussten, dieses wahre, innere Afrika« (Böhme 2006: 254) über die Literatur in die Sexualwissenschaften wanderte, um dort zum biopolitisch diskursivierten »Paradigma aller Perversionen« (ebd.: 376) zu avancieren. Böhme kommentiert:

»Wie den Ethnologen der afrikanische Fetischismus als unproduktiv, kindlich, primitiv und wertlos vorkam, so konstruierten Ärzte und Psychologen gegen Ende des Jahrhunderts den sexuellen Fetischismus mit den selben Attributen als pervers.« (Ebd.: 376)

Das Studium der Diskurse bei so unterschiedlichen Wissenstypen wie literarischen Texten, Kunstwerken, und nicht zuletzt wissenschaftlichen Narrationen, in denen Europa Afrika, die Amerikas sowie den Orient und seine Religionen schildert und erfindet, führt somit nicht etwa in »exotische Randzonen des europäischen Bewusstseins« (Osterhammel 1997: 167), sondern ins Zentrum europäischer Selbstvergewisserung. Es ist nun zu fragen, ob sich in den orientalistischen und kolonialistischen Diskursen, die ja zugleich seit der »Odyssee« die moderne Meistererzählung vom heroischen Kultur-Subjekt und den >Barbaren< (griech.: Fremde) generieren, ein verstecktes Reflexionspotential entdecken lässt, das als Subtext zum normativen Männlichkeitsdiskurs der Moderne rekonstruierbar ist? Das soll zunächst symptomatologisch anhand der Vision einer >weiblich-dionysischen Urzeit< und der Figur der »Großen Mutter« demonstriert werden, für die die deutsche Spätromantik und besonders Bachofens Studien zum »Mutterrecht« von 1861 zentrale Multiplikatoren waren (vgl. Wesel 1990). Der keineswegs homogene Diskurs politisierte, popularisierte und verbreitete sich schnell in andere gesellschaftliche Felder, sowohl in die der sozialistischen und kommunistischen Kapitalismus- und Patriarchatskritik (Engels 1892) als auch in die ethnologische Familien-, Verwandtschaftsund später Matriarchatsforschung (Morgan 1877). Die wissenschaftlichen Diskurse wurden durch literarische Imaginationen, die vornehmlich in kolonialen Grenzzonen verortet waren, begleitet, mythisiert und spätestens um 1900 auch sexualisiert. Der Orient wandelte sich von einem Objekt der 
Macht und des Wissens mehr und mehr zu einem von Abwehr und Verlangen. So kulminierte etwa in Rider Haggards zwanzigfach übersetztem Bestseller und Kolonialroman »She « von 1883 das kolonial Imaginäre im Zerrbild eines matriarchal codierten und zugleich sexualisierten Kannibalismus. Fast könnte man versucht sein, den Absolutheitsschein, den die von Darwin übernommene patriarchale Urhorde und der Urvater bei Sigmund Freud erfahren, gleichsam als Bollwerk gegen die kulturelle Ubiquität der damals frei schwebenden Fantasmen vom »Großen Weiblichen« (Stephan 1997) zu lesen. In »den Texten des 19. Jahrhunderts war die >Rückkehr zur Mutter allgegenwärtig, nicht nur im Orientalismus, aber dort besonders« (von Braun/Mathes 2007: 268). Manche, wie die Saint-Simonisten, erhofften sich gar die soziale Erneuerung von einer orientalischen Maria und von »Mutter Orient« (ebd.: 269).

Materiale Figurationen eines weiblich Erhabenen (Brunotte 1993) entdeckte das moderne Europa freilich zuerst durch die frühe Archäologie in der Gräbersymbolik der Antike (Bachofen 1859). Im Zuge der von den Kolonialregimen getragenen archäologischen Erschließung Ägyptens, Kleinasiens und des Zweistromlandes trat den europäischen Religionsforschern bereits im 18. Jahrhundert eine »faszinierende Welt versunkener Reiche, ebenso abstoßend wie anziehend wirkender Fruchtbarkeitskulte und geheimnisvoller Muttergottheiten « (Kohl 1989: 362) entgegen, die genau mit der gleichzeitig in Europa kulturell zunehmenden Sehnsucht nach dem femininen Orient überein zustimmen schienen. Lebte die performative Autopoiesis des modernen hegemonialen Subjektmodells, wie sie Immanuel Kant in seiner dezidiert männlich codierten »Ästhetik des Erhabenen« entwirft, vor allem im identitätsstiftenden Narrativ der Selbstüberwindung und im Sprung nach »Oben«, ins helle körperlose Reich transzendentaler »Gattungsvernunft«, so eröffneten sich mitten im kolonialen Expansionsszenario nun Blicke nach »Unten«, ins »Dunkle« und in die Abgründe der Vergangenheit. Der wissenschaftliche »Gang zu den Müttern«, der hier in etwa zeitgleich mit Darwins »Entstehung der Arten« (Darwin 1859) versucht wurde, erschloss den Europäern ungeahnte Einblicke und Einsichten in materiale Substruktionen herrschender Gesellschafts- und Geschlechterordnungen.

\section{Bachofens "Mutterrecht": Substruktion des Patriarchats oder orientalisierender Kult?}

Besonders im Werk des Schweizer Rechtshistorikers und Altertumswissenschaftlers Johann Jacob Bachofen zeitigten diese Entdeckungen verborgener Narrationen und Imaginationen Folgen für die kulturellen Geschlechtersemantiken. Anhand antiker Gräbersymbolik und anderen Funden aus der >Alten Welt<, aber auch durch Rückgriff auf ethnographisches Material, meinte er die gattungsgeschichtliche Existenz eines frühen Mut- 
terrechts, dem ein regelloser, von >wilden< Männern beherrschter Hetärismus vorausgehe, rekonstruieren zu können. Bachofens »Mutterrecht« und die darin wissenschaftlich beschworene mütterlich-stoffliche Urkultur steht sicher im Zeichen des spätromantischen Mutterkultes und der zunehmenden Polarisierung und Biologisierung der Geschlechtscharaktere (vgl. Hausen 1976). Andererseits hatte sein Mutterkult Anteil an dem, was Elisabeth Hartlieb im Anschluss an Rebecca Habermas und andere SozialhistorikerInnen als die »Feminisierung des christlichen Glaubens« seit etwa 1800 bezeichnet (Hartlieb 2006: 233ff.). Denn die große zivilisierende Rolle, die der Autor den frühen Religionen und der Frau als zivilisationsbegründendem Geschlecht zuschrieb, habe, so Bachofen, ihren Ursprung im »Religionscharakter des Weibes« (Bachofen 1861/1975: 20), der als »besondere Anlage der Frauen zur Frömmigkei« (ebd.: 19) im weiblichen Charakter verankert sei.

In diesem Buch des Rechtswissenschaftlers, dem Mythos und Religion als zentrale Hebel der Geschichtserkenntnis galten, wurden somit zwei Säulen bürgerlich männlicher Hegemonie erschüttert: 1. die bis dahin unangefochtene Vorstellung von der (Ur-)Familie als einer patriarchalen Institution und 2. die Ideologie von der Überzeitlichkeit männlicher Herrschaft. Bachofen »führte die Vorstellung von einem Weltalter ein, in dem das weibliche Prinzip über das männliche regiere, er wollte nicht allein ein anderes Familienrecht und eine andere Geschlechterordnung, sondern den weiblichen Anfang der Menschheitsgeschichte freilegen « (Ziege 2002: 195). Die Beschwörung der verwilderten Männer der hetärischen Urzeit und der zivilisierenden Rolle des demetrischen Muttertums sind gleichwohl eingeordnet in eine mythische Geschlechtergeschichte, die sich als stufenweise Höherentwicklung vom regellosen Frauentausch, über die streng religiöse und sittliche Monogamie des Mutterrechts bis zum apollinisch-geistigen Vaterrecht vollzieht. Dabei konnte die männliche Herrschaft nur durch einen schmerzlichen Akt der Losmachung des Mannes vom Mütterlich-Leiblichen, des »Geistprinzips« vom »Stoffprinzip« gelingen. Ziel Bachofenscher Geschichtstheologie ist eindeutig die reine, männliche Autonomie. Doch der zu ihr führende Akt der Losmachung, so erläutert er anhand einer Fülle von Beispielen, musste immer wiederholt werden. Ohne Frage überhöhte der Autor mythisch nichts anderes als die bipolare, heteronormative Geschlechterordnung und den spätromantischen Mutterkult des 19. Jahrhunderts. Zugleich wird sein geschichtstheologisches Stufenmodell im »Mutterecht« von einem zyklischen Kreislaufmodell ewiger Wiederkehr konterkariert. Auch ist das Buch auf den zweiten Blick voll von scheiternden Heroen und wird von Krisen- und Geschlechterkampfrhetorik durchzogen. So sind es besonders die Schilderungen der bedrohlichen liminalen Phasen ${ }^{1}$ zwischen den Entwicklungsstufen, die im mythischen

1) Der Begriff der liminalen Zone stammt von dem Ethnologen und Kulturtheoretiker Victor Turner. Er bezeichnet damit den Übergangsbereich, in dem sich 
Gewand zugleich »eine verborgene Instabilität der Geschlechterordnung im 19. Jahrhundert« (Erhart 2001: 75) bergen, das moderne Patriarchat als »Oberfläche einer fortdauernden Spannung « (ebd.) und die familial grundierte bürgerliche Männlichkeit als unsicher kennzeichnen. Nach Walter Erhart liefert Bachofen damit

»[...] eine historisch spekulative Grundlegung dessen, was die psychoanalytische Objektbeziehungstheorie heute als die >Differenzierung zum Mann< bezeichnet: die fortgesetzte Abgrenzung von dem einst symbiotisch erfahrenen weiblich-mütterlichen Objekt [...].« (Ebd.: 81)

Das männliche Individuum wird in wiederholten Narrationen des Sich-LosReißens, des Kampfes und der Selbstvergewisserung selbst erst hergestellt. Für dieses narrative und performative Modell einer Produktion von Männlichkeit in und durch die gefahrvollen rites de passage liefert Bachofens »Mutterrecht« ein paradigmatisches Modell, das als »Ursprungstext über moderne männliche Identität« (ebd.) gelesen werden kann.

\section{Massenangst des Okzidents}

Der Religionswissenschaftler Hartmut Zinser situiert das Werk des konservativen Patriziers Bachofen in die krisenhafte Zeit des von revolutionären Aufständen und Befreiungsbewegungen erschütterten Europas und liest in dessen Reden vom »dionysische[n] Frauenkult [...], der alle Unterschiede« aufhebe und »überall mit der Auflösung der politischen Hierarchien und dem Verfall des staatlichen Lebens« (Bachofen 1861/1975: 40) einhergehe, nichts anderes als die Angst des Bürgers vor der Herrschaft der »ununterschiedenen Masse« (ebd.; vgl. Zinser 1981). Eine Angst, die Bruno Latour freilich bereits seit der epistemologischen Anstrengungen Platons, einen Staat auf reine Vernunftherrschaft zu gründen, als Werkmeister europäischer Erkenntnistheorie vermutet (Latour 1999: 19-27). Wie gezeigt, versucht Bachofen die Gefahr einer Herrschaft der »Vielen« und der Wiederkehr der entdifferenzierenden Kampfphasen zwischen Matriarchat und Patriarchat durch sein geschichtstheologisches Stufenund Geschlechtermodell zu bannen. Diese Anstrengung mündet in ein Plädoyer für die geordnete, nordische Manneskultur und beschwört das »siegreiche Vatertum und [...] die uranischen Sonnenhelden« (Bachofen

in sogenannten Übergangsritualen ein Erfahrungsraum bildet, in dem das, was in der Normalität alltäglicher Beziehungen und im Ensemble sozialer Positionen nicht repräsentiert ist, verkörpert und spielerisch neu zusammengesetzt werden kann. Vgl.: Victor W. Turner, Betwixt and Between: the liminal period in Rites de passage. In: Victor Turner (1967): The Forest of Symbols: Aspects of Ndembu Ritual, Ithaca/New York, S. 93-111. 
1861/1975: 48). Bis zu welchem Grad allerdings das »Mutterrecht« von solchen Heroen des Scheiterns bevölkert ist, die nicht zu hegemonialen Positionen aufsteigen, sondern in Zwischenstufen einer effeminierten Männlichkeit stehen bleiben, das hat zuletzt Susanne Lanwerd gezeigt (Lanwerd 1993: bes. 93, 101ff.). Bachofens Botschaft bleibt zudem in noch einer weiteren Hinsicht ambivalent. Sein Modell der Gynäkokratie enthält auch Vorstellungen von »allgemeiner Brüderlichkeit« (Bachofen 1861/1975: 40) sowie von »Freiheit und Gleichheit« (ebd.: 13), die zwar mit dem Vaterrecht überwunden werden (müssen), denen gleichwohl die Sehnsucht des Autors gehört. Oft übersehen wurde freilich in der Bachofen-Rezeption, dass der in die Religions- und Weltgeschichte projizierte Geschlechterkampf zugleich eine Metapher des kolonialen Diskurses darstellt und für Bachofen »die fortdauernde welthistorische Auseinandersetzung zwischen Okzident und Orient (Kohl 1989: 363) repräsentiert. »Dem Occident«, so der Mythenforscher, »hat die Geschichte die Aufgabe zugewiesen, durch die reinere und keuschere Naturanlage seiner Völker [...] die Menschheit aus den Fesseln des tiefsten Tellurismus, in dem sie die Zauberkraft der orientalischen Natur festhielt, zu befreien « (Bachofen 1861/1975: 36). Mit seiner Beschwörung des >männlich okzidentalen Geistprinzips` und der rasiatisch-orientalischen Gynaikokratie<, die in den »Ländern des sinnenschmeichelnden Orients, zumal in Afrika und Syrien« den Kampf »mit der größten Entschiedenheit aufnehmen « (ebd.: 425), mythologisierte der Religionsforscher nicht allein die bürgerliche Geschlechterordnung des 19. Jahrhunderts, sondern auch die imperiale Politik Europas. Gleichwohl, bei »Bachofen bezeichnete das Mutterecht eine allgemeine Kulturstufe aller Völker vor dem Übergang zum Patriarchat. Die These war nicht unbedingt rassistisch avant la lettre, aber mit dem geopolitischen Gegensatzpaar von Orient und Okzident« (Ziege 2002: 206) versehen. Erst bei Alfred Baeumler, der eine Bachofen-Auswahl, die 1926 unter dem Titel $\gg$ Der Mythos von Orient und Occident. Eine Metaphysik der Alten Welt« erschien, mit einem ausführlichen Vorwort versah, wurde das Mutterrecht als gattungsgeschichtliche Stufe abgeschafft und in das feindliche Gegenüber von weiblich-semitisch-orientalischer versus männlich-nordisch-arischer Völker aufgelöst. Nun verwandelte sich die »Überwindung des Orients durch den Okzident und die Überwindung der Frau durch den Mann [...] rassepolitisch (in) die Überwindung des >Juden < durch die >Germanen« (Ziege 2002: 209).

\section{Jane E. Harrison: Dämonen des Wissens}

\section{Positionen}

Martin Bernal hat in »Black Athena « darauf hingewiesen, dass sich zumindest in Deutschland im Laufe des 19. Jahrhunderts in der klassischen Al- 
tertumswissenschaft das historische Erklärungsmodell für den Ursprung des seit Winckelmann idealisierten Griechentums von den >semitischen ägyptischen zu den >arischen « Einflüssen der dorischen Einwandererstämme verschoben habe, was als Folge letztlich rassistischer Tendenzen auch zu einer religionswissenschaftlichen Abwertung der >Ureinwohner $<$ Griechenlands führe (Bernal 1992: bes. 58). Die geradezu entgegengesetzte Bewegung einer Aufwertung der autochthonen Bevölkerung Griechenlands und Kretas können wir im Werk Jane E. Harrisons beobachten. Sowohl die Entdeckung des >primitiven Rituals und des Performativen als auch die unter dem Namen »Dionysos « ausschwärmende Hinwendung zu vorolympischen, zivilreligiösen Vergemeinschaftungsformen standen im Focus des Wirkens der englischen Archäologin und Gräzistin. Heute würde man ihre sozialen Ideale wohl als kommunitaristisch bezeichnen.

Harrison lebte von 1850 bis 1928 in England und hat als erste Religionswissenschaftlerin im universitären Rahmen geforscht und gelehrt. Ihre Bezugspunkte waren freilich neben den Stammesgesellschaften vor allem die antike griechische Religion. Auch sie erkannte die politische und wissenschaftliche Aktualität ihrer Forschungen und engagierte sich feministisch im Kampf um Wissen und Partizipation. Dabei setzte sie die Kategorie Geschlecht wie das performativ sich selbst als soziales Gebilde erschaffende Kollektiv ins Zentrum ihrer Kultur- und Religionstheorie. Die »Gesellschaft« wird hier nicht wie bei Durkheim, dem Harrison viel verdankt, als eine totalité sui generis (Durkheim-Kritik, vgl. Latour 1999; Lüdemann 2004) gesetzt, sondern als ein ritueller und imaginärer Prozess verstanden, der die Erfindung von und die Kommunikation mit »nichtmenschlichen Wesen« (Latour 1999: 256) einschließt. Steht Bachofens evolutionistische Studie zum »Mutterrecht« eher symptomatologisch für den Orientalismus der deutschsprachigen Religionswissenschaft und der deutsche Männerbunddiskurs, wie er in Baeumlers arischen Beschwörungen gipfelt, für die politischen Dynamiken von Misogynie, Homophobie und Rassismus, so kann am Beispiel der englischen Religionsforscherin verfolgt werden, was passiert, wenn eine Frau aktiv in das Feld vermeintlich reiner (neutraler) Vernunft eintritt, die darüber hinaus noch die Dinge, Artefakte und Rituale zu ihrem Thema erklärt. Dabei drängen sich zugleich etliche Fragen auf: In welchem kulturellen Spannungsfeld steht Harrisons innovative methodische Wende von »Text« und »Schrift« zu »Bild« und »Ritual« (vgl. Schlesier 1994: 155). Und wie verhält sich dieser Medienwechsel wiederum zu der von ihr feministisch angewandten Kategorie »Geschlecht« und zu ihrem Engagement in der Suffragebewegung? Und nicht zuletzt: Auf welche Weise ist eigentlich der Widerstand des Wissenschaftsmilieus von Cambridge gegen Harrison mit ihrem hegemoniekritischen Blick auf die olympische Zeus-Religion verknüpft? Sowie, um diese Frage auch noch zu stellen, was hat das mit ihrer öffentlichen Kritik an den Prinzipien wissenschaftlicher Objektivität zu tun? 


\section{Körperwissen und Bildtänze}

Seit 1874 war die damals 24-jährige Jane Harrison als eine der ersten Frauen Studentin am neu gegründeten Frauencollege, dem Newnham College in Cambridge. Von 1879 bis 1897 lebte sie als vielbeachtetes Beispiel einer selbstständigen New Woman in London und studierte und lehrte Klassische Archäologie am Britischen Museum. Ihre sehr eigenwilligen und methodisch innovativen lectures über griechische Kunst und Archäologie, die für alle Interessierten offen waren, machten sie so bekannt, dass sie bald über London hinaus ausgedehnt werden konnten (Beard 2000: 54). Schon damals entwickelte Harrison ihre Leidenschaft für die Bildkulturen der Antike und begann auf Reisen durch die Museen Europas und in die Mittelmeerländer an den archäologischen Entdeckungen ihrer Zeit hautnah zu partizipieren. So nahm sie an Ausgrabungen von Wilhelm Dörpfeld und Sir Arthur Evans auf der Peloponnes und auf Kreta teil. Von 1898 bis zu ihrer Pensionierung und Übersiedelung nach Paris arbeitete Harrison dann wieder am Newnham College, nun als Research Fellow und als Dozentin. Harrison war, so Robert Ackermann, »the first female British classical scholar to achieve international recognition « (Ackermann 1991: 3), zugleich jedoch eine Wissenschaftlerin, um die viele Gerüchte kreisten. Man empörte sich über ihr familienfernes Leben, ihren Libertinismus in religiösen Dingen, ihre Vorliebe für die Rituale der >Wilden $<$, die zu enge Bindung an ihre Studentinnen und die angebliche $>$ Queerness $<$ in sexuellen Fragen. Zusammen mit ihren Kollegen Gilbert Murray und Francis Macdonald Cornford bildete Harrison den Kreis der sogenannten Cambridge Ritualists, zu dem später auch Arthur Bernhard Cook zählte.

Als am 7. Dezember 1909 die Cambridge Society of Heretics zu ihrem Gründungstreffen einlud, markierte das zugleich eine folgenreiche Erschütterung der intellektuellen, religiösen und nicht zuletzt der androzentrischen Selbstgewissheiten einer der ältesten und bedeutendsten Universitäten Englands. Das Ziel dieser häretischen Gesellschaft war es, »to create a forum for discussion of religion, art, and philosophy independent of Cambridge's centuries-long tie to the Anglican Church, whose structures and principles had presided over all such meetings in the past « (Fiske 2004: 1). Anfänglich aus zwölf Studierenden bestehend, war die Zahl der Mitglieder bereits nach drei Jahren auf über 200 gestiegen. Nicht allein die alt hergebrachten religiösen Normen und Autoritäten wurden in diesem universitätsweit bekannten Kreis zur Disposition gestellt, sondern auch der traditionelle, aus Klassen- und Männlichkeitsdünkel zusammengesetzte Elitismus von Cambridge. Der Kreis war kein exklusiver Herrenclub, sondern für alle offen: $\mathrm{Zu}$ den Mitgliedern der ersten Jahre zählten u.a. Francis Darwin, J.M. Keynes, Virginia Woolf, Edith Sitwell, Clive Bell and Lytton Strachey. Nicht zufällig wurde Jane E. Harrison als eine der keynote speaker für die Gründungssitzung eingeladen, denn »the first woman ever to give university lectures at Cambridge (in 1898), Harrison had become, by 
1909, one of the most controversial figures on campus « (ebd.). Hatte doch schon ihr erstes Hauptwerk, die »Prolegomena to the Study of Greek Religion« von 1903, - nicht zuletzt durch den Vergleich mit oralen Traditionen indigener Kulturen - vehement den »text-based approach to the ancient world that had dominated Greek studies throughout the last century« (ebd.) in Frage gestellt. Es schien ganz so, als stünde der mit der klassischen griechischen Literatur genealogisch verbundene, europäische »Literaturbegriff selbst durch die Dokumentation und Auswertung mündlicher Literaturen zur Disposition« (Schüttpelz 2005: 369). Damit zählte Harrison nicht erst durch ihre spätere Erforschung des rituellen Ursprungs der Tragödie (Harrison 1912) zur kulturtheoretischen und künstlerischen Moderne, sondern bedrohte zugleich das diskursive Machtfundament, auf dem der viktorianische Hellenismus von Cambridge ebenso wie die männlich dominierte, griechisch gebildete Wissenselite basierte.

Mit ihrem Kampf gegen die früher von ihr selbst betriebenen Verehrung der griechischen Skulptur als ideales Kunstwerk und normativ wirksames Körper-Haltungsmodell >edler Ruhe und stiller Einfalt< sowie gegen das Monopol von Schrift und Text als alleinige Ausdrucksmedien der griechischen Kultur und des Studiums derselben, stand sie freilich im Kontext eines pluralen Diskursfeldes. So nahm in ihrer Zeit etwa neben der zunehmenden Popularisierung der Antike durch Zeitschriften, moderne Kunst und Literatur auch die antiidealistische Propagierung einer >dionysischen Ästhetik zu. Bereits 1876 hatte Walter Pater im Anschluss an Nietzsche den Gott Dionysos gefeiert und seine Bedeutung für die modernen Künste beschworen (Pater 1876). Auch neue Wissenschaften wie die junge Archäologie und nicht zuletzt die mit dem Deutschen Wilhelm Mannhardt verbundene populäre Folklore-Forschung sorgten für die Ausweitung des Wissensbegriffs auf die materiale Kultur der Dinge, auf die Techniken und Praktiken der Rituale wie auf die Architektur- und Bildzeugnisse. Harrison verknüpfte jedoch als eine der Ersten (Schüttpelz 2005: 375) in ihrer Kulturanalyse die materialen Zeugnisse und Artefakte mit den schriftlosen Wissenstechniken und -formen der oralen Traditionen indigener Gesellschaften: Erzählungen, Körpergesten, Musik und ekstatischer Tanz avancierten in ihren Religionsanalysen zu gleichberechtigten Medien des religiösen Wissens wie des sozialen Lebens. Diese waren in archäologischen Relikten und Artefakten zwar nicht mehr direkt fassbar, wurden aber gleichwohl für sie in der antiken Ikonographie narrativ und performativ evident (vgl. Schlesier 1994: 145-192). Sicher partizipierte Harrison dabei am allgemeinen Medienumbruch in ihrer Zeit wie an der anthropologischen Wende in den Religionswissenschaften. Im Gegensatz zu Tylors und Frazers rationalistischer Überhebung über alles »Primitive und alle »Survivals« verband die Forscherin freilich bereits in den »Prolegomena« mit dem ethnologischen Vergleich einen Blick auf die räumlichen, zeitlichen und symbolischen Unterwelten des klassischen Olymp: Nicht die 
anthropomorph und zweigeschlechtlich geformte Götterfamilie um den väterlichen Alleinherrscher und hegemonialen Verwandlungskünstler Zeus interessierte Harrison, sondern die archaischen Welten der verschütteten und verdrängten kretisch-minoischer Kultur, die mehr in bildlicher oder figürlicher Form als durch Texte überliefert waren. Dazu zählten die chthonischen Kulte, die archaischen Totengeister und die Heroen. Vor allem waren es die Menschliches mit Außermenschlichem verbindenden Mischwesen, auf die sich Harrison konzentrierte und deren Skandal gerade in der rational nicht auflösbaren Mehrdeutigkeit bestand. In ihrem ersten Hauptwerk untersucht sie mithilfe ihrer neuen, von Karl Otfried Müller inspirierten historisch-kritischen Methode lokale griechische Kultpraxen. So rekonstruiert sie anhand von Ritualanalysen eine chthonische Schicht todesgebundener magischer Religiosität, deren Träger Geister und Heroen, deren zentraler Affekt die Angst und deren Intention die >Reinigung <, >Befreiung $<$ (rituals of >riddance $<$, >exorcisms $<$, Harrison 1903: $7 f$.) ist. Die »Prolegomena beginnen mit der revolutionären These einer grundlegenden Zweiheit der antiken Ritual- und Kultwelt: Einerseits die therapeia - Kulte der olympischen Götter als Ausdruck gegenseitigen Vertrauens und Austausches, verdichtet im do ut des des olympischen Götteropfers - und dann die älteren deisidaimonia, die Reinigungs- und Befreiungsriten, als Ausdruck der Angst vor den älteren Geistern und ehrfurchtgebietenden Mächten. So gewinnt Harrisons Modell des archaischen Opfers 1903 eine ganz eigene Richtung: Nicht das späte olympische do ut des allein sei relevant, sondern auch das angsterfüllte do ut abeas: »I give that you may go and keep away« (Harrison 1903: 7). Im Laufe ihrer Forschung erhebt sie schließlich eine liminale Gestalt aus dem Ensemble von außermenschlichen Figurationen zur Kernfigur der griechischen Frühzeit und zum Schlüssel ihrer Kulturtheorie: den Daimon. Normalerweise definiert als schreckenerregender Totengeist, wurde der Daimon bereits in Harrisons »Prolegomena« zu einer amorphen Potenz, deren bevorzugte Erscheinungsform die Schlange ist (ebd.: 587):

»Während in den Prolegomena die daimones hauptsächlich in der Rubrik des Apotropäischen eingeordnet und dem Bösen, dem Abzuwehrenden zugerechnet werden [...] steht in Themis die positive Seite der daimones im Vordergrund, ihre Tendenz, Fruchtbarkeit zu stiften und durch die Feste des Jahreszyklus die soziale Einigkeit zu erneuern.« (Schlesier 1994: 171)

In »Themis« (1912) verknüpft sie dann die Gestalt des Daimon mit dem »Heros« und lässt diesen für die prätheistischen Phase der Kulturentwicklung (ebd.: 164) zu einem mythischen Schwellenwesen par exellence avancieren, »with greater spiritual influence than the familiar Olympian anthropomorphic divinities (>theoir)« (Fiske 2004: 139). Oft in Schlangengestalt erscheinend, verkörpert der Eniautos-Daimon (Abschnitts-Dämon), so die an Mannhardt und Frazer gemahnende Wortneubildung Harrisons, 
eine spirituelle und soziale Macht, die nicht allein die Vegetation und die Tier- und Dingwelt umfasst, sondern »the whole world-process of decay, death, renewal« (Harrison 1912: XVII). Als Attribut und Begleittier der Erdgöttin (Harrison 1912: 235) erhält der Schlangen-Daimon seine sich ständig wandelnde Ambivalenz an der Peripherie oder im Untergrund hegemonial-olympischer Macht. Diese bestand wie im Fall der Medusa, der Sphingen oder den chthonischen Schlangen- und Drachenwesen nicht allein auf der Mischung von Tier und Mensch, sondern, vor dem späteren Phalluskult, auf der Vielheit des Begehrens, der Bedürfnisse und der Affekte.

In Harrisons Forschungen blieb Griechenland somit nicht länger die lichtvolle Wiege Europas, sondern wandelte sich in »einen Kessel von kulturellen Konflikten und vor allem, in einen meeting ground von indigenen und kolonisierenden Kulturen [...] (Torgovnick 1996: 143). Die olympische Herrschaft des Zeus dekonstruierte sie als Frühform patriarchaler Hegemonie und als Produkt eines langen Unterwerfungs- und Homogenisierungsprozesses, repräsentiert durch die Verdrängung weiblicher Gottheiten und die Aneignung chthonischer Mächte und Potenzen. Harrison partizipierte zwar an der kulturellen Bewegung, die sich über Teile der englischen Literatur, der Archäologie und der Folkloreforschung erstreckte und die davon fasziniert war, dass im minoischen Kreta, also in der Zeit um 2000 vor $u$. Z., eine einzige weibliche Gottheit verehrt wurde. Im Gegensatz zu Bachofen verwechselte Harrison gleichwohl nicht die Kulte und Mythen der Großen Göttin mit einer historisch real existierenden Herrschaftsform.

\section{Ritualpraxis und Denkraum}

Zum Zeitpunkt der ersten Versammlung der Cambridge Society of Heretics war die Forscherin gerade dabei, die zweite Ausgabe der »Prolegomena« vorzubereiten, und schrieb an »Themis«, das einen vom Ritual der Initiation ausgehenden, soziologischen und theaterhistorischen Blick auf die griechische Kultur wirft. Mithilfe ihrer Lehre vom chthonischen Ursprung der griechischen Religion, des neuen Zugangs zur antiken Kultur und - um ein Diktum Klaus Heinrichs zu verwenden - im >Bündnis mit dem Verdrängten ging es Harrison auch um die feministische Aneignung von Wissen. Sicher stehen ihre rationalitätskritischen Tendenzen im Kontext von kulturellen Diskursen, die mit dem Wirken Friedrich Nietzsches verbunden waren. Doch Nietzsche inszenierte 1872 in der »Geburt der Tragödie« das dionysische Ritual zwar einerseits als eine Zertrümmerung des hegemonialen principium individuationis, plaziert aber zugleich - im Satyrchor - ein ekstatisches Modell rein männlicher Vergemeinschaftung an die kurzzeitig freiwerdende Stelle des heroischen Subjekts (vgl. Brunotte 2004). Harrison dagegen setzt die Bakchen bzw. Mänaden als frühesten dionysischen Bund wieder in ihr Recht. Dort wo Nietzsche in 
Isoldes Opfer-Liebestod, im »Unbewusst - höchste Lust« von Wagners Bayreuther »Tristan « die antike Tragödie in der Moderne wieder erstehen lassen möchte, geht Harrison dem performativen Potential konkreter Kulthandlungen nach. So nimmt es nicht wunder, wenn für die Forscherin im mänadischen Dionysoskult ältere, von den kolonisierenden Kulturen verdrängte Dimensionen kollektiver Religiosität wiederkehren (vgl. Harrison 1912: VII-XXV). Dionysos sei als Sohn und Geliebter der Großen Mutter ein demokratischer Gott der Affekte. Zudem trete er immer mit einer Gruppe von berauschten Anhängerinnen auf: den Mänaden. Die Mänaden seien wiederum keine bloß mythischen Erfindungen der Literatur, sondern ganz reale, vom dionysischen Wahn ergriffene Frauen gewesen, die zeitweilig Familie, Haus und Polis verlassen hätten (Brunotte 2004).

Allerdings repräsentierte der » Tanz der Mänade< als bewegtes Körperbild der Antike zugleich ein Kulturmuster der Jahrhundertwende« (Brandstetter 1995: 182), das durch Tänzerinnen wie Isadora Duncan oder durch Theaterstücke wie Hugo von Hofmannsthals »Elektra« (1904) mit dem modernen »Begriff des Weiblichen verknüpft ist« (ebd.). Das freilich in einer Form, in der über den Symptomkatalog der >Hysterie $<$ und in Verknüpfung mit dem >Dionysischen « sich Tendenzen der Moderne bündeln, »die als unkontrollierbar bewusst werden, als Entfesselung von unbekannten Triebkräften erscheinen [...] und als bedrohlich eingestuft werden« (ebd.: 182).

Obwohl sich auch Harrison manchmal der modernen Beschwörung des >Dionysischen < in den Künsten ihrer Zeit bedient, bleibt sie bei dieser ästhetizistischen Dionysosverehrung nicht stehen. Im Tanz, Schrei und Lied der archaischen Kultgruppen siedelt sie vielmehr eine Wunschpotenz und eine schöpferische Magie an, die zu allererst den Gott als Verkörperung und Vision kollektiver Affekte erschaffe. Götter sind keine Substanz sui generis, sondern entstehen performativ und zwar im Handlungsmedium der »material activity of the ancient masses« (Comentale 2001: 479). Harrison verknüpft die feministische Perspektive mit dem Versuch, den subalternen Traditionen und autochthonen Ritualen eine wissenschaftliche Stimme zu verleihen, zugleich allerdings den Text und die Stimme des Wissenschaftlers auch als Fiktion, als ein Produkt von sympathetic imagination zu relativieren. Ihre Kritik am Ideal wissenschaftlicher Objektivität kulminiert in dem Satz: »Knowledge is never, or very rarely, divorced from emotion and action « (Harrison 1915: 225).

Die Religionstheoretikerin konstituierte damit zugleich eine subjektund rationalitätskritische Sphäre, in der zuallererst Wissen und community im emphatischen Sinne entstehe. Dabei geht sie vom bedürftigen und begehrenden Körper als hybrides Grenzobjekt und Akteur der Vermittlung subjektiver und objektiver Willensbildung aus. Ihr Werk, so Comentale, »redefines the public sphere by emphasizing the desiring body and its ability to enact law (Comentale 2001: 479). In dem von Begierde und Bedürfnis dynamisierten, aber gleichwohl spielerischen, kommunikativen Prozess 
symbolischen Handelns haben nach Harrison nicht allein alle Götterimagines und Götternamen ihren Ursprung, sondern auch die Wertordnung der Gesellschaft, die in »Themis« repräsentiert werde: »All religious representations arise from collective action and emotion« (Harrison 1927: XV), heißt es programmatisch noch in der Einleitung zur zweiten Auflage ihres zweiten Hauptwerkes »Themis. Über den sozialen Ursprung der griechischen Religion« von 1927. Die Bedeutung eines Rituals, so erläutert sie in »Themis« einem Nukleus ihrer Kulturtheorie, sei es nicht so sehr eine Handlung zu repräsentieren, sondern auch to »pre-done, to pre-present« (ebd.: 43). Im rituellen Geschehen, das nach Harrison als liminaler Raum zwischen Begierde und Erfüllung ebenso vermittelt wie zwischen Angst und Abwehr, wird ein Raum der Distanz geschaffen. Dieser Raum der Verzögerung, des Aufschubs und der Mimesis ist für die Forscherin zugleich der kulturproduzierende Raum symbolischen Handelns. In direkter Antizipation der Religions- und Kulturtheorie Aby Warburgs, besonders seiner Theorie des distanzschaffenden »Denkraums«, schreibt Harrison: »It is out of the delay, just the space between the impulse and the reaction, that all our mental life, our images, ideas [...] most of all our religion, arise « (ebd.: 44). Im Werk Jane E. Harrisons werden Rituale als Medien des »Dazwischen«, als Affektmodulatoren und Symbolproduzenten stark gemacht, und das nicht um der kathartischen Zerstörung der Affekte, sondern um ihrer kollektiv verbindlichen Formulierung und Formung willen. »Harrisons Ansatz ist zukunftsweisend«, nicht allein weil sie versucht, mythische Erzählung und rituelles Geschehen »auf soziale Wirklichkeit zurück zu führen« (Baudy 1995: 244), sondern dabei zugleich eine moderne Kulturtheorie der symbolischen Praktiken und Formen entwickelt.

\section{Suffrage}

Wenn aber die Politik ritueller Praxis das soziale Kraftfeld darstellt, in dem kollektive Erinnerungen, Ängste und Wünsche symbolisiert, Normen ausgehandelt werden und Macht entsteht, kann es dann neben survivals auch regelrechte revivals einer derartigen Praxis geben (vgl. Comentale 2001: 483)? In einem Essay mit dem Titel »Homo Sum«, der den Untertitel trägt: »Being a letter to an Anti-Suffragist from an Anthropologist « (Harrison 1915), argumentiert Harrison, dass der Gedanke eines rituellen revivals in ihrer Zeit für sie mit dem in symbolischen Akten und Inszenierungs- und besonders Visualisierungsstrategien (vgl. zuletzt Günther 2006) geführten Kampf der Suffragetten zusammenhänge. Sie sei eigentlich keine politische Person gewesen, aber ihre Studien primitiver und antiker Rituale führten sie zu den Suffragetten. Gerade die symbolischen Aktionen und oft antikisierenden Maskeraden der Suffragetten, hätten sie mitten aus ihren Ritualstudien heraus zu der Überzeugung gebracht, dass sie eine »Suffragistin« sein müsste. Für Harrison ging es bei der Suffrage vor allem um 
»a ritualized effort to rewrite the terms of cultural power. She confirms that militant activity is based on the same unity of knowing, feeling, and acting that marked ancient ritual« (Comentale 2001: 483). Das Streben der Suffragetten basiere auf der Begierde zu Wissen, »an awakening of desire to know «, die zugleich, so die Forscherin 1915, ein Wille zur Tat und zur Macht sei: »The wakening of the intention to act, to act more efficiently and to shape the world completely to our will« (Harrison 1915: 26).

Die emotionale Neugier sowie ihre feministischen Fragen an die griechische Kultur ließen Harrison ständig mit dem herrschenden wissenschaftlichen Prinzip >interesseloser Objektivität< kollidieren. Ihre öffentliche Reaktion auf diese Kritik, Harrison schrieb damals (indirekt) an einer eigenen Wissenstheorie, enthielt freilich zugleich eine hochmoderne Tendenz, denn: »Harrison prefigured the current feminist critique of masculinist objectivity; [...]« (Arlen 1996: 172). In einem vielbeachteten Vortrag mit dem Titel: »Woman and Knowledge (Harrison 1915) den sie 1911 vor der London Sociological Society und später vor der National Union of Suffrage Societies hielt, fragt Harrison, warum das Streben nach Wissen als >unweiblich gelte, und antwortet, dass eine der größten wissenschaftlichen Forschungslücken ihrer Zeit darin bestehe, nicht zu wissen, wozu Frauen wirklich befähigt sind. Kämpferisch fährt sie fort: »We must free women before we know what they are fit for intellectually and morally. We must experiment [...]« (ebd.: 139). Sie selbst, die sich ironisch oft als wissenschaftliche Häretikerin bezeichnete, hat durchaus experimentiert.

\section{Tanz um das Haupt Johannes des Täufers oder Der Salome-Skandal ${ }^{2}$}

Harrisons wirkungsvollster Angriff auf die institutionelle und wissenschaftliche Tradition von Cambridge stand im Kontext ihres antiklerikalen Denkens und ihrer Existenz zwischen den avantgardistischen Künstlerund Salonwelten Londons und des elitären und anglikanisch überformten universitären Kosmos von Cambridge. Er ereignete sich 1916, als England mitten im Ersten Weltkrieg stand und die Universität Cambridge als Festung englischer Wissenstradition und Moral besonders patriotisch wirken wollte. Durch eine als antichristlich missverstandene radikale Deutung des »Tanzes der Salome« aus dem Matthäus- und Markusevangelium, die sie in einem Text mit dem Titel »The Head of John Baptist« 1916 vorlegte, brachte sie nicht allein die gräzistischen und theologischen Kollegen, sondern das anglikanische Establishment der Universität in Gestalt des Vizekanzlers gegen sich auf. In harschen Repliken und Attacken ad feminam

2| Der Anfang dieses Abschnittes verdankt entscheidende Inspiration dem Essay »The Daimon Archives: Jane Harrison and the Afterlife of Dead Languages« (Fiske 2005). 
wurde nicht allein der Artikel, den sie in der angesehenen Fachzeitschrift »The Classical Review« (Harrison 1916/17) publiziert hatte, Satz für Satz auseinandergelegt, sondern Harrisons Wissenschaftlichkeit überhaupt in Frage gestellt. Folgt man Shanyn Fiske, die die Attacken und Auseinandersetzungen gesammelt hat, die um Harrisons Salomedeutung von »M.R. James, recent Vice-Chancellor of Cambridge, provost of King's College, antiquarian, medievalist, and specialist in Aprocryhal studies « (Fiske 2005: 140) und anderen Mitgliedern der Cambridge University geführt wurden, dann formt sich folgendes Bild: Da Harrison es gewagt habe, mithilfe der ketzerischen deutschen Methode historisch-kritischer Forschung, den heiligen Text der Bibel mit paganen Mythen griechischer und russischer Provenienz zu vergleichen, sei sie nicht allein völlig inkompetent mit den apokryphen Quellen umgegangen (M.R. James 1915: 1-4; vgl. Fiske 2005: 140f.), sondern habe das sichere christliche Fundament britischer Wissenschaft in Frage gestellt. »That he [the Vice-Chancellor] had, in his own words, >dipped [his] pen in gall and falyed $<$, writes a fellow scholar, indicates that there was far more at stake than textual misinterpretation in the territorial dispute over the expansion of classical studies« (ebd.: 141). Indem der Vizekanzler Harrisons Methode mit den Worten des Reverend FoakesJackson, als die gefährliche »historico-critical school« (ebd.) des deutschen Feindes bezeichnet, die die Kirche und den Glauben angreife, sei Harrison zugleich eine Gefahr für die Stabilität von Moral und Nation.

Was aber hatte Harrison geschrieben und worin lag nun der Skandal ihrer Interpretation des »Tanzes der Salome«? Die Forscherin beginnt damit, das puritanisch-viktorianische Entsetzen angesichts der unzüchtigen biblischen Schilderungen von Salomes Tanz als Symptom für eine vergessene Bedeutung der Legende ernst zu nehmen, sie schreibt:

»Keiner, so nehme ich an, liest die Geschichte von Herodias' Tochter und dem Haupt des Täufers ohne ein Gefühl plötzlichen Entsetzens. Im Alten Testament könnte es stehen; im Neuen wirkt ihre laszive barbarische Wildheit wie ein Gräuel.« (Harrison 1916/17: 216 [Übersetzung U.B.])

Harrison wählt hier den kolonialistisch aufgeladenen Begriff »Savagery« für die Darstellung im Neuen Testament. Aber um uns das Neue Testament nicht zu entfremden, so fährt sie ironisch-einfühlsam fort, hätten wir schon vor langer Zeit fragen sollen: »What lies behind?« (Ebd.) Und bereits kurz nach diesen einleitenden Worten beginnt die Forscherin damit, das Neue Testament umso gründlicher zu entfamiliarisieren. Sie verweigert sich dabei freilich ebenso dem modernen orientalistischen Diskurs wie dem christlichen Antijudaismus in Bezug auf die Gestalt der Salome, die in manchen hochmittelalterlichen Darstellungen »als Gestalt der Ausschweifung, das alte Prinzip der Synagoge verkörpert, die Christus tötete« (Brittnacher 2001: 169). Auch nicht um eine schwüle Familien- und Herrschergeschichte im orientalisierenden Gewand samt Schleiertanz, femme 
fatale und Geschlechterkampf geht es nach Harrison bei »Salomes Tanz«, ebenso wenig jedoch ist Salome der Judasgestalt zu vergleichen, die zwar deutlich negativ codiert, aber gleichwohl ein festgefügter Baustein der Passionsgeschichte und der Inthronisation des christlichen Erlösers sei. Es handele sich bei Salomes Tanz mit dem Haupt Johannes' des Täufers vielmehr um ein ernstes, paganes, vor allem aber um ein primitives Ritual: Es ist der Tanz des neuen Jahresdaimon mit dem Kopf des Alten Jahres:

»The dance of Herodias' daughter with the Head of John Baptist is, mutatis mutandis, the ritual dance of Agaue with the head of Pentheus. It is the dance of the daimon of the New Year with the head of the Old Year, past and slain.« (Ebd.)

Beweisen könne man diese pagane Substruktion des Neuen Testaments durch Hinzuziehung der Apokryphen und durch Vergleiche mit stammesgesellschaftlichen, griechischen und russischen Ritualen, Mythen, Puppenspielen und Tänzen, deren Nachleben bis in die Gegenwart zu erkennen sei (ebd.: 217). Wenn sie darüber hinaus aber schreibt, dass der Tanz von Herodias' Tochter mit dem Haupt Johannes' des Täufers mit dem Ritualtanz der Agaue mit dem Kopf des Pentheus identisch sei, wie er von Euripides am Ende seiner »Bakchen « dargestellt wird, fixiert sie ihre Deutung auf einen im Kontext der Faszinations-, Tanz- und Protestkultur ihrer Zeit aufgeladenen Figur der Mänade (Brandstetter 1995). Agaue, so kurz zur Erinnerung, war die Mutter des Pentheus, die, nachdem sie sich mit aller Macht gegen den fremden Gott Dionysos gewehrt hatte, der dionysischen Ekstase umso heftiger verfiel. Sie nahm dabei als führende Mänade aktiv am kollektiven Zerreißungsmord ihres Sohnes Pentheus, des puritanischen Herrschers von Thebens, teil. Als ekstatische Sohnesmörderin, die mit dem blutigen Haupt des Sohnes tanzt, verkörperte Agaue die gleichsam schreckenerregendste Mischung von Weiblichkeit und Gewalt.

Aber wie kann das sein, fragt Harrison nun rhetorisch mit ihren Lesern, in der Bibel wird an keiner Stelle von dem Tanz der Salome mit dem Haupt, sondern immer um das Haupt erzählt. Das Haupt des Johannes oder gar seine Enthauptung sind nicht Teil ihres Tanzes, sondern ihre Belohnung. Und wieder fühlt sie sich in die (immer noch) viktorianische Innenwelt ihrer gelehrten Leser ein, wenn sie mit Blick auf die ihr mehr als bekannte Londoner Tanzszene scheinbar entrüstet fortfährt:

»To speak of a dance with the Head is to put the laothsome performance of the modern dancer - e.g. Maud Allan - in place of the Gospel story. I have lately met with more than one person who - such is the power of suggestion - had actually made the transition - actually believed the dance with the Head was part of the Gospel story.« (Ebd.)

Salome, die sich im Schleiertanz entblößende Tochter der Herodias, war lange vor Oscar Wildes Theaterstück, das auf französisch geschrieben und 
in London verboten wurde, eine Ikone des Fin de Siècle und die >Göttin der Dekadenzく. Als Frauen versuchten, sich diese Männerphantasie auf der Bühne als Sängerinnen, Tänzerinnen und Choreographinnen anzueignen, war die Reaktion freilich oft feindlich (vgl. Showalter 1985: 156ff.). Aber selbst die Einschätzung von Avantgardekünstlerinnen die Figur betreffend, blieb ambivalent: »Jane Marcus sees Salomé's dance as the New Woman's art form«, gleichwohl derart reduziert und eingesperrt wie »the tarantella danced by Nora in >A Doll's House< [...] (ebd.: 159). Einer der ersten feministischen Versuche, »Salome« in ein weibliches Subjekt zu verwandeln und ihren sexuellen Exhibitionismus umzudeuten, geschah durch die junge »russian actress Ida Rubenstein, whose 1908 performance precipitated an outburst of orientalist, anti-semitic, and misogynist horror « (ebd.). Die wohl berühmteste »Salome« Europas war freilich die der Kanadierin Maud Allan, deren Choreographie Vision of Salome als Tanz mit dem Haupt des Johannes von Harrison erwähnt wurde:

»Allan's interpretation of Salome emphazised the visionary as well as the exhibitionist aspects of the story; the second was called `The Vision of Salome<, and, represented the whole episode with the severed head as a kind of phantasma.« (Showalter 1985: 161)

Maud war eine besondere Künstlerin, ihre Performances führten die $S a$ lomania ihrer Zeit nicht allein auf den Zenit, sie reflektierte die Fantasien, die mit Salome damals verbunden waren, zugleich ironisch. Durch die Verknüpfung neoklassizistischer Tanzelemente mit ihrer eigenen Choreographie eröffnete Maud freilich auch

»a set of codes for female bodily expression that disrupted the Victorian conventional dichotomies of female virtue and female vice and pushed beyond such dualisms. Allan used the >Orient< as a register for female sensual expression, but she also built her dance from a range of other cultural forms, including American physical culture, theatrical posing, and modernist strategies of representations.« (Walkowitz 2003: 6)

Insbesondere ihre »hybrid effect's« (ebd.: 16) auf das Publikum wirkten für die moral majority bedrohlich. So waren Salome und Maud Allan »popular nicknames for transvestite >queens«!« (ebd.: 18). Besonders während des moralischen backlash im Ersten Weltkrieg kam es zu massiven, sowohl sexualpolitischen als auch antisemitischen, Anschuldigungen und Verleumdungen, sowohl Maud Allans Salomedarstellung wie ihre Person und Familie betreffend. Diese endeten 1918 in einem Gerichtsverfahren und dem sogenannten »Klitorisskandal« (ebd.: 22). Dafür waren nicht allein ihre Assoziation mit Oscar Wildes »Salome«, die er bekanntlich auch selbst dargestellt hatte, sondern vor allem die homoerotischen Übertöne verantwortlich, mit denen Teile ihrer weiblichen Anhängerschaft durch die Öffentlichkeit 
und in der Presse geschildert wurden. Kurz nachdem Maud Allan wirklich in einer Wilde-Inszenierung den Tanzpart der Salome übernehmen sollte, beschuldigte Harold Spencer sie und ihre weibliche Fangemeinde in der Zeitung »The Vigilante« unter der Überschrift »The Cult of the Clitoris« des »illicit sex« und der »political intrigue« (Cherniavsky 1991: 242f.).

Inwieweit Harrison, die als New Woman lange Zeit an den kosmopolitischen Salons und Künstlerkreisen Londons partizipiert hatte, diese Ereignisse, Debatten und Moden beim Verfassen ihres Salometextes präsent waren, ist nicht zu rekonstruieren. Darüber hinaus ist fraglich, ob ihre Vorstellungen von Emanzipation mit denen einer Maud Allan kompatibel waren. Die Aufzeichnungen von Mirrlees Hope, Harrisons ehemaliger Studentin und Weggefährtin, legen gleichwohl eine gewisse Nähe zu Isadora Duncan nahe, wenn es dort heißt: »Isadora would dance in studios and Jane would read Greek poetry, which Isadora would interpret [...] « (Hope, Notebook: 120). Ganz so frei oder besser exhibitionistisch wie die Salometänzerin Maud Allan war Harrison wohl kaum, denn, obwohl sie die These vertrat, dass das primitive Ritual den Tanz des neuen mit dem Haupt des alten Jahresdämon enthalte, so schien sie zugleich erleichtert, dass »nicht sinnliche Lüsternheit, sondern ein intensives religiöses Bedürfnis das ursprüngliche Motiv des Tanzes« (Harrison 1916/17: 216) war. Was hier auf den ersten Blick als puritanische Scheu erscheint, ist gleichwohl auch der gelingende Versuch, die orientalisierende und damit zugleich voyeuristisch fixierte Gewalt-Erotik des Stoffes auszublenden. Erst darunter wird nach Harrison eine ernste, weltweit verbreitete rituelle Dynamik sichtbar, in der selbst Jesus Christus, als Haupt der christlichen Kirche, dekonstruiert werde und als paganer Doppelgänger von mythischen Jünglingen wie Adonis, Attis, Osiris oder Tammuz erscheine. Nun wurde Harrison von ihren altphilologischen und anglikanischen Kritikern auch vorgeworfen, dass sie bei den Vergleichen der Salome mit Agaue und Pentheus und der Deutung der Legende überhaupt keine Rücksicht nähme auf das Geschlecht und die generative oder familiale Position der jeweils Agierenden. Und in der Tat, Agaue ist als Mutter die Mörderin ihres Sohnes Pentheus, wie kann sie den Daimon des Neuen Jahres verkörpern, den Salome als Tochter repräsentiert? Wenn Jesus der Daimon des Neuen Jahres ist, daran gemahnen bereits die Worte aus dem Johannesevangelium »Er muss wachsen, ich aber muss abnehmen« (Joh. 3, 30), wie kann Salome diesen dann im Neujahrstanz mit dem Haupt des Johannes vertreten? Ohne je etwas von Gender- oder Queertheorie gehört haben zu können, pariert Harrison diese Kritiken, in dem sie sich erneut auf die Figur des Daimon konzentriert. Um das Körper-Wissen der Dämonen zu beschreiben, wählt sie diesmal den slawonischen Yarilo:

»Yarilo is of shifting sex, like so many daimons, and of various presentment. He is sometime represented as a horse or with o horse's head, sometime as a babe, sometimes as youth, sometimes carried in his mothers arms, sometimes as herself - an 
old woman. When the figure is that of a young man, he is crowned with flowers, in his left hand a bunch of ears of corn, in his right ... a human head." (Harrison 1916/17: 218)

Ich denke, dass die Archäologin Harrison in ihrer Neuaneignung der Antike als daimonisches und plurales Wissensfeld auch einen wichtigen Hinweis zur Salomefaszination ihrer Zeit gegeben hat, einen Hinweis nämlich auf das schwankende Geschlecht der Figur, das gerade für Oskar Wildes' Bearbeitung zum Nukleus der Selbstreflexion wurde (vgl. Showalter 1990). Verfällt diese Salome doch im Theaterstück während ihrer leidenschaftlichen Anrufung des Johanahn im Verlies immer wieder in die durch einen männlichen Rhetor und dessen Begierde codierte Sprache des Salomonischen »Hoheliedes«.

In Harrisons Wirken und ihrer Suche nach dem >unreinen< Wissen der Dämonen verkörpert sich auf zugespitzte Weise, wenn nicht eine Erschütterung, so doch eine enorme Irritation des elitären, androzentrischen Hellenismus, wie er vom wissenschaftlichen Establishment damals gepflegt wurde. Die freilich nicht allein von Harrison verursachte Krise dieser Ordnung leitete letztlich zu einer Demokratisierung von Wissen und zu vielstimmigen Aneignungen der Antike über. Ein feministisches »Nachleben der Antike« (Warburg), das mit modernen Forschungsfeldern wie der Archäologie und Anthropology ebenso verknüpft war wie mit der mythopoetischen Imagination und den Tanzperformances von Frauen, die ihren Mangel an humanistischer Bildung zum produktiven Ausgangspunkt ihrer Neuerfindungen machten. So verwandelten sich in der modernen Literatur einer Virginia Woolf (Carpentier 1998) ebenso wie in der Suffrage-Bewegung und beim Neuen Tanz von Isadora Duncan und Maud Allan in unterschiedlicher Weise die antiken Figuren, Skulpturen und Allegorien in ein selbstreflexiv angewandtes modernes Ausdrucksreservoirs des Erzählens (Phillips 1991; Brandstetter 1995), der Selbstdarstellung und des Protestes. Als wissenschaftliche Muse spielte Harrison auf diese Weise keine unbedeutende Rolle bei den Aufbrüchen von künstlerischen und sozialen Avantgarden aus dem Regime normativer viktorianischer Geschlechterordnung.

\section{Literatur}

\section{Quellentexte von Johann J. Bachofen}

Bachofen, Johann Jacob (1. Aufl. 1861; 1975): Das Mutterrecht. Eine Untersuchung über die Gynaikokratie der alten Welt nach ihrer religiösen und rechtlichen Natur, Frankfurt a.M.: Suhrkamp. 


\section{Quellentexte von Jane E. Harrison}

Prolegomena to the Study of Greek Religion (London 1903, 1908, 1922; New York 1975, 1980, 1991), London/New York, zuletzt: Princetown University Press.

Themis: A Study of the Social Origins of Greek Religion. With an excursus on the ritual forms preserved in Greek tragedy by Gilbert Murray and a chapter on the origin of the Olympic games by F.M. Cornford $(1912,1927)$, zuletzt 1977, London: Merlin Press.

Alpha and Omega (1915), darin »Homo sum« u.a., London: Sidwick \& Jackson.

»The Head of John the Baptist« (1916/1917). In: The Classical Review, S. 216219 .

\section{Andere Texte}

Ackermann, Robert (1990): The Myth and Ritual School, J.G. Frazer and the Cambridge Ritualists, New York/London: Garland.

Arlen, Shelley (1996): »>For Love of an Idea<: Jane Ellen Harrison, heretic and humanist«. In: Women's History Review 5, no. 2, S. 165-19o.

Baudy, Gerhard (1995): »Antike Religion in anthropologischer Deutung. Wandlungen des altertumskundlichen Kult- und Mythosverständnisses im 20. Jahrhundert«. In: Ernst-Richard Schwinge (Hg.), Die Wissenschaften vom Altertum am Ende des 2. Jahrtausends n. Chr., Stuttgart/ Leipzig: Teubner, S. 229-258.

Beard, Mary (2000): The Invention of Jane Harrison, Cambridge (MA)/London: Harvard University Press.

Bernal, Martin $(1987,1992)$ : Schwarze Athene. Die afroasiatischen Wurzeln der griechischen Antike, München/Leipzig: List Verlag.

Böhme, Hartmut (2006): Fetischismus und Kultur. Eine andere Theorie der Moderne, Reinbek bei Hamburg: Rowohlt Verlag.

Brandstetter, Gabriele (1995): Tanz-Lektüren. Körperbilder und Raumfiguren der Avantgarde, Frankfurt a.M.: Suhrkamp Verlag.

Braun, Christina von/Mathes, Bettina (2007): Verschleierte Wirklichkeit. Die Frau, der Islam und der Westen, Berlin: Aufbau Verlag.

Brittnacher, Hans Richard (2001): Erschöpfung und Gewalt. Opferphantasien in der Literatur des Fin de Siècle, Weimar/Köln/Wien: Böhlau Verlag.

Brunotte, Ulrike (1993): Hinab in den Maelstrom. Das Mysterium der Katastrophe im Werk Edgar Allan Poes, Stuttgart: Metzler Verlag.

Brunotte, Ulrike (2004): »Ecstasy and Initiation. Jane E. Harrison's ritual theories and their relationship to Nietzsche, Durkheim and Freud«. In: Paragrana. Internationale Zeitschrift für Historische Anthropologie 13, S. $162-176$.

Calder, William M. III (1991): The Cambridge Ritualists Reconsidered, Atlanta: Illinois University Press. 
Carpentier, Martha (1998): Ritual, Myth, and the Modernist Text: the Influence of Jane Ellen Harrison on Joyce, Eliot and Woolf, Amsterdam: Gordon and Bruch Publishers.

Castro Varela, Mario do Mar/Dhawan, Nikita (2005): Postkoloniale Theorie. Eine kritische Einführung, Bielefeld: transcript.

Chakrabarty, Dipesh (2002): »Europa provinzialisieren. Postkolonialität und Kritik der Geschichte«. In: Sebastian Conrad/Shalini Randeria (Hg.), Jenseits des Eurozentrismus. Postkoloniale Perspektiven in den Geschichts- und Kulturwissenschaften, Frankfurt a.M./New York, S. 283312 .

Cherniavsky, Felix (1991): The Salome Dancer. The Life and Times of Maud Allan, Toronto: McClelland \& Stewart Inc.

Chidester, David (1996): Savage Systems. Colonialism and Comparative Religion in Southern Africa, Charlottesville/London: Indiana University Press.

Comentale, Edward P. (2001): »Thesmophoria: Suffragettes, Sympathetic Magic, and H.D.'s Ritual Poetics«. In: Modernism/modernity 8, No. 3, S. 471-492.

Dietze, Gaby (2005): »Postcolonial Theory«. In: Christina von Braun/Inge Stephan (Hg.), Gender@Wissen, Weimar/Wien: Böhlau/UTB, S. 304324 .

Fiske, Shanyn (2005): »The Daimon Archives: Jane Harrison and the Afterlife of Dead Languages«. In: Journal of Modern Literature 28, No. 2, S. $130-164$.

Frazer, James George (dt. 1922; 1989/2000): Der goldene Zweig. Das Geheimnis von Glauben und Sitten der Völker, 3. gekürzte Auflage, Reinbek bei Hamburg: Rowohlt.

Erhart, Walter (2001): Familienmänner. Über den literarischen Ursprung moderner Männlichkeit, München: Wilhelm Fink Verlag.

Hartlieb, Elisabeth (2006): Geschlechterdifferenz im Denken Friedrich Schleiermachers, Berlin/New York: De Gruyter Verlag.

Hope, Mirrlees (1920?): Notebook, Harrison Archives, S. 120.

Hutton, Ronald (1999): The Triumph of the Moon. A History of Modern Pagan Witchcraft, Oxford: University Press.

King, Ursula (1995): »A Question of Identity: Women Scholars and the Study of Religion«. In: Ursula King, Religion and Gender, Oxford: University Press, S. 219-244.

Kramer, Fritz (1977): Verkehrte Welten. Zur imaginären Ethnographie des 19. Jahrhunderts, Frankfurt a.M.: Suhrkamp.

Kohl, Karl-Heinz (1989): »Cherchez la Femme d'Orient«. In: Gereon Sievernich/Hendrik Budde (Hg.), Europa und der Orient 800-1900, Berlin: Bertelsmann Lexikon Verlag, S. 356-367.

Lanwerd, Susanne (1993): Mythos, Mutterecht und Magie. Zur Geschichte religionswissenschaftlicher Begriffe, Berlin: Reimer Verlag. 
Latour, Bruno (2000): Die Hoffnung der Pandora, Frankfurt a.M.: Suhrkamp Verlag.

Lüdemann, Susanne (2004): Metaphern der Gesellschaft. Studien zum soziologischen und politischen Imaginären, München: Wilhelm Fink Verlag.

Mc Clintock, Anne (1995): Imperial Leather, Race, Gender and Sexuality in the Colonial Contest, New York/London: Routledge.

Osterhammel, Jürgen (1997): »Wissen als Macht: Deutungen interkulturellen Nichtverstehens bei Tzvetan Todorov und Edward Said«. In: Eva-Maria Auch/Stig Förster (Hg.), >Barbaren< und >weiße Teufel<. Kulturkonflikte und Imperialismus in Asien vom 18. bis zum 20. Jahrhundert, Paderborn/München/Wien/Zürich: Schöningh, S. 145-170.

Phillips, K.J. (1991): »Jane Harrison and Modernism«. In: Journal of modern Literature 17, No. 1, S. 465-476.

Robinson, Annabel (2002): Life and Work of Jane Ellen Harrison, Oxford: University Press.

Said, Edward (1978): Orientalism, New York: Vintage.

Schlesier, Renate (1994): Kulte, Mythen und Gelehrte. Anthropologie der Antike seit 1800, Frankfurt a.M.: Fischer-Verlag.

Schüttpelz, Erhard (2005): Die Moderne im Spiegel des Primitiven, München: Wilhelm Fink Verlag.

Showalter, Elaine (1990): Sexual Anarchy: Gender and Culture at the Fin de Siècle, Johns Hopkins University Press.

Stephan, Inge (1997): Musen \& Medusen. Mythos und Geschlecht in der Literatur des 20. Jahrhunderts, Köln/Weimar/Wien: Böhlau Verlag.

Torgovnick, Marianne (1996): »Discovering Jane Harrison«. In: Carola M. Kaplan/Carola M. Simpson (Hg.), Seeing Double. Revisioning Edwardian and Modernist Literature, New York: St. Martin's Press, S. 131-148.

Versnel, Henrik S. (1999): Transition and Reversal in Myth and Ritual, Leiden/New York/Köln: E.J. Brill.

Walkowitz, R. Judith (2003): »The >Vision of Salome $<$ Cosmopolitanism and Erotic Dancing in central London, 1908-1918«. In: The American Historical Review 108, No. 2, April, S. 2-38.

Wesel, Uwe (1990): Der Mythos vom Matriarchat. Über Bachofens Mutterrecht und die Stellung von Frauen in frühen Gesellschaften, Frankfurt a.M.: Suhrkamp Verlag.

Yeğenoğlu, Meyda (1998): Colonial Fantasies. Towards a Feminist Reading of Orientalism, Cambridge: Cambridge University Press.

Ziege, Eva-Maria (2002): Mythische Kohärenz. Diskursanalyse des völkischen Antisemitismus, Konstanz: UVK Verlag.

Zinser, Hartmut (1981): Der Mythos des Mutterrechts. Verhandlung von drei aktuellen Theorien des Geschlechterkampfes, Frankfurt/Berlin/Wien: Ullstein. 


\section{Im "Tropenkoller" - Hybride Männlichkeit(en) in ethnologischen Texten 1900-1960}

HubERTuS BüSCHEL

\section{Einführung: Feldforschung - "The Ethnographer's Magic"}

Im September 1914 schrieb der polnische Ethnologe Bronislaw Malinowski in sein Tagebuch zu Beginn seiner ersten Expeditionsreise nach Britisch-Neuguinea: »Starke Angst vor den Tropen, Grauen vor Hitze und Schwüle - so etwas wie panische Furcht [...]« (Malinowski 1986: 15). ${ }^{1}$ Ein paar Wochen später berichtete er von »Momenten schweren moralischen Zusammenbruchs«, vom »beinah unzugänglichen Dschungel [...] voll Schmutz und Reptilien aller Art, schwül, feucht, ermüdend - wimmelnd von Moskitos und anderen abscheulichen Insekten, Kröten etc.« (ebd.: 28). Von schlagartig aufblitzenden Fragen an sein »Innenleben « ist da auch die Rede (ebd.: 37). Im November dann klagte Malinowski über »Schlaflosigkeit, große Unruhe im ganzen Körper« und Heimweh (ebd.: 45). Im Jahr 1917, zu Beginn seiner erneuten Reise nach Neuguinea, schilderte er jene »Schwere in Kopf und Körper - die [...] Zunahme der spezifischen Schwerkraft« -, die für seine »frühere Verfassung in den Tropen so typisch war« (ebd.: 117). Mehrfach diagnostizierte Malinowski bei sich den »Tropenkoller« (ebd.: 191), diese fatale Mischung aus Benommenheit und Nervenzerrüttung, die von nahezu allen Kolonialbeamten, Missionaren und Ethnologen in den warmen Ländern um 1900 beschrieben wurde. Mit »Tropenkoller« bezeichneten sie physisch-psychische Störungen und Erregungszustände, deren Ursachen im Klima in Übersee, der Ferne von

1) Ich danke allen Teilnehmer/innen der Konferenz »Produktion und Krise hegemonialer Männlichkeit in der Moderne« vom Dezember 2006 für zahlreiche, grundlegende Anregungen und Hinweise. Besonders möchte ich Ulrike Brunotte und Gabriele Dietze für ihre Hinweise danken. 
der westlichen Zivilisation, menschlicher Isolation und sexuellem Entzug gesehen wurden.

Der »Tropenkoller« hat Malinowskis zentraler Bedeutung für die moderne Ethnologie keinen Abbruch getan. Er gilt als >Erfinder< der »teilnehmenden Beobachtung «, der ethnologischen Forschungspraxis, bei der man vor Ort unter den Indigenen eine Zeit lang möglichst »intensiv« lebt (vgl. Kohl 1986: 56-65). Alle Eindrücke werden in »Feldtagebüchern« aufgezeichnet, die in der Regel die wichtigste empirische Grundlage für die eigentliche Studie sind.

Der ethnologische Aufenthalt im »Feld «, das in den $1920 e r$ Jahren immer mehr aufkommende »going native«, war häufig mit der Suche nach den Ursprüngen der westlichen Zivilisation verbunden. Im Urwald Südund Mittelamerikas, in Ostasien, auf den pazifischen Inseln, im Dschungel und der Steppe in Afrika südlich der Sahara forschte man nach »Urszenen, Urriten, Ursitten«, nach dem, was die westliche Zivilisation noch nicht verdeckt oder pervertiert hatte - so die zeitgenössische Sichtweise. »Feldforschung« sollte gegen »Eurozentrismus« immun machen (vgl. Stocking 1984), stand künftig für die Evidenz stiftende Praxis der Ethnologie schlechthin, galt als »the Ethnographer's Magic« (Stocking 1983) und wurde zur unentbehrlichen »Ideologie« ethnologischer Studien (Stagl 1985).

In diesem Sinne rühmte 1922 James G. Frazer in seiner Vorrede zu Malinowskis Studie »Argonauten des westlichen Pazifik« den Aufenthalt im »Feld« als die »sicherste Quelle« ethnologischer Arbeit (Malinowski 1979a: 7). Im auf Frazers Vorwort folgenden Text verkündete Malinowski dogmatisch, wie »Feldforschung « zu sein habe: Man müsse sich »aus dem Umgang mit anderen Weißen herauslösen und in möglichst engem Kontakt mit den Eingeborenen bleiben« (Malinowski 1979a: 28). Alles sei »unmittelbar in der Zeit des Geschehens zu untersuchen«, möglichst frei von »vorgefaßten Ideen « (ebd.: 3of.). Das oberste Ziel müsse sein, »den Standpunkt des Eingeborenen, seinen Bezug zum Leben zu verstehen und sich seine Sicht seiner Welt vor Augen zu führen« (ebd.: 49). Die Zeit »im Liegestuhl auf der Veranda des Missionsgeländes « sei für den Ethnologen nunmehr vorbei (Malinowski 1973: 128f.). Bereits Ende der 2oer Jahre waren einige Schüler und Kollegen Malinowskis Beispiel gefolgt. Darunter waren Raymond W. Firth, der zu dieser Zeit auf einer der Salomon-Inseln lebte, Edward E. Evans-Pritchard, der sich im Feld bei den Azande im Sudan aufhielt, und Gordon Braun, der in Tanganjika Feldstudien unternahm.

Malinowskis eingangs zitierten Zweifel und Ängste waren damals noch weitgehend unbekannt. Erst 1967 veröffentlichte seine Witwe Valetta sein in polnischer Sprache verfasstes Tagebuch in einer englischen Übersetzung (Malinowski 1986 [1967]). In »Argonauten des westlichen Pazifik« stehen Äußerungen über tropische Depressionen, Langeweile und Hoffnungslosigkeit eher am Rande (Malinowski 1979a: 26). 


\section{Einsamkeit und Angst: Ethnologen im "Tropenkoller"}

Malinowskis Tagebuch ist hingegen regelrecht durchtränkt von solchen Bemerkungen. Besonders häufig finden sich hier auch rassistische und sexistische Ausfälle. Mehrmals ist von Malinowskis »starkem Hass auf die Niggers « die Rede (Malinowski 1986: 232, 238). An anderer Stelle ist zu lesen: »Die Eingeborenen gehen mir immer noch auf die Nerven [...]. Ich kann diese deutschen und belgischen Kolonialgräuel verstehen« (ebd.: 240). Und letztendlich fällt der Satz, der das Versprechen Malinowskis »Feldarbeit« endgültig ad absurdum führt und der konterkariert, dass eine »Anteil nehmende Beobachtung« den Eurozentrismus, die Arroganz der »ersten zivilisierten Welt« über die »Unzivilisierten, Primitiven« überwinden helfe. Am zweiten Weihnachtsfeiertag 1917 schrieb Malinowski auf den Trobiand-Inseln:

»Bezüglich Ethnologie: ich sehe das Leben der Eingeborenen als etwas, das bar allen Interesses und aller Bedeutung ist, etwas, das mir so fern ist wie das Leben eines Hundes.« (Ebd.: 151)

Derartig extreme Aussagen stehen - wie Karl-Heinz Kohl herausstellt - in konträrem Gegensatz zu den ethnographischen Schriften Malinowskis über die Trobiand-Inseln, in denen er sich, »bis hin zur tendenziellen Idealisierung, um den Abbau der kulturellen Vorurteile« (Kohl 1987: 48) bemühte; und zwar solcher Vorurteile, die er in seinen unveröffentlichten Tagebüchern allerdings selbst reproduzierte.

Von den extremen Bedingungen im »Feld« und von Zumutungen für den Forscher kann man auch in anderen zeitgenössischen Berichten lesen. So schrieb der preußische Ethnologe und Missionar Günter Tessmann von seiner Expedition zu den Baja im mittleren Sudan: Die »unfreundliche und sogar feindliche Haltung der Eingeborenen « mache ihm sehr zu schaffen (Tessmann 1934: 8). Überdies herrsche jeden Tag eine »unangenehme Hitze« (ebd.: 8), man könne nicht baden, da alles Gewässer von Krokodilen verseucht sei, jenen »scheußlichen Echsen«, die schon mehrfach den »Eingeborenen [...] Arme und Beine zerfleischt« hätten (ebd.: 14). Anfang der 3oer Jahre klagte Edward E. Evans-Pritchard über seinen Feld-Aufenthalt bei den Nuer im Süd-Sudan, dass für ihn das starke öffentliche Interesse der »Eingeborenen « selbst bei »intimsten Verrichtungen« am »schwersten zu ertragen« gewesen sei (Evans-Pritchard 1968: 14). Auch in Claude LéviStrauss' bekannter Arbeit »Traurige Tropen«, die auf seine Feldtagebücher zu Aufenthalten bei den Caduveo und Boróro im Mato Grosso/Amazonas 1936 zurückgeht, finden sich zahlreiche Hinweise auf persönliche Ängste und Anfechtungen. Bereits vor der Ankunft in Brasilien beklagte sich Lévi-Strauss über die »unerträgliche« Hitze auf der Schiffsreise, »die in dem Maße wuchs, in dem [man sich] den Tropen näherte« (Lévi-Strauss 1988: 19). Solche Klagen sind umso bemerkenswerter, da Lévi-Strauss es dezi- 
diert von sich wies, seiner »Gemütsverfassung [im Feld] sonderlich viel Bedeutung « beigemessen zu haben, wie er in den 8oer Jahren in einem Interview sagte (Lévi-Strauss 1989: 7).

Schließlich berichtete der Hamburger Völkerkundler Hans Fischer von seinen ersten »Feldforschungen « in Neuguinea 1958 - ganz in der Tradition Malinowskis - von Mut- und Lustlosigkeit, Fieber und zahllosen Flohstichen (Fischer 1985: 25, 31f., 35, 46f.; vgl. Fischer 1968). In all diesen Texten finden sich somit immer wieder Mitteilungen über Unbill, Probleme und Belastungen im »Feld«, die sich zu persönlichen Krisen der Forscher auswachsen konnten.

Im Folgenden wird zu zeigen sein, dass solche Äußerungen ganz maßgeblich als Symptome einer fundamentalen Auseinandersetzung zu lesen sind: Sie korrespondieren eng mit der als krisenhaft beschriebenen eigenen Geschlechterzugehörigkeit. Die eigene Männlichkeit als quasi unhintergehbare Kern-Identität wurde hierbei - mehr oder weniger bewusst - zur Disposition gestellt und hybrid. Betroffen waren die Männlichkeitsentwürfe der modernen westlich »zivilisierten« Gesellschaften, der Herkunftsgesellschaften der Ethnologen: Mut, Standhaftigkeit, Heterosexualität und Treue. Diese wurden allerdings im »Feld« nicht strikt abgelehnt oder abgelegt. Vielmehr wurden ihre Fragilität und Fraglichkeit in der extremen Erfahrung der tropischen »Wildnis« für vielfache Zwecke instrumentalisiert und möglicherweise auch als Erschütterung erlebt. Dies ist umso bemerkenswerter, da gerade Malinowski deutlich - doch nicht ohne ironischen Unterton - erklärte, bei seinem Gang ins »Feld« das Ziel verfolgt zu haben, die Normen der westlichen Kultur zu verlassen. »Für mich zumindest«, schrieb er 1930, »war die Anthropologie eine romantische Flucht aus unserer genormten Kultur« (Malinowski 1930: 406; vgl. Kohl 1987: 46).

\section{Männer im "Feld»}

Der Kreis derer, die den Kongo-Fluss überschritten, am Strand von SüdseeInseln ankerten oder sich durchs Dickicht des Matto-Grosso schlugen, war nicht nur unter akademischen, sondern auch unter Gender-Gesichtspunkten wesentlich exklusiver als der von kolonialen Siedlern und Beamten. Man hat mittlerweile überzeugend nachgewiesen, wie sehr auch Frauen ihren Beitrag an kolonialer Machtpolitik geleistet haben, wie sie als das »(vermeintlich) >unterlegene< Geschlecht der (vermeintlich) >überlegenen< Rasse« (Gouda 1993) agierten - um eine treffende Formulierung von Frances Gouda aufzugreifen. Frauen, das haben HistorikerInnen spätestens seit den goer Jahren verdeutlicht, trugen sehr wohl zur rassistischen Stigmatisierung, vermeintlichen Zivilisierung und Beherrschung indigener Menschen in Afrika, Südamerika oder Asien bei - ob nun durch gesel- 
lige Vereine, in der Krankenpflege oder in der Rolle der Pastorengattin und Lehrerin. Manche von ihnen, wie Frieda Freiin von Bülow, gossen in Publikationen bisweilen gar beißenden Spott aus über die »Verweichlichung « der Männer in den Tropen, deren »Verkafferung«, so der Terminus der Zeit (vgl. Bülow 1895). Eine Domäne der Männer war der Kolonialismus vor Ort keineswegs.

Eine solche Männerdomäne war hingegen die ethnologische »FeldArbeit« in ihren ersten Jahrzehnten sehr wohl. Tropenmediziner, wie Ernst von Haller, warnten Frauen vor »Feldforschungen« in den warmen Gegenden: Wenn eine Frau am »Tropenkoller« erkranke, dann sei sie geradezu unweigerlich dem Tode geweiht, so schrieb Haller noch 1951. Sie verfüge auch nicht über die »natürlichen Ressourcen« des Mannes, den »sittlichen Anfechtungen« zu entrinnen, die Ferne der »Zivilisation«, die Einsamkeit und das Zusammenleben mit den Indigenen mit sich brächten. »Nervöse Reizbarkeit« und »moralisches Absinken« seien nicht $\mathrm{zu}$ vermeiden (Haller 1951). Zu einer teilnehmenden Beobachtung, die ja auch wissenschaftlich distanziert sei, wären Frauen ohnehin nicht fähig. Der Frau in der »Wildnis« bleibe nur »öde Langeweile« und »Beschäftigungslosigkeit«, was bald »zu Eitelkeiten, Neid, Klatsch, Missverständnissen, Ausschweifungen und Verschwendung«, ja sogar zu Zank mit den »Eingeborenen« führen müsse, so ist bei einem weiteren Tropenmediziner namens Bandmann zu lesen (Bandmann 1954: 1f.). »Gewöhnung an die Tropen«, so Bandmann weiter, sei kaum möglich. Er kenne »nur wenige Frauen, auf die dies zutrifft«; sie seien »meistens von einem Typ, den man als unweiblich bezeichnet« (ebd.: 8).Tatsächlich setzte sich nur eine geringe Anzahl von Frauen über solche Verdikte hinweg. Unter ihnen waren Audrey Richards, die unter den Bemba in Nordrhodesien forschte (vgl. La Fontaine 1972), und Hortense Powdermaker, die zehn Monate in einem Dorf namens Lesu in Neu-Irland/Papua verbrachte (Powdermaker 1933). Beide waren Schülerinnen und enge Vertraute Malinowskis. Abgesehen von diesen Ausnahmen waren »Feldforscher« als Männer unter sich - ähnlich einem »Orden von Erprobten und Eingeweihten« (Stagl 1985: 289).

So sind oben genannte Zitate von Unwägbarkeiten im »Feld « auf den ersten Blick auch als Stilmittel der Inszenierung des Ethnologen als männlicher Heros (vgl. Kohl 1986: 29) zu interpretieren.

Hierfür spricht auch, dass Frauen in der ersten Hälfte des 20. Jahrhunderts kaum solche Schwierigkeiten oder eigene Zweifel während ihrer »Feldforschungen« thematisieren. Hortense Powdermaker stilisiert ihre Zeit auf Lesu sogar als regelrecht paradiesischen Aufenthalt. Mehrfach schwärmt sie über das klar schimmernde Meer im Sonnenschein und von der »warm friendship« der Indigenen (Powdermaker 1933: 17, 25).

Auf den zweiten Blick wird aber deutlich: Männer versuchen sich in ihren Berichten aus dem »Feld« nicht etwa durch Beweise von Standhaftigkeit und Stärke zu übertrumpfen, wie es in einer Männerdomäne voller Herausforderungen und Unwägbarkeiten wie der tropischen »Wildnis« 
nahe liegend wäre. Ganz im Gegenteil wird sogar die eigene Männlichkeit ausgesprochen krisenhaft dargestellt.

\section{Hybride Männlichkeit(en)}

Am 19. September 1914 schreibt Malinowski, eingebettet in Äußerungen über »schwärzeste Depressionen«, Hitze und Langeweile:

»Heute [...] hatte ich einen merkwürdigen Traum. Homosex., mit meinem eigenen Doppelgänger als Partner. Seltsame autoerotische Gefühle; die Empfindung, ich hätte gerne einen Mund wie den meinen geküsst, einen Hals, der wie meiner geschwungen ist, eine Stirn genau wie meine (von der Seite gesehen).« (Malinowski 1986: 22)

Diese Zeilen sind in der Tat nur ein Beispiel für zahlreiche Äußerungen Malinowskis und anderer europäischer oder nordamerikanischer Ethnologen der Zeit zum »Zerfall ihrer eigenen Männlichkeit«, zu homoerotischen Träumen und Phantasien oder - wie sie es nennen - zur drohenden »Verweiblichung« im »Tropenkoller«.

Solche Äußerungen werden hier unter dem postkolonialen Leitbegriff der Hybridität analysiert, der maßgeblich von Homi Bhabha geprägt wurde. Zentral ist in diesem Zusammenhang Bhabhas Definition: »Hybridity represents [...] a disturbing questioning of the images and presences of authority« (Bhabha 1985: 174 ). Die Machtasymmetrie der dominanten Wissenschaftskultur »weißer Ethnologie« ist somit, so die an Bhabha angelehnte, im Folgenden vertretene These, gebrochen von Infragestellungen westlicher Männlichkeitskonstruktionen. Zum anderen verweist Bhabhas Hybriditätskonzept nicht allein auf kulturelle Subversionen in zeitgenössischen Praktiken, sondern auch auf weiterführende Dimensionen der postkolonialen Theorie (vgl. Bhabha 1994).

Durch die Anlehnung an dieses doppelte Hybriditätskonzept wird zum einen versucht, den mit der Artikulation eigener Männlichkeit verbundenen Wahrnehmungen und Erfahrungen im »Feld« gerecht zu werden. Zum anderen geht es darum, die Brüchigkeit, Vielschichtigkeit und Interpretationsspanne, der diese Wahrnehmungen begleitenden oder sie erst formenden Diskurse auszuleuchten. Maßgeblich ist hier die Einsicht postkolonialer Theorien, dass hegemoniale Diskurse sehr häufig paradox, brüchig und fragil sind. »Hybrid ist alles«, so Elisabeth Bronfen, »was sich einer Vermischung von Traditionslinien oder von Signifikanten verdankt, was unterschiedliche Diskurse und Technologien verknüpft, was durch Techniken der collage, des samplings, des Bastelns zustande gekommen ist« (Bronfen 1997: 14).

Kurzum wird hier die These vertreten, dass Diskurse über Homosexualität die eingangs zitierten Äußerungen über im »Feld« erlebte Unbill 
auf die Spitze treiben. Sie stellen die geschlechtlich-kulturell und ethnisch codierte Herkunft des Feldforschers in ihrer Stabilität zumindest symbolisch, aber ausgesprochen fundamental in Frage, bearbeiten den »Platz« des männlichen Weißen in der indigenen Kultur und die Folgen seiner »Entwurzelung« von der eigenen »Zivilisation« (vgl. Bhabha 1994a/b). Unbenommen hiervon ist es eine Tatsache, dass mit dem Gang ins »Feld« häufig Versuche verbunden waren, der Dominanz und Hegemonialität der Herkunftsgesellschaften zu entrinnen bzw. diese abzulegen (vgl. Malinowski 1930: 406). Doch geht es im Folgenden weniger um die aus solchen Bestrebungen $\mathrm{zu}$ vermutende De- und Neukonstruktion von Identitäten, sondern mehr um die hybride Konsistenz der geäußerten Diskurse und ihrer Semantiken selbst. Auch wird Hybridität nicht als statisches Vermischungsverhältnis, sondern als ständig verändertes Resultat aktiver Übersetzungssituationen, von Überschreibungen, Handlungen in »Zwischenräumen« und als »Activities of Displacement« definiert (vgl. Rutherford 1990: 210).

Damit sollen die Konstruktionsleistungen der Diskurse über hybride Männlichkeit(en), die (Selbst-)Inszenierungen des jeweiligen Akteurs, seine Ver- und Bearbeitungen in ihrer Spannbreite sichtbar werden. Denn es gibt zahlreiche vielschichtige Lesarten für hybride Männlichkeit(en) in ethnologischen Texten - wie zu zeigen sein wird (vgl. Kohl 1987).

\section{"Observers Observed "}

Eine erste Lesart nimmt die persönliche Funktion von Tagebucheintragungen von der westlichen »Zivilisation« entfernter Feldforscher in den Blick. Es ist nahe liegend, dass die Zeitgenossen des frühen 20. Jahrhunderts im »Feld « unter »traumatischen« bzw. »exotischen« Erfahrungen standen bzw. es als nötig erachteten, solche zu schildern, wenn der große Abstand von der eigenen Lebenswelt markiert werden sollte. Ein Übermaß an »Exotischem« wird hier oft als Auslöser eines »Traumas« beschrieben, das wiederum die zentralen gesellschaftlichen und moralischen Rollen destabilisiert, die die Herkunftsgesellschaften dem männlichen Forscher zuwiesen. Susan Sontag brachte diese Verflechtung von »Exotismus«, »Trauma« sowie der Destabilisierung von Identitäten und Rollen auf den Punkt: »Der Anthropologe als Mann ist damit beschäftigt, die eigene Seele zu retten« (Sontag 1970: 189).

Raymond W. Firth hat 1966 mit Recht darauf hingewiesen, dass Malinowskis Tagebuch ihm dazu diente, als »Chronik seiner Gedanken und Gefühle [...] sein Leben zu organisieren und dessen tieferen Sinn zu erkennen « und als »Werkzeug und [...] Bezugspunkt, [...] seine Persönlichkeit zu steuern und zu korrigieren « (Firth 1985: 10).

Eine zentrale Bedeutung mag die Lektüre literarischer Werke hierbei gehabt haben. Beispielsweise las Malinowski die Erzählung »Herz der Fins- 
ternis« seines polnischen Landsmannes Joseph Conrad (Conrad 2005). Edward Said weist auf die strukturellen Ähnlichkeiten zwischen Malinowskis Tagebuch und Conrads Erzählung hin und stellt heraus, wie prominent das »Grauen«, die Auflösung aller »westlicher Normen und Werte« sowie das Ringen um Charakterstrukturen in beiden Texten thematisiert wird (Said 1966: 13). George W. Stocking Jr. und James Clifford haben überzeugend argumentiert, dass beide Texte ein Porträt der Identitätskrisen »westlicher Zivilisation« sind, eine Charakter-Skizze von Akteuren, deren Moral sich symbolisch auflöst und zur Disposition steht (vgl. Stocking 1974; Clifford 1988: 98; vgl. Wollaeger 1990). Es sind Beschreibungen kultureller Schwellenzustände und damit verbunden hybrider Erfahrungen, die sowohl das »Herz der Finsternis« als auch Malinowskis Tagebuch kennzeichnen (vgl. Clifford 1988:100). Nicht fehlen darf hier eine geradezu paradoxe Mischung aus Abscheu und Sehnsucht. Karl-Heinz Kohl hat in diesem Zusammenhang den pointierten Ausdruck »Überläufertum zwischen Abwehr und Verlangen « geprägt (Kohl 1987).

Auffällig häufig wird in Malinowskis Tagebuch und in anderen ethnologischen Texten der Zeit nach der »Geschlechtsmoral« und den Geschlechter-Rollen der Urgesellschaften - eben als Ursprung der »westlichen Zivilisation « - gefragt. Kohl bemerkt hierzu, dass die »teilnehmende Beobachtung « die Möglichkeit bot, »durch eine Teilhabe an sauthentischeren< Lebensformen durchaus persönliche Erwartungen und Bedürfnisse befriedigen zu können, ohne deshalb den Anspruch, Wissenschaft zu betreiben, aufgeben zu müssen « (Kohl 1987: 36).

»Oberservers observed « hat George W. Stocking Jr. das Beziehungsgeflecht der »teilnehmenden Beobachtung «wischen »Eigenen«, »Fremden«, »exotischen Erfahrungen« und »traumatischen Aufarbeitungen« genannt (Stocking 1983).

Geradezu wie ein Paradebeispiel dieser »observation of observer « spielte Malinowski in seinem Tagebuch homoerotische »Anfechtungen« durch. Hier geht es ganz offen um Provokationen, die ergründen, wie die Indigenen auf Fragen nach gleichgeschlechtlichen Beziehungen reagieren würden. Unter dem 8. Februar 1915 schrieb Malinowski über einen Abend auf den Trobiand-Inseln:

»Ging in der Dunkelheit mit Diko nach hause. Starke Zuneigung zu ihm. [...] Ich ging mit ihm in die Küche. Eine Schlange lag auf der Veranda. Wir setzen uns auf die Treppe in der Küche. [...] Ich fragte ihn, ob sie hier etwas von Homosex. wüßten. Er sagte nein [...].« (Malinowski 1986: 80)

Zweifellos liegen in diesem Eintrag auch Irritationen und Unsicherheiten, die Gesten, Handlungen und Rituale der Indigenen einzuordnen. Denn in jenem Gespräch war Malinowski erzählt worden, dass die Motu bei der Werbung um ein Mädchen üblicherweise eine auf den Knien der Geliebten sitzende Haltung einnahmen (ebd.: Anm. 48). Aus der derzeitigen 
europäischen Sicht weibliche bzw. so bezeichnete »verweiblichte« Verhaltensweisen - so anscheinend eine Erfahrung Malinowskis - sind nicht mit dem gleichzusetzen, was die Indigenen als »Verweiblichung« bzw. »Homosexualität « definierten, wenn sie solche Kategorien überhaupt kannten. Entsprechend verwundert schrieb Malinowski im Dezember 1917, dass ein Bekannter ihm ohne weitere Umstände oder Absichten »in ein Damennachthemd « gekleidet Essen servierte (ebd.: 136).

Es sei daran erinnert, Malinowski entstammt dem katholischen Krakauer Adel und damit verbunden einem Moralkodex, in dem Homosexualität zweifellos zu dem Unaussprechlichen, Undenkbaren gehörte. Im »Feld« unter den »Primitiven« allerdings, noch dazu geschwächt vom »Tropenkoller« konnte sich auch ein polnisch-katholischer Ethnologe ohne die ständig aufrecht erhaltene moralisch-gesellschaftliche Selbstzensur einem dunklen Rätsel, wie der »Verweiblichung« bzw. der Homosexualität, annähern.

Vor Malinowskis gesellschaftlichem Hintergrund ist es allerdings auch nicht erstaunlich, dass er 1929 in seiner Untersuchung über »Das Geschlechtsleben der Wilden in Nordwest-Melanesien « regelrecht bewundernd über die von ihm konstatierte Verachtung der »Eingeborenen « über die »Abwege und Irrpfade des Geschlechtstriebs« (Malinowski 1988, 357) urteilt:

»Homosexualität, Exhibitionismus, Oral- und Analerotik - um psychoanalytische Bezeichnungen zu gebrauchen - gelten bei den Eingeborenen [...] als unzulängliche und verächtliche Ersatzmittel für die natürliche Betätigung des Geschlechtstriebs. Diese Auffassung [...] führt dazu, dass beinah gar keine Perversionen vorkommen. Sexuelle Verirrungen werden lächerlich gemacht, geben Anlass zu anzüglichen, komischen Anekdoten und werden auf diese Art nicht nur als unschicklich gekennzeichnet, sondern als höchst unerwünscht hingestellt. [...] Öffentliche Ausübung des Geschlechtsaktes oder erotische Betätigung kommt fast gar nicht vor. Es gilt als unziemlich und verächtlich, wenn man nicht sorgsam auf Abgeschlossenheit bedacht ist, wenn man sich neugierig zeigt oder gar andere beim Liebesspiel $\mathrm{zu}$ beobachten versucht. [...] Der Voyeur kommt nicht einmal in der pornographischen Märchen- und Sagenwelt vor. [...] Geschlechtliche Gier zu verraten oder dreist und schamlos um die Gunst des anderen Geschlechts zu werben gilt für Männer und Frauen als schlecht und verächtlich, vor allem aber für Frauen. [...] Der Trobiander verachtet Perversionen, wie er einen Menschen verachtet, der geringe oder unreine Dinge verzehrt statt guter reiner Nahrung, oder einen Mann, der Hunger leidet, weil sein Yamshaus leer ist.« (Ebd.: 357, 367)

Ähnlich »keusch« zeichnete der preußische Feldforscher Günter Tessmann die westafrikanischen Pangwe, die er zwischen 1904 und 1909 erforschte: »Gleichgeschlechtliche Beziehungen« würden als »etwas Unsittliches und Widernatürliches« gelten, denen man mit »größter Verachtung« begegnet (Tessmann 1913: 271). 
Wie diese Äußerungen auch empirisch belegt wurden, sind sie doch zweifellos vom Moralkodex des viktorianischen/wilhelminischen Zeitalters imprägniert (vgl. Kohl 1987: 47). Dessen Spuren finden sich auch noch in Claude Lévi-Strauss' Schilderung in »Traurige Tropen« von 1955, in denen er auf der Basis seiner Feldtagebücher Mitte der 1930er Jahre über die vermeintliche »Feminisierung« der Männer bei den Bororo im MattoGrosso äußerte:

»Auch außerhalb der Zeremonien ist ihre Vorliebe für Schmuck so ausgeprägt, dass [sie] immer neue Zierden erfinden. [...] Ein Stück Rinde, ein paar Federn liefern den unermüdlichen Modisten Material für eine atemberaubende Kreation von Ohrringen. Man braucht nur das Männerhaus zu betreten, um zu ermessen, wie viel Eifer diese robusten Burschen darauf verwenden, sich schön zu machen: in allen Ecken wird geschnippelt, ziseliert, modelliert, geklebt [...] Geschickt wie Garderobieren verwandeln sich diese baumstarken Männer gegenseitig in Küken, indem sie sich Flaum auf die Haut kleben.« (Lévi-Strauss 1988: 219)

Lévi-Strauss hinterließ - anders als Malinowski - nichts über eigene homosexuelle »Anfechtungen«. Hier setzte - bewusst oder unbewusst - der heroische Ethnologe, die eigene Männlichkeit des »weißen Zivilisierten« vor der »Verweiblichung « der »Primitiven« in Szene. In dieser Gegenüberstellung »verweiblichter, wilder Männer « - diesem rassisch-geschlechtlich aufgeladenen »Othering « - vollzieht sich letztendlich auch die Produktion bzw. die Stabilisierung des okzidentalen Mannes (vgl. Dietze 2006: 232f.) - ein Akt, dessen Bedeutung noch unterstrichen wird, je mehr Probleme und Herausforderungen im Feld geschildert werden. Mit Recht hebt Susan Sontag gerade an Lévi-Strauss hervor, er habe im »Feld« eine »totale Beschäftigung « erfahren, in der Anthropologie einen intellektuellen Beruf gefunden, der nicht verlangt, »die eigene Männlichkeit zu opfern«, der hingegen immer wieder »Mut, Abenteuerlust und Körperkraft« unter Beweis stellen lässt (Sontag 1970: 89).

Liest man somit Diskurse über hybride Männlichkeiten zunächst in ihrer Selbstbezüglichkeit, als »Observation of the Observer«, dann erschließt sich ihre zweifache und sehr ambivalente Funktion: Zum einen konnten sie der Bearbeitung, Destabilisierung und Stabilisierung eigener eurozentrischer, in den Herkunftsgesellschaften tradierter Rollenbilder dienen. Zum anderen fungierten rassisch-geschlechtlich aufgeladene Prozesse des »Othering« auch als Mittel der Bearbeitung von »Exotik« und »Trauma«, somit nicht zuletzt der Stabilisierung »weißer« Männer im »Feld« als heroische Vertreter der »westlichen Zivilisation«. Diese Stabilisierung war allerdings vielfach gebrochen, was besonders deutlich wird, untersucht man Äußerungen von Ethnologen zu Kolonialbeamten und Missionaren. Hieraus erschließt sich eine weitere Lesart der Indienstnahme ethnologischer Diskurse über »Verweiblichung«, Schwäche und Homosexualität im »Feld $\ll$. 


\section{Gegen Kolonialbeamte und Missionare}

Die Kritik am Gestus der »Überlegenheit«, an der psychischen und physischen Gewalt und nicht zuletzt am Sexismus von Missionaren und Kolonialbeamten ist gerade prototypisch in ethnologischen Texten der ersten Hälfte des 20. Jahrhunderts zu finden. »Mir liegt nicht viel daran, bei dem Missionar zu wohnen«, so schreibt Malinowski im Oktober 1914, »dieser Mann widert mich an mit seiner [weißen] >Überlegenheit« (Malinowski 1986: 24).

Auch Lévi-Strauss klagte in den »Traurigen Tropen« über das »herablassende« Unverständnis der Hispano-Amerikaner gegenüber den Caduevo am Ufer des Rio Paraguay:

»Unsere Gastgeber hielten sie für faul und degeneriert, für Diebe und Trunkenbolde und pflegten sie barsch von den Weiden zu verjagen. [...] Unsere Expedition erschien ihnen von vornherein zum Scheitern verurteilt [...]; unsere Freunde verhielten sich wie [...] gute koloniale Verwaltungsbeamte, was sie ohnehin besser geworden wären.« (Lévi-Strauss 1989: 159)

Lévi-Strauss bezeichnete dementsprechend den Ethnologen auch als »Symbol der Sühne«. Sein Arbeit sei der »Versuch der Wiedergutmachung« der zerstörerischen Wirkungen, die von europäischen Gesellschaften auf indigene Kulturen ausgingen (zitiert nach: Kohl 1987: 47f.).

Und Hans Fischer schrieb 1958 von seinen »Feldforschungen« in Neuguinea:

»Was mich während der ersten Besuche bei den Missionaren am stärksten irritierte, war ihr Verhältnis zu den Einheimischen. Ein Verhältnis von oben nach unten, das sich in Sprechweise und Körperhaltung, dem täglichen Verhalten und der Beurteilung ausdrückte.« (Fischer 1985: 28)

Es wäre allerdings verfehlt, solche Äußerungen (ausschließlich) als liberale Kritik an Kolonialismus und Mission, als humanitäre Absetzungsstrategien gegen Rassismus zu interpretieren. Ethnologen waren im Feld oft unweigerlich auf Kolonialbeamte und Missionare angewiesen. Sie bekamen ihre Kontakte vor Ort über diese Personengruppen vermittelt und arbeiteten oft im Auftrag der Kolonialregierung, auf jeden Fall aber mit ihrer Genehmigung (vgl. Leclerc 1973: 62f.; Kohl 1986: 12). Vermutlich zielt die formulierte Kritik an Missionaren und Kolonialbeamten daher nicht unmaßgeblich auf Prozesse der wissenschaftlichen Identitätsstiftung ab, mit der sich Ethnologen ihrer eigenen »fortschrittlichen « Professionalität versicherten und ihre Handlungsfelder oder Deutungshoheiten absteckten.

Fest zu halten ist jedenfalls, dass Ethnologen sich geradezu prototypisch ganz gezielt vom Chauvinismus und Sexismus der Kolonialbeamten 
und Missionare zu distanzieren suchten. Als chauvinistisch und sexistisch angesehene Äußerungen wurden als Anteile des hegemonialen Diskurses allerdings auch oftmals geteilt bzw. aufgegriffen, wobei - wie zu zeigen ist - eigene Bearbeitungen heterosexueller Wünsche und Phantasien eine Rolle spielten.

\section{Bearbeitungen von Sexismus und Rassismus}

Es war zumindest in Kreisen kritischer Anthropologen zur Zeit Malinowskis oder Lévi-Strauss' nichts Unbekanntes mehr, dass Imperialismus und Kolonialismus ganz entscheidend von sexuell-rassistischen (männlichen) Unterwerfungsphantasien unter der glatten Oberfläche vermeintlich humanitärer und zivilisatorischer Absichtserklärungen vorangetrieben wurden (Barrell 1991; Hall 1992, 1993; Wallace 2003).

Edmund Morel hatte seit 1897 auf den Völkermord im Kongo aufmerksam gemacht und dabei auch auf Massenvergewaltigungen der Indigenen durch Missionare und Kolonialbeamte hingewiesen (Hochschild 2000; Gehrmann 2003). Und bald bekamen auch die Tahiti-Tagebücher des Malers Paul Gaugin einen zweifelhaften Ruhm; handelte es sich hier um Beispiele eurozentrisch-sexistischer Machtphantasien par excellence, in denen Gaugin beispielsweise schreibt, die Haut der Frauen in Tahiti sei so fest, dass man nicht in sie zwicken könne (vgl. Wallace 2003: 109-137).

Bei Lévi-Strauss gerinnt die Geschichte des westlichen Mannes, der auf »Eingeborene« sexuell übergreift, zu einer geradezu prototypisch abschreckenden Parabel. Die Rede ist von Don Felix, einem Siedler am Rio Paraguay, der »Vertraulichkeiten mit den Indianern« austauschte und $1944 \mathrm{im}$ Busch erschlagen aufgefunden wird (Lévi-Strauss 1989: 161). Lévi-Strauss erklärt diesen Todesfall folgendermaßen:

»Es ließ sich nur schwer vorstellen, dass Junggesellen den Reizen der indianischen Mädchen widerstehen konnten, wenn diese an Festtagen halb nackt herumliefen und mit größter Geduld ihre Körper mit blauen und schwarzen Spiralen bemalten, so dass ihre Haut wie mit einem engen Gewand aus kostbarer Spitze überzogen schien.« (Ebd.: 16of.)

In Malinowskis Tagebuch fallen hing egen zahlreiche, an Gaugins Sexismus erinnernde Äußerungen: So spricht er mehrfach von »nackten Menschenkörpern in Bewegung«, die ihn »erregten« oder von einer »schönen Kori«, die eine »Ahnung des Ewig Weiblichen ausstrahle« und deren tätowierte Haut er sehr »reizvoll« fand (Malinowski 1986: 222, 245, 247). Auch war die Rede von einem »Tierchen«, einem »hübschen, gut gebauten Mädchen «: »Momentan bedauerte ich «, so Malinowski, »dass ich kein Wilder war und dieses hübsche Mädchen nie besitzen konnte« (ebd.: 224). Dann erzählte Malinowski von »ein paar groben Scherzen«, die er beim 
Fotografieren einer Gruppe von »Mädchen« machte, und dass er dafür von einem seiner Informanten getadelt worden sei. Malinowskis Kommentar: »Ich war furchtbar verärgert über die Tatsache, dass dieser Nigger so mit mir zu sprechen gewagt hatte« (ebd.: 238). Mehrfach finden sich Eintragungen in seinem Tagebuch über Bemühungen, ihn beim Anblick indigener Mädchen überwältigende »Lüsternheit« zu überwinden (ebd.: 172). Auch hier schlägt - wie bereits mehrfach an Malinowskis Text festgestellt - der streng katholizistische (?) viktorianisch-wilhelminische Moralkodex durch. Möglicherweise sind solche Äußerungen auch als »Abwehrformen« (vgl. Kohl 1987) eigener homoerotischer Wünsche und Phantasien zu lesen. Andererseits könnten Auseinandersetzungen über Schwäche, »Verweiblichung « und homoerotische Phantasien auch als Versuche zu interpretieren sein, den eigenen (heterosexuellen) Sexismus und Rassismus zumindest zu hinterfragen und zu bearbeiten.

\section{Schlussbemerkung}

Die Darstellungen hybrider Männlichkeit(en) in ethnologischen Texten der ersten Hälfte des 20. Jahrhunderts lassen zahlreiche Lesarten zu, von denen hier einige angeboten wurden. Diskurse über hybride Männlichkeit(en) waren Mittel der Selbstbeobachtung - der »Oberservation of the observer« -, konnten der Infragestellung und (De-)Stabilisierung eigener Männlichkeitsentwürfe sowie der Bearbeitung heterosexueller Phantasien dienen. Sie konnten Teil der Stiftung einer wissenschaftlichen Identität der im »Feld« forschenden Ethnologen in Absetzung zu Missionaren und Kolonialbeamten sein. Und nicht zuletzt boten sie Möglichkeiten der - bewussten oder unbewussten - Verteidigung eines Raumes, in dem Wissenschaftler sich noch weitgehend unangefochten gegen Frauen als Heroen in Szene setzten. Alle diese Deutungen stehen aus historischer Perspektive gleichberechtigt und gleichermaßen wichtig nebeneinander, wenn man das Leben und Arbeiten von Männern im ethnologischen »Feld « in seinen ersten Jahrzehnten, und was sie darüber hinterließen, in den Blick nimmt.

Mit der Einschreibung der Bearbeitung von »Männlichkeit(en)« in die ethnologische Methode der »teilnehmenden Beobachtung « sind somit vielfältige und vielschichtige Infragestellungen eurozentrischer Rollen männlicher Identität zu erkennen (vgl. Kohl 1987). Sie verweisen auf die Ambivalenz und Komplexität hybrider Männlichkeiten im »Tropenkoller« ethnologischer Texte aus dem »Feld «. 


\section{Literatur}

Bandmann, P.J. (1965): »Akklimatisierung und Tropendiensttauglichkeit«. In: Zeitschrift für Tropenmedizin und Parasitologie 5, 1, S. 1-16.

Barrell, John (1991): The Infection of Thomas De Quincey. A Psychopathology of Imperialism, New Haven: Yale University Press.

Bhabha, Homi (1985): »Signs taken for wonders. Questions of ambivalence and authority under a tree outside, Delhi, May $1817 \ll$. In: Henry Louis Gates (Hg.), »Race«, Writing, and Difference, Chicago: University of Chicago Press, S. 163-184.

Bhabha, Homi (1994): »How Newness enters the World: Postmodern Space, postcolonial Times and the Trials of cultural Transnation«. In: ders. (Hg.), The Location of Culture, New York: Routledge, S. 212-235.

Bhabha, Homi (1994a): »The Other Question: Stereotype, Discrimination and the Discourse of Colonialism«. In: ders. (Hg.), The Location of Culture, New York: Routledge, S. 66-84.

Bhabha, Homi (1994b): »Of Mimicry and Man: The Ambivalence of the colonial Discourse «. In: ders. (Hg.), The Location of Culture, New York: Routledge, S. 85-92.

Bronfen, Elisabeth/Benjamin, Marius (1997): »Hybride Kulturen. Einleitung zur anglo-amerikanischen Multikulturalismusdebatte«. In: dies. (Hg.), Hybride Kulturen, Tübingen: Stauffenburg Verlag.

Bülow, Frida von (1895): Tropenkoller. Eine Episode aus dem deutschen Kolonialleben, Berlin/Leipzig: Hillger Verlag.

Clifford, James (1988): The Predicament of Culture. Twentieth-Century Ethnography, Literature, and Art, Cambridge (MA): Harvard University Press.

Conrad, Joseph (2005) [1899]: Herz der Finsternis, München: dtv.

Dietze, Gabriele (2006): »Critical Whiteness Theory und Kritischer Okzidentalismus. Zwei Figuren hegemonialer Selbstreflexion«. In: Martina Tißberger u.a. (Hg.), Weiß - Weißsein - Whiteness. Kritische Studien zu Gender und Rassismus, Frankfurt a.M.: Peter Lang Verlag, S. 219-247.

Evans-Pritchard, Edward E. (1968) [1940]: The Nuer. A Description of the Modes of Livelihood and Political Institution of a Nilotic People, Oxford: Clarendon Press.

Firth, Raymund (1985) [1966]: Einleitung. In: Malinowski (1986), S. 4-11.

Fischer, Hans (1968): Negwa. Eine Papua-Gruppe im Wandel, München: Klaus Renner Verlag.

Fischer, Hans (1985): »Erste Kontakte. Neuguinea 1958«. In: ders. (Hg.), Feldforschungen. Berichte zur Einführung in Probleme und Methoden, Berlin: Reimer, S. 23-48.

Gehrmann, Susanne (2003): Kongo-Greuel. Zur literarischen Konfiguration eines kolonialkritischen Diskurses (1890-1910), Hildesheim: Georg Olms Verlag.

Gouda, Fances (1993): »Das >unterlegene< Geschlecht der >überlegenen< Rasse. Kolonialgeschichte und Geschlechtergeschichte«. In: Hanna 
Schissler (Hg.), Geschlechterverhältnisse im historischen Wandel, Frankfurt a.M.: Campus, S. 185-203.

Hall, Catherine (1992): White, Male and Middle Class: Explorations in Feminism and History, Cambridge: Polity.

Hall, Catherine (1993): »>From Greenland's Icy Mountains ... to Africa's Golden Sand.< Ethnicity, Race and Nation in Mid-Nineteenth-Century England «. In: Gender and History 5, S. 212-243.

Haller, Ernst von (1951): Gesundheitsbüchlein für die Tropen, Stuttgart: Thieme.

Hochschild, Adam (2000): Schatten über dem Kongo: Die Geschichte eines der großen, fast vergessenen Menschheitsverbrechen, Stuttgart: Klett-Cotta.

Kohl, Karl-Heinz (1986) [1979]: Exotik als Beruf. Erfahrung und Trauma der Ethnographie, Frankfurt a.M.: Campus.

Kohl, Karl-Heinz (1987): Abwehr und Verlangen, Frankfurt a.M.: Campus.

La Fontaine, Jean Sybil (Hg.) (1972): The Interpretation of Ritual: Essays in Honour of Audrey Isabel Richards, London: Tavistock Publisher.

Leclerc, Gérard (1973): Anthropologie und Kolonialismus, München: Hanser.

Lévi-Strauss, Claude (1988) [1955]: Traurige Tropen, Frankfurt a.M.: Suhrkamp.

Lévi-Strauss, Claude/Eribon, Didier (1989) [1988]: Das Nahe und das Ferne. Eine Autobiographie in Gesprächen, Frankfurt a.M.: S. Fischer.

Malinowski, Bronislaw (1930): »The Rationalization of Anthropology and Administration«. In: Africa 3, S. 405-429.

Malinowski, Bronislaw (1973) [1926 u.a.]: Magie, Wissenschaft und Religion. Und andere Schriften, Frankfurt a.M.: Syndikat Verlag.

Malinowski, Bronislaw (1979a) [1922]: Argonauten des westlichen Pazifik. Ein Bericht über Unternehmungen und Abenteuer der Eingeborenen in den Inselwelten von Melanesisch-Neuguinea, Frankfurt a.M.: Syndikat Verlag.

Malinowski, Bronislaw (1979b) [1929]: Das Geschlechtsleben der Wilden in Nordwest-Melanesien. Liebe, Ehe und Familienleben bei den Eingeborenen der Trobiand-Inseln, Britisch-Neuguinea, Bd. 2, Frankfurt a.M.: Syndikat Verlag.

Malinowski, Bronislaw (1986) [englisch 1967]: Ein Tagebuch im strikten Sinn des Wortes. Neuguinea 1914-1918, Frankfurt a.M.: Syndikat Verlag.

Powdermaker, Hortense (1933): Life in Lesu. The Study of a Melanesian Society in New Ireland, London: Williams \& Norgate Ltd.

Rutherford, Jonathan (1990), »'The Third Space<. Interview with Homi Bhabha«. In: ders. (Hg.), Identity. Community, Culture, Difference, London: Lawrence \& Wishart Ltd., S. 207-221.

Said, Edward (1966): Joseph Conrad and the Fiction of Autobiography, Cambridge (MA): Harvard University Press. 
Sontag, Susan (1970): »The Anthropologist as Hero«. In: E. Nelson Hayes/ Tanya Hayes (Hg.), Claude Lévi-Strauss - The Anthropologist as Hero, Cambridge (MA): MIT Press, S. 184-196.

Stagl, Justin (1995): »Feldforschung als Ideologie«. In: Hans Fischer, Feldforschungen: Berichte zur Einführung in Probleme und Methoden, Berlin: Reimer, S. 289-310.

Stocking, George W. Jr. (1974): »Emphaty und Antipathy in Heart of Darkness «. In: Regna Darnell (Hg.), Readings in the History of Anthropology, New York: Harper and Row, S. 85-98.

Stocking, George W. Jr. (1983): »The Ethnographer's Magic: Fieldwork in British Anthropology from Tylor to Malinowski«. In: ders. (Hg.), Observers Observed: Essays on Ethnographic Fieldwork, Madison: University of Wisconsin Press, S. 70-121.

Stocking, George W. Jr. (1984): »Radcliffe-Brown and British Social Anthropology«. In: ders. (Hg.), Functionalism Historicized. Essays on British Social Anthropology, Madison: University of Wisconsin Press, S. 106-130.

Tessmann, Günter (1934): Die Baja. Ein Negerstamm im Mittleren Sudan. Materielle und seelische Kultur, Stuttgart: Strecker und Schröder Verlag. Wallace, Lee (2003): Sexual Encounters. Pacific Texts, Modern Sexualities, Ithaca: Cornell University Press.

Wollaeger, Mark (1990): Joseph Conrad and the Fictions of Skepticism, Stanford: Stanford University Press. 


\section{Kämpfe um hegemoniale Männlichkeiten}

\section{in der Ingenieurkultur um $1900^{1}$}

Tanja Paulitz

Im Jahr 1884 hielt der Maschinenbauprofessor und Rektor der Technischen Hochschule Berlin, Franz Reuleaux, im Niederösterreichischen Gewerbeverein einen Vortrag mit dem Titel »Cultur und Technik«. Reuleaux zählte Ende des 19. Jahrhunderts zu den zentralen Protagonisten der Verwissenschaftlichung des Maschinenbaus in Deutschland. Sein Vortrag fand rasch Verbreitung. 1885 wurde er in der »Zeitschrift des Vereins Deutscher Ingenieure (Z-VDI) abgedruckt und noch im selben Jahr ins Englische übersetzt (vgl. Reuleaux 1885a und 1885b). Reuleaux' Konzeption des Ingenieurs orientiert sich am bildungsbürgerlichen Ideal seiner Zeit und überträgt das Modell des umfassend gebildeten Geistesarbeiters auf den Maschinenbau (vgl. Braun 1977; Zachmann 2004). Sein Beitrag »Cultur und Technik« verfolgt gleich mehrere Ziele: das Ingenieurwesen als Wissenschaft zu etablieren und ihre überragende Bedeutung für die moderne westliche Kultur herauszustellen. Diesen kulturellen Status der Technik begründet er in der Überlegenheit Europas über andere Kulturen, die erst durch die Leistungen verwissenschaftlichter Technik ermöglicht worden sei.

»Cultur und Technik« ist als frühes Dokument in eine breitere gesellschaftliche Debatte einzuordnen, die Ende des 19. Jahrhunderts begann und im Zeichen der Professionalisierungsbemühungen der Ingenieure stand. Sie kam erst Anfang des 20. Jahrhunderts zur vollen Entfaltung und wurde vorwiegend von Kulturwissenschaftlern, aber auch von eini-

1| Der Beitrag basiert auf Analysen aus einem laufenden sozialwissenschaftlichen Forschungsprojekt zum Thema »Technisches Konstruieren und Geschlecht in der Informationsgesellschaft«, geleitet von der Verfasserin, gefördert vom Österreichischen Wissenschaftsfond (FWF), vgl. auch www.sts.tugraz.at/paulitz. 
gen Ingenieuren geführt (vgl. Braun 1996: 42). ${ }^{2}$ Die Spannweite der Positionen in dieser Auseinandersetzung reichte vom euphorischen Feiern des technischen Fortschritts bis zu zeittypischen kulturpessimistischen Deutungen, die den Niedergang durch die technisierte Zivilisation prophezeiten (vgl. Dietz/Fessner/Maier 1996; Rohkrämer 1999).

Gegenstand meiner Betrachtung sind die Äußerungen von Ingenieuren in dieser Debatte, mit denen sie vor allem kulturpessimistischen Argumenten widersprachen und die außerdem eine strategische Bedeutung für die professionsbezogenen Anerkennungsbestrebungen der Ingenieure hatten. In diesem Beitrag geht es darum, Geschlecht als bedeutsame Kategorie in den entsprechenden Äußerungen von Ingenieuren zu untersuchen. Professionalisierungskämpfe betrachte ich im Folgenden schwerpunktmäßig als Kämpfe um deutungsmächtiges Wissen und analysiere daher insbesondere die unterschiedlichen co-existierenden Auffassungen vom Ingenieurberuf, von der Ingenieurtätigkeit und ihres gesellschaftlichen Stellenwerts.

Das Unternehmen, Geschlechterdimensionen in den Fachkulturen und Wissensbeständen des Ingenieurbereichs zu untersuchen, stößt auf eine generelle Schwierigkeit: In den entsprechenden Texten bleibt >das< Geschlecht weitgehend implizit. Es ist zwar bekannt, dass die Kernbereiche der Ingenieurwissenschaften, wie etwa der Maschinenbau, bis heute eine klare Männerdomäne darstellen (vgl. z.B. Haffner/Köhnekamp/ Krais 2006). Inwiefern die Gründe für diese Situation auch auf der epistemischen Ebene zu suchen sind, ist jedoch nach wie vor eine weitgehend unterbelichtete Forschungsfrage. Dieser Beitrag möchte Ansatzpunkte zur Analyse von geschlechtlichen Kodierungen fachlicher Inhalte und Grundorientierungen in den >männerdominierten< ingenieurwissenschaftlichen Disziplinen entwickeln. An exemplarisch ausgewähltem Material aus der >heißen Phase< der Herausbildung der Ingenieurwissenschaften soll außerdem gezeigt werden, wie um 1900 Männlichkeit(en) im Feld des Technischen konstruiert wurden.

Im Folgenden möchte ich zunächst die theoretischen Voraussetzungen der Geschlechterforschung für ein solches Vorhaben ausleuchten (1). Im Anschluss soll Reuleaux' Vortrag »Cultur und Technik« einer genauen Analyse unterzogen werden (2). Deren Ergebnisse kontrastiere ich schließlich mit weiteren (kontroversen) Argumentationslinien in der Debatte der Ingenieure zur Kulturfrage (3).

2| Zur Bewertung und Würdigung von Reuleaux' frühem Beitrag im Kontext in den zoer Jahren des vergangenen Jahrhunderts aufgeheizter Debatten vgl. das zeitgenössische technikhistorische Buch von Carl Weihe (1925). 


\section{Zur Analyse des 'Geschlechterwissens، im Feld des Technischen}

Technische Konstruktion gilt geradezu als die Ingenieurtätigkeit par excellence. Ihre ingenieurwissenschaftliche Ausformulierung kann heute auf eine ca. 120-jährige Denktradition und auf zahlreiche kontroverse Debatten in Fachorganen zurückblicken. Wie Ingenieure Maschinen entwerfen, wie technisches Schaffen und technische Kreativität zu verstehen sind und folglich auch Studierenden gelehrt werden können, gehörte zu den epistemischen Grundlagen des frühen Maschinenbaus, wie auch zu seiner Professionalisierung und Institutionalisierung. Die neuere technikgeschichtliche Forschung hat herausgearbeitet, dass sich die Theoriebildung über das Konstruieren durchgängig in einem ambivalenten Spannungsfeld bewegt: Von den frühen Theorie- und Methodenstreits um 1900 bis heute wird die Ingenieurtätigkeit entweder als Kunst oder als Wissenschaft betrachtet (vgl. König 1999; Heymann 2005).

Eine kritische Analyse dieser Konzeptionen technischer Produktivität als geschlechtlich kodierte Tätigkeit fehlt allerdings bislang weitgehend. Zwar kann mittlerweile auf eine recht gute Forschungslage in der Frauen- und Geschlechterforschung verwiesen werden, sowohl im Hinblick auf die Arbeitssituation von Ingenieurinnen als auch hinsichtlich der Zugangsbarrieren zur und Ausschlüsse aus der Männerdomäne Technik (vgl. Rudolph 1994; Wajcman 1991). Heute weiß man auch einiges über die historische Verknüpfung naturwissenschaftlich-technischer Berufe mit dem bipolaren Modell zweier Geschlechtscharaktere der bürgerlichen Moderne (vgl. Hausen 1995; Oldenziel 1999; Zachmann 2004). Die feministische Techniksoziologin Judy Wajcman resümiert in einer aktuellen Übersicht über die vorliegenden sozialkonstruktivistisch orientierten feministischen Forschungsansätze wie folgt: »Weitgehender Konsens ist gegenwärtig, dass weder Männlichkeit, Weiblichkeit noch Technologie feststehende, einheitliche Kategorien sind; vielmehr enthalten sie vielfältige Möglichkeiten und werden in Relation zueinander konstruiert« (Wajcman 2002: 285). Die Beschäftigung mit den Fachkulturen, mit den spezifischen Ausprägungen des >doing gender im Ingenieurbereich, wie auch mit den professionellen Selbstbildern und den alläglichen Deutungsmustern der AkteurInnen steht allerdings nach wie vor am Anfang (vgl. Faulkner 2000; Gilbert 2006). In ähnlicher Weise stellt die Analyse von Männlichkeitskonstruktionen in den Wissensbeständen der Ingenieurwissenschaften ein völlig unterbelichtetes bzw. nur am Rande in Augenschein genommenes Forschungsgebiet dar. Das Desiderat besteht also weniger darin, Technik als Männerdomäne zu identifizieren und den Ausschluss der Frauen zu beschreiben, als vielmehr in der Frage, wie sich Männlichkeit im Verhältnis zu Technik symbolisch konstituiert. In welcher Weise sind bereits die Vorstellungen vom >Technischen< von sozialen Geschlechterkonstruktionen durchdrungen? Wie einheitlich, stabil und konsistent ist 
die Konstruktionsweise technischer Männlichkeit(en) bzw. welche Diskontinuitäten, Widersprüche, Brüche oder auch Transformationen lassen sich auffinden (vgl. Paulitz 2004)?

Um auf diese Fragen Antworten zu erhalten, betrachte ich »Geschlecht « generell als sozial hervorgebrachte Kategorie. Dabei geht es explizit nicht um die Identifizierung >weiblicher< Tätigkeitsfelder im Ingenieurbereich. Ziel ist es vielmehr, ein vertiefteres Verständnis davon zu gewinnen, wie (offen oder verdeckt) im >Wissen< von IngenieurInnen Vorstellungen von Geschlecht erzeugt und transportiert werden. Im Vordergrund steht also das Interesse, Einblicke in die geschlechtliche Aufladung technischer Gegenstände, Verfahren und Konzepte zu gewinnen. Meine Arbeitshypothese lautet: Im Ingenieurbereich diskursivierte Auffassungen über Geschlecht reproduzieren auf der Wissensebene nicht nur die gesellschaftlichen Geschlechterstereotypen, sondern konstruieren maßgebliche Geschlechterkonnotationen neu. ${ }^{3}$ Auf diese Weise normieren sie bestimmte vergeschlechtlichte Vorstellungen vom Ingenieur und von der Technik. Darüber hinaus ist anzunehmen, dass sie auch Ausschlüsse, Barrieren und Diskriminierungen bedingen, mit denen etwa Frauen im Ingenieurstudium und -beruf konkret konfrontiert werden.

Für diese Analyse ist das Konzept »hegemonialer Männlichkeiten« von Robert Connell (1999) prädestiniert, weil es das symbolische Verhältnis zwischen Männlichkeit und Technik nicht als einheitlichen Block im Sinne der männlich codierten technischen Rationalität vorab verengt. ${ }^{4}$ Vielmehr öffnet es eine Forschungsperspektive für das hoch konkurrente Feld der Wissensproduktion innerhalb ingenieurwissenschaftlicher Disziplinen vor allem im Maschinenbau, in dem Ingenieure in der Zeit um 1900 um die Anerkennung ihres sozialen Status in einer eurozentristischen geschlechterseggregierten Klassengesellschaft kämpften. Connells Ansatz ermöglicht es darüber hinaus, Geschlecht als komplexe Kategorie zu begreifen, die im Wechselverhältnis mit anderen gesellschaftlichen Differenzkategorien steht.

Zum gegenwärtigen Zeitpunkt lassen sich innerhalb der feministischen Naturwissenschafts- und Technikforschung relevante theoretische Anschlussstellen für eine solche Untersuchung der Konstruktionen von Männlichkeit im Ingenieurwissen fruchtbar machen. So bietet die Systematik der Naturwissenschaftsforscherin Evelyn Fox Keller (1995), die drei verschiedene analytische Zugänge zum Gegenstandsbereich »Gender and Science« unterscheidet, einen wesentlichen Anknüpfungspunkt:

3। Zur Diskussion um die theoretische Perspektive, die mit dem Stichwort »Konstruktion von Geschlecht« eingenommen wird vgl. die aktuelle Bestandsaufnahme: Helduser/Marx/Paulitz/Pühl 2004.

4| Zur Analyse des Verhältnisses zwischen Männlichkeit und Technik vgl. das kürzlich erschienene Schwerpunktheft der Zeitschrift »Men and Masculinities« (Lohan/Faulkner 2004). 
»Schematically, these [studies on gender and science; T.P.] might be described as studies of (a) women in science, (b) scientific constructions of sexual difference, and (c) the uses of gender in scientific constructions of subjects and objects that lie both beneath and beyond the human skin.« (Keller 1995: 86)

In Anwendung dieser Systematik auf das Feld der Ingenieurwissenschaften geht es hier freilich nicht um die Frage nach den »women in engineering«. Vielmehr wird der dritte Analyseansatz, auch »gender in science genannt (ebd.; H.i.O.), verfolgt. So spricht auch die britische Techniksoziologin Wendy Faulkner in ihren aktuellen Analysen zur Alltagskultur von Ingenieuren von »Gender in/of Engineering « (vgl. Faulkner 2006). ${ }^{5}$ Darüber hinaus sollen hier Einsichten aus jenen neueren Entwicklungen der feministischen Wissenschafts- und Technikforschung berücksichtigt werden, die ethnische Kategorien bei der Analyse in den Blick nehmen (vgl. Harding 1993; Haraway 1989) und Geschlecht als Wissenskategorie in der »colonial science« untersuchen (vgl. Schiebinger 2004).

Das zu diesen Zwecken analysierte Material - Beiträge von Ingenieuren zu den Debatten um »Kultur und Technik« um 1900 - ist nicht ausschließlich dem fachwissenschaftlichen Kontext zuzuordnen. Jene Beiträge eignen sich für die vorliegende Fragestellung jedoch besonders, weil sie den kulturellen Stellenwert der Technik thematisieren, aber auch die Verstehensformen der Ingenieurtätigkeit im Schnittpunkt zwischen Fachdebatte und professionspolitischer Selbstverständigung widerspiegeln. Der Ansatz, die Wissensproduktion im Ingenieurbereich auf seine Geschlechterkonzeptionen hin zu analysieren, versteht die Beiträge der Ingenieure zur Kulturfrage auch im theoretisch-methodologischen Sinne als analytische >Türöffner für weitere Untersuchungen zu epistemischen Ordnungen im Feld des Technischen.

\section{Der "atlantische", hoch qualifizierte Maschinenwissenschaftler}

Franz Reuleaux entwickelte ein spezielles dualistisches Begriffsystem, das er unmittelbar aus seinen maschinenwissenschaftlichen Forschungen ableitete. Dazu kontrastiert er zwei Formen des Umgangs mit der Natur: den sogenannten »Manganismus « und den »Naturismus« (1885: 26f.). Die manganistische Umgangsweise stehe für »das Eindringen in die Geheimnisse der Naturkräfte« (ebd.) und deren zweckrationaler Anwendung in

5| Zur ausführlicheren Begründung der theoretischen Perspektive auf "gender in engineering « und zu aktuellen Forschungsaktivitäten in diesem Gebiet vgl. Paulitz (2007). Zum aktuell laufenden Forschungsprojekt von Wendy Faulkner »Gender in/of Engineering « vgl. http://www.ssu.sps.ed.ac.uk/research/faulkner/ faulkner_g+e_project.html (letzter Abruf: 21.1.2007). 
der Konstruktion von Maschinen. Den Begriff leitet Reuleaux kulturhistorisch aus der Frühgeschichte der Perser her. Dabei bezieht er sich auf einen sogenannten »Volksstamm der Magier« und auf spätere entsprechende Begriffsverwendungen des »Manganon « in der griechischen Antike. »Allerlei Concretes, was geschickt und klug ausgedacht war, wurde so betitelt« (ebd.: 26). Daher sollen sich die Magier darauf verstanden haben, der Natur ihre Geheimnisse, ihre Gesetze, zu entlocken. Der Naturismus hingegen steht für die magische Abwehr bzw. die Beschwörung von Naturmächten oder allenfalls das Ablauschen von Rezeptwissen aus der Natur (vgl. ebd.: 26f.). Dieses Begriffspaar verwendet Reuleaux in »Cultur und Technik« gleichermaßen zur Hierarchisierung der »Völker« wie zur Unterscheidung von Entwicklungsstufen von Individuen und zur sozialen Hierarchisierung des (technischen) Ausbildungssystems.

Der erste Argumentationsschritt nimmt seinen Anfang in einer kulturvergleichenden Überlegung: Reuleaux fragt nach den Gründen für die Vorherrschaft der Europäer und Nordamerikaner - er nennt sie die »atlantischen Nationen « (ebd.: 25) - über die »anderen Völker des Erdenrundes« (ebd.). Er vertritt die These, die besondere Leistung der »Atlantiker« liege in ihrer historisch neu erworbenen Denkweise, und somit in der am naturwissenschaftlichen Ideal orientierten technischen Rationalität. Sie sei aus der Auseinandersetzung mit der ehemals herrschenden Auffassung von der göttlichen Weltordnung hervorgegangen und stelle »eine geistige Riesenarbeit und zugleich ein[en] geistige[n] Kriegszug hinauf zur Höhe freier Erkenntnis« dar (ebd.: 26). Um die Einzigartigkeit dieses >Erfolgs< der westlichen Kultur herauszustellen, entwirft er das Szenario eines gescheiterten Kampfes in der arabischen Welt:

»Wir können es sehen, und zwar sehen an der großen arabischen Völkerfamilie. Bei ihr hatte die Reaction wirklich gesiegt. [...] Und gelähmt liegt sie darnieder jetzt schon ein halbes Jahrtausend. Allah aalam! >Gott allein weiß!< D.h. daher sollst du nicht wissen wollen!« (Ebd.)

Reuleaux stellt hier die »geistig abgetötete Masse« (ebd.) des arabischen Kulturraumes einem >Willen zum Wissen $<$ und einer >lebendigen freien Erkenntnis< der >Atlantiker< gegenüber. In die nicht gelähmte, ungehindert voranschreitende Bewegung des Ideenfortschritts könne ein Volk praktisch qua eigener Entscheidung eintreten und >mitmarschieren<. Diesen Gegensatz im geistigen Vermögen zwischen den »Völkern« fasst Reuleaux mit jenem Dualismus von »Manganismus« versus »Naturismus « in ein binäres Begriffsystem.

Es dient ihm dazu, die >Völker < zu klassifizieren, wobei er Fälle manganistischer und naturistischer Nationen ebenso exemplarisch herausstellt wie Nationen >im Übergang $<$. Unter der Annahme eines globalen Kampfes um Herrschaft vertritt Reuleaux die Meinung, dass man »mit Sicherheit vorausberechnen [könne], dass die Manganisten die Sieger bleiben wer- 
den, oder dass diejenigen Nationen, welche sich nicht entschließen wollen, zum Manganismus überzugehen, auf allmähliche Unterwerfung oder auf Untergang gefasst sein müssen « (ebd.: 27). Folglich stehe Europa seine Vorherrschaft quasi mit Recht zu. Diese Hegemonie sei nicht nur in der >richtigen< Denkhaltung sachlich begründet, sondern auch vom wissenschaftlich-rationalen Fortschrittssubjekt, dem >Culturvolk<, >rechtmäßig erworben. Daraus lässt sich schlussfolgern: Die Reuleaux' naturwissenschaftlich-technischer Weltsicht entliehene Legitimationsargumentation fußt auf der Fähigkeit zur Hervorbringung von Technik. Damit gerät die Frage der intellektuellen technischen Produktivität zur Rechtfertigung der kolonialen Hegemonie Europas.

Die manganistische Vorgehensweise der Ingenieure erklärt Reuleaux wiederum unter Rückgriff auf die von ihm vertretene kinematische Maschinentheorie (vgl. Reuleaux 1875). Das dort vorgeschlagene Verfahren, Maschinen auf Basis systematischer (wissenschaftlicher) Analyse von kleinsten funktionalen, mechanischen Maschinenelemente zu entwickeln, verwendet er im Rahmen seiner kulturtheoretischen Argumentation als übergeordnetes, abstraktes Prinzip. Sein Fazit zu diesem Punkt lautet: Je komplexer die auf kinematischem Wege konstruierte Maschine, umso höher steht die Kultur, die diese hervorzubringen vermag (vgl. ebd.: 44).

Dass Reuleaux sowohl beim >manganistischen wie beim >naturistischen< Menschen selbstverständlich einen Mann unterstellt, wird an einer einzigen Stelle - und dort auch nur en passant - ausgesprochen und somit auf Textebene evident. Und zwar in folgendem Argumentationsschritt: Reuleaux versucht das unterschiedliche Leistungsvermögen der >Völker< mathematisch $\mathrm{zu}>$ beweisen $<$ um gewissermaßen seinen Objektivitätsanspruch zu rechtfertigen. Dazu wählt er das Beispiel der Kohlenförderung und deren Äquivalent an (industrieller) Arbeitsleistung, wobei er die Pferdestärke in die Menge an körperlicher Arbeit des Menschen umrechnet. »Auf jede Pferdestärke die Arbeitsstärke von sechs Menschen, starken Männern [!], gerechnet, ergiebt« usw. (vgl. ebd.: 45; Hervorh. T.P.). Reuleaux vergleicht hier also die Produktivität von arbeitenden Männern verschiedener >Völker< und kommt zu folgendem Ergebnis:

»Wir Atlantiker, das Sechstel der Erdenbewohner, leisten aber mit unserer manganistischen Arbeit weit über viermal soviel, als jene [die sanderen Völker<; T.P.] leisten können. Das Übergewicht der Manganisten über die Naturisten ist also nicht ein zufälliges, sondern wird erworben und heimgezahlt durch nützliche Arbeit und erlangt dadurch auch, rein menschlich genommen, seine Berechtigung. Dies um so mehr, als unsere Arbeitsleistung zu jenen hingeführt wird [...] zur Verbreitung und unter Verbreitung von Cultur und Gesittung. So wird denn die wissenschaftliche Technik zur Trägerin der Cultur, zur kraftvollen unermüdlichen Arbeiterin im Dienste der Gesittung und Bildung des Menschengeschlechtes.« (Ebd.: 45)

Im Hinblick auf die industrielle Arbeit unterscheidet Reuleaux folglich 
zwei Formen produktiver Männlichkeit entlang des Gegensatzpaares körperlicher respektive geistiger Kraft. Dabei erhebt er die durch wissenschaftlich-technische (d.h. manganistische) Leistungsstärke hervorgebrachte Technik schließlich mittelbar auch zur Trägerin allgemein kultureller Werte. Denn neben der materiellen Kultur würden auch Normen und Werte der >Atlantiker in die Welt getragen und durch die materielle technische Basis abgesichert. Es muss hier betont werden, dass Reuleaux' zentrales Anliegen dabei weniger darin besteht, die koloniale Herrschaft an sich zu legitimieren (was er faktisch tut), sondern vielmehr die einzigartige kulturelle Bedeutung der Technik, d.h. des Projekts der Ingenieure, herauszustellen.

In einem zweiten Argumentationsschritt wendet Reuleaux die Begriffe »Manganismus« und »Naturismus« außerdem auf die Vorstellung qualitativ unterschiedlicher Stufen der Individualentwicklung an:

»... Auch in Europa ist derselbe [der Naturismus; T.P.] noch vorhanden, ja, in jedem Menschen steckt ein Stück Naturismus. Demselben wird durch die Erziehung erst die manganistische Anschauung zugesellt, das Verstandesmäßige, das unbarmherzig Logische dem Naiven, der holden Natur bedingungslos Ergebenen in uns; aber auch die Besonnenheit, die ausdauernde Festigkeit gegenüber dem Ansturm ruindrohender Naturmacht, das volle Gegenteil des Fatalismus.« (Ebd.: 27)

Selbst die Individualentwicklung verlaufe vom angeborenen Naturismus zum erworbenen Manganismus. Durch diese generalisierende Verwendung des dualistischen Klassifikationsprinzips entsteht ein enger Verweisungszusammenhang zur Menschheits- und Kollektiventwicklung und zum globalen Machtkampf der >Völker ${ }^{6}$ Im Umkehrschluss naturalisiert Reuleaux auf diese Weise die koloniale Vorherrschaft als evolutionäre Entwicklung eines Volkes von einem vermeintlichen Frühstadium zu einem fortgeschrittenen, überlegenen Stadium. Außerdem überträgt er mit dieser Äußerung seine Einteilung der >Völker und der menschlichen Produktivität zusätzlich auf einen umfassenden Natur-Kultur-Dualismus. Mit dessen Hilfe unterscheidet er schließlich auch zwischen verschiedenen, hierarchisch geordneten Ebenen des technischen Ausbildungssystems, den höher gebildeten Ingenieuren einerseits und den einfachen Technikern andererseits.

Letztendlich wird in »Cultur und Technik « also unter Rückgriff auf das fachwissenschaftlich motivierte Begriffspaar eine recht kleine Gruppe der >eigentlichen Manganisten k konstituiert: Und zwar sind es weiße, europäische, technikwissenschaftlich hochqualifizierte Männer, eine technische Elite also, die Hegemonie beansprucht. Das dualistische Klassifikations-

6| Diese Argumentationsfigur funktioniert durch die implizite Bezugnahme auf die sozialdarwinistische Position von Ernst Haeckel, in denen u.a. Phylogenese und Ontogenese als parallelisierbare Entwicklungsprozesse aufgefasst wurden. 
kriterium selbst erhält durch seine Anwendung auf die drei unterschiedlichen Bereiche umgekehrt auch den Stellenwert eines Universalgesetzes, ähnlich dem Anspruch an die allgemeine Gültigkeit der Naturgesetze.

Im Anschluss an Connell (1999) lässt sich Reuleaux' Konstruktion des >Manganisten als spezifische Konzeption hegemonialer Männlichkeit interpretieren, die im Zuge der Professionalisierung der modernen Ingenieurwissenschaften entsteht. Auch hier zeigt sich der »relationale Charakter« (Connell 1999: 188f.). Die jeweils Hegemonialität beanspruchende Konzeption konstituiert sich im ausdrücklichen Vergleich und in Abgrenzung zum >Anderen<. Interessant ist, dass diese >Anderen $<$ hier nicht die Frauen sind. Zwar basiert Reuleaux' Argumentation auf dem unausgesprochenen Selbstverständnis, dass es dabei nur um technisch produktive Männer gehen kann. Zur Abgrenzung von den >Anderen< werden jedoch explizit ethnische Kategorien einerseits und soziale Hierarchisierungen im zeitgenössischen Bildungssystem andererseits herangezogen. Resümieren lässt sich soweit erstens: In ihrem Kampf um die Verbesserung des sozialen Status des akademisch gebildeten Ingenieurs konstruieren Akteure wie Reuleaux vielfältige Unterschiede zwischen Männern. Zweitens: Die besondere Fähigkeit des Ingenieurs, Maschinen zu entwerfen und zu bauen, wird zum zentralen Argument kultureller Überlegenheit. Technische Produktivität avanciert folglich zu einem machtvollen Feld des Wissens. Die Vergeschlechtlichung dieses Wissens über das Leistungsvermögen von Männern bleibt weitgehend implizit. Hingegen begründen die ihm inhärenten expliziten Ethnisierungen und sozialen Hierarchisierungen den Anspruch der neuen technischen Elite auf gesellschaftlichen Bedeutungszugewinn.

Diese sozialen Konstruktionen >technischer Männlichkeit haben einen durchaus handfesten Hintergrund, wenngleich sich dieser nicht im Sinne eines einfachen Ursache-Wirkungsmechanismus darstellt: Ingenieure befanden sich um 1900 in Deutschland in der sheißen Phase< ihres akademischen Professionalisierungsprozesses. Die auch von den Absolventen der höheren technischen Lehranstalten empfundene soziale Unterprivilegierung lag vor allem darin begründet, dass die Abschlüsse nicht dem Universitätsabschluss gleichgestellt waren. Die Selbstwahrnehmung als Marginalisierte ist damit auch auf Barrieren zurückzuführen, die den Ingenieuren den Zugang zu den höheren Laufbahnen vor allem zur öffentlichen Verwaltung und zu politischen Entscheidungspositionen versperrten (vgl. Dietz/Fessner/Maier 1996). Reuleaux' Argumentationsstrategie, die Wissenschaftlichkeit technischer Produktivität und ihres Leistungspotentials in der kolonialen Welt herauszustellen, steht also im Kontext des Kampfes um soziale Gleichstellung mit anderen akademischen Berufen. Die in »Cultur und Technik« entwickelte Deutung des gesellschaftlichen Stellenwerts der Technik ist daher im professionspolitischen Sinne als Angriff auf die gesellschaftlichen Bildungseliten der Zeit zu interpretieren. In ihnen spiegeln sich aber auch unverkennbar die imperialistischen Ambitionen 
Deutschlands im ausgehenden 19. Jahrhundert (vgl. van Laak 2005), beispielsweise wenn Reuleaux den Beitrag der Ingenieure zum Aufstieg der Nation in der Welt herausstellt und darauf den Hegemonieanspruch der neuen Profession gründet.

\section{Die kraftvolle, künstlerisch-kreative technische Männlichkeit}

Was im Zuge der Reuleaux'schen Konstituierung technischer Rationalität als unwissenschaftlich abgespalten wurde, taucht in anderen Beiträgen der Ingenieure zum Kulturthema partiell als konkurrierende Rationalitätskonzeption wieder auf. Reuleaux' fachinterne Gegenspieler in den kontroversen und polarisierenden Theorie- und Methodendebatten - vor allem nach 1900 - verwarfen das stark am wissenschaftlichen Ideal orientierte Bild des Ingenieurs und stärkten eine Konzeption technischer Produktivität, die sich mehr an der handwerklichen Praxis orientierte (vgl. König 1999: $55 \mathrm{ff}$.). Von Alois Riedler wird das Leitbild des Ingenieurs als Praktiker vorgegeben. Er grenzt sich scharf vom bildungsbürgerlichen Ideal ab, stellt den >Mann der Tat< über den >Stubengelehrten< und begreift das >Ingenieurschaffen als Kunst. Diese neue Argumentation ist als (strategische) Wendung im Kampf der Ingenieure um hegemoniale Männlichkeit zu interpretieren.

Max Eyth etwa, einer der bekannten zeitgenössischen sogenannten Dichter-Ingenieure7, beschreibt seine Position im 1904 veröffentlichten programmatischen Text »Poesie und Technik«, der ebenfalls in der Z-VDI erschien. Dort charakterisiert er den Arbeitsprozess des Ingenieurs als:

»[...] den dunklen Drang, zu schaffen, das halb unbewusste Spielen der Phantasie, das Herbeiziehen unzusammenhängender Erinnerungen und abgerissener Gedanken; dann plötzlich das Erblicken eines Ausweges, eines Lichtes im Halbdunkel, das von keinem Willen abhängig zu sein scheint, das aus einer Richtung kommt, an die der Entdecker im Augenblick gar nicht gedacht hatte. Und dann die jubelnde Freude, wenn das Licht mit jedem Augenblick heller und klarer wird, und schließlich die das ganze Wesen des Mannes durchzitternde Gewißheit: Hier ist wieder einmal eine neue Wahrheit gefunden!« (Eyth 1904: 1132)

7| Als »Dichter-Ingenieure« wurden Ingenieure bezeichnet, die durch ihre Poetisierung des Ingenieurberufes hervortraten. Um 1900 handelt es sich meist um Texte, die an das Genre der Heldenepen erinnern und den Kampf der Ingenieure mit den Naturgewalten literarisch inszenieren (vgl. Zachmann 2004: 120ff.). Dass literarische Texte über Technik nicht selten von Akteuren aus technischen Berufen verfasst wurden, belegt z.B. auch die Studie von Howard Segal (1985) über technische Utopien in den USA. 
Diese Formulierungen stehen im Kontext eines Gefühlsdiskurses, der sich an verschiedenen Stellen im Ingenieurwissen nachzeichnen lässt. Die Rede ist dort vom konstruktiven Gefühl, vom intuitiven Vorgehen etc. Männlichkeit wird bei Eyth zum emphatisch-programmatischen Leistungskriterium: »Die Phantasie und der Wille, die Kraft und die Männlichkeit, die all diese Dinge geschaffen haben, sind noch heute in voller Tätigkeit und arbeiten weiter an der Erschließung unbegrenzter Möglichkeiten« (ebd.: 1131). D.h. in Eyths Konzeption technischer Produktivität als künstlerischkämpferisches Schöpfertum wird Geschlecht zur expliziten Markierung technischer Produktivität und zur Wissenskategorie. Das kolonial-imperialistische Motiv der »Erschließung unbegrenzter Möglichkeiten« schwingt hier im Hintergrund mit. Durch den Anschluss an traditionelle Konzeptionen künstlerischer Tätigkeit und an den Geniediskurs des deutschen Idealismus wird diese Alternativkonzeption zur wissenschaftlich-technischen Rationalität nicht aus dem Feld der Technik ausgeschlossen, sondern geradezu euphorisch gefeiert. So gelingt es meines Erachtens auch, traditionell weiblich codierte Attribute wie das Gefühl, die Intuition oder auch das passive Empfangen, »das von keinem Willen abhängig zu sein scheint« (ebd.: 1132), für die Beschreibung technischer Produktivität zu mobilisieren, ohne die Männlichkeit des Ingenieurs >aufs Spiek zu setzen. Der Verweis auf den Künstler als Ausnahmesubjekt der Moderne erlaubt es ebenfalls, eine hegemoniale Position zu beanspruchen. Wie das Kunstwerk erscheint auch die Maschine als Resultat eines inneren kraftvollen nicht-rationalen Vermögens. Technisches Konstruieren umgibt in dieser Konzeption ein Mysterium. Männlichkeit wird zur kreativen Ressource.

Im Bereich der kulturellen Moderne existiert um 1900, wie Urte Helduser (2005) durch die Analyse der literarischen Programmatik gezeigt hat, ein stark sexualisierter und vergeschlechtlichter Diskurs um ästhetische Produktivität. Technische Produktivität ist daher innerhalb eines breiteren Diskursfeldes über Produktivität seit dem 18. Jahrhundert zu situieren. Im Anschluss an Jochen Schmidts »Geschichte des Genie-Gedankens« (1985) könnte man technische Produktivität auch als einen thematischen Strang verstehen, innerhalb einer breiteren Problematisierung von ökonomischer und künstlerischer Produktivität, die verbunden ist mit dem Wandel zur bürgerlichen Gesellschaft. Das Geniekonzept spiegelt, so Schmidt, nicht nur das neue, auf Produktivkraft begründete Selbstbewusstsein des Bürgers allgemein, sondern auch die Konzeption des Künstlers als autonomer Schöpfer seiner Werke (vgl. Schmidt 1985: XVI).

\section{Konstruktionsmodi technischer Männlichkeiten}

Wie diese Analyse zeigt, lassen sich in der Wissensproduktion der Ingenieure um 1900 zumindest zwei unterschiedliche Modi finden, technische Produktivität zu vergeschlechtlichen, d.h. in beiden Fällen zu maskulini- 
sieren. Beide sind auf signifikante Weise mit anderen gesellschaftlichen Differenzkategorien im Wechselspiel von expliziten und impliziten Codierungen verwoben. Einmal erscheint der Ingenieur als der rationale Maschinenwissenschaftler, das andere Mal als der geniale Maschinenkünstler. Einmal wird implizit eine Welt der Männer unterstellt, die explizit entlang von Nationen- und Klassenzugehörigkeiten differenziert wird. Das andere Mal wird explizit Männlichkeit als produktive Kraft betrachtet, während koloniale Herrschaftsverhältnisse auf der Ebene der Motivik nur implizit mitschwingen. Beide Konzeptionen beanspruchen auf je spezifische Weise Hegemonialität.

Diese beiden Konstruktionsmodi technischer Männlichkeiten sind letztlich vor dem Hintergrund der dualistischen Geschlechterordnung des 19. Jahrhunderts zu deuten, und zwar einerseits - bei Reuleaux - als selbstverständliche Bezugnahme auf diese Geschlechterordnung: Technische Rationalität erfährt dann als Sache der Männer in einem kompetitiven kolonialen Rahmen wie auch im Gefüge umkämpfter sozialer Hierarchisierungen ihre Ausformulierung. Andererseits kommt es - bei von Eyth - zu einer programmatischen Maskulinisierung der im wissenschaftlichen Modell verworfenen (und traditionell weiblich codierten) Handlungsrationalität: Produktive Kraft avanciert dabei zu einem besonderen männlichen Vermögen.

Vor dem Hintergrund dieser Ergebnisse sind vereinheitlichende Konzeptionen von Männlichkeit im Feld des Technischen kritisch zu hinterfragen. Epistemische Ordnungen im Ingenieurbereich sind, so meine Schlussfolgerung, vielmehr auf zum Teil disparate und um Hegemonie kämpfende Deutungen hin zu untersuchen, sowie auf die Verwobenheit mit weiteren sozialen Differenzierungen. Dabei kommt dem Wissensfeld über Produktivität, technisches Schaffen und kreative Kraft sicherlich ein besonderer Stellenwert zu.

\section{Literatur}

Braun, Hans-Joachim (1977): »Methodenprobleme der Ingenieurwissenschaft, 1850-1900«. In: Technikgeschichte 44, S. 1-18.

Braun, Hans-Joachim (1996): »Technik als >Kulturhebel und >Kulturfaktorく. Zum Verhältnis von Technik und Kultur bei Franz Reuleaux«. In: Burkhard Dietz/Michael Fessner/Helmut Maier (Hg.), Technische Intelligenz und »Kulturfaktor Technik«, Münster/New York: Waxmann, S. 36-43.

Connell, Robert W. (1999): Der gemachte Mann. Konstruktion und Krise von Männlichkeiten, Opladen: Leske+Budrich.

Dietz, Burkhard/Fessner, Michael/Maier, Helmut (Hg.) (1996): Technische Intelligenz und »Kulturfaktor Technik«. Kulturvorstellungen von Techni- 
kern und Ingenieuren zwischen Kaiserreich und früher Bundesrepublik Deutschland, Münster/New York: Waxmann.

Eyth, Max von (1904): »Poesie und Technik«. In: Zeitschrift des Vereins deutscher Ingenieure 48, Nr. 31, S. 1129-1134.

Faulkner, Wendy (2000): »The Power and the Pleasure? A Research Agenda for >Making Gender Stick to Engineers«. In: Science, TechnologY Q Human Values 25, S. 87-119.

Faulkner, Wendy (2006): »Läuft alles, Frau Ingenieur? Tanja Paulitz im Gespräch mit der britischen Techniksoziologin Wendy Faulkner über Geschlechterrollen in einer Männerdomäne«. In: Freitag 35, S. 17.

Gilbert, Anne-Francoise (2006): »Technische Fachkulturen und Geschlecht: Eine ethnographische Untersuchung in zwei Ingenieurdisziplinen«. In: Lehre und Forschung in Gender Studies an der Universität Bern 8, S. 20.

Haffner, Yvonne/Könekamp, Bärbel/Krais, Beate (2006): Arbeitswelt in Bewegung. Chancengleichheit in technischen und naturwissenschaftlichen Berufen als Impuls für Unternehmen, hg. v. Bundesministerium für Bildung und Forschung, Berlin.

Haraway, Donna (1989): Primate Visions: Gender, Race, and Nature in the World of Modern Science, New York: Routledge.

Harding, Sandra (Hg.) (1993): The »Racial« Economy of Science, Bloomington: Indiana University Press.

Hausen, Karin (1995): »Ingenieure, technischer Fortschritt und Geschlechterbeziehungen. Historische Reflexionen«. In: Metis 1, S. 5-17.

Helduser, Urte (2005): Geschlechterprogramme. Konzepte der literarischen Moderne um 1900, Köln/Weimar/Wien: Böhlau.

Helduser, Urte/Marx, Daniela/Paulitz, Tanja/Pühl, Katharina (Hg.) (2004): under construction? Konstruktivistische Perspektiven in feministischer Theorie und Forschungspraxis, Frankfurt a.M./New York: Campus.

Heymann, Matthias (2005): »Kunst« und Wissenschaft in der Technik des 20. Jahrhunderts. Zur Geschichte der Konstruktionswissenschaft, Zürich: Chronos.

Keller, Evelyn F. (1995): »The Origin, History, and Politics of the Subject Called 〉Gender and Science . A First Person Account«. In: Sheela Jasanoff et al. (Hg.), Handbook of Science and Technology Studies, London: Sage, S. 80-94.

König, Wolfgang (1999): Künstler und Strichezieher. Konstruktions- und Technikkulturen im deutschen, britischen, amerikanischen und französischen Maschinenbau zwischen 1850 und 1930, Frankfurt a.M.: Suhrkamp.

Lohan, Maria/Faulkner, Wendy (2004): »Masculinities and Technologies. Some Introductory Remarks«. In: Men and Masculinities 6, Nr. 4, S. 319329.

Oldenziel, Ruth (1999): Making Technology Masculine. Men, Women and Modern Machines in America 1870-1945, Amsterdam: Amsterdam University Press. 
Paulitz, Tanja (2004): »Engendering in Engineering. Zur Historisierung von Konstruktion als technische und vergeschlechtlichte Metapher«. In: Urte Helduser/Daniela Marx/Tanja Paulitz/Katharina Pühl (Hg.), under construction? Frankfurt a.M./New York: Campus, S. 103-113.

Paulitz, Tanja (2007): »Konstruktionen von Geschlecht im Wissen der Ingenieure? Ansätze zu einer Geschlechterforschung im Gegenstandsfeld Ingenieurwissenschaften und -praxis«. In: Marjaliisa Hentilä (Hg.), Women in the Academy, Helsinki. (im Druck)

Reuleaux, Franz (1875): Theoretische Kinematik. Grundzüge einer Theorie des Maschinenwesens, Braunschweig: Vieweg.

Reuleaux, Franz (1885a): »Cultur und Technik«. In: Zeitschrift des Vereins deutscher Ingenieure XXIX, Nr. 2, S. 24-28 und Nr. 3, S. 41-46.

Reuleaux, Franz (1885b): »The Influence of the Technical Sciences upon General Culture«. Translated from the German by W. Kunhardt. In: School of Mines Quarterly VII, Nr. 1, S. 67-94.

Rohkrämer, Thomas (1999): Eine andere Moderne? Zivilisationskritik, Natur und Technik in Deutschland 1880-1933, Paderborn/München/Wien/Zürich: Schöningh.

Rudolph, Hedwig (1994): »Ingenieurinnen: Vorberufliche Sozialisation und berufliche Erfahrungen«. In: Peter Lundgreen/André Grelon (Hg.), Ingenieure in Deutschland, 1770-1990, Frankfurt a.M./New York: Campus, S. 93-105.

Schiebinger, Londa (2004): Plants and Empire: Colonial Bioprospecting in the Atlantic World, Cambridge (MA): Harvard University Press.

Schmidt, Jochen (1985): Die Geschichte des Genie-Gedankens in der deutschen Literatur, Philosophie und Politik 1750-1945, 2 Bde., Darmstadt: Wissenschaftliche Buchgesellschaft.

Segal, Howard (1985): Technological Utopianism in American Culture, Chicago/London: University of Chicago Press.

Van Laak, Dirk (2005): Über alles in der Welt. Deutscher Imperialismus im 19. und 20. Jahrhundert, München: Beck.

Wajcman, Judy (1991): Technik und Geschlecht. Die feministische Technikdebatte, Frankfurt a.M.: Campus, 1994.

Wajcman, Judy (2002): »Gender in der Technologieforschung«. In: Ursula Pasero/Anja Gottburgsen (Hg.), Wie natürlich ist Geschlecht?, Opladen: Westdeutscher Verlag, S. 270-289.

Weihe, Carl (1925): Franz Reuleaux und seine Kinematik, Berlin: Verlag Julius Springer.

Zachmann, Karin (2004): Mobilisierung der Frauen. Technik, Geschlecht und Kalter Krieg in der DDR, Frankfurt a.M./New York: Campus. 


\section{Eisige Helden.}

\section{Kältekult und Männlichkeit in den \\ Polarphantasien von Georg Heym}

INGE STEPHAN

\section{Kalt und heiß/Schwarz und Weiß}

Im Jahre 1897 veröffentlichte Jules Verne den phantastischen Roman »Le Sphinx des glaces«, einen Roman, dessen Abenteuer nicht in der Zukunft angesiedelt sind, sondern als Vergangenheit erzählt werden (Verne 1985). Der Roman berichtet von einer merkwürdigen Schiffsreise im Jahre 1838 , die den Kapitän Guy mit einer Mannschaft von verwegenen Männern zum Südpol führt. Guy ist auf der Suche nach Arthur Gordon Pym, dessen »denkwürdige Erlebnisse« (ebd.: 120) Edgar Allan Poe im Jahre 1837/38 als »The Narrative of Arthur Gordon Pym « herausgegeben hatte. Der Kapitän ist von der Idee besessen, dass Poe »keinen Roman geschrieben« habe, sondern dass es sich um ein »historisches Werk« (ebd.: 102) handele. Es gelingt ihm sogar, den zunächst skeptischen Erzähler, der mehr oder minder zufällig zu der Mannschaft gestoßen ist, davon zu überzeugen, dass Pym vielleicht noch leben könne. Auf der Suche findet die Mannschaft nicht nur Spuren des Verschollenen, sondern sie stellt auch fest, dass bereits zahlreiche Expeditionen vor ihnen versucht haben, zum Südpol zu gelangen. Keine aber dringt so weit vor wie Guy mit seinen Männern. Stürme, Nebel, Packeis und Eisberge fordern jedoch auch unter seiner Expedition zahlreiche Opfer. Am Ende ist das Schiff zerstört und ein Großteil der Mannschaft ums Leben gekommen. Die kleine Schar der Überlebenden setzt ihre Reise auf einer riesigen Eisscholle fort und verliert sich schließlich in einer bizarren Eiswüste, in der sie Pym und seine Mannschaft vermuten. In der endlosen Weite des Nebel- und Eismeeres verschmelzen der Erzähler und die gesuchte Romanfigur in einer Halluzination, in der der Erzähler das zu sehen glaubt, was auch Pym seiner Meinung nach gesehen hat: $»[. .$. 
den weißen Riesen, den Riesen des Pols! « (Ebd.: 385; vgl. Brunotte $1993 \mathrm{zu}$ Poe im Allgemeinen) Die Gestalt, auf die die Mannschaft Guys schließlich stößt, ist jedoch nicht dieser halluzinierte weiße Riese und auch nicht die große weibliche Figur, die Pym zu sehen geglaubt hatte. Es handelt sich vielmehr um eine gewaltige Sphinx, ${ }^{1}$ die am Polarkreis auf die Männer zu warten scheint. Zwischen den Tatzen des Ungeheuers entdecken die Männer schließlich die Leiche eines Mannes, den die Kälte konserviert hat. Es ist - wie könnte es anders sein - Arthur Gordon Pym, der Langgesuchte, der in den Armen der Sphinx - einem »riesigen Magnet (Verne 1985: 458) - den Tod gefunden hat. Wenn dem Kapitän und dem Erzähler in Bezug auf das Schicksal von Pym damit auch die »Lösung des Rätsels« (ebd.: 61) gelungen ist, bei der so viele Männer ihr Leben haben lassen müssen, so haben sie doch keineswegs alle »Geheimnisse« aufgeklärt, wie der Erzähler am Schluss des Romans versichert:

»Arthur Pym, der von Edgar Allan Poe so sehr gefeierte Held, hat den Weg gezeigt [...] Andere werden seinen Spuren folgen und der Eissphinx die letzten Geheimnisse der Antarktis entreißen.« (Ebd.: 472)

Mit seinem Roman »Die Eissphinx« (1897) greift Verne Bilder auf, die um 1900 in Kunst, Literatur und Wissenschaft gleichermaßen kursierten. Die Eroberung der Antarktis, von der der Roman phantasiert, hat ihre Entsprechung in der Eroberung des »dark continent«, von der Freud in jener Zeit träumte und bei der er auf eben jene mythische Sphinx stieß, auf die Verne seine Männer im ewigen Eis der Antarktis treffen lässt. Anders als Verne, der das Geheimnis der Sphinx entschlüsselt zu haben vorgibt, hat Freud dieses Geheimnis Zeit seines Lebens nicht lösen können (vgl. Stephan 1997a, 1997b).

Als »Rätsel der Weiblichkeit« verweist es auf das Verhältnis zwischen den Geschlechtern. Dieses Verhältnis aber ist von Machtbegehren und Eroberungslust geprägt. Das Weibliche wird nicht nur in ambivalenten Naturund Landschaftsbildern beschworen, sondern es wird auch zum diffusen Objekt männlicher Eroberungs- und Kolonisierungswünsche gemacht.

In Joseph Conrads Erzählung »Heart of Darkness« (1899) erinnert sich Kapitän Marlow, der mit seinem Flussdampfer immer tiefer in die Welt des Kongos, ins Herz des Schwarzen Kontinents, eindringt, an seine kindliche »Passion für Landkarten«, wobei sich »Schwarz« und »Weiß« in symptomatischer Weise metaphorisch verschränken:

»Zu jener Zeit gab es noch viele weiße Flecken auf der Erde, und wenn ich auf der Landkarte einen erblickte, der besonders einladend aussah (doch das tun sie

1| Vgl. dazu auch die Erzählung »Die Sphinx« von E.A. Poe, wo die Sphinx jedoch kein riesiges Untier, sondern ein kleiner Totenkopf-Falter ist. - Zum Verhältnis von Poe und Verne vgl. Sprout 1967. 
schließlich alle), pflegte ich mit dem Finger darauf zu weisen und zu sagen: Wenn ich einmal groß bin, gehe ich dorthin. Der Nordpol war ein solcher Fleck, wie ich mich erinnere. Nun, dort bin ich nicht gewesen und werde auch nicht mehr versuchen hinzukommen. Der Zauber ist verschwunden. Andere Flecken lagen um den Äquator herum und über alle Breiten beider Hemisphären zerstreut. In einigen von ihnen bin ich gewesen und [...] nun, reden wir nicht davon. Doch da war noch einer - der größte, der weißeste, sozusagen - nach dem ich mich besonders sehnte.

Freilich war er inzwischen längst kein weißer Fleck mehr. Er hatte sich seit meiner Jugend mit Flüssen und Seen und Namen gefüllt. Er hatte aufgehört, ein leerer Raum köstlicher Geheimnisse zu sein - ein weißer Fleck, über dem ein Junge sich in glorreiche Träume verlieren konnte. Er war zu einem Ort der Finsternis geworden. Doch gab es darin vor allem einen Fluß, einen gewaltig großen Fluß, den man auf der Landkarte sehen konnte und der einer riesigen sich aufringelnden Schlange glich, deren Kopf im Meer, deren Leib über eine weite Fläche hingelagert war und deren Schwanz sich in den Tiefen des Kontinents verlor. Und als ich mir die Landkarte im Schaufenster eines Ladens betrachtete, faszinierte mich der Fluß, wie eine Schlange einen Vogel fasziniert.« (Conrad 1977: 15)

Marlow, ein Nachfahre all jener historischen und legendären Eroberer, die Jules Verne in seinem Roman als phantastische Kette von Konquistadoren unterschiedlicher Nationen und Zeiten zusammenschließt, stößt in seinen Träumen auf ein Wesen, das noch gewaltiger als die Sphinx ist: auf eine riesige Seeschlange, eine Mischung aus alttestamentarischem Leviathan und mythischer Gorgo-Medusa. Leviathan, von dessen Unterwerfung unter die Allmacht Gottes die Bibel erzählt (Buch Hiob 40 und 41), verweist ebenso wie Gorgo-Medusa, die von dem Drachenkämpfer Perseus erschlagen wird, auf die Unterworfenen zurück, auf deren zerstückelten Leibern göttliche und menschliche Ordnungen errichtet werden. Auch die Sphinx gehört zu jenen urzeitlichen Fabelwesen, deren Tötung die Voraussetzung für die erfolgreiche Gründung städtischer Zivilisationen ist.

Beide Texte - sowohl der von Verne wie der von Conrad - erzählen Eroberungsgeschichten, in denen koloniale Landnahme und Geschlechtermythologien durch eine Fülle von Bildern und Symbolen miteinander verschränkt sind. Die Helden bilden und härten sich im Kampf mit einer Umgebung, die faszinierend und abschreckend zugleich ist. Das Objekt des männlichen Begehrens ist dabei jeweils an extreme Orte phantasiert. Die öde, majestätische Eislandschaft der Antarktis und die üppige, wilde Tropenlandschaft des Äquators bilden mit ihrer klirrenden Kälte und ihrer flirrenden Hitze einen Gegensatz, wie er größer kaum vorstellbar ist. Am Ziel ihrer Reisen stoßen die Helden jedoch beide Male auf mythische Wesen, die in ihrer tödlichen Potenz weitgehend identisch sind. Während Verne die mörderische Sphinx mit Blick auf ein breites Lesepublikum ausphantasiert, ihre Macht mit einer pseudo-naturwissenschaftlichen Argumentation ein Stück weit entzaubert und koloniale Eroberung und Ausbeutung als Fortschreiten des menschlichen Geistes rechtfertigt, verzichtet 
Conrad darauf, der Todesvision seines Helden eine festumrissene Gestalt zu geben. Die letzten Worte des Sterbenden, »Das Grauen! Das Grauen!« (Conrad 1977: 165), spielen auf jenes tödliche Entsetzen an, das der Anblick des abgeschlagenen Medusenhauptes erregt (vgl. Freud 1941: 47f.; Stephan 1997b: 6off.). Durch seine subtile Erzählweise, die Vieldeutigkeit schafft, restituiert Conrad das >Geheimnis<, ohne jedoch seine Kritik an der Eroberungs- und Ausbeutungspolitik, die seine Helden ins »Herz der Finsternis« treibt, zurückzuhalten. Conrads Helden sind gebrochene Männer, die ihre ursprünglichen Ziele vergessen und sich in einer feuchten Tropenlandschaft verlieren. Vernes Männer - im ewigen Eis gehärtet - steuern ungebrochen neuen Zielen zu. Sie sind Vorläufer jener stählernen Kommandeure, die am Ende des 20. und am Anfang des 21. Jahrhunderts mit ihren Raumschiffen in ferne Galaxien und virtuelle Welten aufbrechen und dort mit eben den mythischen Wesen konfrontiert werden, denen Vernes und Conrads Helden um 1900 begegnet sind.

\section{Der Pol als Fluchtpunkt heroischer Männlichkeit}

Wenn man sich auf der Folie der beiden »Schlüsseltexte« von Verne und Conrad die anderen Texte ansieht, die um 1900 phantasmatisch um die Eroberung des »dark continent« kreisen, fällt auf, dass dieser in der Realität zumeist »weiß« ist, da der Ort des Begehrens in der Arktis oder Antarktis angesiedelt ist. Die realen Polarexpeditionen von Franklin, Andrée, Nansen, Amundsen, Shackleton, Scott, Cook, Peary und anderen lösen um 1900 ein regelrechtes Polarfieber aus, das durch die hohe Medienpräsenz - alle Beteiligten verfassten Tagebücher bzw. Reiseberichte und griffen auf die Fotografie, den Film und den Telegrafen zurück, um ihre Reisen zu dokumentieren und zu propagandieren - weiter gesteigert wurde (vgl. die Überblicksdarstellung von Fleming 2004). Die Eroberung des Nord- und Südpols in den Jahren 1908/1909 und 1912 gehört zu den wichtigsten Medienereignissen des frühen 20 . Jahrhunderts, die nicht zuletzt dadurch eine besondere öffentliche Präsenz erhielt, weil einerseits der Film Motive der literarischen Polarphantasien aufgriff und andererseits die Polarfahrer sich des neuen Mediums bedienten, um ihre Reisen vor den Augen einer staunenden Öffentlichkeit in bewegten Bildern zu verifizieren. Einschlägig sind hier vor allem die Filme »Voyage to the Arctic, or how Captain Kettle discovered the North Pole« (England 1903) von Roger William Paul und »A la Conquête du Pole« (Frankreich 1912) von Georges Méliès sowie die Filme, die die Protagonisten selbst drehten und die noch heute als Materialbasis für heroische Polarfilme dienen.

Wenn man sich mit den »eisigen Helden« um 1900 beschäftigt, ist man also mit einer Fülle von Materialien konfrontiert - den Aufzeichnungen und Hinterlassenschaften der Beteiligten, den imaginären Reisen und Entwürfen von Literatur- und Filmemachern und den medialen Dis- 
kursen, die Realität und Phantastik miteinander zu einem Komplex verschweißen, in dem sich die »Produktion und Krise hegemonialer Männlichkeit in der Moderne« in spektakulärer Weise verdichten.

Der Typus des »eisigen Helden« ist ein Produkt der Kränkung und der Marginalisierungserfahrungen heroischer Männlichkeit zwischen Französischer Revolution und Erstem Weltkrieg, er begleitet die Feier von Nietzsches Übermenschen und den Kältekult der Neuen Sachlichkeit, bereitet die emotionale Vereisung in Faschismus und Stalinismus vor, nimmt den Typus des coolen Mannes um die Wende des 20. und 21. Jahrhunderts vorweg und ist Nährboden für die »Kälte-Kunst« der Gegenwart.

Merkwürdigerweise gibt es bisher sehr wenige Forschungen, geschweige denn Gesamtdarstellungen zu diesem Themenkomplex, die aus genderhistorischer wie -theoretischer Perspektive spannende Einsichten vermitteln können. ${ }^{2}$ Folgende Punkte interessieren mich in diesem Zusammenhang besonders:

1. Die eisigen Helden können als Paradebeispiel für den Zusammenhang von gender, race und class gelesen werden.

2. An ihnen lassen sich die Reichweite und Grenzen von Connells Konzept hegemonialer Männlichkeit diskutieren.

3. Sie stellen einen wichtigen Beitrag zur whiteness-Forschung im Schnittpunkt von Rassismus und Kolonialismus dar.

4. Sie ermöglichen eine Kritik am Männlichkeits- und Heldenideal als einer Mischung von Größenwahn, Menschenverachtung und Verbissenheit in abstruse Ziele.

5. Sie vermitteln einen Einblick in die Struktur und die Funktionsweisen von Männerbünden.

6. An ihnen lassen sich der Anteil und die Bedeutung der unterschiedlichen Medien für die Ausbildung »kalter Männlichkeit« in der Moderne reflektieren.

7. Vor allem der Typus der »großen Erzählung« als einer narrativen Konstruktion heroischer Männlichkeit - neben Autobiographien und Reiseberichte der Akteure treten imaginäre Polarphantasien in Literatur und Film - kann dabei zeigen, wie sich Formen kolonialer Selbstbehauptung und kultureller Selbstdeutung mit Projektionen von Alterität und Abwertung des Anderen und Fremden vermischen.

8. Gerade als Form der Grenzverschiebung und Grenzüberschreitung bieten sich die realen Polarreisen und die Polarphantasien geradezu an, um das Ordnungswissen einer Epoche (inklusive der Geschlechterord-

$2 \mid$ Ansätze dazu finden sich bei Frank 1979, der im Kapitel »Das Scheitern am >Heik: Die Reise ins ewige Eis« (ebd.: 88-102) neben Poes »The Narrative of Gordon Pym« eine Reihe von weiteren Polarphantasien behandelt. Vgl. auch Lethen 1994, Lethen 1987, Baßler/van der Knaap 2004. 
nung) auf die Probe zu stellen, es zu bestätigen, zu revidieren oder gar umzupolen.

Im Folgenden wird versucht, durch die Konzentration auf einen Autor und zwei sehr kurze Texte, an einem konkreten Beispiel, einen Einblick in die Vielschichtigkeit des Diskurses über die »eisigen Helden« um 1900 zu geben.

\section{"Endlos weißes Weiß am fernen Saum «3}

Bei dem Autor handelt es sich um Georg Heym, einen jungen Dichter, der vor allem als Lyriker bekannt geworden ist und von seinem damaligen Verleger als »deutscher Baudelaire« angepriesen wurde (Dietz 1994: $361 \mathrm{f}$.). Heym selbst stellte sich in eine andere Traditionslinie, wenn er 1909 in seinem Tagebuch notierte: »Ich liebe alle, die in sich ein zerrissenes Herz haben, ich liebe Kleist, Grabbe, Hölderlin, Büchner, [...]. Ich liebe alle, die oft so an sich verzweifeln, wie ich fast täglich an mir verzweifle« (Heym 1960: 128, Eintrag vom 20. Juli 1909). Er rebellierte gegen väterliche Instanzen in der Literatur und im Leben. Das »Schwein Göthe« (ebd.: 170, Eintrag vom 16 . Oktober 1911) verschmolz in seiner Wahrnehmung mit dem eigenen Vater, einem konservativen Staatsanwalt, der keinerlei Interesse für die literarischen Ambitionen des Sohnes aufbrachte und den dieser für das eigene Scheitern verantwortlich machte: »Ich wäre einer der größten Dichter geworden, wenn ich nicht einen solchen schweinernen Vater gehabt hätte« (ebd.: 171, Eintrag vom 3. November 1911), vertraute er dem Tagebuch an. ${ }^{4}$ Wie weit er mit einer solchen Einschätzung recht gehabt hat, mag dahingestellt sein - mit knapp 24 Jahren ertrank Heym im Jahre 1912 beim Schlittschuhlaufen auf der Havel bei dem Versuch, den befreundeten Lyriker Ernst Balcke, der im Eis eingebrochen war, zu retten.

3। Heym 1964: 190; vgl. auch die Tagebuchaufzeichnungen vom August 1907, wo Heym vergangene Epochen mit seiner Zeit vergleicht: »Im Jahre 1907 bezwang der Mensch die Erde unter seinen Fuß, indem er ihn dem Nordpol aufsetzte. Und: Im selben Jahr bezwang der Mensch das Luftreich, indem er die Gewalt des Sturms zerbrach. Diese Taten in dem Buch der Menschheit verzeichnet würden wohl das Jahrhundert über viele seiner Schwestern erhöhen. Nur daß die Möglichkeit, seine Träume in die Tat umzusetzen, heut viel schwerer ist, als dies' den Männern jener Tage war« (Heym 1960: 93f.). Vgl. auch das Notat vom 17. April 1908: »Hundert Jahre später möchte ich geboren sein. Dann werden wir den Weltenraum innehaben und mehr denn die Götter sein« (Heym 1960: 106).

4 | Am 2. April 1905 machte Heym dem Vater den kindlichen Vorwurf: »Es ist meinem Vater ganz recht, daß ich mir meine Hände erfriere, warum kauft er mir keine Handschuhe« (Heym 1960: 15). Am 10. Juni 1908 notiert er jedoch: »Mein Vater ist sehr gut« (ebd.: 110). 
Wie auch andere Autoren seiner Zeit war Heym vom Exzentrischen fasziniert. Die Polarexpeditionen verfolgte er mit großer Aufmerksamkeit. Er las Shackletons Reisetagebuch »21 Meilen vom Südpol. Die Geschichte der britischen Südpol-Expedition 1907/09 «(1909 erschienen), sehnte sich selbst aber eher nach dem heißen Süden, wie sein Gedicht »Wär ich ... berühmt « (1910) zeigt, wo er davon träumt, nach Indien oder Afrika zu fahren, »wo Gold liegt und noch unbekannte Länder sind « (Heym 1964: 53)..$^{5}$ Sein Novellenfragment »Die Bleistadt« kreist um das letzte, unerreichbare Geheimnis des Schwarzen Kontinents, während zwei andere, ebenfalls Fragment gebliebene Texte, »Die Südpolfahrer« und »Das Tagebuch Shakletons «, in der Antarktis angesiedelt sind. ${ }^{6}$ Diese beiden Texte sind im Kontext der Faszinationsgeschichte, welche die Eroberung der Pole auslöste, deshalb besonders einschlägig, weil sie ein sehr kritisches Bild der »eisigen Helden« vermitteln, zugleich jedoch vom »Polarfieber« jener Zeit stärker affiziert sind, als die erste Lektüre vermuten lässt. Der kürzere, nur knapp vier Seiten umfassende Text »Die Südpolfahrer« ist eine kurze Momentaufnahme einer Expedition, die aus nur drei Männern besteht: Godefroy, Evans und einem namenlos bleibenden Japaner, die auf dem Weg zum Südpol sind. Der Name Godefroy könnte eine Erinnerung an William Godfrey sein. Dieser war Mitglied der berühmt berüchtigten Kane-Expedition (1853/55) und hat eigene Aufzeichnungen darüber hinterlassen. Freilich war das Ziel dieser Expedition nicht der Südpol, sondern der Nordpol. Bereits diese Verschiebung wie auch die Namensveränderung zeigen, dass es Heym nicht um eine historische Figur noch um eine historische Expedition geht, sondern dass es ihm darauf ankommt, sich mit einem Männertypus auseinanderzusetzen, für den die Polargebiete eine ultimative Herausforderung bedeuten und der bereit ist, für die Eroberung >jungfräulichen Gebietes ‘ mit dem Leben zu bezahlen. Sehr eindrücklich beschreibt Heym das Gefühl von Erhabenheit, das die drei Männer erfasst, als sie sich einer Landschaft gegenüber sehen, die vor ihnen noch niemand betreten hat:

»Nachmittags um drei Uhr standen sie endlich oben auf dem Eisberg und sahen rings um sich den riesigen Horizont. Unendliche meilenweite weiße Ebenen, voll

5I In der dort abgedruckten Fassung des Gedichts ist die Sehnsucht nach Hitze nur in Metaphern wie »bluten« oder »fackeln« aufbewahrt, die konkrete Ausphantasierung findet sich in den Vorstufen des Gedichts (vgl. Heym 1999: 251).

6| Heym 1962, darin »Die Südpolfahrer« (120-123) und »Das Tagebuch Shakletons« (124-143). Die Zitate werden im Folgenden unter Angabe der Seitenzahlen im Text nachgewiesen. - Zu den Polartexten von Heym vgl. die noch immer sehr lesenswerte Arbeit von Metzner 1976, in der dieser »die literarische Darstellung der Suche nach den Erdpolen als Ausdruck apokalyptischen Denkens und als Paradigma verfehlter Existenz« (ebd.: V) deutet. Vgl. auch Braungart/Braungart (1984) und Marx (2001). 
von blauen Lichtern, ein unendliches Glanzmeer der Sonne, die hoch in dem stählernen Blau des antarktischen Äther stand.

Die drei Wanderer nahmen den großen Sextanten von dem Schlitten. Godefroy setzte sich auf die Kufen und berechnete Länge und Breite. Die anderen beiden sahen voraus, in die unendliche Stille, in die maßlose klare Einsamkeit der ebenen Eisfelder. Und den beiden kam wieder der einzige Gedanke, den sie in jeder Stunde hundertmal dachten: Hier hat noch niemand gestanden, diese Stille hat noch niemand zerrissen.« (Heym 1962: 120)

Der Stolz, Pionier zu sein, wird im Text überlagert von Erinnerungen an die Vergangenheit und die Heimat. Evans denkt zurück an ein Mädchen, das er zu Hause gelassen hat, und der Japaner sehnt sich ebenfalls zurück nach einem Mädchen und dem offenen Meer, die zu einem gemeinsamen Bild verschmelzen. Beide Männer sind erschöpft, demoralisiert von den Strapazen und spielen mit dem Gedanken, die »Gefährten zu ermorden«. »Warum erstach er nicht diese weißen Schweine?« (122), lässt der Erzähler den Japaner überlegen. Godefroy jedoch, der sich keinerlei sentimentalen Phantasien überlässt und sich ganz auf das Geschäft des Vermessens konzentriert, erweist sich als ein Führer, der die beiden in Gedanken abtrünnigen Gefährten wieder auf eisigen Kurs zurück bringt und den männlichen Dreierbund neu befestigt:

»Godefroy rief sie zu sich. >Wir sind jetzt auf $88^{\circ} 44^{\prime} 12$ Bogensekunden $<$, sagte er, und ließ sie in seine Karte schauen. >Hier stehen wir<, und er machte einen schwarzen Punkt auf die Karte. >Nach dem Durchschnitt unserer Tagesmärsche brauchen wir noch ungefähr vier Wochen, um an den Pol zu kommen<, seine Stimme wurde leiser, >und ihr wißt, daß der Proviant dafür nicht reicht, kaum selbst wenn wir unsere Ration noch weiter verkürzen. Wollen wir umkehren?«« (122f.)

Obgleich Evans und der Japaner nichts lieber möchten als das, beugen sie sich stumm der Autorität Godefroys und setzen den Weg verbissen weiter fort.

»Und sie sprachen nichts mehr, sie zogen stumpf an dem Schlitten, und sie setzten einen Fuß vor den anderen, immer weiter fort, immer tiefer, über schwankende Eisspalten fort. [...] Aber ferne von ihnen, am weißlichen Himmel tanzte ein kleiner schwarzer Punkt nicht größer wie ein Nadelkopf, das war der Pol. Das war das Geheimnis.« (123)

Um das »Geheimnis « geht es auch in der zweiten, ungefähr 20 Seiten umfassenden Erzählung »Das Tagebuch Shakletons«, die z.T. wörtliche Übereinstimmungen mit der ersten aufweist, von der Narration her aber sehr viel komplexer angelegt ist als der erste Text. Im Zentrum steht das (fiktive) Tagebuch Shackletons, der zu den Heroen der Antarktis-Abenteurer gehört 
und bis heute die Phantasien bewegt.' Heym schreibt den Namen nur mit »k«, obwohl ihm die korrekte Schreibweise mit »ck« vertraut gewesen sein dürfte. Diese Verschiebung kann als Hinweis auf Heyms Bestrebungen zur Fiktionalisierung des >realen Shackletons und seiner >historischen Reise verstanden werden. ${ }^{8}$

Vorangestellt ist dem »Tagebuch« eine längere Vorrede des Herausgebers zu der 125. Auflage, die 1925 in London erschienen ist, wobei die Vorrede absurderweise erst 1926 geschrieben sein soll. Diese Vorrede ist in mehrfacher Hinsicht bizarr: Sie ist in der Zukunft angesiedelt - sowohl Shackleton wie Heym sind zu diesem Zeitpunkt bereits tot - und sie entwirft eine neue Genealogie der Antarktis-Eroberung. Nicht Shackleton ist der Eroberer des Südpols, sondern ein obskurer H.H. Hannawacker, der den Ruhm davongetragen hat. Er hat das Tagebuch in den »knöchernen Händen des erfrorenen« (130) Shackleton gefunden, er ist der wahre Entdecker des Südpols und er hat seine Eroberung erfolgreich vermarkten können, wie die Verweise auf zwei weitere von ihm verfasste Bücher zeigen: »Die Entdeckung des Südpols« ist 1925 in 25. Auflage erschienen, »Das Reich des Südpolarmenschen« 1925 sogar in der 204. Auflage. In einer Anmerkung wird die Auflagenhöhe noch weiter gesteigert, wenn von einer 326. Auflage die Rede ist, die das Buch »Die Entdeckung des Südpols und die Auffindung der Leichen Shakletons und seiner Freunde« erreicht hat, das wohl nicht identisch sein kann mit der »Entdeckung des Südpols«, die 1925 in der 25. Auflage erschienen ist. »Das Tagebuch Shakletons« ist also das dritte oder vierte Erfolgsbuch in einer Reihe von anderen, mit denen Hannawacker - der im Text stets mit H.H.H. abgekürzt ist - seine Expedition vermarktet hat.

Die Vorrede weist jedoch neben den zeitlichen und genealogischen Verschiebungen und den absurden Auflagenhöhen noch eine weitere Merkwürdigkeit auf: Hannawacker zitiert ausführlich aus einem Aufsatz eines indischen Gelehrten, der am 31. Dezember 1910 in der »Review of Psychological Sciences « die phantastische These vertreten hatte, dass es sich bei Shackleton und seinen drei Gefährten in Wahrheit nicht um Menschen, sondern um »Scheinwesen« gehandelt habe:

»Man untersuche sie nur einmal genauer, man meißle ihnen ihre Schädel auf! Ich wette und ich verbürge dafür meinen Kopf, man wird anfänglich alles so finden wie es im Schädel normaler Menschen auszusehen pflegt, die graue Hirnrinde,

7| Vgl. »Shackleton. Die Reisen. Eine Dokumentation in Bildern«. Mit einem Vorwort von Arved Fuchs und einer Einführung von Roland Huntford. Bielefeld 2003 und den Dokumentarfilm »Verschollen im Packeis. Das Antarktis-Abenteuer des Sir Ernest Shackleton« von George Butler (USA 2000).

8| Der Beitrag trägt dieser Differenzierung des Autors Rechnung, indem er die Schreibweise von Heym übernimmt, wenn die Erzählung zitiert wird, sonst aber von Shackleton spricht. 
mit ihren blutdurchzogenen Windungen, darunter die verschiedenen Lappen des Großhirns usw. [...] Untersucht man aber das Große näher [...], so wird man finden, daß da wo sonst auf dem vorderen Hügelpaar die glandula pinealis ruht, nichts, aber auch gar nichts zu finden ist [...].« (124f.)

Für den indischen Gelehrten ist die Sache klar: Shackleton und seine Gefährten sind im Verlauf ihrer Expedition zu »Golems« (125) geworden:

»Dieser Ernest H. Shakleton, den der König zum Pair des Reiches gemacht hat, der da jetzt draußen auf seinem Landsitz sich von den Strapazen der Amerika-Tournee erholt, der dort jede Nacht in den Armen seiner Frau liegt, der sonntags morgens sich loyal die Predigten seines fettigen reverends anhört, der seinen Plumpudding ißt, seine Steuern zahlt, seine Vorträge hält, und ebenso dieser J.B. Adams, Eric Marschall und Frank Wild, sie können mir nur ein schmerzliches Lächeln abpressen. Denn diese da wissen nicht was sie tun. Was sind sie? Automatische Intelligenzen möchte ich sie nennen, oder denkende Uhrwerke, die von jenen unglaublichen Gehirnen am Südpol mit alle dem ausgerüstet wurden, was das Gedächtnis, die Denkweise etc. des wahren Shakleton, Adams, Marschall, Wild ist.« (126)

Auch wenn sich Heym mit dieser Verschwörungsthese und dem Motiv der Golemisierung im Bereich der populären Phantastik seiner Zeit bewegt, so ist doch zugleich deutlich, dass er auf eine Kritik der eisigen Helden zielt. Diese sind für ihn keine Vorbilder und bewunderte Helden, ja nicht einmal Menschen, sondern nur »künstliche Hüllen« eines hybriden Eroberertums, das menschliche Möglichkeiten weit übersteigt. Dabei übernimmt Heym als Autor die Motive der Verschwörung und Golemisierung nur auf der Oberfläche, durch die komplexe narrative Verschränkung verschiedener Diskursebenen - Herausgeberkommentar, Zitation von Forschungsliteratur, abstruse mathematische Formel, Anmerkungen des Herausgebers - stellt er die Vorrede vielmehr ironisch als einen pseudowissenschaftlichen Diskurs aus, der jedoch höchst erfolgreich ist, wie die absurd hohen Auflageziffern signalisieren sollen. Zugleich enthält die Vorrede jenseits der ironischen Brechungen aber einen ernsthaften Kern, wenn der indische Psychologe darauf hinweist, dass das »abendländische Wissen« (126) unfähig sei, zwischen Wirklichkeit und Schein zu unterscheiden. Schon einmal sei es gelungen, die westliche Öffentlichkeit zu täuschen. Der englische Vizekönig in Indien, Lord Curzon, sei von einem Yogi golemisiert und als Rache und Strafe für »die Untaten, die die englische Rasse in Indien vollführt hat « (128), auf schreckliche Weise zu Tode gefoltert worden, während den Engländern ein Golem untergeschoben wurde. Auch in diesem Beispiel erscheint die Golemisierung als unbemerkter Verlust der Seele und als Bestrafung und Konsequenz eines spezifisch abendländischimperialistischen Denkens und Handelns, das sich in diesem Falle jedoch auf eine andere Region bezieht.

Auch das Tagebuch Shackletons bietet nur auf den ersten Blick eine 
heldenhafte Narration. Auch hier mystifiziert der Autor. In Wirklichkeit handelt es sich eigentlich nicht um ein Tagebuch, in dem sukzessive Ereignisse festgehalten werden, sondern um eine Schilderung der Ereignisse im Rückblick: Shackleton sitzt gefangen in einer Eishöhle am Pol und notiert, was mit ihm und seinen Gefährten bisher geschehen ist. Wie in der kurzen Erzählung »Die Südpolfahrer«, die sich wie eine Vorstudie zu dem Tagebuch liest, vermitteln auch die Aufzeichnungen Shackletons ein wenig schmeichelhaftes Bild der Südpolfahrer. Shackleton, aus dessen Perspektive erzählt wird, ist ein gebrochener Mann, der sich und seine Gefährten als »vier Ausgeworfene der Zivilisation« (130) wahrnimmt, die wie ein »Zug sibirischer Sträflinge« (135) durch »die Trostlosigkeit« (133) der antarktischen Eiswüste irren. Auch er hat Mordgelüste und würde die Gefährten am liebsten erschlagen, um der Tortur ein Ende zu machen. Stattdessen setzen die vier Männer ihren Weg fort und erleben eine phantastische Veränderung der Landschaft, die keine »antarktische Luftspiegelung« (ebd.), mit denen sie in der Vergangenheit zu kämpfen hatten, sondern vielmehr phantastische Realität zu sein scheint. Die Temperatur steigt und steigt, und plötzlich befinden sich die vier Männer in einer fruchtbaren Landschaft, die in ein »seltsames Weiß« (139) getaucht ist. In dieser Phantasie des Südpols vermischen sich zwei gegenläufige Vorstellungen: Die Wärme des Südens verbindet sich mit dem »Weiß« der Polarregion zu einem hybriden Bild von Kälte und Hitze, das durch den Erzähler eine weitere phantastische Steigerung erfährt. Am Südpol treffen Shackleton und seine Gefährten auf »Polarmenschen« (142) und geheimnisvolle Schriftzeichen, die sie nicht entziffern können. Sie kommen sich wie frühneuzeitliche Entdecker und Eroberer vor - wie Cortez, der die »Städte Montezumas schaute « (139) oder Pizarro, »der die goldenen Dächer der Inkas zu seinen Füßen sah« (ebd.). Der Erzähler lässt offen, ob Shackletons Vision das Produkt wahnhafter Verblendung ist oder ob die Männer tatsächlich auf eine unbekannte, prä-adamitische Zivilisation am Südpol - auf die »Ultima Thule der Neugier«, wie sie Karl Kraus 1909 in der »Fackel« genannt hat ${ }^{9}$ - gesto-

9| In seinem Beitrag »Die Entdeckung des Nordpols« schreibt Kraus: »Seit Jahrhunderten hatte der Menschheit, die immer vorwärts schritt, ein letztes Etwas zu ihrem Glück gefehlt. Was war es nur? Wovon fieberten Tage und Träume? Was hielt eine Welt in Atem, deren Puls nach Rekorden gezählt wird? Was war das Paradigma aller Begehrlichkeit? Der Trumpf der Streberei? Die Ultima Thule der Neugier? Der Ersatz für das verlorene Paradies? Die große Wurst, nach der auf dem irdischen Jahrmarkt die Wissenschaft alle Schlittenhunde hetzte? Ach es litt die Menschheit nicht beim Tagwerk: Der Gedanke daß das oben ein paar Quadtratmeilen waren, die ein menschlicher Fuß noch nicht betreten hatte, schien unerträglich. [...] An dem Nordpol war nichts weiter wertvoll als daß er nicht erreicht wurde. Einmal erreicht, ist er eine Stange, an der eine Fahne flattert, also etwas, das ärmer ist als das Nichts, eine Krücke der Erfüllung und eine Schranke der Vorstellung. Die Bescheidenheit des menschlichen Geistes ist unersetzlich« (Kraus 1977: 26of.). 
ßen sind. Shackletons »Tagebuch«, das sich am Ende immer mehr verwirrt und in zwei Angstträumen endet, suggeriert, dass es sich um tatsächliche Erlebnisse handelt.

Der erste Traum handelt von einer grässlichen Operation - von Priestern der Polarmenschen in einen magnetischen Halbschlaf versenkt, wird Shackleton unter rituellen Handlungen das Gehirn entfernt. Der Herausgeber versieht diesen Traum mit der erklärenden Anmerkung, dass es sich offenbar um den »Prozeß der Golemisierung, dessen Erinnerung bei Ernest H. Shakleton durch hypnotische Mittel in ein Traumbild verwandelt wurde«, gehandelt habe (143). Dieser rationalistische Kommentar, in dem Traum, Hypnose und Golemisierung in ein scheinlogisches Verhältnis gesetzt werden, wirft ein ironisches Schlaglicht auf die Irrationalität nicht nur der Erklärungsmuster, in die sich der Herausgeber und sein indischer Gewährsmann verwickeln, sondern er kann auch als Kommentar des Autors Heym zu den irrationalen Triebkräften gelesen werden, die Männer wie Shackleton ins Eis treiben.

Die Aufzeichnungen enden mit einem zweiten Traum:

»Ich sah wieder die weite eisige Einöde, sah klar und deutlich, glitzern von tausend bläulichen Kristallen die Furchen, die unser Schlitten durch den Schnee gerissen hatte. Am Horizont tauchen ein paar Punkte auf, sie wachsen langsam, während sie über das Eis wandern. Es sind menschliche Wesen.« (Ebd.)

Dieser zweite Traum, im Präsens gehalten, in dem die Gefährten wieder wie am Anfang über die weiten Schneeflächen wandern, kann als deutlicher Hinweis darauf gelesen werden, dass die Aufzeichnungen über die »Paradiese des Südpols« (139) und die Golemisierung durch die Polarmenschen eine Fiktion in der Fiktion sind, mit denen Heym als Autor auf ein Problem aufmerksam macht, das bereits im Zentrum seiner Erzählung »Die Südpolfahrer« steht: Auf ihrem Weg zum Pol, dessen »Geheimnis« sie lüften wollen, verwandeln sich die »Helden « von >Übermenschen $<$ in »Drahtpuppen« (141), die wie Maschinen dem Pol entgegenmarschieren. Sie verlieren alle menschlichen Züge, erstarren emotional, sind »gleichsam seelisch halbiert« (142). Das, was als phantastische Operation der Schneemenschen erscheint, ist in Wirklichkeit eine unmerkliche Veränderung, die der Gang ins Eis bei den Männern hervorgerufen hat: Das Geheimnis liegt nicht am Pol, wie Godefroy und Shackleton meinen, das Geheimnis liegt in ihnen selbst. Ihre Gier nach Anerkennung und Ruhm hat aus ihnen Eroberungsmaschinen gemacht, die ihre eigenen Träume nach dem offenen Meer, das mit Weiblichkeit assoziiert ist, vergessen haben. Sie sind zu Marionetten bzw. Robotern mutiert. Eingeschlossen im »entsetzlichen ewigen Eismeer gefrorenen Kummers « (134) sind sie zu einer Verkörperung jenes Vereisungsprozesses geworden, für den Franz Kafka bereits 1904 die Metapher des »gefrorenen Meeres in uns« gefunden hat, das seiner Meinung nach nur durch Bücher aufgebrochen werden kann, die wie eine »Axt« auf den 
Leser einschlagen bzw. ihn »mit einem Faustschlag auf den Schädel« wecken. ${ }^{10}$ Auch wenn die beiden Texte von Heym von ihrer literarischen Qualität her gesehen keine kafkasche Axt sind, die das »gefrorene Meer in uns « aufbrechen kann, so sensibilisieren sie doch für den Prozess der Vereisung, der sich im Kältekult um 1900 ankündigt und einen Männertyp hervorgebracht hat, dessen Faszination bis heute ungebrochen ist.

\section{Literatur}

Arktis/Antarktis (1997). Bonn: Kunst- und Ausstellungshalle der Bundesrepublik.

Conrad, Joseph (1977): Herz der Finsternis, Zürich: Diogenes.

Heym, Georg (1960): Dichtungen und Schriften, Gesamtausgabe, Bd. 3: Tagebücher, Träume, Briefe, hg. v. Karl Ludwig Schneider, Hamburg, München: Heinrich Ellermann.

Heym, Georg (1962): Dichtungen und Schriften, Gesamtausgabe, Bd. 2: Prosa und Dramen, hg. v. Karl Ludwig Schneider, Hamburg, München: Heinrich Ellermann.

Heym, Georg (1964): »Die Wanderer« (1910). In: ders.: Dichtungen und Schriften, Gesamtausgabe, Bd. 1: Lyrik, hg. v. Karl Ludwig Schneider, Hamburg, München: Heinrich Ellermann.

Heym, Georg (1999): Gedichte 1910/1912. Historisch-kritische Ausgabe aller Texte in genetischer Darstellung, Bd. 1, hg. v. Günter Dammann, Gunter Martens, Karl Ludwig Schneider, Tübingen: Max Niemeyer.

Kafka, Franz (1999): Schriften, Tagebücher, Briefe. Kritische Ausgabe, Bd. 2.1: Briefe 1900-1912, hg. v. Hans-Gerd Koch, Frankfurt a.M.: S. Fischer.

Kraus, Karl (1977): »Die Entdeckung des Nordpols«. In: ders., Ausgewählte Werke, Bd. 1, hg. v. Dietrich Simon, München: Langen Müller.

Poe, Edgar Allan (1966): »Arabesken, Detektivgeschichten«. In: Werke, Bd. 2, dt. v. Arno Schmidt, Hans Wollenschläger, Olten: Walter, S. 699705 .

10| Anlässlich der Lektüre von Hebbels Tagebüchern äußert sich Franz Kafka gegenüber seinem Freund Oskar Pollok folgendermaßen: »Ich glaube man sollte überhaupt nur solche Bücher lesen, die einen beißen und stechen. Wenn das Buch, das wir lesen, uns nicht mit einem Faustschlag auf dem Schädel weckt, wozu lesen wir dann das Buch? Damit es uns glücklich macht, wie du schreibst? Mein Gott, glücklich wären wir eben auch, wenn wir keine Bücher hätten, und solche Bücher, die uns glücklich machen, könnten wir zur Not selber schreiben. Wir brauchen aber die Bücher, die auf uns wirken wie ein Unglück, das uns sehr schmerzt, wie der Tod eines, den wir lieber hatten als uns, wie wenn wir in Wälder vorstoßen würden, von allen Menschen weg, wie ein Selbstmord, ein Buch muß die Axt sein für das gefrorene Meer in uns. Das glaube ich« (Kafka 1999: 35f.). 
Shackleton. Die Reisen. Eine Dokumentation in Bildern, (2003), mit einem Vorwort von Arved Fuchs und einer Einführung von Roland Huntford, Bielefeld: Delius Klasing.

Verne, Jules (1985): Die Eissphinx, Zürich: Diogenes.

Verschollen im Packeis. Das Antarktis-Abenteuer des Sir Ernest Shackleton (2000), Dokumentarfilm von George Butler (USA).

\section{Monographien}

Brunotte, Ulrike (1993): Hinab in den Mael Strom. Das Mysterium der Katastrophe im Werk Edgar Allan Poes, Stuttgart/Weimar: Metzler.

Fleming, Fergus (2004): Neunzig Grad Nord. Der Traum vom Pol. Aus dem Engl. v. Michael Hein, Bernd Rullkötter, München: Piper.

Frank, Manfred (1979): Die unendliche Fahrt. Ein Motiv und sein Text, Frankfurt a.M.: Suhrkamp.

Freud, Sigmund (1941): »Das Medusenhaupt« (1922). In: ders., Gesammelte Werke, Bd. 17, London: Imago Publishing Company, S. 47f.

Lethen, Helmut (1994): Verhaltenslehren der Kälte. Lebensversuche zwischen den Kriegen, Frankfurt a.M.: Suhrkamp.

Marx, Friedhelm (2001): »First encounter am Südpol. Georg Heyms Polarphantasie >Das Tagebuch Shakletons « . In: Lothar Blum/Achim Hölter (Hg.), »Daß gepfleget werde der feste Buchstab«. Festschrift für Heinz Rölleke, Trier: Wissenschaftlicher Verlag, S. 419-431.

Metzner, Joachim (1976): Persönlichkeitszerstörung und Weltuntergang. Das Verhältnis von Wahnbildung und literarischer Imagination, Tübingen: Max Niemeyer.

Stephan, Inge (1997a): »Im Zeichen der Sphinx. Psychoanalytischer und literarischer Diskurs über Weiblichkeit um 1900«. In: dies., Musen \& Medusen. Mythos und Geschlecht in der Literatur des 20. Jahrhunderts, Köln u.a.: Böhlau, S. 14-36.

Stephan, Inge (1997b): »Faszinosum Gorgo. Medusen-Phantasien bei Freud und Wilhelm Zweig«. In: dies., Musen \& Medusen, S. 60-83.

\section{Aufsätze in Anthologien}

Baßler, Moritz/van der Knaap, Ewout (Hg.) (2004): Die (k)alte Sachlichkeit. Herkunft und Wirkungen eines Konzepts, Würzburg: Königshausen \& Neumann.

Dietz, Ludwig (1994): »Georg Heym«. In: Bernd Lutz (Hg.), Metzler Autorenlexikon. Deutschsprachige Dichter und Schriftsteller vom Mittelalter bis zur Gegenwart, 2., überarb. u. erw. Aufl., Stuttgart, Weimar: Metzler.

Lethen, Helmuth (1987): »Lob der Kälte. Ein Motiv der historischen Avantgarden«. In: Dietmar Kamper/Willem van Reijen (Hg.), Die unvollendete Vernunft: Moderne versus Postmoderne, Frankfurt a.M.: Suhrkamp, S. 282-324. 


\section{Aufsätze in Zeitschriften}

Braungart, Georg/Braungart, Wolfgang (1984): »Golemisierung im Pol-

Paradies. Zur Kritik des neuzeitlichen Zukunftsentwurfs in Georg Heyms Erzählung >Das Tagebuch Shakletons< (1911)《. In: Text Q K Kontext 12/2, S. 266-289.

Brunotte, Ulrike (1993): »Edgar Allan Poes Reise ans Ende der Welt«. In: Freibeuter 57, S. 109-118.

Sprout, Monique (1967): »The Influence of Poe on Verne«. In: Revue de littérature comparée 40, Nr. 1, S. 37-53. 



\section{Zu den Autorinnen und Autoren}

Christina von Braun (Prof. Dr.) ist Kulturtheoretikerin und Filmemacherin. Seit 1994 Lehrstuhl für Kulturwissenschaft an der Humboldt-Universität zu Berlin. Zahlreiche Filmdokumentationen, Bücher und Aufsätze zum Wechselverhältnis von Bild/Schrift, Religion und Geschlechterrollen. Mitglied im Präsidium des Goethe-Instituts, Vorstandsmitglied und Sprecherin der Grünen Akademie bei der Heinrich-Böll-Stiftung; Sprecherin des DFG-Graduiertenkollegs >Geschlecht als Wissenskategorier.

Bücher zum Thema u.a.: Nicht ich. Logik Lüge Libido, Frankfurt 1985; Versuch über den Schwindel. Religion, Schrift, Bild, Geschlecht, Zürich/München 2001; zusammen mit Inge Stephan (Hg.): Gender@wissen. Themenfelder der Geschlechterstudien, Köln 2004; zusammen mit Bettina Mathes: Verschleierte Wirklichkeit. Die Frau, der Islam und der Westen, Berlin 2007; Stille Post. Eine andere Familiengeschichte, Berlin 2007.

Ulrike Brunotte (Prof. Dr., PD), Religions- und Literaturwissenschaftlerin, zz. Gastprofessorin am Gender Kolleg der Universität Wien und Senior Fellow am IFK (Wien). Bis Ende 2006 Oberassistentin am Kulturwissenschaftlichen Seminar der Humboldt-Universität zu Berlin. Forschungsschwerpunkte zu Masculinity Studies, Religion und Literatur, Amerikanischen Puritanismus, Gender und Wissen, Religionstheorie, Historische Anthropologie. Bücher zum Thema: Zwischen Eros und Krieg. Männerbund und Ritual in der Moderne, Berlin 2004; zusammen mit Ch. von Braun/G. Jähnert/G. Dietze/D. Hrzán u.a. (Hg.): >Holy War< and Gender. >Gotteskrieg< und Geschlecht. Gewaltdiskurse in modernen Religionen, Berlin 2006.

Claudia Bruns (Prof. Dr. phil.), Historikerin, seit WS 2007/08 Juniorprofessorin am kulturwissenschaftlichen Seminar der Humboldt-Universität zu Berlin, zuvor wissenschaftliche Mitarbeiterin am interdisziplinären Nordamerikaprogramm der Universitäten Bonn/Köln; Postdoktorandin des Trierer DFG-Graduiertenkollegs Identität und Differenz; Forschungs- 
interessen sind Wissens- und Genderdiskurse der Moderne, insbesondere die Konstruktionen von Männlichkeiten und Männerbund.

Bücher zum Thema: Zusammen mit Tilman Walter (Hg.): Von Lust und Schmerz. Eine historische Anthropologie der Sexualität, Wien 2004, Politik des Eros. Der Männerbund in Wissenschaft, Politik und Jugendkultur, 18801920, Köln 2006.

Hubertus Büschel (Dr. phil.) arbeitet als wissenschaftlicher Mitarbeiter am Historischen Institut der Universität Potsdam und ist assoziiert am Zentrum für Zeithistorische Forschung Potsdam. Seine Forschungsschwerpunkte liegen in der europäischen Geschichte des 19. und 20. Jahrhunderts, der Kulturgeschichte und Historischen Anthropologie sowie im Bereich Afrikanische Geschichte. Sein aktuelles DFG-gefördertes Forschungsvorhaben hat das Thema: »Westdeutsche >Entwicklungshilfe< und ostdeutsche >Solidarität< in Afrika südlich der Sahara 1955-1975. Akteure zwischen Kolonialschuld und Machtstreben«.

Publikationen: »)Shrinking Psychohistory< - Psychoanalyse und Geschichtswissenschaft: Die USA und (West-)Deutschland«. In: Rebekka Habermas/Rebekka von Mallinckrodt (Hg.), Interkultureller Transfer und nationaler Eigensinn. Europäische und anglo-amerikanische Positionen der Kulturwissenschaften, Göttingen 2004, S. 123-140; Untertanenliebe - Der Kult um deutsche Monarchen 1770-1830, Göttingen 2006.

Joseph Croitoru (Dr. phil.) ist Freier Journalist (FAZ). Studium der Geschichte und Kunstgeschichte an der Hebräischen Universität in Jerusalem und (zusätzlich Judaistik) an der Albert-Ludwigs-Universität in Freiburg. Publikationen: Der Märtyrer als Waffe. Die historischen Wurzeln des Selbstmordattentats, München 2003; Die Hamas. Der islamische Kampf um Palästina, München 2007.

Birgit Dahlke (PD Dr.) lehrt als Oberassistentin am Institut für deutsche Literatur der Humboldt-Universität Berlin. Lehr- und Forschungsschwerpunkte sind: Geschlechterkonstruktionen und Jugendkult; DDR-Literatur; neueste deutsche Literatur; Kanon und Geschlecht; deutsch-jüdische Literatur; »Rasse « und Geschlecht in der Literatur vom 18. bis 21. Jahrhundert.

Bücher: Papierboot. Autorinnen aus der DDR - inoffiziell publiziert, Würzburg 1997; Jünglinge der Moderne. Jugendkult und Männlichkeit in deutscher Literatur um 1900, Köln/Weimar/Wien 2006.

Ute Frevert (Prof. Dr.) lehrt seit 2003 Deutsche und Europäische Geschichte an der Yale University (USA). Sie erhielt 1998 den Leibniz-Preis. Ihre Forschungsschwerpunkte sind Geschlechter- und Sozialgeschichte der Moderne, insbesondere Militärgeschichte im Kontext einer Geschichte der Männlichkeiten. 
Sie veröffentlichte allein 14 Monographien, darunter: Die kasernierte $\mathrm{Na}$ tion. Militärdienst und Zivilgesellschaft in Deutschland, München 2001 und Ehrenmänner: Das Duell in der bürgerlichen Gesellschaft, München 1991.

Jay Geller (Dr. phil.) ist Assistant Professor für Modern Jewish Culture an der Vanderbilt Universität. Seine Forschungsinteressen konzentrieren sich auf den Zusammenhang von jüdischer Identität, Gender und Sexualität in der Psychoanalyse Sigmund Freuds.

Veröffentlichung: On Freud's Jewish Body: Mitigating Circumcisions, New York 2007; und als zweiter Teil des Diptychons: Persistent Others: Modernity and the Embodiment of Jewish Identity (in Vorbereitung).

Rainer Herrn (Dr.), Natur- und Sozialwissenschaftler, arbeitet in der Forschungsstelle zur Geschichte der Sexualwissenschaft der Magnus-Hirschfeld-Gesellschaft (Berlin), derzeit Vorbereitung der Ausstellung »Sexuelle Freiheit - Anfang und Ende einer bürgerlichen Utopie« aus Anlass des 75. Jahrestages der Bücherverbrennung und der Plünderung von Magnus Hirschfelds Institut für Sexualwissenschaft im Medizinhistorischen Museum der Berlin Charité.

Internationale Ausstellungen, Lehrveranstaltungen und Vorträge zu Sexual- und Geschlechterwissenschaften sowie zu sexuellen Minderheiten. Ausgewählte Buchveröffentlichungen: Schnittmuster des Geschlechts. Transvestitismus und Transsexualität in der frühen Sexualwissenschaft, Gießen 2005; Schwule Lebenswelten im Osten - Andere Orte, andere Biografien, Berlin 1999; Anders bewegt - 100 Jahre Schwulenbewegung in Deutschland, Berlin 1999; Hg. von: Karsten Witte, Die Körper des Ketzers, Pier Paolo Pasolini, Berlin 1998.

Cornelia Klinger (apl. Prof. Dr.) lehrt Philosophie an der Eberhard-KarlsUniversität Tübingen. Studium der Philosophie, Literaturwissenschaft und Kunstgeschichte in Köln. Seit 1983 ständiges wissenschaftliches Mitglied am Institut für die Wissenschaften vom Menschen in Wien. Ihre Arbeitsschwerpunkte sind: Politische Philosophie, Gender Studies im Bereich Philosophie, Ästhetik, Theoriegeschichte der Moderne.

Buchpublikationen: Die Erfindung des Subjekts, Frankfurt (stw 1730) (im Erscheinen); zusammen mit Wolfgang Müller-Funk (Hg.): Das Jahrhundert der Avantgarden, München 2004; zusammen mit Herta Nagl-Docekal (Hg.): Continental Philosophy in Feminist Perspective: Re-Reading the Canon in German, University Park 2000; Flucht - Trost - Revolte. Die Moderne und ihre ästhetischen Gegenwelten, München 1995.

Martin Lücke arbeitet als Wissenschaftlicher Angestellter in der Lehreinheit Fachdidaktik Geschichte im Historischen Seminar der Universität Leipzig und hat soeben ein Dissertationsprojekt zur Geschichte der männlichen Prostitution abgeschlossen. 
Seine Schwerpunkte in Lehre und Forschung sind: Geschlechter- und Sexualitätsgeschichte und ihre Didaktik, Didaktik der Geschichte und Methodik des Geschichtsunterrichts.

Veröffentlichungen u.a.: zusammen mit Sabine Grenz (Hg.), Verhandlungen im Zwielicht. Momente der Prostitution in Geschichte und Gegenwart, Bd. 1 der Reihe GenderCodes - Transkriptionen zwischen Wissen und Geschlecht, Bielefeld 2006; »Genere e (omo)sessualità: un percorso nella recente storiografia di lingua tedesca«. In: Omosapiens. Studi e ricerche sull'orientamento sessuale 1 (2006), S. 222-227.

Bettina Mathes (Prof. Dr.) ist Professorin an der Pennsylvania State University. Forschungsschwerpunkte: Geschlechter- und Mediengeschichte, Faust, Psychoanalyse, Islam in Europa, DEFA-Filme.

Neueste Veröffentlichungen: Die Imaginierte Nation. Identität, Körper und Geschlecht in DEFA-Filmen, Schriftenreihe der DEFA-Stiftung 2007; zusammen mit Christina von Braun: Verschleierte Wirklichkeit. Die Frau, der Islam und der Westen, Berlin 2007; Under Cover. Das Geschlecht in den Medien, Bielefeld 2006; Verhandlungen mit Faust. Geschlechterverhältnisse in der Kultur der Frühen Neuzeit, Königstein 2001.

Sabine Mehlmann (Dr. phil.) ist seit 2005 wissenschaftliche Mitarbeiterin der Arbeitsstelle Gender Studies der Justus-Liebig-Universität Gießen. Arbeits- und Forschungsschwerpunkte sind: Sex/Gender-Theorien, historische Geschlechter- und Wissenschaftsforschung, humanwissenschaftliche Konstruktionen von Geschlecht, Sexualität und Normalität im 19. und 2o. Jahrhundert. Aktuelles Forschungsvorhaben zum >Krisendiskurs von Männlichkeit seit den 1970er Jahren.

Publikationen: »Das vergeschlechtlichte Individuum - Thesen zur historischen Genese des Konzepts männlicher Geschlechtsidentität«. In: Hannelore Bublitz (Hg.), Das Geschlecht der Moderne. Genealogie und Archäologie der Geschlechterdifferenz, Frankfurt a.M./New York 1998, S. 95-118; Unzuverlässige Körper - Zur Diskursgeschichte des Konzepts geschlechtlicher Identität, Königstein/Taunus 2006.

Tanja Paulitz (Dr. rer. pol.) ist seit 2004 Wissenschaftliche Assistentin am Zentrum für Interdisziplinäre Frauen- und Geschlechterforschung der Technischen Universität Berlin und seit 2006 Lise-Meitner-Fellow am Institute for Advanced Studies on Science, Technology and Society in Graz, Österreich. Aktuelle Arbeitsschwerpunkte: Gender in Ingenieurwissenschaften und -praxis, Technologien, Subjektivierung und Gouvernementalität, Genealogie technischer Rationalität, wissenssoziologische Diskursforschung. Aktuelles Forschungsprojekt zum Thema: Technisches Konstruieren und Geschlecht.

Bücher u.a.: Netzsubjektivität/en. Konstruktionen von Vernetzung als Technologien des sozialen Selbst, Münster 2005; »Geschlechterforschung und 
Technikwissenschaften. Konstruktionen von Wissen in Fachkulturen des Ingenieurbereichs«. In: Zeitschrift für Frauenforschung Q G Geschlechterstudien 4 (2007) (im Erscheinen).

Marilyn Reizbaum (Prof. Dr.) lehrt Englisch am Bowdoin College (USA). Ihre Lehr- und Forschungsschwerpunkte umfassen britischer Modernismus, zeitgenössische schottische und irische Literatur und Kultur, postkoloniale und jüdische Kulturtheorie sowie Geistesgeschichte.

Publikationen: Neben zahlreichen Essays über Joyce zählen: James Joyce's Judaic Other, Stanford 1999, und der gemeinsam mit Kimberly Devlin herausgegebene Band Ulysses: En-gendered Perspectives - Eighteen New Essays on the Episodes, South Carolina 1999, zu ihren zentralen Veröffentlichungen. Neuere Arbeiten befassen sich mit den Themen »Gender and Nationalism in Scotland and Ireland: Making and Breaking the Waves« (2005); »Yiddish Modernisms: Red Emma Goldman« (2005) und »Max Nordau and the Generation of Jewish Muscle« (2004). Der letztgenannte Essay ist Teil ihres aktuellen Buchprojektes mit dem Titel The Art of Degeneration: Jew-ish Science and Modern Arts, in dem sie den Beitrag der Juden an der Konstruktion und Verbreitung der Degenerationstheorie untersucht, wie auch den Einfluss dieser Theorie auf die Kunst des 20. Jahrhunderts.

Inge Stephan (Prof. Dr.) lehrt seit 1994 Neuere Deutsche Literatur an der Humboldt-Universität zu Berlin. Sie ist eine der InitiatorInnen des Graduiertenkollegs Geschlecht als Wissenskategorie, Lehr- und Forschungsschwerpunkte sind: Weibliche Literatur- und Kulturtradition, >Frauenbilder und >Männerbilder<, Geschlechtskonstruktionen in der Literatur vom 18. Jahrhundert bis in die Gegenwart sowie feministische Theorie und aktuelle Gender-Forschung.

Publikationen zum Thema: Medea. Multimediale Karriere einer mythologischen Figur, Köln/Weimar 2006; zusammen mit Christina von Braun (Hg.), Gender@wissen. Themenfelder der Geschlechterstudien, Köln/Weimar/ Wien 2005; zusammen mit Claudia Benthien (Hg.), Männlichkeit als Maskerade. Kulturelle Inszenierungen vom Mittealter bis zur Gegenwart, Köln/ Weimar 2003. 



\section{GenderCodes}

Ute Frietsch, Konstanze

Hanitzsch, Jennifer John,

Beatrice Michaelis (Hg.)

Geschlecht als Tabu

Orte, Dynamiken und

Funktionen der

De/Thematisierung von

Geschlecht

Dezember 2007, 270 Seiten,

kart., zahlr. farb. Abb., 25,80 €,

ISBN: 978-3-89942-713-4

Ulrike Brunotte,

Rainer Herrn (Hg.)

Männlichkeiten und Moderne

Geschlecht in den

Wissenskulturen um 1900

Dezember 2007, 294 Seiten,

kart., $28,80 €$,

ISBN: $978-3-89942-707-3$

Sven Glawion,

Elahe Haschemi Yekani,

Jana Husmann-Kastein (Hg.)

Erlöser

Figurationen männlicher

Hegemonie

September 2007, 218 Seiten,

kart., $24,80 €$,

ISBN: $978-3-89942-733-2$

Sabine Grenz,

Martin Lücke (Hg.)

Verhandlungen im Zwielicht

Momente der Prostitution

in Geschichte und Gegenwart

2006, 350 Seiten,

kart., $29,80 €$,

ISBN: $978-3-89942-549-9$

Leseproben und weitere Informationen finden Sie unter: www.transcript-verlag.de 
